


\section{MARINE BIOLOGICAL LABORATORY.}

Received

Accession No.

Given by

lace,

** No book or pamphlet is to be removed from the Labatory without the permission of the Trustees. 
THE UNIVERSITY OF CHICAGO PRESS CHICAGO, ILLINOIS

THE IBAKER \& TAYLOR COMPANY NEW YORK

THE CAMBRIDGE UNIVERSITY PRESS LONDON

THE MARUZEN-KABUSHIKI-KAISHA TOKYO, OSAKA, KYOTO, FUKUOKA, SENDAI

THE COMMERCIAL PRESS, LIMITED SHANGHAI 


\title{
EVOLUTION, GENETICS AND EUGENICS
}

\author{
By HORATIO HACKETT NEWMAN \\ Professor of Zoulogy in the Lniversity of Chicago \\ THIRD EDITION
}

THE CNIVERSITY OF CHICAGO PRESS

CHICAGO, HLLINOIS 
COPYRIGHT 1921, 1925, AND I932 BI THE UNIVERSITY OF CHICAGO. ALLRIGHTS RESERVED. PLELISHED OCTOBER I 921 SECOND EDITION DECEMBER I925. THIRD EDITION ALRIL I932 SECOND IMPRESSION SEMTEMBER 1933

COMPOSID AND PRINTED BY THE UNIVERSTY OF CHICAGO PRESS CHICIGO, ILLINUIS, U.S.A. 
THIS VOLUME

IS AFFECTIONATELY DEDICATED

TO

MY MOTHER 



\section{PREFACE TO FIRST EDITION}

This book has been prepared to meet a specific demand, long felt here and elsewhere, for an account of the various phases of evolutionary biology condensed within the scope of one volume of moderate size. The present writer has now for sixteen successive years presented in lecture form to large classes of sturlents the subjects of evolution, genetics, and eugenics. Never have we been able to find a single book that would cover the required ground. In fact it has been necessary to require, or at least to recommend, as many as three books. It is believed that the present book will furnish adequate reading material for a major or a semester course in evolutionary biology. Some supplementary readling may be necessary in case an instructor wishes to emphasize one or more phases of the subject; but for a first course in the subject we believe that all of the essential reading material will be found within the text itself.

An effort has been made to present the subject in the best pedagogical order. After a general introluction, a rather long chapter appears in which the whole history of the development of evolutionary science is outlined, together with the names and contributions of the leading evolutionists. Part II is a presentation of the evidences of organic evolution, beginning with the bodies of evidence most definite and direct, and ending with the less definite and more controversial. Part III deals with causo-mechanical theories of evolution with Darwinism as the central topic. Part IV concerns itself with genetics or modern experimental evolution, and Part $\mathrm{V}$ with eugenics, or genetics as applied to human improvement.

The book consists largely of excerpts; some long and some short, from both the older classical evolutionary writers and the modern writers. Our aim has been to select the most significant or characteristic passages from each author. In most cases this icleal has been attained, but it has sometimes happened that we have had to make our selection of material to meet a real need in the book, and accordingly have selected from an author a passage he himself might not consider particularly characteristic of his work. We have succeeded, nevertheless, in welding together out of a collection of isolated chapters and passages what seems to us to be a close approach to a coherent unit. Unification has been accomplished by the aid of editorial connecting passages, introductory statements, criticisms, and summaries. In certain cases it became necessary, for a variety of reasons, 
for the editor to write short chapters on certain topics that were not presented in the available literature in sufficiently brief compass or in sufficiently non-teclnical language.

The one-man textbook is only too often written to emphasize the author's pet theories and is likely to be unduly biased. The present work is completely non-partisan. It consists of the writings of many authors and presents many diverse theories. The student is left to balance the various views one against another and to form his own judgment.

It is very unfortunate, but none the less true, that even in these scientific days, the subject of evolution has a bad name in many communities and in many educational institutions with religious affiliations. The mistake is made of supposing that evolution and religion are diametrically opposed. The present writer has been at some pains to make it clear that evolution and religion are strictly compatible. We teachers of evolution in the colleges have no sinister designs upon the religious faith of our students.

While this book is intended primarily for a college textbook, we have also had in mind the general reader. Apart from a few of the more technical details, the text seems to us very readable. The language of the great classic writers-Darwin, Wallace, Romanes, De Vries, Le Conte-is simple and lucid. Among recent biological books few are written so freshly and vividly as those of Professor J. Arthur Thomson. The clearness and scientific accuracy of Conklin, Saleeby, Guyer, Walter, Lull, Osborn, the Coulters, Downing, Shull, Tayler, Popenoe, Johnson, and others, are familiar to American biologists.

Scrupulous care has been taken to verify all passages quoted, but it is hardly likely that, in so large a mass of material, all errors shall have been avoided. The author and the publishers would welcome as a favor any suggestions or corrections submitted by interested rearlers.

A list of the looks from which material has been quoted is given on pages 612,613. To the authors and publishers of these books and monographs we wish herewith to tender our grateful acknowledgments for their generosity and co-operation. A considerable amount of material for which permission to reprint had been granted fails to appear in the present volume. It is hoped to incorporate this material in an appendix to a later edition, or else to use it in the form of a small volume of supplementary readings.

August ${ }_{15}, 1921$

H. H. N. 


\section{PREFACE TO SECOND EDIIIUN}

A book of this sort somewhat resembles a loose-leaf encyclopedia in that it sujjects itself very readily to revision and rearrangement and thus may be kept abreast of the times. When certain section: prove through actual class use to need revision or restatement or when new discoveries necessitate a change in conclusions, appropriate corrections may be made, new matter added, or whole chapters rewritten. When various topics have shown themselves to be either logically or pedagogically in the wrong order, it is easy to rearrange chapters, for the latter are to a large degree independent. When, finally, any new chapter of superior excellence appears in a new puhlication, it is usually possible through the courtesy of author and pul-lisher to add it to the worthy collection of excerpts alrearly gatherel together.

The writer has been fortunate in that reviewers and colleagues both in America and in Europe have offered many constructive criticisms of the book and suggestions for its improvement. It is hoped that the present edition will adequately reflect this expert advice.

The order of presentation of the evirlences of erohution has been changed from one based on the degree of directness of the evidence to one based on the logical succession of topics and their interdependence. The chapters on "The Mutation Theory" and "The Inheritance of Acquired Characters" have been placed near the end of the book in order that they may be considered in the full light of our present knowledge of genetics. The chapter on "Linkage and Crossing-over" has been rewritten in a more elementary and circumstantial style in order to overcome, if possible, the difficulty that students have always encountered in understanding the somewhat condensed and technical account of Professor Castle. The discussion of mutations has been modernized and considerably extender through the addition of an article written especially for this book by Professor R. Ruggles Gates and of a paper by Professor H. F. Muller. The section on eugenics has been strengthened by the addition of a lucid 
chapter from Albert Edward Wiggam's book The Fruit of the Family Tree. The writer has introduced a considerable amount of new matter of his own which consists chiefly of relatively short introductory, connecting, explanatory, and summarizing statements that serve to cement the otherwise somewhat disconnected excerpts into a coherent whole. Because of the fact that so many of the writer's own contributions are scattered through the book, it is deemed wise to omit his name from all such chapters and passages, with the understanding that all matter not specifically credited to others is his own.

Excerpts from books commonly contain undefined technical terms that perplex the beginning student. This difficulty has been overcome through the addition of a full glossary defining nearly all of the biological terms used in the book.

Grateful acknowledgments for the use of new materials are herewith given to the following authors and publishers: E. G. Conklin, R. R. Gates, S. J. Holmes, D. F. Jones, T. H. Morgan, H. F. Muller, G. H. Thayer, A. E. Wiggam, E. B. Wilson; The Bobbs-Merrill Company, Henry Holt and Company, The Macmillan Company, The Princeton University Press, The Williams and Wilkins Company.

University of Chicago

H. H. NEWMAN

April 6, I925 


\section{PREFACE TO THIRD EDITION}

The first edition of this book was avowedly a book of readings, a source book, consisting almost exclusively of extracts from leading writers on evolutionary topics. The character of the look made it somewhat disjointed. It was criticized for lack of unity of plan and was called by one critic a hodge-porlge. In spite of these defects many teachers found the book valuable as a reading source to accompany lectures.

In the second edition an attempt was made to unify the material by the addition of a consilerable amount of editorial comment in the form of short introductory and transitional chapters. This method of unification was, howerer, not sufficiently rarlical. The result was neither a source book nor an organized textbook. Believing that what most teachers want is primarily a textbook and only secondarily a source book, the anthor has attempted to make the book a text by reorganizing the previously less organized material and by taking out and putting into the Appendix chapters that break the continuity of treatment hut are useful for collateral reading.

Teachers using the book recommended that the historical account of erolution and the section on evilences of evolution be left substantially as they were, lut they suggested that the section on genetics be largely rewritten. This has been done. The plan followed is that of dealing with gencics as the study of the mechanism of evolution, the main factors of which are (I) the persistence factor, heredity; (2) the diversity factor, sexual reproduction and Mendelian heredity; (3) the change factor, mutation; (4) guiding factors, selection, and possibly the Lamarckian factor and orthogenesis; and (5) the dividing factor, isolation in the broad sense. The part on eugenics has also been extensively revised and rewritten. and contains a good deal more factual material. It is hoped that in its present form the book may more nearly meet the needs of college classes in evolutionary biology.

It gives us pleasure to acknowlerlge gratefully the permission given us by The Macmillan Company to use figures 40, 41, 42, 43, 44, 45, and $5 \mathrm{I}$.

H. H. NEWMAN

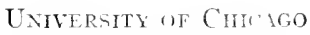

January $\mathbf{1 6 , 1 9 3 2}$ 
$\therefore 8$ 


\section{TABLE OF CONTENTS}

List of Illustrations.

\section{I'ART I. INTRODUCTORY AND HISTORIC.AL}

Cilapter I. INfroduction

What Organic Evolution ls-Detinitions

The Morlern . Ittitule as to the Truth of the Evolution Doctrine . 5

What Oranic Evolution Is Not . . . . . . . . . . S $S$

Cilapter 1I. ilistorical ACCulat of tile Detelopaext of tile

Evolution Timetrí

Evolution among the Greeks

Post-Aristotelians

The Early Theolugians

The Revival of Science

The Great Vaturaliots of the Eichteenth Cantury"

Lamatrek

Cuvier and Cienffroy St. Ililaire

Catastrophism and Lniformitarianism

The Reawakening of the Evolution Idea

Charles Darwin

Summary of Darwin's 'Theories.

Contemporary Opinion Regarding the Validity of Darwin's liews 27

Isolation Therries

Orthogenesis Theories

The Mutation Theory of De Vries

The Rise and Vogue of Biometry

Experimental Breeding

Mendel's Laws

Hybridization and the Origin of Species

Neo-Mendelim Developments .

Heredity and Sex

The Experimental Induction of Hereditary Variations . • • • 45

The Recent Attack upon Erolution in the Lnited States . . . 45

Concluding Remarks

\section{I'ART II. EVIDENCES OF ORGANIC EVOLLTION}

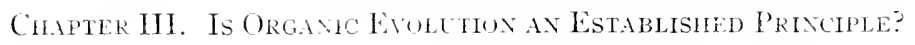

Chapter IV. The Funduextal Pustulate Uxderling All EviDEXES Q E EOLLTIN 
Chapter V. Evidences from Morphology (Comparative Anatomy). Gcorge John Romanes . . . . . . . . . . ${ }_{5}^{8}$

Chapter VI. Enidences from Classification . • . . . 03

The Principles of Classification. A. F. Shull . . . . . . . 93

The Method of Classification. Charles Damoin . . . • . 96

What Is a Species? . . . . . . . . . . . . . . 97

Chapter VII. Eutdence from Blood Tests. IJ. B. Scott . . I 100

Chapter Vilil. Evidences from Embryology . . . . . . 105

The Facts of Reproduction and Development . . . . . . 105

Outline of Animal Development. D. S. Jordan and Y. L. Kellogg. 106

Chapter IX. Critique of the Recapitulation Timeory. IJ. B. Scoti il it

Chapter X. Eimdences from Palaeontology . . . . . . I 24

Strength and Weakness of the Evidence . . . . . . . . I 24

Other Opinions as to the Adequacy of the Evidences from Palaeontology . . . . . . . . . . . . . . . . . I 25

What Fossils Are and How They Have Been Preserved . . . 126

Fossils Classified . . . . . . . . . . . . . . 126

On the Conditions Necessary for Fossilization . . . . . . 127

On the Lapse of Time during Which Evolution is Believed to Have Taken Place . . . . . . . . . . . . . . . I30

On the Principal General Facts Revealed by a Study of the Fossils $\quad$ I32

Fossil Pedigrees of Some Well-known Vertebrates . . . . . I33

Pedigree of the Horse . . . . . . . . . . . . . . $\quad$ I 33

Pedigree of the Camels. IV. B. Scott . . . . . . . . 136

Evolution of the Elephants. A. Franklin Shall. . . . . . 139

Chapter XI. The Erolution of Man: Palaeontulugy. Richard

Swann Lull . . . . . . . . . . . . . . . Itt

Origin of Primates . . . . . . . . . . . . . I4t

Origin of Man . . . . . . . . . . . . . . . . I I

Fossil Man . . . . . . . . . . . . . . . . It7

Evidences of Human Antiquity . . . . . . . . . I57

Future of Humanity . . . . . . . . . . . . . . . . . . I5s

Sinanthropus pekincnsis . . . . . . . . . . . . . I50

Chapter XiI. Evidences from Geographic Distribution . . . i6o

Principles of Geographic Distribution . . . . . . . . . 160

Some of the More Signiticant Facts about the Distribution of Animals . . . . . . . . . . . I6t

The Fauna of Oceanic Islands. Gorge John Romanes . . . . . I6+

The Fauna of Continental Islands-Madagascar and New Zealand. A. R. Hallace . . . . . . . . . . . . . . . 173 


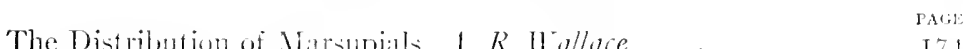
The Distribution of Mitrstipials. . R. H allace • • • • • . I7t The Distribution of Birds. A. R. Il allace . . . . . . . 175 Summary of Mammalian l)ingeral. Hans (iadew . . . . . 177 Summary of the Argument for Evolution as Based on (ieographic Distribution 178

\section{PART III. THE MECHANISM OF ENOLUTION (GENETICS)}

Chaper XIII. Ixtrodectory Statement . • . • . . I $8_{3}$

The Nature and Scope of Genetics . . . . . . . . I $\delta_{3}$

Prereguinites for the study of Genetics . . . . . . . . I 8 t

The Mechanism of Evolution . . . . . . . . . . . . I $\delta_{5}$

The Main Caunal Iactors of Erolution . . . . . . . . I86

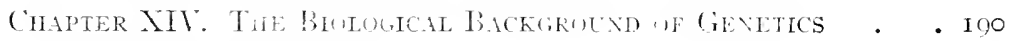

Races and Individurlo . . . . . . . . . . . . . Ino

The Cellular Mate-up of lotividuals . . . . . . . . Ino

1 Typral Cell and Its Component Parto. . . . . . . Ior

Cell Divition - Mlitusis . . . . . . . . . . . . Iot

Difleremiation . . . . . . . . . . I05

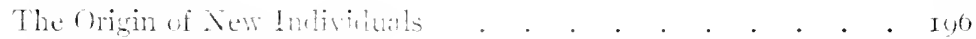

Mon of Reprodution . . . . . . . . . . . I00

The ()rigin of (immetes . . . . . . . . . 200

The Maturing of (iameten . . . . . . . . . 203

The Enion of cannetes-lentibation . . . . . . . 207

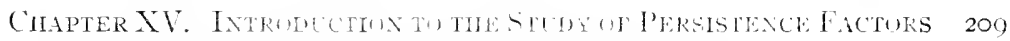

Persistence and biver-ity Ycchaning Contrasted . . . . 210

A Short Lesson in Biometry . . . . . . . . . . . 210

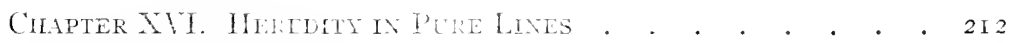

The Nature of I'ure Lines . . . . . . . . . . . 212

The Pure-Line Experiments of Johannen . . . . . . . 2 I 2

Other Examples of f'ure Lines. . . . . . . . . . . 215

Exactly What Is Inherited? . . . . . . . . . . . 2 It

Chapter XVII. Sex Deteraimation Aid Sex Differentiation • 2 ig

Ser Determination . . . . . . . . . . . . . 219

The Chromosumal Mechanism of Sex Determination . . . $22 \mathrm{I}$

Sex Differentiation . . . . . . . . . . . . . 227

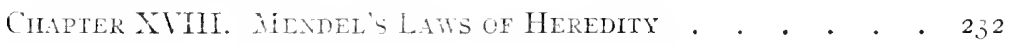

Mendel's Life and Character. J. .1rthm Thomson . . . . . 232

Mendel's Discoveries . . . . . . . . . 232

Mendel's Exphanations. Jolin H. and Merle C. Coulter . . . . 235

Ilustrations of Sinple Mendelian Inheritance in Both Animals and

I'lants. J. Arther Thomson . . . . . . . . . . . 245 
Chipter Xix. 'The Factor Hypotilesis as Al'ilen tu Plants. John M. and Merle C. Coulter . . . . . . . . . . 25.3

I. Presence and Absence Hypothesis . . . . . . . 253

II. Blends . . . . . . . . . • . . . . . 255

III. The Factor Hypothesis . . . . . . . . . . . 257

Chlapter XX. The Factor Hypothesis as Applied to Anmils . 260

Illustrations of the Factor Hypothesis . . . . . . . . 269

The Factorial Analysis of Color in Mice . . . . . . 26,

Different Kinds of Albinos . . . . . . . . . . . . 270

Factorial Analysis of Coat Color in Swine . . . . . $27 \mathrm{I}$

Coat Colors in Guinea Pigs . . . . . . . . . . 272

Chapter XXi. Retiew of Mexdelism . • . . . . . 273

Chapter XXIl. Sex-linked Heredity . . . . . . . . 277

Cimpter XYil. Linkage, Crossing-oter, And the Architecture

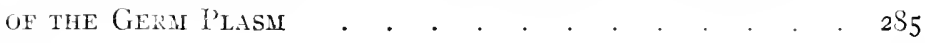

linkage . . . . . . . . . . . . 285

Crossing-over . . . . . . . . . . . . . . . . . $28 S$

Chromosome Maps Indicating the Arrangement of Mendelian Fac-

tors, or Genes, in the Chromosomes . . . . . . . . 291

Linkage in Other Organisms . . . . . . . . . . . 296

Chapter IXIV. Cross-breeding and Intreedng . • . . 299

The Róle of Hybridization in Evolution . . . . . . . . 290

Some Animal Hybrids . . . . . . . . . . . . . 300

Secondary Effects of Cross-breeding and Inbreeding . . . . 302

A. Cruss-breeding . . . . . . . . . . . 302

B. Inbrecling . . . . . . . . . . . . . . . 30 . 3

Chapter IXY. Change Factors. Introduction . . . . 3os

Changing Views as to the Origin of New Hereditary Characters . 308

Lamarck . . . . . . . . . . . . . . 308

Darrin . . . . . . . . . . . . . . 308

Weismann . . . . . . . . . . . . . . . . 309

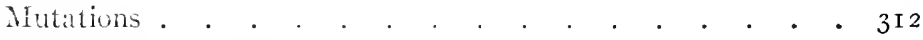

Chapter Melit. The Mutation Theory . . . . . . . . 3i3

New Species (Mutants) of Ocholhera. Hugo De Fries . . . . 3I5

Summary of De Vries's Mutation Theory. Thomas II unl Morgan 322

Later Investications of Mutations . . . . . . . . . . 327

The Neo-Mutationist I'osition. R. Ruggles Gates . . . . . 328

Chromosome Mutations . . . . . . . . . . . 320

Mutation. II. J. Muller. . . . . . . . . . . . . . . 333 
PaAB

The Caruses of Mutations . . . . . . . . . . . . . . $3+0$

Mutation and Evolution. T. H. Horgan . . . . . . . . 3+I

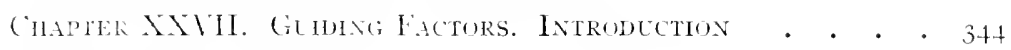

Preliminaty Discustion . . . . . . . . . . . . $34+$

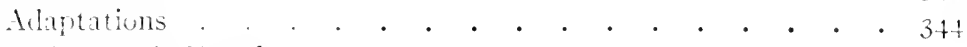

Orthogenetic Trends. . • . . . . . . . . . . 345

I'rogressire fivolution . . . . . . . . . . . 345

Specialization . . . . . . . . . . . . . 340

Increase in Size . . . . . . . . . . . . . . . 34 S

Increase in Intellifence . . . . . . . . . . . . 345

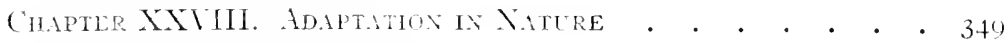

The Nature of Elaptations. . . . . . . . . . . . $34^{\circ}$

Two Categories of Alaptations . . . . . . . . . . 353

Alaptations (lasififul . . . . . . . . . . . . $35+$

Some Special Arantations. . . . . . • • • • • . 355

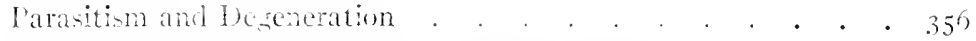

Alaptations ef licep-sea Animals and of cave Animals . . $35^{\circ}$

Color and l'attern in Animali . . . . . . . . . . 300

Coborn's Latws of Aclaptation . . . . . . . . . . . 300

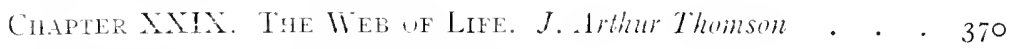

Chaptik XXX. Matrkal Selection . . . . . . . . 383

Summany of Larwin s Natuml-Selection Theory. Fernon L. Kellogs 33

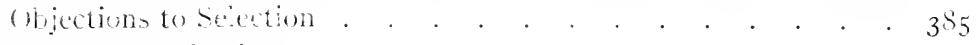

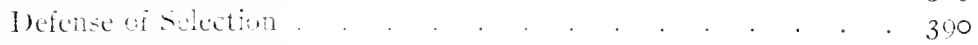

General Define of Selection. I. L. Tuyle . . . . . . . 30 I

Expermentul Suprort of the Efiectiveness of Natural Selection . 304

The Irecent Status of Xatural Sedection . . . . . . 3010

The Relation of Nendulism and the Mutation Theory to Natural

Selection. C. C.. Hatting . . . . . . . . . 390

Chapter MYXi. Are Acretred (iaracters (Modfications)

IIEREDITARY? . . . . . . . . . . . . . $70 \mathrm{I}$

Misunderstandings as to the Question at Issue. J. Arthur Thomson $40 \mathrm{I}$

The Inheritance or Sun-Inheritance of Acquired Characters. Edain

Grant conklin. . . . . . . . . . . . 408

The Other sike of the (ruestion . . . . . . . . . 4It

1 T'onil le Nechinism for the Transmission of Acquired Characters.

Hiche? ?. Ciabr . . . . . . . . . . . . . 416

Recent Experiments believed to Favor the Lamarckian Theory • 423

Chipter XXXit. (Jifer I'ossible Guiding Factors . . . . 420

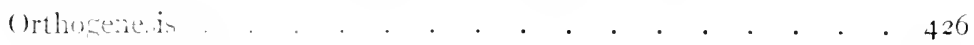

Vitalistic Theries . . . . . . . . . . 428 


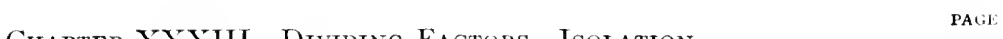

Chapter XXxili. Dividing Factors. Isolation • • • . 430

Introductory . . . . . . . . . . . . . . . . 430

"Isolation" Used in the Broadest Sense . . . . . . . . 431

Isolation and Inbreeding . . . . . . . . . . . 431

Isolation and Selection . . . . . . . . . . . 432

The Various Categories of Isolation . . . . . . . 432

a) Geographic Isolation . . . . . . . . . . . . 432

b) Isolation Due to Sheer Distance Apart . . . . . 435

c) Climatic Isolation . . . . . . . . . . . 436

d) Biotic Isolation . . . . . . . . . . . . 436

e) Reproductive Isolation . . . . . . . . . . 436

f) Psychic Isolation . . . . . . . . . . 438

\section{PART IV. EUGENICS}

Chapter XXXiV. Introduction to Eugenics . . . . . . 44l

Definitions of Eugenics . . . . . . . . . . . . . 441

The Scope of Eugenics . . . . . . . . . . . . 442

The Aims and Ideals of Eugenics . . . . . . . . . 443

Methods of Research in Eugenics . . . . . . . . . . $4+4$

Chapter XXYV. Human Heredity as Revealed by Pedigrees • 446

Weaknesses of the Pedigree Method . . . . . . . . . 440

Some Hereditary Traits in Man . . . . . . . . . . 447

Some Pedigrees of Dominant Characters . . . . . . 450

A Typical Pedigree of a Recessive Character . • . . . 453

Heredity of Mental Traits in Man . . . . . . . . 456

The Heredity of Feeble-mindedness . . . . . . . . 458

Insanity and Heredity . . . . . . . . . . . . 46 I

Pedigrees of Royal Families . . . . . . . . . 462

Chapter XXXYi. The Statistical Study of Heredity in MaN • 470

Introduction . . . . . . . . . . . . . . . 470

Galton's Statistical Studies of Heredity in Man . . . . . 47 I

Criticism of Galton's Work . . . . . . . . . . 474

Galton's Data in the Light of Genetics . . . • • 475

Chapter Xtxit. Twins and Heredity . • • • . • . 476

I. The Biology of Twins . . . . . . . . . . . 476

Various Kinds of Twins . . . . . . . . . . . 476

The Origin of Identical Twins . . . . . . . . 478

II. The Twin Method of Studying Heredity in Man . . . . 480

III. Crime and Destiny . . . . . . . . . . . . . $4 s_{t}$

IV. Twins and the Relative Potency of Heredity and Environment +85 


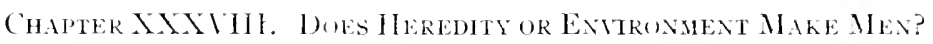

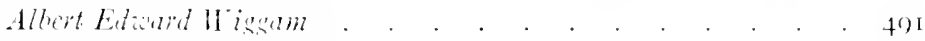

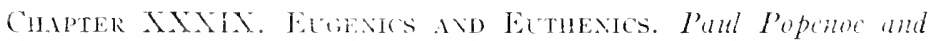
Rosidell H. Johnson . . . . . . . . . . . . . 50\%

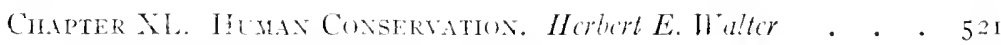

I. How Mankind May Be Improved . . . . . . . . 521

2. More Factir Needed . . . . . . . . . 521

3. Further Application of What We Know Necessary . . • . 522

4. The Restriction of Lndesirable (ierm l'lasm . . . . . . 523

5. The Conservation of Desirable Cierm Plasm . . . . . 528

6. Who shall Sit in Julmment? . . . . . . . . . 530

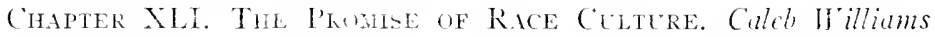
Salcely.

\section{I'ART V. ACCHSSORY REDIING}

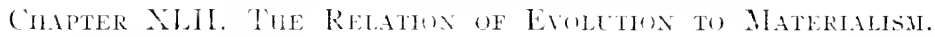
Joseph Le Conte . . . . . . . . . . . . . . 547

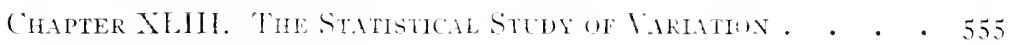

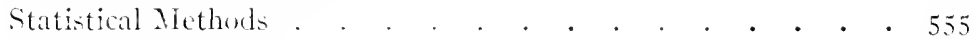

Bimodal and Multimotal Curves . . . . . . . . . . $55^{8}$

The Coeficient of Correlation . . . . . . . . . . . . 554

Chapter Alit. The Pirsical Basis of Mexdelisi. Ermest $B$.

Bulderk and Roy E. Clensen . . . . . . . . . . . 56r

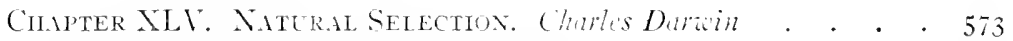

Founlation Stones of Natural Selection . . . . . . . . . 573

Darwin's Own Estimate as to the Rôle of Natural Selection in

Evolution . . . . . . . . . . . . . . 573

Effects of Habit and of the Lse or Disuse of Parts; Correlated

Variation: Inheritance . . . . . . . . . . 574

Darwin's Idea of the Causes Respronsible for the Origin of Inomes-

tic Races . . . . . . . . . . . 575

Darwin's Idea of the Origin of Varieties, Species, and Genera in

Nature . . . . . . . . . . . . 575

The Term "Struggle for Existence" Used in a Large Sense . . 576

Geometrical Ratio of Increase . . . . . . . . . . . . 5 5

Natural Selection; Or the Survival of the Fittest . . . . . 57 .

Sexual Selection . . . . . . . . . . . . 534

Illustrations of the Action of Natural Selection, or the Survival

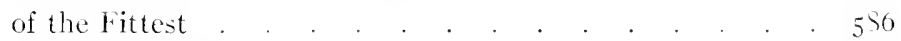

Summary of Chapter on Natural Selection . . . . . . . 557

Difficulties and Objections to Natural Selection as Seen by. Darwin 590 
Auswer to the First Difficulty

Answer to the First Difficulty . . . . . . . . . . 591

Answer to the Second Difliculty: Organs of Extreme Perfection an.l Complication . . . . . . . . . . . . $59 \mathrm{I}$

Darwin's Summary of His Answer to the Third Difficulty, That of Accounting for the Acquisition and Modification of Instincts through Natural Selection . . . . . . . . 595

Darwin's Summary of His Answer to the Difficulty as to the Inability of Natural Selection to Account for the Fact That Species When Crossed Are Sterile or Produce Sterile Offspring, Whereas Vithen Varieties Are Crossed Their Fertility is Unimpaired . . . . . . . . . . . . . . 596

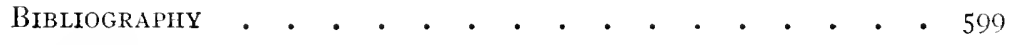

GLOSSARY • • • • • • • • • • • • • • 602

INDEX . . . . . . . . . . . . . . 6II 


\section{LIST OF IILUSTRATIONS}

FIGURE:

I. SKELETUN UF SEIL

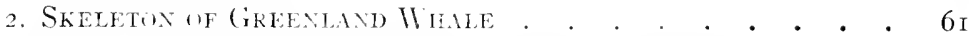

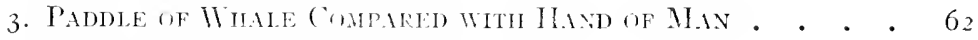

4. Wiscof Reptile, MAmile, AxD Bird . . . • • • • 63

5. Sketetur of Dingmis ratis . . . . . . . . 66

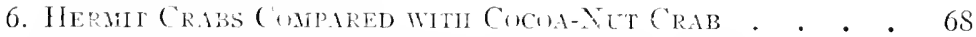

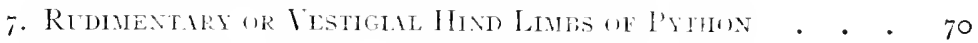

S. Aptery unstialis . . . . . - . . . . . . . . 7 I

o. Illestratius uf the Nictitative Membrine in Variuls Aximils . . . . . . . . . . . . . 76

io. Rudmentary, ok Vestrila and Cseless, Mescles of tile JUMAN EAR . . . . . . . . . . . . .

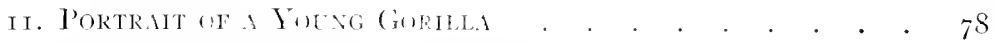

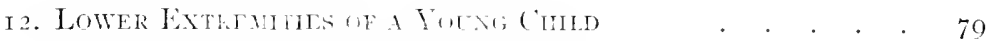

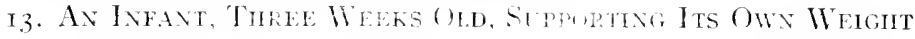
FOR ONEK TW, MINIES. . . . . . . . . . . SO

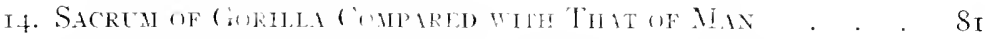

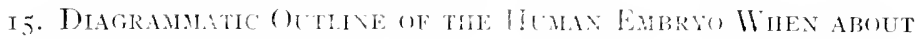
SEVEN WiRk (ILD . . . . . . . . . . . . 82

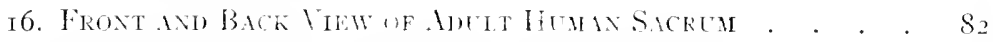

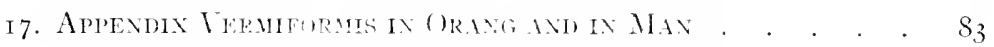

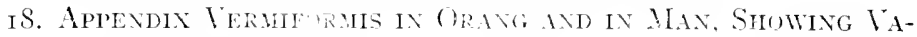
RLATON IN THE OKANG . . . . . . . . . . . . 83

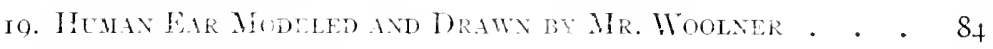

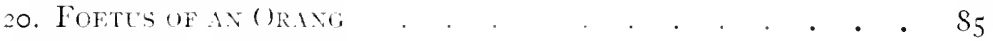

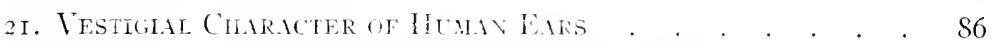

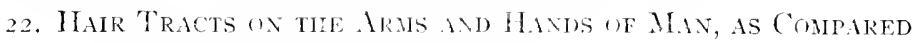

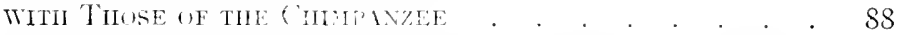

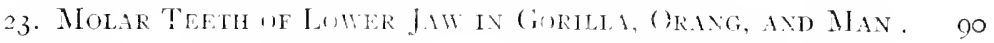

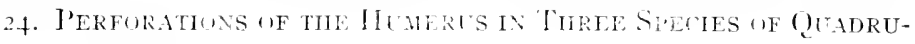
$\operatorname{MiNA}$

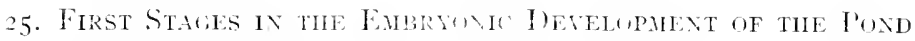
SNAIL, L., . . . . . . . . . . . . . . . . . . .

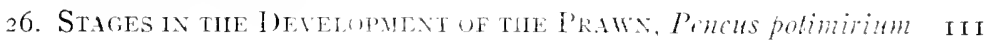
$\mathrm{xx}$ : 
FIGURE

27. Later Stages in the Development of tile Prawn, Peneus potimirium

28. Metamorpiosis of a Barnacle, Lepas

I I 2

29. Embryos in Corresponding Stage of Develophent of Sihare,

Fowl, AND MAN . . . . . . . . . . . . . IIS

30. Total Geologic Time Scale . . . . . . . . . iz I

3i. Feet and Teeth in Fossil I'edigree of the Horse . . . I35

32. Four Stages in the Evolution of the Cameline Skull . 137

33. Four Stages in the Evolution of the Cameline Fore Font . izs

34. Evolution of Head and Molar Teetil of Mastodons and

Elephants . . . . . . . . . . . . 140

35. Skull of Java Ape-Man, Pithecanthropus erectus . . . . I50

36. Jaws of Man and of tile Apes . . . . . . . . . I5I

37. Restoration of Premistoric Men . . . . . . . . . 153

38. Neanderthaloid Skuld of La Chapelle-aux-Simts . . I5t

39. Skeleton of Neandertifal Man . . . . . . . . 555

40. Diagram of a Typical Cell . . . . . . . . . . 102

4. Diagram of the Early limases of Mitosis . . . . . . iof

42. Diagram of the Midde l'ilases of Mitusis . . . . . 105

43. Diagram of the End Phases mf Mitosis . . . . . . 100

44. The Germ Track in Ascaris . . . . . . . . . 20 I

45. Diagran of tile Germ Track in Ascuris . . . . . 20,3

46. Thle Germ Trach in Miastor . . . . . . . . . 204

47. Diarram To Illustrate Spermatogenesis . . . . . 205

4. Diagram To Illustrate Oögenesis . . . . . . . . 206

49. Diagram Showing Parallel between Maturation of Sperai-Cell AND OF Otul . . . . . . . . . . 207

50. Diagram To illustrate Fertilization . . . . . . 208

51. Diagram To Illustrate tie Results of Selection in Pure LINES . . . . . . . . . . . . . 2 . 216

52. An Armadillo Egg Showng Quadruplet Embryos . . 220

53. Diagram Shoming Cimomosome Relations ix tife DeterminaTION OF SEX . . . . . . . . . . . . . . 222

54. A Typical Opposite-sexed Pair of Cattle Twixs . . 230

55. Diagram Illestrating Bemaitor of Chromosomes in Mendel's Cross of Tall and Dwarf l'eas . . . . . . 240

56. Diagram Illustrating Behatior of First IIybrin GeseraTION WHEN INBRED 
57. Diagram Ilefestrativg Dimitrid Ratio

5S. Diagram Simwixi I Iow tie Origixal Schene Mest Be Modi-

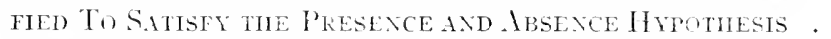

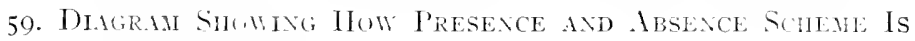
ACTUMLY LSED

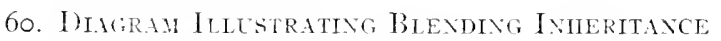

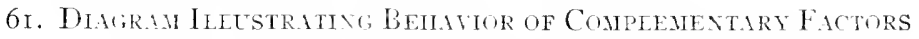
256

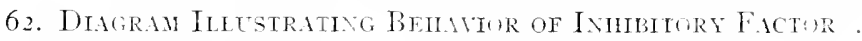

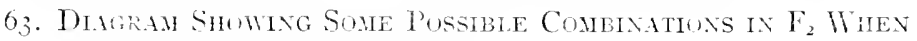
$\mathrm{F}_{\mathrm{I}}$ of Firute 62 Is INBRed . . . . . . . . . . 262

64. Dharad Shening the Hiterozygote Sittation * . . 262

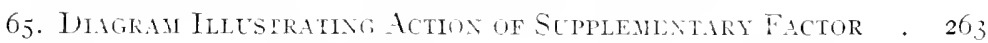

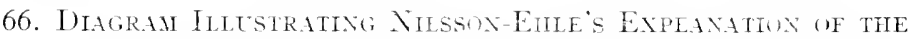

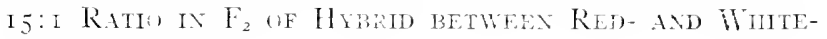

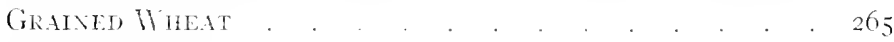

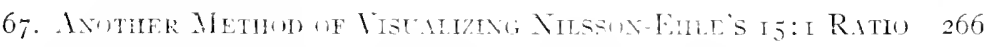

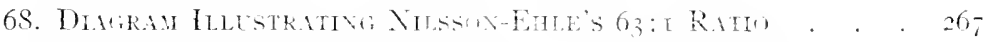

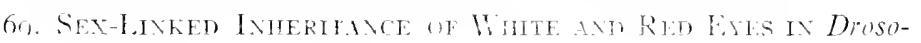
philil . . . . . . . . . . . . 280

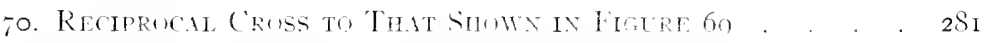

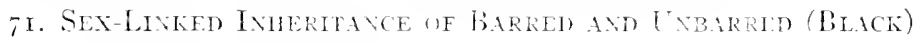

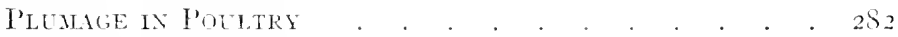

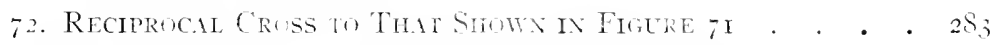

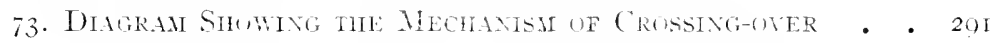

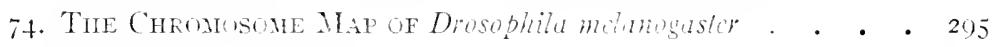
75. Oenothere lamarkima . . . . . . . . . . . 3It

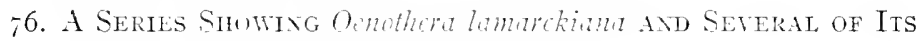
MLTANTS GROMIVG SIDE BT SIDE

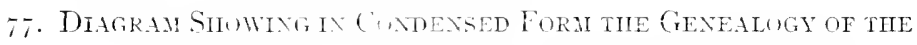

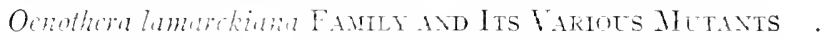

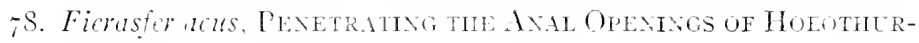
IANS .

79. Kallima, the "I)eAd-Leif Butterfey" . . . . . . . 36!

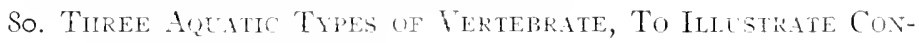
VERGent IDAfTATIN. . . . . . . . . . . . . 367

Si. Pedigree Srawhin Meredity of Brachydactyly . . . . $45 \mathrm{I}$ 
TIGURE PAgF

82. Pedigree Showha Heredity of Cataract . • • • . 452

83. Pedigree Silowing Heredity of Albinism . . • • . 454

8. Pedigree Showing Heredity of Nigitt-ibindness . • • • 455

85. Penigree of tile Darwin-Galton-lVedgewood Famley . . 45;

86. I'edigree Showing Heredity of Feeble-mintidess . . . 460

87. Pedigree Showing Heredity of Feeble-mindedness . . †60

88. Diagram To Illustrate Galton's "Law of Iilial Regres-

SION" . . . . . . . . . . . . . . 472

89. Diagram To Illustrate Galton's "Law of Ancestral Simkes in Inimeritance" . . . . . . . . . . . . . . 473

90. Typical Fraternal Twins . • • • • • • • • • 477

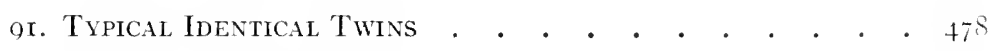

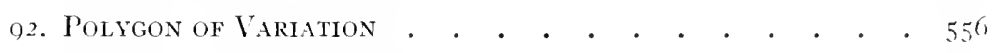

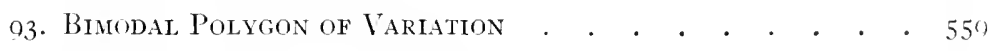

04. Correlation Table of Sixty-Day Oats . . . . . . . 560

95. Cirronosones of Drosophila melanogaster . . . . . . . 562

96. Diagram of Mitosis . . . . . . . . . . . . 564

07. The Reduction Division . . . . • • . • . . 566

98. Diagram of Cimbomatin Interciange • • • • • • . 568

99. Diagram of Independent Segregation . . . . . . . 560

ioo. Diagram Showing Chromosome Relations in tile Injieri-

TANCE OF SEx . . . . . . . . . . . . . $57 \mathrm{I}$ 


\section{PART I}

NTRODUCTURY AND HISTORICAL 


\section{CHAPTER I \\ INTRODUCTION}

\section{WHAT ORGANIC EVOLUTION IS-DEFINITIONS}

The following selections are representative both of the older and of the newer attitudes of thinkers on the subject of organic evolution. The earlier writers were greatly impressed with the sublimity of the idea and found it in full accord with their religious faith. The later writers are less awed by the vastness of the process and hence adopt a more completely materialistic attitude. It is not necessary, however, to discard one's religious beliefs in order to adopt a scientific attitude toward the problems of organic evolution. ${ }^{\mathrm{I}}$ These points of view are well expressed in the following quotations.

"The world has been evolied, not created; it has arisen little by little from a small beginning, and has increased through the activity of the elemental forces embodied in itself, and so has rather grown than suddenly come in to being at an almighty word. What a sublime idea of the infinite might of the great Architect! the Cause of all causes, the Father of all fathers, the Ens entium! For if we could compare the Infinite it would surely require a greater Infinite to cause the causes of effects than to produce the effects themselves.

"All that happens in the world depends on the forces that prevail in it, and results according to law; but where these forces and their substratum, Matter, come from, we know not, and here we have room for faith. "-Erasmus Darwin, ${ }^{2}$ as interpreted by Weismann.

"When I first came to the notion, . . . . of a succession of extinction of species, and creation of new ones, going on perpetually now, and through an indefinite period of the past, and to continue for ages to come, all in accommodation to the changes which must continue in the inanimate and habitable earth, the idea struck me as the grandest which I had ever conceived, so far as regards the attributes of the Presiding Mind."-From a letter of Sir Charles Lyell to Sir John Herschel, 1836.

I See Joseph Le Conte, Relation of Evolution to Materialism, Appendix.

- From R. S. Lull, Organic Evolution (The Macmillan Company. Reprinted by permission). 
"It is interesting to contemplate a tangled bank, clothed with many plants of many kinds, with birds singing on the bushes, with various insects flitting about, and with worms crawling through the damp earth, and to reflect that these elaborately constructed forms, so different from each other, and dependent upon each other in so complex a manner, have all been produced by laws acting around us. These laws, taken in the largest sense, being Growth with Reproduction; Inheritance which is almost implied by reproduction; Variability from the indirect and direct action of the condition of life, and from use and disuse; a Ratio of Increase so high as to lead to a struggle for Life, and as a consequence to Natural Selection, entailing Divergence of Character and the Extinction of less-improved forms. Thus, from the war of nature, from famine and death, the most exalted object which we are capable of conceiving, namely, the production of the higher animals, directly follows. There is a grandeur in this view of life, with its several powers, having leeen originally breathed by the Creator into a few forms or into one; and that, while this planet has gone cycling on according to the fixed law of gravity, from so simple a beginning endless forms most beaut iful and most wonderful have been, and are being evolved. "-Charles Darwin, Orisin of Species, concluding paragraph.

"Speaking broadly we find as a fact that transmutation of species through the geologic ages has been accompanicd !y increasing divergence of type, by the increased specialization of certain forms, and by the closer and closer adaptation to conditions of life on the part of the forms most highly specialized, the more perfect adaptation and the more elaborate specialization being associated with the greatest variety or variation in the environment. Accepting for this process the name organic evolution, Herbert Spencer has deduced from it the general law, that as life endures generation after generation, its character, as shown in structure and function, undergoes constant differentiation and specialization. In this view, the transmutation of species is not merely an observed process, but a primitive necessity involved in the very organization of life itself."-D. S. Jordan and V. L. Kellogg, Evolution and Animal Life (1908), p. 4.

"The Doctrine of Evolution is a body of principles and facts concerning the present condition and past history of the living and lifeless things that make up the universe. It teaches that natural processes 
have gone on in the earlier ages of the world as they do to-day, and that natural forces have ordered the production of all things about which we know."-Henry Edward Crampton, The Doctrine of Evolution (IgI I), P. I.

"Evolution is the gradual development from the simple unorganized condition of primal matter to the complex structure of the physical universe; and in like manner, from the beginning of organic life on the habitable planet, a gradual unfolding and branching out into all the varied forms of beings which constitute the animal and plant kingdoms. The first is called Inorganic, the last Organic Evolution." --Richard Swann Lull, Organic Evolution (rgr7), p. 6.

\section{THE MODERN ATTITUDE AS TO THE TRUTH OF THE EVOLUTION DOCTRINE}

"Among that public which, though educated and intelligent, is not yet professionally scientific, there has been, of late, a widespread belief that naturalists have become very doubtful as to the truth of the theory of evolution and are casting al out for some more satisfactory substitute, which shall better explain the infinitely varied and manifold character of the organic world. This belief is an altogether mistaken one, for never before have the students of animals and plants been so nearly unanimous in their acceptance of the theory as they are to-day. It is true that there are still some dissentient voices, as there have been ever since the publication of Darwin's 'Origin of Species,' but the whole trend of scientific opinion is strongly in favor of the evolutionary hypothesis."--William Berryman Scott, The Theory of Evolution, p. I.

"But the biological sciences were still slower [than the physical sciences] to come to their true position as dignified science. Here was the last stronghold of the supernaturalist. Thrust out from the field of 'physical science' it was in the phenomena of life that the last stand was made by those who claim that supernatural agency intervenes in nature in such a way as to modify the natural order of events. When Darwin came to dislodge them from this, their last intrenchment, there was a fight, intense and bitter, but, like all attempts to stay the progress of human knowledge, this final struggle of the supernaturalists was foredooned to failure. The theory of evolution has taken its place beside the other great conceptions of natural relations, and largely through its establishment biology has become truly a science 
with a large group of phenomena consistently arranged and properly classified. The discussion which followed the publication of Darwin's 'Origin of Species' lasted for nearly a generation, but it is now practically closed, so far as any attempt to discredit evolution as a true scientilic generalization is concerned. Scientists are no longer questioning the fact of evolution; they are busied rather with the attempt to further explore and more perfectly understand the operation of the factors that are at work to produce that development of animals and plants which we call organic evolution."-Maynard M. Metcalf, $A n$ Outline of the Theory of Organic Evolution (IgI I), pp. xxii-xxiii.

"Biologists turned aside from general theories of evolution and their deductive application to special problems of descent, in order to take up objective experiments on variation and heredity for their own sake. This was not due to any doubts concerning the reality of evolution or to any lack of interest in its problems. It was a policy of masterly inactivity deliberately adopted; for further discussions concerning the causes of evolution had clearly become futile until a more adequate and critical view of existing genetic phenomena had been attained."-E. B. Wilson (address as president of the American Association for the Advancement of Science, I9I.4).

"The theory of development, as it was revived by Darwin nearly half a century ago, is in its modern form prevailingly unhistorical. True, it has forced beneath its sceptre the methods of investigation of all the sciences which deal with the living world and to-day almost completely controls scientific thought. . . . . And yet science does not sincerely rejoice in its conquests. Only a few incorrigible and uncritically disposed optimists steadfastly proclaim what glorious progress we have made; otherwise, in scientific as in lay circles, there prevails a widespread feeling of uncertainty and doubt. Not as though the correctness of the principle of descent were seriously questioned; rather does the conviction steadily grow that it is indispensable for the comprehension of living nature, indeed selfevident."-Gustav Steinmann (translated by W. B. Scott from Die Abstammungslehre [1908], pp. I-2).

"The many converging lines of evidence point so clearly to the central fact of the origin of forms of life by an evolutionary process that we are compelled to accept this deduction, but as to almost all the essential featurcs, whether of cause or of mode, by which specific 
diversity has become what we perceive it to be, we have to confess an ignorance nearly total."--W'iliam Bateson, Problems of Genetics (r913), p. 248.

"The demonstration of evolution as a universal law of living nature is the great intellectual achievement of the nineteenth century. Evolution has outgrown the rank of a theory, for it has won a place in natural law beside Newton's law of gravitation, and in one sense holds a still higher rank, because evolution is the universal master, while gravitation is among its many agents. Nor is the law of evolution any longer to be associated with any single name, not even with that of Darwin, who was its greatest exponent. It is natural that evolution and Darwinism should be closely connected in many minds, but we must keep clear the distinction that evolution is a law, while Darwinism is merely one of the several ways of interpreting the workings of this law.

"In contrast to the unity of opinion on the law of evolution is the wide diversity of opinion on the causes of evolution. In fact, the causes of the evolution of life are as mysterious as the law of evolution is certain. Some contend that we already know the chief causes of evolution, others contend that we know little or nothing of them. In this open court of conjecture, of hypothesis, of more or less heated controversy the names of lamarck, of Darwin, of Weismann figure prominently as leaders of different schools of opinion; while there are others, like myself, who for various reasons belong to no school, and are as agnostic about Lamarckism, as they are about Darwinism or Weismannism, or the more recent form of Darwinism, termed Mutation by De Vries.

"In truth, from the period of the earlier stages of Greek thought man has been eacer to discover some natural cause of evolution, and to abandon the idea of supernatural intervention in the order of nature. Between the appearance of The Origin of Species, in 1859 , and the present time there have been great waves of faith in one explanation and then in another: each of these waves of confidence has ended in disappointment, until finally we have reached a stage of very general scepticism. Thus the long period of evolution, experiment, and reasoning which began with the French natural philosopher, Buffon, one hundred and fifty years ago, ends in 1916 with the general feeling that our search for causes, far from being near completion, ba only just begun. 
"Our present state of opinion is this: we know to some extent how plants and animals and man evolve; we do not know why they evolve. We know, for example, that there has existed a more or less complete chain of beings from monad to man, that the one-toed horse had a four-toed ancestor, that man has descended from an unknown ape-like form somewhere in the Tertiary. We know not only those larger chains of decent, but many of the minute details of these transformations. We do not know their internal causes, for none of the explanations which have in turn been oflered during the last hundred years satisfies the demands of observation, of experiment, of reason. It is best frankly to acknowledge that the clief causes of the orderly evolution of the germ are still entirely unknown, and that our search must take an entirely fresh start."-H. F. Osborn, The Origin and Evolution of Life (Charles Scribner's Sons), r9 8 , pp. viii-x.

\section{WHAT ORGANIC EVOLUTION IS NOT}

I. The evolution doctrine is not a creed to be accepted on faith, as are religious faiths or creeds. It appeals entirely to the logical faculties, not to the spiritual, and is not to be accepted until proved.

2. It does not teach that man is a direct descendant of the apes and monkeys, but that both man and the modern apes and monkeys have been derived from some as yet unknown generalized primate ancestor possessing the common attributes of all three groups and lacking their specializations.

3. It is not synonymous with Darwinism, for the latter is merely one man's attempt to explain how evolution has occurred.

4. Contrary to a very widespread idea, evolution is by no means incompatible with religion. Witness the fact that the early Christian theologians, Augustine and Thomas Aquinas, were evolutionists, and the majority of thoughtful theologians of all creeds are today in accord with the evolution idea, many of them even applying the principle to their studies of religion; for religious ideas and ideals, like other human characters, have evolved from crude beginnings and are still undergoing processes of refinement.

5. The evolution idea is not degrading. Quite the contrary; it is ennobling as is well brought out by the classic statement of Darwin on page 4 and by that of Lyell, on page 3 .

6. The evolution doctrine does not teach that man is the goal of all evolutionary process, but that man is merely the present end product of one particular series of evolutionary changes. The goal 
of evolution in general is perfection of adaptation to the conditions of life as they happen to be at any particular time. Many a highly perfected creature has reached the goal of its evolutionary course only to perish because it was too hirhly perfected for a particular environment and could not withstand the hardships incident to radically changed world-conditions. Many evolutions therefore haic i.een completed, while others are still awaiting the opportunity to speed up toward a new goal.

7. Evolution is therefore not entirely a thing of the past. Obviously some species, including Man perhaps, are nearly at the end of their phrsical evolution, but there are always certain generalized plastic types awaiting the next great opportunity for adaptive specialization. 


\section{CHAPTER II}

\section{HISTORICAL ACCOUNT OF THE DEVELOPMENT OF THE EVOLUTION THEORY}

The chief sources of material for the present chapters are: Osborn's From the Greeks to Darwin ${ }^{\mathrm{r}}$ and Judd's The Coming of Evolution. ${ }^{2}$

Professor Osborn studies the evolution of the evolution idea as a biologist would investigate the evolution of a group of species, using all of the available sources of evidence at his disposal. The fragments of ancient writing and the crude imaginings of early natural philosophers are the fossils of the evolution idea, many of them ancestors of modem principles; fragments of ancient or discarded ideas that still persist, though irrelevant to modern thought, are the vestigial structures that proclaim kinship between the past and the present; parallelisms between the development of ideas in the minds of independent thinkers do not prove plagiarism, but indicate common descent from the same ancestral ideas.

This whole history is an important chapter in the story of human evolution in general, for it deals with the evolution of a characteristic human faculty-that of appreciating the broad relations that exist between the past and the present. This faculty has evolved as truly as bas an organic system such as the nervous system, and is unquestionably closely bound up with the latter.

The evolution theory is a vast fabric of interrelated and interdependent facts and principles. The fabric has been gradually woven out of separate threads and now stands strong though flexible, with strands reaching into all sciences and tending to unify all science.

It was only after the lesser ideas came to be clearly apprehended that it was possible for the master minds of Lamarck and of Darwin to weave them together into a consistent fabric and to bring the facts together uncler the one great conception, that of organic evolution. Classification was a science, comparative anatomy had made much progress, the principles of embryology were fairly well understood,

'II. F. Osborn, From the Greeks to Darritin (The Macmillan Company, igo8).

${ }^{2}$ John W. Judd, The Coming of Evulution (Cambridge University Press, I9I I . 
much palaeontological discovery had been made, before it was found that the facts from these sources all pointed to one general principle, and only one, that master-principle "organic evolution."

We shall now trace the development of the evolution idea from its inception among the Greeks to its present status, and shall first give a brief account of Greek evolution.

\section{EVOLUTION AMIONG THE GREEKS}

The early Greek thinkers were sea people. "Along the shores and in the waters of the blue Aegean," says Osborn, "teeming with what we now know to be the earliest and simplest forms of animals and plants, they founded their hypotheses as to the origin and succession of life. .... The spirit of the Greeks was vigorous and hopeful. Not pausing to test their theories by research, they did not sufier the disappointments and delays which come from one's own efforts to wrest truths from Nature."

The Greeks were anticipators of Nature. Their speculations outstripped the facts; in fact were usually made with "eyes closed to the facts." Their theories were inextricably bound up with current mythology, were naïve, vague, and, from our modern point of view, ridiculous; yet they contained many grains of truth and were the germs out of which grew the saner ideas of subsequent thinkers.

Thales $(624-548$ B.c.) was the first of the Greeks to theorize about the origin of life. "He looked upon the great expanse of mother ocean and declared water to be the mother from which all things arose, and out of which they exist." This idea anticipates the modern idea of the aquatic or marine origin of life, and also the present idea as to the indispensability of water in all vital processes.

Anaximander (6II-547 B.C.) has been called the prophet of Lamarck and of Darwin. While his theories were highly mythical in character, he conceived the idea of a gradual evolution from a formless or chaotic condition to one of organic coherence. He saw vaguely the idea of transformation of aquatic species into terrestrial, even deriving man from aquatic fishilke men (mythical mermen) who were able to emerge from the water only after they had undergone the necessary changes required for land life. This idea involves that of adaptation, one of the cornerstones of the modern evolutionary structure.

Anaximenes (588-524 B.c.), a pupil of Anaximander, "found in air the cause of all things. Air, taking the form of soul, imparts life, motion, and thought to animals." It is questionable whether this is a 
prophecy of the importance of oxygen and oxidation in vital processes. Anaximenes also introduced the idea of abiogenesis (spontaneous generation of living sulstance), his idea being that animals and plants arose out of a primordial terrestrial slime wakened into life by the sun's heat. This primordial terrestrial slime is perhaps a prophecy of Oken's "Urschleinı" or of protoplasm.

Xenophanes (576-480 B.c.), proluably another pupil of Anaximander, "agreed with his master so far as to trace the origin of man back to the transition period between the fluid or water and solid or land stages of the development of the earth." He was the first to recognize fossils as the remains of animals once alive, and to see in them proof that once the seas covered the entire surface of the earth.

Heraclitus ( $535-475$ B.C.), the first of a group of physicists, was the great proponent of the philosophy of change. He was imbued with the idea that all was motion, that nothing was fixed. "Everything was perpetually transposed into new shapes." Although Heraclitus did not apply his ideas to living creatures and their evolutions, his philosophy was influential in molding the ideas of his successors.

Empelocies (495-435 B.c.) "took a great stride beyond his predecessors, and may justly be called the father of the Evolution idea. . . . . He believed in Abiogenesis, or spontaneous generation, as the explanation of the origin of life, but that Nature does not produce the lower and higher forms simultaneously or without an effort. Plant life comes first, and animal life developed only after a long series of trials." He thought that all creatures arose through the fortuitous combination of scattered and miscellaneous parts which were attracted or repelled by the forces of love or hate (the two great forces in Nature). Thus arose every sort of combination of parts, some more or less harmonious and complete, others with ill-assorted organization, lacking in some parts, double or triple in others. Some of these combinations could not survive, because of their incompleteness and incongruity, but "other forms arose which were able to support themselves and multiply." This is a sort of vague prophecy of the survival of the ittest or of natural selection. Four sparks of truth may be found in Empedocles' philosophy, "first, that the development of life was a gradual process; second, that plants were evolved before animals; third, that imperfect forms were gradually replaced (not succeeded; by perfect forms; fourth, that the natural cause of the production of perfect forms was the extinction of the imperfect." 
Democritus (b. 45 B.c.), said to have been the first comparative anatomist, contributed to the substructure of evolution the idea of the "adaptation of single structures and organs to certain purposes."

A naxagoras (500-42S B.C.) was the first of the Greeks "to attribute the adaptations of Nature to Intelligent Design, and was thus the founder of Teleology," an idea that has played a retarding function in the history of evolution.

"With Aristotle (384-322 B.c.) we enter a new world," says Osborn. "He towered above his predecessors, and by the force of his genius created Natural History." The evolution idea took a great step forward with Aristotle and reached a stage beyond which it did not go for many centuries. He covered nearly the whole field, touching upon most of the foundation stones of the complex problem. His ideas, like those of all the Greeks, were often vague and, in the light of present knowledge, incoherent; but, considering the meager factual background with which he had to work he had a surprising grasp of the whole situation. Some of his principal ideas were:

1. He had a clear idea of laws of Nature ("Necessity"), anrl attriluted all erolutionary changes to natural causes.

2. He opposed the ideas of Empedocles as to the fortuitous origin of adaptive characters, and favored the idea of intelligent design in nature. He was therefore a teleologist.

3. Hence he rejected the hypothesis of the survival of the fittest, because it was based on chance.

4. He "had substantially the modern conception of the Evolution of life, from a primordial soft mass of living matter."

5. He had an idea of a linear phylogenetic series, beginning with plants, then plant-animals, such as sponges and sea anemones, then animals with sensibility, and thence by graded stages up to Man.

6. "He perceived the unity of type in certain classes of animals, and considered rudimentary organs as tokens whereby Nature sustains this unity."

7. "He anticipated Harvey's doctrine of Epigenesis in embryonic development."

8. "He fully perceived the forces of hereditary transmission, of the prepotency of one parent or stock, and of Atavism and Reversion."

9. He is the father of that ancient fallacy called "prenatal influences," and believed in the inheritance of acquired characters, as is shown in the following passage: 
"Children resemble their parents not only in congenital characters, but in those acquired later in life. For cases are known where parents have been marked by scars and children have shown traces of these scars at the same points; a case is also reported from Chalcedon in which a father had been branded with a letter, and the same letter somewhat blurred and not sharply defined appeared upon the arm of the child."

\section{POST-ARISTOTELIANS}

With Aristotle the evolution idea reached a high watermark and thereafter the tide steadily declined. Pliny, Epicurus, Lucretius, and others kept the idea alive, but added nothing of importance to Aristotle's contribution.

Lucretius (99-55 B.c.) appears to have been chiefly a follower of Empedocles in so far as his ideas as to the origin of animals are concerned. He ignored Aristotle and his much more advanced philosophy of Nature, finding the earlier, more mythical conceptions hetter suited to poetic expression. He was not truly an evolutionist, for he believed that all animals and plants arose fully formed from the earth. Lucretius is of importance chiefly as a retarding factor, for his ideas were accepted and admired even up to the eighteenth century; witness Milton's immortal verse:

"The Earth obey'd, and straight, Op'ning her fertile womb, teem'd at a birth Innumerous living creatures, perfect forms, Limb'd and full grown."

\section{THE FARLY THEOLOGIANS}

The evolution idea made no progress from the time of Aristotle until the revival of learning in the Middle Ages. The chief inhibiting factor was the church, which favored traditional knowledge and the special-creation idea in its most literal form. Yet the early theologians, such as Gregory, Augustine, and Thomas Aquinas, were openminded about the evolution idea and attempted to reconcile it with the scriptural account of creation.

"Gregrory of Nyssa (33I-396 A.D.) taught," says Osborn, "that Creation was potential. God imparted to matter its fundamental properties and laws. The objects and completed forms of the Universe developed gradually out of chaotic material." 
A ugustine (353-430 A.D.) conceived the idea, now so generally adopted by theologians, that the biblical account of creation is allegorical. "In explaining the passage 'In the beginning God created heaven and the earth,' he says:

"In the beginning God made the heaven and the earth, as if this were the seed of the hearen and the earth, although as yet all the matter of heaven and of earth was in confusion, but because it was certain that from this the heaven and the earth would be, therefore the material itself is called by that name."

Thomas Aquinas (1225-74), who wrote much later and was one of the leading church authorities, satisfied himself with merely expounding Augustine: "As to the production of plants, Augustine holds a different view, . . . . for some say that on the third day plants were actually produced, each in its kind-a view favoured by the superficial reading of Scripture. But Augustine says that the earth is then said to have brought forth grass and trees causaliter; that is, it then received the power to produce them. For in those first days .... God made creation primarily or causaliter, and then rested from His work."

\section{THE REYTVAL OF SCIENCE}

During the long centuries until the awakening of science in the Middle Ages the evolution idea smouldered along in the minds of a few thinkers, but it was only when a few daring spirits broke the trammels of scholasticism and began once more to give free rein to observation and speculation that the idea once more burst into flame and began its second great period of advance.

A small group of natural philosophers, scarcely more scientific in their methods than the Greeks, were the first to revive interest in the evolution idea. Of these the names of Bacon, Descartes, Leibnitz, and Kant are the most famous.

Francis Bacon ( $156 \mathrm{I}-\mathrm{I} 626$ ) did much to revive the vogue of Aristotelian ideas. He also added some new ideas: (I) that the mutability of species was the result of the accumulation of variations; (2) that variations of an extreme kind, equivalent to "mutations," sometimes occur; (3) that new species might arise by a degenerative process from old species.

Emmanuel Kant (I724-1804) was purely a philosopher, not an observing naturalist, but he profited by the writings of the contemporary naturalists, especially those of Buffon and Katupertuis. His. 
general ideas of evolution were comprehensive and summed up the best features of all preceding writers, but he did not contribute anything new to the pressing problem of the causes of evolution.

Real progress was not to be made through further speculation. What was most needed was facis, and it was the task of the naturalists to furnish these. The earliest of the eighteenth-century naturalists were still anticipators of Nature in that their theories outran their facts. Of these the names of Bonnet and Oken are the best known.

Bonnet ( $1720-93$ ) was an evolutionist only in the sense that he believed that the adult organism is present in the egg and evolves from it by a process of unfolding or expansion. He was a zoölogical observer of some note, however, and made some of the most important contributions of his time to the general subject. He believed "that the globe had been the scene of great revolutions, and that the chaos described by Moses was the closing chapter of one of these; thus the Creation described in Genesis may be only a resurrection of animals previously existing." This theory admits of no progress and is scarcely worthy of the name evolution.

Oken (1776-1851) is known chiefly for his "Urschleim" doctrine and his ideas of cells as vesicular units of life. According to him, "Every organic thing has arisen out of slime and is nothing but slime in various forms. This primitive slime originated in the sea from inorganic matter." These ideas are purely speculative, but suggest our modern ideas of protoplasm and cells.

THE GREAT NATURALISTS OF THE EIGHTEENTH CENTURY

Three great names stand out above all the rest during this period: those of Linnaeus, Buffon, and Erasmus Darwin.

Linnaeus ( $1707-78$ ) was the father of taxonomy. He contributed facts rather than theories; he invented our present system of binomial nomenclature of both animals and plants, and a great many of his generic and specific names still persist. Unfortunately he was an ardent advocate of the special-creation idea, holding that all of the true species were created as they are known today, except that new combinations may have arisen through hybridization or through degeneration. His influence was great, but was reactionary and proved a serious hindrance to the progress of the evolution idea.

Buffon (1707-88), born the same year as Limnaeus, has been recognized as the father of the modern applied form of the evolution idea. He attempted to explain particular cases on an evolutionary 
basis. He lived at a time when it was dangerous to express views that might be interpreted as unorthodox, and this may account for the apparent lacl: of conviction in his own ideas; for he wavered between special creation and evolution. His chief contribution is the idea of the direct influence of the environment in the modification of the structure of animals and plants and the conservation of these modifications through heredity. This seems to imply that he believed in the inheritance of acquired characters. $\mathrm{He}$ expressed himself as believing that climate has had a direct effect in the production of various races of man, that new rarieties of animals have been formed through human intervention (an idea implying artificial selection), that similar results are produced by geographic migration and through isolation. He expressed the view that there is a great struggle for existence among animals and plants to prevent overcrowding and to maintain the balance of Nature. This appears to be an anticipation of Malthus' ideas on population, which were so influential in shaping the theories of Charles Darwin and of Wallace.

While many of his ideas appear to be highly advanced for his time, his special applications are open to serious criticism. He reasons, for example, that the pig as it exists at present could not have been formed on any original complete and perfect plan, but seems to have been formed as a compound from other animals. It has useless parts which could hardly have been a part of a perfect plan as originally conceived. He thought that "the ass is a degenerate horse, and the ape a degenerate man."

On the whole Buffon was not a strong advocate of evolution and his influence was far from being as important as some recent writers appear to believe.

Erasmus Darwin (1731-1802), grandfather of Charles Darwin, was a physician, a naturalist, and a minor poet. Undoubtedly he transmitted to his grandson his thoughtful habit and love of science and was influential in shaping his ideas on evolution. The elder Darwin's theories as to the causes of evolution closely paralleled those of Lamarck, his distinguished contemporary in France, but it is now very generally conceded that the ideas of the two men were independently derived from similar materials. Erasmus Darwin laid little emphasis on the direct action of the environment, which had been Buffon's main dependence, and dwelt on the internal origin of adaptive characters. "All animals," he said, "undergo transformations which are in part produced by their own exertions, in response to 
pleasures and pains, and many of these acquired forms or propensities are transmitted to their posterity." One could ask for no clearer statement of the idea that acquired characters are inherited.

The fierceness of the struggle for existence was clearly recognized by Dr. Darwin. He considers that this struggle is beneficial to Nature as a whole because it checks the too rapid increase of life. One step farther in the argument, and he would have arrived at the idea of the survival of the fittest, but he never took that step. He agreed with the early Christian fathers in his belief that the powers of development were implanted within the first organisms by the Creator and that subsequent evolution of adaptive characters went on without further divine intervention. The power of improvement rests within the creature's own organizations and is due to his own efforts. The effects of these efforts, he believes, are transmitted to offspring so that there might be a cumulative effect throughout many generations of the results of effort.

Erasmus Darwin was perhaps the first to express clearly the ideas that millions of years have been required for the processes of organic evolution and that all life arose from one primordial protoplasmic mass. He writes as follows:

"From thus meditating upon the minute portion of time in which many of the above changes have been produced, would it be too bold to imagine, in the great length of time since the earth began to exist, perhaps millions of ages before the commencement of the history of mankind, that all warm-blooded animals have arisen from one living filament, which the first great Cause imbued with animality, with the power of acquiring new parts, attended with new propensities, directed by irritations, sensations, volitions, and associations, and thus possessing the faculty of continuing to improve by its own inherent activity, and of delivering down these improvements by generation to posterity, world without end?"

\section{LAMARCK}

Lamarck ( $1744^{-1} 829$ ), the greatest of French evolutionists, is now looked upon as "the founder of the complete modern Theory of Descent." Osborn considers him "the most prominent figure between Aristotle and Darwin. One cannot compare his Philosophie zoölogique with all previous and contemporary contributions to the evolution theory or learn the extraordinary difficulties under which he laboured, and that his work was put forth only a few years after he had turned 
from Botany to Zoölogy, without gaining the greatest admiration for his genius. No one has been more misunderstood, or judged with more partiality by over or under praise. The stigma placed upon his writings by Cuvier, who greeted every fresh edition of his words as a 'nouvelle folie,' and the disdainful illusions to him by Charles I)arwin (the only writer of whom Darwin ever spoke in this tune) long placed him in the light of a purely extravagant, speculative thinker. Yet, as a fresh instance of the certainty with which men of science finally obtain recognition, it is gratifying to note the admiration which has been accorded to him in Germany by Haeckel and others, by his countrymen, and by a large school of American and English writers of the present day; to note, further, that his theory was finally taken up and defended by Charles Darwin himself, and that it forms the very heart of the system of Herbert Spencer."

Lamarck's main theory of evolution was expressed by him in the form of his four "laws":

I. Life, by its proper forces, continually tends to increase the volume of every body which possesses it, and to increase the size of its parts, up to a limit which brings it about.

II. The production of a new organ in the animal body results from the supervention of a new want which continues to make itself felt, and a new movement which this want gives rise to and maintains.

III. The development of organs and their powers of action are constantly in ratio to the employment of these organs.

IV. Everything which has been acquired, impressed upon, or changed in the organization of individuals during the course of their liie is preserved by generation and transmitted to new individuais which have deccended from those which have undergone these changes.

It is about the last "law" that the controversy rages, for it urholds the idea that acquired characters are inherited, now known as the "Lamarckian doctrine."

A somewhat more specific statement of Lamarck's theory of evolution may be summed up in the following list of factors which he considered as playing an essential rôle in evolution.

I. "Tavorable circumstances attending changes of environment, coil, food, temperature, etc., supposed to act directly in the case of plants, indirectly in the case of animals and man."

2. "Needs, new physical wants or necessities induced by the changed conditions of life. Lamarck believed that change of habits 
may lead to the origination or modification of organs; that changes of function also modify or create new organs. By changes of environment animals become subjected to new surroundings, involving new ways and means of living. Thus, certain land birds, driven by necessity to obtain their food in the water, gradually assumed characters adapting them for swimming, wading, or for searching for food in the shallow water, as in the case of the long-necled kinds."

3. "Use and disuse. To use an organ is to develop it; not to use it is to eventually lose it. The anterior limbs of birds became capable of sustained flight through use; the hind limbs of whales are lost through disuse, etc."

4. "Competition. Nature takes precautions not to overcrowd the earth. The stronger and larger living things destroy the smaller and weaker. The smaller multiply very rapidly, the larger slowly. A physiological balance is maintained."

5. "The transmission of acquired characters. The advantages gained by every individual as the result of the structural changes resulting from use or disuse are handed down to its descendants who begin where the parent leaves off, and so are able to continue the progression or retrogression of the character."

6. "Cross-breeding. "If when any peculiarity of form or any defects whatsoever are acquired, the individuals in this case, always pairing, they will produce the same peculiarities, and if for successive generations confined to such unions, a special distinct race will then be formed. But perpetual crosses between individuals which have not the same peculiarities of form result in the disappearance of all the peculiarities acquired by the particular circumstances."”

7. "Isolation. "Were not man separated by distances of habitation, the mixtures resulting from crossing would obliterate the general characters which distinguish different nations.' This thought is expressed in his account of the origin of men from apes, and is not applied to living things in general."

In addition to his theories as to the causes of evolution, Lamarcl: was the first to present the irlea of the tree of life, or phylogenetic trer, as a mode of representing animal relationships. All previous classifications had been based on the idea of a single linear phylogenetic series, each lower group leing supposedly ancestral to a higher group, and all in a single chain.

We may best sum up Lamarck's work and influence in the words of Osborn: 
"I.amarck, as a naturalist, exhibited exceptional powers of definition and description, while in his philosophical writines upon Evolution, his speculation far outran his ofservations, and his theory suffered from the absurd iilustrations which he brought forward in support of it. . . . . His critics spread the impression that he believer animals acquired new organs simply by wishing for them. His really sound speculation in Zoölogy was also injured by his earlier thoroughly worthless speculation in Chemistry and other branches of science. Another marked defect was, that Lanaarck was completely carried away with the belief that his theory of the transmission of acquired characters was adequate to explain all the phenomena. He did not, like his contemporaries, Erasmus Darwin and Goethe, perceive and point out, that certain problems in the origin of adaptations were still left wholly untouched and unsolved..... His arguments are, in most cases, not inductive, but deductive, and are frequently found not to support his law but to postulate it.

"It is now a question whether Lamarcli's factor is a factor in Evolution at all! If it prove to be no factor, Lamarck will sink gradually into obscurity as one great figure in the history of opinion. If it prove to be a real factor, he will rise into a more eminent position than he now holds,--into a rank not far beluw Darwin."

CUVIER AND GEOFFROY ST. HILAIRE

Georges Cuiver $\left(1769-183_{2}\right)$ deserves especial mention as one of the strongest negative factors in the development of the evolution idea. He was, first of all, an opponent of Lamarck, and, second, of evolution in generai. He ranged himself with Linnaeus as a special creationist and adrocated the idea of fixity of species. "All the beings," said he, "belonging to one of these forms (perpetual since the beginning of all things, that is, the Creation) constitute what we call species." So able was Cuvier and so much in favor at the French court that he succeeded in throwing Lamarck's views into disrepute and thus greatly retarded the progress of evolution. He was brilliant as a comparative anatomist and palaeontologist and will long be known for his discoveries in these feldis.

E. Geoffroy St. Hilaire $\left(1772-18_{44}\right)$ did his best to defeat the retarding influence of Cuvier. The two engaged in a long and bitter controversy over the evolution idea. While not a supporter of Lamarckism proper, he was a thoroughgoing evolutinnist, favoring 
the doctrine of Buffon, that the direct action of the environment was the sole cause of evolution. He also, in a sense, anticipated De Vries, in that he believed that new species might be formed by transmutation or sudden large variations occurring in one generation. "Hence the underlying causes of transformations," he said, "were profound changes induced in the egg by external influences, accidents as it were, regulated by law." The controversy between Cuvier and St. Hilaire was a losing one for the latter. The cards were stacked against him and after him the evolution idea was retired to comparative obscurity until revived by Charles Darwin.

\section{CATASTROPHISM AND UNIFORMITARIANISM}

The development of the science of geology had a profound influence upon that of evolution. The prevailing theories as to historical geology during the Middle Ages involved the idea of "catastrophism." 'According to this view all important changes in the earth's crust represented sudden radical transformations, involving earthquakes, volcanic outbursts, floods, sudden upliftings of submerged areas, or equally sudden submergence of land bodies. From these ideas naturally grew the related idea of great, world-wide destructions of animals and plants, followed by re-creation of new faunas and floras. Cuvier, for example, interpreted the more or less distinct fossil strata as being the result of a series of tremendous cataclysms, the last of which had been the great deluge of Scripture, in which Noah figured prominently. He thought that at each cataclysm great floods of water had covered the earth, that the existing aninals had been buried in mud and thus preserved as fossils, and that a new creation followed each cataclysm. The great strength of this conception was that it appeared to give scientific support to both special creation and the Mosaic account of the "Flood." As compared with the pure evolutionary conception, this alternative was highly acceptable to the church and was proclaimed as orthodox. The Scotch philosopher and geologist, Hutton, who lived during the last half of the eighteenth century, combated the idea of catastrophism by advocating the doctrine of "uniformitarianism," a view involving the idea that past changes on the earth were the result of the same sort of gradual changes as are observed to be taking place today-in brief, that there has been a strict uniformity of change throughout the entire period of geologic history. There may have been, according to this view, local catastrophes, 
such as volcanic outbursts, earthquakes, and floods, but the main trend of change has been slow and constant, due largely to erosion and allied phenomena. This view had practically no influence on the ideas of the time and for a long period the idea of catastrophism triumphed over the more truly evolutionary view of uniformitarianism; thus the evolution idea was destined to lie dormant till revived by Charles Darwin.

\section{THE REAWAKENING OF THE EVOLUTION IDEA}

A number of important influences paved the way for the rehabilitation of the evolution idea at the hands of the younger Darwin. Which of these was the most important it is difficult to say. Probably Charles Lyell's Principles of Geology and Malthus' On Population were the most suggestive works that Darwin encountered. He was also doubtless influenced by Robert Chambers' Vestiges of Natural History of Creation which appeared in 1844 .

Charles Lyell (1797-1875) so successfully rehabilitated the doctrine of uniformitarianism in geology that it became very generally accepted, thus paving the way for a more favorable consideration of the idea of organic evolution. Charles Darwin as a very young man took Lyell's Principles of Geology with him on his voyage on the "Beagle" and read it with the greatest devotion, as is evidenced by his dedication of the journal of his voyage: "To Charles Lyell, Esq., F.R.S., this second edition is dedicated with grateful pleasure, as an acknowledgment that the chief part of whatever scientific merit this Journal and other works of the author may possess, has been derived from studying the well-known, admirable Principles of Geology."

Malthus' influence on Darwin's ideas is well expressed by Judd as follows:

"Fifteen months after this 'systematic inquiry' began [referring to Darwin's exhaustive working over of his notes taken during his voyage on the 'Beagle'], Darwin happened to read the celebrated work of Malthus 'On Population' for amusement, and this served as a spark falling on a long prepared train of thought. The idea that as animals and plants multiply in geometrical progression, while the supplies of food and space to be occupied remain nearly constant, and that this must lead to a struggle for existence of the most desperate kind, was by no means new to Darwin, for the elder De Candolle, Lyell, and others had enlarged upon it; yet the facts with regard to 
the buman race, so strikingly presented by Malthus, brought the whole question with such vividness before him that the idea of 'Natural Selection' flashed upon Darwin's mind."

\section{CHARLES DARWIN (I8O9-82)}

Charles Darwin is without question the foremost figure in the development of the evolution idea and probably in the development of science in general. The publication of his book, The Origin of Species, in 1859 , was the most important event in biological history. As has been already shown, Darwin's chief ideas had been anticipated not by one but by several of his predecessors. Nevertheless, he was the first to furnish a really adequate proof of the fact of evolution and his causo-mechanical theory to explain the method of evolution was supported by a mass of systematically arranged data such as has been paralleled neither before nor since. Darwin was the first evolutionist effectively to employ the inductive method, that of everywhere seeking facts first and then devising theories to fit the facts. $\mathrm{He}$ never allowed speculation to outstrip observation, as nearly all of his predecessors had done, but made theory await the amassing of facts in its support, until the accumulation of the latter seemed almost to speak out the theory of themselves. Our greatest debt to Darwin is due to his establishment of the factual basis of evolution; his selection theory was relatively of minor significance in so far as its value in the development of the evolution idea was concerned. Yet this latter theory gained the widest acceptance among the scientifically inclined during the entire post-Darwinian period. It has been viciously assailed on all sides and has tottered repeatedly under the attacks of well-trained adversaries. Some of the weaker elements of the theory have given way under stress, and the whole selection factor as a primary causal factor in evolution has been seriously called into question; but since Darwin's time the fact of cvolution has been almost universally accepted.

The story of Darwin's life is almost a romance. "Born in 1809 ," says Lull," "this emancipator of human minds from the shackles of slavery to tradition saw the light of day upon the very day that ushered in the life of Abraham Lincoln, the emancipator of human bodies from a no more real physical bondage. Darwin studied first at Edinburgh, but finding medicine unsuited to his tastes, entered Christ's College, Cambridge, as a candidate for the church. His love

' Richard Swann Lull, Organic Evolution (The Macmillan Company, 1917). 
of Nature, however, dominated all other interess and shortly after graduation an opportunity came to join the ship 'Beagle' as naturalist in a voyage of exploration around the world. The five years spent upon this memorable journey, the narrative of which is so admirably set forth in the book, A Maturaist's l'oyage around the World, resulted in the accumulation of the first of Darwin's great series of olsservations, the final decision to devote his life to zoölogical research, and the beginning of that illness which made him a life-long invalid. This last factor necessitated a retired life and thus proved of indirect benefit, as it enabled him to accomplish the immense amount of work which he did without being impeded by the distractions of a public career."

SUMMARY OF DARWIN'S THEORIES

Since two subsequent chapters are to be deroted to Darwinism, only an outline of Darwin's theories need be presented in the present historical account.

Although Darwin was an all-round biologist and gave attention to practically every phase of evolutionary liology. he is known especially for his selection theories. There are three of these: the theory of artificial selection, the theory of natural selection, and the theory of sexual selection.

a) Artificial selection.-According to Darwin the commonest method of producing, under human culture, new races of animals and plants is that of selection. The breeder selects from among the highly variable individuals of a parent-race those which possess the beginnings of desired modifications, and he breeds them together, expecting that the offspring will show the desired character, some in a more highly perfected condition, others in a less. The ones that vary favorably are again selected for breeding stock, and the same process is carried on until the desired character has been perfecteci.

Although we now know that this is far from leing a typical experience among breeders, it appeared to Darwin to be so typical that he transferred the selection idea from the breeder to Nature, making Nature the selecting agency responsible for the production of natural wild species. His argument is as follows:

b) Natural selection.-The following factors are involved:

I. All animals and plants tend to multiply in geonetrical ratio.

2. There is not food or room for a nuch larger number of animals and plarts than now exist. 
3. All members of a species vary in many if not all directions.

4. Those that vary in the more favorable directions, so as better to fit them to meet the conditions of life, survive in larger numbers than those varying in less favorable directions. This is Spencer's "survival of the fittest."

5. The survivors of one generation become the parents of the next and, therefore, the more favorable characters are passed on more largely than the less favorable.

6. There is in each generation a slow but definite approach toward complete adaptation to life-conditions.

7. Variations neither useful nor harmful would not be affected by natural selection, and would be left either as fluctuating variations or as polymorphic characters.

c) Sexual selection.-This theory was offered to supplement that of natural selection, because Darwin considered the latter as inadequate to explain the facts of sexual dimorphism, or secondary sexual characters. The theory is as follows: There is always a contest among males for possession of females, in which the inferior males are eliminated either because they are, on the one hand, less courageous or weaker cr less well equipped with weapons of combat, or because, on the other hand, the more attractive males, whether on account of colors, cdors, phosphorescence, behavior, etc., would succeed in winning matcs i: om those less endowed. Thus would be enhanced the sexual dimoinism until it reaches extremes in many cases that are truly remial'sable.

The natre of Alfred Russell Wallace (I822-I9I3) will always be associated with that of Charles Darwin as co-author of the theory of natural seicetion. Wallace at the age of twenty-six went on a naturalistic expedition, primarily for collecting specimens from new regions. He covered almost the same ground as did Darwin in his voyage on the "Beagle." Wallace had read Lyell's Principies of Geology, Malthus' On Population, Chambers' Vestiges of Creation. While in Sarawak he tells us: "I was quite alone with one Malay boy as cook, and during the evenings and wet days, I had nothing to do but to look over my books and ponder over the problem which was rarely absent from rny thoughts." While thus engaged the idea of natural selection came to him as though by a sudden flash of insight. When the idea was still in process of formation he wrote it out on thin paper and mailed it to Darwin, stating that he considered the idea new and asking Darwin to show it to Lyell, who had expressed interest in a 
former paper of Wallace. The ideas were expressed under the title On the Tendency of Varielies to Depart Indefinitely from the Original $T y p e$ and it proved to be an unusually concise and lucid statement of the main points of the natural-selection theory. Darwin at once wrote to Lyell as follows:

"I never saw a more striking coincidence; if Wallace had my IS sketch, written in $I_{4} 2$, he could not have made a better short abstract! Even his terms now stand as heads of my chapters. Please return to me the MS which he does not say he wishes me to publish but I shall, of course, at once write and offer to send it to any journal. So all my originality, whatever it may amount to, will be smashed, though my book, if it ever have any value, will not be deteriorated, as all the labour consists in the application of the theory. I hope you will approve of Wallace's sketch, that I may tell him what to say."

Lyell insisted that Darwin publish an abstract of his own work simultaneously with that of Wallace, and this course was carried out. Darwin's generosity was equaled by that of Wallace who wrote, in I870:

"I have felt all my life and still feel the most sincere satisfaction that Mr. Darwin had been at work long before me, and that it was not left for me to attempt to write The Origin of Species. I have long since measured my own strength and know well that it would be quite unequal to the task."

Still later he wrote: "I was then (and often since) the 'young man in a hurry,' he [Darwin] the painstaking student, seeking ever the full demonstration of the truth he had discovered, rather than to achieve immediate personal fame."

One must perforce admit the nobility of character of both men; but there can be no serious competition between the two for the honor of being called the originator of the natural-selection theory.

\section{CONTEMPORARY OPINION REGARDING TEE VALIDITY OF DARWIN'S VIEWS}

At first Darwin was inclined to believe that the selection factor was all-sufficient to account for the origin of species, as well as that of adaptations; but as time passed he modified his earlier more sanguine views and came to the conclusion "that natural selection has been the main but not the exclusive means of modification." Many of his followers went to such extremes in their advocacy of the all-sufficiency of natural selection as would not have met with Darwin's approval. 
"'The first effect of Darwin's works," says McFarland," "was to carry the world of science by storm, but at the same time to arouse intense hostility on the part of the theologians who found the theory of descent .... incompatible with the doctrines of Creation. In this conflict Darwin took no part, but was championed by Huxley, while Bishop Wilberforce led the opposition. The battle was long and bitter, there was much acrimonious writing on both sides, but the theory of descent-the doctrine of evolution-was found to be invulnerable and at present the theologians themselves have accepted it and even make use of it in their own work.

"But as the years flew by the Darwinian doctrines began to meet with assaults from the scientists themselves, who, having endeavored to prove their validity, began to find them inadequate to the requirements of expanding knowledge. The question was asked, 'What is the origin of the fittest ?' Given the fittest, we easily understand how it is perpetuated, but how does it arise? In the striking phrase of someone: 'Natural selection might explain the survival of the fittest but fails to account for the arrival of the fittest!"”

Darwin's main supporters during the most trying controversial period were Herbert Spencer and Thomas H. Huxley.

Herbert Spencer (1820-1903) was an extremely able supporter of the general theory of evolution, but was more definitely an advocate of Lamarckism than of natural selection. His rôle was that of a champion of the whole philosophy of evolution as opposed to special creation, and it was largely due to his forceful writings that Darwinism won the battle against dogmatism. Spencer tried to explain the structure of protoplasm (living substance) on a physicochemical basis. He thought of the structural units of protoplasm as comparable with the molecules of chemical compounds, each local region of the protoplasm in the organism being made up of different kinds of units, which he called "physiological units." This conception of the physical basis of organic structure had a considerable influence in shaping Darwin's ideas and was probably the basis of the latter's provisional theory of "pangenesis." This theory was probably the first consistently worked out theory of the mechanics of heredity. It was thought that every part of the body is continually giving off its particular kind of units ("gemmules") into the blood. These gemmules are transported by the blood stream to all parts of the body and $1918)$.

IJ McFariand, Biology, General and Medical (The Macmillan Company, 
collect in the germ cells. This was supposed to account for the fact that from the germ cell will develop an organism like the parent in various details. If a part of the body was modified through functioning or through changed environment, it would have modified gemmules, which, in turn, would go to the germ cells and carry over the modification to the next generation. This theory was not satisfactory even to Darwin and is now only of historical interest.

Spencer is best known in the history of the evolution theory as an ardent neo-Iamarckian. He states his belief as follows: "Change of function produces change of structure; it is a tenable hypothesis that changes of structure so produced are inherited." This idea prevailed until it was cast down by Weismann.

Thomas Henry Huxley (I $825-95$ ), one of the keenest, most analytical thinkers of the nineteenth century, not only defended the general doctrine of evolution against Bishop Wilherforce and his aids, but was an able investigator in the fields of comparative anatomy and embryology. "At the British Association at Oxford in I850," says Judd, "after an American professor had indignantly asked "Are we a fortuitous concourse of atoms?' as a comment on Darwin's views, Dr. Samuel Wilberforce, the Bishop of Oxford, ended a clever but flippant attack on the Orisin by enquiring of Huxley, who was present as Darwin's champion, if it 'was through his grandiather or his grandmother that he claimed his descent from a monkey?'

"Huxley made the famous and well-deserved retort: 'I assertedand I repeat - that a man has no reason to be ashamed of having an ape for his grandfather. If there were an ancestor whom I should feel ashamed of recalling, it would rather be a man-a man of restless and versatile intellect-who not content with success in his own sphere of activity, plunges into scientific questions with which he has no real acquaintance, only to obscure them by aimless rhetoric, and distract the attention of his hearers from the real point at issue by eloquent digressions and skilled appeals to religious prejudice!'

"Huxley himself accepted the theory of Natural Selection-but not without some important reservations-these, however, did not prevent him from becoming its most ardent and successful champion. Darwin used to acknowledge Huxley's great service to him in undertaking the defense of the theory - a defense which his own hatred of controversy and state of health made him unwilling to undertake-by laughingly calling him 'my general agent' while Huxley himself in replying to the critics, declared he was 'Darwin's bulldog.'" 
Ernst Haeckel (1834-1919) was one of the earliest and most influential followers of Darwin in Germany. In his Generelle Morphologie, published in I866, seven years after the Origin of Species first appeared, he applied the doctrine of evolution, and especially the theory of natural selection, to the whole field of vertebrate morphology. Beyond question Haeckel overapplied the theory and in a sense weakened its influence by his rather uncritical use of materials. His writings have been translated into most languages and "are popularly believed to represent the best scientific thought on the matter." Biologists today, however, are apt to look askance at Haeckel's works and to consider that they did more harm than good to Darwinism.

August I'eismann (1834-I9I4) was the first really original evolutionist after Darwin. Like other thinkers of his time, he realized that further progress in the knowledge of the causal basis of evolution lay in further investigation of the causes of variation and the physicai basis of heredity. Weismann has been classed as a neo-Larwinian because he was a strong advocate of some form of selection, but his "selection" was not the selection of Darwin. Realizing that the greatest weakness of the natural-selection theory lay in its inadequacy as an originator of variations, he proposed the "germinal-selection" theory. He contended that all heritable variations have their origin in the germ cell, and therefore that a new type of organism arises only from a changed type of germ cell. The germinal-selection theory stands out in striking contrast with Darwin's "pangenesis" theory. The former is centrifugal, the latter centripetal. "Determiners" of new characters, according to Weismann, arise in the germ plasm and work outward to all parts of the developing body; while the "gemmules," Darwin's equivalent of determiners, originate in the body tissues and are carried to the germ cells in each generation. According to Weismann, there is a struggle among the determiners for the a vailable food and favorable positions in the germ cell, and those that receive the most food and the best positions gain an initial advantage, so that they are able to initiate the development of larger or more perfectly adapted organs. The descendants through cell division of these favored determiners are in a position to compete with other determiners on a more favorable footing in each succeeding generation, so that the character represented by them steadily increases in a linear or definitely directed fashion until it reaches the state of complete adaptation or fitness. Such a character may even continue its direct line of advance beyond the point of maximum fitness and result in 
what are known as overspecializations. The theory therefore would, if well founded, account not only for the initial stages of new adaptive characters, but also for overspecializations, two phenomena that natural selection was unable to account for. Not only were pro. gressive evolutionary changes explained by germinal selection, but regressive changes seemed to be even more readily accounted for on this basis. In the struggle among determiners in the germ cell some of the less favored units would be handicapped at the outset by insufficient food or unfavorable position and would produce smaller or less effective structures. Progressively, from generation to generation, these weakened determiners would lose ground and become less and less successful in competition until they were weaklings among determiners and would be able to initiate only degenerate or vestigial structures, or else would die out and lose their place altogether, thus accounting for total losses of structures.

This theory does not exclude natural selection, but rather increases its importance, for every structure that arises to the threshold of utility or disutility meets the winnowing process of natural selection. The fitter individuals survive in the long run and these perpetuate the germ cells in which the successful determiners reside.

A slightly different explanation of degenerating structures involves the principle of "panmixia." According to this idea, changing environmental conditions may render certain adaptive organs of lessened value or of no value, as would be the case in the eyes of cave animals. In different individuals the eye determiners would vary in their success in competition with other determiners, and since natural selection would no longer put a premium on perfect eyes, all grades of eyes would be equally inherited and gradually the poorer or degenerate eyes would become more numerous, till finally there would be no good eyes in the race. Thus it will be seen that the germinal-selection theory was auxiliary to natural selection and tended to support the latter at two of its weakest points. But the supporting theory itself has the fundamental weakness of lacking a factual basis. It is purely hypothetical and cannot be put to an experimental test. Every time an objection to the theory was raised an auxiliary hypothesis was added to explain away the difficulty, till finally it fell to the ground through sheer top-heaviness, unable further to support its intricate structure of interrelated hypotheses.

A much more valuable and lasting contribution of Weismann was his theory of "germinal continuity" and of the "apartness of the germ plasm." The whole theory has come to be known as the "germ-plasm 
theory," which forms the framework of nearly all of our modern genetics. According to this view the germ plasm is immortal in that it is perpetuated from generation to generation through the instrumentality of mitotic cell division, each germ cell being the product of the division of a previous germ cell back to the first germ cell that arose at the dawn of life. Thus a germ cell cannot be a product of the soma, but the soma is the product of germ cells. The soma loses its generalized characters and specializes in various ways. Once specialized, soma cells are believed to have lost their capacity to play a germinal rôle. Specialization means mortality. Thus the relationship between parent and offspring is not that the parent gives rise to the offspring, but that the same germ plasm gives rise to both parent and offspring.

The logical conclusion to which this line of reasoning leads is that the changes in the soma, no matter how produced, are helpless to produce any effect upon the germ plasm, since germ cells come only from germ cells and not from soma cells. Consequently Weismann led the assault against Lamarckism and won the day so conclusively that even in these modern times few biologists have the temerity to express aloud any definite belief in the inheritance of acquired characters. Weismann's germ-plasm idea is the cornerstone of modern genetics, though there are some forward-looking biologists who, looking at things with a physiological bias, cannot make themselves believe in the total independence of any tissue- even the sacred germ plasm.

Weismann's influence was very great, especially during the last decade of the nineteenth century, and his theories gave rise to an immense amount of research, chiefly of a cytological and embryological character.

\section{ISOLATION THEORIES}

Among the theories subsidiary to natural selection as an aid to species forming are the various isolation theories. One of the weaknesses inherent in natural selection had to do with the probable swamping out of new types by promiscuous breeding with the more numerous individuals of the older types. "Anything," says Metcalf, "which divides a species into groups, which do not freely interbreed, is said to segregate (isolate) the members of the species into these subdivisions."

Some American writers, especially Jordan and Kellogg, Gulick, and Crampton, have dealt with the isolation factor in evolution and believe 
that it is a major factor of as great importance in species forming, or nearly so, as natural selection. But the prevailing opinion seems to be that isolation is really a kind of selection, more like artificial selection than anything else, which separates out certain pure lines and prevents promiscuous interbreeding. Various agents are known to produce isolation by erecting barriers to interbreeding between groups of individuals within a species. These segregative factors may be geographical, climatic, reproductive, physiological, or, in plants, the result of soil diversity. Thus a mountain range, on the two sides of which a species migrates, effectively separates the species into two independent groups. Heat, cold, moisture, etc., separate others. Reproductive incompatibility between new and older types is equally effective, as is assortative mating of like with like. Like natural selection, isolation has nothing to do with the origin of new types, but merely aids in the preservation of types when once formed. Were there not spontaneous variations among animals and plants, there would be nothing to isolate. Therefore isolation plays only an auxiliary rôle, helping to preserve new races once they are formed.

\section{ORTHOGENESTS THEORIES}

"The orthogenetic evolution theories of various authors, based upon the assumed occurrence of variations in determinate lines or directions (a restricted and determinate variation as compared with the nearly infinite, fortuitous, and indeterminate variation assumed in the selection theories), are of several types. The mention of two will reveal pretty well the more important characters of all. Not a few biologists have always believed in the existence of a sort of mystic, special vitalistic force or principle by virtue of which determination and general progress in evolution is chiefly fixed. Such a capacity, inherent in living matter, seems to include at once possibility of progressive or truly evolutionary change. Not all evolution is in a single direct line, to be sure; ascent is not up a single ladder or along a single geological branch, but these branches are few (as indeed we actually know them to be, however the restriction may be brought about) and the evolution is always progressive, that is, toward what we, from an anthropocentric point of view, are constrained to call higher and higher or more ideal life stages and conditions.

"Other naturalists also seeming to see this source of determinate or orthogenetic evolution, but not inclined to surrender their disbelief in vitalism, in forces over and beyond the familiar ones of the 
physicochemical world, have tried to adduce a definite causomechanical explanation of orthogenesis. The best and most comprehensive types of this explanation are those essentially Lamarckian in principle, in which the direct influence of environmental conditions, the direct reactions of the life stuff to stimuli and influences from the world outside, are the causal factors in such an explanation. But while every naturalist will grant that such factors do change and control in a considerable degree the life of the individual, most see no mechanism or means of extending this control directly to the species."

The above-quoted paragraphs from Jordan and Kellogg will serve to place before the reader the general ideas involved in the orthogenesis conception. A brief account of the various special theories of orthogenesis follows:

Carl von Nägeli's ideas of orthogenesis involve a belief in a sort of mystical principle of progressive development, a something, quite intangible, that exists in organic nature, which causes each organism, to strive for or at least make for specialization or perfect adaptation. This idea of an inner driving and directing force reminds one of the "entelechy" of Driesch, or Bergson's "creative evolution." Nägeli believed that animals and plants would have developed essentially as they have without any struggle for existence or natural selection. This form of orthogenesis theory, then, is alternative to natural selection.

Theodore Eimer's theory of orthogenesis is more scientific and less mystical than Nägeli's. He believed that lines of evolution were not miscellaneous and haphazard, but were confined to a few definite directions, determined at their initial stages not by natural selection but by the laws of organic growth, aided by the inleritance of acquired characters. A new character makes a beginning as would the first step in a slow chemical change, or series of such changes, and it must go through to a fixed end, under given conditions, just as surely as does the chemical process. Only when a given character or line of evolution results in the production of a very positive advantage or disadvantage to the species does natural selection siep in to interfere with orthogenesis. The causes of orthogenesis are said "to lie in the effects of external influeñces, climate, nutrition, or the given constitution of the organism."

Actual species-forming, or the breaking-up into specific units of the orthogenetic lines of change, depends, according to Eimer, upon

'Jordan and Kellogg, Evolution and A nimal Life (D. Appleton and Company). 
three factors: a standstill or cessation of development on the part of some lines; sudden development by leaps (practically mutations); and hindrance or difficulty of reproduction (the type of thing that Romanes emphasized as physiological isolation ten years later). Eimer illustrated his theories by the evolution of color patterns in lizards and those on the wings of butterflies. In both he believed that longitudinal stripes were primitive, that rows of dots followed these which were in turn followed by crossbands, reticular patterns, anil finally by solid coloration. This hypothetical phylogenetic order is more or less closely paralleled by the ontogenetic order, in the lizards at least.

It will be noted that Eimer's theory places natural selection in a subordinate position, but does not dismiss it altogether, as is done by Nägeli. It aids natural selection in explaining adaptations in that it furnishes for natural selection various characters of selective value, which may be either perpetuated or eliminated according to their itility.

E. D. Cope, a leading American palacontologist of the past cencury, had an orthogenetic theory involving his ideas of "bathmism" (growth force), "kinetogenesis" (direct effect of use and disuse and environmental influence), and "archaesthetism" (influence of primitive consciousness). It may be said that his ideas were Lamarckian throughout. In common with the majority of palaeontologists of later date-Oshorn, Williston, Hyatt, Smith, and others-Cope felt the need of some factor other than natural selection to explain the apparent steady progress of characters in definitely directed lincs as seen in the fossils. It is natural therefore that palaeontologists almost universally lay hold of both Lamarckian and orthogenesis ideas.

Charles Olis Whitman, who, until his death over twenty years ago, was considered the leading American zoölogist, had strong leanings toward orthogenesis. In one of his few publications he says:

"Natural selection, orthogenesis, and mutation appear to present fundamental contradictions; but I believe that each stands for truth, and reconciliation is not far distant. The so-called mutations of Oenothera are indubitable facts; but two leading questions remain to be answered. First, are these mutations now appearing, as is agreed, independently of variation, nevertheless the products of variations that took place at an earlier period in the history of these plants? Secondly, if species can spring into existence at a single leap, without the assistance of cumulative variations, may they not also originate with such 
assistance? That variation does issue a new species, and that natural selection is a factor, though not the only factor, in determining results, is, in my opinion, as certain as that grass grows although we cannot see it grow. Furthermore, I believe I have found indubitable evidence of species-forming variation advancing in a definite direction (orthogenesis), and likewise of variations in various directions (amphigenesis). If I am not mistaken in this, the reconciliation for natural selection, and orthogenesis is at hand."

In concluding this brief account of orthogenesis, it should be said that definitely directed evolution is now believed to be one of the laws of organic evolution, but that we have no clear ideas as yet as to what are its underlying causes. Therefore orthogenesis is not a causomechanical theory of evolution at all.

THE MUTATION THEORY OF DE VRIES

The theory of "mutations" is associated with the name of $H u g o$ De Vries, the well-known Dutch botanist; that of "heterogenesis," with the name of $H$. Korchinsky, a Russian.

Though Korchinsky anticipated De Vries by several years, his work was not supported by the large amount of experimental data that characterized that of the great Dutch worker. The relative claims for recognition as the founder of the mutation theory are almost on a par with those of Darwin and Wallace for the naturalselection theory. Both Darwin and De Vries held back their theories until they appeared to be adequately supported by personally collected facts.

There is a striking parallelism between the ideas and conclusions of De Vries and those of Korchinsky, and since this is true a résumé of De Vries's better-known work will serve to give the essentials of the whole conception.

De Vries began his genetic experiments by a study of the variations of plants in the field. After learning their normal variability in nature, he transferred them to the experimental garden and there attempted to improve them by selection. He found that the improved living conditions due to better soil and cultivation induced a wider range of variability in size, luxuriance, and fecundity. Such variations were plus or minus in their character, fluctuating about a mean or average. It was exactly this type of variability that Darwin emphasized as the raw material of evolution; but De Vries found by experiment that selection had no permanent hereditary effect when based 
to fluct uating variations, since the iatter were merely somatic responses on variable growth conditions. This negative finding led him to renewed interest in discontinuous or saltatory variations as the only alternative to fluctuating or continuous variations.

He looked far and wide among species of wild plants for a species that might exhibit a significant amount of saltatory variation and finally discovered in the evening primrose (Oenothera lamarckiana) what seemed to exhibit exactly the hoped-for characteristics. This large, stately plant with conspicuous yellow blooms had escaped from cultivation and was growing wild in the fields. In addition to a large number of plants that showed only minor differences among themselves, De Vries found several individuals growing among the typical individuals which differed not merely in degree but in kind. These were as different as distinct varieties, and, when the seeds were planted in the garden they bred true to their kind. The only question now was whether they had actually arisen from typical parents. To test this possibility, seeds of several typical plants were planted in the garden; the result being not only a repetition of the peculiar types observed in the field, but of about a dozen other true breeding types with well-marked differences from the parent-species and among themselves.

These new types De Vries considered as new elementary species and he called them "mutants." They came into existence suddenly in one generation and, as a rule, bred true. Whatever factors were responsible for mutations, the seat of origin must have been in the germ cell and not in the soma. Consequently they were inherited fully from the start. The same mutations occurred in considerable numbers and in successive years. In one case a given mutation occurred only once in eight years of observation. Some mutants were robust and successful, others were weak and incapable of living under natural conditions, athers were sterile. On the basis of these results, which are reported in detail in chapter xxyi, De Tries came to the conclusion that evolution was based upon the sudden appearance of new varieties or elementary species and not upon the natural selection of fluctuating variations.

The mutation theory compared and contrasied with the natural selection theory.-It will be recalled that the raw material upon which natural selection works is the minute individual or continuous variation that is universal in all living forms and is known to be largely somatic in character and due to differences in environment. Darwin 
did not distinguish between somatic and germinal variations. The essential feature of mutations is that they are germinal in origin and therefore come forth full-fledged in the first generation arising from the changed germ. Darwin recognized "saltatory variations" or "sports," which are mutations, but did not consider them of suffciently frequent occurrence to furnish an adequate material for selection.

De Vries, on his side, did not discard the principle of selection, but showed that selection acted as between mutants, serving to eliminate those which are unfit and allowing the sufficiently fit to survive alongside the parent-types. According to Darwin's view, the new types arose only at the expense of the old, for only through the elimination of the old (less fit) types could the new types progress toward further fitness. Darwin's view was ill suited to explain the origin of new distinct types, because the process of selection proceeded by imperceptible steps. De Vries's view gives us distinctly different, pure breeding types at once that, if isolated, would be new elementary species from the first.

In conclusion it may be said that the mutation theory was at first intended as a substitute for natural selection, but that later the selection idea was adopted as a directive principle, guiding mutations toward adaptiveness.

\section{THE RISE AND VOGUE OF BIOMETRY}

No historical account of the development of the evolution idea would be complete without a statement of the rôle played by biometry in the study of evolutionary data. Biometry is the statistical study of variation and heredity. During the last decade of the nineteenth century it became obvious to those who had followed the progress of the subject that farther advance toward the solution of the problem of the causes of evolution must come from a better understanding of variation and heredity, the two fundamental factors involved. Three main modes of attack were developed during these years: the statistical (biometry), the experimental (chiefly breeding work), and the microscopical (cytology or the study of the minute structure of the germ cells).

Sir Francis Galton, a cousin of Charles Darwin, was the founder of biometry. He applied certain already understood principles that had been developed mainly in the study of the laws of chance to the study of variations, and, by comparing the boiled-down formulas 
resulting from his computations of parental generations with those of offspring, he arrived at two laws of heredity: the law of filial regression, and that of ancestral shares of inheritance. The essence of the first was that the offspring of exceptional parents tend to regress toward mediocrity in proportion to the degree of parental exceptionalness. The second law was really explanatory of the first, for it was found that the offspring inherit not only from parents, but from the various grades of ancestors, and it was the pulldown of a miscellaneous ancestry that made for regression toward mediocrity. It appeared that half of the hereditary influence could be assigned to parents, half of the remainder to grandparents, half of the remaining remainder to great-grandparents, and so on down the line.

Karl Pearson, a pupil and follower of Galton, has carried the study of biometry to a more highly refined state. His attempt has been to apply to the study of evolution the precise quantitative methods which are used in physics and in chemistry. While much of Pearson's work is far beyond the range of the average professional biologist today, it is extremely useful as a tool in handling data in which great accuracy is demanded. Frequently, however, the methods are far too refined for the material, and much time is wasted in handling crude data by means of highly refined instruments of measurement and ultraaccurate mathematical methods.

On the whole the contributions of biometry to our understanding of the causes of evolution are rather disappointing. About the only clean-cut finding has been the discovery that some variations are continuous and others discontinuous. The former are capable of being expressed in a single curve with a single mode, while the latter are expressed in bimodal or polymodal curves. If material is homogeneous to start with it is likely to give monomodal curves, but if it is heterogeneous, its heterogeneity will be revealed by the plural modes. In a subsequent connection (chapter xliii) some further account of the details of biometry will be presented. We must for the present be content with having placed biometry in its setting as one step in the arlvance of the evolution idea.

\section{EXPERINENTAL BREEDING}

"While De Vries," says Castle, " was engaged in his studies of the evening primrose he hit upon an idea far more important, as most biologists now believe, than the idea of mutation, though De Vries

IW. E. Castle, Genetics aind Eugenics (Ilarvard University Press, 1920), p. 82 
himself, both before and since, has seemed to regard it as of minor importance. He called this the 'law of splitting of hybrids.' The same law, it is claimed, was independently discovered about the same time by two other botanists, Correns in Germany, and Tschermak in Austria. Further, historical investigations made by De Vries showed that the same law had been discovered and clearly stated many years previously by an obscure naturalist of Brünn, Austria, named Gregor Mendel, and we have now come to call this law by his name, Mendel's Law. Mendel was so little known when his discovery was published that it attracted little attention from scientists and was soon forgotten, only to be unearthed and duly honored years after the death of its author. Had Mendel lived forty years later than he did, he would doubtless have been a devotee of biometry, for he had a mathematical type of mind and his discovery of a law of hybridization was due to the fact that he applied to his biological studies methods of numerical exactness which he had learned from algebra and physics. In biology he was an amateur, being a teacher of the physical and natural sciences in a monastic school at Brün. Later he became head of the monastery and gave up scientific work, partly because of other duties, partly because of failing eyesight."

There had been plant-hybridizers before Mendel, but their lack of exactness in technique had prevented them from discovering the law of segregation or splitting of hybrids.

Joseph Gottlieb Kölreuter ( 733 -1806), who really belonged to the period of Lamarck, barely missed making the discovery that was afterward made by Mendel. The salient features of his work are according to Castle:

"I. Kölreuter established the occurrence of sexual reproduction in plants by showing that hybrid offspring inherit equally from the pollen plant and the seed plant.

" 2 . He showed that hybrids are commonly intermediate between their parents in nearly all characters observed, such for example as size and shape of parts.

"3. Many hybrids are partially or wholly sterile, especially when the parents are very dissimilar (belong to widely distinct species). Such hybrids often exceed either parent in size and vigor of growth.

"4. Kölreuter did not observe the regular splitting of hybrids which Mendel and De Vries record, but some of his successors did, particularly Thomas Knight ( 1 799) and John Goss (1822) in England,

IOp. cit., p. 86. 
who were engaged in crossing the garden peas with a view to producing more vigorous and productive varieties, and Naudin (1862) in France, who made a comprehensire survey of the facts of hybridization in plants and came very near to expressing the generalization which Mendel reached four years later."

\section{MENDEL'S IAWS}

"The earliest experimental investigations of heredity," says Locy $^{I}$ in a concise summary of Mendel's work, "were conducted with plants, and the first epoch-making results were those of Gregor Mendel (1822-I884), a monk and later abbot, of an Augustinian monastery at Brün, Austria. In the garden of the monastery, for eight years before publishing his results, he made experiments on the inheritance of individual (or unit) characters in twenty-two varieties of garden peas. Selecting certain constant and obvious characters, as color, and form of seed, length of stem, etc., he proceeded to cross these pure races, thus producing hybrids, and thereaiter, to observe the results of self-fertilization among the hybrids.

"The hybrids were produced by removing the unripe stamens of certain flowers and later fertilizing them by ripe pollen from another pure breed having a contrasting character. The results showed that only one of a pair of unit characters appeared in the hybrid of the next generation, while the other contrasting character lay dormant. Thus, in crossing a yellow-seeded with a green-seeded pea, the hybrid generation showed only yellow seeds. The character thus impressing itself on the entire progeny was called dominant, while the other that was held in abeyance was designated recessive.

"That the recessive color was not blotted out was clearly demonstrated by allowing the hybrid generation to develop by self-fertilization. Under these circumstances a most interesting result was attained. The filial generation, derived by self-fertilization among the hybrids, produced plants with yellow and green seeds, but in the ratio of three yellow to one green. All green-seeded individuals and one-third of the yellow proved to breed true, while the remaining two thirds of the yellow-seeded plants, when self-fertilized, produced yellow and green sceds in the ratio of three to one.

"Subsequent breedings gave an unending series of results similar to those obtained with the first filial generation.

William A. Locy, The if ain Currents of Zoology (Henry Holt \& Company, 10:8), pp. 37-30. 
"This great principle of alternative inheritance was exhibited throughout the extensive experiments of Mendel, and it is now recognized as one of the great biological discoveries of the nineteen' $h$ century."

The essential feature of Mendel's discovery was not the phenomenon of dominance, for relatively few instances of pure dominance have been discovered; but it was the phenomenon of segregation. By segregation is meant that although determiners for opposed hereditary characters derived from diverse parental sources may unite in a common germ plasm for one generation, they segregate out pure, or unmodified by their association together, in the next and subsequent generations. This law of segregation depends on the idea that the germ cell is composed of bundles of separately inheritable unit characters, which may be paired or grouped, shuffled and redealt like cards, so as to give an infinite number of permutations and combinations without affecting the unit determiners themselves.

From the evolutionary standpoint it is supposed that new unit characters arise by mutations and are fully hereditary. They cannot be swamped out by interbreeding unless they are recessive, for they will dominate the old characters. Even recessive characters could be perpetuated by segregation, or by the union of two individuals possessing the determiner in the recessive condition as well as the dominant. Thus a knowledge of the behavior of unit characters in heredity reveals part of the mechanism for conserving new characters if they are advantageous or even sufficiently fit to survive.

New types or species might arise through processes of hybridization and the survival of individuals possessing the most favorable combinations of characters.

"Evolution from this point of view," says Morgan, " largely in introducing (by mutations) new factors that influence characters already present in the animal or plant.

"Such a view gives us a somewhat different picture of evolution from the old idea of a ferocious struggle between the individuals of a species with the survival of the fittest and the annihilation of the less fit. Evolution assumes a more peaceful aspect. New advantageous characters survive by incorporating themselves into the race, improv. ing it and opening to it new opportunities. In other words, the emphasis may be placed less on the competition between the indi-

${ }^{x}$ T. H. Morgan, A Critique of the Theory of Evolution (Princeton University Press, igr6), pp. $87,88$. 
viduals of a species (because the destruction of the less fit does not in itself lead to anything that is new) than on the appearance of new characters and morlifications of old characters that become incorporated in the species, for on these depends the evolution of the race."

\section{HYBRIDIZATION AND THE ORIGIN OF SPECIES}

As a consequence of the great interest aroused by Mendel's hybridization experiments the question has arisen as to the rôle of hybridization in organic evolution. Certain it is that a vast number of animal and plant races now existing are mixed or hybrid in nature and are continually splitting up into various Mendelian segregates. How many pure races are there today? Some authors think that no variable races today are pure. Lotsy goes so far as to claim and attempt to prove that unit characters are fixed and that the only source of variation is hybridization, or amphimixis. Biologists tociay would not be willing to go thus far with Lotsy, but it seems beyond question that hybridization has pliyed an important rôle in the production of very many greups now living. It is of interest to recall that Linnaeus, though a special creationist, admitted the possibility of the origin of new species by hybridization.

\section{NEO-MENDLLIAN DEVELOPMENTS}

Since the rediscovery of Mendel's paper by De Vries and its perusal by thousands of biologists the world over, Mendelian breeding experiments with all manner of animals and plants has been the ruling passion of geneticists. Among the leading neo-Mendelians are Bateson, Morgan, Castle, Correns, East, Iurst, Shull, Tschermak, and the pupils of these.

Perhaps the first two mentioned, Batcson and Morgan, have coniributed most largely to an understanding of the intricacies of the Mendelian operations. Bateson has become so imbued with the idea that all mutations are the result of the loss of factors that he proposes the hypothesis that "evolution has taken place through the steady loss of inlibiting factors," as Morgan puts it. "Living matter was stopped down, so to speak, at the beginning of the world. As the stops are lost, new things emerge. Living matter has changed only in that it becomes simpler." It is quite probable that Bateson, in proposing so radical a view, intended to be taken only hail-serionsly. Apart from this, his best-known expression of opinion, Bateson is the 
author of a large amount of fine work in genetics and will rank high in the history of the subject.

T. H. Morgan, our leading American geneticist, is best known for his researches into the mechanism of Mendelian inheritance. Through the statistical study of ratios and linkages of characters in the fruit fly Drosophila, it has been possible to chart the localities of the determiners or genes of at least 400 mutant characters. He has shown that four linked groups of genes exist, corresponding to the four kinds of chromosomes of the germ cells; one of these groups is sex-linked and is therefore to be assigned to the X-chromosome of the mutant male. Two other large groups are to be located in the two large autosomes, and one very small group is assumed to be located in the microsome. Not only have characters, or their determiners, been assigned to given chromosomes, but they have been located in a linear series on a given chromosome. So accurately have these loci been determined that they may be used to predict unknown breeding ratios. It would seem that when a theory serves so well that it may be used to predict the results of experiments, such a theory must be founded on facts. Morgan and his collaborators in genetics are now convinced that they have discovered the actual mechanism of heredity in the behavior of the chromosomes in maturation and fertilization and that it is unexpectedly simple. Their views have aroused considerable opposition, but they have apparently met successfully all attacks up to the present. If it be true that the actual machinery of variation and heredity has been discovered, we are farther along in our understanding of the causo-mechanical basis of evolution than we could have hoped to be at so early a date.

\section{HEREDITY AND SEX}

Since Darwin's theory of sexual selection, sex has been a complicating factor in evolutionary theories, and one of the chief advances of the present century has been in connection with the factors controlling sex determination and sex differentiation. The evolution of sex has also been a subject for considerable research.

It now appears that sex is an inherited Mendelian character, the determiner of which is carried in a definite chromosome or group of chromosomes. Cytological examination of germ cells, under the able leadership of $E$. B. Wilson, has now made it certain that sex, if not directly the result of the presence or absence of specilic chromosomes, at least is absolutely correlated with such chromosomes. It appears, however, that the sex which is setuled by the chromosome 
mechanism at the time of fertilization may or may not realize its normal somatic differentiation, depending upon the presence or absence of the proper environment. Cases are on record in which an individual germinally determined as a female may be caused to develop the secondary sexual characters of the male, or even to produce sperms instead of eggs. A great deal of extremely interesting work on sex control and sex reversals has been done within the last half-dozen years and new discoveries are being made almost daily. In fact, it might be saicl that the genetic study of sex marks the high-tide level of modern genetic advance.

\section{THE EXPERIMENTAL INDUCTION OF HEREDITARY VARIATIONS}

With the problem of the mechanism of the heredity of individual differences solved, at least in its more important essentials, attention has gradually shifted to the problem as to how individual differences arise. They seem to arise suddenly and as though of their own accord, and the study of their heredity does not throw much light on the problem of their origin. At the present time a massed attack is being made upon the problem of the mode or modes of origin of new hereditary characters. The most striking success in the artiicial induction of mutations has been obtainerl by $I . F$. M uller, using as his material the already intensively studied fruit fly, Drosophita melanogaster. By the use of rather heavy closes of X-rays he succeeded in increasing the frequency of mutations about I, 500 per cent. Nearly all of the mutations produced by this methor were the same as those that occur spontaneously, but many more occur in a given time.

Many other investigators, following Muller's methods, have succeeded in greatly hastening the pace of mutation in various animals and plants. The ability to produce such large numbers of mutants at will furnishes abundant material for genetic investigation and promises greatly to increase our knowlerge of the in timate details of the mechanisms of variation and heredity.

The most pressing problem of the present is that of discovering how and when genes act during the course of development in producing the characters of the organism. Some progress has been marle in this direction.

TIIE RECENT ATTACK UPON EVOLUTION IN TIIE UNITED STATES

The recent highly advertised attack upon the validity of the principle of evolution by certain individuals and religious bodies is hardly to be considered as forming a part of the histury of the science, 
but it is significant as an influence that may serve either greatly to accelerate or to retard the progress of our science. The writer's own experience is that the controversy has greatly enhancel popular interest in this subject, as evidenced by the growing demand for books on evolution and allied suljects and the marked increase in the numbers of students in the colleges who wish to elect courses along these lines.

\section{CONCLUDING REMARKS}

Now that we have traced the evolution of the science of organic evolution from its crude beginnings among the Greeks up to the present, we are in a position to go back and make a systematic study of some of the more important phases of evolutionary science. Charles Darwin found it necessary to prove the fact of organic evolution before attempting to discover its causes. His method of proof was to marshal a great array of facts which agree with the idea of descent with modification; and we shall follow Darwin's method in the subsequent chapters dealing with the evillences of evolution.

Note.--In the first half of the present historical account many short passages are presented in quotation marks without mentioning the source of the quotation. In all such cases it will be understood that these passages are from H. F. Osborn: book, From the Greeks to Darwin (The Macmillan Company). 
PART II

EVIDENCES OF ORGANIC EVOLUTION 



\section{CHAPTER III}

\section{IS ORGANTC EVOLUTION AN ESTABLISHED PRINCIPLE?}

I. Is there definite proof of organic evolution?

2. If so, what is the nature of the proof?

3. What are the evidences of evolution, and in what ways do these bear witness that evolution has occurred and is still occurring?

Before presenting in any detail the several bodies of data that constitute the "evidences of evolution," let us anticipate a little by attempting to answer the three questions just propounded.

I. Reluctant as he may be to admit it, honesty compels the evolutionist to admit that there is no absolute proof of organic evolution. But, for that matter, there is no absolute proof of anything that depends on records of past events. We have no absolute proof that Caesar or Napoleon once lived, or fought, or conquered. Al] we have are the accounts left by the historians which we accept without question because they are the products of human thought and imagination. There is no absolute proof for either of the more or less directly opposed theories of the origin of the material universe: the "nebular hypothesis" of Laplace, and the "planetesimal hypothesis" of Chamberlin and Moulton. Both of these theories rest upon exactly the same types of evidences as does the theory of organic evolution, viz., the amassing of facts which appear to be explicable on the assumption that the one or the other theory is true. If all of the facts are in accord with it, and none are found that are incapable of being reconciled with it, a working hypothesis is said to have been advanced to the rank of a proved theory. As yet it is impossible to say that either of these theories as to the origin of the universe has been proved. Yet there is much less popular opposition to the acceptance of these theories as facts than there is to the general theory of organic evolution. Similarly, there are certain widely accepted theories of the origin of the present conditions of the earth's crust, and its liquid and gaseous envelopes. The accepted theory, as given us by Hutton and especially by Lyell, is essentially an evolutionary theory and depends for its proof on almost exactly the same types of evidence as does that 
of organic evolution. The basis of the accepted theory of geological evolution is the "uniformitarian doctrine" of Lyell, which assume" that the key to the past lies in the present, that the changes that are going on today are of the same order and kind as those of the past, and, finally, that there is neither beginning nor end to the earth's evolutionary history, but that a slow and orderly development has gone on and will continue indefinitely. The proof of this conception consists of an array of facts derived from a study of the earth's crust, including its stratified structure, of traces of aninal and plant life preserved in the rocks, of observed changes in continental contours going on today, of erosion going on in coasts and streams, and of a considerable array of facts derived from a study of other worlds than ours in the making. The theory of geologic evolution meets with scarcely any opposition today, althourh its foundations are no more securely based than are those of organic evolution.

In a sense the proofs of the atomic, ionic, and electron theories are even less absolutely established than is that of orranic evolution, because no one has ever seen nor ever can see an atom, an ion, or an electron. Chemical and physical facts are rationalized by assuming the existence of these units with their various properties. The only evidences of the existence of atoms, ions, and electrons appear in the facts that, on the assumption that they exist, the whole array of observed chemical and physical phenomena are rationalized and bound together into a coherent, consistent, and intelligible system. In other words, with the atomic, ionic, and electron theories chemistry and physics are highly rational sciences; without these theories the phenomena of physics and chemistry would be a hopeless hodgepodge. Yet who would say that these fundamental theories are absolutely proved?

The only type of proof of phenomena that cannot be directly observed or that pertain to the remote past is circumstantial proof By analogy we conclude that certain changes took place thus and so in the past because we observe similar changes going on today. Every past event has left a trace, and it is the task of the historian, antiquarian, or evolutionist to discover and to interpret these traces. Sometimes the traces exist as vestiges in modern life and are meaningless unless related to their origin in the past. The task of the student of organic evolution is to gather all of the traces of past changes both in living creatures today and in the preserved remains of creatures of the remote past. A collection of traces of evolution involves many 
apparently unrelated boties of phenomena. 'There are evilences of crolution in the groming of animals into phyla, ranses, oriers. families, gencra, species, varieties, and races; in the homokgies that exist in general structure and in particular organs between different rroups of animals and plants; in the orderly process of ontogeny or embryonic development of the individual; in actual blood relationship, based upon chemical reactions; on the succession of extinct animals and plants found as fossils imbedded in the geologic strata: in the present geographical distribution of the various groups of animals and plants, in the light of data derived from a study of geological changes; and finally, in experimental evolution, which involves the observation under experimental control of changes in organisms and the origin of new varieties or elementary species

2. The nature of the proof of organic evolution, then, is this: that, using the concept of organic evolution as a working bypothesic it has been possible to rationalize and render intelligible a vast array of olserved phenomena, the real facts upon which evolution rests. Thus classification (taxonomy), comparative anatomy, embryology, palaeontology, zoögeography and phytogeography, serology, renetics, become consistent and orderly sciences when based upon evolutionary foundations, and when viewed in any other way they are thrown into the utmost confusion. 'There is no other generalization known to man which is of the least value in giving these bodies of ract any sort of scientific coherence and unity. In other words, the working hypothesis works and is therefore acceptable as truth until overthrown by a more workable hypothesis. Not only does the hypothesis work, but, with the steady accumulation of further facts, the weight of evidence is now so great that it overcomes all intelligent opposition by its sheer mass. There are no rival hypotheses except the outworn and completely refuted idea of special creation, now retained only by the ignorant, the dogmatic, and the prejudiced.

3. In answer to the question, "What are the evidences of evolution and in what ways do these bear witness that evolution has occurred and is still occurring?" we may present an ordered list of subjects that are to be taken up serially in detail. In connection with each of these bodies of evidence the cluaracter of their witness-bearing will be discussed.

Some of the evidences are more direct and freer from purely interpretative construction than others. Some evidences are primary and foundational; some are in themselves rather inconclusive, but serve 
to confirm other facts, and, when reinforced by other evidences, are themselves strongly substantiated. Perhaps the crowning evidence of the truth of evolution is that all of these diverse bodies or phenomena invariably support one another and all point in the same direction and to the same conclusion, viz., that organic evolution is a fact.

In the former edition of this book the evidences of evolution were presented in a somewhat arbitrary order, the evidences that seemed to furnish the most direct proof being, for pedagogical reasons, presented first and the more controversial evidences last. Experience, however, has shown that for an appreciation of the data from paleontology and from geographic distribution the student must have a knowledge of the principles of morphology (comparative anatomy) and of classification. We have, therefore, changed the order of presentation of the evidences to one that has the authority of precedent. The order of treatment will be as follows:

I. The fundamental assumption underlying all the evidences.

II. Comparative anatomy (homologies and vestigial structures): the evidence of the fact that structures in unlike organisms have a common plan and mode of origin; that changes have occurred that are in some way related to changes in habit or environment.

III. Classification: the evidence that the present groups of animals and plants have arisen by "descent with modification."

IV. Serology (blood-precipitation tests): the evidence that the chemical specificity of the blood parallels taxonomic specificity.

V. Embryology (the doctrine of recapitulation): the evidences that the embryonic development of the individual follows the main outlines of the evolutionary history of its ancestors.

VI. Paleontology: the evidences afforded by a study of the distribution in time (vertical distribution in the earth's strata) of the fossil remains of extinct animals and plants.

VII. Geographic distribution: the evidences afforded by present (also, to some extent, past) horizontal distribution of contemporaneous animals and plants.

VIII. Genetics (experimental evolution): evidences that heritable variations have occurred under observation in large numbers and in many species of animals and plants, and that new varicties of animals and plants have been produced by processes known to man and to a large extent controlled by him. 


\section{CHAPTER IV}

\section{THE FUND AMENTAL, POSTULATE UNDERLYING ALL EVIDLNCES OF EVOLUTION}

Every science rests in last andysis un cortain postulates or justifrable assumptions, certain verified or verifable truths that must be admitted before any progress can be make in gaining a further understanding of the content of that science. Geology, for example, must assume as valid the Jymamical laws of Newton and the law of gravitation, as well as basic laws of chemistry. Biology assumes the validity of the laws of physics and cliemistry, for biology is the fundamental science of the transformations of matter and of energy in living matter; but, in addition, there are also some biological postuktes that seem to be so well established that they have come to be thought of as truisms.

One of the truisms of biology is the familiar fact that like produces like. How surprised one would be if sparrows hat anything but sparrows for offspring, or if two Caucasic parents were to have a Negro child! Now, a careful survey of the situation revculs the fact that the only postulate the evolutionist needs is no more nor less than a logical extension of what the layman considers a truism or a self-evident fact, namely, that fundamental structural resemblance signifies genetic relationship; that, generally speaking, the degree of closiness of sinutural resemblance runs esschtially purallel with closeness of kinship. Most biologists would say that this is not nerely a postulate, but one of the best-established liws of life. Howerer obrious the validity of this postulate may be, it is the plinin duty of one who attempts to justily the erolutionary principle to aroid taking any steps that are open to the least bit of valinl criticism. If we cannot rely upon this postulate, which may be called the principle of hemology, we can make no sure prorgess in iny attempt to estatblish the valinity of the principle of evolution.

The postulate we are now discussing is tantamount to an allimattion of the fact of herdity. We rely upon this fact in our everytay life. When we plant a certain kind of seet we expect to get a certain kind of plant; when we breed a certain kind of dog we expect ofispring 
of the same breed. It would be a freak of nature were we to discover any marked exception to the laws of heredity. Furthermore, our ordinary daily contacts with other members of our own species have taught us that, as a rule, the more closely alike people are, the more clusely are they related. We recognize that children of the same family are more alike in their personal characteristics than are members of the same race not so closely related. Whenever we see two people whose resemblance is very great we assume a relatively close kinship. Thus, everyone has had the experience of meeting two people so strikingly alike that it is almost impossible to distinguish them apart, and of immediately assuming that such persons are identical, or duplicate, twins. Now the interesting thing about such twins is that they are vastly more closely related than are ordinary brothers and sisters, or even than are fraternal twins, who are only brothers and sisters that happen to have been conceived and born simultaneously as the result of the fertilization of two egg cells. For duplicate twins are the products of the early division into two equivalent parts of a single embryo derived from one fertilized egg. No closer kinship can well be imagined than this, for the two individuals bear the same relationship to each other as do the bilateral halves of one individual.

The writer has had an exceptional opportunity of determining the exact degree of resemblance existing between separate offspring derived from a single egg. It so happens that a peculiar species of mammal, the nine-banded armadillo of Texas, always gives birth to four young at a time. These quadruplets are invariably all of the same sex in a litter and are nearly identical even in their finest anatomical details, such as the numbers and arrangements of the plates and scales in the armor and the numbers of hairs in a given area of the skin. A detailed study of the embryonic history of this species has proved beyond any question that in every case the four young in a litter result from a very early division of a single embryo derived from a single fertilized egg (see Fig. 52). Large numbers of sets of quadruplets were studied statistically to determine the exact degree of their resemblance to one another. A comparison of over two hundred sets revealed the somewhat startling fact that on the average they were over 93 per cent identical (more technically, they showed a coefficient of correlation of over .93). The remarkable closeness of this degree of resemblance may be fully appreciated when it is realized that the only structural resemblance belonging to this order of closeness is that existing between the right and left antimeric halves of a single indi- 
vidual, such as the right and left sides of your own face or your two hands, and that the next degree of closeness of resemblance is that between siblinge (brothers and sisters), who are only 50 per cent identical (having a coefficient of correlation of only .5 ); while cousins of various gratles have proportionately lower and lower degrees of resemblance in exate ratio with their grades of kinship.

This, then, is a crucial test of the valiclity of the postulate that closeness of resemilance is in proportion to closeness of kinship, for we have in identicial twins and in armadillo quadruplets the closest resemblance associated with the closest possible genetic relationship, and we also see that there is an exact proportion between all other known grades of kinship and their relative degree of resemblance.

Employing the principle of homology in a somewhat broader way, and in a way that is hardly likely to be questioned even by the most captious, we account for the common possession of certain structural peculiarities by all members of a given kind or species of animal or plant by saying that such characters have been derived from a common ancestor. It is only a short step in logic to conclude that two similar kinds or species of aninal have been derived one from the other or both from a common ancestral species. Once having taken this step, we are on the road that leads inevitably to an evolutionary interpretation of natural groups. If the principle of heredity holds for siblings (ofispring of the same parents), for races, for species, where are we to draw the line? It does not seem reasonable to admit that structural resemlances between siblings, between races, between species, are accounted for as the product of heredity, and to deny that equally plain resemblances of essentially the same sort among the species of a genus or among the genera of a family have a similar hereditary basis. It is logically impossible to draw the line at any level of organic classification and say that structural resemblance is the product of heredity up to such and such a level, but that beyond this arbitrarily chosen point heredity ceases to operate.

The principle of heredity and its necessary implications constitute the only postulate that is necessiry for the evolutionist to make in wrter to go aheat on al somm basis with a presentation of the exidences of exolution. (bive him this one puint, and he asks no further concesions. Ant this is not so much of a concession as it might seem at hirst blush, for the sfecial creationist assumes more potency for lerelity than dues the whatimist, since he belieres in descent without movifation, a surk of stereotyped heredity, slavishly duplicating 
forever a fixed set of structural patterns without variation or improvement. Since, then, both special creationist and evolutionist find it equally necessary to assume the principle of heredity, there should be little argument on this score. But let the reader beware at this point in the discussion, for if he admits the postulates already presentedand how can he help but admit them?-he cannot avoid the inevitable conclusion that the theory of descent with modification is the only reasonable explanation of organic resemblances and differences.

\section{HOMOLOGY VERSUS ANALOGY}

Much difficulty in connection with the study of resemblances and differences in animals and plants is occasioned by a failure to understand the fact that there are two kinds of resemblances and differences. Structures that are similar in anatomical detail and in their mode of embryonic origin, irrespective of whether they perform the same or different functions, are known as homologous. The test of homological equivalence is a study of the anatomical details of the adult structure followed by a study of the developmental history of the part in question. If the part under examination be a bone, for example, this bone must have a certain relation to the other bones, must occur in a certain part of the body, must be supplied with certain muscle attachments, in order to be considered homologous with another bone that has the same relations. If two structures have the same anatomical relations and arise from equivalent embryonic rudiments they are said to be homologous, in spite of small or great differences in relative size, appearance, or function. If structures are homologous it is believed that they represent the same hereditary units and that these equivalent hereditary units have been derived from the same or similar ancestors.

Analogous structures are of an entirely different sort. They may be more or less superficially alike in form or in function, usually in both, though anatomically quite different. As an example of analogous structures let us examine the three types of aquatic vertebrates shown in Figure So. These three kinds of vertebrates, one a fish, one a reptile, and the third a mammal, might be mistaken by the casual observer to be all fishes of difierent kinds. All have the same fusiform body with lines best adapted for swift locomotion in the water; all have median, paired, and caudal fins; all swim in about the same way. Yet the resemblance is only skin-deep, as it were, for beneath the surface the one is all fish, the second all reptile, and the third all mammal. The structures that look alike and function alike are, from the stand- 
point of anatomical relations and embryonic derivation, entirely different. The resemblances which are so obvious supericially are examples of analogy, not of homology, and are the result of molding unlike materials into a seml, lance of likeness in adaptation to a common environment. Analogous structures, while not considered as evidences of kinship, are strong evidences of descent with modification, for their very existence implies that they have been changed from a former condition to one in which they are adapted to a new medium. To illustrate this point, call to mind that both the ichythyosaur and the purpuise ( $\mathrm{rg}$. So, $B$ and $C$ ) belong to groups that are fundamentally terrestrial air-breathing vertebrates, and that whatever they have that is fishlike must be interpreted as adaptive modifications for aquatic life. This type of conception and the way in which it bears witness for organic evolution is well brought out in the next chapter by George John Romanes, a chapter that for a generation has been considered a classic. A few of the statements in this chapter would, in all probability, be somewhat altered if the author were to rewrite it in the light of newer knowledge, but on the whole the statements made would still have the support of the most critical of modern anatomists. 


\section{CHAP'TER V \\ EVIDENCES FROM MORPHOLOGY (COMPARATIVE ANATOMY)I $^{\mathrm{r}}$}

GLORGE JOHN ROMANES

The theory of evolution supposes that hereditary characters admit of being slowly modified wherever their modification will render an organism better suited to a change in its conditions of life. Let us, then, observe the evidence which we have of such adaptive modifications of structure, in cases where the need of such modification is apparent. We may begin by again taking the case of the whales and porpoises. The theory of evolution infers, from the whole structure of these animals, that their progenitors must have been terrestrial quadrupeds of some kind, which gradually became more and more aquatic in their habits. Now the change in the conditions of their life thus brought about would have rendered desirable great modifications of structure. These changes would have begun by affecting the least typical-that is, the least strongly inherited-structures, such as the skin, claws, and teeth. But, as time went on, the adaptations would have extended to more typical structures, until the shape of the body would have become affected by the bones and muscles required for terrestrial locomotion becoming better adapted for aquatic locomotion, and the whole outline of the animal more fish-like in shape. This is the stage which we actually observe in the seals, where the hind legs, although retaining all their typical bones, have become shortened up almost to rudiments, and directed backwards, so as to be of no use for walking, while serving to complete the fish-like taper of the body (Fig. r). But in the whales the modification has gone further than this so that the hind legs have ceased to be apparent externally, and are only represented internally-and even this only in some species-by remnants so rudimentary that it is difficult to make out with certainty the homologies of the bones; moreover, the head and the whole body have become completely fish-like in shape (Fig. 12). But profound as are these alterations, they affect only

- From G. J. Romanes, Danwin and after Darwin (copyright 1892 ). Used by special permission of the publishers, The Open Court Publishing Cnmpany. 


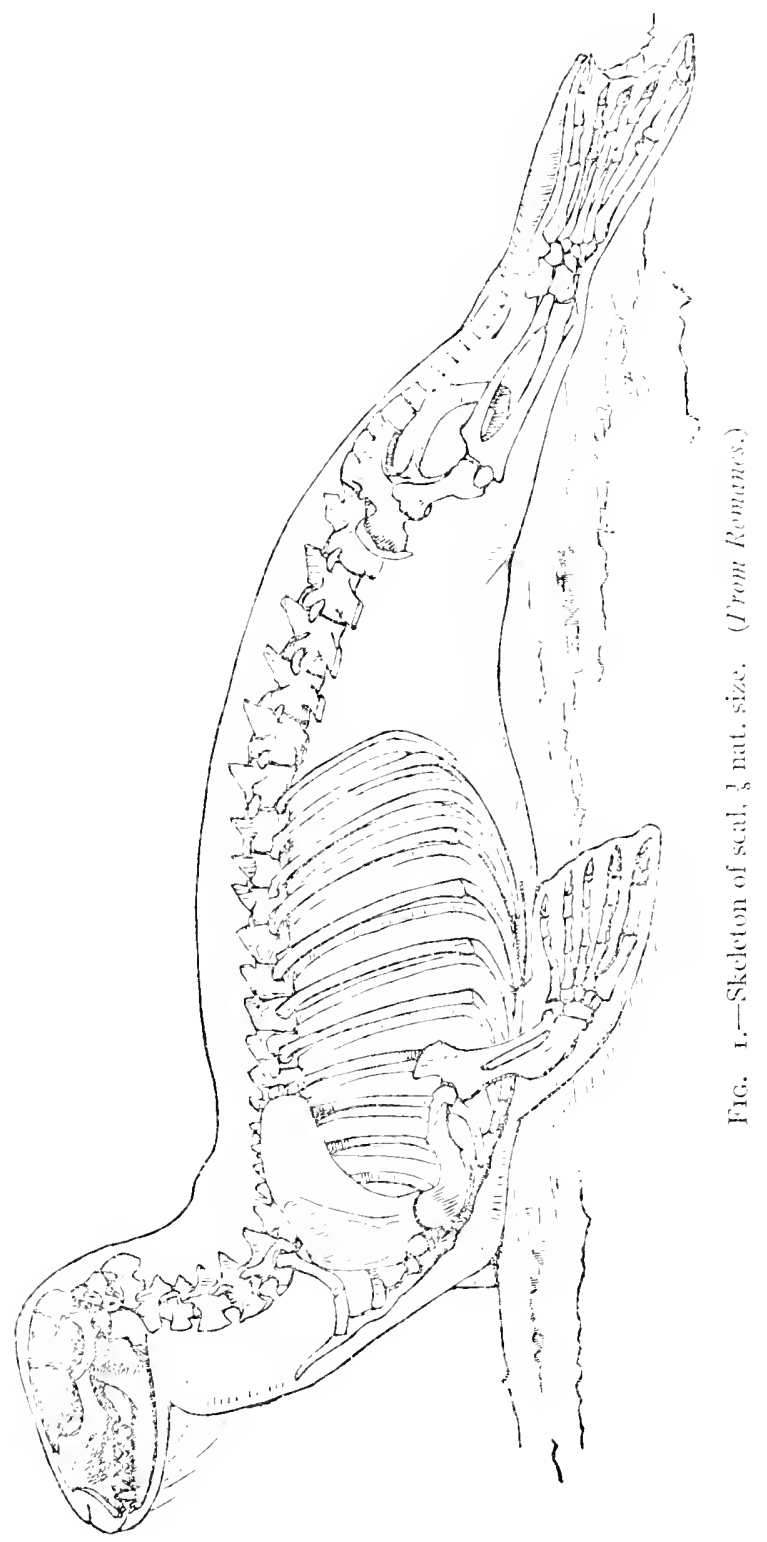


those parts of the organism which it was for the benefit of the organism to have altered, so that it might be adapted to an aquatic mode of existence. Thus the arm, which is used as a fin, still retains the bones of the shoulder, fore-arm, wrist, and fingers, although they are all enclosed in a fin-shaped sack, so as to render them useless for any purpose other than swimming (Fig. 3). Similarly, the head, although it so closely resembles the head of a fish in shape, still retains the bones of the mammalian skull in their proper anatomical relations to one another; but modified in form so as to offer the least possible resistance to the water. In short, it may be said that all the modifications have been effected with the least possible divergence from the typical mammalian type, which is compatible with securing so perfect an adaptation to a purely aquatic mode of life.

Now I have chosen the case of the whale and porpoise group, because they offer so extreme an example of profound modification of structure in adaptation to changed conditions of life. But the same thing may be seen in hundreds and hundreds of other cases. For instance, to confine our attention to the arm, not only is the limb modified in the whale for swimming, but in another mammal-the bat-it is modified for flying, by having the fingers enormously elongated and overspread with a membranous web.

In birds, again, the arm is modified for flight in a wholly different way-the fingers here being very short and all run together, while the chief expanse of the wing is composed of the shoulder and forearm. In frogs and lizards, again, we find hands more like our own; but in an extinct species of flying reptile the modification was extreme, the wing having been formed by a prodigious elongation of the fifth finger, and a membrane spread over it and the rest of the hand (Fig. 4). Lastly, in serpents the hand and arm have disappeared altogether.

Thus, even if we confine our attention to a single organ, how wonderful are the modifications which it is seen to undergo, although never losing its typical character. Everywhere we find the distinction between homology and analogy which was explained in the last chapter - the distinction, that is, between correspondence of structure and correspondence of function. On the one hand, we meet with structures which are perfectly homologous and yet in no way analogous; the structural elements remain, but are profoundly modified so as to perform wholly different functions. On the other hand, we meet with structures which are perfectly analogous, and yet in no way homologous; totally different structures are modified 


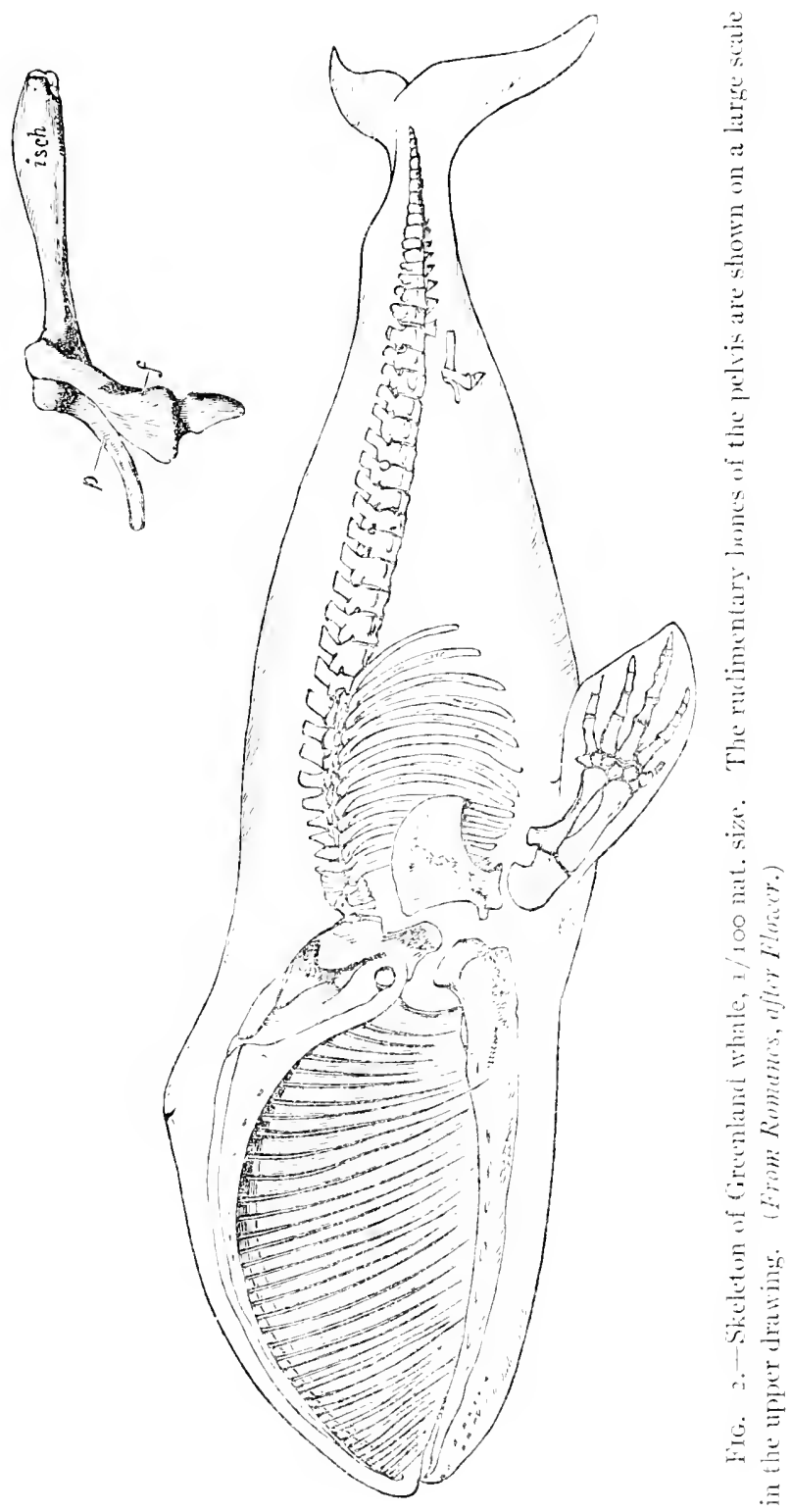


to perform the same functions. How, then, are we to explain these things? By design manifested in special creation, or by descent with adaptive modification? if it is said by design manifested in special creation, we must suppose that the Deity formed an archetypal plan of certain structures, and that he determined to arlhere to this plan through all the modifications which those struct ures exhibit. But, if so, why is it that some structures are selected as typical and not others? Why should the vertebral skeleton, for instance, be tortured
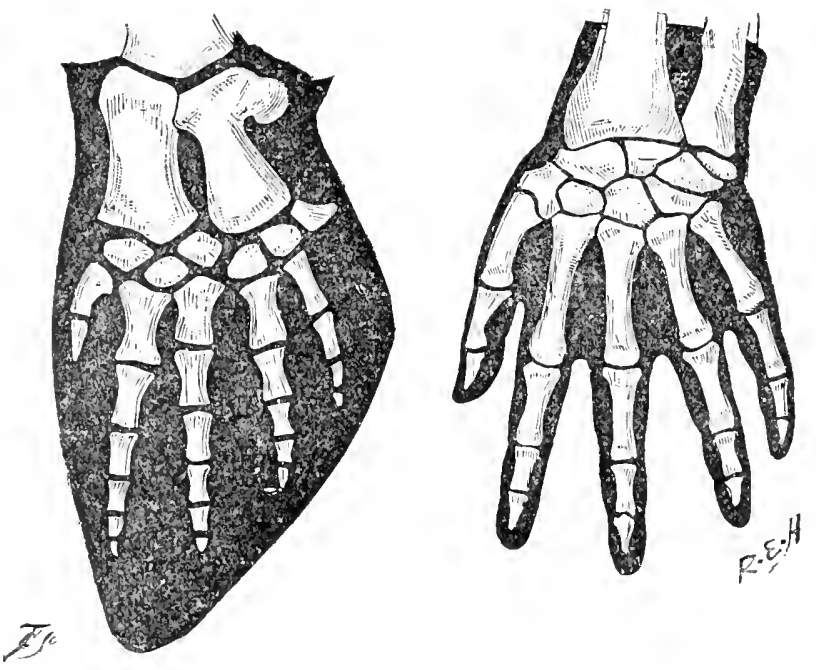

FiG. 3.-Paddle of whale compared with hand of man. (From Romanes.)

into every conccivable variety of modification in order to subserve as great a variety of functions; while another structure, such as the eye, is marle in different sub-kingdoms on fundamentally different plans, notwithstanding that it has throughout to perform the same function? Will any one have the hardihood to assert that in the case of the skeleton the Deity has endeavored to show his ingenuity, by the manifold functions to which he has made the same structure subservient; while in the case of the eye he has endeavored to show his resources, by the manifold structures which he has adapted to serve the same function? If so, it becomes a most unfortunate circumstance that, throughout both the vegetable and animal kingdoms, all cases which can be pointed to as showing ingenious arlaptation of the 


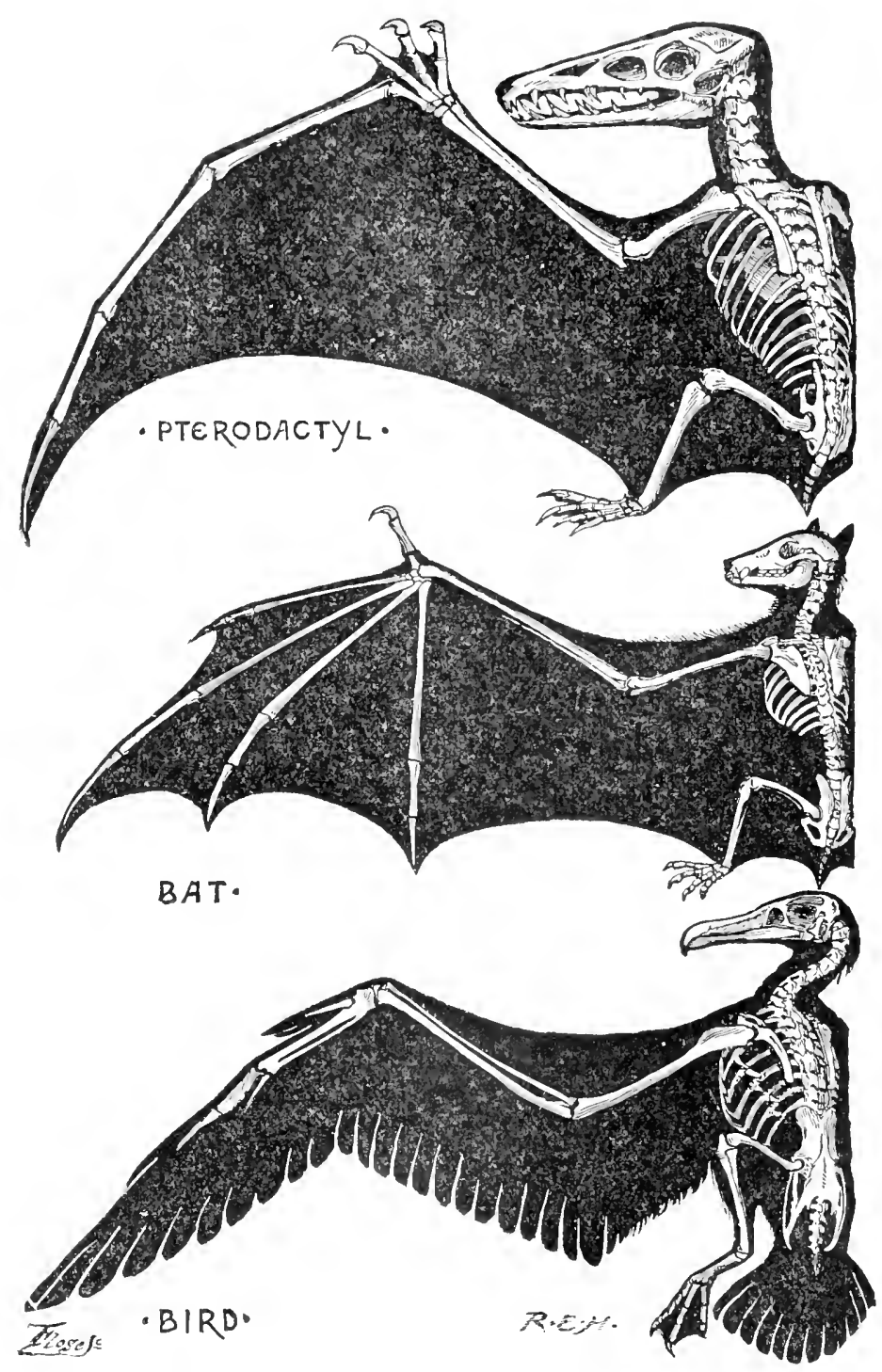

FIg. 4--Wing of reptile, mammal, and bird. (From Romanes.) 
same typical structure to the performance of widely different functions-or cases of homology without analogy-are cases which come within the limits of the same natural group of plants and animals, and therefore admit of being equally well explained by descent from a common ancestry; while all cases of widely different structures performing the same function-or cases of analogy without homology, are to be found in different groups of plants or animals, and are therefore suggestive of independent variations arising in the different lines of hereditary descent.

To take a specific illustration. The octopus, or devil-fish, belongs to a widely different class of animals from a true fish; and yet its eye, in general appearance, looks wonderfully like the eye of a true fish. Now, Mr. Mivart pointed to this fact as a great difficulty in the way of the theory of evolution by natural selection, because it must clearly be a most improbable thing that so complicated a structure as the eye of a fish should happen to be arrived at through each of two totally different lines of descent. And this difficulty would, indeed, be a formidable one to the theory of evolution, if the similarity were not only analogical but homological. Unfortunately for the objection, however, Darwin clearly showed in his reply that in no one anatomical or homologous feature do the two structures resemble one another; so that, in point of fact, the two organs do not resemble one another in any particular further than it is necessary that they should, if both are to be analogous, or to serve the same function as organs of sight. But now, suppose that this had not been the case, and that the two structures, besides presenting the necessary superficial or analogical resemblance, had also presented an anatomical or homologous resemblance, with what force might it have then been urged,-your hypothesis of hereditary descent with progressive modification being here excluded by the fact that the animals compared belong to two widely different branches of the tree of life, how are we to explain the identity of type manifested by these two complicated organs of vision? The only hypothesis open to us is intelligent adherence to an ideal plan or mechanism. But as this cannot now be urged in any comparable case throughout the whole organic world, we may, on the other hand, present it as a most significant fact, that while within the limits of the same large branch of the tree of life we constantly find the same typical structures modified so as to perform very different functions, we never find any of these particular types of structure in other large branches of the tree. That is to say, we never find typical structures 
appearing except in cases where their presence may be explained by the hypothesis of hereditary descent; while in thousands of such cases we find these structures undergoing every conceivalle variety of adaptive modification.

Consequently, special creationists must fall hack upon another position and say,-Well, but it may have pleased the Deity to form a certain number of ideal types, and never to have allowed the structures occurring in one type to appear in any of the others. We answer,-Undoubtedly such may have been the case; but, if so, it is a most unfortunate thing for your theory, because the fact implies that the Deity has planned his types in such a way as to suggest the counter-theory of descent. For instance, it would seem most capricious on the part of the Deity to have made the eyes of an innumerable number of fish on exactly the same ideal type, and then to have made the eye of the octopus so exactly like these other eyes in superficial appearance as to deceive so accomplished a naturalist as Mr. Mivart, and yet to have taken scrupulous care that in no one ideal particular, should the one type resemble the other. However, adopting for the sake of argument this great assumption, let us suppose that God did lay down these arbitrary rules for his own guidance in creation, and then let us see to what the assumption leads. If the Deity formed a certain number of ideal types, and determined that on no account should he allow any part of one type to appear in any part of another, surely we should expect that within the limits of the same type the same typical structures should always be present. Thus, remember what efforts, so to speak, have been made to maintain the uniformity of type in the case of the fore-limb as previously explained, and should we not expect that in other and similar cases a similar method should have been followed? Yet we repeatedly find that this is not the case. Even in the whale, as we have seen, the hind-limbs are either altogether absent or dwindled almost to nothing; and it is impossible to see in what respects the hind-limbs are of any less ideal value than the fore-limbs--which are carefully preserved in all vertebrated animals except the snake, and the extinct Dinornis, where again we meet in this particular with a sudden and sublime indifference to the maintenance of a typical structure (Fig. 5). Now I say that if the theory of ideal types is true, we have in these facts evidence of a most unreasonable inconsistency. But the theory of descent with continued adaptive modification fully explains all the known cases; for in every case the degree of divergence from the typical structure which an 
organism presents corresponds, in a general way, with the length of time during which the divergence has been going on. Thus we

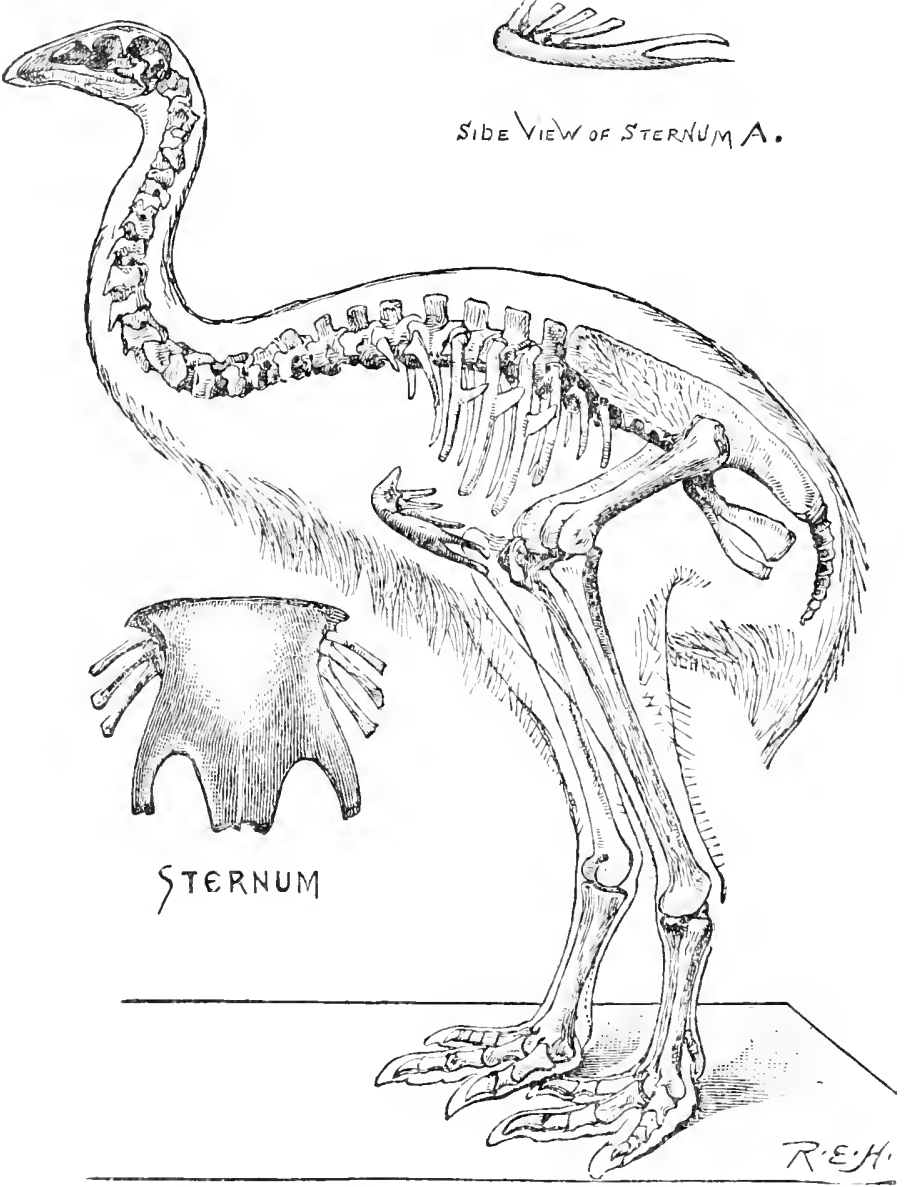

Fig. 5.- Skeleton of Dinomis grazis, $\frac{1}{10}$ nat. sizc. Drawn from nature (British Museum). As separate cuts on a larger scalc are shown, (I) the sternum as this appears in mounted specimens, and (2) the same in profile, with its (hypothetical) scapulo-coracoid attached. (From Romancs.)

scarcely ever meet with any great departure from the typical form with respect to one of the organs, without some of the other organs being so far modified as of themselves to indicate, on the supposition 
of descent with modification that the animal or plant must have been subject to the modifying influences for an enormously long series of generations. And this combined testimony of a number of organs in the same organism is what the theory of descent would lead us to expect, while the rival theory of design can offer no explanation of the fact, that when one organ shows a conspicuous departure from the supposed ideal type, some of the other organs in the same organism should tend to keep it company by doing likewise.

As an illustration both of this and of other points which have been mentioned, I may draw attention to what seems to me a particularly suggestive case. So-called soldier-or hermit-crabs are crabs which have adopted the habit of appropriating the empty shells of mollusks. In association with this peculiar habit, the structure of these animals differs very greatly from that of all other crabs. In particular, the hinder part of the body, which occupies the mollusk-shell, and which therefore has ceased to require any hard covering of its own, has been suffered to lose its calcareous integument, and presents a soft fleshy character, quite unlike that of the most exposed parts of the animal. Moreover, this soft fleshy part of the creature is especially adapted to the particular requirements of the creature by having its lateral appendages-i.e., appendages which in other crustacea perform the function of legs- modified so as to act as claspers to the inside of the mollusk-shell; while the tail-end of the part in question is twisted into the form of a spiral, which fits into the spiral of the mollusk-shell. Now, in Keeling Island there is a large kind of crab called Birgus latro, which lives upon land and there feeds upon cocoa-nuts. The whole structure of this crab, it seems to me, unmistakably resembles the structure of a hermit-crab (Fig. 6). Yet this crab neither lives in the shell of a mollusk, nor is the hinder part of its body in the soft and fleshy condition just described; on the contrary, it is covered with a hard integument like all the other parts of the animal. Consequently. I think we may infer that the ancestors of Birgus were hermit-crabs living in mollusk-shells; but that their descendants gradually relinquished this habit as they gradually became more and more terrestrial, while, concurrently with these changes in habit, the originally soft posterior parts acquired a hard protective covering to take the place of that which was formerly supplied by a mollusk-shell. So that, if so, we now have, within the limits of a single organism evidence of a whole series of morphological changes in the past history of its species. First, there must have been the great change from an 


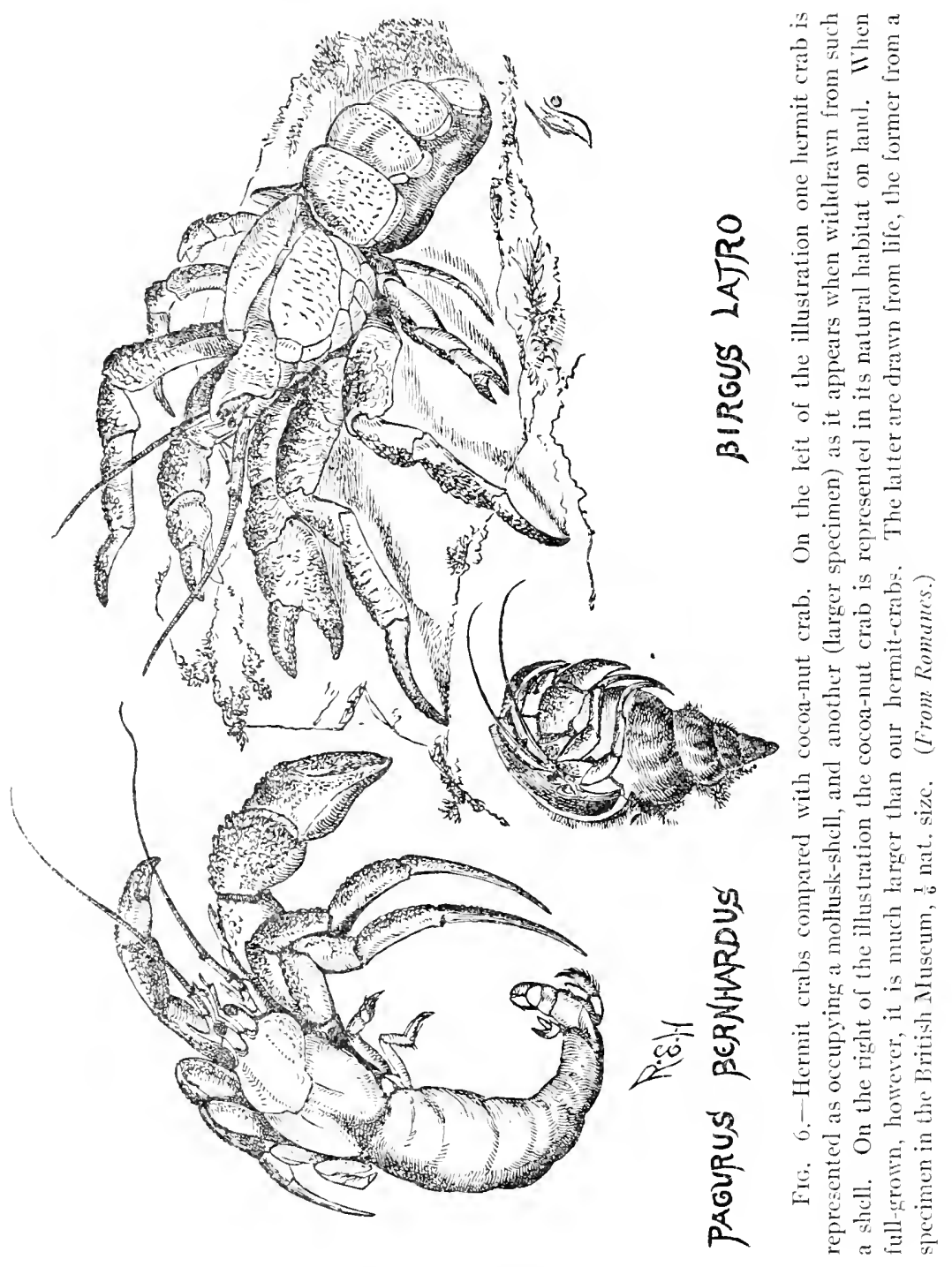


ordinary crab to a hermit-cra' in all the respects previously pointed out. Next, there must have been the change back again from a hermit-crab to an ordinary crab, so far as living without the necessity of a mollusk-shell is concerned. From an evolutionary point of view, therefore, we appear to have in the existing structure of Birgus a morphological record of all these changes, and one which gives us a reasonable explanation of why the animal presents the extraordinary appearance which it does. But, on the theory of special creation, it is inexplicable why this land-crab should have been formed on the pattern of a hermit-crab, when it never has need to enter the shell of a mollusk. In other words, its peculiar structure is not especially in keeping with its present habits, although so curiously allied to the similar structure of certain other crabs of totally different habits, in relation to which the peculiarities are of plain and obvious significance

I will devote the remainder of this chapter to considering another branch of the argument from morphology, to which the case of Birgus serves as a suitable introduction: I mean the argument from rudimentary structures.

Throughout both the animal and vegetable kingdoms we constantly meet with dwarfed and useless representatives of organs, which in other and allied kinds of animals and plants are of large size and functional utility. Thus, for instance, the unborn whale has rudimentary teeth, which are never desticed to cut the gums; and throughout its life this animal retains, in a similarly rudimentary condition, a number of organs which never could have been of use to any kind of creature save a terrestrial quadruped. The whole anatomy of its internal ear, for example, has reference to hearing in air, as Hunter long ago remarkcd, "is constructed upon the same principle as in the quadruped"; yet, as Owen says, "the outer opening and passage leading therefrom to the tympanum can rarely be affected by sonorous vibrations of the atmosphere, and indeed they are reduced, or have degenerated, to a degree which makes it difficult to conceive how such vibrations can be propagated to the ear-drum during the brief moments in which the opening may be raised above the water."

Now, rudimentary organs of this kind are of such frequent occulrence, that almost every species presents one or more of themusually, indeed, a considerable number. How, then, are they to be accounted for? Of course the theory of descent with adaptive modi. fication has a simple answer to supply-namely, that when. from 
changed conditions of life, an organ which was previously useful becomes useless, it will be suffered to dwindle away in successive generations, under the influence of certain natural causes which we shall have to consider in future chapters. On the other hand, the theory of special creation can only maintain that these rudiments are former for the sake of adhering to an ideal type. Now, here again the former theory appears to be triumphant over the latter; for, without waiting to dispute the wisdom of making dwarfed and useless structures merely for the whimsical motive assigned, surely if such a

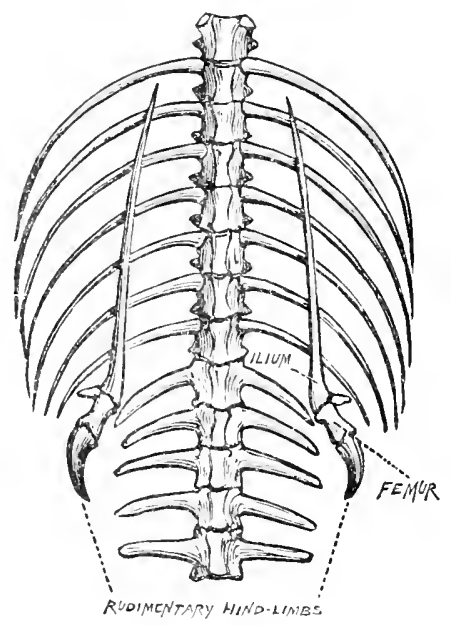

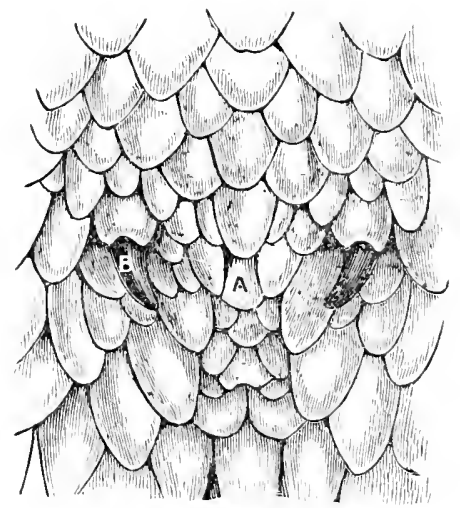

B. HORNY VENT,

B. HORNY TERMINATION OF

FIG. 7.- Rudimentary or vestigial hind limbs of python, as exlibited in the skeleton and on the external surface of the animal. Drawn from nature, $\frac{1}{4}$ nat. size. (From Romanes.)

method were adopted in so many cases, we should expect that in consistency it would be adopted in all cases. This reasonable expectation, howerer, is far from being realized. We have already seen that in numberless cases, such as that of the fore-limbs of serpents, no vestige of a rudiment is present. But the vacillating policy in the matter of rudiments does not end here; for it is shown in a still more aggravated form where within the limits of the same natural groups of organisms a rudiment is sometimes present and sometimes absent. For instance, although in nearly all the numerous species of snakes there are no vestiges of limbs, in the Python we find very tiny rudiments of the hind-limbs (Fig. 7). Now, is it a worthy conception of Deity that, while neglecting to maintain his unity of ideal in the case of 
nearly all the numerous species of snakes, he shoukl have atkled at tiny rudiment in the case of the Python-and even in that case should have maintained his ideal very inefficiently, inasmuch as only two limbs, insteal of four, are representerl? How much more reisonable is the naturalistic interpretation; for here the very irregularity of their appearance in rlifferent species, which constitutes rudimentary structures one of the crowning difficulties to the theory of special design, furnishes the best possible evidence in favour of hereditary

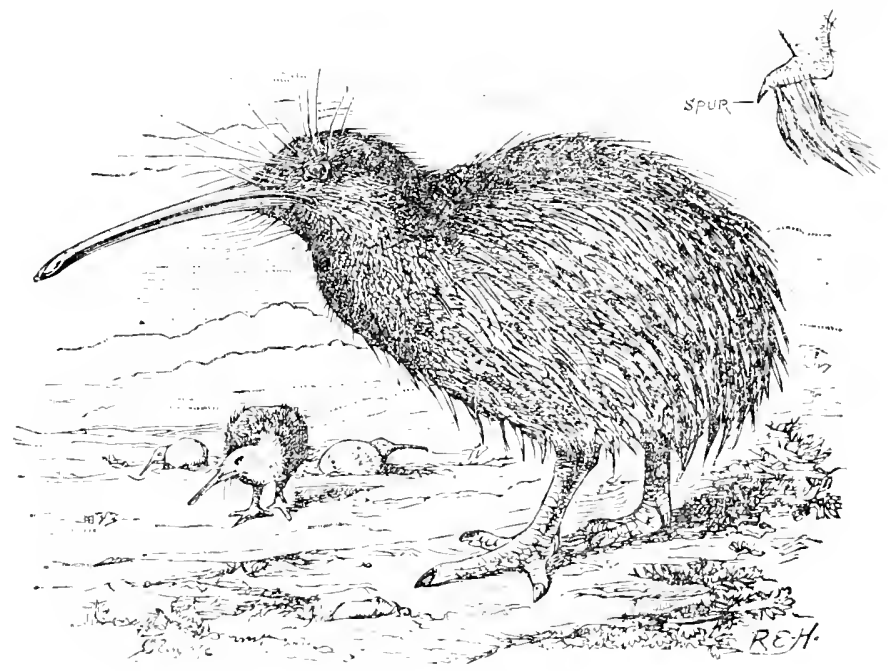

Fig. S.-1 plery austrulis. Drawn from life in the Zoölogical Gardens, $\frac{1}{6}$ nat. size. The external wing is drawn to a scale in the upper part of the cut. The surroundings are supplied from the most recent descriptions. (From Romanes.)

descent; seeing that this irregularity then becomes what may be termed the anticipated expression of progressive dwindling due to inutility. Thus, for example, to return to the case of wings, we have already seen that in an extinct genus of bird, Dinornis, these organs were rediced to such an extent as to leave it still doubtful whether so much as the tiny mulinent hypothetically supplied to Figure 5 was prescnt in all the species. Ind here is another well-known case of another genus of still existing birt, which, as was the case with Dinornis, occurs only in New Zealand (Fig. 8). Upon this islant there are no four-footed enemies-either existing or extinct-to escape from which the wings of birls would be of any service. Conse- 
quently we can understand why on this island we should meet with such a remarkable dwindling away of wings.

Similarly, the logger-headed duck of South America can only flap along the surface of the water, having its wings considerably reduced though less so than the Apteryx of New Zealand. But here the interesting fact is that the young birds are able to fly perfectly well. Now, in accordance with a general law to be considered in a future chapter, the life-history of an individual organism is a kind of condensed recapitulation of the life-history of its species. Consequently, we can understand why the little chickens of the logger-headed duck are able to lly like all other ducks, while their parents are only able to flap along the surface of the water.

Facts analogous to this reduction of wings in birds which have no further use for them, are to be met with also in insects under similar circumstances. Thus, there are on the island of Madeira somewhere between 500 and 600 species of beetles, which are in large part peculiar to that island, though related to other-and therefore presumably parent-species on the neighboring continent. Now, no less than 200 species-or nearly half the whole number-are so far deficient in wings that they cannot fly. And, if we disregard the species which are not peculiar to the island-that is to say, all the species which likewise occur on the neighboring continent, and therefore, as evolutionists conclude, have but recently migrated to the island,-we find this very remarkable proportion. There are altogether 29 peculiar renera, and out of these no less than 23 have all their species in this condition.

Similar facts have been recently observed by the Rev. A. E. Eaton with respect to insects inhabiting Kerguelen Island. All the species which he found on the island - viz., a moth, several flies, and numerous beetles-he found to be incapable of flight; and therefore, as Wallace observes, "as these insects could hardly have reached the islands in a wingless state, even if there were any other known land inhabited by them, which there is not, we must assume that, like the Madeiran insects, they were originally winged, and lost their power of flight because its possession was injurious to them"-Kerguelen Island being "one of the stormiest places on the globe," and therefore a place where insects could rarely afford to fly without incurring the danger of being blown out to sea.

Here is another and perhaps an even more suggestive class of facts. 
It is now many years ago since the editors of Silliman's journal requested the late Professol Agassiz to give them his opinion on the following question. In a certain dark subterranean cave, called the Mammoth Cave, there are found some peculiar species of blind ishes. Now the editors of Silliman's Journal wished to know whether Professor Agassiz would hold that these fish had been specially created in these caves, and purposely deroided of eyes which could never be of any use to them; or whether he would allow that these fish had probably descended from other species, but, having got in to the dark cave, gradually lost their eyes through disuse. Professor Agassiz, who was a believer in special creation, allowed that this ought to constitute a crucial test as between the two theories of special design and hereditary descent. "If physical circumstances," he said, "ever modified organised human beings, it should be easily ascertained here." And eventually he gave it as his opinion, that these fish "were creater] under the circumstances in which they now live, within the limits over which they now range, and with the structural peculiarities which now charactcrise them."

Since then a great dical of attention has been paid to the fauna of this Mamnoth cave, and also to the faunas of other dark caverns, not only in the New, but also in the Old World. In the result, the following general farts have been fully established.

r. Not only fish, but many representatives of other classes, have been found in dark caves.

2. Wherever the caves are totally dark, all the animals are blind.

3. If the animals live near enough to the entrance to receive some degree of light, they may have large and lustrous eyes.

4. In all cases the species of blind animals are closely allied to species inhabiting the district where the caves occur; so that the blind species inhabiting the American caves are closely allied to American species, while those inhabiting European caves are closely allied to European species.

5. In nearly all cases structural remnants of eyes admit of being detected, in various degrees of obsolescence. In the case of some of the crustaccans of the Mammoth cave the foot-stalks of the eyes are present, although the eyes themselves are entirely absent.

Now, it is evident that all these general facts are in full agreement with the theory of evolution, while they offer serious difficulties to the theory of special creation. As Darwin remarks, it is hard to imagine conditions of life more similar than those furnished by deep 
limestone caverns under nearly the same climate in the two continents of America and Europe; so that, in accordance with the theory of special creation, very close similarity in the organizations of the two sets of faunas might have been expected. But, instead of this, the affinities of these two sets of faunas are with those of their respective continents - as of course they ought to be on the theory of evolution. Again, what would have been the sense of creating the useless footstalks for the imaginary support of absent eyes, not to mention all the other various grades of degeneration in other cases? So that, upon the whole, if we agree with the late Professor Agassiz in regarding these cave animals as furnishing a crucial test between the rival theories of creation and evolution, we must further conclude that the whole body of evidence which they now furnish is weighing on the side of evolution.

So much, then, for a few special instances of what Darwin called rudimentary structures, but what may be more descriptively designated-in accordance with the theory of descent-obsolescent or vestigial structures. It is, however, of great importance to add that these structures are of such general occurrence throughout both the vegetable and animal kingdoms that, as Darwin has observed, it is almost impossible to point to a single species which does not present one or more of them. In other words, it is almost impossible to find a single species which does not in this way bear some record of its own descent from other species; and the more closely the structure of any species is examined anatomically, the more numerous are such records found to be. Thus, for example, of all organisms that of man has been most minutely investigated by anatomists; and therefore I think it will be instructive to conclude this chapter by giving a list of the more noteworthy vestigial structures which are known to occur in the human body. I will take only those which are found in adult man, reserving for the next chapter those which occur in a transitory manner during earlier periods of his life. But, even as thus restricted, the number of obsolescent structures which we all present in our own person is so remarkable, that their combined testimony to our descent from a quadrumanous ancestry appears to me in itself conclusive. I mean, that even if these structures stood alone, or apart from any more general evidences of our family relationships, they would be sufficient to prove our parentage. Nevertheless, it is desirable to remark that of course these special evidences which I am about to detail do not stand alone. Not only is there the general analogy 
furnished by the general proof of evolution elsewhere, but there is likewise the more special correspondence between the whole of our anatomy and that of our nearest zoölogical allies. Now the force of this latter consideration is so enormous that no one who has not studied human anatomy can be in a position to appreciate it. For without special study it is impossible to form any adequate idea of the intricacy of structure which is presented by the human form. Yet it is found that this enormously intricate organisation is repeated in all its details in the bodies of the higher apes. There is no bone, muscle, nerve, or vessel of any importance in the one which is not answered to by the other. Hence there are hundreds of thousands of instances of the most detailed correspondence, without there being any instances to the contrary, if we pay due regard to vestigial characters. The entire corporeal structure of man is an exact anatomical copy of that which we find in the ape.

My object, then, here is to limit attention to those features of our corporeal structure which, having become useless on account of our change in attitude and habits, are in the process of becoming obsolete, and therefore occur as mere vestigial records of a former state of things. For example, throughout the vertebrated series, from fish to mammals, there occurs in the inner corner of the eye a semitransparent eye-lid, which is called the nictitating membrane. The object of this structure is to sweep rapidly, every now and then, over the external surface of the eye, apparently in order to keep the surface clean. But although the membrane occurs in all classes of the sub-kingdom, it is more prevalent in some than in others-e.g., in birds than in mammals. Even, however, where it does not occur of a size and mobility to be of any use, it is usually represented, in animals above fishes, by a functionless rudiment, as here depicted in the case of man (Fig. 9).

Now the organisation of man presents so many vestigial structures thus referring to various stages of his long ancestral history, that it would be tedious so much as to enumerate them. Therefore I will yet further limit the list of vestigial structures to be given as examples, by not only restricting these to cases which occur in our own organisation; but of them I shall mention only such as refer us to the very last stage of our ancestral history-viz., structures which have become obsolescent since the time when our distinctively human branch of the family tree diverged from that of our immediate forefathers, the Quadrumana. 


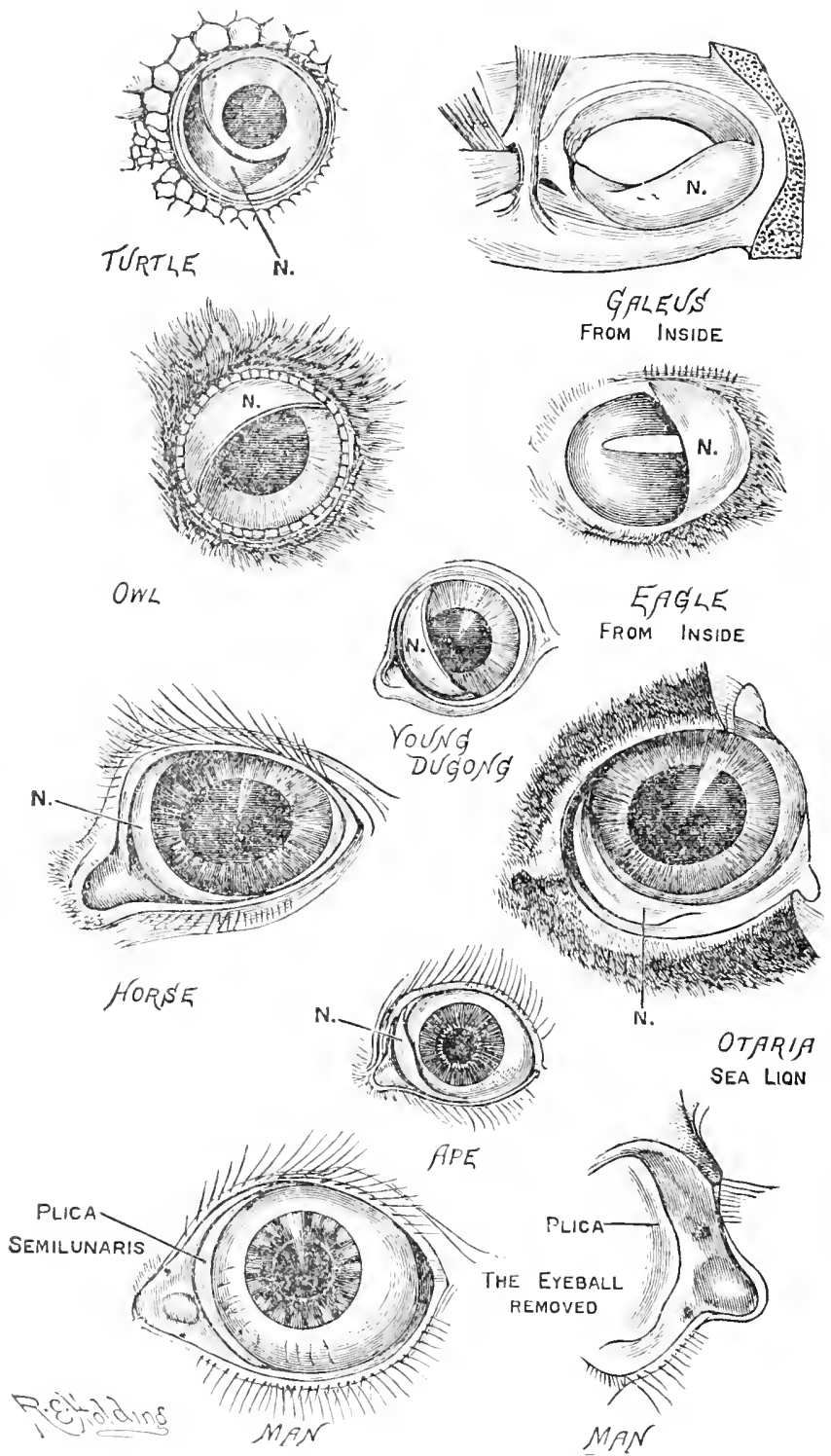

FIG. 9.-Illustrations of the nictitating membrane in the various animals named, drawn from nature. The letter $N$ indicates the membrane in each case. In man it is called the plira scmilunaris and is represented in the two lower drawings under this name. In the case of the shark (Galeus), the muscular membrane is shown as dissected. (From Romanes.) 
I. Muscles of the external ear.-These, which are of larese size and functional use in quadrupeds, we retain in a dwindled and useless condition (Fig. Io). This is likewise the case in anthropoid apes; but in not a few other Ouardrumana (e.g. baboons, macacus, magots, etc.) degeneration has not proceeled so far, and the ears are voluntarily movable.

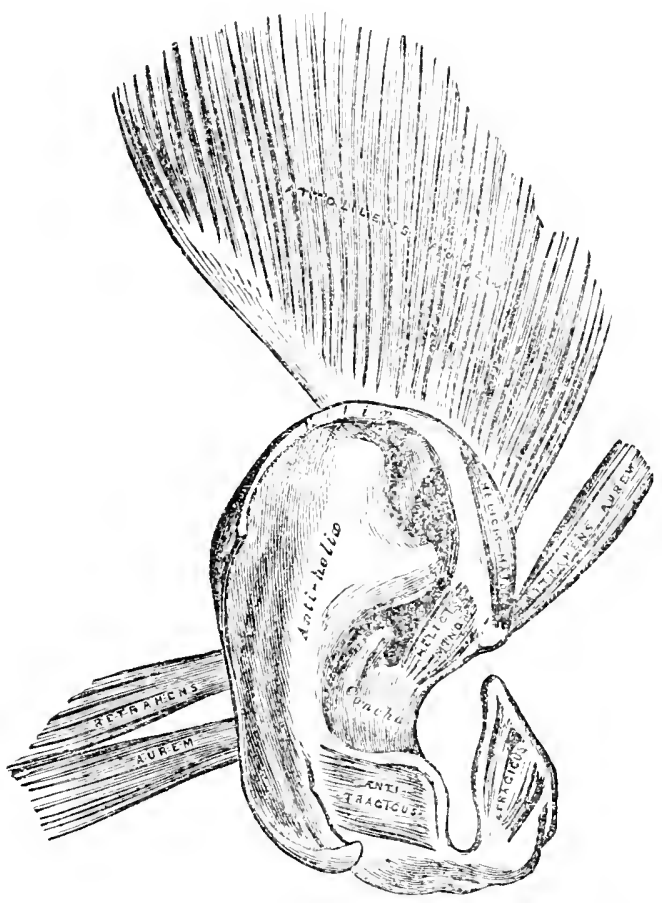

FIG. 10.-Rudimentary, or restigial and useless, muscles of the human ear. (From Romanes, afler Gray.)

2. Panniculus carnosis. - A large number of the mammalia are able to move their skin by means of subcutaneous muscle, as we sce, for instance, in a horse, when thus protecting himself against the sucking of flies. We, in common with the Quxlrumana, possess an active remnant of such a muscle in the skin of the forehead, wherely we draw up the eyebrows; but we are no longer able to use other considerable remmants of $\mathrm{it}$, in the scalp and clsewhere,-or more correctly it is rarely that we meet with persons who can. But most of the Cuadrumana (inclurling the anthropoirs) are still able to co so. 
There are also many other vestigial muscles, which occur only in a small percentage of human beings, but which, when they do occur, present unmistakable homologies with normal muscles in some of the Quadrumana and still lower animals.

3. Feet.-It is observable that in the infant the feet have a strong reflection inwards, so that the soles in considerable measure face one another. This peculiarity, which is even more marked in the embryo than in the infant, and which becomes gradually less and

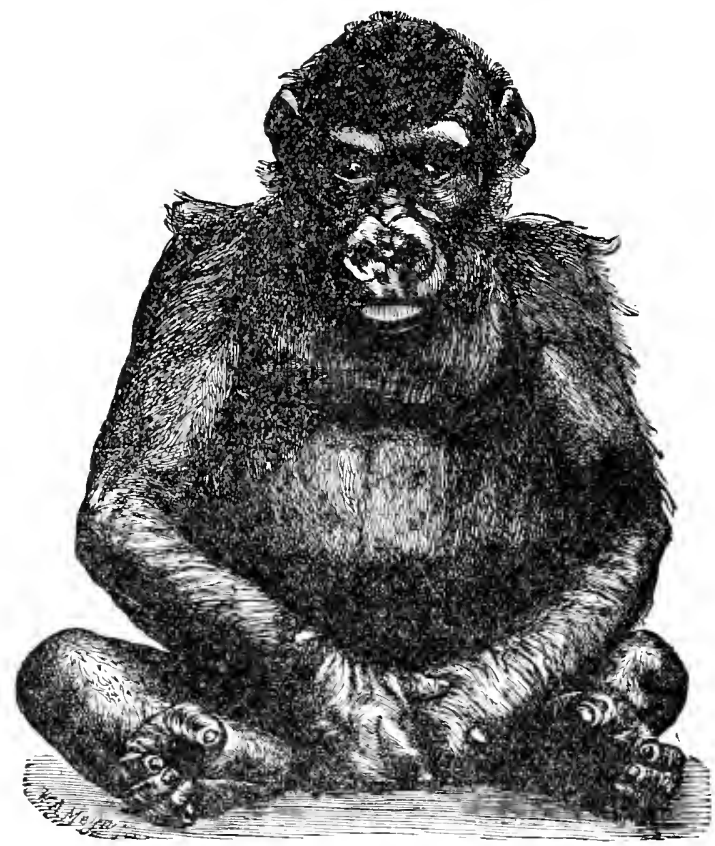

FIG. I I. - Portrait of a young gorilla. (From Romanes, after Hartmann.)

less conspicuous even before the child begins to walk, appears to me a highly suggestive peculiarity. For it plainly refers to the condition of things in the Quadrumana, seeing that in all these animals the feet are similarly curved inwards, to facilitate the grasping of branches. And even when walking on the ground apes and monkeys employ to a great extent the outside edges of their feet, as does also a child when learning to walk. The feet of a young child are also extraordinarily mobile in all directions, as are those of apes. In order to show these points, I here introduce comparative drawings of a young ape and the 
lower extremities of a still younger child. These drawings, moreover. serve at the same time to illustrate two other vestigial characters, which have often been previously noticed with regard to the infant's foot. I allude to the incurved form of the legs and the lateral extension of the great toe, whereby it approaches the thumb-like character of this organ in the Quadrumana. As in the case of the incurved position of the legs and feet, so in this case of the lateral extensibility of the great toe, the peculiarity is even more marked in embryonic

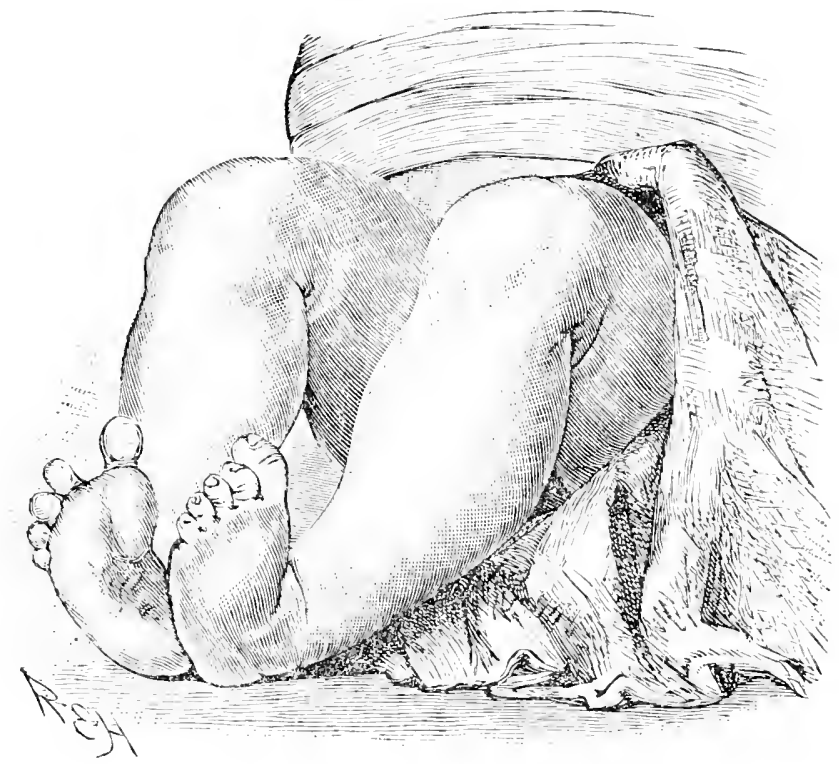

FIG. I 2.-Lower extremities of a young child. Drawn from life, when the mobile feet were for a shor time at rest in a position of extreme inflection. (From Romanes.)

than in infant life. For, as Professor Wyman has remarked with regard to the foetus when about an inch in length, "The great toe is shorter than the others; ant, instead of being parallel to them, is projected at an angle from the side of the foot, thus corresponding with the permanent condition of this part in the Quadrumana." So that this organ, which, according to Owen, "is perhaps the most characteristic peculiarity of the human structure, "when tracerl back to the early stages of its development, is found to present a notably less degree of peculiarity. 
4. Hands.-Dr. Louis Robinson has recently observed that the grasping power of the whole human hand is so surprisingly great at birth, and during the first few weeks of infancy, as to be far in excess of present requirements on the part of a young child. Hence he concludes that it refers us to our quadrumanous ancestry-the young of anthropoid apes being endowed with similar powers of grasping, in order to hold on to the hair of the mother when she is using her arms for the purposes of locomotion. This inference appears to me justifiable,

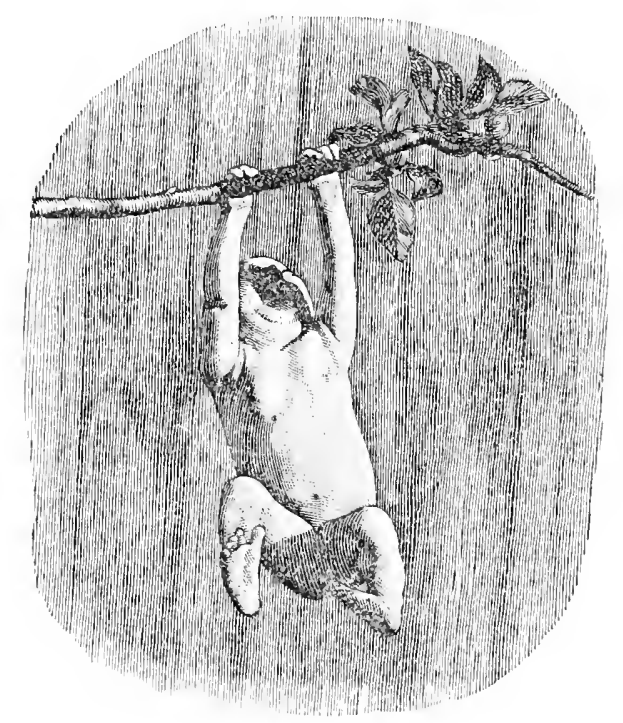

FIG. I3.--In infant, three weeks old, supporting its own weight for orer two minutes. The attitude of the lower limbs, feet, toes, is strikingly simian. Reproduced from an instantaneous photograpl, kindly given for the purpose by Dr. L. Robinson. (From Romanes.)

inasmuch as no other explanation can be given of the comparatively inordinate muscular force of an infant's grip. For experiments showed that very young balies are able to support their own weight, by holding on to a horizontal bar, for a period varying from one half to more than two minutes. With his kind permission, I here reproduce one of Dr. Robinson's instantaneous, and hitherto unpublished, photographs of a very young infant. This photograph was taken after the above paragraph (3) was written, and I introduce it here because it serves to show incidentally - and perhaps even better than the preceding figure-the points there mentioned with regard 
to the feet and great toes. Again, as Wr. Rolsinson olserves, the attitude, and the disproportionately large development of the arms as compared with the lers give all the photographs a striking resemblance to a picture of the chimpanzee "Sally" at the Zoölogical Gardens. For" invariably the thighs are lent nearly at right angles to the body, and in no case did the lower limbs hang down and take the attitude of the erect position." He adrds, "In many cases no sign of distress is evinced, and no cry uttered, until the grasp luegins to give way."
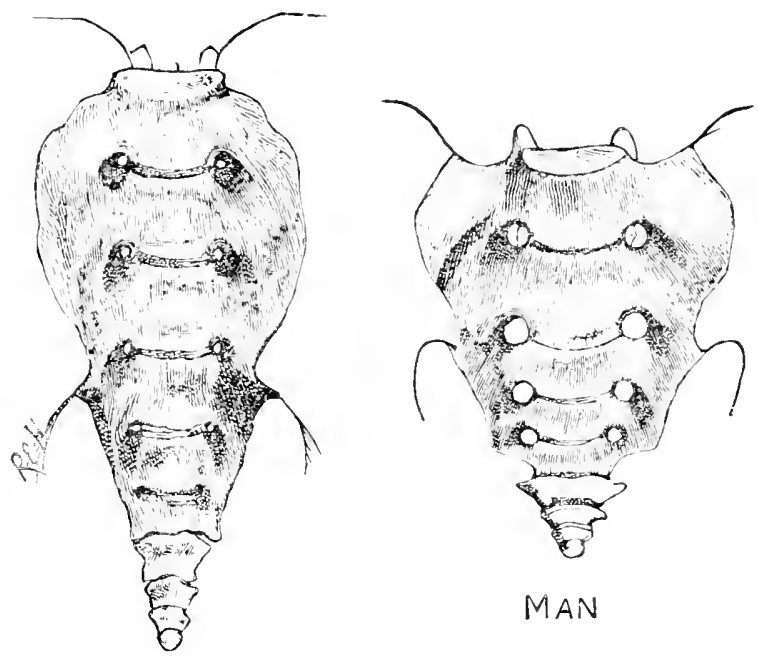

MAN

\section{GORILLA}

FIG. 14.- Siacrum of gorilla compared with that of man, showing rudimentary tail bones of each. Drawn from nature. (From Romanes.)

5. Tail.-The absence of a tail in man is popularly supposed to constitute a difficulty against the doctrine of his quadrumanous descent. As a matter of fact, however, the absence of an external tail in man is precisely what this doctrine would expect, seeing that the nearest allies of man in the quadrumanous series are likewise destitute of an external tail. Far, then, from this deficiency in man constituting any difficulty to be accounted for, if the case were not so-i.e., if man did possess an external tail, - the difficulty would he to understand how he had mang ged to retain an organ which had heen renounced by his most recent ancestors. Nevertheless, as the anthro- 
poid apes continue to present the rudimentary vestiges of a tail in a few caudal vertebrae below the integuments, we might well expect to fincl a similar state of matters in the case of man. And this is just

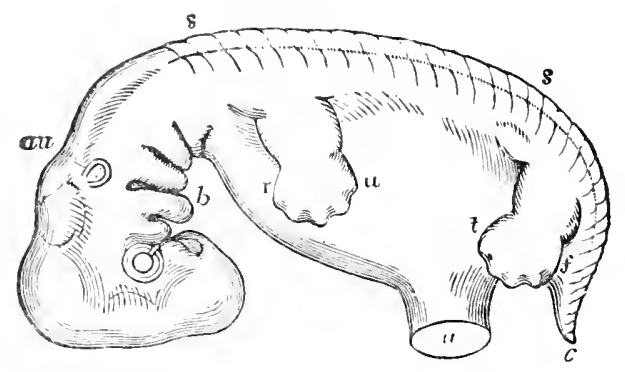

Frg. I5.-Diagrammatic outline of the human embryo when about seven weeks old, showing the relations of the limbs and tail to the trunk. (After Allen Thompson.) $r$, the radial, and $u$, the ulnar, border of the hand and forearm; $t$, the tibial, and $f$ the fibular, border of the foot and lower leg; au, ear; $u$, spinal corl; $u$, umbilical corrl; $h$, bronchial gill slits; $c$, tail. (From Romanes.)
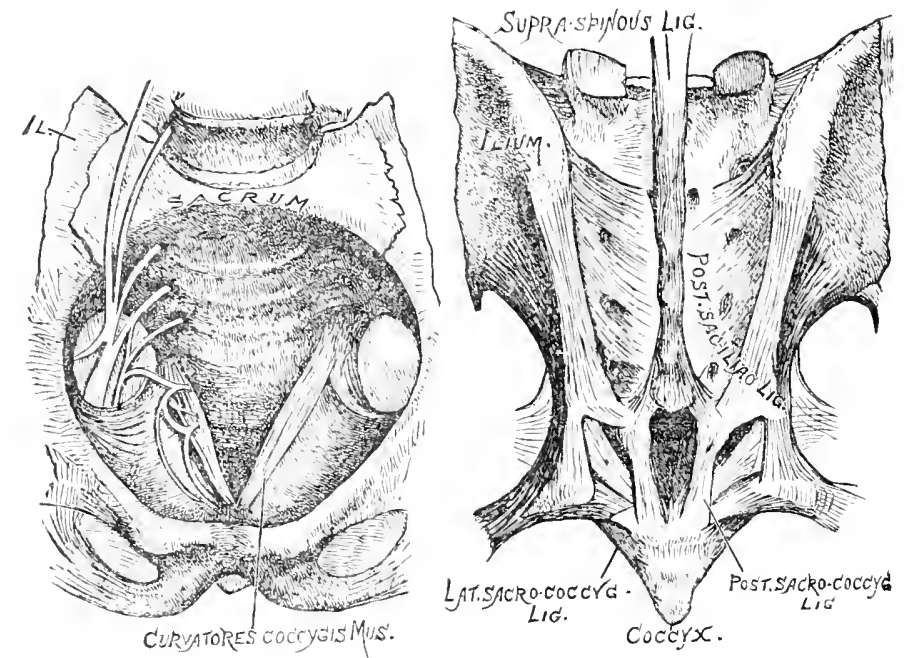

FIG. I6.-Front and back view of adult human sacrum, showing abnormal persistence of restigial tail muscles. (From Romanes.)

what we do find, as a glance at these two comparative illustrations will show (Fig. I4). Moreover, during embryonic life, both of the anthropoid apes and of man, the tail much more closely resembles 
that of the lower kinds of quadrumanous animals from which these higher representatives of the group have descended. For at a certain stage of embryonic life the tait, both of apes and of human beings, is
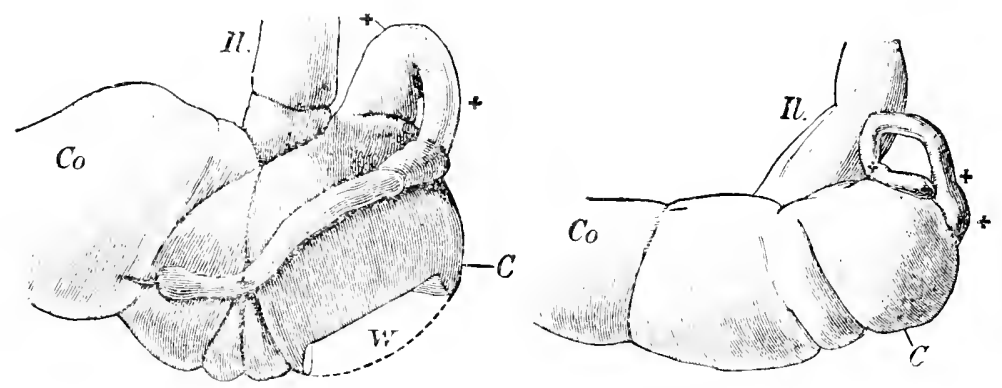

FIG. I7.-Appendix vermiformis in orang and in man. $I l$, ilium; Co, colon; $C$, coecum; Ir, a window cut in the wall of the crecum; $x x$, the appentix. (Frm Remints.)

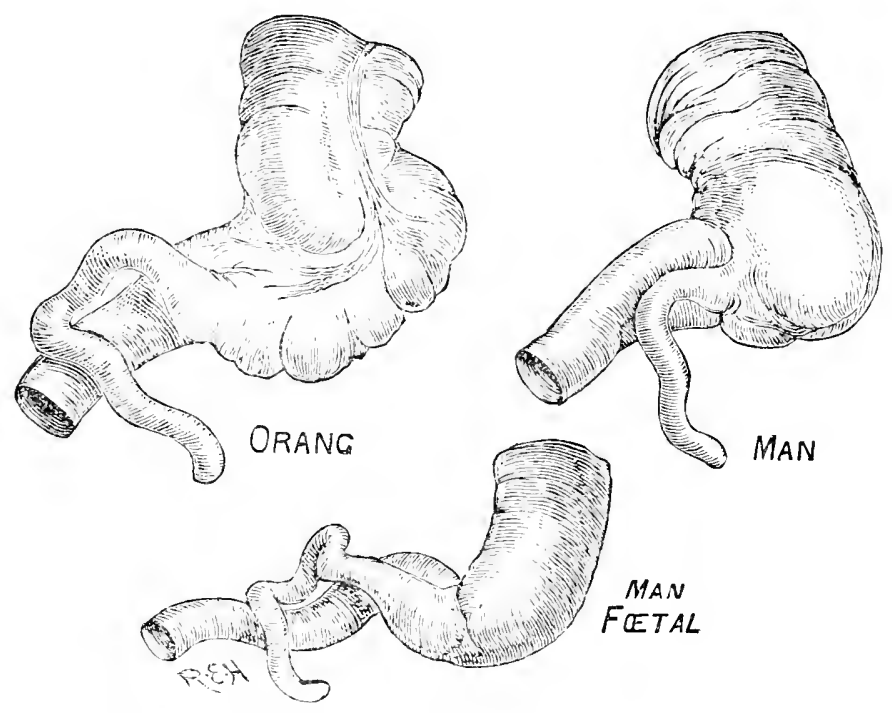

FIG. 18-The same, showing variation in the orang. (From Romines.)

actialiy longer than the legs (see Fig. I5). And at this stage of development, also, the tail armits of being moved by muscles which later on dwindle away, Occasionally, howerer, these muscles persist. and are then described ly ana tomists as abriomatities. The illustra- 
tions on page 82 (Fig. I6) serve to show the muscles in question, when thus found in adult man.

6. Vermiform appendix of the coecum.-This is of large size and functional use in the process of digestion among many herbivorous animals; while in man it is not only too small to serve any such purpose, but is even a source of danger to life-many persons dying every year from inflammation set up by the lodgement in this blind tube of fruit-stones, etc.

In the orang it is longer than in man (Fig. I7), as it is also in the human foetus proportionally compared with the adult (Fig. I8). In some of the lower herbivorous animals it is longer than the entire body.

Like the vestigial structures in general, however, this one is highly variable. Thus Figure I 8 serves to show that it may sometimes be almost as short in the orang as it normally is in man-both the human subjects of this illustration having been normal.

7. Ear.-Mr. Darwin writes:

"The celebrated sculptor, Mr. Woolner, informs me of one little peculiarity in the external ear, which he has often observed both in men and women.... The peculiarity consists in a little blunt point, projecting from the inwardly folded margin, or helix. When prescnt, it is developed at birth, and according to Professor Ludwig Meyer, more frequently in man than in woman. Mr. Woolner made an exact model of one such case, and sent me the accompanying drawing [Fig. r9]. . . . The helix obviously consists of the extreme margin of the ear folded inwards; and the folding appears to be in some manner connected with the whole external ear being permanently pressed backwards. In many monkeys, which do not stand high in the order as baboons and some species of macacus, the upper portion of the ear is slightly pointed, and the margin is not at all folded inwards; but if the margin were to be thus folded, a slight point would necessarily project towards the centre. . . In Figure 20 is shown an accurate copy of a photograph

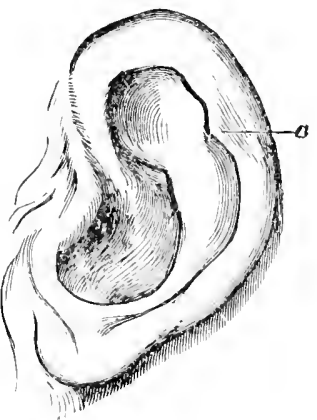

FIG. I 9.-Human ear, moleled and drawn by Mr. Woolner. a, the projecting point. (From Romanes.) of the foetus of an orang (kindly sent me by Dr. Nitsche), in which it may be seen how different the pointed outline of the ear is at this period from its adult condition, when it hears a close general 
resemblance to that of man (including even the occasional appearance of the projecting point shown in the preceding woodcut). It is

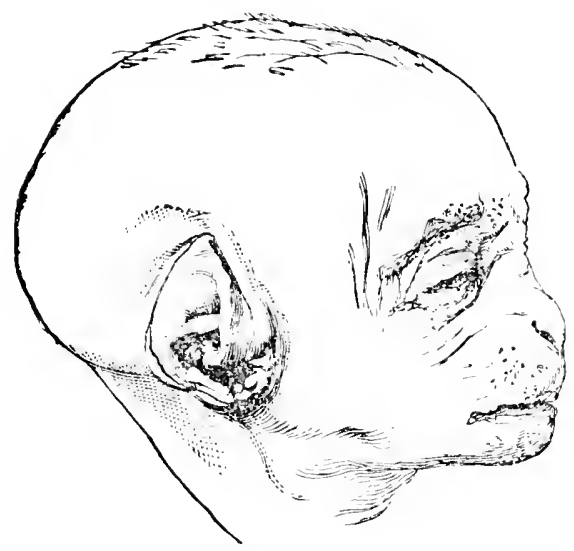

Fig. 20.-Foetus of an orane. Evact copy of a photograph, showing the form of ear at this early stage. (From Romanes.)

evident that the folding orer of the tip of such an ear, unless it is changed greatly during its further development, would give rise to a point projecting inwards." ${ }_{\mathbf{t}}$

The woodcut on page 86 (Fir. $2 \mathrm{I}$ ) serves still further to show vestigial resemblances between the human ear and that of apes. The last two figures illustrate the general resemblance between the normal ear of foetal man and the car of an adult orangoutang. The other two figures on the lower line are intended to exhibit occasional modifications of the adult human ear, which approximate simian characters somewhat more closely than does the normal type. It will be observed that in their comparatively small lobes these ears resemble those of all the apes; and that while the outer margin of one is not unlike that of the Barbary ape, the outer margin of the other follows those of the chimpanzee and orang. Of course it would be easy to select individual human ears which present either of these characters in a more pronounced degree; but these ears have been chosen as models because they present both characters in conjunction. The upper row of figures likewise shows the close similarity of hair-tracts, and the direction of growth on the part of the hair itself, in cases where the human hair happens to be of an abnormally hirsute character. But this particular instance (which I do not think has been previously noticed) introduces us to the subject of hair, and hair-growth, in general.

8. Hair.-Adult man presents rudimentary hairs over most parts of the body. Wallace has sought to draw a refined distinction between this restigial coating and the useful coating of quadrumanous animals, in the absence of the former from the human back. But even

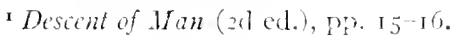




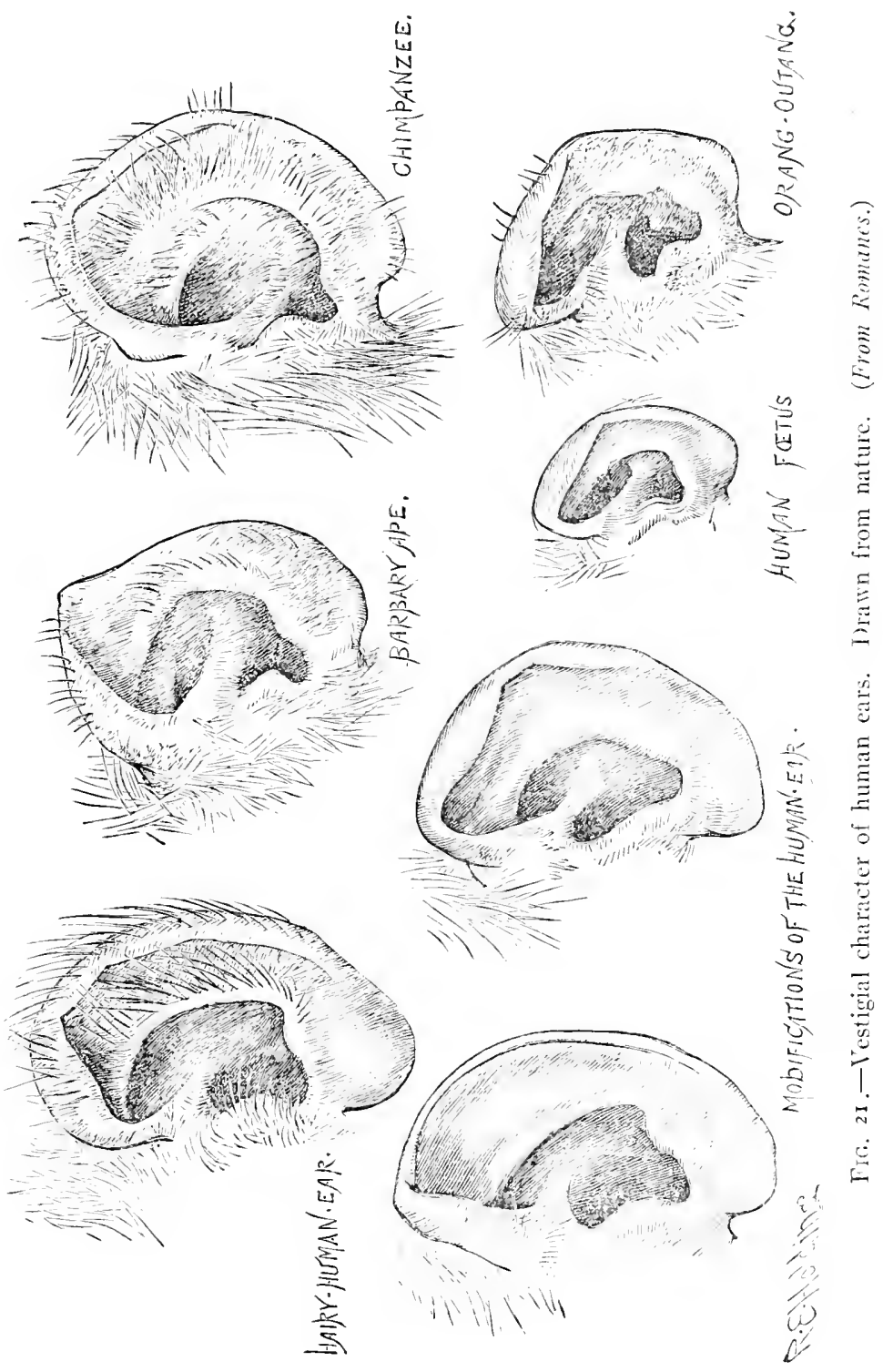


this refined distinction does not hold. On the one hand, the comparatively hairless chimpanzee which died last year in the Zoölogical Gardens (T. calvus) was remarkably denuded over the back; anil, on the other hand, men who present a considerable development of hair over the rest of their bodies present it also on their backs and shoulders. Again, in all men the rudimentary hair on the upper and lower arm is directed towards the elbow-a peculiarity which occurs nowhere else in the animal kingdom, with the exception of the anthropoid apes and a few American monkeys, where it presumably has to do with arboreal habits. For, when sitting in trees, the orang, as observed by Mr. Wallace, places its hands above its head with its elbows pointing downwards; the disposition of hair on the arms and fore-arms then has the effect of thatch in turning the rain. Again, I find that in all species of apes, monkeys, and baboons which I have examined (and they have been numerous), the hair on the backs of the hands and feet is continued as far as the first row of phalanges; but becomes scanty, or disappears altogether, on the second row; while it is invariably absent on the terminal row. I also find that the same peculiarity occurs in man. We all have rudimentary hair on the first row of phalanges, both of hands and feet: when present at all, it is more scanty on the second row; and in no case have I been able to find any on the terminal row. In all cases these peculiarities are congenital, and the total absence or partial presence of hair on the second phalanges is constant in different species of Quadrumana. For instance, it is entirely absent in all the chimpanzees, which I have examined, while scantily present in all the orangs. As in man, it occurs in a patch midway between the joints.

Besides showing these wro features with regard to disposition of hair on the human arm and hand, the woodcut on page SS (Fig. 22) illustrates a third. By looking closely at the arm of the very hairy man from whom the drawing was taken, it could be seen that there was a strong tendency towards a whorled arrangement of the hairs on the backs of the wrists. This is likewise, as a general rule, a marked feature in the arrangement of hair on the same places in the gorilla, orang, and chimpanzee. In the specimen of the latter, however, from which the drawing was taken this characteristic was not well marked. The downward direction of the hair on the backs of the hands is exactly the same in man as it is in all the anthropoid apes. Again, with regard to hair, Darwin notices that occasionally there appears in man a few hairs in the eyebrows much longer than the others; and that they seem to be 


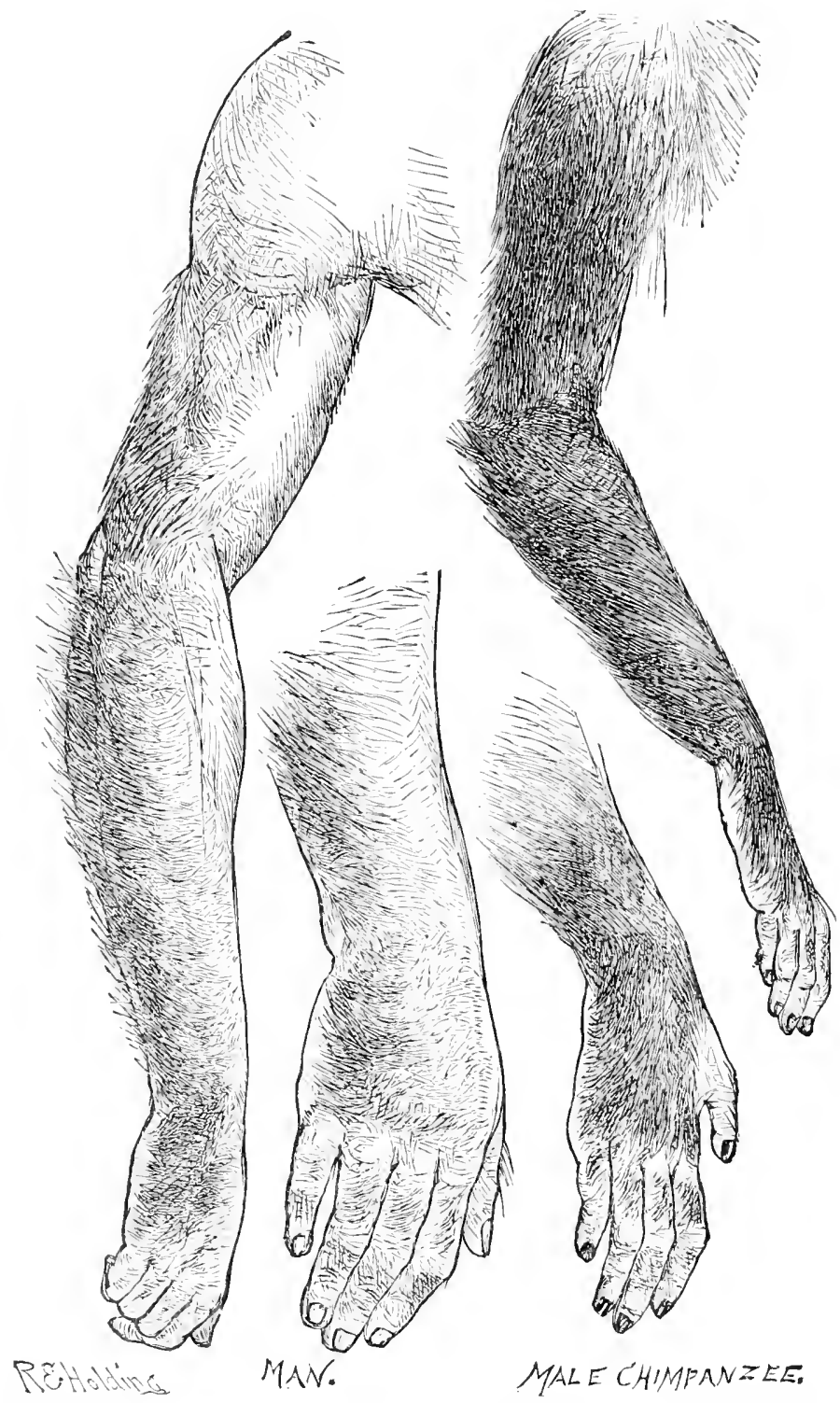

FIG. 22, - Hair tracts on the arms and hands of man, as compared with those of the chimpanzee. Drawn from life. (From Romanes.) 
representative of similarly long and scattered hairs which occur in the chimpanzee, macacus, and baboons.

Lastly, it may be here more conveniently observed than in the next chapter on Embryology, that at about the sixth month the human foetus is often thickly coated with somewhat long dark hair over the entire body, except the soles of the feet and palms of the hands, which are likewise bare in all quadrumanous animals. This covering, which is called the lanugo, and sometimes extends even to the whole forehead, ears, and face, is shed before birth. So that it appears to be useless for any purpose other than that of emphatically declaring man a child of the monkey.

\section{Teeth.-Darwin writes:}

"It appears as if the posterior molar or wistom teeth were tending to become rudinentary in the more civilized races of man. These teeth are rather smaller than the other molars, as is likewise the case with the corresponding teeth in the chimpanzee and orang; and they have only two separate fangs. . . . . They are also much more liable to vary, both in structure and in the period of their development, than the other teeth. In the Melanian races, on the other hand, the wisdom-teeth are usually furnished with three separate fangs, and are usually sound (i.e., not specially liable to decay); they also differ from the other molars in size, less than in the Caucasian races."

Now, in addition to these there are other respects in which the dwindling condition of wisdom-teeth is manifested-particularly with regard to the pattern of their crowns. Indeed, in this respect it would seem that even in the anthropoid apes there is the beginning of a tendency to degeneration of the molar teeth from behind forwards. For if we compare the three molars in the lower jaw of the gorilla, orang, and chimpanzee, we find that the gorilla has five well-marked cusps on all three of them; but that in the orang the cusps are not so pronounced, while in the chimpanzee there are only four of them on the third molar. Now in man it is only the first of these three teeth which normaliy presents five cusps, both the others presenting only four. So that, comparing all these genera together, it appears that the number of cusps is being reduced from behind forwards; the chimpanzee having lost one of them from the third molar, while man has not only lost this, but also one from the second molar,-and it may be added, likewise partially (or even totally) from the first molar, as a frequent variation among civilized races. But, on the other hand, variations are often met with in the opposite direction, where the 
second or the third molar of man presents five cusps-in the one case following the chimpanzee, in the other the gorilla. These latter variations, therefore, may fairly be regarded as reversionary. For these facts I am indebted to the kindness of Mr. C. S. Tomes.

Io. Perforations of the humerus.-The peculiarities which we have to notice under this heading are two in number. First, the supra-condyloid foramen is a normal feature in some of the lower Quadrumana (Fig. 24), where it gives passage to the great nerve of
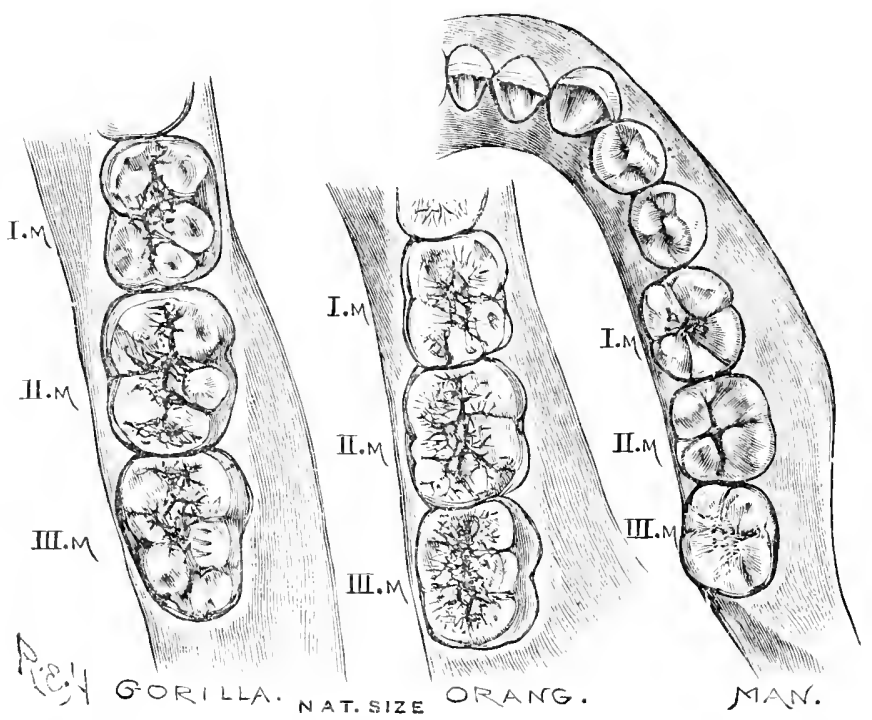

FIG. 23. - Molar teeth of lower jaw in gorilla, orang, and man. Drawn from nature, nat. size. (From Romanes.)

the forearm, and often also to the great artery. In man, however, it is not a normal feature. Yet it occurs in a small percentage of cases-viz., according to Sir IV. Turner, in about one per cent, and therefore is regarded by Darwin as a vestigial character. Secondly, there is inter-condyloid foramen, which is also situated near the lower and of the humerus, but more in the middle of the bone. This occurs, but not constantly, in apes, and also in the human species. From the fact that it does so much more frequently in the bones of ancient - and also of some sarage-races of mankind (viz. in 20 to 30 per cent of cases), Darwin is disposed to regard it also as a vestigial feature. 
On the other hand, Prof. Flower telis me that in his opinion it is but an expression of impoverished nutrition during the growth of the bone.

Ir. Flattening of Tibia.-In some very ancient buman skeletons there has also been found a lateral flattening of the tibia, which rarely occurs in any existing human beings, but which appears to have been usual among the earliest races of mankind hitherto discovered. According to Broca, the measurcments of these fossil human tibiae resemble those of apes. Morcover, the bone is bent and strongly
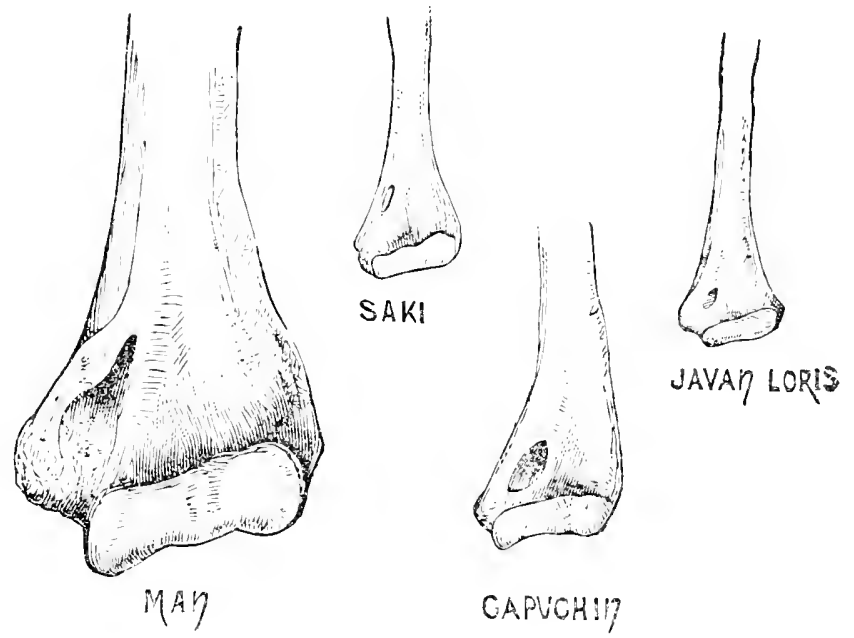

FIG. 24. - Perforations of the humerus (supra-condyloid foramen) in three species of Quadrumana where it normally occurs, and in man, where it does not normally occur. Drawn from nature. (From Romancs.)

convex forwards, while its angles are so rounded as to present the nearly oral section seen in apes. It is in association with these ape-like human tibiae that perforated humeri of man are found in greatest abundance.

On the ether hand, however, there is reason to doubt whether this form of tibia in man is really a survival from his quadrumanous ancestry. For, as Boyd-Dawkins and Hartmann have pointed out, the degree of flattening presented by some of these ancient human bones is greater than that which occurs in any existing species of anthropoid ape. Of coure the possibility remains that the unknown sprecies of ape from which man descended may have had its tibia more Hattened than is now whorvahle in any of the existing species. Nerer- 
theless, as some doubt attaches to this particular case, I do not press it - and, indeed, only mention it at all in order that the doubt may be expressed.

Similarly, I will conclude by remarking that several other instances of the survival of vestigial structures in man have been alleged, which are of a still more doubtful character. Of such, for example, are the supposed absence of the genial tubercle in the case of a very ancient jaw-bone of man, and the disposition of valves in human veins. From the former it was argued that the posisessor of this very ancient jaw-bone was probably speechless, inasmuch as the tubercle in existing man gives attachment to muscles of the tongue. From the latter it has been argued that all the valves in the veins of the human body have reference, in their disposition, to the incidence of blood-pressure when the attitude of the body is horizontal, or quadrupedal. Now, the former case has already broken down, and I find that the latter does not hold. But we can well afford to lose such doubtful and spurious cases, in view of all the foregoing unquestionable and genuine cases of vestigial structures which are to be met with even within the limits of our own organization-and even when these limits are still further limited by selecting only those instances which refer to the very latest chapter of our long ancestral history. 


\title{
CHAPTER VI
}

\section{EVIDENCES FROM CLASSIFICATION}

\author{
THE PRINCIPLES OF CLASSIFICATION ${ }^{1}$
}

A. F. SHULL

The International Code.-Some of the essential features of the international Code are as follows. The first name proposed for a venus or species prevails on the condition that it was published and accompanied by an adequate description, definition or indication, and that the autbor has applied the principles of binomial nomenclature. This is the so-called law of priority. The tenth edition of the Sytema Naturae of Linnaeus is the basis of the nomenclature. The author of a genus or species is the person who first publishes the same in connection with a definition, indication or description, and his name in full or abbreviated is given with the name; thus, Bascanian anthonyi Stejneger. In citations the generic name of an animal is written with a capital letter, the specific and subspecific name without initial capital letter. The name of the author follows the specinc name (or subspecific name if there is one) without intervening punctuation. If a species is transferred to a genus other than the one under which it was first described, or if the name of a genus is changed, the author's name is included in parentheses. For example, Bascanion anthonyi Stejneger should now be written Coluber anthonyi (Stejneger), the generic name of this snake having been changed. One species constitutes the type of the genus; that is, it is formally designated as typical of the genus. One genus constitutes the type of the subfamily (when a subfamily exists), and one genus forms the type of the family. The type is indicated by the describer or if not indicated by him is fixed by another author. The name of a subfamily is formed by adding the ending -inae, and the name of a family by adding -idae to the root of the name of the type genus. For example, Colubrinae and Colubridae are the subfamily and family of snakes of which Coluber is the type genus.

The basis of classification. - Early systematists largely employed superficial characters to differentiate and classify animals, and their

I From A. F. Shull, Principles of A nimul Biology (copyright ro20). Used by special permission of The McGraw-Hill Book Company 
classifications were thus largely artificial and served principally as convenient methods of arrangement, description and cataloging. Since the time of the development of the theory of descent with modifications by Lamarck (I809) and Darwin (I859), there has been an attempt to base the classification on relationships. Very nearly related animals are put into the same species. They are related because they descend from a common ancestry, and that common ancestry could not in most cases have been very ancient, otherwise evolution within the group would have occurred and the species would have been split into two or more species. Species that are much alike are included in one genus, being thus marked off from the species of another genus. The similarity of the species of a genus is held to indicate kinship, but since there is greater diversity among the individuals of a genus than among the members of a species, the common stock from which the species of a genus have sprung must have existed at an earlier time, in order that evolution could bring about the degree of divergence now observed. In like manner, a family is made up of genera, and their likeness is again a sign of affinity. But to account for the greater difference between the extreme individuals belonging to a family, evolution must have had more time, that is, the common source of the members of a family must have antedated the common source of the individuals of a genus. Orders, classes, and phyla are similarly regarded as having sprung from successively more remote ancestors, the time differences being necessary to allow for the differences in the amount of evolution. This statement is in general correct. However, since evolution has probably not proceeded at the same rate at all periods, nor in all branches of the animal kingdom at any one time, the time relations of the groups of high or low rank must not be too rigidly assigned. Thus certain genera, in which evolution has been slow, are probably much older than some families in which evolution has been rapid. It is not improbable, also, that some genera are quite as old as the families which include them; but in no case can they be older. Furthermore, different groups are classified by taxonomists of different temperaments, so that groups of a given nominal rank may be much more inclusive (and hence older) in one branch of the animal kingdom than in another. On the whole, nevertheless, the groups of higher rank have sprung from ancestry more remote than that of the groups of lower rank.

The means of recognizing the kinship implied in classification permit some differences of opinion. It is recognized that likeness in 
structural characters is the chief clue to affinities. However, the evidential value of similarity in one or several structures unaccompanied by the similarity of all parts is to be distrusted, since animals widely separated and dissimilar in most characters may have certain other features in common. Thus, the coots, phalaropes and grebes among birds have lobate feet but, as indicated by other features, they are not closely related; and there are certain lizards (Amphisbaenidae) which closely resemble certain snakes (Typholopidae) in being blind, limbless, and having a short tail. The early systematists were very liable to bring together in their classification analogous forms, that is, those which are functionally similar; or animals which are superficially similar. In contrast with the early practice, the aim of taxonomists at the present time is to group forms according to homology, which is considered an indication of actual relationship. Since a genetic classification must take into consideration the entire animal, the search for affinities becomes an attempt to evaluate the results of all morphological knowledge, and it is also becoming evident that sther things besides structure may throw light unon relationships. The fossil records, geographical distribution, ecology and experimental breeding may all assist in establishing affinities.

The method of taxonomy. - It is evident that before the relationships of animals can be determined the forms must be known, for unknown forms constitute breaks in the pedigrees of the groups to which they belong. Moreover, as pointed out above, the structural characters, variation and distribution must be known before a form can be placed in the proper place in a genetic system. For these reasons an important part of systematic work is the description of forms and an analysis of their differences. After the Linnaean system was adopted zoölogists attacked this virgin field and for many years "species making" predominated. Even at the present time when other aspects of zölogy have come to receive relatively more attention it is an interesting fact that the analytical method prevails in systematic studies, and taxonomy suffers from, and in part merits, the criticism that it is a mere cataloging of forms and ignores the higher goal of investigation, namely, the discovery of the course of evolution. Miany systematists, however, recognize that the ultimate purpose of taxonomic work is to discover the relationships as well as the differences between the descrilsed forms in order that the course of evolution may be determined. In other words, it is arpreciated that while analytical studies are necessary they are only preliminary. and 
that upon their results must be built synthetic studies, if taxonomy is to fulfil its purpose.

\section{THE METHOD OF CLASSIFICATION}

CHARLES DARWIN ${ }^{x}$

Naturalists, as we have seen, try to arrange the species, genera, and families in each class, on what is called the Natural System. But what is meant by this system? Some authors look at it merely as a scheme for arranging together those living objects which are most alike, and for separating those which are most unlike; or as an artificial method of enunciating, as briefly as possible, general propositions,that is, by one sentence to give the characters common, for instance, to all mammals, by another those common to all carnivora, by another those common to the dog-genus, and then, by adding a single sentence, a full description is given of each kind of dog. The ingenuity and utility of this system are indisputable. But many naturalists think that something more is meant by the Natural System; they believe that it reveals the plan of the Creator; but unless it be specified whether order in time or space, or both, or what else is meant by the plan of the Creator, it seems to me that nothing is thus added to our knowledge. Expressions such as that famous one by Linnaeus, which we often meet with in a more or less concealed form, namely, that the characters do not make the genus, but that the genus gives the characters, seem to imply that some deeper bond is included in our classifications than mere resemblance. I believe that this is the case, and that community of descent-the one known cause of close similarity in organic beings-is the bond which, though observed by various degrees of modification, is partially revealed to us by our classifications.

Let us now consider the rules followed in classification, and the difficulties which are encountered on the view that classification either gives some unknown plan of creation, or is simply a scheme for enunciating general propositions and of placing together the forms most like each other. It might have been thought (and was in ancient times thought) that those parts of the structure which determined the habits of life, and the general place of each being in the economy of nature, would be of very high importance in classification. Nothing can be more false. No one regards the external similarity of a mouse to a shrew, of a dugong to a whale, of a whale to a fish, as of any

' From The Origin of Species 
importance. These resemblances, though so intimately connected with the whole life of the being, are ranked as merely "adaptive or analogical characters": but to the consideration of these resemblances we shall recur. It may even be given, as a general rule, that the less any part of the organisation is concerned with special halits, the more important it becomes for classification. As an instance: Owen, in speaking of the dugong, says, "The generative organs, being those which are most remotely related to the habits and food of an animal, I have always regarded as affording very clear indications of its true affinities. We are least likely in the modifications of these organs to mistake a merely adaptive for an essential character." With plants how remarkable it is that the organs of vegetation, on which their nutrition and life depend, are of little signification; whereas the organs of reproduction, with their product the seed and embryo, are of paramount importance! So again in formerly discussing certain morphological characters which are not functionally important, we have seen that they are often of the highest service in classification. This depends on their constancy throughout many allied groups; and their constancy chiefly depends on any slight deviations not having been preserved and accumulated by natural selection, which acts only on serviceable characters.

\section{WHAT IS A SPECIES?}

"Each kind of animal or plant, that is, each set of forms which in the changes of the ages has diverged tangibly from its neighthors, is called a species. There is no absolute definition for the word species. The word kind represents it exactly in common language, and is just as susceptible to exact definition. The scientific idea of species does not differ materially from the popular notion. A kind of tree or bird or squirrel is a species. Those individuals which agree very closely in structure and function belong to the same species. There is no absolute test, other than the common judgment of men competent to decide. Naturalists recognize certain formal rules as assisting in such a decision. A series of fully intergrading forms, however varied at the extremes, is usually regarded as forming a single species. There are certain recognized effects of climate, of climatic isolation, and of the isolation of domestication. These do not isually make it necessary to regard as distinct species the extreme forms of a series concerned." ${ }^{\prime}$

\footnotetext{
' From D. S. Jordan and V. L. Kellngg, Erolution and t nimal Lile.
} 
'The term 'species' was thus defined by the celebrated botanist De Candolle: 'A species is a collection of all the individuals which resemble each other more than they resemble anything else, which can by mutual fecundation produce fertile individuals, and which reproduce themselves by generation, in such a manner that we may from analogy suppose them all to have sprung from one single individual.' And the zoölogist Swainson gives a somewhat similar definition: 'A species, in the usual acceptation of the term, is an aninal which, in a state of nature, is distinguished by certain peculiarities of form, size, colour, or other circumstances, from another animal. It propagates, after its kind, individuals perfectly resembling the parent; its peculiarities, therefore, are permanent." " $x$

As will have become apparent, the significant assumption underlying classification is that the closest fundamental similarities between animals (or plants) are found in the forms most closely related and that the greatest differences are found in those forms which are unrelated or at best very distantly related. The assumption implies the idea of descent with modification, which is no more nor less than evolution. Using this evolutionary basis, we can arrive at an extremely satisfactory classification both of living and of extinct forms; and there is no other basis of classification that works.

The question might well be asked whether it is possible to test the validity of the assumption that degrees of resemblance vary directly with closeness of blood relationship? Two direct tests of this may be and have been made. The closest of blood relatives possible are individuals that have been derived by the dividing of a single egg. Armadillo $^{2}$ quadruplets have been shown to be thus derived, and detailed studies of the closeness of resemblance existing between members of a given set indicate that they are vastly more alike than are the simultaneously born offspring of animals which give birth to several young, but in which each young is derived from a separate egg. If we use the index of correlation to indicate the degree of similarity between individuals we find that ordinary brothers or sisters are only about $5^{\circ}$ per cent alike, while armadillo quadruplets are over $9 \circ$ per cent alike. Identical or duplicate twins in human beings are believed to have an origin from one egg, after the fashion of the armadillo,

x From A. R. Wallace, Darininism.

${ }^{2}$ See H. H. Newman, Thr Rimlngy of Twins (1917), University of Chicago Press. 
though the proof has not been forthcoming. Everyone is familiar with the remarkable similarity, amounting almost to identity, between such twins. Thus we are able to show that the closest blood relationship known is associated with the closest rescmblance. The next degree of resemblance is between members of the same fanily, brothers, sisters, cousins, etc., and we do not hesitate to explain this resemblance as due to blood relationship. In this we merely accept the known principles of heredity.

The second direct test of the validity of the assumption that degrees of resemblance run parallel with degrees of blood relationship is found in connection with "blood-precipitation tests." This evidence, as presented by Professor Scott, forms the substance of the next chapter. 


\title{
CHAPTER VII
}

\section{EVIDENCE FROM BLOOD TESTS}

\author{
W. B. ScotT
}

Here may be conveniently considered the very interesting and significant blood tests which have been made in the last fifteen years by various physiologists and especially by Dr. George H. F. Nuttall, of the University of Cambridge. Though there are several methods of making these tests, the "precipitation method" employed by Dr. Nuttall will be quite sufficient for the ends sought in these lectures. The method and significance of the tests can best be explained by taking as an example human blood, which, of course, has been most extensively and minutely studied, because of its legal importance as well as its scientific interest. Ordinary chemical analysis is unable to determine the differences in blood-composition between various animals, but that there were important differences had long been understood. This was shown by the fact that, in performing the operation for the transfusion of blood, it was not practicable to substitute animal for human blood, since the former might cause serious injury to the patient.

The precipitation method of making blood tests is as follows: Freshly drawn human blood is allowed to coagulate or clot, which it will do in a few minutes, if left standing in a dish, and then the serum is drained away from the clot. Blood-serum is the watery, almost colourless part of the blood, which remains after coagulation. Small quantities of this serum are injected, at intervals of one or two days, in to the veins of a rabbit and cause the formation in the rabbit's blood of an anti-body, analogous to the anti-toxin which is produced in the blood of a horse by the injection of diphtheria virus. After the last injection the rabbit is allowed to live for several days and is then killed and bled, the blood is left until it clots and the serum drained off and preserved. The serum obtained thus from a rabbit is called "anti-human" serum and is an exceedingly delicate test for human blood, not only when the latter is fresh, but also when it is in the form of old and dried blood-stains, or even when the blood is

'From W. B. Scott, The Theury of Evolution (copyright 1917). Used by special permission of the publishers, The Macmillan Company. 
putrid. Stains, for example, are soaked in a very weak solution of common salt and, if necessary, the blood solution is filtered until it is quite limpid and clear. Into the blood solution a few drops of the anti-human serum are conveyed and, if the stains are of hunan biood, a white precipitate is formed and thrown down, but if the stains are of the blood of some domestic animal, such as a pig, sheep, or fowl, no such reaction follows. In the same manner as above described, we may prepare anti-pig, anti-horse, anti-fowl, etc., etc., sera by injecting the fresh-drawn serum of a pig, horse, fowl, or any other animal into the rabbit, instead of human blood-serum. In some countries, notably in Germany and Austria, this test has already been adopted by the courts of justice and has been found extremely useful in the detection of crime.

Further investigation showed that these blood tests might be employed to determine the degrees of relationship between different animals, for, although a prompt and strong reaction is usually obtained only from the blood of the same species as that from which the original injection into the rabbit was taken, the blood of nearly allied species, such as the horse and donkey, for example, gives a weaker and slower precipitation. By using stronger solutions and allowing more time, quite distant relationships may be brought out. Nuttall and his collaborator, Graham-Smith, made many thousands of such experiments bearing upon the problems of relationship and classification and it is of great significance to note that their highly interesting and important results contain few surprises, but, in almost all cases, merely serve to confirm the conclusions previously reached by other methods, such as comparative anatomy and palaeontology. It will be instructive to quote some of these results, the quotations being taken from "Blood Immunity and Blood Relationship, by G. H. F. Nuttall, including Original Researches by G. L. Graham-Smith and T. S. P. Strangeways," Cambridge, rgo4.

"In the absence of palaeontological evidence the question of the interrelationship amongst animals is based upon similarities of structure in existing forms. In judging of these similarities, the subjective element may largely enter." "The very interesting observations upon the eye made by Johnson also demonstrate the close rela tionships between the Old World forms and man, the macula lutea tending to disappear as we descend in the scale of New World Monkeys and being absent in the Lemurs. The results which I published upon my tests with precinitins directly supported this evidence, for the reactions 
obtained with the bloods of Simiidae (i.e., Man-like Apes) closely resemble those obtained with human blood, the bloods of Cercopithecidae (Old World Monkeys) came next, followed by those of Cebidae and Hapalidae (New World Monkeys and Marmosets) which gave but slight reactions with anti-human serum, whilst the blood of Lemuroidea gave no indication of blood-relationship." "A perusal of the pages relating to the tests made upon the many bloods I have examined by means of precipitating anti-sera, will very clearly show that this method of investigation permits of our drawing certain definite conclusions. It is a remarkable fact . . . . that a common property has persisted in the bloods of certain groups of animals throughout the ages which have elapsed during their evolution from a common ancestor, and this in spite of differences of food and habits of life. The persistence of the chemical blood-relationship between the various groups of animals serves to carry us back into geological times, and I believe we have but begun the work along these lines, and that it will lead to valuable results in the study of various problems of evolution."

The general conclusions on interrelationships, so far as they are of particular interest for our purpose, reached by Nuttall and GrahamSmith as the result of many thousands of blood tests, may be summarized as follows:

I. If sufficiently strong solutions be used and time enough be allowed, a relationship between the bloods of all mammals is made evident.

2. The degrees of relationship between man, apes and monkeys have already been noted.

3. Anti-carnivore sera show "a preponderance of large reactions amongst the bloods of Carnivora, as distinguished from other Mammalia; the maximum reactions usually take place amongst the more closely related forms in the sense of descriptive zoölogy."

4. Anti-pig serum gives maximum reactions only with the bloods of other species of the same family, moderate reactions those of ruminants and camels, and moderate or slight reactions with those of whales. Anti-llama serum gives a moderate reaction with the blood of the camel, and the close relationship between the deer family and the great host of antelopes, sheep, goats and oxen is clearly demonstrated.

5. Anti-whale serum gives maximum reactions only with the bloods of other whales and slight reactions with those of pigs and ruminants. 
6. A close relationship is shown to exist between all marsupials, with the exception of the Thylacine, or so-called Tasmanian Wolf.

7. Strong anti-turtle serum gives maximum reactions only with the bloods of turtles and crocodiles; with those of lizards and snakes the results are almost negative. With the egg-albumins of reptiles and birds a moderate reaction is given.

8. Anti-lizard serum produces maximum results with the bloods of lizards and reacts well with those of snakes.

9. These experiments indicate that there is a close relationship between lizards and snakes, on the one hand, turtles and crocodiles on the other. They further indicate that birds are more nearly allied with the turtle-crocodile series than with the lizard-snake series, results for which palaeontological studies had already prepared us.

Io. "Tests were made by means of anti-sera for the fowl and ostrich upon 792 and 649 bloods respectively. They demonstrate a similarity in blood constitution of all birds, which was in sharp contrast to what had been observed with mammalian bloods, when acted upon by anti-mammalian sera. Differences in the degree of reaction were observed, but did not permit of drawing any conclusions."

II. I have already called attention to the fact that the problematical Horseshoe-crab is indicated by its embryology to be related to the air-breathing spiders and scorpions rather than to the marine Crustacea. It is of exceptional interest to learn that embryology is supported by the results of the blood tests.

It must not be supposed that there is any exact mathematical ratio between the degrees of relationship indicated by the blood tests and those which are shown by anatomical and palaeontological evidence. Any supposition of the kind would be immediately negatived by the contrast between the blood of mammals and that of birds. It could hardly be maintained that an ostrich and a parrot are more nearly allied than a wolf and a byena and yet that would be the inference from the blood tests. Like all other anatomical and physiological characters, the chemical composition of the blood is subject to change in the course of evolution and these developmental changes do not keep equal pace in all parts of the organism. It is the rule rather than the exception to find that one part of the structure advances much more rapidly than other parts, such as the teeth, the skull, or the feet. The human body is, fortunately for us, of rather a primitive kind, while the development of the brain is far superior to that of any other mammal and this great brain development has 
necessitated a remodeling of the skull. On the other hand, the skeleton, limbs, hands and feet are but slightly specialized. In the elephant tribe, so far as we can trace them back in time, there has been little change, save in size, in the structure of the body or limbs, while the tecth and skull have passed through a series of remarkable changes. It is for this reason that it is unsafe to found a scheme of classification, which is meant to be a brief expression of relationship, upon a single character, for the result is almost invariably misleading. The results of blood tests must be critically examined and checked by a comparison with the results obtained by other methods of investigation, but after every allowance has been made, these tests are very remarkable.

The blood tests have brought very strong confirmation to the theory of evolution and from an entirely unexpected quarter; they come as near to giving a definite demonstration of the theory as we are likely to find, until experimental zoölogy and botany shall have been improved and purfected far beyond their present state. 


\section{CHAT'TER VIII}

\section{EVIDENCES FROM EMBRYOLOGY}

\section{THE FACTS OF REPRODUCTION AND DEVELOPMIENT}

It is now definitely known that all living creatures are mortal, at least as individuals, but they all have the capacity of continuing their life by the reproduction of offspring. This physical immortality is based upon an actual transmission from parent to offspring of some material substance which is so organized chemically as to be fully representative of the race or stock to which the parent belongs.

Reproduction may be asexual or sexual. In asexual development a new individual may be prorluced by a process of fission (dividing the parent into two or more parts, each of which has the capacity to develop into a whole new individual); by budding (the production of new individuals by means of outgrowths of the parent-body); or by giving off spores or eggs capable of development without fertilization (parthenogenesis). In sexual reproduction two kinds of parentindividuals exist: one a female which is capable of giving off relatively large single cells, called ergs (ova); and the other a male, which is capable of producing minute, usually motile cells, called spermatozoa. A union of ovum and spermatozoön is usually necessary before the ovum can begin its development. It is the sexual method of reproduction that will chiefly concern us here, and, for present purposes, we may omit any further mention of the various asexual methods.

An ovum may be conceived of as an individual of some definite species or race reduced to the very lowest terms. It exhibits the characteristic cell structure, consisting of cytoplasm and nucleus, cell membrane, nuclear membrane, usually a centrosome (Fig. 40). Further details as to the minute structure of the nucleus are given in chapter xhiv, where the mechanism of Mendelian heredity is dealt with.

"The reproductive cells from the two sexes," says Wright," "have very different appearances. In mammals, the ovum is a relatively large, spherical cell, just visible to the naked eye.

- From Sewall Writht, Principles of Livestock Breeding, United States Depart ment of Agriculture, Bulletin No. gos. 
"In birds, the yolk of an egg is really a single ovum, distended to an enormous size by food material. The sperm cell is very much smaller and can be seen well only with a high-power microscope. It is something like a tadpole in shape, having a small cell body, containing a little nucleus, and attached to this a long, whiplike process which beats rapidly while the cell is alive, enabling it to seek out and unite with the large passive egg in the act of fertilization. Enormous numbers of sperm cells are produced by the male, but only one takes part in fertilization. After the first has penetrated the membrane of an egg cell, a change takes place in the latter which prevents the entrance of others.

"The sperm activates certain formerly inert substances in the egg and the new combination cell (the zygote) starts almost at once to produce a new individual."

\section{OUTLINE OF ANIMAL DEVELOPMENT ${ }^{1}$}

\section{S. JORDAN AND v. L. KELLOGG}

The embryonic development is from the beginning up to a certain point practically alike, looked at in its larger aspect, for all the manycelled animals. That is, there are certain principal or constant characteristics of the beginning development which are present in the development of all many-celled animals. The first stage or phenomenon of development is the simple fission of the germ cell into halves (Fig. $25, b$ ). These two daughter cells next divide so that there are four cells $(c)$; each of these divides, and this division is repeated until a greater or lesser number (varying with the various species or groups of animals) of cells is produced. These cells may not all be of the same size, but in many cases they are, no structural differentiation whatever being apparent among them.

The phenomenon of repeated division of the germ cell is called cleavage, and this cleavage is the first stage of development in the case of all many-celled animals. The germ or embryo in some animals consists now of a mass of few or many undifferentiated primitive cells lying together and usually forming a sphere (Fig. $25, e$ ), or perhaps separated and scattered through the food yolk of the egg. The next stage of development is this: the cleavage cells arrange themselves so as to form a usually hollow sphere or ball, the cells lying side by side to

- From D. S. Jordan and V. L. Kellogg, Evolution and Animal Life (copyright 1907). Used by special permission of the publishers, D. Appleton \& Company. 
form the outer circumferential wall of this hollow sphere $(f)$. This is called the blastula or blastoderm stage of development, and the embryo itself is called the blastula or blastoderm. This stage also is common to all the many-celled animals. The next stage in embryonic derelopment is formed by the bending inward of a part of the blastoderm cell layer, as shown in $(\mathrm{g}$ ) (or the splitting off inwardly of cells from a special part of the blastula cell livyer). This bending in may produce a small depression or groore; but whatever the shape or extent of the sunken-in part of the blastoderm, it results in clistinguishing the blastoderm layer into two parts, a sunken-in or inner portion called

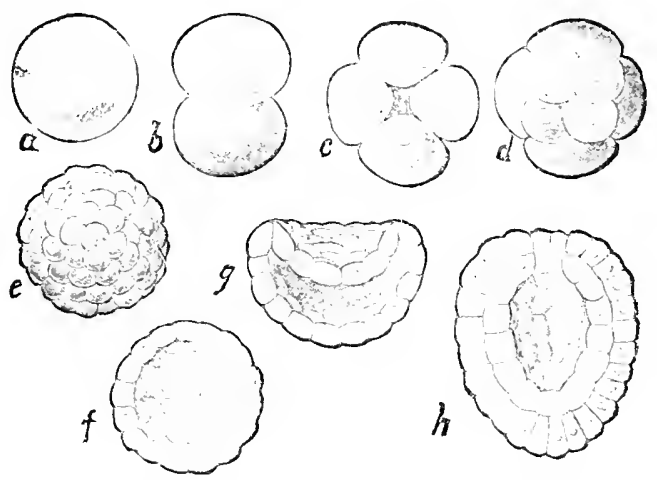

FIG. 25.-First stages in the embryonic development of the pond snail, Lymnatus. $a$, egg cell; b, first cleavage; $c$, second cleavage; $d$, third cleavage; $\ell$, after numerous clearages; $f$, blastula-in section; $g$, gastrula just formingin section; $h$, gastrula completer-in section. (From Jordan and Kellosg, after Rabl.)

the endoblast and the other unmodified portion called the cctoblast. Endo- means within, and the cells of the endoblast often push so far into the original blastoderm carity as to come into contact with the cells of the ectoblast and thus obliterate this cavity $(h)$. This third well-marked stage in the embryonic development is called the gastrula. stage, and it also occurs in the derelopment of all or nearly all manycelled animals.

In the case of a few of the simple many-celled animals the embryo hatches-that is, issues from the ergy at the time of or very soon after reaching the gastrula stage. In the higher animals, however, development goes on within the egg or within the body of the mother until the embryo becomes a complex body, composed of many various 
tissues and organs. Almost all the development may take place within the egg, so that when the young animal hatches there is necessary little more than a rapid growth and increase of size to make it a fully developed mature animal. This is the case with the birds; a chicken just hatched has most of the tissues and organs of a full-grown fowl, and is simply a little hen. But in the case of other animals the young hatches from the egg before it has reached such an advanced stage of development; a young starfish or young crab or young honeybee just hatched looks very different from its parent. It has yet a great deal of development to undergo before it reaches the structural condition of a fully developed and fully grown starfish or crab or bee. Thus the development of some animals is almost wholly embryonic development-that is, development within the egg or in the body of the mother-while the development of other animals is largely postembryonic, or larval development, as it is often called. There is no important difference between embryonic and postembryonic development. The development is continuous from egg cell to mature animal, and whether inside or outside of an egg it goes on regularly and uninterruptedly.

The cells which compose the embryo in the cleavage stage and blastoderm stage, and even in the gastrula stage, are apparently all similar; there is little or no differentiation shown among them. But from the gastrula stage on, development includes three important things; the gradual differentiation of cells into various kinds to form the various kinds of animal tissues; the arrangement and grouping of these cells into organs and body parts; and finally the developing of these organs and body parts into the special condition characteristic of the species of animal to which the developing individual belongs. From the primitive undifferentiated cells of the blastoderm, development leads to the special cell types of muscle tissue, of bone tissue, of nerve tissue; and from the generalized condition of the embryo in its early stages, development leads to the specialized condition of the body of the adult animal. Development is from the general to the special, as was said years ago by von Baer, the first great student of development.

A starfish, a beetle, a dove, and a horse are all alike in their beginning-that is, the body of each is composed of a single cell, a single structural unit. And they are all alike, or very much alike through several stages of development; the body of each is first il single cell, then a number of similar undifferentiated cells, and then a 
blastoderm consisting of a single layer of similar undifierentiated cells. But soon in the course of development the emisyos begin to differ, and as the young animals get further and further along in the course of their development, they lecome more and more different until each finally reaches its fully developed mature form, showing all the grcat structural differences between the starfish and the dove, the beetle and the horse. That is, all animals begin development apparently alike, isut gradually diverge from each other during the course of development.

There are some extremely interesting and sirnificant things about this divergence to which attention should be given. While all animals are apparently alike structurally at the beginning of derelopment, so far as we can see, they do not all differ noticeably at the time of the first divergence in development. The first divergence in development is to be noted between two kinds of animals which belong to different great groups or classes. But two animals of different kinds, loth belonging to some one great group, do not show differences until later in their development. This can best be understood by an example. All the butterflies and beetles and grasshoppers and flies belong to the great group or class of animals called Insecta, or insects. There are many different kinds of insects, and these kinds can be arranged in subordinate groups (orders), such as the Diptera, or flies, the Lepidoptera, or butterflies and moths, and so on. But all have certain structural characteristics in common, so that they are comprised in one great class--the Insecta. Another great group of animals is known as the Vertebrata, or backboned animals. The class Vertebrata includes the fishes, the batrachians, the reptiles, the birds and the mammals, each composing a subordinate group, but all characterized by the possession of a backbone or, more accurately speaking, of a notochord, a backbonelike structure. Now, an insect and a vertebrate diverge very soon in their development from each other; but two insects, such as a beetle and a honeybee, or any two vertebrates, such as a frog and a pigeon, do not diverge from each other so soon. That is, all vertebrate animals diverge in one direction from the other great groups, but all the members of the great group keep together for some time longer. Then the subordinate groups of the Vertebrata, such as the fishes, the birds, and the others, diverge, and still later the different kinds of animals in each of these groups diverge from each other.

That the course of development of any animal from its beginning to fully developed adult form is - in all its essentials - fixed and certain 
is readily seen. All rabbits develop in the same way; every grasshopper goes through the same developmental changes from single egg cell to the full-grown, active hopper as every other grasshopper of the same kind - that is, development takes place according to certain natural laws; the laws of animal development. These laws may be roughly stated as follows: All many-celled animals begin life as a single cell, the fertilized egg cell; each animal goes through a certain orderly series of developmental changes which, accompanied by growth leads the animal to change from a single cell to the many-celled, complex form characteristic of the species to which the animal belongs; this development is from simple to complex structural condition; the development is the same for all individuals of one species. While all animals begin development similarly, the course of development in the different groups soon diverges, the divergence being of the nature of a branching, like that shown in the growth of a tree. In the free tips of the smallest branches we have represented the various species of animals in their fully developed condition, all standing more or less clearly apart from each other. But in tracing back the development of any kind of animal we soon come to a point where it very much resembles or becomes apparently identical with the development of some other kind of animal, and, in addition, the stages passed through in the developmental course may very much resemble the fully developed, mature stages of lower animals. To be sure, any animal at any stage in its existence differs absolutely from any other kind of animal, in that it can develop into only its own kind of animal. There is something inherent in each developing animal that gives it an identity of its own. Although in its young stages it may be hardly distinguishable from some other kind of animal in similar stages, it is sure to come out, when fully developed, an individual of the same kind as its parents were or are. A very young fish and a very young salamander are almost indistinguishably alike, but one is sure to develop into a fish and the other into a salamander. This certainty of an embryo to become an individual of a certain kind is called the law of heredity. Viewed in the light of development, there must be as great a difference between one egg and another as between one animal and another, for the greater difference is included in the less.

The significance of the developmental phenomena is a matter about which naturalists have yet very much to learn. It is believed, however, by practically all naturalists that many of the various stages in the development of an animal correspond to or repeat, in many 
fundamental features at least, the structural condition of the animal's ancestors. Naturalists believe that all backboned or vertebrate
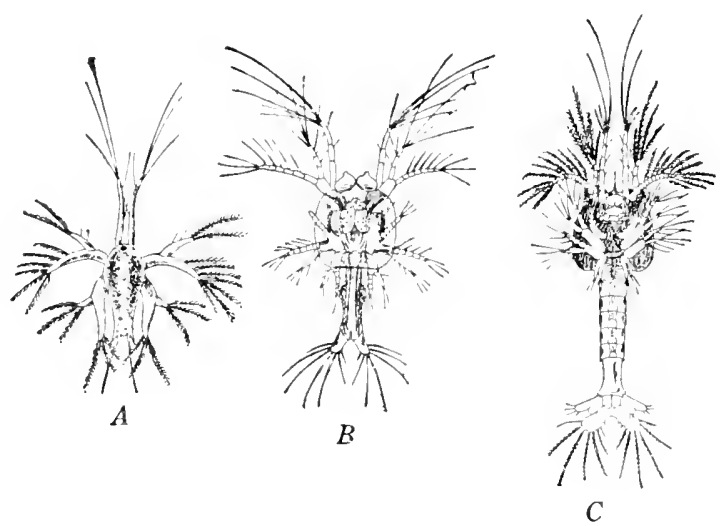

FIg. 26 - Stages in the development of the prawn, Penus potimirium. A Nauplius larra; $l$, first zoëa stage; $C$, second zoëa stage. (From Jordan and Kellogg, after Fritz Wiiller.)
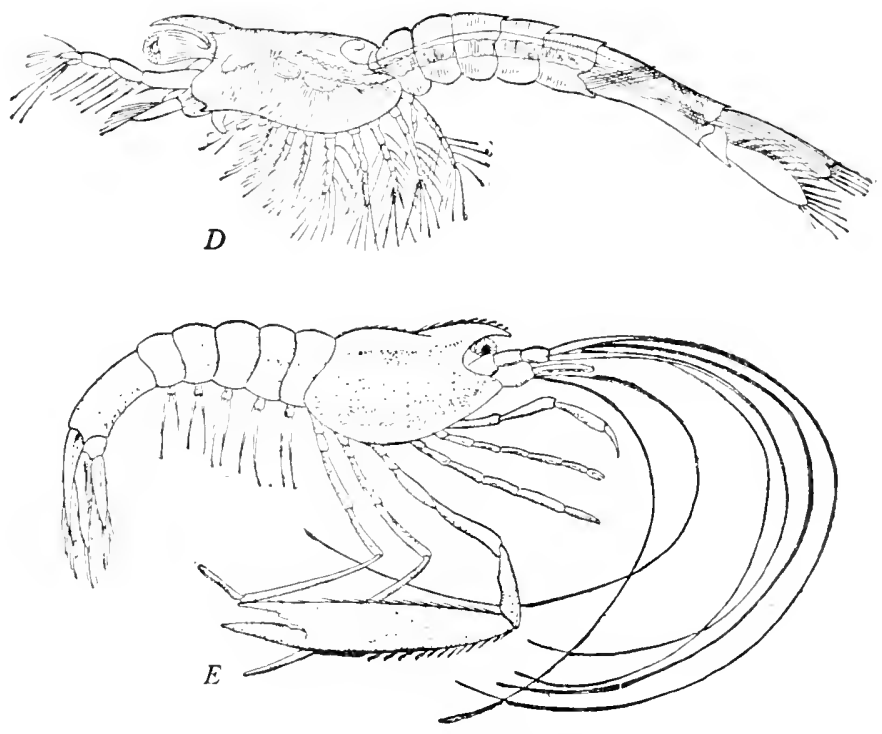

FIs. 27. - Later stages in the development of the prawn, Pencus potimirium. $D$, Mysis stage; E, adult stage. (From Jordan and Kellogg.) 
animals are related to each other through being descencled from a common ancestor, the first or oldest backboned animal. In fact, it is because all these backboned animals - the fishes, the batrachians, the reptiles, the birds, and the mammals-have descended from a common ancestor that they all have a backbone. It is believed that the descendants of the first backboned animal have in the course of many generations branched off little by little from the original type until there came to cxist very real and obvious differences among the backboned animals-differences which among the living backboned animals are familiar to all of us. The course of development of an individual animal is betiered to be a very rapid and eridently much condensed and. changed recapitulation of the history which the species or kind of animal to which the devcloping intividual belongs has passed through in the course of its descent through a long scrics of gradually changing ancestors. If this is true, then we can readily understand why a fish and a salamander, a tortoise, a bird, and a rabbit, are all much alike, as they really are, in their earlier stages of development, and gradually come to differ more and more as they pass through later and later derelopmental stages. A crab has a tail in one of its derelopmental stages, so that at that time it looks like and really is like the mature stage of some tailed crustacean like a craytish. A bamacle, which looks

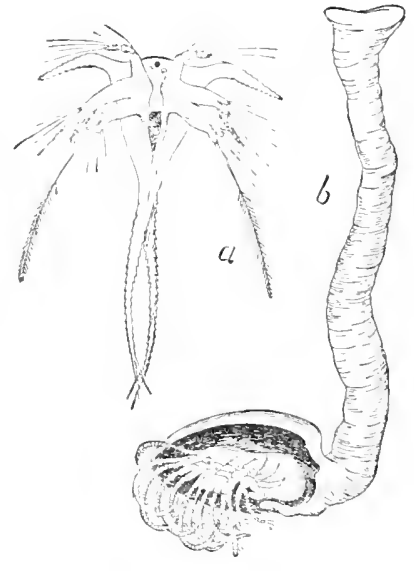

FIG. 2 S.-. Metamorphosis of a harnacle, Lepas. a, larva; b, adult. (From Jordan and Kellogg.) little like a crayfish or crab in its mature stage, is hardly to be distinguished in its immature life from a young crab or lobster. Sacculina, which is a still more degenerate crustacean, is only a sort of feeding sac with rootlet-like processes projecting into the body of the host crab on which it lives as a parasite, but the young free-swimming Sacculina is essentially like a barnacle, crayfish, or crab in its young stage.

However, it is obvious that this recapitulation or repetition of ancestral stages is never perfect, and it is often so obscured and modified by interpolated adaptive stages and characters that but little of an animal's ancestry can be learned from a scrutiny of its development. 
The fascinating biogenetic law of Müller and Hacckel summed up in the phrase, "ontogrny is a recapitulation of phylogeny," must not be too heavily leaned on as a support for any speculations as to the phyletic affinities of any species or group of species of organisms. "Embryology is an ancient manuscript with many" of the sheets lost, others displaced, and with spurious passages interpolated by a later hand." 


\title{
CHAPTER IX
}

\section{CRITIQUE OF THE RECAPITULATION THEORY ${ }^{\wedge}$}

\author{
w. B. SCOTT
}

Embryology is the study of the development of the individual organism from its beginning in the egg to the attainment of the adult condition. This individual development is called ontogeny and the question of the relation of ontogeny to the ancestral history of the species, or phylogeny, constitutes one of the main problems of embryology. Around this problem many controversies have raged, controversies which have by no means arrived at a definite solution, even to-day. Thirty years ago the "recapitulation theory" was well-nigh universally accepted, according to which the individual development, or ontogeny, was regarded as an abbreviated repetition of the ancestral history of the species, or phylogeny. Haeckel called this theory the "fundamental biogenetic law" and upon it he established his whole "History of Creation." Nowadays, that "fundamental law" is very seriously questioned and by some high authorities is altogether denied. However, even those who take this extreme position concerning the recapitulation theory see in the facts of embryology one of the strongest supports of the doctrine of evolution.

It was very early recognized that the recapitulation theory could not be applied with literal exactness, but was subject to certain important exceptions and qualifications.

I. That the history must have been enormously abbreviated. After three weeks of incubation the tiny speck of protoplasm, which forms a circular mark on the yolk of a hen's egg, is developed into a fully formed chick, ready for hatching and able in large degree to take care of itself. On the other hand, the evolution of birds from their invertebrate ancestors, through the fishes, amphibians, and reptiles, the separation of the gallinaceous stock from other birds and the differentiation of this particular species were extremely slow processes, extending through unnumbered millions of years. Admitting recapitulation to the fullest extent, it is evidently a physical impossibility

From W. B. Scott, The Theory of Evolution (copyright 19r7). Used by special permission of the publishers, The Macmillan Company. 
that it shouk be a perfect repetition of phylogeny; very much of the long story must of necessity be omitted.

2. Through ail the stages of development the embryo must be rendered able to live and grow and thrive through adaptation to its surroundings and changes in its environment. In some animals development takes place within the body of the mother; in others the embryo is protected by the hard egg-shell, as in birds, while the eggs of certain fishes and many invertebrates float freely in the sea and are almost without protection. Such differences in environment necessitate differences in the mode of development, while the presence or absence of a large amount of inert food-material, or yolk, exerts a great influence in determining the steps of ontogeny.

3. Many animals pass through a larval stage of development, in which the immature young leads an independent and self-sustaining existence, during which it is very different in appearance and structure from its adult parents. Familiar instances of this mode of development are to be found in the tadpole, which is the larva of the frog, and the caterpillar, the larva of a butterfly. Larvae are fully subject to the struggle for existence and must adapt themselves to their environment and to changes in that environment, exactly as do adults, if they are to survive. In this way many changes are introduced into the ontogeny which can have no phylogenetic significance. It is found in several known instances, that nearly allied species, living under different conditions, have quite different modes of ontogeny, though their ancestral history must have been substantially identical. In one and the same species of marine worms, for example, which inhabits both the warm Mediterranean and the cold waters of the North Sea, the larva of the northern form is quite distinct from that of the southern. In attempting to interpret the meaning of embryological facts, it is thus necessary to distinguish sharply between those features which are derived from a long inheritance, and are therefore called palingenetic, from those which have been secondarily introduced in response to the changing needs of embryonic or larval life. These secondary features are termed cenogenetic.

"If we are compelled to admit that cenogenetic characters are intermingled with palingenetic, then we cannot regard ontogeny as a pure source of evidence regarding phyletic relationships. Ontogeny accordingly becomes a field in which an active imagination has full scope for its dangerous play, but in which positive results are by nc means everywhere to be obtained. To attain such results, the palin- 
genetic and cenogenetic phenomena must be sifted apart, an operation which required more than one critical grain of salt. On what grounds shall this critique be based? Assuredly not by way of a vicious circle on the ontogeny again; for if cenogenetic characters are present in one case, who will guarantee that a second case, used for a comparison with the first, does not likewise appear in cenogenetic disguise? If it once be admitted that not everything in development is palingenetic, that not every ontogenetic fact can be accepted at its face value, so to speak, it follows that nothing in ontogeny is immediately available for the critique of embryonic development. The necessary critique must be drawn from another source."

These remarks of Gegenbaur's were called forth by the state of wild speculation into which embryological work had fallen. As there were no generally accepted canons of interpretation for the facts of embryological development, different writers interpreted these facts in the most divergent and contradictory manner, resulting in a chaotic confusion, which led to a strong reaction against the whole method, though there can be little doubt that this reaction has gone too far.

"It must be evident to any candid observer, not only that the embryological method is open to criticism, but that the whole fabric of morphology, so far as it rests upon embryological evidence, stands in urgent need of reconstruction. For twenty years embryological research has been largely dominated by the recapitulation theory; and unquestionably this theory has illuminated many dark places and has solved many a perplexing problem that without its aid might have remained a standing riddle to the pure anatomist. But while fully recognizing the real and substantial fruits of that theory, we should not close our eyes to the undeniable fact that it, like many another fruitful theory, has been pushed beyond its legitimate limits. It is largely to an overweening confidence in the validity of the embryological evidence that we owe the vast number of the elaborate hypothetical phylogenies which confront the modern student in such bewildering confusion. The inquiries of such a student regarding the origin of any of the great principal types of animals involve him in a labyrinth of speculation and hypothesis in which he seeks in vain for conclusions of even an approximate certainty."

Many other equally vigorous and well-deserved criticisms of the embryological method might be cited, but it should be emphasized that these criticisms are all directed against the application of the method to the solution of definite and concrete problems of descent and 
relationship. None of them denics and many strongly afirm that embryology affords some of the strongest and most convincing evidence in favor of the evolutionary theory.

Let us examine some of this evidence. To begin with, it should be noted that, in following out the ontogeny or individual development, the observer witnesses the formation of something new, not merely the enlargement and unfolding of a pre-existing organism, though the theory of preformation, which was widely accepted in the eirhteenth century, looked upon ontogeny precisely in that way, as the growth of a germ which was the miniature of the parent. Such a theory was possible only before the development of microscopic technique had enabled the observer to detect the actual successive steps of change. The egg is a single cell, with the nucleus and all the parts of other undifferentiated cells, though it may be enormously cnlarged by the presence of food-yolk. In the hen's egg this food-yolk is quite inert and the activity of development is confined to the minute disc of protoplasm on the outside of the yolk, while in the frog's egg the yolk is disseminated, though not uniformly, throughout the egg and in the mammalian egg, which is microscopic in size, there is no yolk. It is a very remarkable fact that all of the vertebrated animals, lishes, amphilians, reptiles, birds and manmals, however different their habits and modes of life, have a mode of ontogeny which is of even more characteristically and unmistakably the same plan than is the type of their adult structure, which was described in the last chapter. The egg, or the active portion of it, divides in a definite and regular manner into a very large number of cells, which arrange themselves in definite layers, an outer and an inner, and within these layers cell-aggregates form incipient organs, which, step by step, take on the adult condition. Not only is the plan and type of development essentially similar throughout the whole phylum of the vertebrates, but, in accordance with the recapitulation theory, many structural features which are permanent in lower forms appear in the embryos of higher and more advanced types. In the latter, however, these features ars transitory and, in the course of development, they either disappear, or are so modified as to be very different, sometimes unrecognizalle, in the adults.

At a certain stare of the ontoreny the embryo of a mammal has sill-pouches like a fish, the skeletal supports of the gill-pouches, the arteries and veins which supply them with blood, the structure of the heart, in short, the entire plan of the circulatory system is fish-like. 
At a later stage most of the gill-pouches have been obliterated, but one is retained and converted into the Lustachian canal, which connects the throat with the middle ear, inside of the ear-drum. Similarly, the embryological evidence shows that the lungs of air-breathers have been derived from the swim-bladder of fishes, a conclusion which had already been reached by comparative anatomy, for in a remarkable
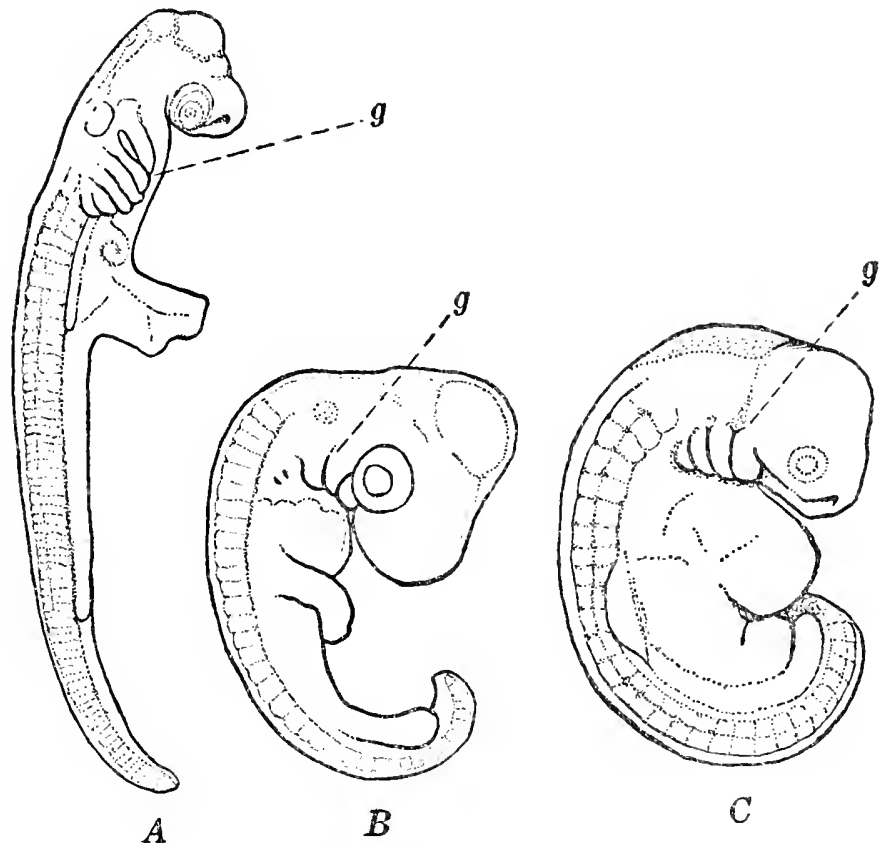

FIG. 29.-Embryos in corresponding stage of development of shark $(A)$, fowl $(B)$, and man $(C) ; g$, gill slits. (From Scott.)

group, known as the Dipnoi or lung-fishes, the air-lladder is utilized for purposes of respiration.

It has been objected that, while embryology may prove relationship within a single type, it fails to demonstrate any connection between different types, but this is not altogether true. The Tunicata, a curious group of marine animals once referred to the Mollusca, are shown by their ontogeny to be related to the vertebrates and the same is true of certain marine worms (Balanoglossus). Indeed, most modern zoölogists have adopterl a scheme of classification, in which 
the type Chordata includes not only the true vertebrates, but also the Lancelet (Amphioxus), the tunicates, and Balanoslossus; this scheme is founded upon the embryological evidence. Among the invertebrates even more remarkable examples have been observed. Such radically different types as the seginented worms and the shellfish (Mollusca) are brought into relationship by their ontogeny and their closely similar types of larvae, as are also, though less distinctly, the brachiopods or lamp-shells, and the Bryozoa. The Horseshoecrab, or King-crab, so abundant along our Atlantic coast, was long of uncertain affinities; originally referred to the Crustacea, largely because of its marine habits of life, eml,ryology makes much more probable its relationship to the air-breathing scorpions and spiders, a result which has been examined previously from another point of view in connection with blood-tests.

Even before the publication of Darwin's Origin of Species one of the great stumbling blocks in the way of the theory of special creation was the existence in a great many animals of rudimentary organs, or such as are so far reduced and atrophied as to be of no service to their possessors. An analogy employed by my lamented friend, Mr. Richard Lydekker, may be advantageously repeated here. Let us suppose that a screw-steamer, with longitudinal shaft leading aft from the engine-room to the stem, where it carries the propelier, should, on close examination, reveal many signs that it has originally been a "side-wheeler," or paddle-boat. Recognizable remnants of paddleboxes, of bearings for a transverse shaft, and the like, are found; what would be the inevitable conclusion? No one would maintain that a naval architect, in possession of his senses, in constructing a screwsteamer would deliberately introduce features which are useful and appropriate only in a paddle-boat. The only reasonable explanation would be that the vessel had originally been built as a paddle-boat and had subsequently been converted into a screw-steamer and in the conversion it had not been found necessary completely to eradicate ali traces of the original construction. Obviously, the same reasoning applies to rudimentary organs. The only satisfactory explanation of such useless remnants is that their possessors are descendants of ancestors in which those organs were fully functional. It seems quite absurd to assume that, in a separately and specially created animal, useless structures, reminiscent of other animals in which the same structures are useful and valuable, should be included, merely to indicate ideal relationships and community of plan. 
It was sought to break the force of this very serious objection to the theory of special creation by saying that apparently useless organs may nevertheless have functions which are still unknown to us and may be revealed by future discovery. In certain cases, like that of the thyroid gland in the neck, this contention has been justified, but there are many others to which it does not apply. For example, in the great and varied whale-tribe (order Cetacea) which includes the right, or whalebone, whales, the sperm-whales, the porpoises, dolphins, etc., the forelimbs have been converted into swimming paddles, but the hind limbs appear to have vanished completely, leaving no externally visible trace. Internally, however, recognizable remnants of the hind limb-bones may be found in various stages of reduction, which differ in the different members of the order. In the Greenland Right Whale the hip-bone, thigh-bone and shin-bone are indicated; in the Finwhale only the hip-bones and a minute rudiment of the thigh-bone are to be found; in the toothed whales only an almost unrecognizable remnant of the hip-bone is left and in one of the dolphins even that has disappeared. Similarly, the snakes have lost their limbs completely, so far as external appearance is concerned, and in most members of the group no trace of limbs is to be found on dissection, but in certain snakes the rudiments of limbs are to be detected. Leaving aside all preconceptions, which is the more probable explanation of such phenomena, the theory of special creation or the theory of evolution?

Even if it were admitted that all rudimentary organs and structures found in the adult have a certain unknown use and value, no one could maintain this with regard to the countless instances of structures which are developed in the embryo, but disappear entirely before birth. It is possible to mention but a very few of such instances out of the great number that have already been observed and recorded, but these few will suffice to illustrate the principle involved.

"Examples of this may be cited from the most widely different groups: in the embryo of insects, especially of beetles, pairs of legs are formed within the egg, not only on the head and thorax, but also on the abdomen, but while those on the head are transformed into mouth-parts, those on the thorax are farther developed in their jointing and musculature to be locomotive legs, those on the abdomen are again resorbed. In many fresh-water worms, the eggs of which are laid in a cocoon, from which they are hatched as a finished, minute, crawling worm, larval organs are nevertheless formed, which recall those of the Trochophore, the larva of the original worms, which swims 
freely in the sca. However, these larval organs .... are never properly functional, since no actually free-swimming larva is developed but the embryo merely floats in the albuminous fuid of the cocoon.

"A particularly beautiful example is offered by the whales in their embryolorical development, which has been thoroughly studied by Kulenthal. In the adlult condition they show only the anterior extremities, but in the embryo the posterior pair, with their skeletal parts, are formed, but are afterwards completely atrophied. Although they are mammals, in the adult condition they have absolutely no covering of hair, since in their aquatic life another and more effective protection against loss of heat is given by means of a thick layer of blubber; only a few coarse bristles, partly with particular functions, have persisted on a few parts of the body. But in the embryo a dense covering of hair is formed, which is later transformed in a peculiar manner and atrophied. Further, a series of whales have no teeth in the adult condition, but only the well-known, ecl-trap-like, horny plates, from which whale-bone is produced. Nevertheless, in the cmljryo there is a dentition of numerous teeth, which are, however, resorbed, without ever piercing the gum."

Throughout the great group of the ruminants, which includes the oxen, bufialues, bison, sheep, goats, antelopes, deer and girafies, the collar-bone is invariably lacking, since it is superfluous on account of the exclusively locomotive manner in which the fore legs are employed. In the embryo sheep the collar-bone is established and even, to some extent ossified, but is subsequently resorbed and disappears entirely. No doubt, the collar-bone will be found in many other embryo ruminants, when the proper examination shall have been made, but its demonstrated presence in the foetal sheep is sufficiently striking. In the higher manmals the number of teeth was originally 44, or I I on each side of both upper and lower jaws, but in most of the modern or existing groups of these higher mammals this number has been very considerably reduced through the suppression of certain teeth. We have every reason to believe that the ancestors of the forms with reduced dentition possessed teeth in full numbers and that there has actually been a loss of teeth in the course of descent. This conclusion is abundintly confirmed by the facts of embryology. 'Take, for example, the great group of the gnawing mammals or Rodentia, in which the front teeth or incisors, above and below, are reduced to one on each side, except in the rabbits. The incisors are chisel-shaped and

'Otto Maas, Die Absitumungslehre, pp. 273-74. 
are faced with hard enamel, so that the action of the upper teeth upon the lower keeps the cutting edges extremely sharp; these teeth do not form roots, but continue to grow throughout the lifetime of the animal. Between the chisel-like incisors and the grinding teeth, there is a long toothless gap, which, we assume, was, in the ancestors of the rodents, occupied by the second and third incisors, the canine and two or more grinders. This conclusion is justified by the facts of embryology; for instance, in the embryo of the squirrel several of the missing teeth are begun as distinct tooth-germs, but fail to develop, never cut the gum and are resorbed before birth.

All available evidence points to the conclusion that birds are descended from reptiles, a conclusion which is especially strengthened by the facts of palaeontology and will be examined more at length in the following lecture. Such a descent explains many otherwise puzzling features in the ontogeny of birds, in which reptilian characteristics appear in transitory fashion and are either modified so as to take on typically bird-like character, or are suppressed altogether. A remarkable example of this is the formation of rudimentary teeth in certain embryonic biids, followed by their resorption and disappearance before hatching.

It can hardly be contended that these rudimentary structures, which are confined to the embryonic stages of development and of which no trace remains in the adult, are so indispensable to the processes of ontogeny, that they were specially created to serve this temporary purpose. For such a contention there is not a particle of evidence and the theory of evolution, which regards these structures as useless remnants, due to inheritance from ancestors in which the structures are functional, offers much the most satisfactory solution of the problem that has yet been suggested.

Embryology further shows that evolution is not invariably an advance from lower and simpier to higher and more complex types, but may be by way of degeneration and degradation. The adoption of a parasitic mode of life is very apt to cause such degradation, and some very remarkable instances of the degeneration of parasites have heen observed. An instructive example that may be cited is that of Sacculina, a nondescript creature that is parasitic on certain species of crabs. The parasite is attached to the body of its victim, underneath the tail, by means of root-like fibres which penetrate and ramify throughout the interior of the crab. The root-like fibres absorb nutriment and convey it to the body of the parasite, which is reduced to a 
mere bag, without appendages, muscies, nervous systen, sensory apparatus, direstive tract, or any determinable organs save those of reproduction. The creature has the power of assimilating the nutritive juices which are conveyed to it by the root-like filaments from the body of its host, and the power of reproduction, and it must have some respiratory and excretory capacity, though there are neither gills nor glands. From an examination of the adult parasite alone, it would be quite impossible to classify it and determine the type and class to which it should be referred, but embryology solves the problem. From the egg is hatched a free-swimming larva, which has jointed appendages, nervous, muscular and digestive systems and, in short, clearly belongs to that group of the Crustacea which includes the harnacles. This is degeneration carried nearly to the utmost possible extreme and yet the individual development shows the derivation of this otherwise problematical parasite and the steps through which it passed in its deterioration.

It was stated above that several distinguished naturalists altogethar reject the recapitulation theory as a means of interpreting the facts of emiryology. They do this on the ground that, inasmuch as changes and innovations in form or structure must arise in the germplasm, at the rery beginning of ontogeny, there is no reason why such changes might not involve the whole course of embryological development. To my mind this a priori objection to the recapitulation theory is quite without force in riew of the great body of observed facts, but there is no time to enter upon a discussion of such an abstract and difficult problem. For our present purpose, however, it is important to note that these objectors are staunch evolutionists and find in the community of mode in ontogeny between different classes of organisms one of the strongest arguments in support of the evolutionary doctrine. 


\section{CHAPTER X}

\section{EVIDENCES FROM PALAEONTOLOGY}

\section{STRENGTII AND WEAKNESS OF THE EVIDENCE}

The word palaeontology means literally the science of ancient life. Practically, it is the study of the fossil remains of extinct animals and plants, including any traces of their existence, such as footprints, impressions in slate, clay, or coal. The evidence from the fossils has definite elements of strength in that it deals with actual organisms that formerly inhabited the earth's surface. Many of these species must have left descendants, some of which are doubtless living in a modified condition today. Palaeontology should be able either strongly to support or to contradict the idea of evolution. If its data accord with the evolution idea and are opposed to the special creation idea, the fossils may be said to be evidences of evolution.

The weakness of the studiy of fossils lies in the fact that extremely few samples of the living forms that have existed in the past have been preserved, and of those that have been preserved only a very small percentage have been dug up and studied by capable scientists. Many types of animals and plants, moreover, are soft and capable of preservation only under such exceptional conditions that but a rare specimen here and there over the world, scattered through various widely separated strata, has been found. Only very common or abundant types are likely to have been preserved and discovered, for the chances of an uncommon form being preserved would be small and the further chances of these infrequently preserved specimens being found would be infinitely smaller.

The great majority of fossil remains are fragmentary or preserved very incompletely, so that only the hard parts have come down to us. There are, of course, many important exceptions to this rule, and these are our chief reliance in interpreting ancient life.

That Darwin fully realized the vulnerable points in the palaeontological record is shown by the following quotation from the Origin of Species:

"I look at the geological record as a history of the world imperfectly kept and written in a changing dialect; of this history we possess 
the last volume alone, relating only to two or three countries. Of this volume only here and there a short chapter has been preserved; and of each page only here and there a few lines. Each word of the slowly changing language, more or less different in the successive chapters, may represent the forms of life which are entombed in our successive formations and which falsely appear to us to have been abruptly introduced."

\section{OTHER OPINIONS AS TO THE ADEQUACY OF THE EVIDENCES FROM PALAEONTOLOGY}

"The primary and direct evidence in favour of evolution can be furnished only by palaeontology. The geological record, so soon as it approaches completeness, must, when properly questioned, yield either an affirmative or a negative answer: if Evolution has taken place there will its mark be left; if it has not taken place there will lie its refutation."-T. H. Huxley.

"The geological record is not so hopelessly incomplete as Darwin believed it to be. Since The Origin of Species was written our knowledge of that record has been enormously extended, and we now possess no complete volumes, it is true, but some remarkably full and illuminating chapters. The main significance of the whole lies in the fact that, just in proportion to the completeness of the record is the unequivocal character of its testimony to the truth of the evolutionary theory."W. B. Scott.

"On the other hand, matters have greatly improved since Darwin wrote his oft-cited Chapter $\mathrm{X}$; many lands then geologically unknown have been explored and many of the missing chapters and paragraphs in the history of life have been brought to light. The most ancient biologically intelligible period of the earth's history is called the Cambrian and, compared with the succeeding periods, the Cambrian has always been poor in fossils, great areas and thicknesses of rocks being entirely barren. No one could doubt that our knowledge of Cambrian life was most incomplete and inadequate. A few years ago Dr. C. D. Walcott, Secretary of the Smithsonian Institution, discovered in the Canadian Rockies a most marvelous series of Cambrian fossils of an incredible delicacy and beauty of preservation, which have thrown a flood of new and unexpected light into very dark places. It is clear that the Cambrian seas swarmed with a great variety and profusion of life, but thai in only a few places, so far known to us, 
were conditions such that these delicate creatures could be preserved. It is not possible to say how far the difficulty caused by the imperfection of the geological record will be removed by the progress of discovery. Even as matters stand to-day, the astonishing fact is that so much has been preserved, rather than that the story is so incomplete. Notwithstanding all the difficulties, the palaeontological method remains one of the most valuable means of testing the theory of evolution, because certain chapters in the history of life have been recorded with a minuteness that is really very surprising."W. B. Scott, Theory of Evolution. (The Macmillan Company. Reprinted by permission).

\section{WHAT FOSSILS ARE AND HOW THEY HAVE BEEN PRESERVED}

"Fossils are only animals and plants which have been dead rather longer than those which died yesterday."-T. H. Huxley.

"Fossils are either actual remains of bones or other parts preserved intact in soil or rocks, or else, and more commonly, parts of animals which have been turned into stone, or of which stony casts have been made. All such remains buried by natural causes are called fossils." Jordan and Kellogg.

\section{FOSSILS CLASSIFIED}

Class I. The actual remains of recently extinct animals and plants which have been buried or surrounded by some sort of preserving material constitute the first type under consideration. Such remains have undergone little or no change of the original organic matter into inorganic. Thus we find the complete bodies of great hairy mammoths frozen in the arctic ice. These are so well preserved that dogs have fed upon their flesh. Nearly a thousand species of extinct insects, including many ants, have been obtained practically intact from amber, a form of petrified resin. Innumerable mollusk shells, teeth of sharks, pieces of buried logs, bones of animals buried in asphalt lakes and bogs, have been found in a well-preserved condition.

Class 2. Petrified fossils. - The process of petrification involves the replacement, particle for particle, of the organic matter of a dead animal or plant by mineral matter. So completely is the finer structure preserved that microscopic sections of preserved tissues, especially of plants, have practically the same appearance as sections made from living organisms. Various mineral materials have been employed in petrification, such as quartz, limestone, or iron pyrites. 
Class 3. Casts and impressions.-Very frequently the animal or plant has been buried in mud or has lain on a sofi mud flat only long enough to have left its impress in the plastic material. Subsequently the entire organism has decayed and been dissolved away, and its place has been taken by a mineral deposit. Thus only the external appearance has been preserved, as would be the case in making plaster-of-paris casts. Sometimes traceries of soft-bodied animals have been left upon forming slate or coal that are almost as accurate in detail as a lithograph.

Perhaps the most remarkable fossils known are those found by Professor Charles D. Walcott in the marine oily shales of British Columbia. A large number of soft-hodied invertebrates of Cambrian age have been found so wonderfully preserved that not only are the external features revealed, but sometimes even the details of the internal organs may be seen through the transparent integument.

Some authorities include among fossils such traces of extinct life as footprints, utensils and tools of extinct man, and even the restiges of archaic sea beaches. Perhaps this is stretching the definition of the term "fossil" too far.

ON THE CONDITIONS NECESSARY FOR FOSSILIZATION

"Examination and study of the rocks of the earth reveal the fact that fossils or the remains of animals and plants are found in certain kinds of rocks only. They are not found in lava, because lava comes from volcanoes and rifts in the earth's crust, as a red-hot, viscous liquid, which cools to form a hard rock. No animal or plant caught in a lava stream will leave any trace. Furthermore, fossils are not found in granite, nor in ores of metals, nor in certain other of the common rocks. Many rocks are, like lava, of igneous origin; others, like granite, although not originally in the melted condition, have been so heated subsequent to their formation, that any traces of animal or plant remains in them have been obliterated. Fossils are found almost exclusively in rocks which have been formed by the slow deposition in water of sand, clay, mud, or lime. The sediment which is carried into a lake or ocean by the streams opening into it sinks slowly to the bottom of the lake or ocean and forms there a layer which gradually hardens under pressure to become rock. This is called sedimentary rock, or stratified rock, because it is composed of sedi- 
ment, and sediment always arranges itself in layers or strata. In sedimentary or stratified rocks fossils are found. The commonest rocks of this sort are limestone, sandstone, and shales. Limestone is formed chiefly of carbonate of lime; sandstone is cemented sand, and shales, or slaty rocks, are formed chiefly of clay.

"The formation of sedimentary rocks has been going on since land first rose from the level of the sea; for watcr has always been wearing away rock and carrying it as sediment into rivers, and rivers have always been carrying the worn-off lime and sand and clay downward to lakes and oceans, at the bottoms of which the particles have been piled up in layers and have formed new rock strata. But geologists have shown that in the course of the earth's history there have been great changes in the position and extent of land and sea. Sea bottoms have been folded or upheaved to form dry land, while regions once land have sunk and been covered by lakes and seas. Again, through great foldings in the cooling crust of the earth, which resulted in depression at one point and elevation at another, land has become ocean and ocean land. And in the almost unimaginable period of time which has passed since the earth first shrank from its hypothetical condition of nebulous vapor to be a ball of land covered with water, such changes have occurred over and over again. They have, however, mostly taken place slowly and gradually. The principal seat of great change is in the regions of mountain chains, which, in most cases, are simply the remains of old folds or wrinkles in the crust of the earth.

"When an aquatic animal dies, it sinks to the bottom of the lake or ocean, unless, of course, its flesh is eaten by some other animal. Even then its hard parts will probably find their way to the bottom. There the remains will soon be covered by the always dropping sediment. They are on the way to become fossils. Some land animals also might, after death, get carried by a river to the lake or ocean, and find their way to the bottom, where they, too, will become fossils, or they may die on the banks of the lake or ocean and their bodies may get buried in the soft mud of the shores. Or, again, they are often trodden in the mire about salt springs or submerged in quicksand. It is obvious that aquatic animais are far more likely to be preserved as fossils than land animals. This inference is strikingly proved by fossil remains. Of all the thousands and thousands of kinds of extinct insects, mostly land animals, comparatively few specimens are known as fossils. On the other hand, the shell-bearing 
mollusks and crustaceans are represented in almost all rock deposits which contain any kind of fossil remains."-Jordan and Kellogg. ${ }^{x}$

The study of geology teaches us that the earth's outer zones have undergone within the period of vertebrate history numerous profound changes which in general we may term climatic changes. There have been periods of continental subsidence, accompanied by ocean-foor elevations, during which great continental plains have been covered with comparatively shallow seas. The marine faunas of the seas have migrated into these shallows and representatives of them have been buried in sediment. When the reverse change has accurred and the continental plain has been again elevated, the sedimentation of the shallow-sea period forms a great rocky stratum laden with marine fossils. Between periods of subsidence millions of years clapsed, and therefore a break in the continuity of the entombed fossils is to bc expected. Discontinuity between the fossil faunas in adjacent strata is the invariable rule. Were it not for this periodicity of subsidence and elevation there would be no boundaries between consecutive geologic strata.

In addition to the methods of fossilization mentioned, a few others deserve notice. Many animals of the arid plains have been fossilized by becoming imbedded in dust or sand drifts which have piled up against rocky outcrops or have filled in dried-up arroyos. Some very valuable fossils have been recovered from asphaltic deposits as the result of animals falling into liquid or semiliquid lakes or pools of asphalt.

Not only are external organs preserved with precision, but even delicate internal structures, such as the brains or the viscera of vertebrates, have been found in such a perfectly natural shape that the comparative anatomy could be worked out with confidence.

On the whole, then, we must conclude that the earlier pcssimism regarding the inadequacy and insufficiency of fossil data is giving way before a steadily increasing optimism, due to the very rapid advance in technique and the surprisingly abundant discoveries of the modern palaeontologist. The more enthusiastic of the new school of fossilhunters do not despair of ultimately bringing to light all of the really essential links in the chain of evidence necessary to place the evolution theory beyond the reach of controversy.

${ }^{I}$ From D. S. Jordan and V. L. Kellogg. Evolution and A nimal Life (copyricht (1907). Used by special permission of the publishers, D. Apjleton \& (ompany. 
ON THE LAPSE OF TIME DURING WHICH EVOLUTION IS BELIEVED TO HAVE TAKEN PLACE

"Independently of our not finding fossil remains of such infinitely numerous connecting links [referring to the objection that all steps in the evolution of modern types should be revealed in the fossils], it may be objected that time cannot have sufficed for so great an amount of organic change, all changes having been effected slowly. It is hardly possible for me to recall to the reader who is not a practical geologist, the facts leading the mind feebly to comprehend the lapse of time. He who has read Sir Charles Lyell's grand work on the Principles of Geology, which the future historian will recognize as having produced a revolution in natural science, and yet does not admit how vast have been the past periods of time, may at once close this volume. Not that it suffices to study the Principles of Geology, or to read special treatises by different observers on separate formations, and to mark how each author attempts to give an inadequate idea of the duration of each formation, or even of each stratum. We can best gain some idea of past time by knowing the agencies at work, and learning how deeply the surface of the land has been denuded, and how much sediment has been deposited. As Lyell has well remarked, the extent and thickness of our sedimentary formations are the result and the measure of the denudation which the earth's crust has elsewhere undergone. Therefore a man should examine for himself the great piles of superimposed strata, and watch the rivulets bringing down the mud, and the waves wearing away the sea-cliffs, in order to comprehend something about the duration of past time, the monuments of which we see all around us."-Charles Darwin, Origin of Species.

"In 1862," says Schuchert," "the physicist, Lord Kelvin ... . . held that as our planet was continually losing energy in the form of heat, the globe was a molten mass somewhere between $20,000,000$ and $400,000,000$ years ago, with a probability of this state occurring about $98,000,000$ years ago. Finally in 1897 he concurred in Clarence King's conclusion that the globe was a molten mass about 24,000,000 years ago. Both of these conclusions, however, were wrought out under the Laplacian hypothesis, and now many geologists hold that the earth never was molten. While geologists have not been able to fit their evidence into so short a time, they have ever since been trying to keep their

x C. Schuchert, Text-Book of Geology, Part II, Historical Geology (1915). 


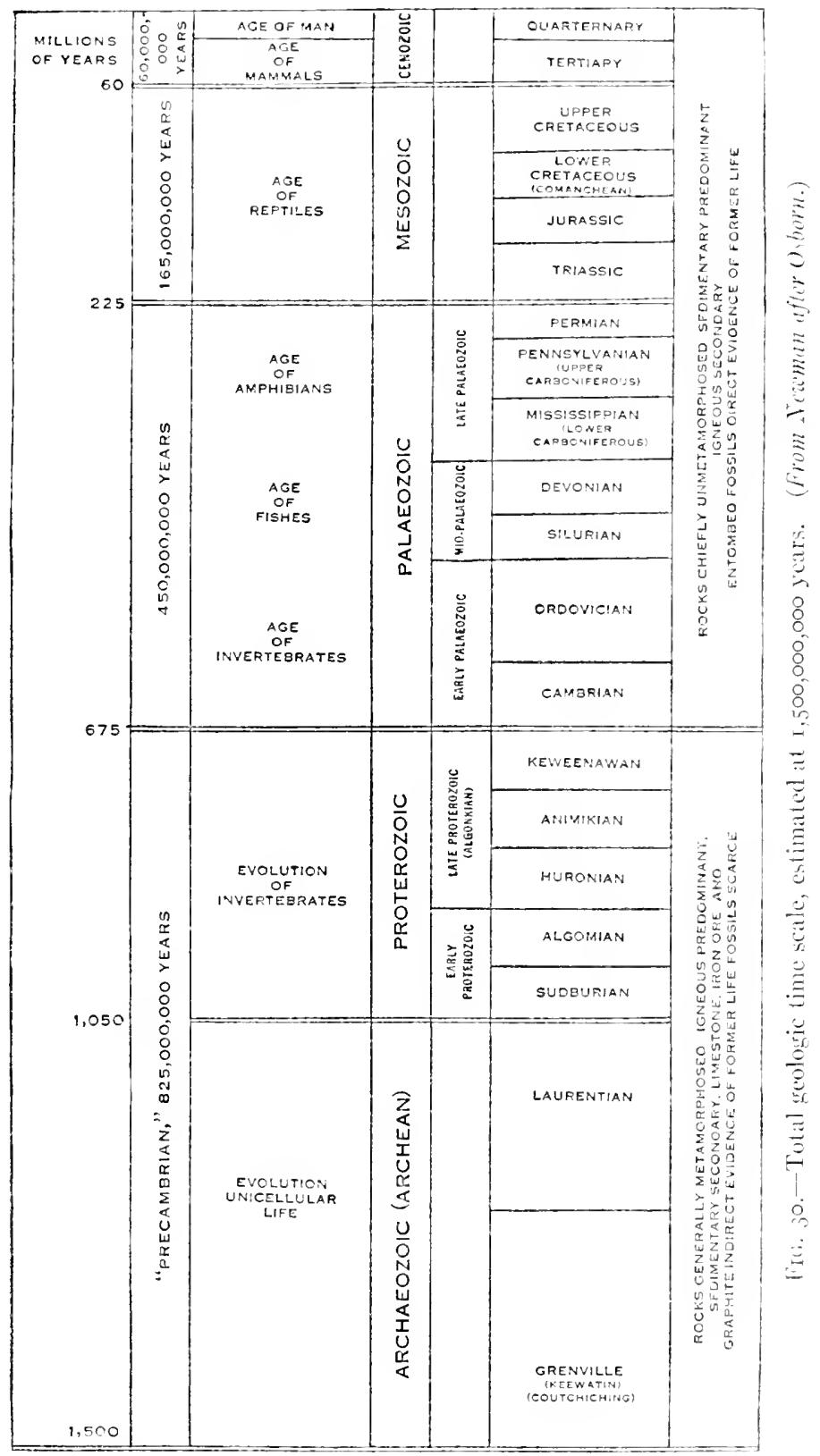


estimates within the bounds of Lord Kelvin's older calculations. Walcott, in I893, on the basis of the stratigraphic record and the known discharge of sediment by rivers, concluded that 70,000,000 years had elapsed since sedimentation began in the Archeozoic. Sir Archibald Giekie places the time at $100,000,000$ years, and most geologists have tried, although with difficulty, to fit the record within these estimates.

"Since the discovery of radium, all of the calculations previously made have been set aside by the new school of physicists, and now the geologists are told they can have $1,000,000,000$ or more years as the time since the earth attained its present diameter. . . . Even if finally it shall turn out that the physicists have to reduce their estimates as to the age of certain minerals and rocks, geologists nevertheless appear to be on safer ground in accepting their estimates than those based either on sedimentation, chemical denudation, or loss of heat by the earth."

The last decade has seen the demise of the outworn objection to evolution based on the idea that there has not been time enough for the great changes that are believed by evolutionists to have occurred. Given $100,000,000$ or $1,000,000,000$ years since life began, we can then allow $1,000,000$ years for each important change to arise and establish itself. We can also understand why it is that so little change can be noted in the majority of wild animals and plants within the historic period. A thousand years in the development of the race is like a second in the development of an individual and, though no one can notice any change in a growing creature in a second or a minute, very radical changes can be noted in an hour or a day or a year. We cannot see any movement in an hour hand of a clock, but it moves with certainty around the dial in a relatively short time. There is therefore no shortage of time. Evolution may have been infinitely slow, but time has been infinitely long. The accompanying time scale shows the lapse of time and the distribution in time of the main groups of animals (Fig. 3c).

\section{ON THE PRINCIPAL GENERAL FACTS REVEALED BY A STUDY OF THE FOSSILS}

I. None of the animals or plants of the past are identical with those of the present. The nearest relationship is between a few species of the past and some living species which have been placed in the same genera. 
2. The animals and plants of each geologic stratum are at least generically diiferent from those of any other stratum, though belonging in some cases to the same families or orders.

3. The animals and plants of the oldest (lowest) geologic strata represent all of the existing phyla, except the Chordata, but the representatives of the various phyla are relatively generalized as compared with the existing types.

4. The animals and plants of the newest (highest) geologic strata are most like those of the present and help to link the present with the past.

5. There is, in general, a gradual progression toward higher types as one proceeds from the lower to the higher strata.

6. Many groups of animals and plants reached the climax of specialization at relatively early geologic periods and became extinct.

7. Only the less specialized relatives of the most highly specialized types survived to become the progenitors of the modern representatives of their group.

8. It is very common to find a new group arising near the end of some geologic period during which vast climatic changes were taking place. Sucl an incipient group almost regularly becomes the dominant group of the next period, because it developed under the changed conditions which ushered in the new period and was therefore especially favored by the new environment.

9. The evolution of the vertebrate classes is more satisfactorily shown than that of any other group, probably because they represent the latest phylum to evolve, and most of their history coincides with the period within which fossils are known.

Io. Most of the invertebrate phyla had already undergone more than half of their evolution at the time when the earliest fossil remains were deposited.

POSSIL PEDIGREES OF SOME WELL-KNOWN VERTEBRATES

PEDIGREE OF THE HORSE

Of all fossil pedigrees that of the horse is most often mentioned in evolutionary literature. The main facts have been known for about forty years, and there is a rather general consensus of opinion as to the history as a whole. It appears practically certain that the horse family (Equidae) arose from a group of primitive five-toed ungulates or hoofed manimals called Condylarthra that lived in Eocene times. 
No particular member of this extinct group has been found that fulfils all the requirements of a primitive horse ancestor, so the chances are that the real ancestral condylarthran has not been discovered.

"The course of their [Equidae] evolution," says Dendy, " "has evidently been determined by the development of extensive, dry, grass-covered, open plains on the American continent. In adaptation to life on such areas structural modification has proceeded chiefly in two directions. The limbs have become greatly elongated and the foot uplifted from the ground, and thus adapted for rapid flight from pursuing enemies, while the middle digit has become more and more important and the others, together with the ulna and the fibula, have gradually disappeared or become reduced to mere vestiges. At the same time the grazing mechanism has been gradually perfected. The neck and head have become elongated so that the animal is able to reach the ground without bending its legs, and the cheek teeth have acquired complex grinding surfaces and have greatly increased in length to compensate for the increased rate of wear. As in so many other groups, the evolution of these special characters has been accompanied by gradual increase in size. Thus Eohippus, of Lower Eocene times, appears to have been not more than eleven inches high at the shoulder, while existing horses measure about sixty-four inches, and the numerous intermediate genera for the most part show a regular progress in this respect.

"All these changes have taken place gradually, and a beautiful series of intermediate forms indicating the different stages from Eohippus to the modern horse [Equus] have been discovered. The sequence of these stages in geological time exactly fits in with the theory that each one has been derived from the one next below it by more perfect adaptation to the conditions of life. Numerous genera have been described, but it is not necessary to mention more than a few."

The first indisputably horselike animal appears to have been Hyracotherium, of the Lower Eocene of Europe. Another Lower Eocene form is Eohippus, which lived in North America, probably having migrated across from Asia by the Alaskan land connection which was in existence at that time. In Eohippus the fore foot had four completely developed hoofed digits and a "thumb" reduced to a splint bone; in the hind foot the great toe had entirely disappeared and the little toe is represented by a vestigial structure or splint bone.

'Arthur Dendy, Oullines of Evolutionary Biology (D. Appleton \& Company, $1016)$. 
Then came in succession Orohippus, of the Lpper Eocene. Mesohippus of the Lower Miocene. Pliohippus of the L'pper Pliocene, and finally

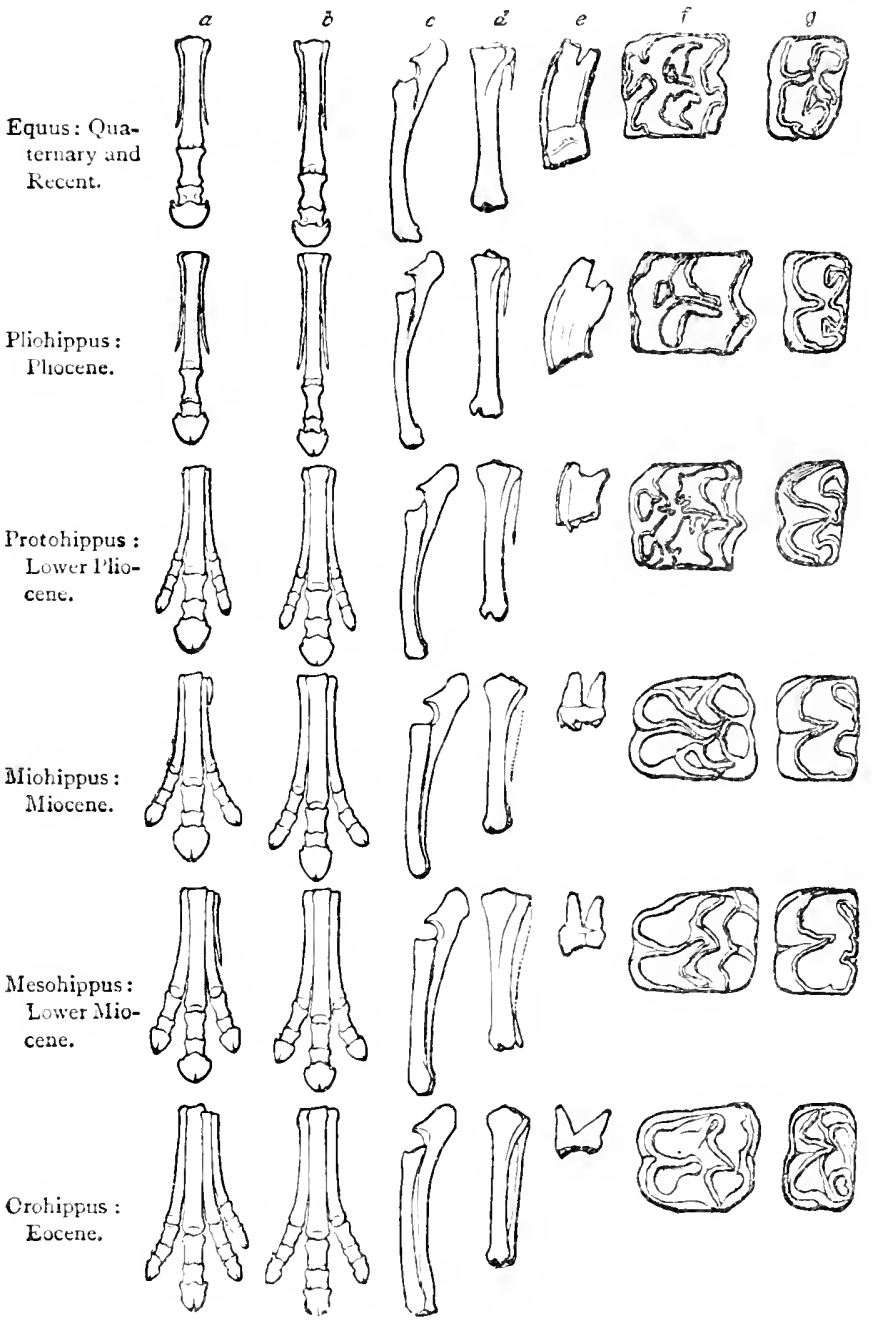

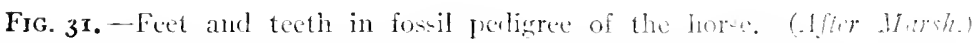
a, bones of the fore foot; $b$, bones of the hind fiot; $c$, rutius ant what d, fibulat and tibia; $e$, roots of a tooth; $f$ and $g$, crowns of uiper and lower teeth.

Equus of the Quaternary and Recent. Other genera might be mentioned, but the history of this series has been pictured in a classic 
diagram by Marsh, and in this (Fig. 3I) the reader may trace upward from Orohippus to Equus the steady changes in fore and hind feet, bones of the forearm, bones of the lower leg, and the grinding teeth of upper and lower jaws.

So definitely and clearly has the horse pedigree been worked out that, according to Dendy, "the palaeontological evidence amounts to a clear demonstration of the evolution of the horse from a five-toed ancestor along the lines indicated above."

For a long time the palaeontological series of the horse was unrivaled by other vertebrate types, but now we have almost equally complete series for several other modern types, notably the camels and the elephants. We shall present herewith accounts of the pedigree of the camels by Professor Scott, and that of the elephants by I'rofessor Shull. And, to conclude the vertebrate pedigrees, we shall present in the next chapter that of man as given by Professor Lull.

In extenuation of the use of vertebrate material to the exclusion of invertebrate, the present writer has only this to offer, that vertebrate material is more intelligible to the non-biological reader and is more in his own field of knowledge and interest.

\section{PEDIGREE OF THE CAMELS ${ }^{1}$}

W. B. ScotT

There remains one family of mammals with which it is necessary to deal and that is the camel tribe. This family has two well-defined subdivisions, the camels of the Old World and the llamas, guanacos, etc., of South America. For a very long time, the family was entirely confined to North America and did not reach its present homes until the Pliocene epoch of the Tertiary period. The skeleton of a Patagonian guanaco may be taken as the starting point of our inquiry. In this animal the third incisor and the canine are retained in the upper jaw, all the incisors and the canine in the lower. The anterior two grinding teeth have been lost and the others are moderately highcrowned. The skull is broad and capacious behind, narrow and tapering in front. The neck is long and its vertebrae very curiously modified. The limbs are long and slender and have undergone nearly the same modifications as in the horses; the ulna is greatly reduced, interrupted in the middle and its separated portions are fused with the radius. In the hind leg the shaft of the fibula has been completely:

I From W. B. Scott, The Theory of Evolution (copyright 1917). Used b: special permission of the publishers, The Macmillan Company. 
suppressed; the uprer end fuses with the tibial, while the lower remains as a small separate bene, wertged in betwen the tibia and the hee?bone. The feet are very long and slender, with two toes in each; the
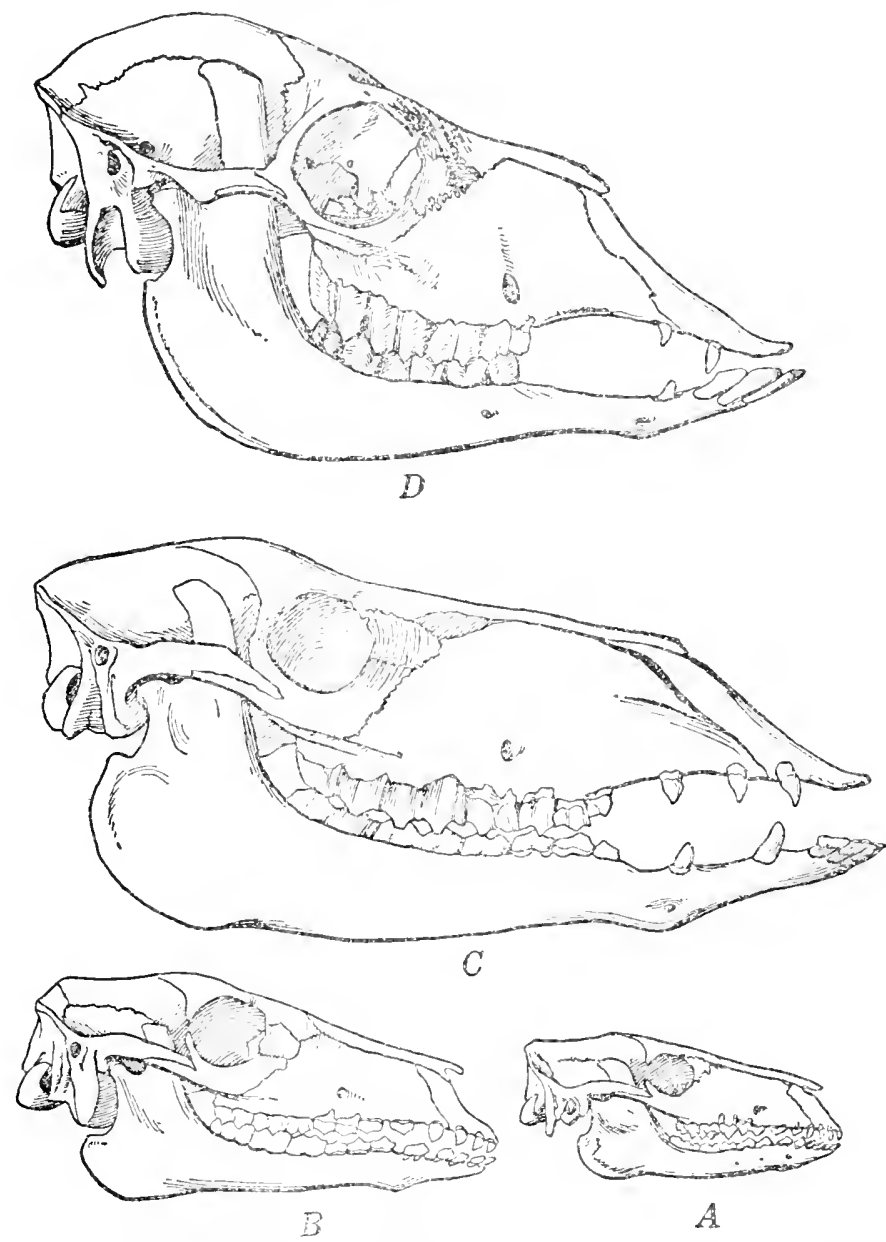

Fig. 32.-Four stares in the erolution of the cameline skull. 1, Protyopus,

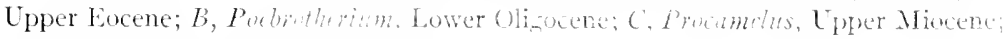
$D$, guanaco, Recent. (frim sint.)

long bones of the fuot are co-ossified to form a "camnon-bone," the very young skeleton showing that this co-osification does actually take place. The toes profure are free, giving the "cloven hoof," lout the hoofs are very small and the weight is carried upon a soft, thick pat. 

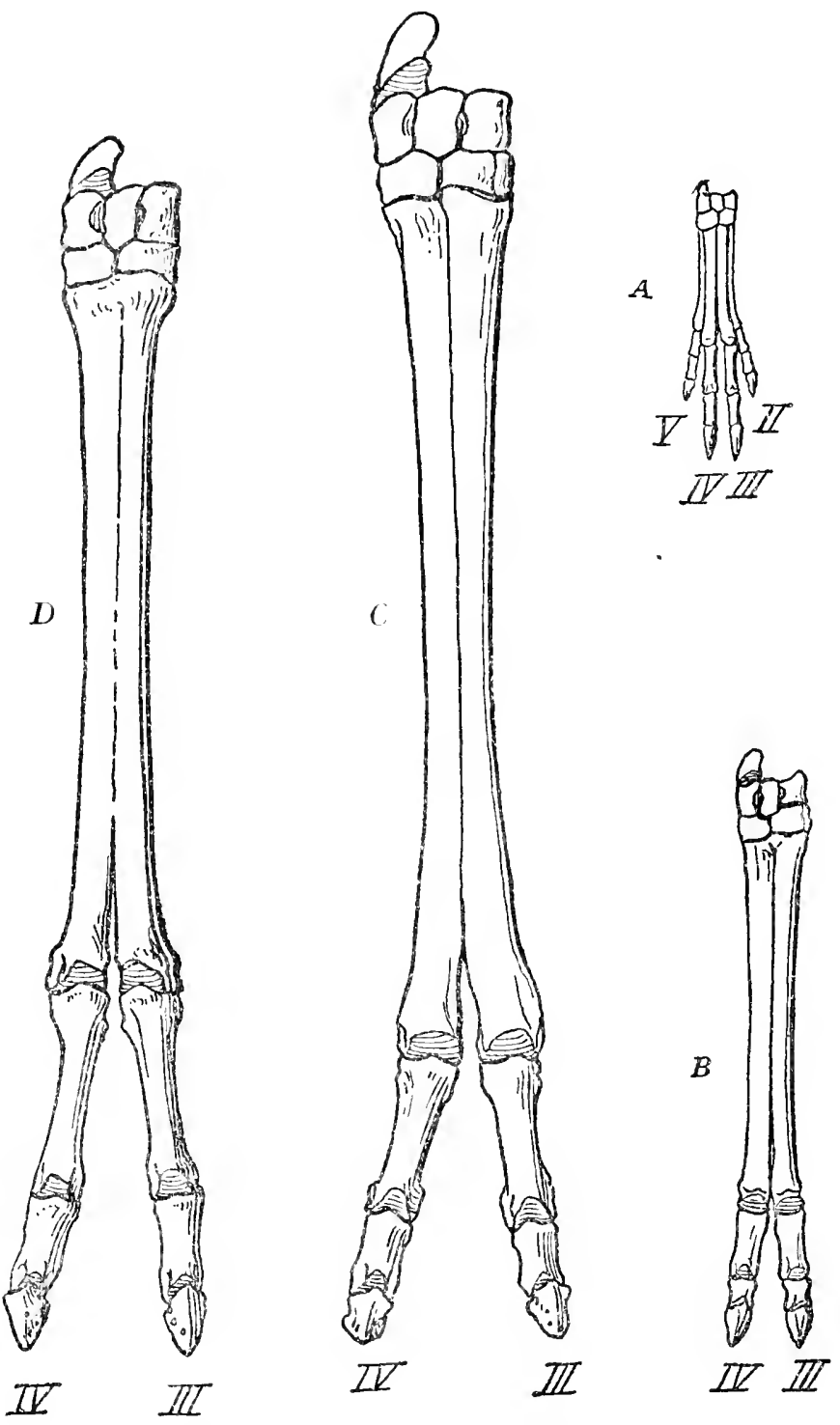

FIG. 33. - Four stages in the evolution of the cameline fore foot. A, Protylopus, Upper Eocene; B, Poëbrotherium, Lower Oligocene; C, Procamelus, Upper Miocene; $D$. guanaco, Recent. (From Scott.) 
Were there time enough to do so, we mirht trace the development of this family hackward, step by step, through all the many stages letween the Pleistocenc and the Upper Eocene in quite as unbroken sequence and in as fuli detail as can be chone for the horses. We must, however, pasz over all the intermediate steps and consider the ancestral camels of the Upper Iocene. These were very little animals, hardly larger than a jack rablit, which had the full complenent of teeth, 44 in total number, and all with very low crowns. The limbs, and especially the feet, are relatively short, the una is complete and separate, as is also the funla; there are four toes in each foot, though the lateral pair of the hind foot are extremely slender, and there is no co-ossification to form camnon-bones. The hoofs are nell developed. in form like those of an antelope, so that there can have been no pad. For the present, the line cannot Le carried back of the Lpper Eocene. the probable ancestors from the middie and Lower Eocene being, as yet, represented only by fragmentary specimens.

In addition to this main stem of cameline descent which resulted in the modern species, there were two short-lived side branches which should be mentioned. One, ending in the Lower Miocene, was the series descriptively called "gazelle-camels," small animals with very" long and slender legs, evidently swift runners. The other series, the so-called "girafle-camels," terminated in the Lpper Miocene; these were browsers and display an increasing stature, especially in the length of the neck and fore limbs. They adapted themselves to the growing aridity of the western plains.

\section{EVOLUTION OF THE ELEPHANTS}

A. FRANKLIN SHULL

The mastodon-elephant series shows a larger number of obvious changes than most of the other series named, all of these changes except that of the body having to do with features of the head. From the numerous specimens of elephant-like forms available, the following are selected (following Lull) as probably representing a direct line of evolution: Woeritherium from the Upper Eocene of Egypt; Palucomastodon from the Lower Oliogocene of Egypt, also from India; Trilophodon from the Miocene of Europe. Africa, and North America; Mastulon from the Pliocene and Pleistocene of

'From A. F. Stull, Frinciples of Animal Binlngy (copyright rozo). Used bs specia! nermiscion of the pullishere. The Mcliaw-Hill Bools Company. 
North America, Europe and Asia; Stegodon from the Pliocene of southern Asia; and Elephas from the Pleistocene of the Americas, Europe, and Asia, as well as the living elephants of Asia and Africa.

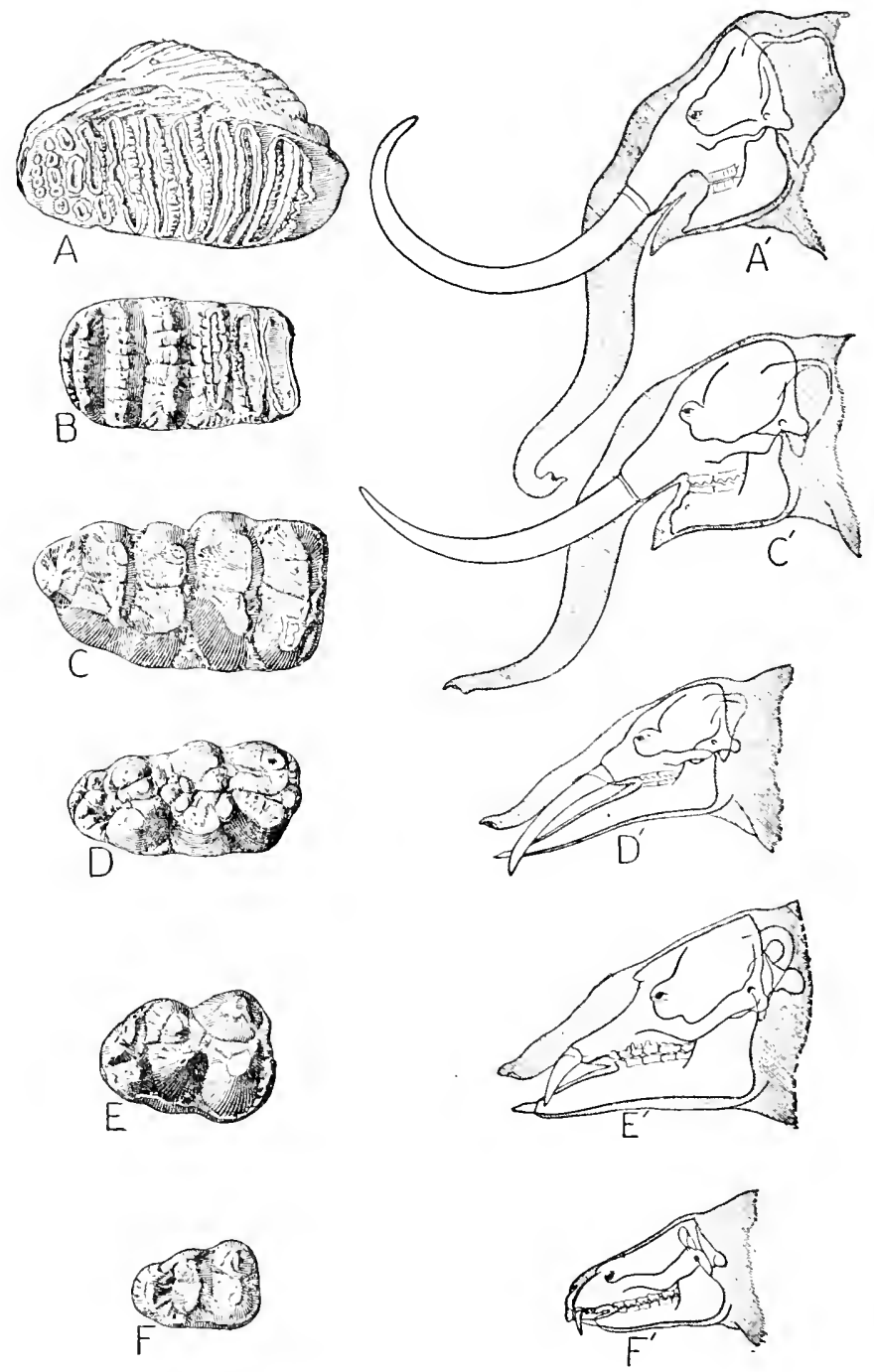

FIG. 34. - Evolution of head and molar teeth of mastodons and elephants. A, A', Elc phas, Pleistocene; 1 , Stegodon, Pliocene; C, C', Mastodon, Pleistocene; $D, D^{\prime}$, Trilophodon, Niocene; $E, E^{\prime}$, Palacomastodon, Oligocene; $F, F^{\prime}$, Mocritherium, Eocene. (From Iull.) 
A study of Figure 34 in connection with the following account will disclose the more striking steps of evolution. These forms differed from one another in a number of features, but the differences between any member of the series and the one that precedes or that which follows were so small that the series is obviously a continuous one. Moeritherium was very different from the modern elephant, but the intermediate forms completely bridged the gap. The series exhibits an enormous increase in size of body, changes in the form and size of the teeth, a reduction in the number of teeth, an alteration in the method of tooth succession, the enlargement of certain teeth to become tusks, the elongation and subsequent shortening of the lower jaw, the development of the upper lip and nose into a proboscis, and an increase in the height of the skull through the development of large cavities in the substance of the bone. These features are described in the several forms seriatim.

Moeritherium.-The earliest animal recognized as belonging to the elephant series, Moeritherium by name, was recovered from the late Eocene and early Oligocene deposits of northern Egypt. It was slightly over three feet in height. The features suggesting elephantine affinities are the high posterior portion of the skull (Fig. $34, F)$; composed of somewhat cancellate bone, that is, bone containing vpen spaces; the elongation of the second pair of incisors in each jaw to form short tusks; the indication of transverse ridges on the molar teeth (Fig.34,F); and the position of the nasal openings some distance back of the tip of the upper jaw, indicating probably a prehensile upper lip. There were 24 teeth, and the neck was long enough to enable the animal to put its head to the ground. It probably fed upon tender shoots and swamp vegetation.

Palaeomastodon.-This form also lived in Egypt, but has recently been found in India. It dates rrom early Oligocene time. Palaeomastodon was of somewhat larger size than the preceding form, the posterior part of the skull was distinctly higher (Fig. $34, E^{\prime}$ )--with a greater development of cancellate bone, and the neck was somewhat shortened. The upper incisors of the second pair were more elongated as tusks and bore a band of enamel on their front surfaces. The lower second incisors were present, but not enlarged. All other incisors and the canines had disappeared. The molar teeth $(E)$ resembled those of Moeritherium but were larger. The lower jaw was considerably elongated, and the total number of teeth was still high (26). The nasal openings had receded until they were just in front of the eyes, 
which is believed to indicate the existence of a short proboscis extending at least to the tips of the tusks.

Trilophodon.-Trilophodon, a great migrant and consequently wide-spread over sereral continents as stated above, exhibited in several respects a striking advance over Palaeomastodon; but this advance was in the main in the same direction as was indicated by the change from Moeritherium to Palaeomastodon. Trilophodon was a huge animal, nearly as large as modern Indian elephants. The tusks were considerably longer (Fig.34, $D^{\prime}$ ) and still bore a band of enamel. The molar teeth were large and greatly reduced in number, so that only two were present at any one time on each side of each jaw. The surface of these teeth bore a somewhat larger number of transverse crests (Fig. $3 ;, D$ ) than were present in the earlier forms. The lower jaw was enormously elongated, so that it projected as far forward as the tusks. Thr great weight of the lower jaw and tusks was associated with a considerable development of cancellate bone in the skull, to which the supporting muscles of the neck were attached. Presumably there was a proboscis which extended to or beyond the tips of the tusks and lower jaw.

Mastodon.-The mastodons on the whole represent a line of development which became extinct; but in their incipient stages they appear to have given rise to the succeeding forms leading to the elephants. The body was somewhat larger than that of Tirloploodon, being about the size of the Indian elephant. The tusks $\left(C^{\prime}\right)$ were much elongated ( 9 feet or more), but the lower jaw was greatly shortened and the lower incisor teeth were reduced or wanting. The molar teeth (Fig. $34, C$ ) were scarcely more complex than earlier forms, and numbered two on each side of each jaw. They were still crushing teeth, and the food must have been tender twigs and succulent plants; indeed, remains of such objects have been found in the region of the stomach of the fossil mastodons.

Stegodon.-This animal is of interest chiefly because the molar teeth bore five or six well-defined transverse ridges (Fig.34, B). These ridges were due to plates of enamel extending up through the tooth, and inclosing a substance known as denime. Over the enamel in an unworn tooth was a thin coat of a third substance called cement, but there was not much of this substance between the ridges. In the latter respect Stegodon differed, as is pointed out below, from the elephants and mammoths. On the whole, Stegodon was intermediate between the mastodons and elephants. 
Elephas.- In this genus are included a number of extinct forms (the mammoths) from three or four continents, and the living elephants. The extinct forms, though called mammoths, were not large animals, being no larger than the Indian elephant of today, and not so large as the living African species. Some of the features of the elephants, their :ize, the short neck, the long proboscis, and the heavy tusks are matters of common observation. The still is very high and short (Fig. $34 \cdot 4^{\prime}$ ). The height is due chiefly to the development of cancellate bone, not to the enlargement of the brain, which is still quite small. As stated ahove, the high skull affords the neccsary leverage for the muscles that support the weight of the tusks. The molar teeth are distinctly grinding teeth (Fir. 34, A). Each tooth bears a number of transverse ridges, about ten in the African elephant and two dozen or more in the Indian species. These ridges are worn down by the chewing of harsh food, so that the upper surface displays a number of flattened tubular plates of enamel inclosing dentine and bound together by cement. A tooth is completely worn out by use, and is replaced by another. The method of replacement, however, is peculiar. While the tusks (incisors) are of two sets, one following the other like milk and permanent teeth of other mammals, the grinders succeed one another in continuous fashion. There are never more than two visible grinders on each side of each jaw. As they wear out they move forward in the jaw, and are replaced by new teeth appearing behind. New molars thus enter at intervals of two to four years in young elephants, and at intervals of 15 to 30 years in later life. If an elephant lives long enough ( 60 years or more) it develops a total of 28 teeth, including tusks, but has not more than ten (often less) at any one time.

Correlated with the nature of the teeth of the elephants are their food and chewing habits. Whereas the ancestral forms whose molars bore prominent elevations lived on twigs and tender herbage which they crushed in mastication, the mammoths with their flattened tooth surfaces devoured grasses, sedgres, and other harsh vegetation which they ground with lateral motion of the teeth upon one another. In this respect modern elephants are like the mammoths.

In the changes described above is found one of the most beautiful and best established evolutionary series with which the palaeontologist is acquainter. Only a fow others equal or approach it in clearness and compicteriess. 


\title{
CHAP'TER II \\ THE EVOLUTION OF MAN: PALAEONTOLOGY ${ }^{\mathbf{2}}$
}

\author{
Ricitard Swann Lull
}

\section{ORIGIN OF PRIMATES}

Stock.-There is but little doubt that two important orders of modern manmals, the Carnivora and the Primates, had a common origin, diverging mainly along lines determined by a dietary contrast, as the former have become more strictly flesh-eating or predaceous, the latter largely fruit-eating and as a consequence more completely arboreal. Back of each group lie as annectant forms the Insectivora, not perhaps such as are alive to-day, as all these are highly specialized along diverse lines, but generalized insectivores possessing, because of their primitiveness, a wider range of potential adaptation. Matthew is "disposed to think of these, our distant ancestors, at the dawn of the Tertiary, as a sort of hybrid between a lemur and a mongoose, rather catholic in their tastes, living among and partly in the trees, with sharp nose, bright eyes, and a shrewd little brain behind them, looking out, if you will, from a perch anong the branches, upon a world that was to be singularly kind to them and their descendants." Thus we can define the stock as a relatively large-brained arboreal insectivore, of primitive but adaptable dentition, and especially of progressive mentality.

Time.- The time of primate origin must have been not later than basal Eocene, as primates, clearly definable as such, are found in the Lower Eocene rocks of both Europe and North America.

Place.-The simultaneous appearance of the primate in the Old World and the New gives rise to the same conclusions as to their place of origin and their migrations thence as with other modernized manmals. It suffices now to say that their ancestral home was boreal Holarctica, probably within the limits of the present continent of Asia, whence they migrated southward along the three great continental radii. The impelling cause of this migration was the increasing northern cold, before which the boreal limitations of the tropical forests retreated, carrying with them the primates which, in

"From R. S. Lull, Orgmic Emlution (copyright I9I7). Used by special permission of the publishers, The Macmillan Company. 
general, are utterly dependent upon such an environment for their sustenance.

Geologic record.-Primates are found in the North American sediments from Lower to Upper Eocene time, when they became extinct. Thus, while their remains constitute a relatively large percentage of the total fauna of the Eocene, primates are utterly unknown on this continent from that time until the coming of man. In Europe the record is similar except that the extinction occurred at a somewhat later date, the Oligocene. Furthermore, they reappear in Europe in the Lower Miocene, at the time of the proboscidean migration out of Africa, whence these primates may also have come. Their second European extinction was in the Upper Pliocene shortly before the first appearance of mankind.

But in southern Asia, Africa, and South America the evolution of primates seems to have been continuous since the first great southward migration. The evidence, however, is not so much the historical documents as the presence of primates in those places at the present time, the fossil record is not entirely lacking although highly incomplete. The South American monkeys may have had their origin in the ancient North American primates, or more doubtfully, the stock may have come by way of Africa. Scott inclines toward the latter view although he says the evidence is by no means conclusive.

\section{ORIGIN OF MAN}

Stock.-According to W. K. Gregory, the stock from which man arose was some big-brained anthropoid related most nearly to the chimpanzee-gorilla group, an assumption based upon anatomical evidences, in spite of wide differences in habitus and consequent adaptation.

Place.--Evidences point to central Asia as the place of descent from the trees of the human precursor, the reasons for this belief being several. First, it was central for migrations elsewhere; Europe, on the other hand, where the most conclusive, in fact almost the exclusive evidence for fossil man is found, is too small an area for the divergent evolution of the several human species. Second, Asia is contiguous to the oldest known human remains, which, as we shall see, wcre found in Java. Third, it was the seat of the oldest civilizations, not only of the existing nations which, like the Chinese, trace their recorded history back to a hoary antiquity, but of nations which preceried them by thousands of years, and whose records have not yet come to light. 
This antiquity vastly exceeds that of the nations of Europe or of the Americans or of Africa. Fourth, central Asia is the source of almost all of our domestic animals, many of which have been subjected to human will and control for thousands of years, and this is equally true of many of our domestic plants. This is not due to the fact that man first reached civilization in Asia, but rather that he chose for his companions the highest and best of their several evolutionary lines, and Asia was the place of all others upon earth where the evolution in general of organic life reached its highest development in late Cenozoic time (Williston). Fifth, climatic conditions in Asia in the Miocene or early Pliocene were such as to compel the descent of the prebuman ancestor from the trees, a step which was absolutely essential to further human development.

Impelling cause.-We look for a gcologic cause back of this most momentous crisis in the evolution of humanity and we find it in continental elevation and consequent increasing aridity of climate, especially to the northward of the Himalayas. W1th this increased aridity and tempering of tropical heat came the dwindling of the forested areas suitable to primate occupancy. Barrcll has suggested that this diminution left residual forests comparable to the diminishing lakes and ponds of the Devonian, which upon final desiccation compelled their denizens to become terrestrial or perish. The dwindling of the residual forests would have an effect upon the tree-dwellers which may be expressed in precisely the same words. Once upon the ground the effect upon even a conservative type-and the primates in general, where constant conditions prevail, are slow of change-would be the rapid acquisition of such adaptations as were necessary to insure survival under the new conditions. The other man-like apes had, unfortunately for their further evolution, reached a region where tropical forests continued to be available and hence have retained their arboreal life and with it a stagnation of progress. The result has been. at any rate on the part of the three larger forms, a degeneracy from the estate of their common ancestry with mankind; the gibbons seem to have deteriorated less, while terrestrial man has risen to the summit of primate evolution.

Time.-The time of the descent is not later than early Pliocene nor earlier than Miocene time; when the terrestrial ape-man became what we would call human was perhaps later, but certainly during the Pliocene, which makes the age of man as such measurable in terms of hundreds of thousands of years! 
Significance of the descent from trees.-As a result of the descent from the trees, certain definite factors were called into play, each of which had its effect on the further evolution. Briefly enumerated, these are: (r) Assumption of the erect posture; (2) liberation of the hands from their ancient locomotor function to become organs of the mind; (3) loss of the easily obtainable food of the tropical forests, necessitating the search for sustenance, both plant and animal, and man became a hunter; (4) need of clothing with increasing inclemency of the weather, especially during the long winters; (5) freedom from climatic restrictions--when an omnivorous diet and clothing were acquired man was no longer limited to one definite habitat and the result was dispersal; (6) the development of communal life, rendered possible by the terrestrial habitat. Primates are at best gregarious, submitting, as in the gorilla, to the leadership of the strongest male, but it is only by communal life with its attendant division of labor that man can rise above the level of utter savagery.

Evolutionary changes. - Juman evolutionary changes which are recorded are: more erect posture, shorter arms, perfection of thumb opposability, reduction of muzzle and of size of teeth, loss of jaw power, development of chin prominence, increase in skull capacity, diminution of brow-ridges, diminution in strength of zygomatic or temporal arch, increase in size and complexity of brain, especially frontal lobes, development of articulate speech.

\section{FOSSIL ILAN}

Fossil remains of man are found under two conditions, in river valley deposits and in limestone caverns which served first as a dwelling-place and later as a sepulture. Of these the caverns have been by far the most productive, but they contain only the remains of the later races, as the caverns according to Penck did not become available for human occupancy before middle Pleistocene time.

The rarity of human fossils may be explained, first, by the various burial customs which seldom are sufficiently perfect to preclude the possibility of alternate wetting and drying or of rapid oxidation, both of which are prohibitive of fossilization. If man liverl and died in the forests the chances for his fossilization, in common with other forest creatures, was very remote, for the remains of such are almost invariably destroyed by other animais, by dampness, or by fungi, and rarely attain a natural burial in sefiment. If, on the other hand, he dwelt 
in the open, the chances of so shrewd a creature being caught in the flood waters and thus buried in sediment were not very great. However we account for it, the fact remains that relics of ancient man are rare and are valued accordingly.

In North America.-Repeated instances of seemingly ancient man have been brought to light in North America, such as the "Caleveras skull" of the California gold-bearing gravels, which was satirized by Bret Harte; the Nebraska "Loess man," and those of the Trenton gravels; none of which, with the possible exception of the last-mentioned, has proved to be really old in the geologic sense. Indirect evidence of human antiquity, that is, the association of North American man with animals which are now extinct, while very rare, has been reported in at least two highly authentic instances. The first of these was at Attica, New York, and is attested by Doctor John M. Clarke, the New York state geologist. Four feet below the surface of the ground, in a black muck, he found the bones of the mastodon (Mastodon americamus), and $\mathbf{I} 2$ inches below this, in undisturbed clay, pieces of pottery and thirty fragments of charcoal. The charcoal may have been of natural origin, but the presence of the pottery seems conclusive. The other instance was that of the remains of a herd of extinct bison (Bison antiquus) found near Smoky Hill River, Logan County, Kansas, and thus described by Professor Williston: An "arrow-head was found underneath the right scapula of the largest skeleton, embedded in the matrix, but touching the bone itself. The skeleton was lying upon the right side. . . . . The bone bed when cleared off . . . . contained the skeletons of five or six adult animals, and two or three younger ones, together with a foetal skeleton within the pelvis of one of the adult skeletons. The animals had evidently all perished together, during the winter. There was no possibility of the accidental intrusion of the arrow-head in the place where found. . . . . It must have been within the body of the animal at the time of death, or have been lying on the surface beneath its body."

What at this writing is claimed to be another genuine case of such an association, this time of the actual human bones, has just been announced from Florida. This find, which has been reported by State Geologist Sellards, was made at Vero, eastern Florida, in I9ז3. The fossil human bones are from two incomplete skeletons and are found in strata which also contain remains of the following extinct species: Elephas columbi, Equus leidyi, a fox, a deer, the ground-sloth, Megalonyx jeffersoni, and the American mastodon. 
In South America.-A number of finds have been recorded from South America, notably by the late Florentino Ameglino of Buenos Aires, who contributed so largely to our knowledge of South American prehistoric life. An expert from Washington, Doctor Ales Hrdlicka, has studied with the utmost care the locality and character of each of these finds in the Western World, and has expressed the opinion that none is of an antiquity greater than that of the pre-Columbian Indians.

Further evidence lies in the uniformity of type, except for minor distinctions, of all native American peoples. There is no such racial differentiation as that seen in the Old World, and the argument is that there has not been time for such a deployment. The area and conditions as an adaptive radiation center are surely ample.

In Africa.-The only African relics thus far reported are those of prehistoric cultures, comparable to those of Southern Europe, in certain caverns of the Barbary States. There has also been reported from Oldoway ravine, German East Africa, a human skeleton of undoubted antiquity. It is described, however, as being neither a very early nor a primitive type.

In Asia.--Asia has given us in Pithecanthropus the oldest known relic of the Hominidae, found at Trinil in the island of Java. Osborn says: "It is possible that within the next decade one or more of the Tertiary ancestors of man may be discovered in northern India among the foothills known as the Siwaliks. Such discoveries have been heralded, but none have thus far been actually made. Yet Asia will probably prove to be the center of the human race. We have nuw discovered in solithern Asia primitive representatives or relatives of the four existing types of anthropoid apes, namely, the gibbon, the orang, the chimpanzee, and the gorilla, and since the extinct Indian apes are reluted to those of Africa and of Europe, it appears probable that southern Asia is near the center of the evolution of the higher primates and that we may look there for the ancestors not only of prehuman stages like the Trinil race but of the higher and truly human types."

In Europe.-It is in Europe, however, that the tale of human prehistory is the most complete, not only through the happy accident of preserval, but because it has been much more thoroughly explored than has the Asiatic evolutionary center. The latter, however, holds the greatest hopes for future exploration since, as we have emphasized, Europe is too small to be an adaptive radiation center and European 
prehistoric man represents waves of migration from the greater continent.

Nevertheless the European record has enabled us to name and define a number of distinct human species, and here the record of the cultural evolution of man is also unusually complete. Hence European chronology is taken as a standard in describing discoveries from any portion of the world.

\section{CHRONOLOGICAL TABLE}

(Adapted from Osborn, 1915)

Postglacial Thie.................. 25,000 years

Upper Palaeolithic culture

Crô-Magnon man

Fourti Glacial Stage (W'ürm, Wisconsin). . . . 5 50,000 years

Close of Lower Palacolithic culture

Neanderthal man

Third Interglactal Stage............... i 50,000 years

Beginning of Lower Palateolithic culture

Piltdown and pre-Neanderthaloid men

Third Glacial Stage (Riss, Jllinoian) ......... 175,000 years

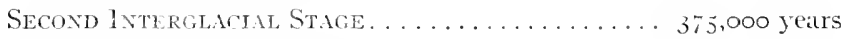

Heillelberor man

Second Glacill Stage (Mindel, Kansas) . . . . . . + +00,000 years

First Interglicid Stage............. 475,000 years Pithcanthropus, ape-man

Finst GlicinL Stige (Günz, Nebriskinn) . . . . . 500,000 years

Pithecanthropus.--The Tava ape-man, Pithecanthropus erectus (Fig. 35) was discovered in Trinil, on the Solo or Bengawan River in central Java, in r894. The type consists of a calvarium or skull cap, a left thigh bone, and two upper molar teeth. The skull is characterized by its limited capacity, about twothirds that of man; and by the low flat forehead and beetling brows. Ience not only was the brain limited in its total size, but this was especially true of the

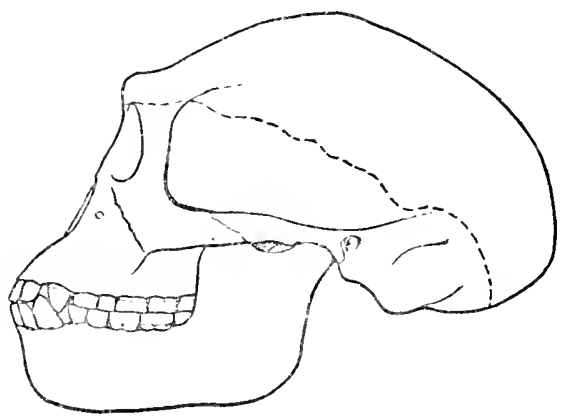

Fic. 35. - Skull of Java ape-man, Pilhecanthropus cretus. (From Lull, after Dubois.) frontal lobes, which, as we have seen, are the seat of the higher intellectual faculties. Thus, as Osborn says, although touch, taste, and 
vision were well developer there was a limitat fackly for profiting by experience and accumulated tratition. The fenner as sociated with

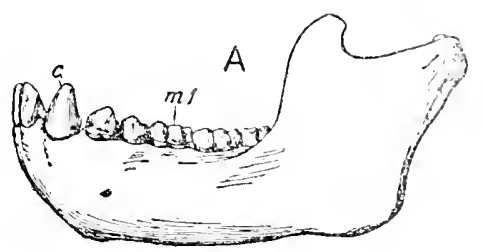

the sult is remarlatile for its kneth and slint curbature as comarel with the primitive Yeankrthal race of Europe and indicentes a creature fully socectomentineastallas the aremere Inmpean of tolay, the huthe leing extimated at 5

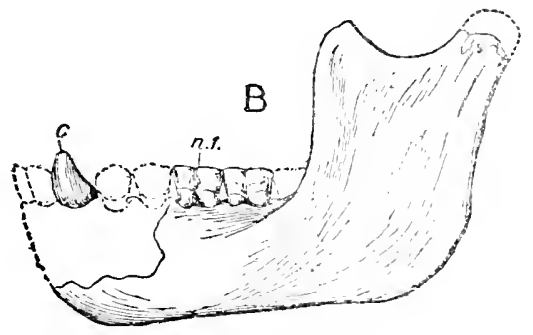
hinches as combred with 5 fuet 3 inches fo: the Neanduthels and 5 feet $S$ inches, the aryen height of modem males. The erect posture of crarte implies the libuation oi the homds from any part in the fucomoror function. The weth are somewhat ape-like,

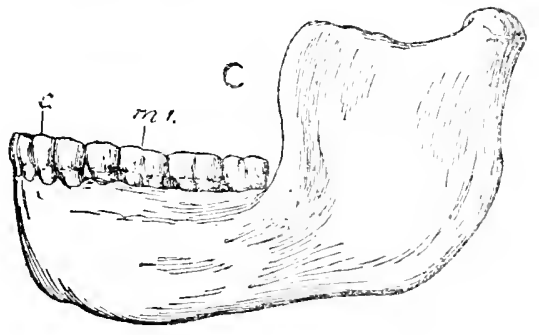
lout a more human than are troce of the gribon, and the Inomin mode of mastication bas been accuired. Certain authoritics have tried to prove that Pithecunther pus is nothing l,ut a large gifon, bit the weight of auhority considers it prehuman, though not in

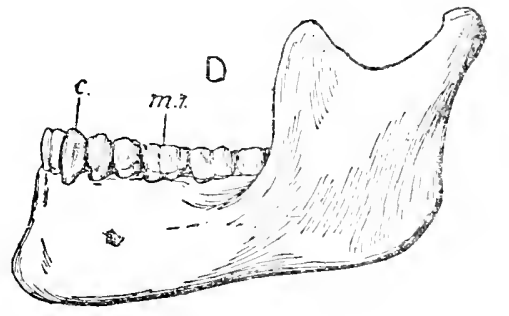

Fig, 3f.-Jaws, left outer aspect, of 1 , chimpanze, $P$ ' $n$, sp ; ; $F$, fosil chimpunae, Pan welus, found in association with lint down man; C, Heidelbers man, hom:e heidelbergensis; I, modern nuen, It. suptins. (From Lull, afler Troodaure?.) the line of direct development intolumanity. It is nevertheless a highy impontant transitionel iom.

Asociated whin the Pithecuttropts raming are those of a number of the contemporag animals which fix the das aseither oi the Liper pliocene or lowernot Pleistucene lexiud, which lamg rember in tems of years gives an esimated ane of about 500,000: 
Heidelberg man.-Homo heidelbergensis, the Heidelberg man, represents the oldest recorded European race, geologically speaking. The type was discovered in 1907 in river sands, 79 feet below the surface, at Mauer, near Heidelberg, South Germany. The relic consists of a periect lower jaw with the dentition (Fig. 36,C). The description by the discoverer, Doctor Schoetensack, follows (from Osborn):

"The mandible shows a combination of features never before found in any fossil or recent man. The protrusion of the lower jaw just below the front teeth (the chin prominence) which gives shape to the human chin is entirely lacking. Had the teeth been absent it would have been impossible to diagnose it as human. From a fragment of the symphysis of the jaw it might well have been classed as some gorilla-like anthropoid, while the ascending ramus resembles that of some large variety of gibbon. The absolute certainty that these remains are human is based on the form of the teeth-molars, premolars, canines, and incisors are all essentially human and although somewhat primitive in form, show no trace of being intermediate between man and the anthropoid apes but rather of being derived from some older common ancestor. The teeth, however, are small for the jaw; the size of the border would allow for the development of nuch larger teeth. We can only conclude that no great strain was put on the teeth, and therefore the powerful development of the bones of the jaw was not designed for their benefit. The conclusion is that the jaw, regarded as unquestionably human from the nature of the teeth, ranks not far from the point of separation between man and the anthropoid apes. In comparison with the jaws of the Neanderthal races ... . we may consider the Heidelberg jaw as pre-Neanderthaloid; it is, in fact, a generalized type."

Associated with the Heidelberg jaw is an extensive warm-climate fauna: straight-tusked elephant (E. antiquus), Etruscan rhinoceros, primitive horse, bison, wild cattle (urus), bear, lion, and so on, all of which aid in establishing the date of the jaw as Second Interglacial and its age, conservatively estimated, at from 300,000 to 375,000 years. The cultural evolution of Heidelberg man is indicated by the presence of eoliths, flint implements of the crudest workmanship, if indeed their apparent fashioning is not merely the result of use.

Neanderthal man.-The original specimen of the Neanderthal man, Homo neanderthalensis or primigenius (Figs.37,38,39) was discovered in 1856 not far from Düsseldorf in Rhenish Prussia. Here the valley of the Düssel forms the deep Neanderthal ravine, whose 
limestone walls are penetrated by caverns, in one of which the remains were found. What was doubtess a perfect skeleton at the time of its

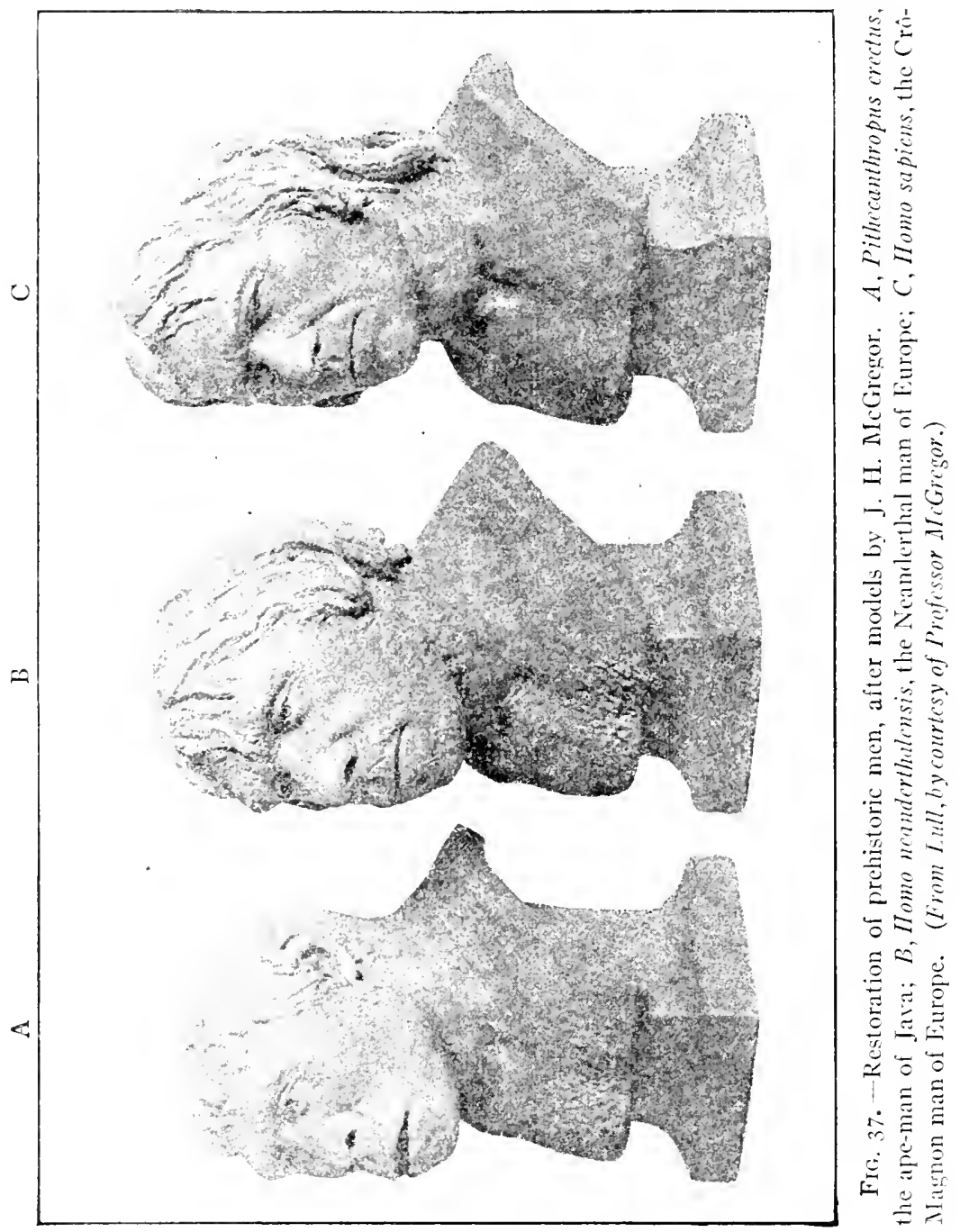

discovery was so injured by its finders that only a portion of it, which is now preserved in the Provincial Museum at Bonn, was saved. "This prophet of an unknown race was for a time utterly without honor 
though of course the subject of a most heated controversy, being considered as non-human, or, as Virchow believed, owing its distinctive characters to disease. The sagacity of Huxley threw true light upon the problem, though it was not until the mute testimony of other representatives of the race (the men of Spy) was offered that even Huxley's masterful conception of the Neanderthal characters was taken as an accepted fact. Professor Huxley's description of the Neanderthal type is classic. He says:

"The anatomical characters of the skeletons bear out conclusions which are not flattering to the appearance of the owners. They were short of stature but powerfully built, with strong, curiously curved thigh bones, the lower ends of which are so fashioned that they must have walked with a bend at the knees.

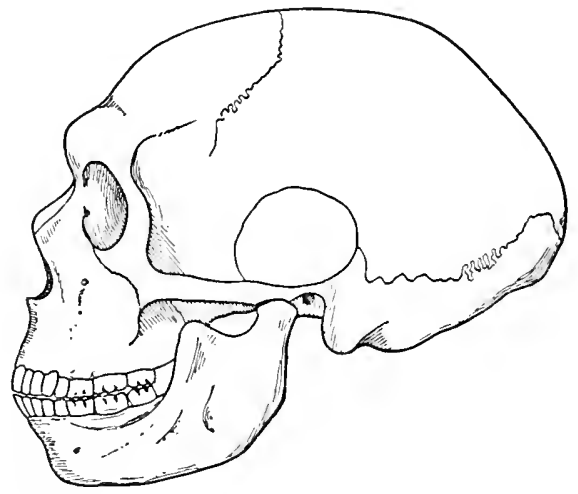

FIG. 39.-Neanderthaloid skull of La Chapelle-aux-Saints (Homo neanderthalcnsis). (From Lull, after Boule.)

Their long depressed skulls had very strong brow-ridges; their lower jaws, of brutal depth and solidity, sloped away from the teeth downwards and backwards in consequence of the absence of that especially characteristic feature of the higher type of man, the chin prominence."

Subsequently several more specimens have come to light, at Spy in Belgium, at Krapina in Croatia, at Le Moustier, La Chapelle-auxSaints and La Ferrassie in France, and at Gibraltar, which, while differing in various details, effectually serve to establish the race, whose main characteristics are: Heary, overhanging brows, retreating forehead, long upper lip; jaw less powerful than that of the Heidelberg man but very thick and massive; chin generally strongly receding but in process of forming; dentition extraordinarily massive in the La Chapelle specimen, whereas in those of Spy the teeth are small. The skull in many characteristics is nearer to the anthropoids than to modern man.

The brain is large and its volume is surely human, but the proportions are again less like those of recent man than like the anthropoids. The chest is large and robust, the shoulders broad, and 
the hand large, but the lingers are redatively short, he thumb lacking the range of motement wen in molem nam. The linee was somewhat bent, the leg powerful, with a short slin and chmsy foot, clearly

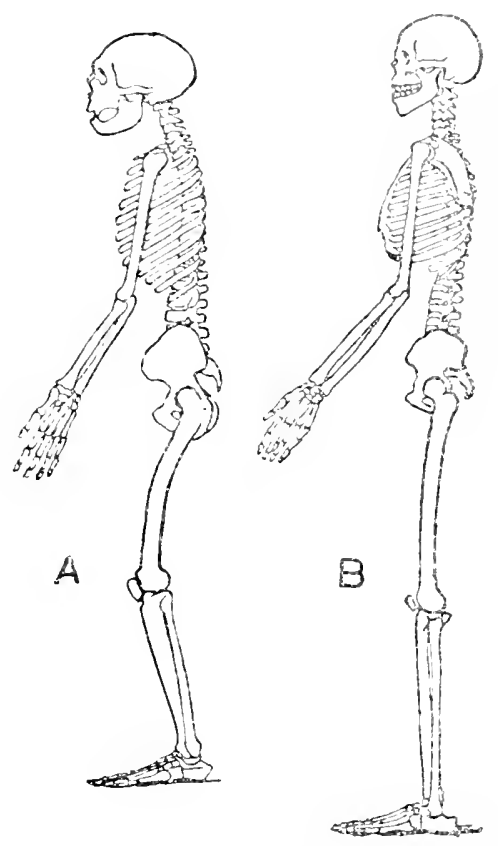

FIc.39.-Skcicton of Nemerther man. A, Bumo menhe rhatists. comfared with that of a living native

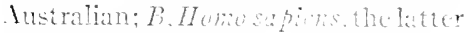

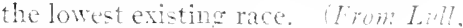
ufterlloodatiti) worked fints. This can have but one interpretatjun, the awaliening within this ancient type of the instinctive ljelief in immortality:

Piltown man. - In IOI 2 was anounced the discotery of a very ancient man from the Thimes gravels at Piltdown, Sussex, England. Here again the skull was injured ant party lost, so that the question of its proper restoration has jecn hic subject of consilieable controversy. The material consists of portions of the cranial walls, nasal bones, a canine tookh, and part of a lower faw. The brain-case in this instance is typically human, excet for the remartaljy thick cranial walls. The forehead is high and lacks the superorbital rilges of Neanderthal man and Pithecunhropus. While the stull is of com- 
paratively high human type, the associated jaw and canine tooth clearly are not, and some difficulty was met in explaining their evolutionary discrepancy. That has apparently been answered, however, by the conclusion that the association of the material is purely accidental and that the jaw not only does not belong with the skull, but that it is not even human but is that of a fossil chimpanzee. That being the case, there seems to be no reason for the exclusion of the Piltdown nan, who has been named Eoanthropus dawsoni, from the direct line of human ancestry. The specimen is not, perhaps, so surely dated as are those of the other European races, but it is associated with a warm-climate fauna and is generally considered to belong to the Third Interglacial stage-from 100,000 to 150,000 years old, and hence vastly more ancient than the more primitive Homo neanderthalcnsis. (See Fig. 36, B.)

Crô-Magnon man.- - The original finds of the men of the CrôMagnon race, Homo sapiens, were made at Gower, Wales, and at Aurignac, France. In the latter place seventeen skeletons came to light in 1852 , but were buried in the village cemetery and thus lost to science, and not until I869, when five more skeletons were discovered at Crô-Magnon, France, was the race established. These individuals, an old man, two young men, a woman and a child, are thus the types of the race. This magnificent race is thus characterized:

Skull large but narrow, with a broad face, hence disharmonic. Facial angle equalling the highest type of Homo sapiens. Jaw thick and strong, with a narrow but very prominent chin. Forehead high and orbital ridges reduced. Brain not only of ligh type but very large, that of the women exceeding the average male of to-day.

The stature of the old man was 6 feet 4.5 inches; the average for males being 6 feet $\mathrm{r} .5$ inches, for women 5 feet 5 inches, a great disparity. The lower segments of the limbs were long, in contrast with the Neanderthal type, hence the men of Crô-Magnon were swiftfooted, while those of Neanderthal were slow. Osborn says: "The wide, short face, the extremely prominent cheekbones, the spread of the palate and a tendency of the upper cutting teeth and incisors to project forward, and the narrow, pointed chin recall a facial type which is best seen to-day in tribes living in Asia to the north and to the south of the Himalayas. As regards their stature the Crô-Magnon race recall the Sikhs living to the south of the Himalayas. In the disharmonic proportions of the face, that is, the combination of broad cheekbones and narrow skull, they resemble the Eskimo. The 
sum of the Crô-Magnon characters is certainly Asiatic rather than African, whereas in the Grimaldis (of which specimens have been founci in association with Crô-Mlagnons at the Grotte des Enfants, Mentone) the sum of the characters is decidedly negroid or African."

The Crô-Magnons again show by their elaborate burial customs how old and well founded is the belief in life after death. They are supposed to be the people who left on the walls of the caverns of France and Spain the marvelous examples of Upper Palaeolithic art of which Professor Osborn's book gives so adequate a description. They lived for a while contemporaneously with the mon of Neanderthal and may have contributed somewhat to the final extinction of the latter. In the course of time, however, they too declined, although to this day survivors of the race may be seen in Dordogne, at Landes, near the Garonne in Southern France, and at Lannion in Brittany. Osborn says:

The decline of the Crô-Magnons, with their artistic culture, "may have been partly due to environmental causes and the abandonment of their vigorous nomadic mode of life, or it may be that they had reached the end of a long cycle of psychic development. . . . We know as a parallel that in the history of many civilized races a period of great artistic and industrial development may be followed by a period of stagnation and decline without any apparent environmental cause."

Europe was repopulated after Crô-Magnon decline by later invaders from the Asiatic realm, the so-called Mediterranean narrowheaded and the Alpine broad-haded types, etc., probably differentiated in Asia in early Palaeolithic times. The repopulation took place in the Upper Palacolithic.

\section{EVIDENCES OF HUMAN ANTIQUTTY}

Great variation.-These, briefly summarized, are, first, great variation. If man is monophyletic, that is, derived from a single prchuman species, and there is no reason to believe otherwise, he must be old, for while the adaptations to ground-dwelling after the descent from the trees were doubtless relatively rapidly acquired, the differentiation into the various races, due perhaps largely to climatic influences rather than to any notable environmental change, must have been slowly attained. As corroborative evidence we have but to point to the mural paintings on Egyptian monuments, dating back 
several thousand years, in which are depicted the Ethiopian, Caucasian, and the like, which are in some instances striking likenesses of the present-day Egyptians.

Universal distribution is, in animals, another mark of antiquity: in man, it is probably less so because of his greater intelligence. And yet before transportation had become a science man's spread over land and sea was extremely slow.

High intelligence as compared with that of the anthropoids is also a mark of antiquity, for the brain, especially the type of brain found in the higher human races, must have been very slow of development. Our study of fossil man shows this.

Communal life, division of labor and all of the complicated interactions which it brings about, and the development of law and religions all have taken time. When we realize that Babylonian texts, twice as remote as the patriarch Abraham, give evidence of highly perfect laws and of a civilization which must have antedated their production by centuries, we gain another yet more emphatic impression of human antiquity. Add to all this the palaeontological evidence of man's association with various genera and numerous successive species of prehistoric animals of which he alone survives, and the evidence is complete.

\section{FUTURE OF HUMANITY}

Because of his intelligence and communal co-operation man is no longer subject to the laws which govern the adaptation of animals to their environment. Osborn's law of adaptive radiation, which, as we have seen, applies equally well to the insects, reptiles, and mammals, fails in its application to mankind; and yet man has become as thoroughly adapted to speed, fight, to the fossorial and aquatic as they; but his adaptation is artificial and to a very small extent only affects his physical frame, while theirs is natural and the stamp of environment is deeply impressed upon the organism.

Man's physical evolution has virtually ceased, but in so far as any change is being effected, it is largely retrogressive. Such changes are: Reduction of hair and teeth, and of hand skill; and dulling of the senses of sight, smell, and hearing upon which active creatures depend so largely for safety. That sort of charity which fosters the physically, mentally, and morally feeble, and is thus contrary to the law of natural selection, must also in the long run have an adverse effect upon the race. 
Man is hardly as yet subject to Malthus' law, for while he is increasing more rapidly than any other animal, owing largely to the care of the young which makes the expectation of life of the new-born relatively very high, his migratory ability, but above all his intelligence, save him from the application of the law. A single new discovery such as that of electricity may increase his food supply and other life necessities several fold. His future evolution, in so far as it is progressive, will be mental and spiritual rather than physical, and as such will be the logical conclusion of the marvelous results of organic evolution.

\section{Sinanthropus pekincusis}

A remarkable new discovery has come to light during the last few years and rleserves to be added to the foregoing account by Professor Lull: the discovery of Pekin man, Sinauthropus pekinensis. Next to Pithecanthropus in the fossil series of primitive man, and only a stage more atvanced, is this newly discovered genus. A few years ago, Professor Davidson Black found some fossil teeth near Pekin, China. which, though distinetively human, were different enough from any others known to be assigned to a new crenus of man. Search for further remains in the same neighborhoor brought to light two lower jaws containing the kind of teeth discovered ly Hack. The investigation was climaxed a little later when the Chinese anthropolngist, IV. C. Pei, unearthed in the same neighborhood a complete cranium. At last reports, collectors had brought in parts of skeletons of at least ten individuals. While Sinunthropus is more like Pithecanthropus than any other extinct genus of man, it is a more advanced type and helps materially to bridge the gap between Pithecunthropus and the higher human genera. At this writing further details about this new genus would be inappropriate, since investigations upon it are still in progress. 


\section{CHAPTER XII}

\section{EVIDENCES FROM GEOGRAPHIC DISTRIBUTION}

\section{PRINCIPLES OF GEOGRAPHIC DISTRIBUTION}

Just as palaeontology may be said to be a study of the vertical distribution (distribution in time) of organisms, so geographic distribution may be called a study of the horizontal distribution of organisms, on the earth's surface at any given time (spatial distribution). We are chiefly to be concerned with the present spatial distribution of animal and plant species, but equally interesting studies have been and still may be made of the horizontal or contemporaneous existence of extinct forms. Much new knowledge has been gained by combining the data of palaeontology with those of geographic disiribution. In fact, neither field can be studied profitably without recourse to the other. This fact was clearly perceived by J. A. Thomson in his little manual on Evolution when he combined the two types of evidence in one chapter under the title "Evidences of Evolution from Explorer and Palaeontologist."

It was a consideration of the present and of the past distribution of Edentates that led Charles Darwin to his first clear concept of descent with modification. In his voyage on the "Beagle" he found that present-day Edentates (armadillos, sloths, anteaters), a very peculiar group of archaic mammals, are practically confined to South America. When he also found that the only fossil Edentates, resembling but also differing from the existing types, are also confined to South America, he easily arrived at the only inference permitted by the facts: that the present Edentates are the modified descendants of the Edentates of the past.

The following quotations from both an older and a recent writer will give the reader a clear idea of the ways in which the general facts of geographic distribution bear witness to the truth of the evolutionary principle.

"The theory," says Wallace," "which we may now take as established-that all the existing forms of life have been derived from other forms by a natural process of descent with modification, and that this same process has been in action during past geological time-should

${ }^{1}$ From A. R. Wallace, Durwinism (r889). Used by special permission of the publishers, The Macmillan Company. 
enable us to give a rational account not only of the peculiarities of form and structure presented by animals and plants, but also of their grouping together in certain areas, and their general clistribution over the earth's surface.

"In the absence of any exact knowledge of the facts of distribution, a student of the theory of evolution might naturally anticipate that all groups of allied organisms would be found in the same region, and that, as he travelled farther and farther from any given centre, the forms of life would differ more and more from those which prevailed at the starting-point, till, in the remotest regions to which he could penetrate, he would find an entirely new assemblage of animals and plants, altogether unlike those with which he was familiar. He would also anticipate that diversities of climate would always be associated with a corresponding diversity in the forms of life.

"Now these anticipations are to a considerable extent justified. Remoteness on the earth's surface is usually an indication of diversity' in the fauna and flora, while strongly contrasted climates are always accompanied by a considerable contrast in the forms of life. But this correspondence is by no means exact or proportionate, and the converse propositions are often quite untrue. Countries which are near to each other of ten differ radically in their animal and vegetable productions; while similarity of climate, together with moderate geographical proximity, are often accompanied by marked diversities in the prevailing forms of life. Again, while many groups of animals-genera, families, and sometimes even orders-are confinerl to limited regions, most of the families, many genera, and even some species are found in every part of the earth. An enumeration of a few of these anomalies will better illustrate the nature of the problem we have to solve.

"As examples of extreme diversity, notwithstanding geographical proxinity, we may adduce Madagascar and Africa, whose animal and vegetable productions are far less alike than are those of Great Britain and Japan at the remotest extremities of the great northern continent; while an equal, or perhaps even a still greater, diversity exists between Australia and New Zealand. On the other hand, Northern Africa and South Europe, though separated by the Mediterranean Sea, have faunas and floras which do not differ from each other more than do the various countries of Europe. As a proof that similarity of climate and general adaptability have had but a small part in determining the forms of life in each country, we have the fact of the enormous increase 
of rabbits and pigs in Australia and New Zealand, of horses and cat tle in South America, and of the common sparrow in North America, though in none of these cases are the animals natives of the countries in which they thrive so well. And lastly, in illustration of the fact that allied forms are not always found in adjacent regions, we have the tapirs, which are found only on opposite sides of the globe, in tropical America and the Malayan Islands; the camels of the Asiatic deserts, whose nearest allies are the llamas and alpacas of the Andes; and the marsupials, only found in Australia and on the opposite side of the globe in America. Yet, again, although mammalia may be said to be universally distributed over the globe, being found abundantly on all the continents and on a great many of the larger islands, yet they are entirely wanting in New Zealand, and in a considerable number of other islands which are, nevertheless, perfectly able to support them when introduced.

"Now most of these difficulties can be solved by means of wellknown geographical and geological facts. When the productions of remote countries resemble each other, there is almost always continuity of land with similarity of climate between them. When adjacent countries differ greatly in their productions, we find them separated by a sea or strait whose great depth is an indication of its antiquity or permanence. When a group of animals inhabits two countries or regions separater by wide oceans, it is found that in past geological times the same group was much more widely distributed, and may have reached the countries it inhabits from an intermediate region in which it is now extinct. We know, also, that countries now united by land were divided by arms of the sea at a not very remote epoch, while there is good reason to believe that others now entirely isolated by a broad expanse of sea were formerly united and formed a single land area. There is also another important factor to be taken account of in considering how animals and plants have acquired their present peculiarities of distribution,-changes of climate. We know that quite recently a glacial epoch extended over much of what are now the temperate regions of the northern hemisphere, and that consequently the organisms which inhabit those parts must be, comparatively speaking, recent immigrants from more southern lands. But it is a yet more important fact that, down to middle Tertiary times at all events, an equable temperate climate, with a luxuriant vegetation, extended to far within the Arctic circle, over what are now barren wastes, covered for ten months of the year with snow and ice. The 
Arctic zone has, therefore, been in past times capable of supporting almost all of the forms of life of our temperate regions; and we must take account of this condition of things whenever we have to speculate on the possible migration of organisms between the old and new continents."

"Many of the facts of distribution," says Shull, "are capable of interpretation by the assumption that evolution has operated with the other factors. If each kind of animal has arisen from a pre-existing kind, then each group of related animals must have had an ancestral form, and if the component parts of the groups are widespread the range of the ancestral form may be considered to be the center of dispersal of the group. The facts of distribution can apparently be interpreted only on this basis.

"Accepting evolution, along with the other factors which can be recognized, the method of distribution is generally conceived to be as follows. The ancestral form tends to spread in all directions. In some directions it is limited by unfavourable conditions either throughout its life or for some time. In other directions it extends its range. Anywhere within its range new types of individuals may arise through the process of evolution. These new types may be fitted to occupy new regions, and if they are formed near the limits of the range they may find opportunity to spread into areas which are inaccessible to the unaltered nembers of the species. Thus may arise recognizably distinct forms coincident in range with certain environmental conditions. If particular forms, or the individuals of a single form, are accidentally (or possibly by sporadic migration) transferred across barriers the distribution of the group becomes discontinuous. If rhese processes have been going on for a long time, that is, if the common ancestors of a group of forms existed long ago, the range may have had time to become very extensive, or its discontinuity very marked. If, contrariwise, the ancestors were comparatively recent, the range is likely to be much smaller. For this reason, groups that have diverged far enough to have attained the rank of families are on the whole more widespread than those so nearly allied as to be considered genera. Should the environment become altered within a given range, the occupying form might be driven from it or destroyed.

- From A. F. Shul!, Principles of Animal Biology (copyright ro2o). Used b special permission of the publishers, The McGraw-Hill Book Company. 
If the environment in a region adjoining a range should change in a favourable manner, the range might be extended at that point without any alteration on the part of the animals.

"The distribution of animals is inferred to be in harmony with this method, which involves, it will be noted, the factors of migration, evolution, physiological and morphological dependence upon the environment, the diversity and changeableness of the earth's surface, and extinction; and in this manner are explained the differences in geographical position, differences in size of range, differences in the continuity of range and the fact that ranges are at first continuous, differences in physical and biological conditions which characterize the ranges of different forms, and the geographical proximity of apparently related forms."

\section{SOME OF THE MORE SIGNIFICANT FACTS ABOUT THE} DISTRIBUTION OF ANIMALS

THE FAUNA OF OCEANIC ISLANDS

GEORGE JOHN ROMANES

Turning now from aquatic organisms to terrestrial, the body of facts from which to draw is so large, that I think the space at my disposal may be best utilized by confining attention to a single division of them-that, namely, which is furnished by the zoölogical study of oceanic islands.

In the comparatively limited-but in itself extensive-class of facts thus presented, we have a particularly fair and cogent test as between the alternative theories of evolution and creation. For where we meet with a volcanic island, hundreds of miles from any other land, and rising abruptly from an ocean of enormous depth, we may be quite sure that such an island can never have formed part of a now submerged continent. In other words, we may be quite sure that it always has been what it now is-an oceanic peak, separated from all other land by hundreds of miles of sea, and therefore an area supplied by nature for the purpose, as it were, of testing the rival theories of creation and evolution. For, let us ask, upon these tiny insular specks of land what kind of life should we expect to find? To this question the theories of special creation and of gradual evolution would agree in giving the same answer up to a certain point. For both theories would agree in supposing that these islands would, at all

× From G. J. Romanes, Darwin and after Darwin (copyright 1892). Used by special permission of The Open Court Publishing Company. 
events in large part, derive their inhabitants from accidental or occasional arrivals of wind-blown or water-floated organisms from other countries-especially, of course, from the countries least remote. But, after agreeing upon this point, the two theories must part company in their anticipations. The special-creation theory can have no reason to suppose that a small volcanic island in the midst of a great ocean should be chosen as the theatre of any extraordinary creative activity, or for any particularly rich manufacture of peculiar species to be found nowhere else in the world. On the other hand, the evolution theory would expect to find that such habitats are stocked with more or less peculiar species. For it would expect that when any organisms chanced to reach a wholly isolated refuge of this kind, their descendants should forthwith have started upon an independent course of evolutionary history. Protected from intercrossing with any members of their parent species elsewhere, and exposed to considerable changes in their conditions of life, it would indeed be fatal to the general theory of evolution if these descendants, during the course of many generations, were not to undergo appreciable change. It has happened on two or three occasions that European rats have been accidentally imported by ships upon some of these islands, and even already it is observed that their descendants have undergone a slight change of appearance, so as to constitute them what naturalists call local varieties. The change, of course, is but slight, because the time allowed for it has been so short. But the longer the time that a colony of a species is thus completely isolated under changed conditions of life the greater, according to the evolution theory, should we expect the change to become. Therefore, in all cases where we happen to know, from independent evidence of a geological kind, that an oceanic island is of very ancient formation, the evolution theory would expect to encounter a great wealth of peculiar species. On the other hand, as I have just observed, the special-creation theory can have no reason to suppose that there should be any correlation between the age of an oceanic island and the number of peculiar species which it may be found to contain.

Therefore, having considered the principles of geographical distribution from the widest or most general point of view, we shall pass to the opposite extreme, and consider exhaustively, or in the utmost possible detail, the facts of such distribution where the conditions are best suited to this purpose- that is, as I have already said, upon cceanic islands, which may be metaphorira $\eta_{v}$ regarded as having been 
formed by nature for the particular purpose of supplying naturalists with a crucial test between the theories of creation and evolution. The material upon which my analysis is to be based will be derived from the most recent works upon geographical distribution-especially from the magnificent contributions to this department of science which we owe to the labours of Mr. Wallace. Indeed, all that follows may be regarded as a condensed filtrate of the facts which he has collected. Even as thus restricted, however, our subject matter would be too extensive to be dealt with on the present occasion, were we to attempt an exhaustive analysis of the floras and faunas of all oceanic islands upon the face of the globe. Therefore, what I propose to do is to select for such exhaustive analysis a few of what may be termed the most oceanic of oceanic islands-that is to say, those oceanic islands which are most widely separated from mainlands, and which, therefore, furnish the most unquestionable of test cases as between the theories of special creation and genetic descent.

Azores.-A group of volcanic islands, nine in number, about 900 miles from the coast of Portugal, and surrounded by ocean depths of I, 800 to 2,500 fathoms. There is geological evidence that the origin of the group dates back at least as far as Miocene times. There is a total absence of all terrestrial Vertebrata, other than those which are known to have been introduced by man. Flying aninals, on the other hand, are abundant: namely, 53 species of birds, one species of bat, a few species of butterflies, moths and hymenoptera, with 74 species of indigenous beetles. All these animals are unmodified European species, with the exception of one bird and many of the beetles. Of the 74 indigenous species of the latter, 36 are not found in Europe; but 19 are natives of Madeira or the Canaries, and 3 are American, doubtless transplanted by drift-wood. The remaining I4 species occur nowhere else in the world, though for the most part they are allied to other European species. There are 69 known species of land-shells, of which 37 are European, and 32 peculiar, though all allied to European forms. Lastly, there are 480 known species of plants of which 40 are peculiar, though allied to European species.

Bermudas.-A small volcanic group of islands, 700 miles from North Carolina. Athough there are about roo islands in the group, their total area does not exceed 50 square miles. The group is surrounded by water varying in depth from 2,500 to 3,800 fathoms. The 
only terrestrial Vertebrate (unless the rats and mice are indigenous) is a lizard allied to an American form, but specifically distinct from it, and therefore a solitary species which does not occur anywhere else in the world. None of the birds or bats are peculiar, any more than in the case of the Azores; but, as in that case, a large percentage of the land-shells are so-namely, at least one quarter of the whole. Neither the botany nor the entomology of this group has been worked out; but I have said enough to show how remarkably parallel are the cases of these two volcanic groups of islands situated in different hemispheres but at about the same distance from large continents. In both there is an extraordinary paucity of terrestrial Vertebrata, and of any peculiar species of bird or beast. On the other hand, there is in both a marvellous wealth of peculiar species of insects and land-shells. Now these correlations are all abundantly intelligible. It is a difficult matter for any terrestrial animal to cross 900 , or even 700 miles of ocean: therefore only one lizard has succeeded in doing so in one of the two parallel cases; and living cut off from intercrossing with its parent form, the descendants of that lizard have become modified so as to constitute a peculiar species. But it is more easy for large flying animals to cross those distances of ocean: consequently, there is only one instance of a peculiar species of bird or bat-namely, a bull-finch in the Azores, which, being a small land-bird, is not likely ever to have had any other visitors from its original parent species coming over from Europe to keep up the original breed. Lastly, it is very much more easy for insects and land-mollusca to be conveyed to such islands by wind and floating timber than it is for terrestrial mammals, or even than it is for small birds and bats; but yet such means of transit are not sufficiently sure to admit of much recruiting from the mainland for the purpose of keeping up the specific types. Consequently, the insects and the land-shells present a much greater proportion of peculiar species-namely, one half and one fourth of the land-shells in the one case, and one eighth of the beetles in the other. All these correlations, I say, are abundantly intelligible on the theory of evolution; but who shall explain, on the opposite theory, why orders of beetles and land-moilusca should have been chosen from among allother animals for such superabundant creation on oceanic islands, so that in the Azores alone we find no less than 32 of the one and 14 of the other? And, in this connection, I may again allude to the peculiar species of beetles in the island of Madeira. Here there are an enormous number of peculiar species, though they are nearly all related to, 
or included under the same genera, as beetles on the neighboring continent. Now, as we have previously seen, no less than 200 of these species have lost the use of their wings. Evolutionists explain this remarkable fact by their general laws of degeneration under disuse, and the operation of natural selection, as will be shown later on; but it is not so easy for special creationists to explain why this enormous number of peculiar species of beetles should have been deposited on Madeira, all allied to beetles on the nearest continent, and nearly all deprived of the use of their wings. And similarly, of course, with all the peculiar species of the Bermudas and the Azores. For who will explain, on the theory of independent creation, why all the peculiar species, both of animals and plants, which occur on the Bermudas should so unmistakably present American affinities, while those which occur on the Azores no less unmistakably present European affinities? But to proceed to other, and still more remarkable, cases.

The Galapagos Islands. - This archipelago is of volcanic origin, situated under the equator between 500 and 600 miles from the West Coast of South America. The depth of the ocean around them varies from 2,000 to 3,000 fathoms or more. This group is of peculiar interest, from the fact that it was the study of its fauna which first suggested to Darwin's mind the theory of evolution. I will, therefore, begin by quoting a short passage from his writings upon the zoölogical relations of this particular fauna.

"Here almost every product of the land and of the water bears the unmistakable stamp of the American continent. There are twenty-six land birds; of these, twenty-one, or perhaps twenty-three, are ranked as distinct species, and would commonly be assumed to have been here created; yet the close affinity of most of these birds to American species is manifest in every character, in their habits, gestures, and tones of voice. So it is with the other animals, and with a large proportion of the plants, as shown by Dr. Hooker in his admirable Flora of this archipelago. The naturalist, looking at the inhabitants of these volcanic islands in the Pacific, distant several hundred miles from the continent, feels that he is standing on American land. Why should this be so? Why should the species which are supposed to have been created in the Galapagos Archipelago, and nowhere else, bear so plainly the stamp of affinity to those created in America? There is nothing in the conditions of life, in the geological nature of the islands, in their height or climate, or in the proportions in which the several classes are associated together, which closely resembles the 
conditions of the South American coast; in fact, there is a considerable dissimilarity in all these respects. On the other hand, there is a considerabie desree of resemblance in the volcanic nature of the soil, in the climate, height, and size of the islands, between the Galapagos and Cape de Verde Archipelagoes; but what an entire and absolute difference in their inhabitants! The inhabitants of the Cape de Verde Islands are related to those of Africa, like those of the Galapagos to America. Facts such as these admit of no sort of explanation on the ordinary view of independent creation; whereas in the view here maintained it is obvious that the Galapagos Islands would be likely to receive colonists from America, and the Cape de Verde Islands from Africa; such colonists would be liable to modification-the principle of inheritance still betraying their original birthplace."

The following is a synopsis of the fauna and flora of this archipelago, so far as at present known. The only terrestrial vertebrates are two peculiar species of land-tortoise, and one extinct species; five species of lizards, all peculiar - two of them so much so as to constitute a peculiar genus;- and two species of snakes, both closely allied to South American forms. Of birds there are 57 species, of which no less than $3^{\delta}$ are peculiar; and all the non-peculiar species, except one, belong to aquatic tribes. The true land-birds are represented by $3 \mathrm{I}$ species, of which all, except one, are peculiar; while more than half of them go to constitute peculiar genera. Moreover, while they are all unquestionably allied to South American forms, they present a beautiful series of gradations, "from perfect identity with the continental species, to genera so distinct that it is difficult to determine with what forms they are most nearly allied; and it is interesting to note that this diversity luars a distinct relation to the probabilities of, and facilities for, migration to the islands. The excessively abunlant rice-bird, which breeds in Canada, and swarms over the whole United States, migrating to the West Indies and South America, visiting the distant Bermudas almost every year, and extending its range as far as Paraguay, is the only species of land-bird which remains completely unchanged in the Galapagos; and we may therefore conclude that some stragglers of the migrating host reach the islands sufficiently often to lieep up the purity of the breed" [Wallace]. Again, of the thirty peculiar land-birds, it is observable that the more they difier from any other species or genera on the South American continent, the more certainly are they found to have their nearest relations among those South American forms which have the 
more restricted range, and therefore the least likely to have found their way to the islands with any frequency.

The insect fauna of the Galapasos lstauds is scanty, and chieny composed of beetles. These number 35 species, which are nearly all peculiar, and in some cases go to constitute peculiar genera. The same remarks apply to the twenty species of land-shells. Lastly, of the total number of flowering plants (3.32 species) more than one half ( 74 species) are peculiar. It is observable in the case of these peculiar species of plants-as also of the peculiar species of Lirds-that many of them are restricted to single islands. It is also observable that with regard both to the fauna and fora, the Galapagos Islands as a whole are very much richer in peculiar species than either the Azores or Bermudas, notwithstanding that both the latter are considerabiy more remote from the nearest continents. This difference, which at first sight appears to make against the evolutionary interpretation, really tends to confirm it. For the Galapagos Islands are situated in a calm region of the globe, unvisited by those periodic storms and hurricanes which sweep over the North Atlantic, and which every year convey some straggling birds, insects, seeds, etc., to the Azores and Bermudas. Notwithstanding their somewhat greater isolation geographically, therefore, the Azores and Bermudas are really less isolated biologically than are the Galapagos Islands; and hence the less degree of peculiarity on the part of their endemic species. But, on the theory of special creation, it is impossible to understand why there should be any such correlation between the prevalence of gales and a comparative inertness of creative activity. And, as we have seen, it is equally impossible on this theory to understand why there should be a further correlation between the degree of peculiarity on the part of the isolated species, and the degree in which their nearest allies on the mainland are there confined to narrow ranges, and therefore less likely to keep up any biological communication with the islands.

St. Helena.--A small volcanic island, ten miles long by eight wide, situated in mid-ocean, $\mathrm{r}, \mathrm{r}$.0 miles from Africa, and $\mathrm{I}, 800$ from South America. It is very mountainous and rugged, bounded for the most part by precipices, rising from ocean depths of I7,000 feet, to a height above the sea-level of nearly 3,000. When first discovered it was richly clothed with forests; but these were all destroyed by human agency during the 16 th, I 7 th, and I 8 th centuries. The records of civilization present no more lamentalle instance of this kind of destruction. 
Lrom a nercly pecuntiry pint of view the alvolition of these primeval forests las powed an inepualle loss; but from a scientific point of rew the loss is inculculatile. These forests serred to harbour countless forms of life, which exterrled at least from the Wiocene age, and which, having found there an ocem refure, survived as the last remnants of a remote gerburical ench. In those days, as Mr. Wallace ofserves, St. Helena must have formenl a kind of natural nuseum or vivarium of archaic species of all clisses, the interest of which we can now only sumise from the few remants of those remnants, which are - ill left among the more inaccessible portions of the mountain peals ind crater edges. These remants of remunts are as follows:

There is a total absence of all indigerous mamals, reptiles. iresh-water fish, and true land-birds. There is, however, a species of plover, allied to one in South Airica; but it is specifically distinct, and therefore peculiar to the island. The insec life, on the other hand, is abundant. Of beetles, no less than 129 species are believed to be aloriginal, and, with one single excejtion, the whole number are peculior to the island. "But in addition to this large amount of specific peculiarity (perhaps unequalled anywhere else in the world) the beetles of this island are remarkable for their generic isolation, and for the altogether exceptional proportion in which the great divisions of the order are represented. The species belong to 39 renera, of which no less than 25 are peculiar to the islund; and many of these are such isolated forms that is is impossible to find their allies in any particular country" [Mallace]. More than tro-thirds of all the species belong to one group of weerils - a circumstance which serves to explain the great wealth of leelle-population, the weevils reing beetles which live in wood, and St. Helena having been originally a densely wooded island. This circumstance is also in accorlance with the riew that the peculiar insect fami has been in large part evolved from ancestors which reached the island by means of fioating timber; for, of course, no explanation can be suggested why specia! creation of this highly peculiar insect fauna shonid have run so disproportionately into the prodiction of weevils. About two-thirds of the whole number of beetles, or over 80 species, show no close affinity with any existing insects, while the remaining third have some relations, though of ten very remote, with Furopean and Arican forms. That this high degree of pecuiarity is due to hish antiguity is further indicated, wcording to our theory, by the large number of species which some of the types comprise. Thiss, the 54 species of Cossonulae may he 
referred to three types; the II species of Bembidium form a group by themselves; and the Heteromera form two groups. "Now, each of these types may well be descended from a single species, which originally reached the island from some other land; and the great variety of generic and sprecific forms into which some of them have diverged is an indication, and to some extent a measure, of the remoteness of their oriwin" [Wallace]. But, on the counter-supposition that all these r 28 peculiar species were separately created to occupy this particular island, it is surely unaccountable that they should thus present such an arborescence of natural affinities amongst themselves.

Passing over the rest of the insect fauna, which has not yet been sufficiently worked out, we next find that there are only 20 species of indigenous land-shells - which is not surprising when we remember by what enormous reaches of ocean the land is surrounded. Of these 20 species no less than $\mathrm{I}_{3}$ have become extinct, three are allied to European species, while the rest are so highly peculiar as to have no near allies in any other part of the globe. So that the land-shells tell exactly the same story as the insects.

Lastly, the plants likewise tell the same story. The truly indigenous flowering plants are about 50 in number, besides 26 ferns. Forty of the former and ten of the latter are peculiar to the island, and, as Sir Joseph Looker tells us, "cannot be regarded as very close specific allies of any other plants at all." Seventeen of them belong to peculiar genera, and the others all differ so markedly as species from their congeners, that not one comes under the category of being an insular form of a continental species. So that with respect to its plants, no less than with respect to its animals, we find that the island of St. Helena constitutes a little world of unique species, allied among themselves, but diverging so much from all other known forms that in many cases they constitute unique genera.

Sandwich Isiands. - These are an extensive group of islands, larger than any we have hitherto considered-the largest of the group being about the size of Devonshire. The entire archipelago is volcanic, with mountains rising to a height of nearly 44,000 feet. The group is situated in the middle of the North Pacific, at a distance of considerably over 2,000 miles from any other land, and surrounded by enormous ocean depths. The only terrestrial vertebrates are two lizards, one of which constitutes a peculiar genus. There are 24 aquatic birds, five of which are peculiar; four bircls of prey, two of which are peculiar; and Io land-birds, all of which are peculiar. 
Moreover, these 16 land-hirds constitute no less than to peculiar renera, and even one peculiar family of five genera. This is an amount of peculiarity far cxceeding that of any other islands, and, of course, corresponds with the great isolation of this archipelago. The only other animats which have here been carefully studied are the landshells, ant these tell the same story as the birds. For there are no less than 400 species which are all, without any exception, peculiar; while about three-quarters of them go to constitute peculiar genera. Again, of the plants, 620 species are believed to be endemic; and of these $3 i 7$ are peculiar, yielding no less than 39 peculiar genera.

THE FAUNA OF CONTINENTAL ISLANDS-MAD AGASCAR AND NEW ZEALAND'

\section{A. R. WALLACE}

The two exceptions just referred to are Madagascar and New Zealand, and ail the evidence goes to show that in these cases the land connection with the nearest continental area was very remote in time. The extraordinary isolation of the productions of Madagascar-almost all the most characteristic forms of mammalia, birds, and reptiles of Africa being absent from it-renders it certain that it must have been separated from that continent very early in the Tertiary, if not as far back as the latter part of the Secondary period; and this extreme antiquity is indicated by a depth of considerably more than a thousand fathoms in the Nozambique Channel, though this deep portion is less than a huncired miles wide between the Comoro Islands and the mainland. Madagascar is the only island on the globe with a fairly rich mammalian fauna which is separated from a continent by a depth greater than a thousand fathoms; and no other island presents so m.ıny peculiarities in these animals, or has preserved so many lowly organised and archaic forms. The exceptional character of its productions agrees exactly with its exceptional isolation by means of a very deep arm of the sea.

New Zealand possesses no known mammals and only a single species of batrachian; but its geological structure is perfectly continental. There is also much evidence that it does possess one mammal, although no specimens have been yet obtained. Its reptiles and birds are highly peculiar and more numerous than in any truly oceanic island. Now the sea which directly separates New Zealand from Australia is more than 2,000 fathoms deep, but in a north-west direc-

x From A. R. Wallace, Daruvinism (copyright I889). Used by special permission of the publishers, The Macmillan Company. 
tion there is an extensive bank under I,000 fathoms, extending to and including Lord Howe's Island, while north of this are other banks of the same depth, approaching towards a submarine extension of Queensland on the one hand, and New Caledonia on the other, and altogether suggestive of a land union with Australia at some very remote period. Now the peculiar relations of the New Zealand fauna and flora with those of Australia and of the tropical Pacific Islands to the northward indicate such a connection, probably during the Cretaceous period; and here, again, we have the exceptional depth of the dividing sea and the form of the ocean bottom according well with the altogether exceptional isolation of New Zealand, an isolation which has been held by some naturalists to be great enough to justify its claim to be one of the primary Zoölogical Regions.

\section{THE DISTRIBUTION OF MARSUPIAJ'S}

\section{A. R. WALLACE}

This singular and lowly organised type of mammals constitutes almost the sole representative of the class in Australia and New Guinea, while it is entirely unknown in Asia, Africa, or Europe. It reappears in America, where several species of opossums are found; and it was long thought necessary to postulate a direct southern connection of these distant countries, in order to account for this curious fact of distribution. When, however, we look to what is known of the geological history of the marsupials the difficulty vanishes. In the Upper Eocene deposits of Western Europe the remains of several animals closely allied to the American opossums have been found; and as, at this period, a very mild climate prevailed far up into the arctic regions, there is no difficulty in supposing that the ancestors of the group entered America from Europe or Northern Asia during early Tertiary times.

But we must go much further back for the origin of the Australian marsupials. All the chief types of the higher mammalia were in existence in the Eocene, if not in the preceding Cretaceous period, and as we find none of these in Australia, that country must have been finally separated from the Asiatic continent during the Secondary or Mesozoic period. Now during that period, in the Upper and the Lower Oölite and in the still older Trias, the jaw-bones of numerous small mammalia have been found, forming eight distinct genera, which

Irom A. R. Wallace, Darwinism (copyright I889). Used by special permission of the publishers, The Macmillan Company. 
are believed to have been either marsupials or some allied lowly forms. In North America also, in beds of the Jurassic and Triassic formations, the remains of an equally great variety of these small mamnalia have been discovered; and from the examination of more than sixty specimens, belonging to at least six distinct genera, Professor Narsh is of the opinion that they represent a generalised type, from which the more specialised marsupials and insectivora were developed.

From the fact that very similar mammals occur both in Europe and America at corresponding periods, and in leats which represent ia long succession of geological time, and that during the whole of this time no frasments of any higher forms have been discovered, it seems probable that both the northern continents (or the larger portion of their area) were then inhabited by no other manmalia than these, with perhaps other equally low types. It was, probahly, not later than the Jurassic age when some of these primitive marsupials were able to enter Australia, where they have sirce remained almost completely isolated; and, being free from the competition of higher forms, they have developed into the great variety of types we row behold there. These occupy the place, and have to some extent accuired the form and structure of distinct orders of the higher mammals-the rodents, the irsectivora, and the carnivora-while still preserving the essential characteristics and lowly organisation of the marsupials. At a much later period-probably in late Tertiary times-the ancestors of the various species of rats and mice which now abound in Australia, and which, with the gerial bats, constitute its only forms of placental mammals, entered the country from some of the adjacent islands. For this purpose a land connection was not necessary, as these small creatures might easily be conveyed among the branches or in the crevices of trees uprooted by foods and carried down to the sea, and then floated to a shore many miles distant. That no actual land connection with, or very close approximation to, an Asiatic island had occurred in recent times, is suficiently proved by the fact that no squirrel, pir, civet, or other widespread mammal of the Easteri hemisphere has been able to reach the Australian continent.

THE DISTRIBLTION OF BLRDS

A. R. WALLACE

These vary much in their powers of flight, and their capability of traversing wide seas and oceans. Many stimming and wading birds

I From A. R. Wallace, Darwinism (copyright $x 8 g x$ ). I'sed by special permission of the publishers, The Macmillan Company. 
can continue long on the wing, fly swiftly, and have, besides, the power of resting safely on the surface of the water. These would hardly be limited ly any width of ocean, except for the need of food; and many of them, as the gulls, petrels, and divers, find abundance of food on the surface of the sea itself. These groups have a wide distribution across the oceans; while waders-especially plovers, sandpipers, snipes, and herons-are equally cosmopolitan, travelling along the coasts of all the continents, and across the narrow seas which separate them. Many of these birds seem unaffected by climate, and as the organisms on which they feed are especially abundant on arctic, temperate, and tropical shores, there is hardly any limit to the range even of some of the species.

Land-birds are much more restricted in their range, owing to their usually limited powers of flight, their inability to rest on the surface of the sea or to obtain food from it, and their greater specialisation, which renders them less able to maintain themselves in the new countries they may occasionally reach. Many of them are adapted to live only in woods, or in marshes, or in deserts; they need particular kinds of food or a limited range of temperature; and they are adapted to cope only with the special enemies or the particular group of competitors among which they have been developed. Such birds as these may pass again and again to a new country, but are never able to establish themselves in it; and it is this organic barrier, as it is termed, rather than any physical barrier, which, in many cases, determines the presence of a species in one area and its absence from another. We must always remember, therefore, that, although the presence of a species in a remote oceanic island clearly proves that its ancestors must at one time have found their way there, the absence of a species does not prove the contrary, since it also may have reached the island, but have been unable to maintain itself, owing to the inorganic or organic conditions not being suitable to it. This general principle applies to all classes of organisms, and there are many striking illustrations of it. In the Azores there are eighteen species of land-birds which are permanent residents, but there are also several others which reach the islands almost every year after great storms, but have never been able to establish themselves. In Bermuda the facts are still more striking, since there are only ten species of resident birds, while no less than twenty other species of land-birds, and more than a hundred species of waders and aquatics are frequent visitors, often in great numbers, but are never able to establish themselves. 
SUMMARY OF MAMMALIAN DISPERSAL

HANS GADOW

Australia as the earliest great mass of land permanently severed from the rest is in almost undisturbed possession of the lowest mammals. It is the sole refuge of the monotremes, and the marsupials have narrowly escaped a similar fate. They take us to the next independent continent, South America. This had three chances, or epochs, of being stocked with mammals. Within the Cretaceous period it seems to have received its marsupial stock from the north, the progenitors of all modern marsupials. A second influx during the early Tertiary brought edentates and rodents as its first Placentals from Africa, and those queer Ungulates, the Toxodonts and Pyrotheria, unless we prefer to look upon these Eocene extinct orders as truly aboriginal to South America, when this was still continuous with the ancient Brazil-Afro-Indian Gondwanaland. The third and last inroad came once more from the north, when with the close of the Miocene permanent connection with North America was re-established. This brought the modern odd-toed and pair-toed Ungulates, with dogs,s, cats and bears in their wake, and lastly man.

There remains the huge North World. Eurasia and North America have always formed a wide circumpolar ring, which repeatedly broke and joined again. Whatever group of terrestrial creatures was developed in the eastern, Asiatic, half, was sure to turn up in the western, and vice versa.

Lastly, the mysterious African continent. It began originally as the centre of the ancient equatorial South World; it has lost these connections and has become joined to the northland, after many vicissitudes. It is therefore most difficult to apportion its fauna rightly; moreover for fossils it is almost a blank, except Egypt. It must have had some share in the evolution of mammals, like edentates, rodents, insectivores, hyrax, elephants, sirenians and lemurs, all groups with an ancient stamp. But what share it had, against Eurasia, in the development of say ungulates, carnivores, monkeys, we do not know. Not much is likely to have originated in Europe; the elephants, rhinos, hippos, lions and hyaenas were migrants rather from than to Africa, rarely across some Mediterranean bridge, usually by Asia Minor.

The more dominant forms of our present fauna have originated, to use an expression of Darwin's, "in the larger areas and more efficient

'From Hans Gadow, Wanderings of Animals (19 13 ), Cambridge University Press. 
workshops of the north," and the balance is in favour of Asia as the cradle of modern mammals.

Is it an idle dream to think of the future? A survey of the past reveals the vanishing of whole faunas from extensive countries, which were then repeopled by other forms from elsewhere. What has happened before, may happen in times to come. Countless groups, once flourishing, are no more; many others have had their day and are now on the decline, whilst others are flourishing now, are even in the increase and seem to have a future before them. Such favoured assemblies are the toads and frogs, lizards and snakes, Passerine birds and rodents, mostly the small-sized members of their tribes; the days of giants are past. All this has happened in the natural course of events, without the influence of man, who only within most recent times has become the most potent and destructive factor to the ancient faunas of the world.

\section{SUMMARY OF THE ARGUMENT FOR EVOLUTION AS BASED ON GEOGRAPHIC DISTRIBUTION}

On the hypothesis of special creation or on any other hypothesis except evolution that has even been suggested, the extremely intricate patchwork of animal and plant distribition remains an unsolvable picture puzzle, without rhyme or reason. When this puzzle is attacked with the aid of the evolutionary idea, the key to the whole maze is furnished and the difficulties clear up with remarkable ease. The whole hodgepodge makes sense and we can understand many previously irreconcilable facts. In no field does the working hypothesis of evolution work to such advantage as in this field.

On the basis that a species arises at one place, spreads out over large areas, becoming modified as it goes, that new species are formed from old through modification after isolation from the parent-stock, how do the facts of distribution look when examined in detail?

I. Cosmopolitan groups, those with the widest distribution, are those to whom no barriers are sufficient to check migration, e.g., strong fliers, Man, earthworms carried by MIan.

2. Restricted groups are usually those to which barriers are readily set un and are frequently the last remnants of a formerly successful fauna or flora, which continue to survive only in some restricted area where the conditions are ratber more favorable than elsewhere. 
3. The stuly of the diatribution of species belonging to a single genus reveals that the more primitive or generalized species occupy a central position and the most specialized species are at the outer bounclaries of the distributional area.

4. The faunas and floras of continental islands are just what we should expect on the basis that there was at one time a land connection with the nearest continent; that at this time the faunas and floras were the same on both island and continent: hat, later, the continent and island were separated by an impassable harrier of ocean; and that the inhabitants of the two bodies evolver separately.

5. The faunas and floras of oceanic ishnds are likc those of the nearest mainland and are of those types, for the most part, that migh: most readiy have been blown there by the wind or carried on floating cébris.

6. The conclusions arrived at by students of geographic distribution, past and present, as to the existence of former land connections, now broken, are borne out by the independent findings of geologists and geograrhers. 

PARTIL

THE MECHANEM OF EVULETION (GENETICS) 
. 


\section{CHIPTER XII}

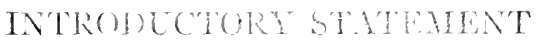

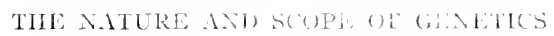

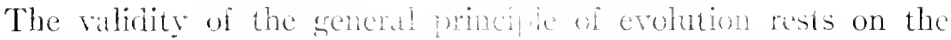
kind of evidence presentert in preving hapters. Folumes could be written giving further evidenes thesus stet. Tery few thoughtful frersons, once confronted with then cintences, fait to be convinced as to the reality of erolutions.

It is one thing to know Uhat evolution has onored and has followed certain courses, but quite another thing to molestand what forces underly the process. I guing porvers inust hate cardses, and it is our purpose in this scction of the cotrsc to present an account of

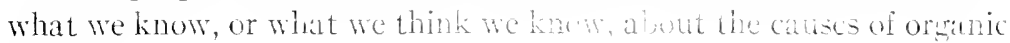
evolution.

Our methor of etudy is one that lepents on the validity of the doctrine of uniformitarianism. Exactly as in the science of geobyg the methor of investigation is that of sulising in detail the changes

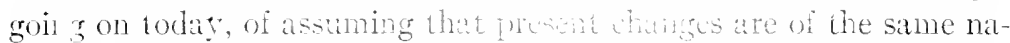
ture as changes in the past, anci that the pat may le inter]reted in terms of what we discover about the ritsuld Thus, long series of generations of rapilly breeting aninds and lanss are studied intensively over periods of ycurs, sume syectes having teen bred for over twenty-five years, or lor at iest seven humel andions, a period equivalent in number of generations to 25000 fars of human life. Hundreds of milions oi individuals have becn janzed in review before the keenly trained eyes of an amy of competut investigators, all on the lookout for the sightest change from the nomal. Any observed change is then Iollowed lhrough subsequent gererations to determine whether it is hereditary and how it afects the success of individuals possessing it. Studies oi this sort, torether with examinations of the

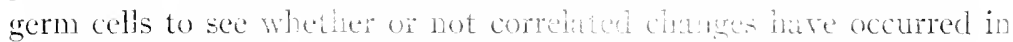
their materiats, and mathematical calcohbons of the rolative frequencies with which difirest thratcters ocen in combination with one another, have led to an madersturling of the anchenisn of erointion far more complete and detaled than angene it decade or so ago could possibly have hoperi to attain.

The experimental and analyical stuly of the jrucesses and mech- 
anisms of evolution is the province of that branch of evolutionary biology known as Gonetics.

Three principal methods of attack upon the problems of genetics are as follows:

a) Experimental breeding.--This method, first carried out systematically by Mendel, consists of breeding together two individuals differing in certain well-defined characters and of determining the ratios in which the contrasting parental characters reappear in successive generations of descendants. Mendel's method has been extremely fruitful and in connection with the second method, that of cytology, has thrown a flood of light on the actual workings of the mechanisms of evolution.

b) Cytology.-This method involves the microscopic study of the germ cells, especially during the period of reproduction. 'The observed changes that go on in connection with sexual reproduction have been found to constitute a mechanism adequate to explain the peculiar hereditary regularities constituting Mendel's laws of heredity. Also it has been found that most aberrations in heredity are associated with correlated aberrations in the mechanism of reproduction. Experimental breeding and cytology have been most intimate and successful collaborators.

c) Statistical analysis.--While experimental breeding and cytology lay stress upon the type of change or the mode of heredity in individuals, statistical methods deal chiefly with group changes and with the characteristics of populations. Often evolutionary trends or group changes, quite undetectable in separate individuals, can be detected by statistical methods. Also, the statistical consequences of a certain type of change in a few or many individuals can be predicted for any given number of generations. While the methods of statistical analysis are as a rule too difficult for any but the expert, they are becoming more and more essential as a part of the technique of genetics.

d) Observations of changes going on in nature.-Attempts are made to discover evidences of changes in nature equivalent to those observed in the laboratory, and there is now considerable evidence favoring the conclusion that laboratory observations are reliable criteria of what takes place in nature.

PREREQUISITES FOR THE STUDY OF GENETICS

In order profitably to pursue the study of genetics, one must first understand the fundamentals of biology in general, for the mechanism 
of evolution is largely within the living organism itself. One must be iamiliar with the units of life: cells, organisms, generations. One must unclerstand the methods of reproduction and the mechanisms of heredity and variation resident in the cellular components of the organism. Also, one must never forget that organisms live and grow and reproduce only if in an appropriate environment and that the enviromment has much to do with the expression of hereditary characters. In addition, the environment acts as a guiding factor, directing the course of evolution along lines of fitness or adaption. The highly varicel character of the environment, moreover, tends to favor a high degree of diversity in organisms and thus to give rise to a vast multiplicity of different types.

In view of all this, it will be necessary for the general student who has had no previous training in biology to learn the fundamentals of this subject before proceeding with the more specific materials of genetics.

\section{THE MECHANISA OF EVOLUTION}

At the beginning of the present century very little was known about the actual mechanism of evolution. We had Darwin's theory of natural selection, Weismann's theory of germinal continuity, and a statistical knowledge of certain aspects of variation and heredity. Something wals known about the rôle of isolation in species-forming, and the general fact of orthogenesis was appreciated. With the rediscovery in I 900 of Mendel's work and the announcement by De Vries of the mutation theory, genetics really began. Thirty odd years of intensive research by hundreds of specialists have contributed so much to our understanding of the workings of evolution that we now consiller that we know something about the main causes of evolution.

Evolution is now looked upon as an extremely complicated process. There is 110 one cause of evolution, as the extreme proponents of natural selection once held; rather, there are many causes, each acting upon and in co-ordination with all the others. The mechanism of evolution is like an intricate jiece of machinery manufacturing a complex product. Each part is geared up with other parts. Some parts are concerned with feeding in the raw materials, others with separating and distributing the raw materials, others with assembling and shaping up) the various parts into something useful and with discarding defective and useless parts, and still others with sorting out the different kinds of products and keeping them in separate lots. 
No man-made mechanism is so intricate as is the mechanism of evolution, for all man-made machines are clesigned to turn out uniform products, while the evolution machine is especially adapted to turn out highly diverse products.

Although we recognize that none of the causal factors of evolution are independent, it makes for clearness of exposition to subdivide the complex machine into five separate factors, each in itself complex enough for further sublivision.

\section{TIIE MAIN CAUSAL FACTORS OF ETOLUTION}

I. Persistence factors.--Under this head are included all agents that make for persistence of type in organisms, resulting in relative constancy of form and function over long periods of time. When characters persist unchanged from generation to generation, they are said to be hereditary. It is part of our plan to find out what parts of the mechanism promote constancy of type. Some of the principal reasons for this constancy are the following:

a) The relative stability of the unit materials of heredity, the genes.

b) The relative constancy of bundles of genes, the clromosomes.

c) The relative constancy and perfection of operation of the mechanism of mitotic cell division, a mechanism that aids in maintaining the constancy of $(a)$ and $(b)$.

d) The relative constancy of the principal factors of the environment over long periols of time.

II. Diversity factors.- "I Iiversity" may be defined as variety without the introduction of anything definitely new. It involves, first the kaleidoscopic recombination of all the various hereditary unit characters without any change in the unit characters themselves, and, second, the almost equally varied expression of characters under the influence of a highly variable and diversified environment.

The chief agent in promoting diversity of combinations is sexual, or gametic, rejroduction. And the specific mechanisms involved are the mechanisms of meiosis and fortilization, which are later to be described in eletail.

The recombinations of unit characters, while apparently random in individual cases, give constant statistical ratios that are known as "Mendelian ratios." Mendel's Laws of heredity in general are, in fact, the laws of the random assortment and recombination of unit characters through the instrumentality of meiosis and fertilization. 
Much of the entless diversty of living lecings is, however, not

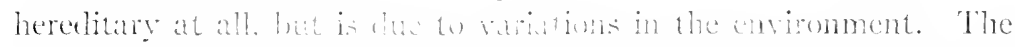

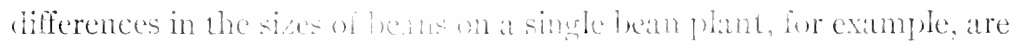
purely envirommental in orizin, as experinents have shown, and not in the lewst herediun?

III. Change factors. - Chathege in contrabl with diversity, involves the introdution of new unit daraters or new gene arrangements.

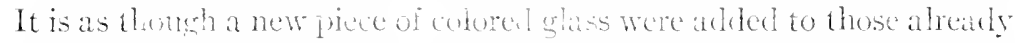
present in the kathilusore, or a piece of a different color sublituterl

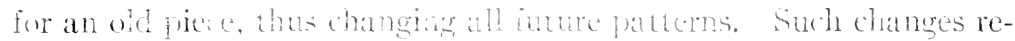
sult from the rare molification of indivituat aences from equally rare changes in the nunber of chromosmes, and from the shifting of groups of genes within a chromusume or from one chromosome to another. The medhanisms involved are:

(a) Gene mutations.

b) Slijs in the regularity of mitwis involving ireqularitis in the relatively constant operatums of heredity. The result is at change in the manler of thmanomes. Sereral kimis of suh irregularitis are known and all are calted chromosomal aberatiens.

c) Breaks in chromosomes, follower lay the rewnion of the broken

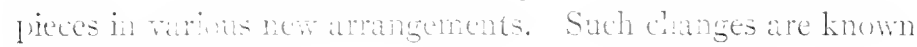
as tratolotitins.

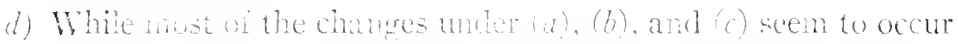
spontaneousty, there in some erifence that they mat have environmental caturs. Fence the envionment ma be the ultimate change factor.

IV. Guiding factors. Exwhtion has heen tore the mest part order-

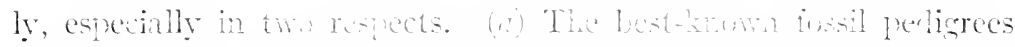

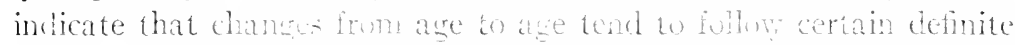
trends. We hare previnuly spoken of this phenomenon as orthoschesis. (b) Evidumary changes have also been, at leatst to a large

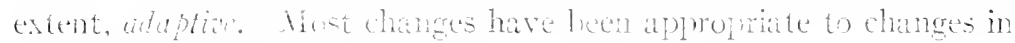
the envirement.

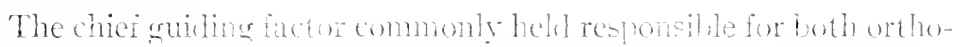

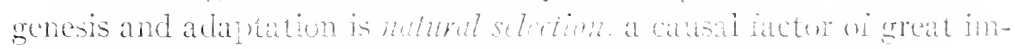
portance that will be dicussed critically in its pwoper pluce.

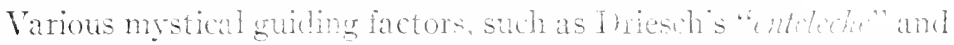

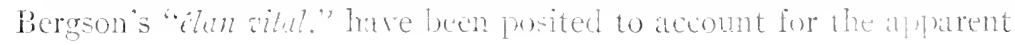


purposiveness of evolution, but there is little evidence for the existence of such factors.

Lamarck's theory of the inheritance of acquircd characters was also designed to explain the adaptive character of cvolutionary change, but there are many reasons for doubting the validity of this theory.

V. Dividing factors.--One of the most striking features of living organisms is their multiplicity of different kinds: phyla, classes, orders, families, grenera, species, and varieties. Evolution has involved the subdivirling of old types into numbers of new ones. The whole process has been one of the branching out into numerous diverging lines of descent. All those agencies that promote the splitting of all old species into two or more new ones are classed as isolation factors. There are many means of isolating portions of a species from other portions of the same species. These may for convenience be called:

a) Geographic isolation.

b) Reproductive isolation.

c) Psychic isolation.

d) Environmental isolation.

In general, any agent that prevents a particular variant of a species from breeding with the more typical members of that species tends to help to establish the variant type and aids in the production of a distinct new variety, species, or genus, depending on the degree of completeness of isolation and the length of time involved.

All of these factors are necessiry agents in bringing about the kind of evolution that we know has occurred. With perfect heredity and no diversity or change factors, the organic workl would be at a standstill. Successive generations would be exact duplicates of one another. Offspring would be exactly like their parents, and no evolution would be possible. The diversity and change factors, without the conserving factor, heredity, would produce nothing but chaos. Two successive generations would be utterly unrelated, offspring would be nothing like their parents, and change would merely run riot. With the heredity, diversity, and change mechanisms operating as they are known to do, but without any guiling factor, living things would be little more than a chaotic collection of monstrosities, unfit and ill assorted. With all the other factors opuating as they are known to do, but with no dividing factor, erolution would proceed along but one front line of advance. There would be no multiplicity of groups, no system of 
branching retationships. Thes it is whious that the factors of erolution are to be conceived of, not as indepentent modanisms, but as interdepentent parts of whe grand merhanism.

It is our purpose to discusin in detail the various component factors of the mechanisn of ewhun atproximately in the order in which ther have been listed in this outline. 


\section{CHAPTER XIV}

\section{THE BIOLOGICAL BACKGROUND OF GENETICS}

\section{R.ACES AND INDIVIDUALS}

Evolution is racial change. In order that a race may change, the individuals comprising the race must in large numbers exhibit changed conditions. One or a few individuals changing in some peculiar way may not at all affect the status of the species as a whole. It is well, then, to remember that true evolutionary changes are mass changes involving whole populations through successive generations. A race or a species is to be looked upon as a vast unit continuous in time and space. The members of a race are all descended from common ancestors and are interbrecding in all sorts of ways. If one should work out a diagram of the genetic relationships of the nembers of a large species, such a diagram of comnecting lines of relationship would constitute an almost solid mass of interlacing lines. An intricately interconnected group of individuals constituting a race is then a true evolutionary unit. Just as cells are the structural units of life, so races are the colutionary units of life. Let us now briefly examine the constitution of a race.

At any given period of time a race consists of a large group of individuals. Some of these are related as parents and offspring, others as brothers and sisters, others as cousins of varying grades; and all doubtless trace back to some common ancestors a score of generations ago. The individuals constituting the race at one period are not at all the same individuals that consituted that race a few years previously, and none of them will be represented in that race a few years hence. Individuals, then, are temporary components of the race; but the race itself is permanent and relatively constant, though slowly changing as a whole.

It is our problem to determine the relation of the inclividual to the race and to account for both the relative constancy and the slow change of the race made up as it is of such mortal units as individuals. More specifically, we must study the make-up of the individual and learn how replacements are male when individuals wear out.

THE CELLULAR ALAKE-UP OF INDIVIDUALS

All living things, except possibly the filterable viruses and bacteriophages, are made up of vital units known as cells. Many of the 
lower organisms are unicellular, but all of the higher organisms are multicellular.

A complex oranism such as a man or an insect consists of millions of cells. Each cell bears a life of its own, but is dependent for its supplies of food and oxyen wixn other cells, and in turn performs some function that is of value to the organism as a whole. The division of labor and interdependence of the immumerable cells of the cellrepublic, the organism, is reflected in the fact that groups of cells of a particular sort constitute tissues, that rarious combinations of tissues form organs, and that various combinations of organs form systems, such as the nervous system, the digestive system, the circulatory system, and others. No matter how elaborate the specialization of organs and systems may be, every living part is composed of cells. Cells are perhaps the most fundamental units of life in about the same sense that atoms are the fundamental units of matter itseli. Nso, ceils possess certain mechanisms which are the principal agents both in preserving constancy of form and function (heredify) and in promuting diversity and change (variation). Hence, if we desire to understand how evolution takes place, it behoores us to make a careful examination of the constitution of cells.

\section{A TIPICAL CELI AND ITS COMPONENT PARTS}

Cells vary in size and in form according to the special functions they subserve; but in spite of their numerous specializations they have many features in common. The diagram of a cell shown in Figure 40 is not meant to represent any particular kind of cell, but is a composite of many kinds of cells. Of course, no one kind of cell contains all of the cell organs shown in this diagram.

The two most important subdivisions of the cell are the nucleus and the cytosume, or cytorlasm.

The nucleus is a more or less centrally situated bory, commonly spherical in form, and separated most of the time from the cytosome by a molear membranc. Within the nucleus is a characteristic material known as chromatin, which at times condenses into definite bodies known as chromosomes, each chromosome consisting of a bundle of genes, or hereditary units.

The cytosome consists of all the rest of the cell except the nucleus. All the vast hordes of cells of different sorts constituting a given complex organism are ilenticai in their nuclei, but in any cell the cytoplasm differs in its form and structure according to its location in the 
organism and its special function. Thus a nerve cell and a muscle cell of a given organism may be utterly different in general form and function, but the nuclei of both are the same. Since the specific hereritary materials of the individual are possessed equally by all of the cells of that individual, it follows that the differences in cells and tissues must be solely cytoplasmic. How these differences arise is a problem

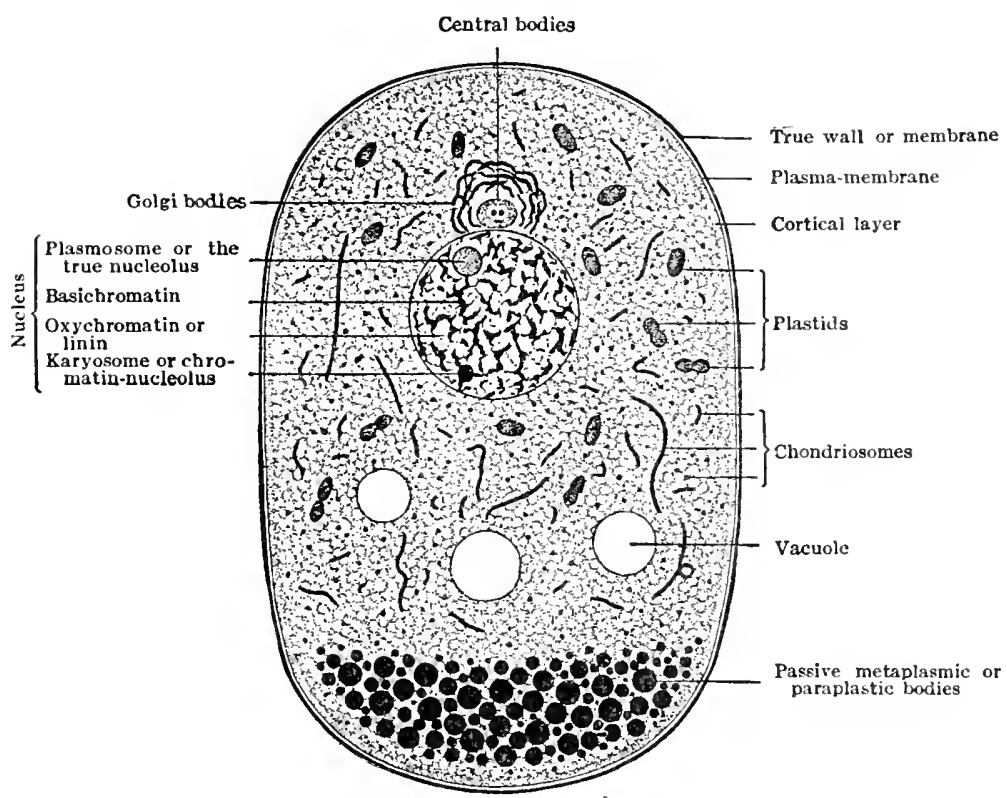

FIG. 40.-Diagram of a typical cell. Its cytoplasmic basis is shown as a granular meshwork or framework in which are suspended various differentiated granules, fabrillae, and other formed components. (From E. B. II ilson.)

of individual development rather than one of racial evolution. Many of the slow and steady trends in evolution, however, are believed by some authorities to be the result of general hereditary changes in the cytoplasm, but there is a great deal of evidence favoring the conclusion that the nucleus is the chief organ of heredity and of variation in the cell.

Details of the nucleus.- The nucleus, except during the process of mitotic cell division, is surrounded by a definite membrane, the muclcar membrane, which separates the clear nuclear sap from the cytoplasm outside the nucleus. During the resting stage, between two cell divisions, there is a network of linin fibers running throughout the nucleus. 
Upon this linin network are strung numerous granules of a deeply staining substance, or substances, called chromatin gramules. Other nuclear bodies, known as muclcoli, plasmosomes, and karyosomes, are found in some nuclei, but they may be ignored so far as our knowledge of their rôle in evolution is concerned.

Chromosomes. - Far more important for our purposes than any other cellular components are the chromosomes. Preparatory to the process of mitosis the diffusely scattered granules of chromatin condense into semi-solid masses, sometimes spherical or ovoid, sometimes rodlike, sometimes $\mathbf{V}$-shaped, etc. These are the chromosomes. Each species of organism possesses in all its cells a certain definite number and kind of chromosomes. Man has ${ }_{4} 8$, Drosophila melanogaster has 8 , Oenothcra lamarckiana has $\mathrm{I}_{4}$, Ascaris megalocephala has 4 in one variety and 2 in another, some crustaceans and some roses have over a hundred chromosomes. Careful studies of the chromosomes of numerous species of both animals and plants have revealed the significant fact that, except in the males of some species, the numbers of chromosomes are even. Furthermore, it is possible to match them up in pairs according to their sizes ant shapes. The significance of this becomes clear when we remember the fact that an individual starts out from a zygote (fertilized egg) which is a composite cell to which each parent has contributed one full set of chromosomes.

Genes.-At this time it seems well to anticipate the later results of genetic research to the extent of stating that each kind of chromosome contains a unique series of hereditary units (genes). Certain genes lie in certain chromosomes, and all the genes in a particular chromosome are probably arranged in linear orter like beads on a string. Since the orderly arrangement of genes in bundles (chromosomes) and their specific arrangement within a given bundle are both important in heredity, it is essential that this specific organization be maintainerl during development and reproduction. It is also essential for persistence of type from generation to generation that the complete organization, not only of nucleus but of the cytosome, be maintainerl. This is accomplished by that heredity mechanism par exccllence, the mechanism of mitosis.

The central body. - Imbedled in the cytoplasm, usually in close proximity to the nuclear membrane, lies a structure known as the central body (centrosome). In most animal cells this structure is well defined, but it is absent in most plant cells. The central bxyly is primarily associated with cell clivision, as will be seen later. 
CELL DIVISION-MITOSIS

Each cell during periods of growth and development grows to a defmite size and then divides into two daughter cells. Repeated cell
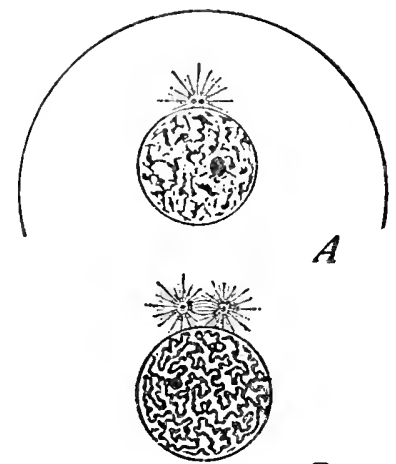

$B$
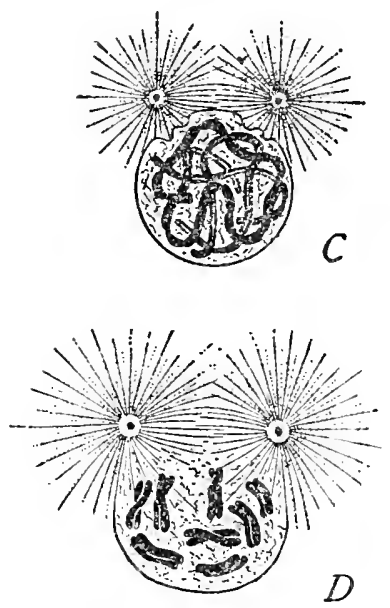

Fig. HI.-Diagram of the early phases of mitosis in Ascuris. A, vegetative nucleus; $B$, fine spireme; $C$, coarse spireme; $D$, late prophase with chromosomes, spindles forming. (From E. B. Irilson.) divisions multiply vastly the numbers of cells in a developing embryo, until in higher organisms millions of cells are produced. To make what might easily be a long story as short as possible, let it be sufficient to state that the chief features of mitotic cell division (mitosis) are as follows: The central body divides, and the two centers migrate apart, spinning between them a spindle of fibers, the mitotic spindle (Fig. + I). The nuclear membrane disappears; and, as the two central bodies migrate farther and farther apart, the chromosomes, which have in the meantime gradually become more and more compact, move toward the equator of the spindle, each attached by two fibers probably composed of linin, one fiber leading to one pole of the spindle, the other fiber to the other pole (Fig. 42). Usually even before migrating into the spindle each chromosome has become a double body, a pair of joined twins, each one the exact duplicate from end to end of the other. Each gene in the gene-chain has previously twinned, so that each gene in each chromosome is a double or twin gene. The chromosomes now arrange themselves in a plane at right angles to the long axis of the spindle, each chromosome having one of its twin halves directed to one pole and the other to the opposite pole. All of the stages up to this point of equilibrium are known as prophases of mitosis, the equilibrium phase being the metaphase (Fig. 42, E). 
Now the real separation phase of division lecgins. The twin onmponents of each chromosome seem to be pulled apdrt, possibly ly the fibers attachei] to them, and one win migrates to one pote, the other twin to the other (Fig. 4.j, $I$ ). Slowly the various chromosome wins approach unposite poles and inally cluster closely about the latter. It this point the cell wall constricts at the equafor and soon divides the single cell into twin taughter cells (Fig. 13,I). Net only are the chromosomes divided mericulously into ergual lots, but all the cytoplasmic parts of the cell are so divided that each (laughter cell comes to

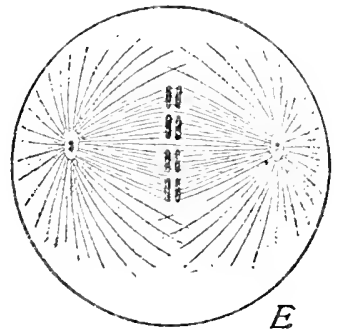
have exactly the same detaled organization as had the mother cell from which they were derivet. The periorl tluring which chromosome halves migrate to the poles of the spindle is called the anaphase, while that during which the chromosomes lose their density and reform the chromatin network with which we started is called the teloplase.

By means of this elaborate routine of division the exact specific organization of the cell is maintained, at least in the grim track. In this process of mitusis, we have a riew of the mechanics of heredity. which, if uninterrupted, would maintain perfect constancy of type for all time unless a new order of environment were to alter the expression of a fixed hereditary complex, or some other mechanism promoring diversity were to intervene.
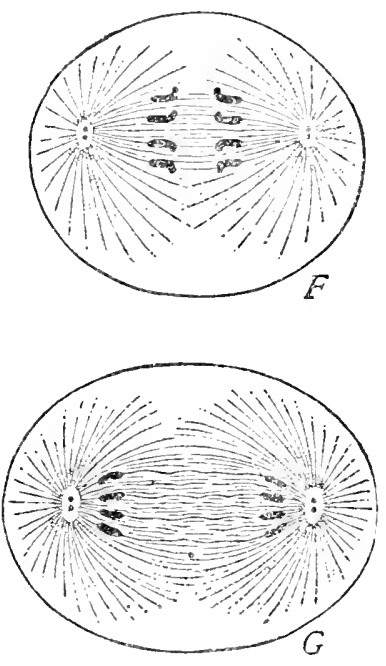

FIG. 42--T)iagram of the mirklle phases of mitosis. E, metaphase; $F, G$, carlicer and later anaphases. (Erom II ilson.)

\section{DIFFERENTIATIN}

Not merely do cells multiply in the process of embryonic development, but at every step differentiation of cells for the periormance of different specialized functions is going on. The mechanism of differentiation is at present very incompletely understood, and what we do know is of a technical nature and thificult to present withont a back- 
ground of embryological lore. In very brief, it must suffice for present purposes to state that differentiation is accomplished partially by unequal cell division, in which the two daughter cells come to possess different cytoplasmic contents; partially by the differences in position of cells with respect to the environment; partially by differences in

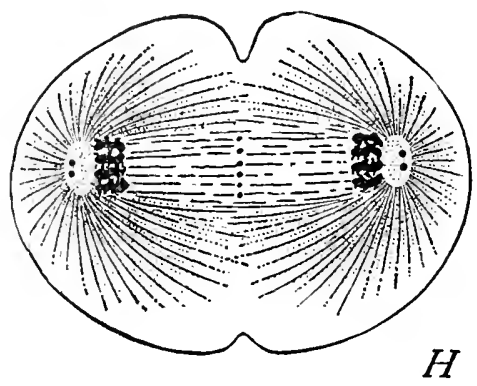

the relations of certain cells to other cells that have already assumed special characters owing to their original position or their special relation to the environment; and partially by the fact tha' certain genes are effective only at a given time in development or when cells are in a certain physiological state. All cells in an organism are believed to possess the same genes,

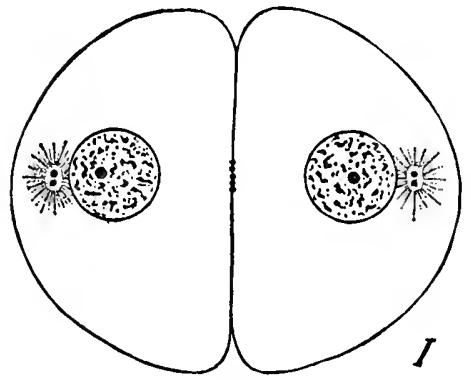

FIG. 43.-Diagram of the end phases of mitosis. $I I$, the beginning of constriction of the cell membrane; $I$, the completed division. (From Wilson.) but particular genes become effective only under special conditions of time and place. Some such complex of intricate interrelations, at present very obscure even to the most advanced students of embryology, seems to underly cellular differentiation. While the geneticist cannot avoid all responsibility for the solution of these insistent problems, he may with some appropriateness delegate them, for the present at least, to the expcrimental embryologist. At any rate, it seems best at the present juncture to sidestep the problems of diiferentiation and to get back on surer ground, more familiar to geneticists and more applicable to their problems.

\section{THE ORIGIN OF NEW INDIVIDUALS}

\section{MODES OF REPRODUCTION}

Since individuals, the temporary components of the race or species, are continually running their courses and dying off, replacements are necessary if the race is to persist. The replacement of old individuals by new is commonly called reproduction. There are numerous modes 
of reproduction, but they may all be classified in to two main categories: somulogenic and cytogenic. Somatogenic reproduction is accomplished without the instrumentality of sex and involves the subdivision of the farent body into two or many fragments, each of which has the power to reconstitute a whole new indivirlual like the parent. In unicellular organisms somatogenic reproduction involves the division of the onecelled borly into two or more cells each capable of growing into a fullsized individual; in multicellular organisms the products of division are multicellular fragments. Cy.togenic reproduction is accomplished ly means of unicellular germ cells which must pass through processes wi growth and division in order to reconstitute the multicellular body typical of the species to which they belong.

The essential feature of all reproductive processes is that some portion of the parent is isolated, or physically cut off, from the parent's borly, an integral part of which it formerly was. On ceasing to be a part of an organized system, it exercises its prerogative of developing it system of its own in the image of the one from which it was derived. This is true whether the isolated part be a single cell or a multicellular fragment. This is perhaps to be expected in view of the fact that (ach cell possesses the hereditary organization characteristic of the ruce or specics.

Varieties of somatogenic reproduction.-In mnicellular organisms the irincipal modes of sexless reproduction are transverse fission, in Which the division is across the long axis of the cell; longitudinal fissim, in which the division is parallel with the long axis; and multiple fission, in which the nucleus divides several times before the cytoplasm martitions the several nuclei off to form separate cells. In multicellular organisms the principle modes of somatogenic reproduction correspond rather closely to those among unicellulars, but several special modes are added. Transerse fission is common among worms of variwus kinds and among the larrae of certain jelly fishes. Longitudinal fission takes place in the early embryos of a number of mammals, as in armalillos and in man, resulting in true quadruplets and true twins terived from an original single embryo. Multiple fission occurs in a number of parasitic insects, in which the multicellular embryo sublivirles into hundrerls of cell-masses each of which becomes a complete individual. In addition to these types of fission, multicellular orgunisms reproduce by budding, which may be simple or multiple. liuding involves the outgrowth of a minor portion of the parent body, the latter body being left intact-this being in contrast with 
tission processes in which the cntire parent body is distributed among the progeny. Gemmulation is a peculiar form of somatogenic reproduction found among sponges, involving the gathering together of samples of all the various kinds of cells into compact little balls called gemmules, which survive the dead parent and escape to form new sponges when the parent body disintegtrates.

1rtificial propagation of both plants and animals is made possible through the ability of many organisms to regenerate a whole new individual from a small part of a parent organism. Thus sponges may be cut up into minute fragments and distributed like seeds upon a slab of concrete, each fragment growing up into a sponge of the parental type. Everyone is familiar with the fact that gardeners propagate many plants by planting cuttings, and that potato tubers (enlarged parts of the underground stem) may be cut into as many fragnents as there are "eyes" and that each will produce a plant with tubers like the parental tuber.

All the cells involved in somatogenic reproduction are the product of ordinary mitotic division, which maintains so painstakingly the hereditary organization of the species. No wonder, then, that this mode of reproduction makes for a high degree of constancy of type. Apart from the effects of differences in the environment, which appear not to be inherited, there is nothing about somatogenic reproduction to favor diversity or change. If one desires to study pure heredity uncomplicated by sex and its diversifying effects, one should study successive generations produced by somatogenic reproduction.

Varieties of cytogenic reproduction.-All those forms of reproduction in which single cells become separated from parent bodies to give rise to new individuals fall into this category. The first and simplest form of cytogenic reproduction is spore formation. Among plants, reproduction by spores is well-nigh universal, though many also make use of gametes. A spore is nothing more than a small cell produced by nitosis from previous cells. Spores are commonly motile, some being furnished with flagella by means of which they travel through the water, others being so light as to be wind-borne. To reproduce a new organism, a spore, after a period of rest, merely divides and redivides and thus forms a new multicellular body.

In some of the lower plants motile spores, all visibly similar, swim about actively in swarms, and then pair off two by two and fuse to form zygoles from which new plants develop. These mating cells are called gameics. This is the most primitive expression of sex in plants. 
Further specialization of sex cells involves, first, the differentiation of gametes into liarge passive gametes (eggs) and small motile gametes (sperms) and, second, the differentiation of sex individuals, males and females.

At this point, it is important to emphasize the fact that sex, although it appears to be so intimately associated with reproduction, is in no way essential to reproduction. In fact, it is a hindrance rather than a belp to the mere multiplication of individuals. Sex is a mechanism that has been superimposed upon reprutuction and has a function only remolely assuciated with the latter. In a word, sex is the diversity mechunism, with which we shall deal fully at the proper time.

The female gamete, or egg, is ahrays relatively linge. Eren the tiniest of eggs, such as those of placental mammals, are relatively large as compared with tissue cells. The human egg (orum), for example, has a cubic content of alout a thousand times that of the arerage tissuc cell, while the eggs of Jirds and sharks are thousands of times bulkie, than mammalian eggs. This great increase in the size of eggs is clue largely to the accumulation of food material (yolk) that serves to sustain the embryo and give it a good start in life. Most eggs are, when full grown, spherical or ovoid in form; and most of them are protected by envelopes of one kint or another.

Wale gametes, or sperms. are highly variable in shape and are relatively extremely small and active. Most of the cytoplasm of the sperm is specialized for locomotor purposes. Sume sperms have one long tail like a snake (Fig. $47, f$ ), others have two or several tails, and still others have numerous racliating locomotor processes resembling the thorns of a sand hurr. In general, a sperm gives the impression of being a highly specialized cell one of whose main functions is that of finding and penetrating the egg. Sperms are thousands, sometimes millions, of times as numerous as eggs, thus making it more probable that at least one sperm will reach each mature egg.

When the sperm approaches the egg, it seems to be guided, at least in some cases, by a specilic chemical substance given off by the egro. When egrg and sperm meet, the latter penetrates the former more or less completely (Fig. 50, a). Sometimes the whole sperm enters the ugrg, sometimes only the head of the sperm containing the nucleus and a minute amount of cytoplasm. On entering the egg cytoplasm, the sperm nucleus grows at the expense of the latter and becomes nearly or quite as large as the egg nucleus (Fig. $50, c, d, e$ ). The unism of egg and sperm is called fertilization, and the product of the union is a syrote. 
The term "zygote" is also sometimes used to designate the organism that develops from the united gametes.

Gametic reproduction is very frequently evaded in both animals and plants by the use of a process known as parthenogenesis, or "virgin birth," in which eggs develop without any aid from sperms. Some instances of this peculiar aberration of gametic reproduction will be discussed in a special chapter on the biology of sex (chap. xvii). Here we have the anomalous situation of gametic (or marrying) reproduction without the presence of both sexes. Long-continued parthogenesis involves the reduction of diversity and results in constancy as marked as that which is associated with various forms of sexless reproduction.

While the great majority of animals and plants are sexually dimorphic, consisting of male individuals that produce sperms and female individuals that produce eggs, large numbers of both animals and plants are monoecious, having both sexes present in one individual. Such forms among animals are known as hermaphrodites. In some hermaphrodites eggs are fertilized by own sperms, in others mating occurs in which a mutual exchange of sperms takes place. In the latter instances the advantages of sex in enhancing diversity are retained, and mating is facilitated because any two adult individuals may mate; but in the former instances where self-fertilization occurs, diversity is reduced to the level found among organisms reproducing by asexual methods. It is possible, therefore, to produce from such self-fertilizing monoecious species pure lines in which all progeny of a single individual are genetically identical. In a later connection we shall make use of such forms as these to study heredity in its simplest expression (chap. xv).

\section{THE ORIGIN OF GAMETES}

Two important questions arise in connection with gametes: (a) From what cells in the parent body do gametes arise? (b) What changes occur in germ cells that make it possible for them to unite in pairs to form zygotes?

The germ track.-The question as to whether germ cells are derived from parental tissues that have been more or less specialized for other functions, or whether they are derived from an unbroken series of germ cells set apart from bodily functioning at all times, is one of great importance for theories of heredity. The prevailing view of biologists is that, at least in the higher animals, and possibly in all animals and plants, the germ cells are produced from cells that have never in any 
generation gone through a period of specialization for any particular bodily function. Iis animals these cells are believed to be set apart early in ontugeny (ihe development of the individual) and localized in sex glands, or gonats. In plants the germ track is believed to be maintained in the meristematic cells of growing points, but germ cells are not so definitely localized as in most animals.
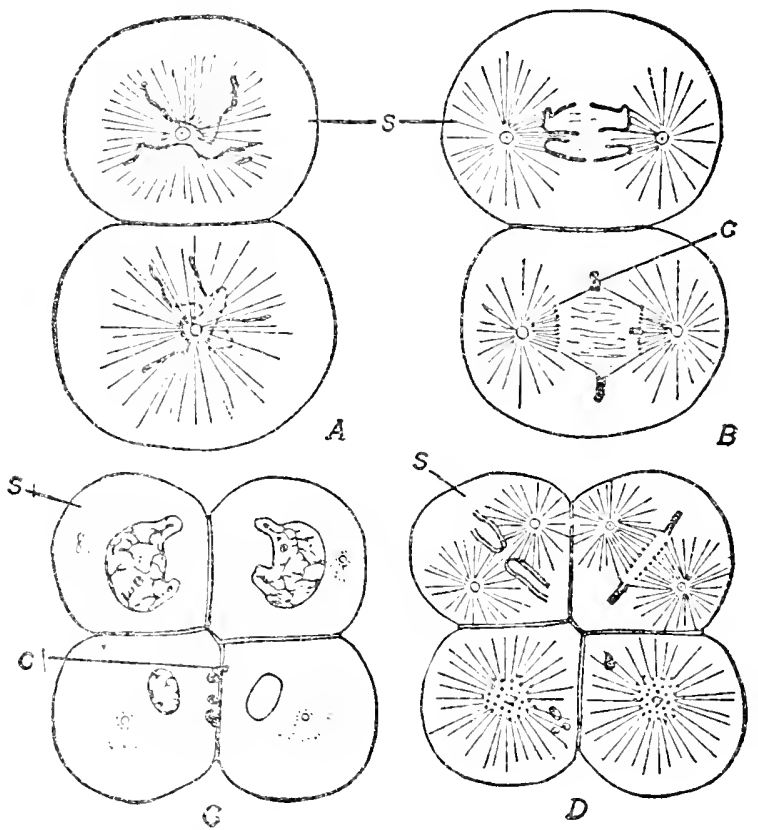

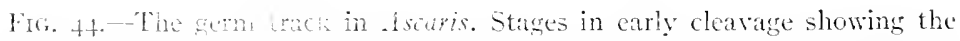
chromatin dininution proces in all cells except the stem cell $(5)$. (From Poreri, I'y

In some animals the germ track is very clear and unmistakable from the beginning uf une generation to that of the next. The classic instances of germinal continuity are those of the roundworm, .1scuris megalocephat and the Hy, Miastor anericana.

In the variety of i scarts known as unizalcns, which possesses only two chromosonies to each cell (incidentally the lowest number known), the developmental stages are as follows: at the first division of the zygute two cells are formed in the usual way, each cell with two long loop-like chromosmes (1.ig. 4+. .1). One of these two cells, howerer, undergoes a striking nuclear change involving the breaking-ofif of the 
ends of the chromosomes and the disintegration into small chromatin granules of the mildle portions. The large ends of the chromosomes are discarcled into the cytoplasm and absorbed, while the smaller granules are all that the descendants of this cell have for chromosomes. It is significant that the progeny of such cells form only body cells, in this case skin and nerve cells (Fig. 44, 1). The other cell remains just like the original zygote and is a stem cell or germ cell. This cell then divides, and one of the daughter cells retains the full germinal character, while the other breaks down its chromosomes as before and gives rise to tissues that line the digestive tract (Fig. $44, B$ ) Once more the germ cell divides and one of its daughter cells undergoes chromosome breakdown, its cell progeny forming chiefly such tissues as muscles, blood vessels, and connective tissues (Fig. 44, D). From this point on, the germ cells are definitely set apart and contribute no further to the soma. They give rise to nothing but germ cells and ultimately to gametes. The unbroken series of cells with intact chromosomes from the zygote to gametes is the germ track, and the chromosomes of these cells carry the so-called germ plasm. The rest of the embryo constitutes the soma or somatoplasm. The relation of body to germ plasm is well shown in the accompanying diagram (Fig. 45).

A second example of a well-defined germ track is found in Mi iastor (Fig. 46, A), in which a single deinite germ cell (p.g.c.) is set aside at the very first division of the zygote. The other cell divides repeatedly, casting out parts of the chromosomes, as in Ascaris, and ultimately giving rise to all the soma. Even in a fairly advanced embryo (Fig. $46, B)$ the large germ cells are clearly seen in a small group $\left.(o \ddot{o g})_{3}\right)$. These give rise ultimately to the gametes.

While in vertebrates the germ track is ill defined and difficult to follow, there seems to be no doubt that it exists. Some investigators, however, claim that the original primordial germ cells disintegrate and come to naught and that the gametes arise from a new lot of germ cells that are derived afresh from generalized epithelium. If that be the case, it seems fair to consider this epithelium as part of the germ track and not as a differentiated part of the soma. At least it may be said with confidence that in none of the higher mammals are germ cells ever derived from specialized body cells such as muscle cells, nerve cells, or gland cells. Our question as to the origin of the germ cells seems to be answered. They are derived in an unbroken series from previous germ cells by the process of mitosis. This is the basis of Weismann's concept of the continuity of the germ plasm. 
THE MATERING OF GAMETES

The primordial germ cells, previously described as having been set apart from the soma at a relatively early period of development and located in germ glands (ocurits and testes), pass through a period of comparative inactivity until sexual maturity arrives. At the dawn

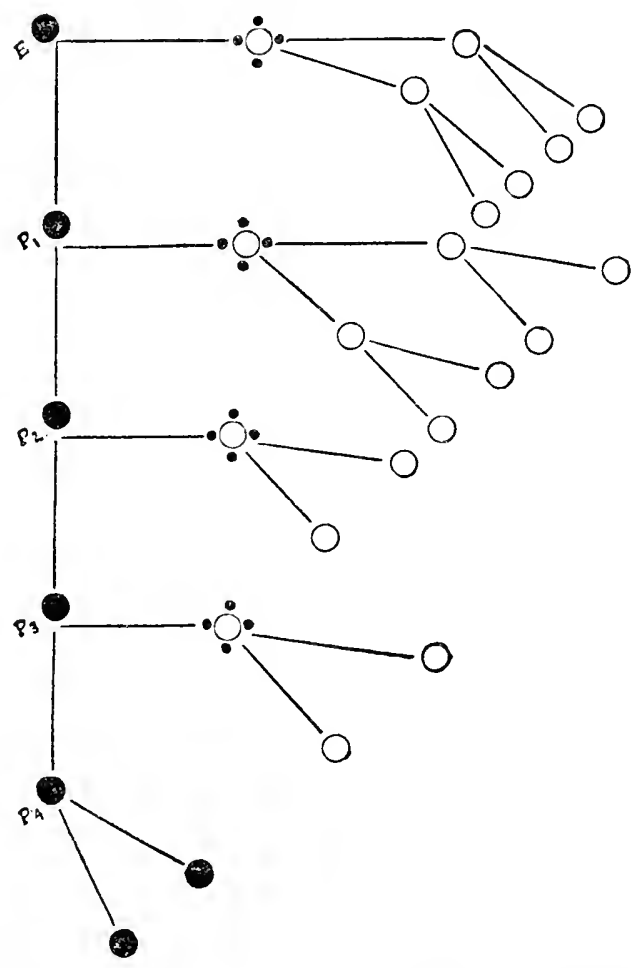

FIG. 45.-Diagram of the germ track in Ascaris. E; egrr; $P_{1}, P_{2}, P_{3}$, stem (germinal) cells; $P_{4}$, primordial germ cell. Circles represent somatic cells, while the four black dots outside of the circles represent the masses of chromatin that are eliminated. (From Boceri, IgIO.)

of sexual maturity the germ cells wake up and enter upon a period of great activity, during which mature gametes are produced. The history of the production of gametes differs somewhat in the two sexes. That of the male, called spermatogenesis, is a little simpler than that of the female, called oögcnesis, and will be described first.

Spermatogenesis. - The first sign of renewed activity of the male germ cells is evidencerl by a succession of rapid cell divisions, the 
mechanism of mitosis being used. After many thousants of germ cells have been produced, multiplication is stopped and growth sets in, the growth in the male cells being very slight as compared with that of female cells. During the period of growt the chromosomes not only split to form twin chromosomes, as though in preparation for mitosis, but whole homologous chromosomes unite in pairs, a process known
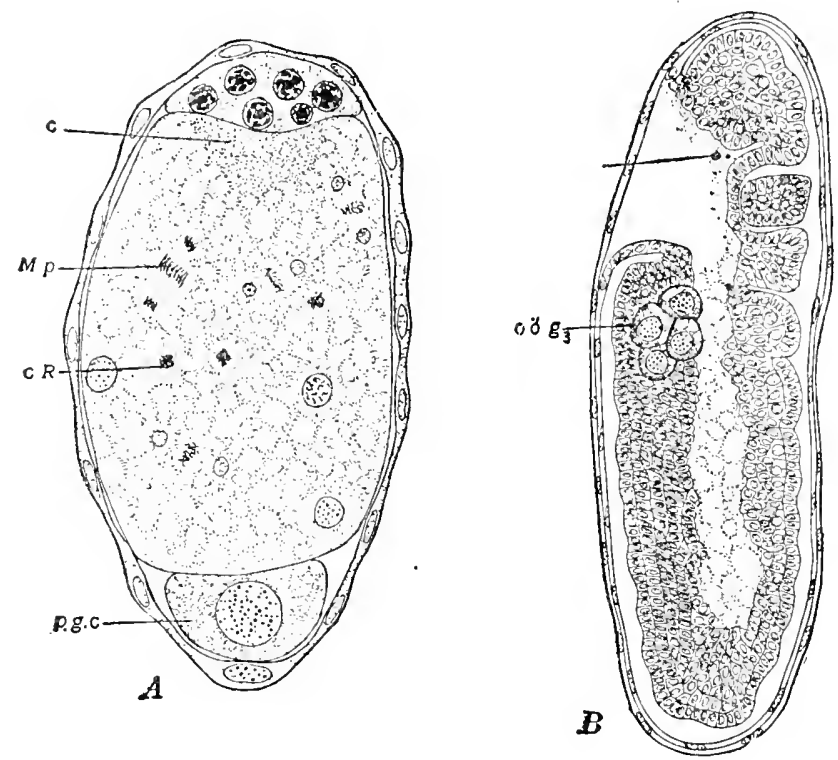

FIG, 46.- The germ track in Miastor americana. A, germ-cell (p.g.c.) set apart in the eight-celled stage of cleavage. (Afler $11 \mathrm{egner}$.) The walls of the remaining seven somatic cells have not yet formed, though the resting or the dividing ( $/ I p)$ nuclei may be seen; $C R$, chromatin fragments cast off from the somatic cells; $B$, scction lengthwice of a later embryo of 1 Hiastor; the primordial egg-cells $\left(0 \ddot{\partial} g_{3}\right)$ are conspicuous. (From Guyer, after Hegner.)

as synapsis. The result is that, instead of the set of single chromosomes characteristic of the zygote, there are groups of four (tctrads), each tetrad composed of two pairs of twin chromosomes bound together. There are just half as many tetrads as there are chromosomes in the zygote. Now follow two special cell divisions, known as meiosis, without any further change in the chromosomes. The result is that one chromosome of each tetrad goes to each of the four matured sperm cclls. In one of these divisions, the so-called reduction division, both twins of an originally single chromosome pass together to one cell, 
which results in a reduction of the mumler of chromosomes chatas teristic of the zyote to one-half (Fig. 47 ). The other division simply separates twin chromosomes as in ordinary mitusis. The result is that each gamete has only one of each kind of chromosome and therefrre only onc-half the number possessed by the zyote and the primorial germ cells. It is customary to speak of the somatic or zyoutic
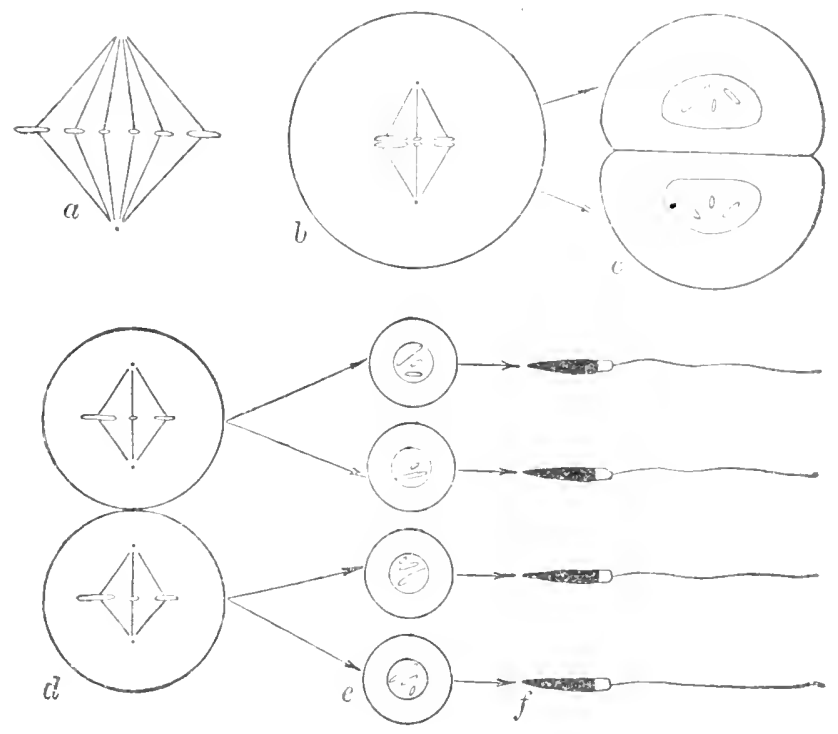

Fir. 47.-- Diagram to illustrate spermatogenesis. a, showine the dipl inl number of chromosonic six is arbitrarily chosen) as they occur in mivisions of ordinary cells and spermaturguia; b, the biring (symapsis of correpunding mates in the frimary spernatocyte preparatory to rediction; ce each secondary spemat xyte receives three, the haphid number of chromosones; d, fis isi,n of the secon liary spermatocytes to form e, spermatids, which transform into f, spermatozon. IFim Guver.)

number as diploid, or $2 n$, and the gametic number as hapioid, or $n$. The final phase of spermatogenesis consists of an elaborate sfecializattion of the male gamete, consisting of the development of locomotor organs and adaptations for penetrating the egg.

Oögenesis.- The prind of multiplication is essentially the since as in spermatogenesis exeren that iewer and larger cells are jumbert. The periorl of grome is rery mathed, for it is during this jeri w that the erge accumulates the yolk, which is usually massed at the receted pule. The nuteus and central body, confined to a small resim at 
clear protoplasm at the animal pole, are not in a position to bring about an equal cell division. Hence the maturation divisions are very unequal (Fig. 48). The first maturation division results in a large cell, not appreciably smaller than the full-grown egg, and a very tiny cell, called the first polar body. The second maturation division results in a sccond polar body and the mature female gamete, or unfertilized egg. Sometimes the first polar body divides again, sometimes not. Typically, however, four female gametes are produced, corresponding in

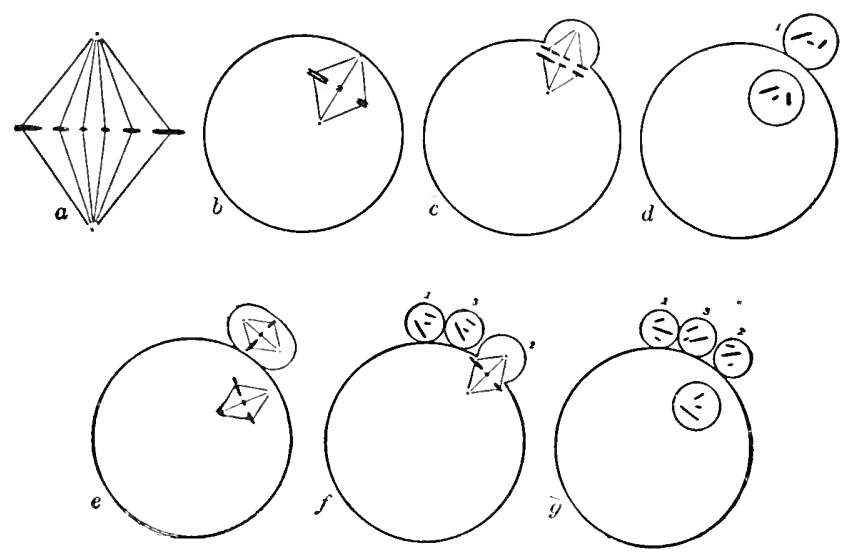

FIG. 48.-Diagram to illustrate oögenesis. a, showing the diploid number of chromosomes (six is arbitrarily chosen) as they occur in ordinary cells and in ö̈gonia; $b$, the pairing of corresponding mates preparatory to reduction; $c, d$, the reduction division, giving off the first polar body; $\varepsilon$, egg preparing to give off the second polar body, first polar body ready for division; $f$, second polar body ready for division; $g$, second polar body given off, division of first polar body completed. The egg nucleus, now known as the female pronucleus, and each polar body contain the reduced or haploid number of chromosomes. (From Guyer.)

number to male gametes similarly produced; but three out of every four eggs, namely, the polar bodies, are abortive and die because of deficiency of cytoplasm, leaving only the one large well-nourished egg as the progeny of each primordial germ cell that completed the period of growth. Synapsis and the reduction division are the same in oögenesis as in spermatogenesis (Fig. 49).

Now, during both spermatogenesis and oögenesis the united pairs of homologous chromosomes, one derived from the father and one from the mother of the previous generation, arrange themselves during the reduction division quite independently of one another, so that some maternal and some paternal chromosomes enter each gamete. Where 
there are large numbers of chromosomes, very many different assortments of matemal and patermal chromosomes are produced. This shuffling and dealing of parental heredity materials constitutes one of the principal means of increasing diversity in organisns, and therefore one of the most important mechanisms of evolution. A relatively

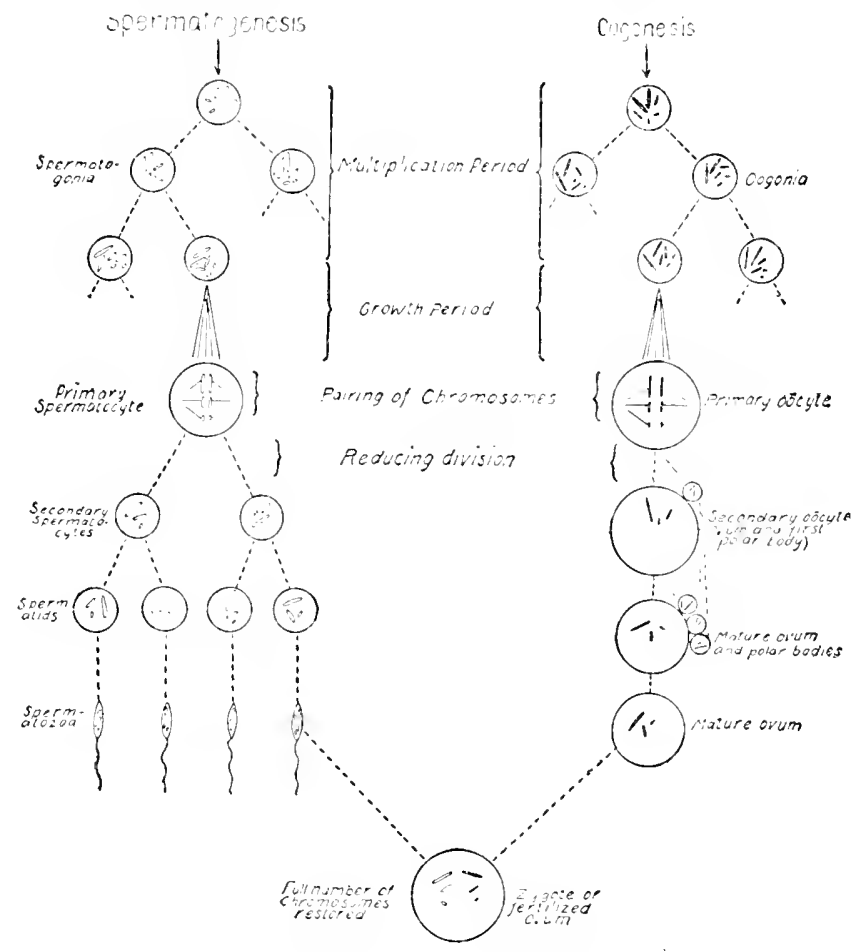

Fig. 40.-Diagram showing the parallel between maturation of the spermcell and maturation of the orum. (From Guycr.)

simple case of the assortment of different chromosomes to gametes is shown in Figure 90.

TIIE CNION OF G.AHETES-FERTIIEATIN

Once the gametes are mature they are reary for the fertilization process (Fig. 50). It seems to be a matter of pure chance that any particular sperm finds and enters any particular egg. Since there are usually hundreds of different kinds of eggs and equally large numbers of different kinds of sperms, the number of possible kinds of zygotes produced is extremely great. If, for example, a species has only 
twenty chromosomes-less than half that possessed by man-there would be $(2)^{\mathrm{ro}}$, or $\mathrm{r}, \mathrm{O} 24$ different gametes in each scx. And since each kind of egg is as likely to be fertilized by one kind of sperm as another, there might be produced (ro24) ${ }^{2}$, or $1,048,576$ different zygotes. Hence, meiosis and fertilization together constitute an extremely effer-
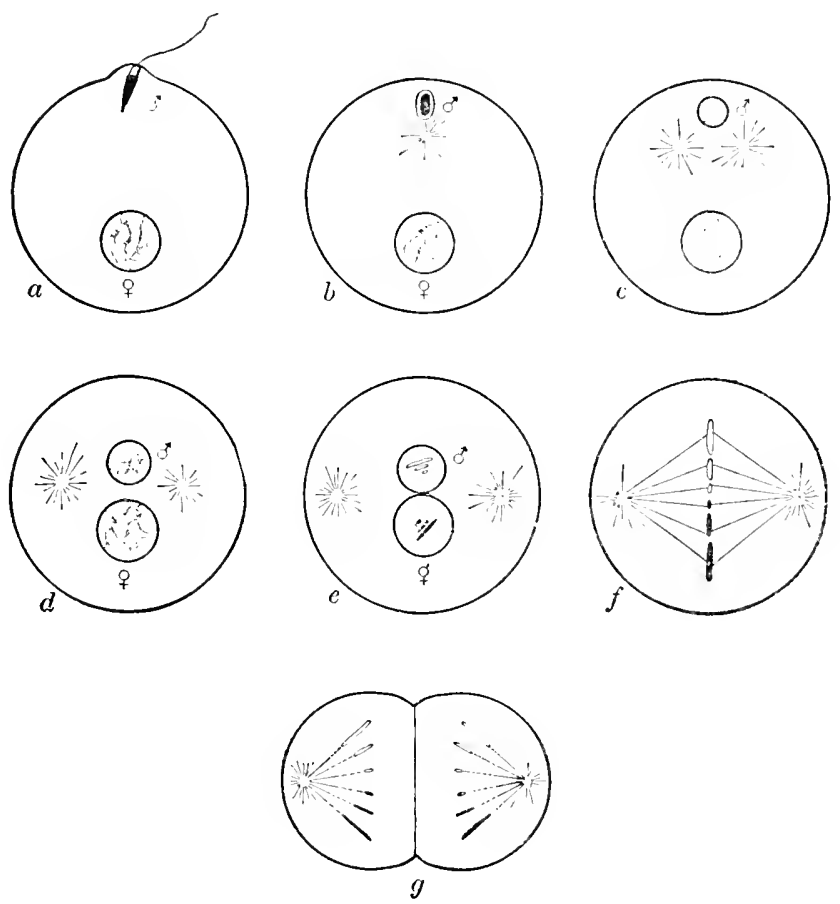

FIG. 50.-Diagram to illustrate fertilization. $\sigma^{7}$, male pronucleus; of, femalc pronucleus; observe that the chromosomes of maternal and patemal origin respectively do not fuse. (From Guyer.)

tive mechanism for increasing diversity. This is the chiei rôle played by sex in evolution.

This abbreviated account of biological processes is all that is needed for our purpose and should, we believe, enable the student to follow intelligently the accounts of heredity, variation, selection, and isolation that are to follow. A more detailed account of the processes of mitosis, meiosis, and fertilization may be found in chapter xliv, "The Mechanism of Mendelian Heredity." 


\section{CIIPTER XV}

\section{INTHUCTHA TO THE STTDF OF

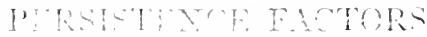

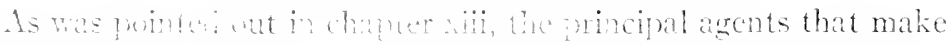

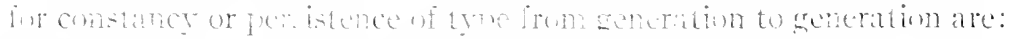

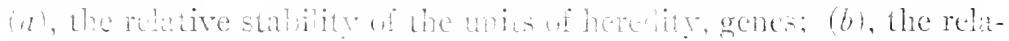

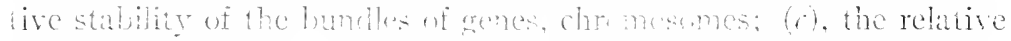

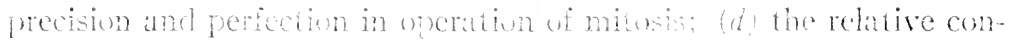
stuncy of the envimment over long perionts.

Laborions ataile of gene chanes, esmocially in the fruit fly. brosophitu, have shown that wenes are excecingly stathe. IIullur

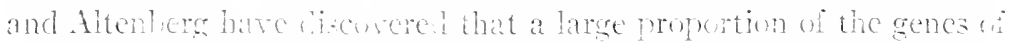

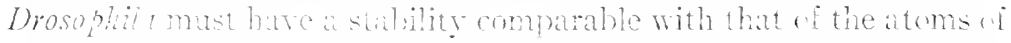
the elerent rathm, whith have an average unchored life of abut two thousand years. (if course, whe there are humbels, possibly thousands of genes in weth cell, the chance wi somegene change being wherved during any given period will denend un the numbers of anes present and the mumer of in irituals examinet.

Cleromosones are probathy almost equally stable except for cross-

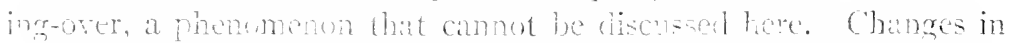

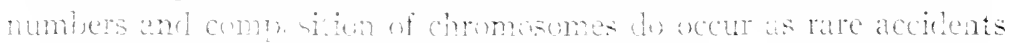

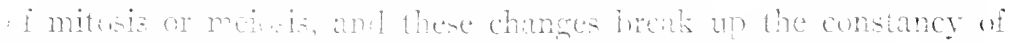

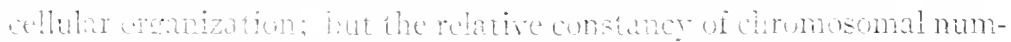
bers and w ther genic antont constitutes one of the most impurtant

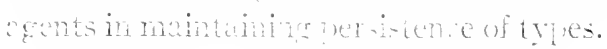

Tarius kinris in imeutarives in the characteristically constant and nearly perfect mechinism of mitusis are responsilde for rare

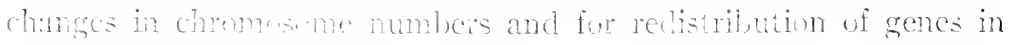

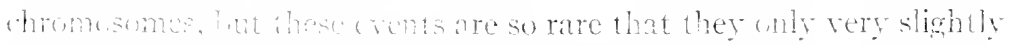

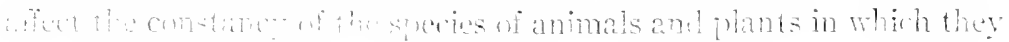
(1)

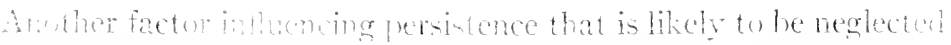

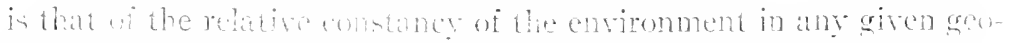

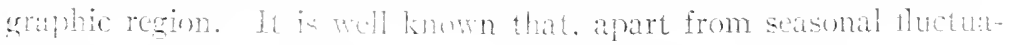

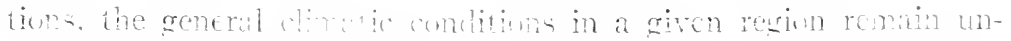

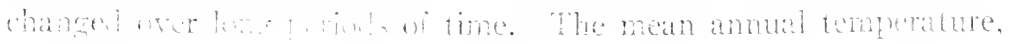


the mean annual rainfall, and the general character and direction of air movements remain essentially the same for very long periods. Such constancy of environment could hardly fail to exercise a standardizing effect upon animal and plant communities, and thus aid in maintaining constancy in the expression of racial characters.

Persistence and diversity mechanisms contrasted.-It is customary in courses in genetics to introduce the study of heredity by presenting an outline of Mendelian heredity. This seems to us a mistake, for Mendelian heredity is really not essentially a persistence factor, but rather a most effective diversity factor. It breaks up constancy of combinations of unit characters and promotes multiplicity of recombinations of such characters. For this reason we shall begin our discussion of the persistence factors in evolution with the study of heredity in pure lines, in which the persistence mechanism is free to operate without being complicated by the diversity mechanism. Since biometric methods are necessary for the study of variation and hereclity in pure lines, it is necessary to introduce a brief statement about these methods.

A short lesson in biometry.- When character differences are either qualitative or are sharply defined, they are easily handled by Mendelian methods. If for example, all individuals are either black or white, tall or short, heavy or light, and no gradations occur between the two alternatives, it is easy to follow the distinct types through successive generations. If, on the other hand, there occur all gradations between black and white, all gradations between tall and short, and all gradations between heavy and light, it is no longer possible to classify each individual in some particular category. When this is the case the only possible method of finding out how much is inherited, and how much is not, is to study whole generations of progeny as units, and to determine what is the characteristic of one whole generation as compared with the next whole generation. Such a comparison requires statistical methods.

Suppose, for example, we want to find out whether the size of bean seeds is hereditary or merely environmental, we shall have to measure the seeds of the parent and compare them with those of the offspring. There would be nothing gained by comparing a selected seed of the parent with one of the offspring. We must compare the total of one with the total of the other. It is necessary, then, to find a method or methods of comparing the parent condition as a whole with the offspring condition as a whole. Some simple method must be devised 
that gives due credit to each of the variants in the two generations. One method conmonly used is the graphic methor. Thus each seed of the parent generation is measured and plotted on a graph in which the horizontal line (the abscissa) represents a series of size classes varying from the smallest ones at one end and the largest at the other, and the perpendicular line (the ordinate) represents the frequencies of indiriduals in the varying size classes. A line connecting high points in each of the size classes will form a curiation cure which will be characteristic of the group. Such a curve has a high point near the middle (called the mode), and the curve slopes gradually toward each end. This curve not only represents the distribution of the different sizes in the group but shows the most commonly occurring size class, the morlal class. I similar curve is made for the offspring generation, and the parent curve is compared with the offspring curve. The two may be compared with respect to mode, mean, average, and standard deviation, and a great deal may be learned, that can be learned in no other way, about the variation and heredity of such grarluated or fluctuating characters as weight.

For further information about statistical methods in genetics, the reader is referred to a short chapter in the Appendix (chap. xliii). It will hardly be necessary here to do more than indicate that pure-line work, such as that of Johamnen, Jennings, Tower, and Wright, discusserl in the next chapter, could not have been done without the use of biometrical methods. 


\section{CHAPTER XVI \\ HEREDITY IN PURE LINES}

THE NATURE OF PURE LINES

When alt the individuals in a family line-offspring, parents, grandparents, and so forth-have just the same hereditary materials (genes and chromosomes), the whole family connection is known as a "pure line." Pure lines may originate in at least three ways: (a) by asexual modes of reproduction, such as fission and budding; (b) by sexual reproduction of hermaphrodite or monoecious parents, such a parent being a double-sexed, male-female, individual, in which both eggs and sperms are provided by the same parent; $(c)$ by prolonged close ir ${ }^{-}$ breeding, brother-and-sister mating, for many generations.

Members of pure lines, if they are genuinely pure, will all be exactly alike in their bodily characters if they develop under identical environ. mental conditions, untess some change, such as a mutation, occurs. When clifferences occur among members of a pure line, we can be sure that such differences are not innate, but are che to external, or environmental, causes.

Much may be learned about heredity from a study of perligrees of individuals in pure lines. In pure lines heredity presents itself in its simplest form, uncomplicated by the mechanism of diversity. Here we can study the operations of heredity modified by only one other factor, the environment. Some of the facts that are brouglnt to light by our studies of pure-line heredity will serve to simplify and elucidate the more complex aspects of Mendelian heredity.

THE PURE-LINE EXPERIMENTS OF JOILINNSEN

One familiar with the field of genetics never thinks of pure-line breeding without thinking of Johannsen and his famous nineteen beans. He was interested in pure-line breeding primarily as a means of improving certain kinds of beans for economic reasons. He thought he might be able to produce uniformly bigger beans by always planting only the biggest sceds. In order to avoid the complexities of mixed races, he worked with pure lines, keeping each pure line quite separate from the others. Although he experimented with nineteen pure lines, we shall not at tempt to follow up the results of more than two of them. 
The lirst thisg he rid was to collect all the socks (we would call

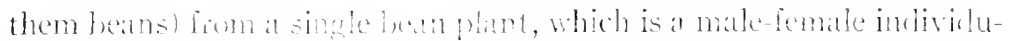

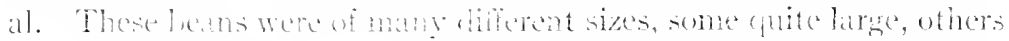

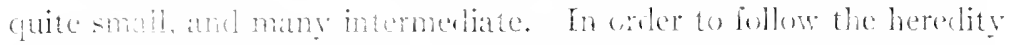

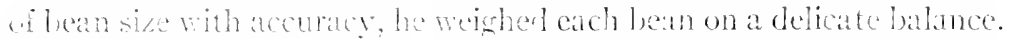

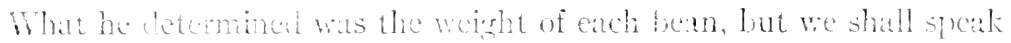
af burs and smanl size insteal of heary and light weirht. Since some fer of the beans were very hare and some few very small, what more natuml than to select the lungert leans to be the seeds for the next areneration of plants, and to expect that the heans of the newt and the

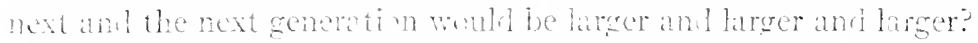

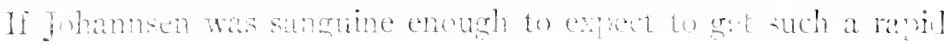

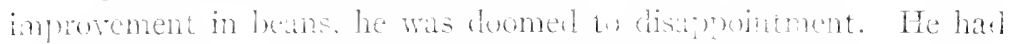

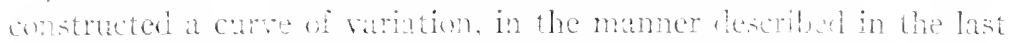

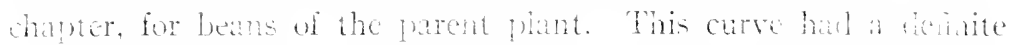

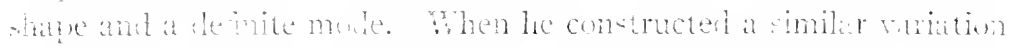

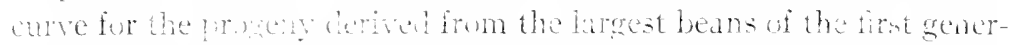

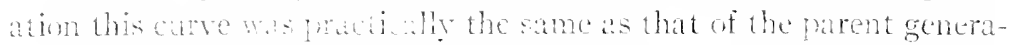

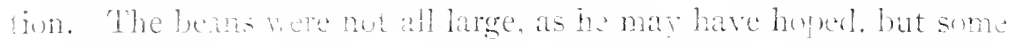
were latge, sune small, and many intermediate, juet as in the parent

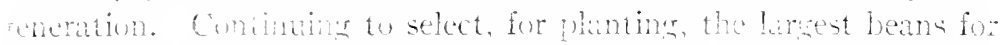

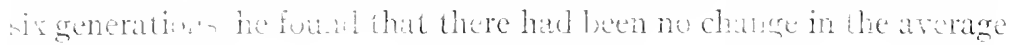
ize of bears, and the momixer of largest beans hut not increaser. selection there hat then purertess when operating upon individuab wh incenol terent?

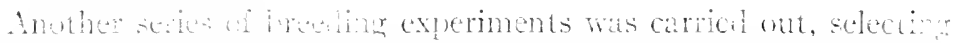

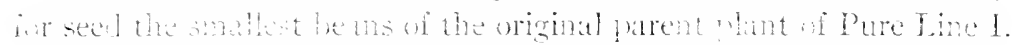
the bean progeng of the scombl generation differel not at all from those letred fom tha larest lean of this pure line. They gave the same varian cume an! the sane arerage as the lotter, and this was maintane for six generins. It made no biference whether the lagest, the smallost, w the average beans were selected for planting; solung as hey homed to the same pure line, the same rariation curve and the same arowan men maindaner.

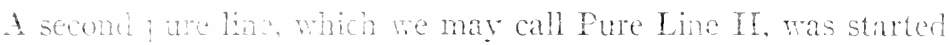

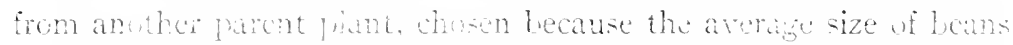
mas dintictly logs than that w the first pure line. The statisticat

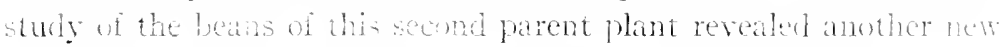
and sigrincun fact, namely, that the beans, when arranged atcond ing to sizes gave a varidin sure diftering markelly from that of 
Pure Line I. The snape of the curve, the mode, and average size were different. Again selection for six generations of, first, the largest beans for seed, and second, the smallest beans for seed, did not affect the variation curve, morle, or average. Once again, selection within a pure line was quite ineffective.

The same results were obtained in all the rest of the nineteen original pure lines with which Johannsen experimented.

A somewhat more concrete idlea of the results obtained may be secured through the perusal of the following table which gives in terms

RESULTS OF SELECTION IN PURE LINE I

\begin{tabular}{|c|c|c|c|c|}
\hline \multirow{2}{*}{ HARVEST YeAR } & \multicolumn{2}{|c|}{$\begin{array}{c}\text { Mean Wlight of Selected } \\
\text { Parent SeEd }\end{array}$} & \multicolumn{2}{|c|}{$\begin{array}{l}\text { MEAN WEIGHT OF } \\
\text { OFFSPRING }\end{array}$} \\
\hline & Minus & Plus & $\begin{array}{l}\text { From Xlinus } \\
\text { Parent }\end{array}$ & $\begin{array}{l}\text { From Plus } \\
\text { Parent }\end{array}$ \\
\hline $1902 \ldots \ldots \ldots \ldots$ & 60 & 70 & 63.15 & $64 \cdot 85$ \\
\hline I903 . . . . . . . . . & 55 & 80 & 75.19 & 70.88 \\
\hline I004 $\ldots \ldots \ldots \ldots \ldots$ & 50 & $S 7$ & $54 \quad 59$ & 50.68 \\
\hline I905 . . . . . . . . & 43 & 73 & $6.3 \cdot 55$ & 63.64 \\
\hline 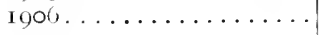 & 46 & 84 & $74 \cdot 3^{8}$ & 73.00 \\
\hline I907 $\ldots \ldots \ldots \ldots \ldots$ & 56 & $8 I$ & $09.0 \%$ & 67.66 \\
\hline
\end{tabular}

of average bean weight the results of selecting plus and minus parents for six generations in Pure Line I, the plus parents being largest beans and minus parents being smallest beans.

It will be seen that in the last year of this selection experiment (I907) the smallest beans, averaging $56 \mathrm{cg}$. in weight, produced a progeny weighing, on the average, $69.07 \mathrm{cg}$., while the largest beans of the same year, averaging $S_{I} \mathrm{cg}$., produced progeny of practically the same average weight as did the smallest beans, namely, $67.66 \mathrm{cg}$. The difference is not statistically significant. The influence of the environment in bean weight is clearly shown in the data for the year 1904, which was a bad year for growth. In this year, the average weight of progeny from both large and small beans was greatly reduced, being respectively $56.68 \mathrm{cg}$. and $54.59 \mathrm{cg}$. That this loss in weight was not inherited is shown by the results in subsequent years in which the average returned to that seen in the first year of selection. It is also interesting to note that in the years 1903 , I906, and 1907 the lighter parents produced a heavier progeny than did the heavier parents.

From these experiments Johannsen came to the conclusion that plus and minus fluctuations about the mode were due to differences in 
the environment and were not inlerited, and that what was really inherited was merely a potentiality to produce beans of a certain average weight which may be modified by the environment. It was also obvious that these environmental modifications had no effect on sulsequent generations, that is to say, they are not inherited. Selection, therefore, has no effect unless there are hereditary differences among the individuals selected.

All the members of a giren pure line are identical genetically, that is, there are no differences in their genes. Johannsen called a group of individuals that are alike in their genes a genotype, and spoke of all such individuals, whether alike in seed size or not, as genotypically identical. Hence individuals that breed alike, whether they look alike or not, are members of the same genotype. On the other hand, each of the nineteen pure lines is a different genotype though some beans in each pure line may be exactly of the same size as some beans in others. Johannsen designated individuals that look alike and have the same somatic characteristics, whether they are genotypically alike or not, members of the same phenotype; in other words, they may be phenotypically identical though genotypically different. Phenotypic clifferences, unless also associated with genotypic differences, are not hereditary. This conclusion is a highly important one for all our further study of heredity.

Another significant conclusion may be reached from these experiments, namely, that environmentally produced differences, if they are merely phenotypic in character, play no important part in evolution, except in so far as they may favor the survival of certain indiviciuals possessing genotypic differences. Hence, environmentally produced differences in the soma have only an indirect influence on the course of evolution.

\section{OTIIER EXANIPLES OF PURE LINES}

IV. L. Tower, in a long series of experiments on the potato beetle, Lcptinotarsa decemlineata, came to similar conclusions. He produced a pure line, not by making use of a self-fertilizing species, but by closely inbreeding a bisexual family for a long time. This stock was tested and found to be genotypically pure, yet there was a considerable amount of variability in the shade of color in the color patterns, and in other ways. For twelve generations he selected and bred from the darkest specimens, and from the lightest specimens, keeping the two series separate (Fig. $5 \mathrm{I}$ ). The result was that, instearl of getting 
darker specimens predominating in one serics and lighter specimens in the other, he obtained at final generation of indivituals showing practieally the same range of variability in both series, and in neither series

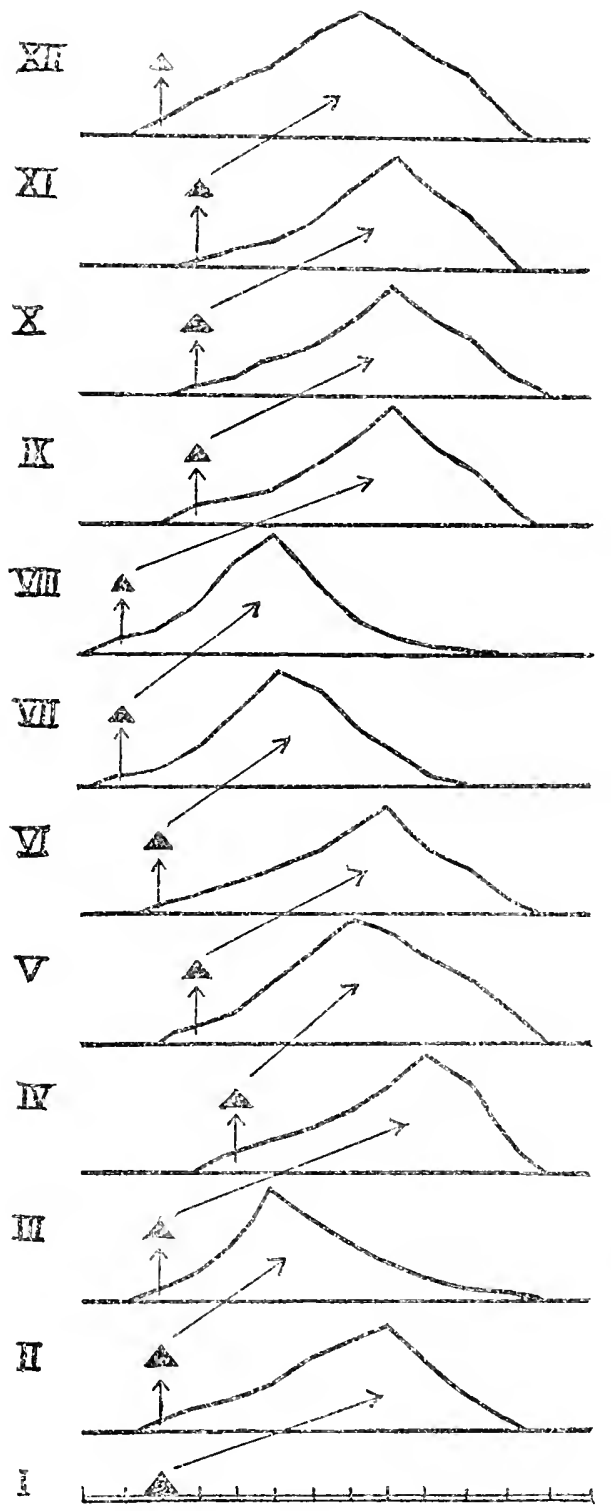
was there any consistent change from the condition present at the begimning of the cxperiment.

More recently Sewali Wriglit, working in connection with the Bureau of Animal Industry, has produced a considerable numiber of pure lines by long continued brother-and-sister mating in guinea pigs. Sixteen families have been established by over thirty generations of the closest possible inbreeding. No selection was practiced. The result was that most of the pure lines showed marked reduction in fertility and in vigor, as compared with the control cross-bred stock. Each line, howerer, differed from all the others in these

FIG. 5I.-Diagram to illustrate the results of selection in pure lines. Ineffectiveness of selcetion through exelve generations within a homozygous strain in the case of the Colorado potato-beetle (Leptinotursu). In each generation extreme dark specimens were selected as the parents of the succeding generation but the progeny always swune back to the type. (Ifler Twate) 
respects, as a d a

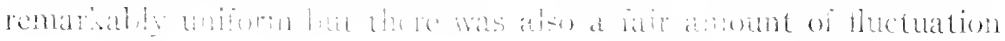

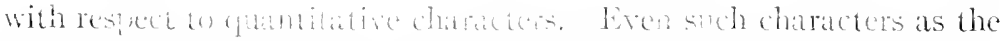

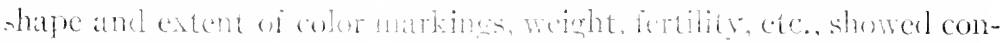

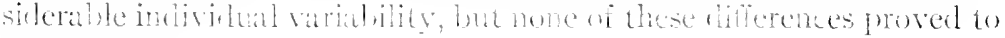
be hereclitiry.

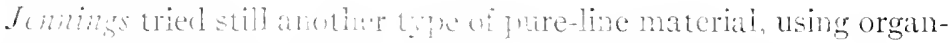

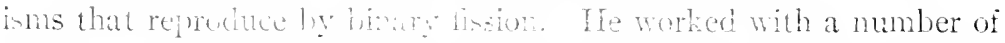

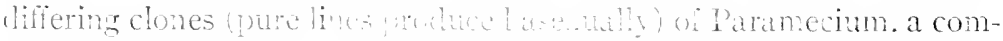
mon ciliate protozon. I':h secter Itranedun was isolated in a

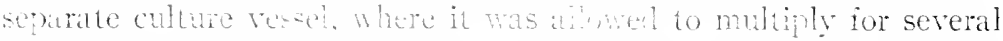

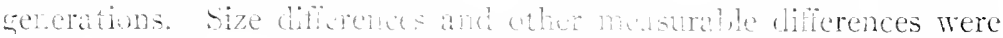

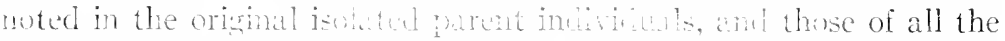

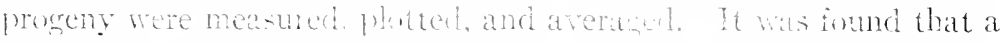

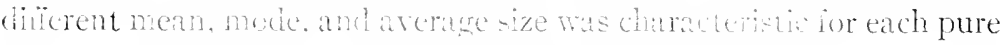

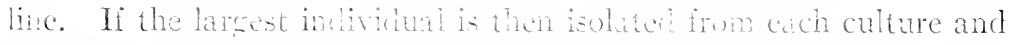

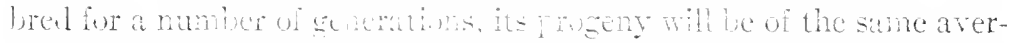

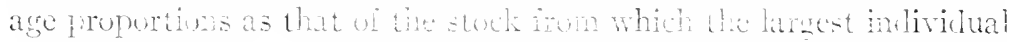

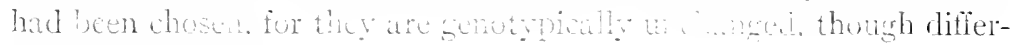
ing filerotgriat?.

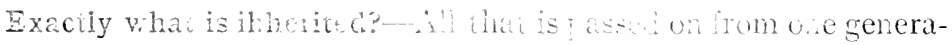

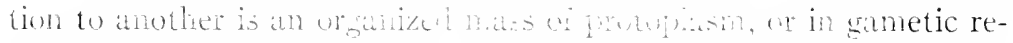

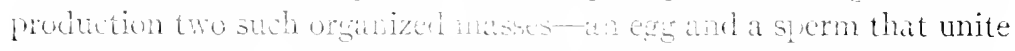

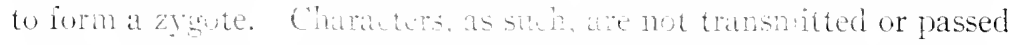

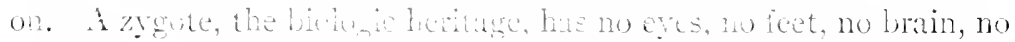
irstinets. All it poreses is a we cethite nuclear and eytoplasmic

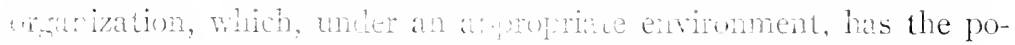

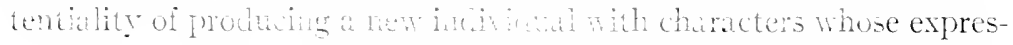

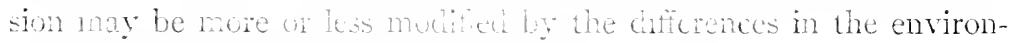
ment within the or mism or ontale of it.

Specihally, tet ws state anctly whet was inherited in Johannen's pure lines, Pure Jine iffus in is herchitary potentialities from Pure Line II in that. under the given curditions of the entronment, it

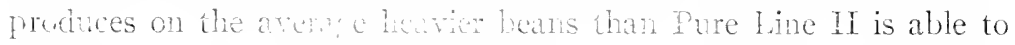

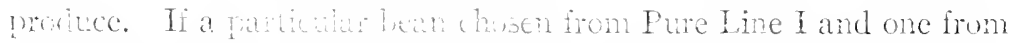

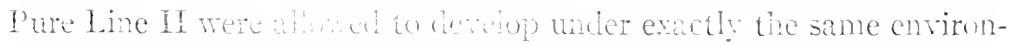

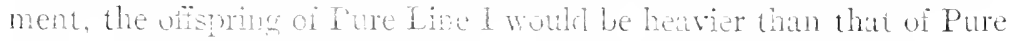

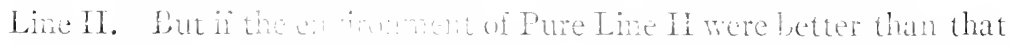

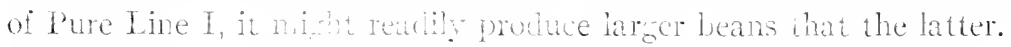
But this convonnentaby inducted difference would not ise inherited. 
Exactly what, then, is inheriterl? A certain complex of genes and a certain cytoplasmic organization are all that can be said to be inherited. These heritages are to be conceived of as potentialities capable of working with the environment to produce individuals with certain particular characters. Individuals will differ from one another partly because the materials constituting the zygote are different and partly because their environments are different. To what extent heredity and environment determine individual differences we must not attempt to decide at present. We shall be in a much better position to deal with this problem after we have discussed the other factors of the evolution mechanism. 


\section{CHAPTER XY'TI}

\section{SEX DETERMINATION AND SEX DIFFERENTIATION}

Introductory statement. - In chapter xiv we have spoken of sexual reproduction as one of the mudes of cytogenic reproduction. We have also referred several times to the ways in which sexual reproduction constitutes the main mechanism of diversity. Two questions with regard to sex, however, have not yet been broacheil: (a) What determines the sex of the individual? (b) How do the secondary sexual characters of individuals develop? These two questions will be answered in the present chapter.

SEX DETERIINATION

The question as to what determines whether an animal shall be a male or a female is a very ancient ore, and it is only during the present century that we have solved the puzzle.

A great many theories of sex determination have been proposed, some of which are as follows:

a) Hippocrates and some subsequent theorists believed that the sex of the offspring depended on the relative vigor of the parents, the more vigorous parent giving his or her sex to the offspring.

b) Thury thought that the sex of the offspring depended on the degree of ripeness of the ovum at the time of fertilization.

c) Various writers claim that statistics show that germ cells from the right ovary produce males and those from the left ovary females.

d) The nutrition theory.--The egg is a much more highly nourished cell than the spermatozoön, and the idea seems natural that high rlegrees of nourishment of the mother produce female offspring and lower degrees of nourishment male offspring. Professor Schenk of Vienna gained a huge reputation by controlling the diet of certain royal prospective mothers and predicting the sex of the offspring accordingly. He was correct in his predictions several times, but his success was short-lived. His early predictions were merely lucky, just as one might be who could guess heads or tails correctly several times in succession.

Some color is lent to the nutrition hypothesis by the fact, if it is a fact, that aiter war or farrine, when the nutrition of mothers has been 
low, more males than hemales are born. This is probably a case of differential prenatal mortality. liy that we mean that more femates die unborn than males, becuuse the latter are hardier and stand prenatal malnutrition better.

c) Sex is detwininat at the time of fertilization.-Perhaps the best cvidence that sex is determined at the very beginning of development

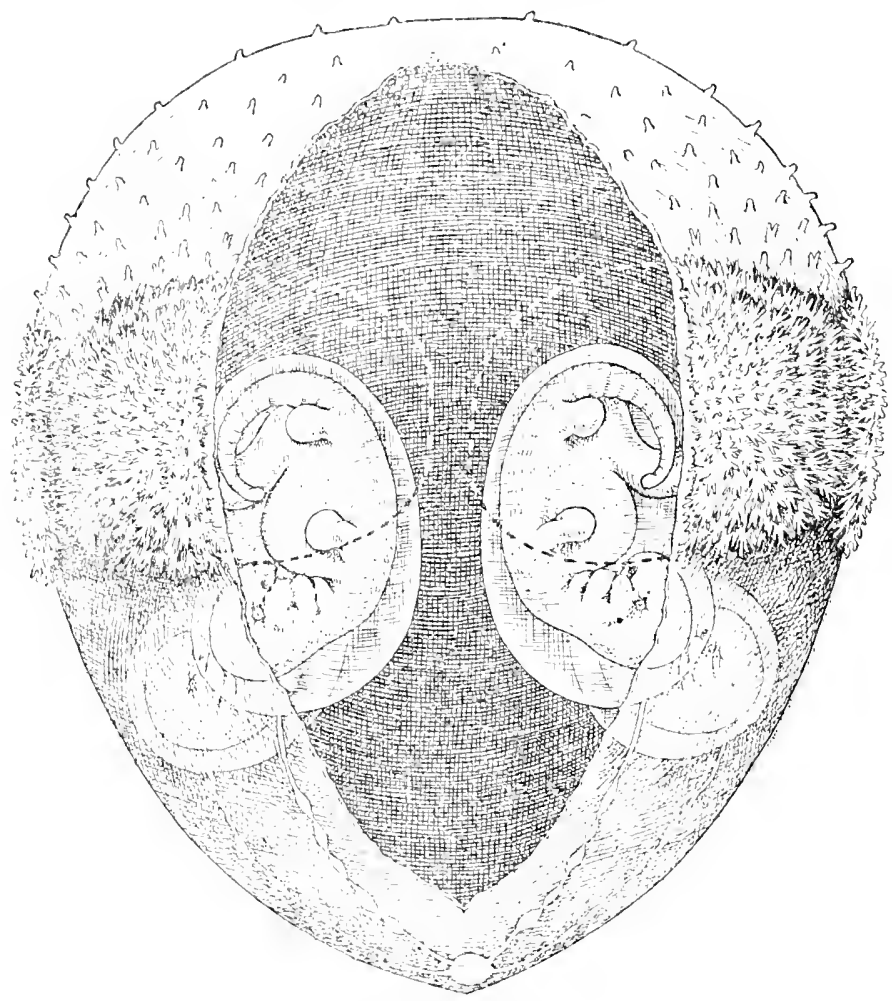

Fr. 52.- In armadillo egr about six weeks after fertilization, showing the quadruplet futues cerived from the single ceg and all destined to be of the same sex. (lirom hiomm

is derived from one-gen twins and quadruplets. In the nine-banded armadillo practically every fenale gives birth to quadruplets, four essentially identical young being produced in eacl litter. All in a given set of quakiruldets are invariably of the same sex, either four males or four females. Newman and Patterson have shown that each sct of cuadruplets comes from a single egg which at a very early stage 
divides into four parts to form four fetuses (figr. 52 ). The conclusion is that sex was detemined before the sepatation took phace. Human

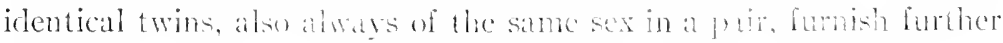

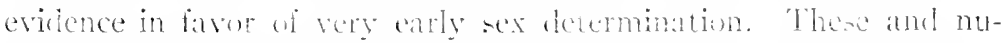
merous other sinilar farts justify the conchusion that sex is determined at the time of fertilization.

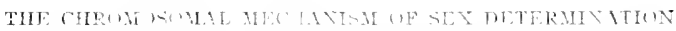

In two previous chapters (chays. and ani) descriptions of the typicai modes of chromesomal sex fetemination have been given. In order to facilitate a clear understanding of this important matter, it seens well to recapitulate one typical instance. I'erhaps the hestknown instance of sex determination is that of Drosophilu melunesuster. alreuly describer and figured (Iig. 5.3) ?y Bubuck and Clatuscin. In this insect the female body culls and the ummaturated germ colls are characterized by the presence of two ses chromosomes (X-chromosomes), which are shown in hlack at the top of the left-hand column of the accompanying figure. The chromosomes are readily distinguishable by being of medium size and straight. The male body cells and unmaturated germ cells (top of right column) are just like those of the female except that there is substituted for one of the X-chromosomes a hook-like chromosome, known as a Y-chromosome. Now in the process of maturation of the gern cells, which results in the formation of gametes with the haploid or half-somatic number of chromosomes, each of the egrss (female gametes) receives an X-chromosome. All eggrs are therefore alike in their chromosome content, including the sex chromosome. The case is different on the male side; for two kinds of gametes are formed, one kind with an X-chromosome and the other with a $Y$-chromosome. These are formed in exactly equal numbers, as one of each is produced at every reduction division. Each egr must be fertilized by one or the other of these two kinds of sperms, and in the long run as niany eggs will reccive an X-chromosome as will receive a Y-chromosome. Those that receive an X-chromosome will be characterized by having two $\mathrm{X}$-chromosomes, which is the typical female condition, and thus a new female individual is started in life; while those that receive no $\mathrm{X}$-chromosome, but a Y-chromosome, will have the $\mathrm{XY}^{+}$composition characteristic of the male sex, and will give rise to males. The female sex may thus be desimnated as XX and the male sex as XY. We have shown for Drosoplila the exact mechanism that operates in determining whether an individual 
shall be a male or a female, and in addition we have explained why equal numbers of both sexes are continuously produced.

How general is the chromosomal mechanism of sex-determina-
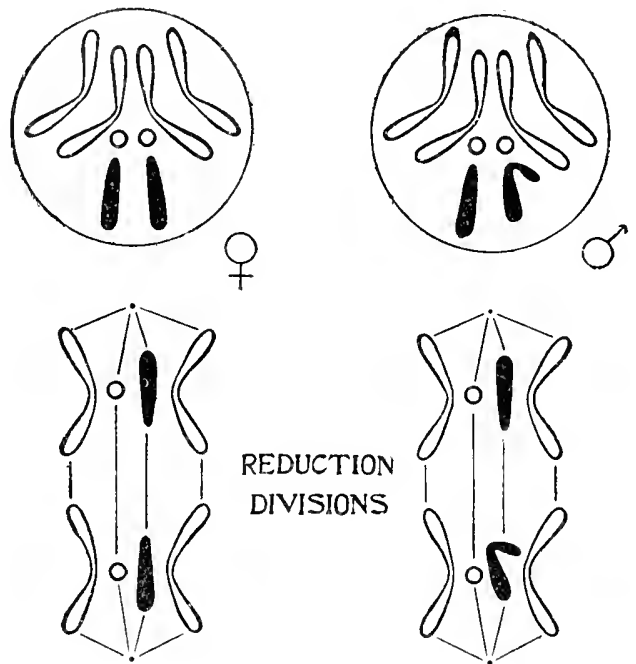

REDUCTION DIVISIONS
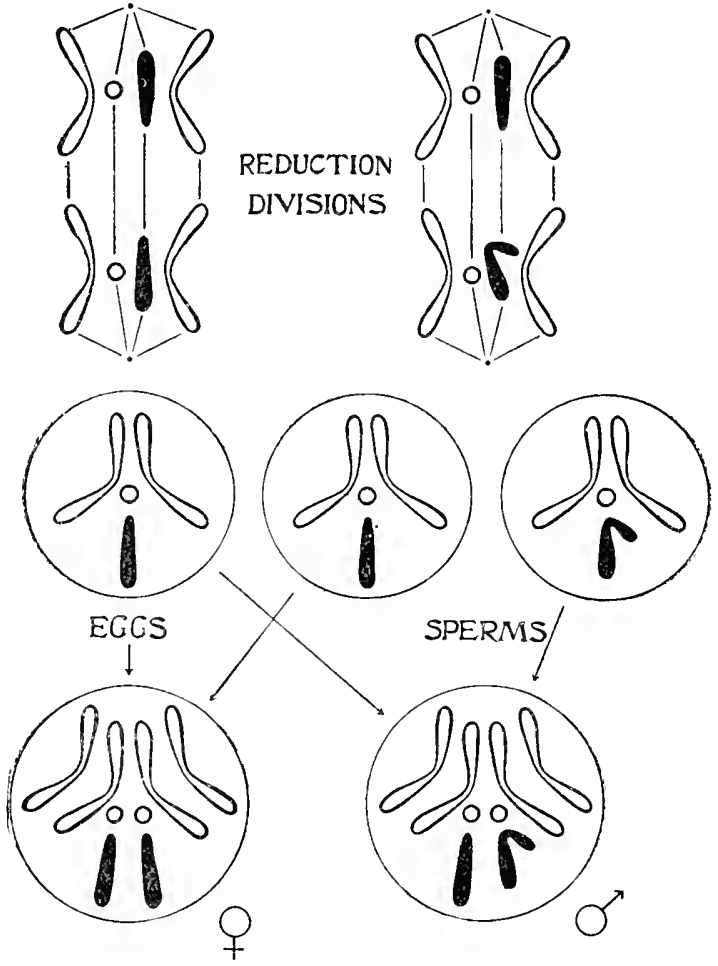

FIG. 53.-Diagram showing chromosome relations in the determination of sex in Drosophila ampelophila. (From Babcock and Clausen.)

tion?-"To what extent," says E. B. Wilson, "sex may be determined by an automatically operating nuclear mechanism such as has been here described is unknown; but a mechanism that exists in the same 
general form in organisms as diverse as bryophytes, nematodes, echinoderms, arthropods and vertebrates is beyond a doubt of far-reaching significance, and may be as widely distributed as Mendelian heredity generally." While the same general scheme holds for all forms that have been investigated, there exist many interesting differences in the details of operation of the sex-determining machine. Some of the simpler variations of the process are as follows:

a) Variations of the $Y$-chromosome.-Beginning with a condition such as that described for Drosophila, in which the $\mathrm{Y}$-chromosome is larger than the $\mathrm{X}$-chromosome, there is a long series of species in which the $\mathrm{Y}$-chromosome becomes smaller and smaller until it dwindles away to nothing and the male chromosome condition becomes $\mathrm{XO}$ instead of XY. In the females of such species the condition remains XX.

b) Variations of the $X$-chromosome.-In a number of species of animals the $\mathrm{X}$-chromosome may be represented by from two to nine components, each of which at times has the appearance of a separate chromosome. In a species of roundworms, Ascaris canis, for example, the diploid chromosome number of the female is thirty-six and that of the male is thirty, the difference being due to the fact that there are two sets of six X-components in the female and only one set in the male. In the reduction division of the male germ cell, the six $\mathrm{X}$-components all go in a group to one gamete and none to the other, so that two kinds of gametes are produced, one with eighteen chromosomes and the other with twelve chromosomes. All the female gametes have eighteen chromosomes. Apart from the fact that the X-chromosome is in six pieces instead of but one, the mechanism of sex determination is the same as it is in a group that has but one $\mathrm{X}$-chromosome.

c) Linkage of sex chromosome with autosome.-In a great many species of insects the X-chromosome has been found to be united to one end of one of the autosomes, never losing this relation during the entire chromosome cycle. Apart from this apparently secondary union with an autosome, the behavior of the $\mathrm{X}$-chromosome is the same as in the XO cases described above. Hence the mode of sex determination is in line with the types already discussed.

d) Female digamety.-In this mode of sex determination two different kinds of eggs are produced, while the sperms are all alike. In other words, there is simply an exchange between the sexes of the nuclear differences characterizing males and females. Thus in the Lepidoptera (butterflies and moths) the females have either the XY or the XO type of chromosome complex, while the males always have the $\mathrm{XX}$ condi- 
tion. Though the cytological evidence is still incomplete, it is practically certain that hircls have the same peculiar method of chromosomal sex determination as the Lepidoptera, for they have the same type of sex-linked herclity as the latter and the opposite of that seen in mammals and most insects. Apart from the change of the digametic condition from one sex to the other, the mechanism remains the same.

Sex chromosomes in parthenogenesis. - When it became known that parthenogenetic species (those in which eggs are capable of developing without fertilization) in some cases produce males and in other cases produce females from parthenogenetic eggs, this seemed to be out of accord with the theory of the chromosome mechanism of sex determination. It is interesting to know, however, that, now that we know the histories of the chromosome cycles in these species, the facts are not only fully in accord with the chromosome theory, but greatly strengthen it and enlarge its range of applicability. Two kinds of parthenogenesis are known, which may be designated diploid and haploid. In the former, the developing egg and embryo has the full somatic number of chromosomes; in the latter, only half the somatic number characteristic of the species is present.

a) Diploid parthenogenesis. - In these species only one maturation division occurs, and this division is not the reduction division; hence each egg retains the diploid number of chromosomes, including two $\mathrm{X}$-chromosomes (XX). The result is that all eggrs that behave in this way develop into females. Thus in aphids and phyloxerans many successive generations, of all females are produced. After a series of female generations, a mixed generation appears in which males are produced parthenogenetically along with females, but from smaller eggs. Examination reveals the fact that male-producing eggs have, after maturation, two less chromosomes than the female-producing eggs. This was explained by the observation that when the first maturation takes place, two chromosomes (obviously consisting of a double $\mathrm{X}$-element) are cast out into the polar body, while all the autosomes and two of the $r$-chromosomes remain in the egg nucleus. In this way the male produced from this egg comes to have only two $\mathrm{X}$-chromosomes, while the femalc has four. This is really the equivalent of $\mathrm{XX}$ for the femate and $\mathrm{XO}$ for the male. In gamete formation the males produce two kinds of gametes, one with the double $\mathrm{X}$-element and the other with no X-element. Only the former of these is viable; and this accounts for the fact that all fertilized eggs produce females, for both gametes surply double X-elements. This 
whole rather intricate wory is thus seen to be merely a variant upon the typicat scheme of chromosonal sex determination.

b) Haphid parthenenesis. - This lind of parthormmesis is now known to necur in rotifers, in several orders of insects, and in arachnicls. it is practically miverst ameng the IIymenoptrora (hees, wasps, ants, etc.), and we may uce the case of the honcy bee as an illustration. In haploid parthenogenesis the ege develops after having undergone the reduction division; it therefore has only half the somatic number of chromosomes, including but one X-chromosome. Snvarially the progeny from haploid parthenogenesis are maies, which we might expect from the fact that they have but one $\mathrm{x}$-chromosene. In the bees the queen seems to be able to detemine whether an egr sets fertilized or not. An egg descends the ovidnct, passes the semina? recejracle containing a supply of sperms acquired during the mating act, and if sperms are viven oft, fertilization occurs and a female is prorucul; but if an egg slips past the seminal receptacle without being fertilue l. the result is a male (drone). Now these drones are the mates of the fut ure queens, and must supply the spermatura for the naxt generation of egrs. They already possess the reduce! number of chomosomes, so they cannot well undergo the reduction division in formine gametes. It is intertsting to note, however, that a sort of vestinint reduction division takes place resulting in the fomm tion of a timy cell without any nucleus and a larger cell with all the chromocomes (incluling one shomosome)

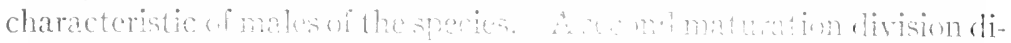

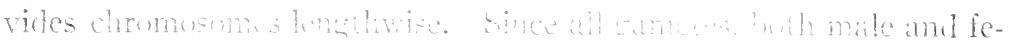

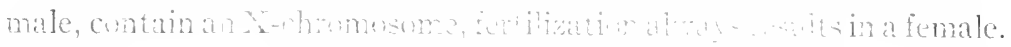

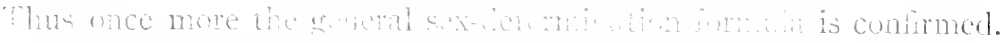

Sex-chromosomes in hemaphrodiss aud gJnandromorphs.-Lermaphotites are individuals which are furetiondlly loth male and lumale, that produce both ers and spems in the sane boly. Irermaphroditism is common in snails, flatwomm, curthrolns, nematodes, tunicates, and in several other phyla of animals. Sie have unfortunately very little information about the chromosome situations in these forms. In one species of nomatode ( 1 notistomun nirovenosum). however, it is known that there is an alternation of generations hetween a parasitic hermaphroditic generation and a free-ling dioecious generation (with separate males and females). In the lioecious generation males and females are aloot equally numerns. All fertibed eggs of this generation prouluce parasitic hermantrubles. These produce from their gonar's first ongonia and hat spermatngonia, the form- 
er producing eggs and the latter spermatozoa. It is known that all eggs of the hermaphrodite generation have six chromosomes, while the sperms have either five or six. Self-fertilization takes place, and half of the fertilized eggs produce males with (eleven chromosomes) and half produce females (with twelve chromosomes) of the free-living generation. The males of the dioecious generation produce two kinds of gametes with respectively five and six chromosomes, and one would expect males and females to be produced from fertilization; but this is not what happens, for only hermaphrodite individuals with twelve chromosomes are produced. It seems certain that only one of the two kinds of spermatozoa (that with six chromosomes) is viable, and that the hermaphrodite generation is chromosomally female. How can a female produce spermatozoa of two kinds, one with six and the other with five chromosomes? This is explained by the fact that in the second maturation division one of the $\mathrm{X}$-chromosomes remains near the equator of the spindle, and does not become included within the daughter-nucleus. Thus one of the daughter-cells is without an $\mathrm{X}$-chromosome and is male-producing when fertilization takes place. Further investigation of the chromosomes of hermaphrodites will doubtless be in agreement with what we already know.

Gynandromorphs are individuals made up of some female body regions and some male body regions. Thus, an insect may have male secondary sexual characters on one half of the body and female characters on the other; or the anterior end may be male and the posterior, female. The chromosomal basis for these conditions is not entirely clear, but Morgan and Bridges have shown that all of the peculiarities of the hereditary behavior can be explained on the assumption that in the first or second cleavage division one of the X-chromosomes lags behind and is excluded from one of the daughter-cells. Thus one daughter-cell gets $\mathrm{XX}$ and the other $\mathrm{X}$, which accounts for the fact that all the cell descendants of one cell have the female characters and all those of the other cell, male characters.

Intersexes and their bearing on sex determination.-Bridges, during his experiments with Drosophila, encountered in certain strains anomalous individuals that were neither male nor female, but intersexes. On cytological examination these were found to have a changed chromosome complex. One type, for example, was found to have three of one kind of autosomes (instead of the usual two) but only two $\mathrm{X}$-chromosomes. The interesexual condition in this case might be explained by the assumption that the autosomes have a male-produc- 
ing tendency and that one set of extra autosomes is sufficient partially to overcome the female tendency of two $\mathrm{X}$-chromosomes, thus producing intersexes. Again, individuals with three $\mathrm{X}$-chromosomes but only the usual supply of autosomes were super-females somatically, but unbalanced in their physiology and non-viable. These results show that, in the words of E. B. Wilson, "the actual performance of the zygote, therefore, is the common effect of the whole group, and is turned this way or that as the result of a quantitative balance between $X$-chromosimes and autosomes."

\section{SEX DIFFERENTIATION}

It now becomes necessary to distinguish clearly between sex determination and sex differentiation. When we say that by means of a chromosomal mechanism sex is determined, exactly what do we mean? We answer that the sex of an individual arising from a fertilized egg (in the case of parthenogenesis, an unfertilized egg) has been settled. Now as a matter of fact only one thing has been settled irrevocably, and that is that one individual will have the chromosome composition characteristic of a male and another individual that of a female. A male is usually an individual that produces spermatozoa and a female one that produces ova. Is it irrevocably settled beyond possibility of reversal that a zygote with the $\mathrm{XX}$ chromosome composition must produce eggs and one with the $\mathrm{X}$ composition, spermatozoa? This question has apparently been answered by Geoffrey Smith in his work on parasitically castrated crabs and by Richard Goldschmidt on Gypsy moths. In the first case, individual crabs whose testes had been infested by the parasitic cirripede, Sacculina, were gradually changed over in their whole metabalism to such an extent that cells destined to produce spermatozoa produced ova. In the second case, when certain varieties of moth were crossed, all of the germ cells produced females with ova, whereas half of the eggs had the XX and half the $\mathrm{X}$ chromosome content. This evidently means that some individuals with the male chromosome character produced eggs. From these results we may be justified in concluding that not even this most fundamental difference of sexes, that of the female producing ova and the male spermatozoa, is irrevocably predetermined at fertilization.

Lest the reader be confused, however, we hasten to add that under natural conditions of life an individual with the male chromosomal content produces spermatozoa and one with the female chromosomal content produces eggs, and that only rare accidental or unnatural 
conditions disturb the normal course of events. For purposes of practical genetics we may then define a female as an inclividual that produces ova and a male as one that produces spermatozoa.

Secondary sexual characters.- Usually males and females differ from each other in many other characters besides the production of eggs or sperm. Often one sex is larger, stronger, more elaborately ornamented and colored than the other and possesses characteristic accessory sex organs whose function it is to facilitate the bringing together of the eggs and the sperm. All of the differences between the sexes other than the primary difference of egg or sperm production are called secondary sexual characters. Usually very young animals show only slight differences in secondary sexual characters and the differences increase markedly at sexual maturity. We speak of the gradual divergent development of the two sex types as sex differentiation. The question arises as to whether or not the chromosomal differences are the causes of the differentiation of secondary sexual characters. These secondary sexual characters are all somatic, and, since the soma is the product of cell division of the zygote, the soma cells must have either the male or the female chromosomal character. That the chromosomal mechanism in the somatic cells is not sufficient of itself to bring about, unaided, the differentiation of secondary sexual characters can be shown readily in at least many animals.

In the mammals, for example, it is known that the early removal of the testes or ovaries results in a retention of the juvenile or undifferentiated condition of secondary sexual characters. Evidently some influence is exerted by the tissues of the gonad that is necessary for the full differentiation of sex characters. The current theory is that certain glandular cells that form part of the body of ovary or testes excrete materials into the blood that stimulate various tissues in different ways and produce dimorphic results. The specific substances produced by these glands are called "hormones," for want of a better name. To test the efficiency of these hormones the crucial experiment of taking out the gonads of a young rat or guinea pig and implanting the gonad of an individual of the opposite sex has been many times performed. For example, Steinach castrated young male rats and then successfully grafted into them ovaries from young female rats. The result was that these young rats which started to be males became much altered in a female direction, the mammary glands becoming greatly enlarged, their instincts more feminine than masculine, and in a number of other particulars they showed more or less pronounced evirlences of feminization. Conversely, spayed 
females with engrafted testes showed a tendency toward male differentiation, especially in instincts. These experiments have been largely confirmed by C. R. Moore.

In birds it is of interest to note that practically complete reversial of secondary sexual characters may be induced if young females are entirely deprived of the ovary. The condition is described by L. V. Domm as follows:

"The larger percentage of our birds have assumed adrlitional male characters following removal of the oraries, until they are practically complete replicas of the male, and, to those not familiar with their history, they are regarded as unmistakable males. Thus we find that they assume the complete male plumage, spurs grow as they do in the normal cock, head furnishings increase in size until they can not be distinguished from those of the normal male.

"Other birds in the pen regard them as males and when a strange cock is introduced they fight as would other cocks, very frequently assuming the initiative, some of them having been observed to come off victorious in such a comlat. Many of these birds crow regularly. When aroused by a disturlance, it was found that their reaction is very similar to that of the male; the sounds they make, together with their reaction on such occasions, reminds one very much of the young male just prior to maturity.

"One set of experiments may be mentioned as an example: Out of the one lot of fourteen females of the same hatch, one was kept as control and thirteen were operated upon between the ages of six weeks and six months; twelve of these have developed all the characteristics of the male mentioned above, some being completely cock-feathered, while the others are fast becoming so. The other one of the thirteen is very capon-like in appearance except perhaps for size and can not be readily distinguished from her capon brothers by those not knowing her history. This lird has assumed complete male plumage, is developing spurs; but the comb, wattles and earlobes are pale and small, resembling those of the capon.

"In some of our cases individuals which have assumed more or less complete male characters as concerns head furnishings, plumage and spurs, are reverting toward the female type as shown by the female type of plumage reappearing.

"Our results indicute that the female in the brown leghorn fowl has many potentialities of the male, which are normally inhilited by the presence of the ovary, and that these potentialities can assert 


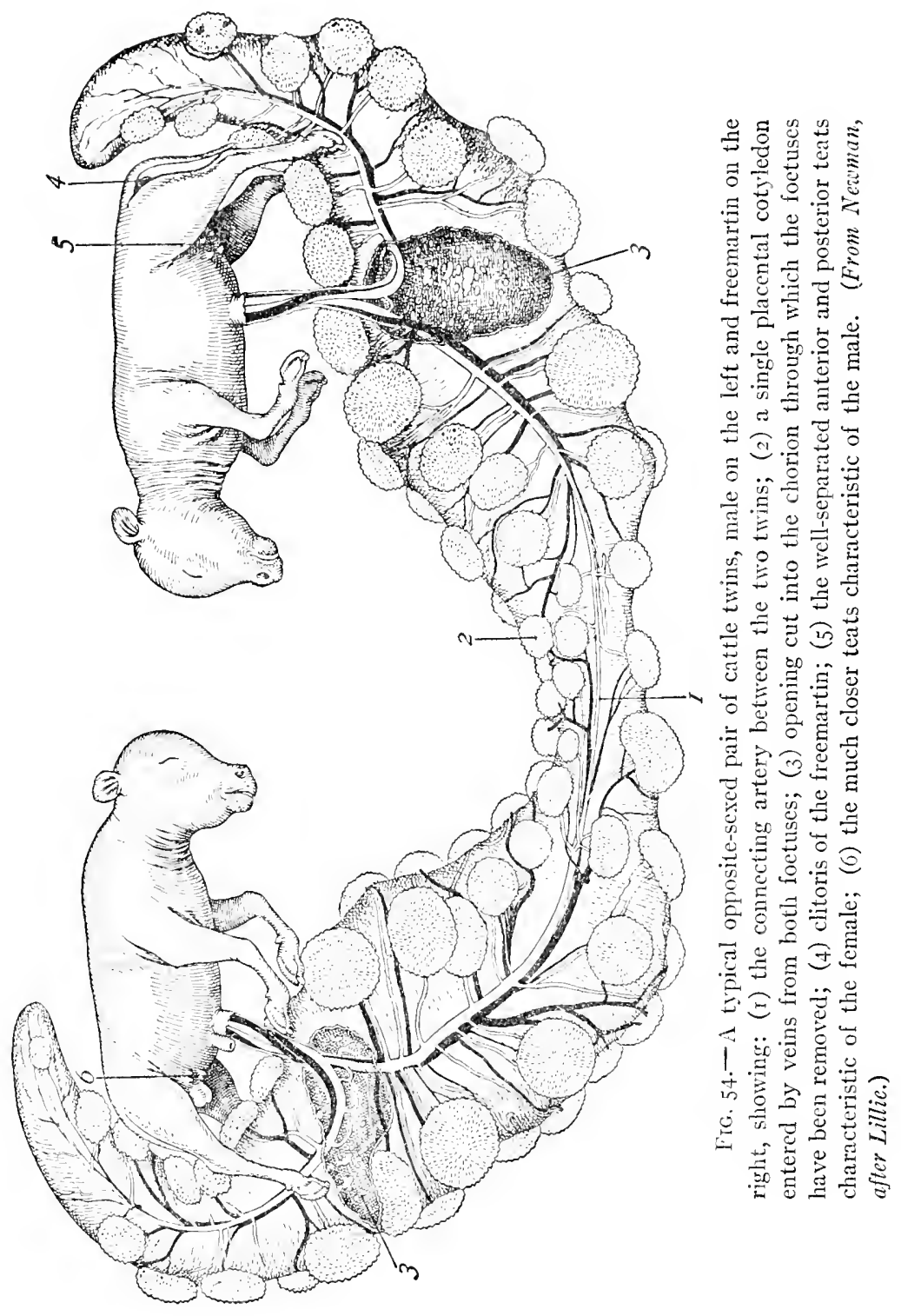


themselves approximately fully after the complete removal of the ovary at an early age."

A beautiful experiment conducted by nature herself helps to drive home the hormone theory of sex differentiation. In cattle, as shown recently by $\mathrm{F}$. R. Lillie, twins occur in a small percentage of cases and involve the simultaneous fertilization of two eggs. These eggs lie as a rule in opposite horns of the forked uterus, but owing to the growth of their embryonic membranes the two individuals come to fuse circulations so that there is an admixture of blood (Fig. 54). The result is that if the twins are zygotically of the same sex no untoward effect of blood admixture is apparent, but when the twins are zygotically a male and a female, the female individual is always stopped in its female differentiation and becomes more or less completely transformed in a male direction. It appears, however, that at the time when blood admixture occurs, the female individual has already differentiated so far with respect to the external genitalia and in other respects that, even though subsequent development be entirely male in character, the resultant individual is always a sterile creature, neither fully a female nor a complete male. Such individuals have long been known as "freemartins." As a rare exception to the general rule an occasional case has appeared in which a male and a female pair fail to undergo blood admixture. In such cases both develop into normal animals. It now appears that the reason why the female sex is the one to suffer is that the male gonads differentiate precociously, before the female, and inhibit the subsequent development of female gonads. Hence the only hormones in the blood of both twins are the male hormones.

In conclusion we may say then that, in mammals, though chromosomes tend to determine the primary sex differences, they have no effect on the differentiation of secondary sexual characters. These are due to substances secreted by the gonads that have been called hormones. 


\section{CHAPTER XVHI \\ MENDEL'S LAWS OF HEREDITY}

MENDEL'S LIFE AND CHARACTER

J. ARTIIUR THOMSON

Gregor Johann Mendel was born in 1822, the son of well-to-do peasants in Austrian Silesia. He became a priest in 1847 , and studied physics and natural science at Vienna from $185 \mathrm{I}$ to $\mathrm{I} 853$. Thence he returned to his cloister and became a teacher in the Realschule at Brünn. It was his hobby to make hybridisation experiments with peas and other plants in the garden of the monastery, of which he eventually became abbot. Apart from two papers, one dealing with peas and a shorter one with hawkweeds, and some meteorological observations, he does not seem to have published much. But what he did publish, if small in quantity, was large in quality. He died in I884.

\section{MENDEL'S DISCOVERIES}

In I 866 Gregor Johann Mendel, Abbot of Brünn, published what some regard as one of the greatest of biological discoveries. After many years of patient experimenting, chiefly with the edible pea, he reached a very important conclusion in regard to the inbreeding of hybrids, which is often briefly referred to as "Mendel's Law." His publication was practically buried in the Proceedings of the Natural History Society of Brünn; those who knew of it, as Nägeli for instance did, failed to realise its importance: in fact, Mendel's epoch-making work was lost sight of amid the enthusiasm and controversy which the promulgation of Darwinism (1858) had evoked. Mendel's Law seems to have been rediscovered independently in 1900 by the botanists, De Vries, Correns, and T'schermak; and to Mr. Bateson we owe much, not only for his recognition of the far-reaching importance of the abbot's work, but also for a notable series of experiments in which he has confirmed and extended it.

From J. Arthur Thomson, Bredity (conyright 1907). Used by special permission of the Rulishers, John Murray, London. 
Mendel's experiments. - What Mendel sought to discover was the law of inheritance in hybrid varieties, and he selected for experiment the edible pea (Pistm sativum). The trial plants, he says, must possess constant differentiating characters, and must admit of easy artificial pollination; the hybrids of the plants must be readily fertile, and readily protectable from the influence of foreign pollen. These conditions were afforded by peas, and twenty-two varieties or subspecies of pea were selected, which remained constant during the eight years of the experiments. Whether they were called species, or subspecies, or varieties, is a matter of convenience; the names Pisum quadratum, $P$. saccharatum, $P$. umbellatum, etc., do in any case represent groups of similar individuals which breed true inter se. It should be noted that these peas have the particular advantage, for experimental purposes, that they are habitually self-fertilised-in North Europe, at least.

In studying the different forms of peas, Mendel found that there were seven differentiating characters which could be relied on:

I. The form of the ripe seeds, whether roundish, with shallow wrinkles or none, or angular and decply wrinkled:

2. The colour of the reserve material in the cotyledons-pale yellow, bright yellow, orange, or green;

3. The colour of the seed-coats, whether white, as in most peas with white flowers, or grey, grey-brown, leather brown, with or without violet spots, and so on;

4. The form of the ripe pods, whether simply inflated, or constricted, or wrinkled;

5. The colour of the unripe pods, whether light or dark green, or vividly yellow, this colour being correlated with that of stalk, leafveins, and blossoms;

6. The position of the flowers, whether axial or terminal; and

7. The length of the stem, whether tall or dwarfish.

Mendel's results; the Law of Dominance.-Having defined the differentiating characteristics of the varieties, Mendel proceeded to make crosses between these, investigating one character at a time. Thus, pollen from a pea of the round-seeded variety was transferred to the stigma of a pea of the angular-seeded variety, the stamens of the artificially pollinated flower being, of course, removed before they were ripe. The same was done all along the line.

What was the result in the hybrid or cross-bred offspring? It was found that they showed one of each pair of contrasted characters, to 
the total, or almost total, exclusion of the other. No intermediate forms appeared.

Mendel called the character that prevailed dominant, and the character that was suppressed, or apparently suppressed, recessive. And the first big result was that crosses between a plant with the dominant character and a plant with the recessive character yielded offspring all resembling the dominant parent as regards the character in question. Let us for shortness call the parents $D$ and $R$, and the first result may be expressed thus: $\mathrm{D} \times \mathrm{R}=\mathrm{D}$.

It must be carefully noted that the complete dominance which Mendel observed has been shown in other cases to be the exception rather than the rule. Thus a cross between a "Chinese" primula with wavy crenated petals and a "star" prinula with flat simply notched petals is intermediate between the two parents; and yet, as the next generation shows, the case is one of Mendelian inheritance.

In many cases the hybrid, while on the whole dominant, may show some influence of the recessive character but not nearly enough to warrant us in speaking of a blend. Thus, when white (dominant) Leghorn poultry are crossed with brown (recessive) Leghorn, most of the offspring have some "ticks" of colour. When these are inbred they produce a quarter brown (extracted recessives) and threequarters pure white or white with a few ticks. The dominance is not quite perfect.

The Law of Splitting or Segregation.-In the next generation the cross-bred plants (products of $\mathrm{D}$ and $\mathrm{R}$, or $\mathrm{R}$ and $\mathrm{D}$, but all apparently like $D$ ) were allowed to fertilise themselves, with the result that their offspring exhibited the two original forms, on the average three dominants to one recessive. Out of $\mathrm{I}, 064$ plants, 787 were tall, 277 were dwarfs.

When these recessive dwarfs were allowed to fertilise themselves they gave rise to recessives only, for any number of generations. The recessive character bred true.

When the dominants, on the other hand, were allowed to fertilise themselves, one-third of them produced "pure" dominants, which in subsequent generations gave rise to dominants only; and two-thirds of them produced once again the characteristic mixture of dominants and recessives in the proportion of $3: \mathrm{I}$.

The general results may be expressed in the scheme. The result of the hybridisation is a generation $\left(F_{\mathrm{r}}\right)$ like the dominant parent. They may be represented by the symbol $D(R)$, for they 


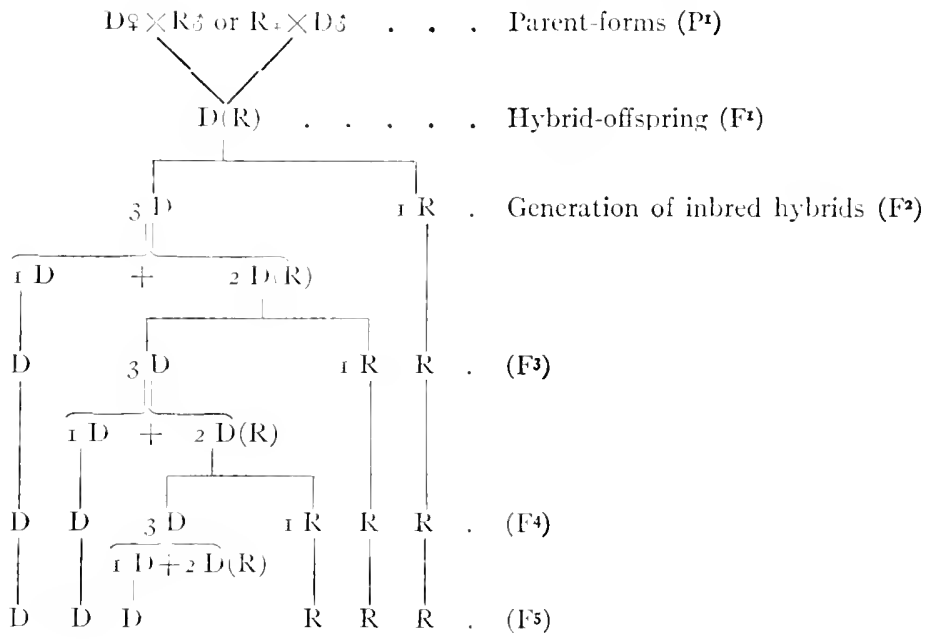

carry with them the possibility of having of spring with the recessive character; that is to say, the recessive character remains latent in the inheritance.

When these $\mathrm{I}(\mathrm{R}) \mathrm{s}$ are inbred (self-fertilised, in the case of peas) they have ofispring $\left(\mathrm{F}_{2}\right)$, some of which resemble the recessive parent, while others resemble the dominant parent, and these occur in the proportion of $\mathrm{I}: 3$. When those resembling the recessive parent are inbred, they frced true - i.e., they give rise to a line of pure recessives. Those resembling the dominant parent are all apparently alike, but their sulseguent history shows that they may be divided into a set which breed true to the dominant type and a set which behave like the first generation of hybrids-i.e., they go on splitting up into dominantlike forms and pure recessives. These two sets occur in the proportions of $\mathrm{I}: 2$.

A case of peas. - Let us consider a concrete case. Peas with rounded seeds were crossed with peas having angular wrinkled seerls. In the offspring the character of roundness was dominant; the angular wrinkled character had disappeared or receded. It was not lest, as the next generation showerl.

The hylsrid offspring, all with rounded seeds, were allowed to selffertilise. In their progeny roundish seeds and angular wrinkled seeds occurred in the proportions of $3: 1$. Here were the recessives atsin, and when they were allowerl to self-fertilise they prorluced pure recessives only, with angular wrinkled seeds. 
The dominants, however, were not all pure dominants, for when they were allowed to self-fertilise they produced one-third pure dominants and two-thirds "impure" dominants, the latter being distinguished by the fact that in their offspring recessives reappeared in the proportion of one recessive to three dominants.

The outstanding facts, taking the case of yellow-seeded and greenseeded peas, may be thus summarised:-

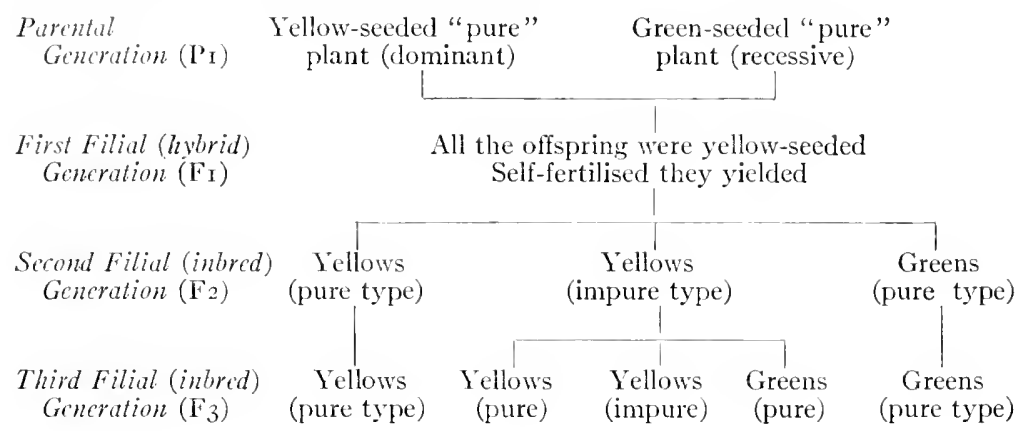

Thus intercrossing of forms with contrasted characters results not in transitional blends, but in the dominance of one character and the recession of another. Self-fertilisation (the extreme of inbreeding) of the hylurids results in a number of pure recessives and a number of dominants in the proportion $\mathrm{I}: 3$; some of these dominants (one-third) are pure, and produce only dominants; some (two-thirds) are apparently pure, but produce dominants and recessives in the old proportion, $3: \mathrm{I}$.

A case of mice.--Let us take a concrete case from among animals. A grey house-mouse is crossed with a white mouse; the offspring are all grey. Greyness is dominant; albinism is recessive.

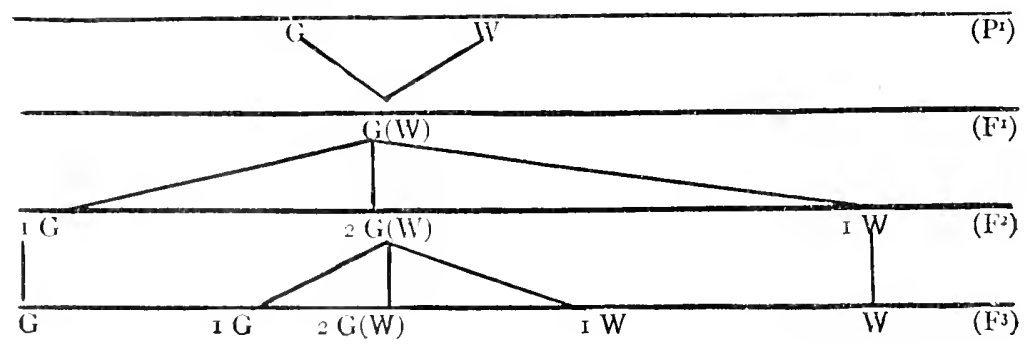


The grey hybrids are inbred; their offspring are grey and white in the proportion 3:I. If these whites are inbred they show themselves "pure," for they produce whites only for subsequent generations. But when the greys are inbred they show themselves of two kinds, for one-third of them produce only greys, which go on producing greys; while the other two-thirds, apparently the same, produce both greys and whites. And so it goes on.

Summary.-In his exceedingly clear exposition of Mendelism (I905) Mr. R. C. Punnett states the result thus: "Wherever there occurs a pair of differentiating characters of which one is dominant to the other, three possibilities exist: there are recessives which always breed true to the recessive character; there are dominants which breed true to the dominant character, and are therefore pure; and thirdly, there are dominants which may be called impure, and which on self-fertilisation (or in-breeding, where the sexes are separate) give both dominant and recessive forms in the fixed proportion of three of the former to one of the latter."

Schematic representation of Mendel's Law.-Following Mr. Punnett's suggestion, with slight modifications, we may use the symbols $\mathrm{P}_{\mathbf{1}}, \mathrm{P}_{\mathbf{2}}, \mathrm{P}_{\mathbf{3}}$ for the parental, grandparental, and great-grandparental generations; $F_{x}$ for the first filial (hybrid) generations, $F_{2}, F_{3} . F_{4}$ for the subsquent inbred generations. The symbol $D(R)$ means a dominant with the recessive character unexpressed, but potentially present; DD or RR means pure "extracted" dominants or recessives-i.e., those pure forms which are sifted out from the inbreeding of "impure" dominants.

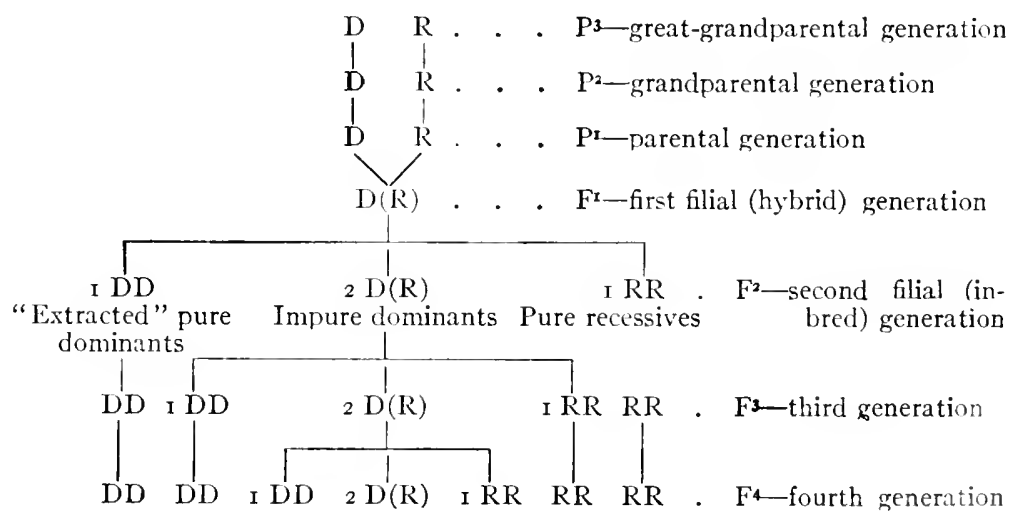




\section{MENDEL'S EXPLANATIONS}

JOHN M. COULTER AND MERLE C. COULTER

Mendel's explanation of this behavior involved three theses which at that time were new to biology. These theses must be kept distinct from one another.

I. Independent unit characters.-This means that an organism, although representing a morphological and physiological unity, from the standpoint of heredity is a complex of a large number of independent heritable units. Thus if one pea plant is tall and another one is dwarf the behavior of the hylurid produced from them with reference to this character will be the same, no matter what other characters the parent plants may have had. In other words, the characters are independent units, unaffected by other characters or units. The character of tallness from a tall plant with wrinklerl seeds or purple flowers will act just the same as from a tall plant with smooth seeds or white flowers. Tallness is a unit and its behavior in inheritance is independent of all other units.

2. Dominance.--In the germ plasm there are certain determiners of unit characters which dominate during the development of the body, causing these characters to dominate over others and thus become visible. The characters dominated over and thus not allowed to express themselves are called recessive characters. These recessive characters are present in the germ plasm, but cannot express themselves and become visible as long as the dominant characters are present. When a dominant character is alssent, however, its recessive alternate is free to express itself and become visible.

For example, in the casc of tall and dwarf peas, tallness is a dominant character and dwarfness is its alternative recessive. When a dwarf appears, therefore, there is present no dominant tallness to suppress it. In the $\mathrm{F}_{\mathrm{r}}$ generation all the individuals were tall because, although they had all received the recessive character of dwarfness from one of the parents, they had received the dominant character of talness from the other parent, and so dwarfness did not appear in any of them. Such pairs of alternative characters are now commonly called allelonorphs. Thus tallness and dwarfness are allelomorphs in the pea, one dominant over the other, which is therefore recessive.

3. Purity of gametes.-A gamete can contain only one of two alternative characters. For example, it may contain the character

I From Coulter and Coulter, Plant Genetics (The University of Chicago Press copyright I9r8). 
for tallness or for dwarfness, but not both. In other words, allelomorphs cannot be represented in the same gamete. If the gamete having the character for tallness unites with one having the character for dwarfness, the resulting zygote will contain both, but will produce a tall individuai because tallness is dominant over dwarfness. When this tall hybrid produces gametes, however, one-half of them will contain the character for dwariness. Thus the alternative characters are "segregated" in gamete formation and no gamete will have both characters.

These three theses, independent unit characters, dominance, and purity of gametes (better called segregation), make up the theoretical explanation of Mendel's law. Independent unit characters was of course a necessary conception. It was original with $M$ Iendel, and has also been original with other investigators, but this conception does not represent the essential feature of Mendel's law. The idea of dominance had been somewhat vaguely proposed before Mendel's time. In the old literature on animal breeding one meets theories of prepotency, which were proposed again and again before the discovery of Mendel's work in I900. In any event Mendel was the first to formulate definitely the theory of dominance among unit characters. It should be realized also that dominance is not an essential feacure of Mendel's theory. Many cases are known in which dominance fails, but in other regards the Mendelian inheritance is strictly followeci.

The essential feature of Mendel's theory is his conception of the purity of gametes, brought about by the segregation of alternative characters. The striking fact is that this conception, purely theoretical with Mendel, has since been confirmed by cytology. In the mechanism of cell division each chromosome is divided into two equal parts and each daughter-cell receives one of these parts. It is a reasonable inference that cliromosomes are bearers of hereditary characters. In the production of gametes the number of chromosomes, characteristic of the organism is reduced one-half. As a consequence each gamete carries only one-half the characters of the individual that produced it. An application of these statements to an explanation of Mendel's $3:$ I ratio will illustrate the situation.

For convenience we will assume that the nuclei of Mendel's peas have four chromosomes each (Fig. 55 ). In the case of a tall plant two of the four chromosomes carry the character for tailness, that is, something that determines the production of the tall character in the somatoplasm, which is practically the body butilder. This unknown 
something is called by various names in the literature of genetics, the commonest one being determiner. In our illustration, therefore, two of the four chromosomes carry the determiner for tallness. At this point two questions may be asked.

I. Why do just two of the four chromosomes carry the determiner for tallness rather than all of them or only one of them? Just here it would be difficult to explain why no more than two of the four chromosomes are represented as carrying the same determiner. This will be explained later. It is easy to answer, however, why the determiner is being carried by more than one chromosome. When gametes are formed the chromosome number is reducerl one-half. Since every gamete from a pure tall plant carries the determiner for tallness there

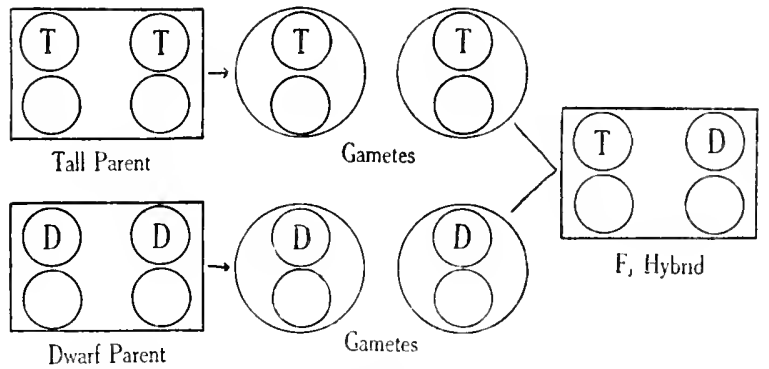

FIG. 55.-Diagram illustrating behavior of chromosomes in Mendel's cross of tall and dwarf peas. Large rectangular figures, nuclei of zyotes or mature individuals; large circles, gametes; small circles within zygotes and gametes, chromosomes; letters on chromosomes, determiners ( $T$, tallness; $D$, dwarfness). (From Coulter and Coulter.)

must have been at least two chromosomes carrying the determiner before the gametes were formed.

2. Do these two chromosomes carry any other determiner than that for tallness? In a tentative way this question may be answered in the affirmative, but a fuller discussion of the situation must be deferred. There is much experimental evidence that indicates that more than one determiner is carried on a single chromosome. In some cases also there are more Mendelian determiners than there are chromosomes.

The situation is represented in Figure 55. This shows a somatic cell with the diploid or $2 x$ number of chromosomes. In the formation of gametes this number is reduced to the haploid, or $x$ number, which in this case is two. The diagram shows that the reduction separates 
(segregates) the two chromosomes carrying the character for talliness, so that each gamete contains one. This occurs for the of her chancters as well as for that of tallness. From the tall plant, therefore, all the gametes will contain the character for tallness, and from a hwarf plint all of the gametes would contain the character for ciwarnes. When these two individuals are crossed the aygote will contain botir characters, and these two characters will be transmitted together in the succeeding cell generations. The individual from such a zygote of course would be tall, but at the same time it woukl be carrying a recessive determiner for dwarfness, and this lact would be shown by

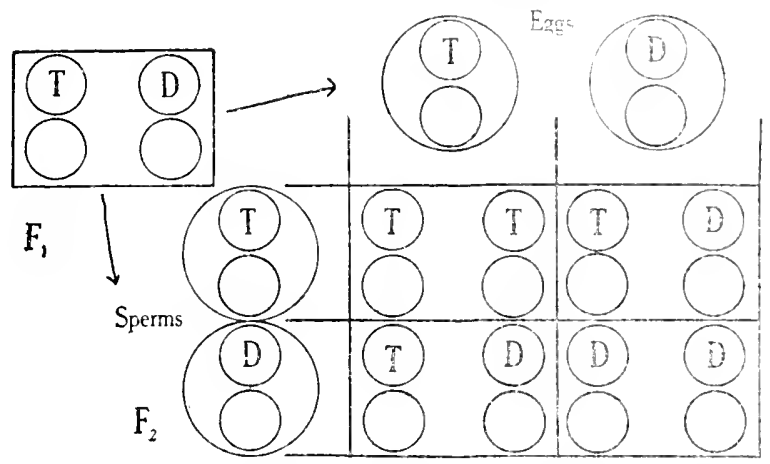

FIg. 56.-Diagram illustrating behavior of first hylorid generation $\left(F_{1}\right)$ when inbred. Illustrates meaning of "segregation" and "purity of ganctes" and how: chance matings of $F_{1}$ gametes result in 3: I ratio in $F_{2}$ seneration; dwarf individual produced only by zysote in lower right-hand corner. (From Conlter and Coulter.)

its behavior in breeding. The result of inbreeding such hybricls is indicated in the accompanying diagram ( $\mathrm{ig} .56$ ), which represents the chance matings of two kinds of gametes. 'The obrious results are three tall individuals and one dwart. This is the so-called monohy ryit ratio, which means the ratio when a single pair of allelomorphs is considered.

Before discussing the further development of Mentel's law it will be necessary to explain some of the teminology of genetics. When each gamete carries the same kind of doterminer the zygote is said to receive a double dose; when a zygote receives only a single such determiner it is said to receive a single dose. In Figure 56 one zygote recaives a double dose of tallness and two others a single dose. These phrases are more or less common in the literature of the subject, lut the more 
frequent terminology is as follows. When two similar gametes unite to form a zygote it is called a homozygote; when the two pairing gametes are different the zygote is called a heterozygote. Using this terminology it is evident that the 3:I ratio of the $F_{2}$ generation is really a $\mathrm{I}: 2: \mathrm{I}$ ratio, as follows: I homozygote for the dominant character, 2 heterozygotes, and I homozygote for the recessive character. The $1: 2:$ I ratio therefore is the significant one and appears as a $3: 1$ ratio only because of dominance.

In the experiment represented in Figure $5^{6}$ three tall individuals appear in the $F_{2}$ generation. Superficially the individuals look alike, but it is realized that I differs from the other 2 in germinal constitution, for I will produce only one kind of gamete, while the other 2 will produce two kinds. To indicate this situation Johannsen has introduced some appropriate terminology. Organisms which seem to be alike, regardless of their germinal constitution, are said to be phenotypically alike, or to belong to the same phenotype. On the other hand, organisms having identical germinal constitution are said to be genotypically alike, or to belong to the same genotype. From the standpoint of phenotypes only, Mendel's $\mathrm{F}_{2}$ generation shows the $3: \mathrm{r}$ ratio; but if genotypes are considered, it shows the $\mathrm{I}: 2: \mathrm{I}$ ratio. In other words, this group of forms contains two phenotypes but three genotypes.

Referring again to Figure 56 several things may be inferred. It can be seen what will happen in the $F_{3}$ generation when the $F_{2}$ individuals are inbred. The dominant homozygote will produce only dominant homozygotes in the $\mathrm{F}_{3}$ generation and will continue to produce them as long as it is inbred. The two heterozygotes will split up in the $\mathrm{F}_{3}$ generation in the same $\mathrm{I}: 2: \mathrm{I}$ ratio as did their hybrid parents of the $F_{1}$ generation. The recessive homozygote will produce only recessive homozygotes as long as it is kept pure by being inbred.

It is interesting to consider what will happen if a heterozygote form is crossed with a homozygous recessive. It should be obvious that one-half of the progeny would be pure recessives, while the other half would be heterozygotes, that is, there would be a $I: I$ ratio. A similar result would be obtained by crossing a heterozygote with a dominant homozygote, although all the immediate progeny would show the dominant character. The real situation would be revealed, however, when this progeny was inbred, for one-half would be homozygous (pure breeders) and the other half would be heterozygous (hybrid breeders). 
Thus far we have consirlered only what is called the monohyluric ratio, that is, the ratio obtained from one pair of contrasting characters, such as tallness and dwarfness. The next step is to consider the dihybrid ratio. Mendel also used contrasting seed characters, finding, for example, that smoothness in seerls is dominant to a wrinklerl condition. Introrlucing this pair of contrasting characters into the situation we have been consilering, the dihybrid ratio will be the result. Crossing a tall, smooth-seeded individual with a dwarf wrinkled-seeded inclividual it is evident that all of the $F_{I}$ or first hybrid generation will be tall, smooth-seeded individuals, since both of these characters are rlominant. In the $\mathrm{F}_{2}$ generation, however, the following ratio will appear: 9 tall smooth, 3 dwarf smooth, 3 tall wrinkled, I dwarf wrinkled; which is a $9: 3: 3: 1$ ratio. This is the dihybrid ratio, the explanation of which may be indicated in Figure 57 . The question may be raised why the characters for tallness and smoothness are not representer on the same chromosome. If they were, the result would be a simple monohybrid ratio, except that the tall individuals would always be smooth-seeded as well, and dwarfs would be always wrinkled-seeded. The possibility of one chromosome carrying two different determiners will be considered later, but at present we shall assume that these determiners are on different chromosomes.

Figure 57 shows that we are dealing with two homozygotes, each producing only one kind of gamete, so that all the hybrid progeny will be similar, both genotypically and phenotypically, that is, with the same germinal constitution and the same appearance. By inbreeding these $F_{x}$ individuals, it will be seen that four linds of gametes are inrolved. Crossing these four kinds of gametes the resulting combinations are indicated in Figure 57 . The result is four phenotypes, as follows: Nos. I, 2, 3, 4, 5, 7, 9, 10, I3 are tall smooth indiriduals; Nos. I , I 2, I5 are dwarl; Nos. 6, 8, I 4 are tall wrinkled; No. i 6 is dwarf wrinkled. This is the $9: 3: 3: 1$ ratio.

It will be noticed that Nos. I, 6, I I, I6 are homozygotes and therefore will breed trie; but the rest are heterozygotes, either for one pair of characters or for both, and these would split into various types upon further breeding.

The next step is the trihybrid ratio. Mendel found yellow seeds dominant over green seeds, and if this pair of characters is included with those used above the trihybrid result can be observed. The experiment would consist in crossing tall, smooth, yellow indixiduals with dwarf, wrinkled, green individuals; and it is obrious that the 
hybrid progeny would all be tall, smooth, yellow, since these three characters are dominant. Inbreeding the hybrids gives the following result in the $\mathrm{F}_{2}$ generation: 27 tall smooth yellow, 9 tall smooth green,

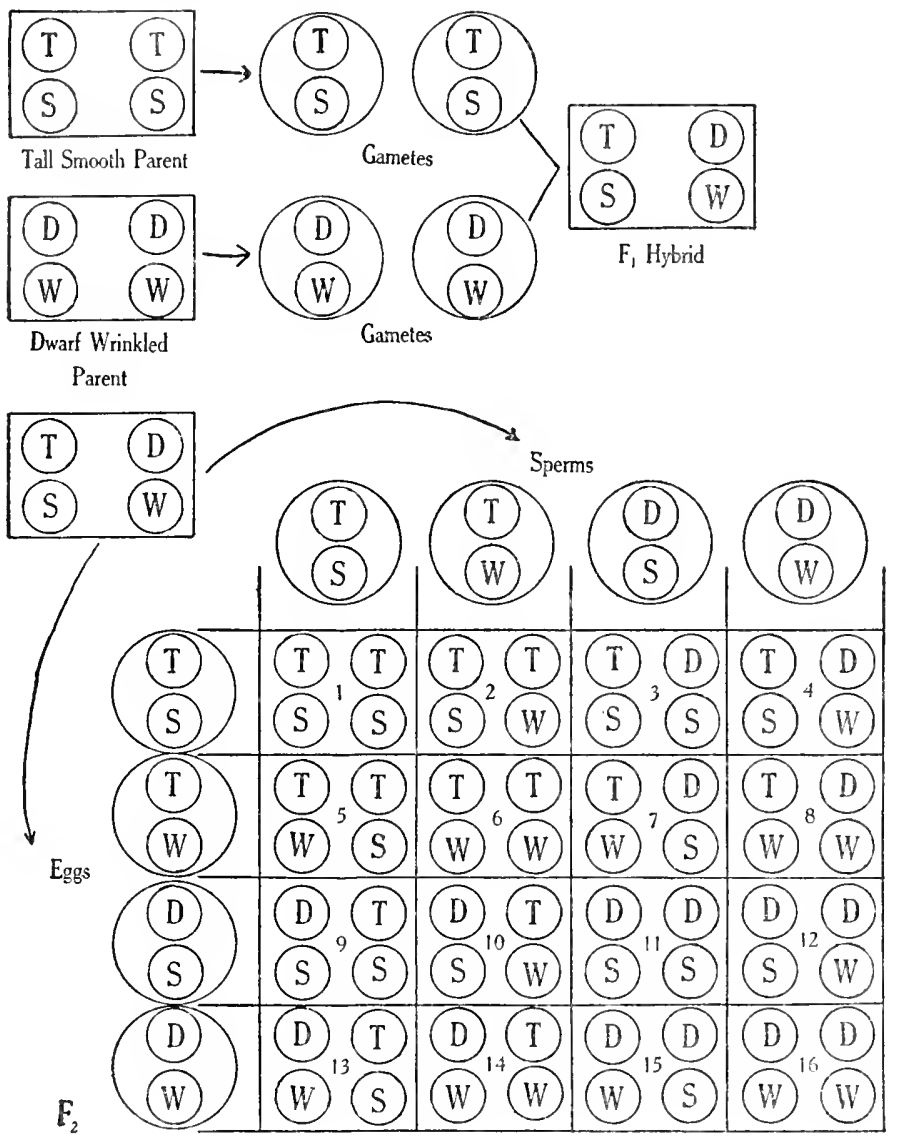

Fig. 57.-Diagram illustrating dihybrid ratio. Upper part shows how original parents were crossed to give $F_{x}$ hybrid; lower part shows $F_{I}$ hybrid producing four kinds of gametes; chance matiugs among these gametes, when $F_{x}$ is inbred, result as indicated in the large set of squares and explains the $9: 3: 3$ : I ratio in the $\mathrm{F}_{2}$ generation. (From Coulter and Coulter.)

9 tall wrinkled yellow, 9 dwarf smooth yellow, 3 tall wrinkled green, 3 dwarf smooth green, 3 dwarf wrinkled yellow, I dwarf wrinkled green. The trihybrid ratio therefore is $27: 9: 9: 9: 3: 3: 3: x$. This involves 64 individuals and 8 phenotypes. 


\section{ILLUSTRATIONS OF SIMTLE MENDELIAN INHERITANCE IN BOTI ANIMIALS AND PLANTS ${ }^{2}$}

J. ARTHUR THOMSON

How far has Mendel's experience been confirmed?-There has been confrrmatory work by Correns (on peas, maize, and gardenstock), by Tschermak (on peas), by De Vries (on maize, etc.), by Bateson and his collaborators (on a large variety of organisms), by Darbishire (on mice), by Hurst (on rabbits), by 'Toyama (on silkmoths), by Davenport (on poultry), and so on. There are some difficulties and not a few discrepancies, but, as Bateson says, "the truth oi the law enunciated by Mendel is now established for a large number of cases of most dissimilar characters."

In experimenting with Lychnis, Atropa, and Datura, Bateson and Saunders found that the phenomena conformed with Mendel's law "with considerable accuracy, and no exceptions that do not appear to be merely fortuitous were discovered. In the case of Matthiola (garden-stock), the phenomena are much more complex. There are simple cases which follow Mendelian principles, but others of various kinds which apparently do not. The latter cases fall into fairly definite groups, but their nature is obscure."

In experiments with poultry, the phenomena of dominance and recession were detected; interbreeding of the hybrid offspring resulter in a mixed progeny, "some presenting the dominant, others the recessive character, in proportions following Mendel's Law with fair consistency, though in certain cases disturbing factors are to be suspected."

The general result, so far, is that Mendel's law has received confirmation in a number of very dissimilar cases.

Domizant and recessive characters. - Let us first of all collect a number of instances of contrasted characters which behave in relation to one another as dominants and recessives.

Pisum sativtm.........
$\begin{gathered}\text { Dominant } \\ \text { Tallness } \\ \text { Round seeds } \\ \text { Coloured seed-coats } \\ \text { Yellow albumen in coty- } \\ \text { ledons } \\ \text { Purple flowers }\end{gathered}$
Sweet pea............ Thll ordinary form

Recessive
Dwarfness
Wrinlled seeds
White seed-coats
Green albumen in coty-
ledons
White flowers
Dwarf or "cupid" vari-
ety

From J. Arthur Thomzon, IIeredily (copyright 1907). Used by special permision of the publisher, John Murray, Lon lon. 


\begin{tabular}{|c|c|}
\hline & Dominant \\
\hline Stocks. & Coloured \\
\hline Wheat and barley. ........ & . Beardless \\
\hline & $\begin{array}{l}\text { Later ripening Rivett } \\
\text { wheat }\end{array}$ \\
\hline & Non-immune to "rust" \\
\hline Maize. . & “Starch" seed \\
\hline $\begin{array}{r}\text { Nettles (Urtica pilulifera and } \\
\text { U. dodartii).............. }\end{array}$ & Serrate leaf margin \\
\hline Mirabilis julapa and M.rosea & Rose colour \\
\hline Mice...$\ldots \ldots \ldots \ldots$ & Coloured coat \\
\hline & Normal \\
\hline Rabbits. & $\begin{array}{l}\text { Coloured coat } \\
\text { Angora fur }\end{array}$ \\
\hline Poultry. & $\begin{array}{l}\text { "Rose" comb of Ham- } \\
\text { burghs and Wyandottes }\end{array}$ \\
\hline
\end{tabular}

Cattle.................Hornlessness

\author{
Recessive \\ White \\ Bearded \\ Early ripening Polish \\ wheat \\ Immune to "rust" \\ "Sugar" seed
}

\section{Entire leaf margin}

Other colours

Albino coat

"Waltzing" variety

Albino coat

Short fur

High serrated "single" comb of Leghorns and Andalusians

Horns

Banded shell

Other instances in plants.-As is well known, there are two almost equally common forms of wild primrose: (A) thrum-types, with short styles and with anthers at the top of the corolla-tube; and (B) pin-types, with long styles and with anthers half way down the tube. The thrum-type is dominant over the pin-type.

The original species of Chinese primrose (Primula sinensis) has a palmate leaf. About r860 a sport arose (from seed) which had a pinnate or "fern" leaf. The palmate form is dominant, and the fern leaf is recessive.

The deformed "Snapdragon" variety of sweet pea behaves as a recessive to the normal type.

The 2-row barley has certain lateral flowers which are exclusively staminate; in 6-row barley all the flowers are staminate and pistillate, and all set seed. Mr. Biffen crossed these forms, and found that the more negative character was dominant. The offspring were 2-rowed.

Maize.-When the common or starchy round-seeded maize is crossed with the wrinkled-seeded sugar-maize, the round starchy character dominates. When an egg-cell of the wrinkled sugar-maize stock is fertilised by a pollen-cell of the round starchy stock, the result is a round seed with starchy endosperm. If this seed is sown, it becomes a plant which, on self-fertilisation, forms a cob with a mixture of round starchy and wrinkled sugary seeds in the ratio $3: \mathrm{r}$. The wrinkled seeds yield sugar-maize; the round seeds yield two "impure rounds" to one "pure round." Correns has observed a very interesting case in which two pairs of contrasted characters are implicated. 
One variety, Zea mays alba, which has smooth white seeds, was crossed with another variety, Zea mays coeruleodulcis, which has wrinkled blue seeds. The hybrids $\left(\mathrm{F}_{\mathrm{x}}\right)$ had smooth blue seeds, one character of each parent being dominant, and one character of each parent being recessive. The hybrids were inbred, and the progeny $\left(\mathrm{F}_{z}\right)$ showed four combinations-smooth blue, smooth white, wrinkled blue, and wrinkled white (the dominant characters are italicised).

In the next generation $\left(\mathrm{F}_{3}\right)$, the wrinkled white, inbred, yielded wrinkled white-a case of extracted recessives, breeding true. The smooth whites and wrinkled blues, inbred, yielded partly forms like themselves and partly wrinkled white. The smooth blues, inbred, yielded the same combinations as in $\mathrm{F}_{3}$.

A finer corroboration of Mendelian could hardly be wished.

Nettles.-Correns crossed two "species of stinging-nettle," Urtica pilulifera $L$. and $U$. dodartii $L$., which resemble one another except as regards leaf-margin, strongly dentate in the former, almost entire in the latter. The hybrid offspring $\left(F_{s}\right)$ have all dentate leaves like the male or the female parent, as the case may be. The dentate character is absolutely dominant. The inbred (self-fertilised) hybrids produce offspring $\left(\mathrm{F}_{2}\right)$ of two kinds, with dentate and with entire margins, on an average in the Mendelian proportion, $3: \mathrm{I}$.

"Immunity to rust in wheat.-Some kinds of wheat are very susceptible to the fungoid disease known as 'rust'; others are immune. The quality of immunity to rust is recessive to the quality of predisposition to rust.

"When an immune and a non-immune strain are crossed together the resulting hybrids are all susceptible to 'rust.' On self-fertilisation such hybrids produce seed from which appear dominant 'rusts' and recessive immune plants in the expected ratio of $3: 1$. From this simple experiment the phrase 'resistance to disease' has acquired a more precise significance, and the wide field of research here opened up in this connection promises results of the utmost practical as well as theoretical importance. To the question, 'Who can bring a clean thing out of an unclean?' we are beginning to find an answer, nor is the answer the same as that once given by Job" ( $R$. C. Punnett).

Silkworms.-Toyama paired Siamese silkmoths with yellow or with white cocoons; the offspring produced only yellow cocoons. When the hybrids were inbred, the result was two sets, one producing white cocoons, the other producing yellow cocoons, and the proportion was Mendelian-25.037 white and 74.96 yellow. The whites bred 
true; the yellows when inbred showed themselves to be pure dominants or "yellows" and dominant-recessives--i.e., splitting up again into yellows and whites in the usual proportion. More intricate experiments confirmed this general result.

It must be noted, however, that Coutagne has made much more elithorate experiments with different results, which in many cases cannot be interpreted on the Mendelian theory. Thus he found (I) that the hybrid forms were sometimes blends of the parents and different from both; (2) that in other cases the brood included some like one parent in a particular character, some like the other parent, and some intermediate; and (3) that in other cases the individuals showed no fusion of characters, but resembled one or other parent. It is likely that the discrepancy may be explained as due to considerable diversity of origin in the domesticated races of silkworm, so that, while they breed true when left to themselves, a disturbance of the usual routine leads to the liberation of latent characters.

Lina iapponica.-Miss McCracken has made a fine study of the hereditary relations in this Californian beetle, which occurs in two types, spotted (dominant) and black (recessive). They are always crossing in natural conditions, but there are no intermediates, and it is easy by isolation to rear a "pure" spotted race and a "pure" black race. When spotted forms are paired they may produce only spotted progeny - a case of extracted dominants. In other cases, however, they yield spotted and black forms ( 1,02 I spotted, 345 black), i.e., in the Mendelian proportion of $3: 1-a$ case of dominant-recessives inbred.

Snails.-Lang paired "pure" five-banded forms of the common or garden snail, Helix hortensis, with bandless forms from bandless colonies. The young of the first generation were all bandless, the banded character being recessive. When these were paired the offspring were bandless and banded in the Mendelian ratio, 3:1. Further experiments confirmed this, not only as regards bands, but also as regards colour (yellow or red), size, and the form of the umbilicus. It may be said, therefore, that common snails (Helix hortensis and Helix nemoralis) illusirate Mendelian inheritance.

Poultry.-Numerous breeding experiments with poultry have been made by Bateson, Bateson and Punnett, Hurst, Davenport, and others, many of which show Mendelian phenomena with great clearness, while others are strangely conflicting. One of the reasons for the complicated results is evidently to be found in the difficulty of securing thoroughly "pure" breeds, for many that breed true as long as they 
are inbred tend to liberate latent characters when the ordinary course of breeding is departed from.

Hurst contrasts the following characters, which nsually show themselves dominants and recessives; but it has to be admitted that the dominance-always complete for some characters-is for others frequently, or even always incomplete-i.e., showing traces of the corresponding recessives.

Dominant Characters
Rose comb
White plumage
Extra toes
Feathered shanks
Crested head
Brown eggs
Broodiness

Recessive Characters
Leaf comb, single comb
Black plumage, buff plumage
Normal toes
Bare shanks
Uncrested head
White eggs
Non-broodiness

Davenport's copiously illustrated work is also of great interest. He shows in case after case that the character dominant in the first hybrids is more or less influenced by the recessive character. Polish fowls with a large hernia of the brain on the top of the head were paired with Minorcas with normal heads. The hybrids showed no hernia, but most of them showed a frontal prominence. When the hybrids were inbred the hernia occurred in 23.5 per cent-a close approximation to the theoretical 25 per cent.

Single-combed black Minorcas were crossed with white-crested black Polish fowls with a very small bifid comb. The hybrids had combs single in front, split behind. When the hybrids were inbred there resulted in a total of ror offspring, 29.7 per cent with single combs (like Minorcas), 46.5 per cent with $Y$-shaped combs, and 23.8 per cent with no combs or only papillae (like the Polish forms). Here, again, the result is in a general way Mendelian, but the $\gamma$-like comb is a complication.

Pigeons.-R. Staples-Browne crossed a web-footed pigeon (an occasional discontinuous variation) with a normal form, and got six normal young. In other words, the web-foot character is recessive to the normal foot character. The hybrids were inbred, and in one case produced nine with normal feet and three with webbed-feet-a Mendelian splitting-up. But from another pair of hybrids seventeen normal offspring resulted. Thus, the illustration of Mendelian inheritance is inconclusive. Besides the numbers were too small.

We have noticed elsewhere that crossing different breeds of pigeons often results in forms which more or less resemble the reputed original 
ancestor, the wild rock dove; in other words, reversions occur. Often, however, the results seem quite anomalous, which is probably due to the number of latent characters which different races of pigeons appear to carry.

Mice.-Mendelian phenomena have been carefully studied in mice. Thus, when a grey mouse is paired with an albino, the hybrid offspring are always grey. When these are inbred, they yield greys and albinos, approximately in the proportion of $3: \mathrm{I}$. Thus Cuénot obtained 198 grey, and 72 albinos.

Darbishire has obtained many results which harmonise well with Mendelian theory, while others require some ingenuity if they are to be fitted in with this interpretation. As a good case we may cite one where the inbreeding of pigmented mice-derived from crossing pigmented and albino individuals-yielded I 59 pigmented young and 55 albinos ( 53.5 being the theoretical anticipation). When similar hybrids were paired with pure albinos, they yielded 69 pigmented and 69 albino forms, precisely as the theory would lead us to expect:

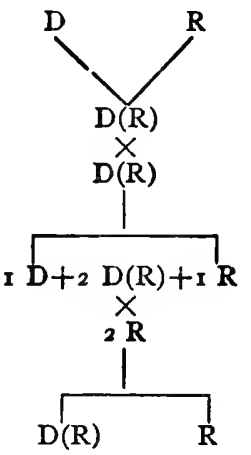

Cuénot crossed an albino $A G$ (with latent grey) with an albino $A B$ (with latent black), and obtained albinos (AGAB). He crossed a black mouse $\mathrm{CB}$ with an albino $\mathrm{AY}$ (with latent yellow), and obtained yellow mice (CBAY). He then paired AGAB (albino) with $\mathrm{CBAY}$ (yellow) and obtained $\mathrm{I} 5 \mathrm{I}$ young-8I albinos, 34 yellow, 20 black, I 6 grey; the theoretical anticipation being -76 albinos, 38 yellow, i 9 black, 19 grey. This is an exceedingly striking and convincing case.

Waltzing mice.-The mice of this interesting Japanese breed have among other peculiarities the habit of waltzing round in circles. When waltzing mice are crossed with normal mice, their abnormal quality behaves as a recessive. 
Guinea-pigs.-If a black guinea-pig of pure race be crossed with a white one the offspring will be all black, and if these are mated with each other the recessive white character reappears on the average in one in four of their offspring. These whites mated with each other produce only white offspring, while the black are as usual of two kinds, pure blacks and impure blacks. Similarly, as Professor Castle has shown, a rough coat is dominant over a smooth coat, and a short coat over a long coat.

Rabbits.- Hurst paired white Angora rabbits (with pink eyes and silky hair) with "Belgian hare" rabbits (with pigmented skin, dark eyes, and short yellow fur). The hybrids were pigmented like the "Belgian hares," but the fur was grey like that of the wild rabbit. These hybrids were inbred, and I4 distinct types resulted - an apparent "epidemic of variation" to which Mendel's theory has supplied the clue, for four pairs of contrasted characters are involved in the hybrid inbreeding-namely, short hair versus long hair, pigmented coat versus albinos, grey versus black coat, uniform versus marked coat (Dutch marking latent in the albinos), and the $\mathrm{I}_{4}$ distinct types illustrate the possible combinations.

As regards short hair versus long hair, Hurst found that when the short-coated hybrids were inbred they produced short-haired forms like the Belgian hare grandparent, and long-haired forms like the Angora grandparent. Out of 70 which reached the age of two months or more, 53 were short-haired and i 7 long-haired-a close approximation to the Mendelian anticipation, 52.5:17.5. Similarly, as regards pigmented coat versus albino, the hybrids, when inbred, yielded 132 pigmented and 39 albino forms- - a close approximation to the Mendelian expectation, I $29: 43$; and so on.

Cats.-There are some interesting results as to colour (Doncaster). Thus, "pure" orange $\&$ crossed by "pure" black of gives tortoiseshell females and yellow males, but black crossed by orange gives black males or females, tortoiseshell females, and orange males. It seems that orange usually dominates over black in males, while in females the orange (for some unknown reason) is less dominant and tortorseshell results. Male tortoiseshell cats are very rare. In this case the results are complicated by some peculiarity wrapped up with "sex."

When a male tortoiseshell is paired with a female tortoiseshell the kittens are tortoiseshell, orange, and black-which is what Mendelian theory would lead us to expect.

Man.-Evidence of Mendelian phenomena in man is as yet very scanty. It appears that the condition known as brachydactylism. 
where the fingers are all thumbs with two joints instead of three, is dominant over the normal. In five generations chronicled by Farabee about half of the offspring were of the abnormal type, though the marriages were apparently always with unrelated normal individuals. Moreover, no normal member of the lineage is known to have transmitted the abnormality. Another good case has been recently discussed by Drinkwater.

Of great interest also is Mr. Nettleship's account of the descen(lants of one Jean Nougaret (born I637), who was afflicted with "nightblindness"- a condition apparently due to loss of visual purple. It seems to behave like a unit character. There are records of over 2,000 individuals; and the night-blindness is dominant over normal eyesight. The notable point is that during two and a half centuries no normal member of the lineage who married another normal, whether related or not, ever transmitted the disease.

Human eye-colour affords another illustration. It is largely determined by the presence or absence of two distinct layers of pigment. In the true blue eye only one of these pigmentary layers is visibly present, the posterior purple pigment of the choroid, which, being reflected through the fibrous structure of the iris, produces the blue colour. In the absence or partial absence of this pigment the eye appears to be "pink," as in albinos. In the ordinary brown eye two layers of pigment are present, for in addition to the posterior purple layer there is also an anterior brown layer, in front of the iris. Major C.C. Hurst found that the eye with two layers of visible pigment (duplex) is dominant and the eye with one layer of visible pigment (simplex) recessive. Or, putting it in another way, the presence of the brown front layer is dominant to its absence. Practically the same conclusion was reached independently by Professor and Mrs. Davenport.

The Davenports and Major Hurst have also brought forward some evidence illustrating in typical Caucasians the dominance of dark to fair skins, their segregation in the same family, and the apparent purity of the extracted fair individuals. Hurst also gives evidence that "fiery red" hair behaves as a recessive to brown, and that the musical sense or temperament is also recessive. It seems as if an individual is non-musical owing to the presence of an inhibitory factor preventing the expression of musical temperament which is potentially present in everyone (Hurst, I9I2).

It would be interesting to have precise information as to the progeny of Eurasians who intermarry, for here the original hybrids result from the mixture of two very distinct races. 


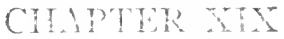 \\ THE FACTOR HYPOTHESIS AS APRLIED TO PLANTS}

JOHN M. COTLIER a IT ATRLE C COUT.TFR

Thus far we have been consiclering Mendel's law in its simple form and have enlarged but little upon Mendel's original statement. The value of the law is apparent. Upon its republicution in Inoo it was taken up by biologists and numerous breeders set to work to test it. As a consequence data for and against it bergan to accumulate. As might be expected, there was much apparent evidence against the law, but as geneticists developed a better conception of the mechanism the contradictory evidence was explained away. Almost every type of inheritance has now beer explained according to Mendel's law. Some of the explanations are very complicated and cannot be in cluded in this presentation. A few of the more important cises, however, will be presented.

\section{PRESENCE AND AESENCE HXPOTHESIS}

This may be regarded as a new method of Miendelian thought. It was first suggested by Correns, but later was worked out in detail by other geneticists, especially Hurst, Batesin, Shull, and East. It is merely a modifcation of the mechanism invoived. For example, in the case of a hybrid obtained by crossing tall and dwarf parents the result had been explained as due to the fact that one chromosome bears a rleterminer for tallness and the other one of the pair carries the determiner for dwarfness. In other woords, each one of a pair of allelomorphs is represented by a determiner, two tetcrminers thus being present. Dwarfness in this case would be the result of the interaction of that determiner and its environment during the development of the body; and the same for tallness. When hoth were present, however, the conception of the situation was as follows. The determiner for dwarfness, setting up its usual series of reactions, early became paralyzed by the determiner for tallness or its products. This result was called the dominance of the character for tallness. It was as if the determiner for tallness completely prevented the activity of the determiner for dwarfness. This conception was apparently borne out

IFrom Coulter and Coulter, Plint Genitics (The University of Chica Press. copyright 1918$)$. 
l,y the facts and was the explanation of the mechanism generally accepted.

Accorling to the presence and alsence hypothesis, however, the situation is looked at from an entirely different point of view. Tallness is the result of a determiner, but dwarfness is merely the result of the absence of the determiner for tallness. The dominant character is produced by an inheritalle determiner, but the recessive character appears only when the dominant determiner is lacking. - This conception has some evident advantages and may modify the previous Mendelian diagram, as shown in Figure 58 . This appears to be a simpler mechanism to account for the phenomenon called dominance. In the case of the dwarf form there is a normal course of development; in the case of the tall parent or hybrid, however, an additional determiner

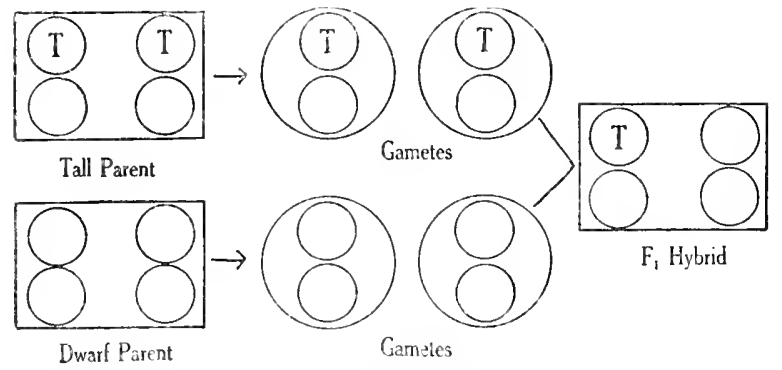

FIG. 58.-Diacram showing how the original scheme must be modified to satisfy the presence and absence hypothesis. (From Coulter and Coulter.)

stimulates cell growth, or cell division, or both. It is a simpler and more useful conception, so long as it fits the facts. Some investigators, however, claim that it cannot be applied to all the situations that have been discovered.

[It should be emphasized here that the word "determiner" as used in the foregoing paragraphs is not synonymous with the word "gene." A recessive character is not due to the absence of a gene, but merely to the alssence of something that is present in the dominant gene. In this form the presence and absence idea is acceptable.]

Additional advantages of the presence and absence hypothesis will appear in connection with a consideration of blending inheritance and of cumulative factors in inheritance. Attention, however, should be called to the fact that those who accept the presence and absence 
hypothesis do not use the form of notation thus far used in explaining Mendelian inheritance. Assume that $T$ is used to express the determiner for tallness, its same letter $(t)$ is used to express the absence. For example, instead of using $D$ for dwarfness, $t$ is used for "lack of tallness" (Fig. 50). It is a matter of convenience to have a symbol to represent the recessive, the alsence of something that is present in another individual.

In summary, the essential difference between the presence and absence hypothesis and that of dominant and recessive is that in the former case the recessive determiner has no existence at all, while in the latter case it exists, but is in a latent condition when associated with the dominant.

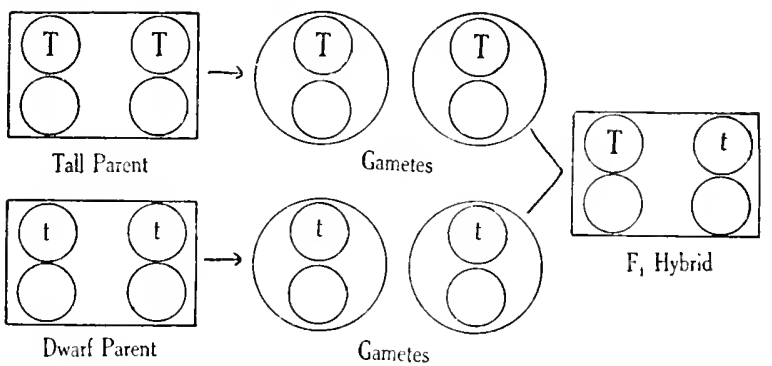

Fig. 59.-Diagram showing how presence and absence scheme is actually used, with small letter representing "absence." (From Couller and Coulter.)

\section{BLENDS}

This type of inheritance when first discovered was thought to be in direct conflict with Mendel's law. It is a case in which dominance seems to fail, for the two alternative characters both express themselves and the result is an average between them. It is easy to explain this situation in accordance with the presence and absence hypothesis without any violation of Mendel's law.

The classic example of blending inheritance was presented by Correns in breeding work upon Mirabilis Jalapa, the common fouro'clock. Correns crossed red and white rarieties, and all the hybrid progeny had rose pink flowers. This was a color blend, distinctly intermediate between the colors of the two parents. The $F_{\mathrm{I}}$ generation, therefore, seemed to contradict Mendel's law in that one color character was not completely dominant over the other. The real situation, however, appeared in the $\mathrm{F}_{2}$ generation obtained by inbreeding 
individuals of the $F_{I}$ generation which showed the blend. By inbreeding the pink hybrids Correns obtained the perfect I:2: I ratio, that is, I red like one graudparent, 2 pink like the hybrid parent, and I white like the other grandparent. Segregation was evidently taking place, the only unusual thing being the apparance of the $\mathrm{F}_{\mathrm{I}}$ indiviluals, and that was explained immediately as failure of dominance (see Fig. 60).

The question this introduces, therefore, is that of a mechanism which could account for such a result. The easiest explanation offered is that the red parent was a homozygote for redness (double dose) and the hybrid a heterozygote (single dose); the inference is that

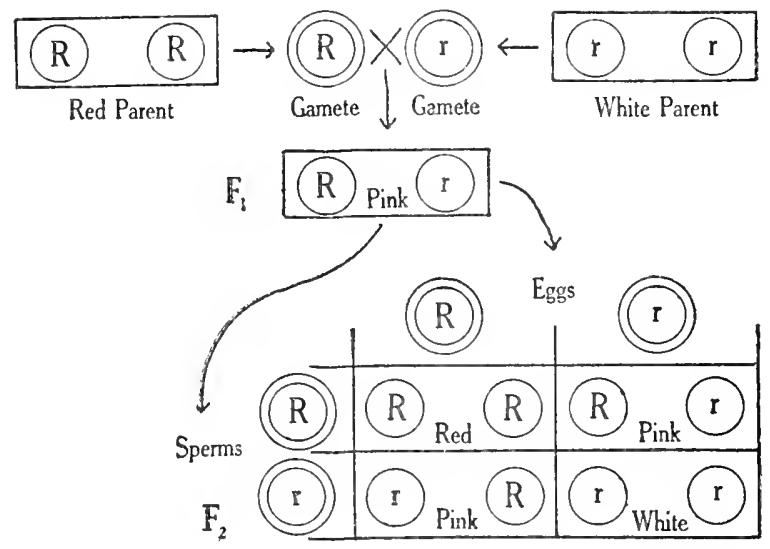

FIG. 6o.-Diagram illustrating blending inheritance, discovered by Correns in Mirabilis jalapa. (From Conlter and Coulter.)

a single dose produces pink while a double dose produces red. A theoretical explanation of this occasional difference in the result of double and single doses is as follows. Imagine that the body cells of a plant have a certain capacity for expressing hereditary characters. In such a case, just as a given quantity of solvent can dissolve only a given amount of solute, so the lody cells can express hereditary characters only to a definite limited extent. In the four-o'clock a single dose of redness may be thought of as half saturating the body cells, while a double dose completely saturates them. In cases showing complete dominance, however, a single dose completely saturates the cells and a double dose can do nothing more. This analogy assists in visualizing on the one hand the necessary mechanism of blends (apparent failure 
of (tominance) and on the other hand that for cases of complete dominance.

Another example of simple hicnding inforitance is the case of Adzuki beans, described hy Blakestee. In this bean the mottling of the seed coat is dominant to the lack of mothling. In the hybrid condition, however, the mottling is lirhter than in the pure or homozygous condition. Heterozygous plants, therefore, can lis easily distinguished from homozygous plants, so that the $\tau: 2:$ r ratio is evident on external inspection rather than the usual 3 : ratio.

\section{THE FACTOE HYPOTHESIO}

Mendel concluded that each plant character derents upon a single determiner. Inheritance, however, has proved to be a nutich more complex phenomenon than indicated by ifendel's pras. Ratios have appeared that were puzzling, and geneticists were forced to the conclusion that there may be a compound determiner for a single character. This conception is called the facior hypotheris, and the growing complexity of genetics has developed in connection with this hypothesis. With the consideration of factors insiead of determiners one passes from elementary to advanced genetics. Previousiy we have used the word determiner, implying Mendel's idea that a single determiner is responsible for the development of a plant character, and this has been true of the examples of inheritance previously considered. It is understood now, howerer, that a chavicier is requently determined by the interaction of two or more scparitel heritable factors, and hence the factor hypothesis. The distinction between factors and determiners should be made clear. In case only one factor is involved in determining a character, there is no distinction betreen fiztor and leterminer; and in such a case the term factor should not be used.

r. Complementary factors.- This is the simplest expression of the factor hypothesis and it may be illustrated by some of East's work. Crossing red-grained and white-grained corn he obtained all red in the Fr generation. This would suggest that the Fa generation would show 3 red to 1 white; but it showed o reds to 7 whites, which dici not sugrest Mendelian inheritance. It is in accord with Mendel's law, however, if we consider that two complementary faciors are necessary to produce the red character, and that each of these factors is inherited separately. Such a situation would give a dihyrid ration as indicuted

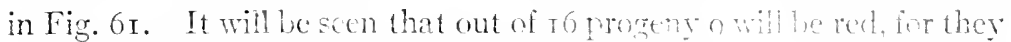
alone contain the complenentary factors; the uher 7 witl le white. 
The situation is thus explained by the dihybrid ratio, but although only one character is involved that character depends upon two complementary factors.

Another situation is worth noting. No. 6 of the diagram is white because it contains only one of the necessary factors; No. I I is white

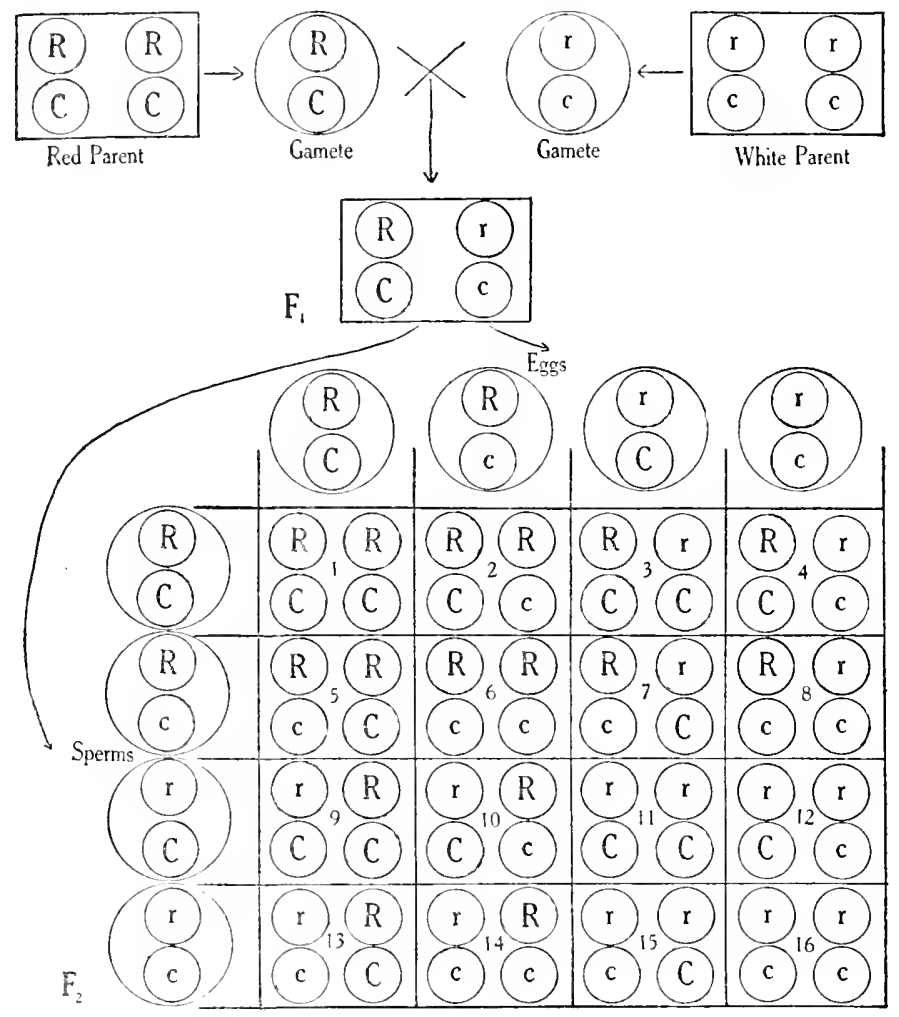

Fig. 6r.-Diagram illustrating behavior of complementary factors in cross between red-grained and white-grained corn. $R$ and $C$ must both be present to produce red-grained corn. (From Coulter and Coulter.)

for the same reason, but its germinal constitution is just the opposite. What would happen if these two are crossed? There is only one possibility, since each is a homozygote producing only one kind of gamete. The result would be red, and thus a cross between two whites would produce only reds. What would happen from crossing Nos. 6 and $I_{5}$, the former being a homozygote and the latter a heterozygote? 
It is obvious that the resulting progeny would be one-half white and one-half red, although both parents are white. The same result would be secured in crossing Nos. I I and i4. A cross between Nos. I4 and I5, both of which are heterozygotes, would result in 3 whites and I red, the ordinary $3: 1$ ratio. These illustrations show how differently the same phenotype may behave in inheritance. In each case two whites were crossed, that is, the same phenotypes, but three different ratios were obtained because the genotypes were different.

The striking feature of this situation is that one can cross two whites and get a red. This gives an insight into the so-called phenomenon of reversion. For example, in the course of numerous breeding experiments Bateson obtained two strains of white sweet peas, each of which when normally "selfed" bred true to the white color; but when these two were artificially crossed all the progeny had purple flowers, like the wild Sicilian ancestors of all cultivated varieties of the sweet pea. This appeared to be a typical case of reversion. Further breeding, however, showed that this was just such a case of complementary factors as we have been considering. One of Bateson's white strains had one of the factors for purple and the other strain harl the other factor.

Complementary factors have been defined and the method of their inheritance described, but is there any mechanism to explain the situation? A suggestion may be obtained from plant chemistry. The most prominent group of pigments in plants is the group of anthocyanins, which are produced as follows. Plants contain compounds called chromogens, which are colorless themselves but which produce pigments when acted upon by certain oxidizing enzymes or oxidases. This is a sufficient mechanism for the behavior of complementary factors. If one of East's white strains of corn contained a chromogen capable of producing red but lacked the necessary oxidase it would remain colorless. If the other white strain contained the oxidase but no chromogen it would remain colorless. In crossing them, however. chromogen and oxidase would be brought together and a red-grained hybrid would be the result. Inbreeding such red-grained individuals of course would give red and white progeny in a ratio of $9: 7$, as explained in connection with East's corn. This seems to be the explanation of the behavior of complementary factors in many cases of color inheritance.

Where other characters are involved the mechanism must be somewhat different. In some cases the two factors may be the enzyme 
and the compound the enzyme attacks, as in the oxidase and chromogen situation just described. On the other hand, we might be dealing with two chemical compounds that are inert when occurring separately but active when brought together, active in such a way as to produce a distinctly new character. Also two active substances might neutralize one another when brought together in a hybrid, and the failure in their activity might result either in a new character or the failure of some parental character to develop. Such are some of the possible mechanisms to explain the behavior of complementary factors.

Hybridızing, therefore, is much like mixing chemicals in a test tube. We know that very wide crosses cannot be made successfully; but the surprising thing is that certain very close crosses are constantly unsuccessful, even though both parents may cross freely with closcly related types. We obtain a glimpse of the possibility of such apparently inconsistent behavior when we consider the chemical possibilities suggested by the behavior of complementary factors.

The origin of complementary factors is an interesting field of speculation. Did they originate together or separately? A natural inference would be that they originated together, for neither would be of any use without the other. It should be remembered, however, that the idea of use as explaining the occurrence of everything in a plant is being abandoned; one must think rather of a plant as a complex physico-chemical laboratory. No one claims that all chemical reactions are useful; they are simply inevitable; and plant characters are the result of chemical reactions and physical necessities. Even though we assume the simultaneous origin of two complementary factors, they would have to be put on separate chromosomes, for the factors are separately inherited.

The other alternative is to suppose that these factors originated independently in the history of a plant. In this case, of course, the first one to be produced would remain functionless until finally its complement came into existence. This might be an explanation of what are called latent characters. Also they might have not only originated independently but in different varieties or species. In this case if natural hybridizing should bring them together the result would be the appearance of a new character, and this may have been a very important factor in the origin of species.

This may serve as an introduction to the factor hypothesis, with complementary factors as an illustration, simply because it is the simplest situation. There are many other kinds of factors recognized. 
but we shall not attempt to list all of the proposed types. A simple illustration of the better linown types is as follows:

a) A complententury factor is atded to a dissimilar factor to produce a particular character.

b) An inhibitory factor prevents the action of some other factor.

c) A supplenentury factor is added to a dissimilar factor with the result that the character is modified in some way.

d) I cumbutive factor, when adfed to another similar factor, affects the degree of development of the character.

Some examples of these types will make them clear, those for complementary factors having been given previously.

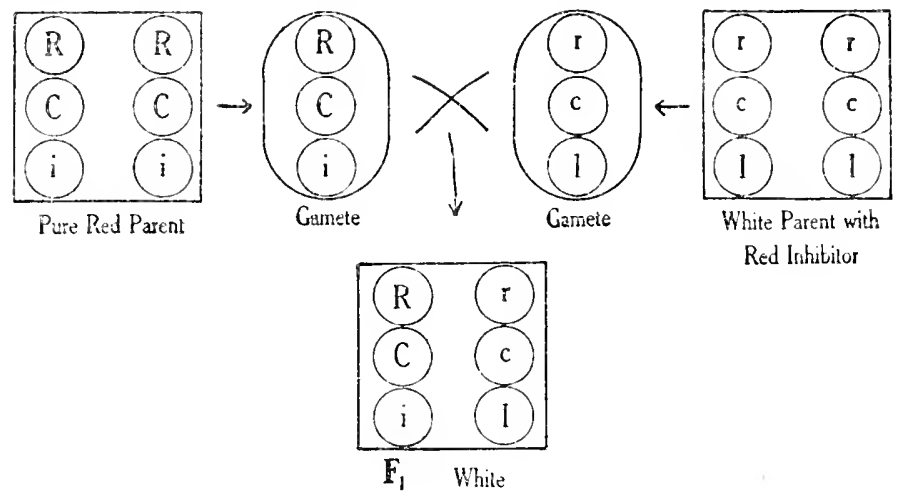

Fic. (2.- - Jiagram ilhstrating behavior of inhibitory factor. (From Coulter and (oullit.)

2. Inbibitory facters.--Recalling East's experiment with redgrained com it will be remembered that when both factors for red were present the grain was red, but when either factor was absent the grain was white. Later he crossed these strains with a new white strain, and the result was surprising. The pure red strain produced gametes carring both the red factors, and it would be expected that whatever such a sanvete mated with would result in red progeny; but when this pure rul was crossed with the new strain of white the progeny were all white, although the hylrids certainly contained loth factors for red. The explanation which first occurred to Last, and which later experiments confirmed, was that the new white strain contained an inhilitory factor, which prevented the derelopment of red even though both the complementary factors for red were present. 
Figure 62 illustrates the situation and shows why all the individuals of the $F_{I}$ generation are white. It is interesting to note further the possibilities of white and red in the $\mathrm{F}_{2}$ generation. They would be

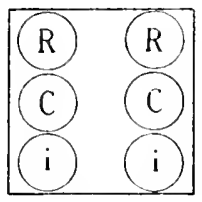

$\operatorname{Red}$

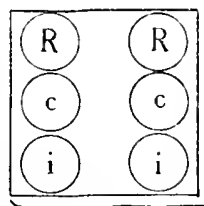

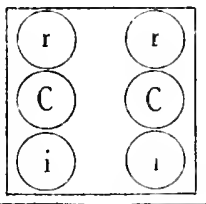

White

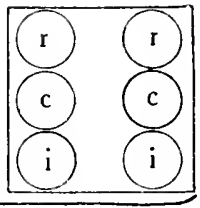

i

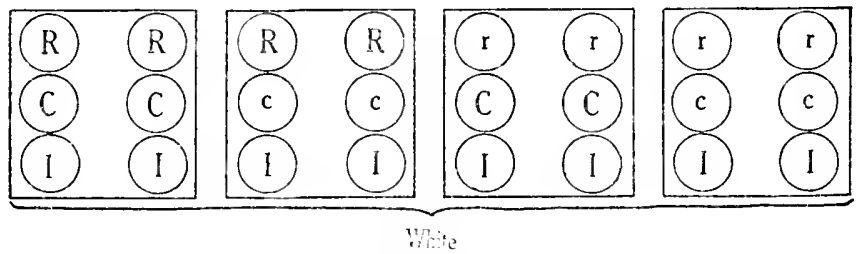

Fig. 63.-Diagram showing some possible combinations in $F_{2}$ when $F_{1}$ of lizure 62 is inbred. Individual on left end of upper set red-grained, because $k$ and $C$ both present and $I$ absent; other individuals in upper set white, because lacking $C$ or $R$ or both; individuals in lower set with inhibitory factor and therefore white, whatever other combinations of factors they may contain. (From Coulter (ind Coultir.)

numerous, since we are dealing with trihỵbrict ratios (see Fig. 63). This does not exhaust the possiljilities, for the cases given were

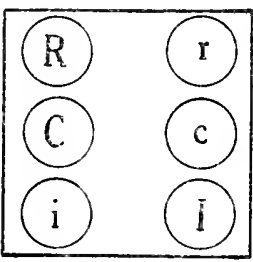

Fig. 64.- (From Coulter and Couther. homozygotes, each producing a single kind of gamete. There remains for consideration the heterozygote situation (see Fig. 64).

The possible mechanism of the inhibitory factor is as follows. We have assumed that red is prorkuced only when the enzyme is present to oxichize the chromogen. Enzymes are very sensitive; their activities may be affected or completely checked by various agents. Suppose that $I$ of the diagram be such an agent and the necessary mechanism is apparent. When $I$ is present $R$ is paralyzed, so that it canot oxidize $($.

3. Supplementary factors.- A supplementary factor is one that is added to a dissimilar factor, with the resuit that a character is modified in some way. 
In his work upon red-grained races of corn East found necasionally a few purple grains. His conception of the situation is as follows. The pure red plant contains two complementary factors, one $(C)$ a chromogen, and the other $(R)$ an enzyme, which when brought together produced the red color. The purple grains, however. must be explained by the presence of still another facior $(P)$, the resulting situation being represented in Figure $6_{5}$. Or course when $C$ is alsent no pigment whatsoever can be produced. As a consequence we will assume that the presence of $C$ is constant, and that $P$ and $R$ are varialıles. For a similar reason we will assume that the alsence of $I$ is constant. The figure shows three possililities, from which the following conclusions may he drawn: (I) when $P$ and $R$ are both present the result is purple grains; (2) red appears only in the absence of $P$; (3) $P$ although present will not derelop any color in the absence of $R$.

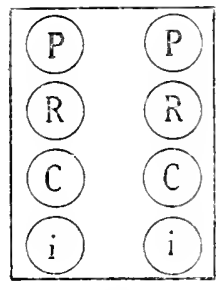

Purple

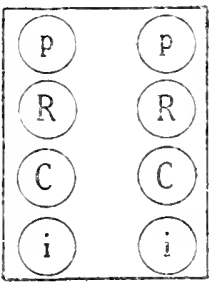

Red

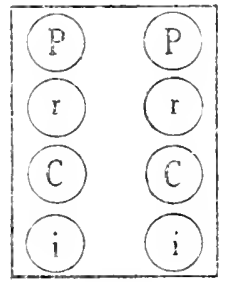

White

Fic. 65.-Diagram illustrating action of suplementary factor. (From Coulter and Coulteri

This is a typical case of a supplementary factor, that is, one which is added to a dissimilar factor, with the result that the color character is modified. The mechanism of this situation will make clearer the beharior of the supplementary factor. If $C$ is the chromogen and $R$ the enzyme, what is $D$ ? The suggested answer can be obtained from plant chemistry. It is found that the purple pignent is produced by the same substance as the red, but represents a higher state of oxidation. The concluion is obrious. C is oxidized by $R$ up to a certain point, where red is produced: but if $P$ is also mesent it represcnts an additional enzme, which attacks the red ignent and oxidizce it still further into purple. $P$ is incarable of attacking the orimal chromogen, but when $R$ carries the attack to a certain point, $P$ can function and carry the oxidation further. As a consequence $P$ without $R$ gives white grains, while $R$ gives red grains only in the absence of $P$. 
4. Cumulative factors. - These will be considered under the next heading, "Inheritance of quantitative characters."

In addition to the four types of factors given, the literature of renetics also contains discussions on intensifying factors, diluting factors, distribution factors, etc. These, however, do not introduce any new mechanisms.

5. Inheritance of quantitative characters. -This phase of the factor hypothesis, if true, is of fundamental importance not only to genetics but to general biology. It is based upon the conception of cumulative factors, and as it is presented it will be realized that it throws light not only upon numerous breeding experiments but also upon variation in general, which means evolution also. A cumulative factor was defined as one which, when added to another similar factor, affects the degree of development of the character.

It will be recalled that Correns crossed red and white strains of Mirabilis and obtained pink hybrids. The suggested explanation of this result was that a single dose of the red determiner gives pink while a double dose gives red. When Correns inbred these pink hybrids, he obtainal the result 1resented in Figure 60, that is, I red, 2 pink, I white. This resut is ofrious and the mechanism is plain.

With this diagram in mind we shall consider some of the experiments of Nilsson-Ehle at the Swedish Experiment Station. $\mathrm{He}$ crossed two strains of wheat with red and white kernels. The $F_{I}$ individuals had light red liernels, which of course suggests a repetition of the situation shown by Mirabilis in the experiment of Correns. The $\mathrm{F}_{2}$ generation, however, showed a very difierent result. The reds and whites appeared in the ratio of $15: \mathrm{I}$; but in addition to this, among the 15 reds there could be distinguished varying degrees of redness. Nilsson-Ehle suspected that I5:I meant a dihybrid ratio, I6 individuals being necessary to give the ratio, so that he constructed the tentative scheme shown in Figure 66.

This shows a regular dihybrid ratio, except that the two factors involved are similar. Applying the single dose and double dose conception, as used in the case of Corren's pink Mirabilis, we reach the following conclusions: No. I only has four doses and therefore it only is deep red; Nus. 2, 3, 5, 9 have three doses and are somewhat lighter red; Nos. 4, 6, 7, I0, II, I 3 have two doses and are still lighter red; Nos. 8, I2, $\Upsilon_{4}, I_{5}$ have one dose and are very light red; while No. I6 alone has no dose and is the only pure white. This accounts for the 15:1 ratio, and the different shades of red. This is entirely in 
accord with the conceptions that have been presenterl, and only two assumptions are necessary: ( $\mathrm{I}$ ) that dominance is absent, and two doses have twice the effect of one; (2) that the independent similar factors are cumulative in their operation, and are paired with their absence in the hybrid. This was Nilsson-Ehle's conception, and of

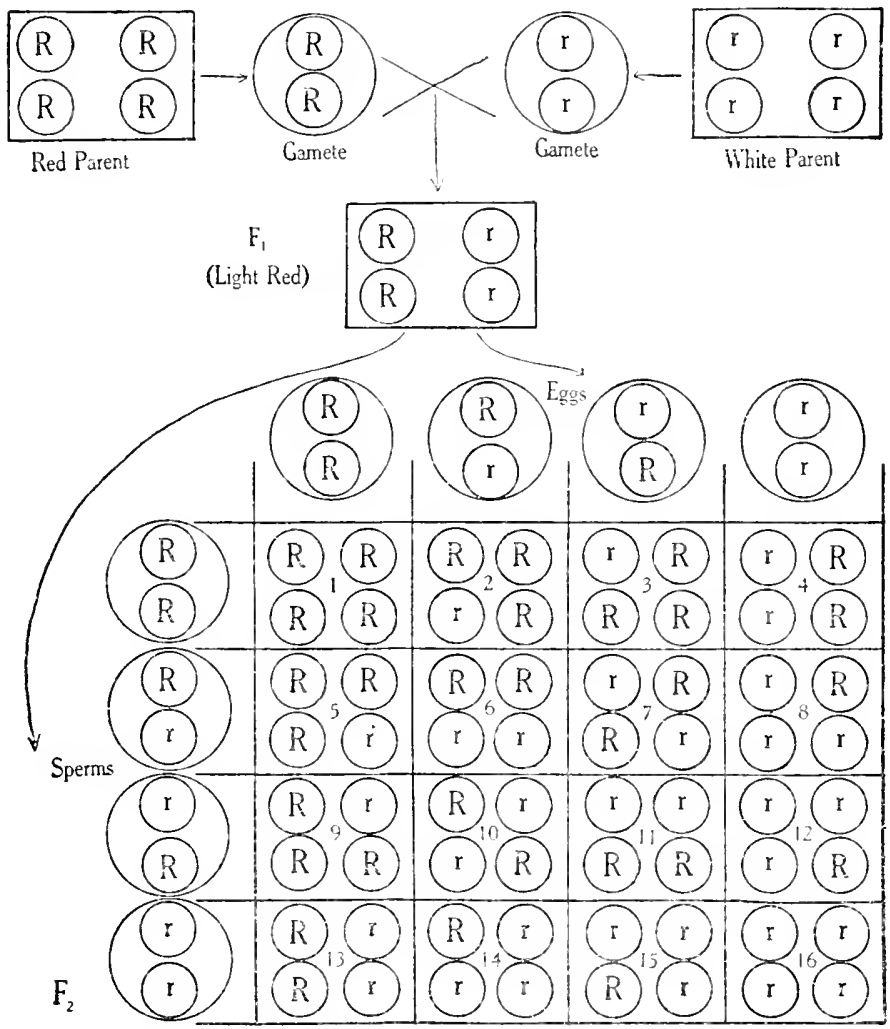

Fig. 66.-Diagram illustrating Nilsson-Ehle's explanation of $\mathrm{r}_{5}$ : I ratio obtained in $\mathrm{F}_{2}$ generation from cross between red-grained and white-grained wheat. (From Coulter and Coulter.)

course he tested it by further experimental work, the results consistently confirming the conception.

Since it is important to fix this conception clearly in mind, another type of diagram may represent the facts even more clearly. The proportion of individuals showing the various degrees of redness in the $\mathrm{F}_{2}$ is graphically recorded in Figure 67, each dot representing one dose of the factors in question. 
Continuing these investigations, Nilsson-Ehle next discovered a new strain of red-grained wheat, which, when crossed with the pure white strain, yielded $F_{\mathrm{r}}$ hybrids of intermediate intensity of red as before. The $F_{2}$ generation, however, showed a different situation. Reds and whites were obtained in the proportion of $63: 1$; the 63 reds as before falling naturally into different groups on the basis of degree of redness. Applying the same conception as before Nilsson-Ehle

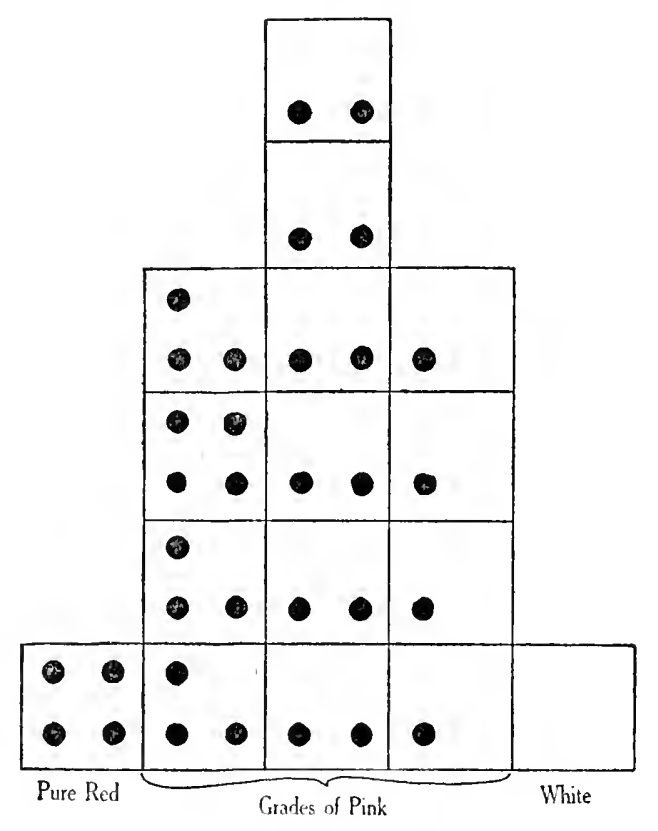

FIG. 67.-Another method of visualizing Nilsson-Ehle's I 5 : I ratio (see Fig. 66). (From Coulter and Coulter.)

discorered that in this case he was dealing with a trihybrid situation. Without constructing the usual Mendelian diagram, which would have to be extensive enough for 64 indivichals, the situation as it appeared in the $F_{2}$ generation may be represented by Figure 68 . If the graph is surmounted by a curve we recognize the regular "probability curve," exactly the kind of curve biometricians use to represent the fluctuating individuals about a specific type.

This conception of cumulative factors, therefore, has far-reaching significance. For a long time biologists have recognized individual 
variation within the species. Darwin depended upon it as the basis of his theory of natural selection as the origin of species; in fact, ever

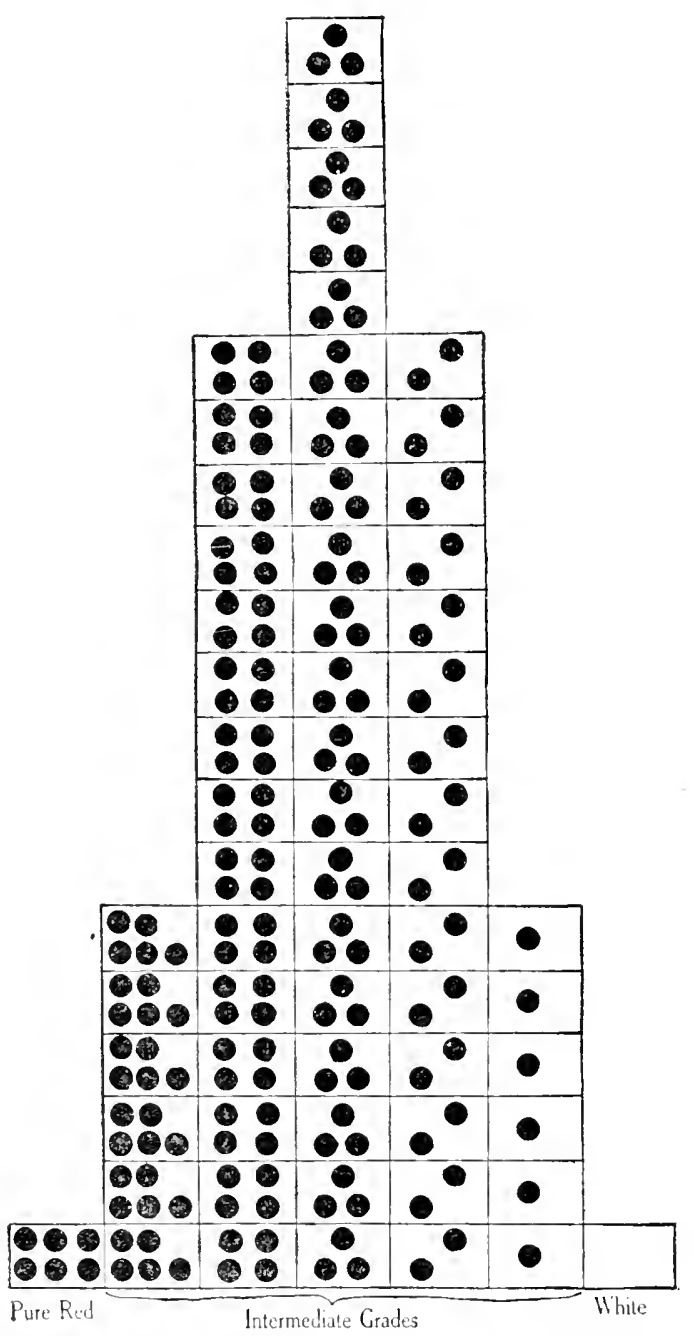

Fig. 68.-Diagram illustrating Nilsson-Ehle's 63: I ratio. (From Coultor and Coulter.)

since Darwin's Origin of Species, individual variation has been fundamental in our conceptions. To account for this universally recognized phenomenon, Darwin proposed his transportation hypothesis as 
a possible explanation, which, as will be recalled, did not long survive. Weismann offered in explanation his germinal selection, which was soon discarded because it was beyond the possibility of experimental testing. Aside from these two attempts to explain individual variation no other comprehensive scheme had been presented. Biologists had simply recognized the fact of individual variation without any conception of the mechanism. They knew that individual variation existed but had even stopped asking why it existed.

The importance of this new theory, therefore, is obvious. It is an ingenious explanation of the inheritance of quantitative characters and of the existence of individual variations. Furthermore, the theory has not been developed through meditation, but has its basis in scientific experiments. It is imaginative to a certain extent, of course, as is every other valuable theory, but unlike most such theories it has a substantial foundation, namely, Mendel's law. 


\section{CHAPTER XX}

\section{THE FACTOR HYPOTHESIS AS APPLIED TO ANIMALS}

Immediately after the announcement by De Vries in r 900 of the rediscovery of Mendel's paper, zoölogists in Europe and in America began experiments in animal breeding with the idea of discovering to what extent Mendel's laws were applicable. It was soon found that the principles of unit characters, dominance, segregation, monohybrid, dihybrid, and trihybrid ratios were of practically universal application. A number of instances of Mendelian heredity in animals have already been presented in the preceding chapter and no more simple Mendelian cases need be described. For a considerable period the animal-breeders proceeded no farther in their analysis of the mechanism of heredity than Mendel had done so many years before. In time, however, new facts came to light that needed further analysis, and the older Mendelism was superseded by neo-Mendelism. This new phase in the study of heredity is in the forefront of interest today. Neo-Mendelian heredity in plants has already been discussed. It remains for us to present the data on some phases of neo-Mendelism in animals.

\section{ILLUSTRATIONS OF THE FACTOR HYPOTHESIS}

TEE FACTORIAL ANALYSIS OF COLOR IN MICE

Miss Durham, after extensive breeding experiments with numerous strains of differently colored mice, has been able to show that the appearance of a particular color in an individual mouse is dependent upon the presence or absence of several independently inherited factors, evidently represented by genes in as many different chromosomes. It seems possible to classify these factors as follows:

$$
\begin{aligned}
& B=\text { black pigment, which masks chocolate pigment } \\
& b=\text { absence of } B, \text { which gives chocolate } \\
& I=\text { intensity factor } \\
& i=\text { absence of intensity, or dilution factor } \\
& C=\text { a complementary color factor acting with } P \\
& P=\text { a complementary pigment factor acting with } C
\end{aligned}
$$

If either $C$ or $P$ is absent, albino mice result no matter what other color factors may be present. 
The factorial make-up of the various mice in Miss Durham's experiments would, then, be represented as follows:

$$
\begin{aligned}
& B I C P=\text { black } \\
& B i C P=\text { blue (dilute black) } \\
& \text { bICP }=\text { chocolate (absence of black) } \\
& \text { biCP }=\text { silver fawn (dilute chocolate) }
\end{aligned}
$$

The following experiments indicate the mode of heredity on the factorial basis:

I. $P$ Black $(B I C P) \times$ Silver-fawn $(b i C P)$

$\mathrm{F}_{\mathbf{1}} \quad$ Ioo per cent Black (BICP-biCP)

$\mathrm{F}_{2}$ Black $(B I C P)$ Blue $(B i C P)$ Chocolate $(b I C P)$ Silver-fawn

$$
9
$$$$
3
$$

2. $P$ Blue $(B i C P) \times$ Chocolate $(b I C P)$

$\mathrm{F}_{\mathrm{I}} \quad$ Ioo per cent Black $(B i C P-b I C P)$

$\mathrm{F}_{2}$ Black $(B I C P)$ Blue (BiCP) Chocolate (bICP) Silver-fawn

9

3. $P$ Blue $(B i C P) \times$ Silver-fawn $(b i C P)$

$\mathrm{F}_{\mathrm{I}} \quad$ Ioo per cent Blue $(B i C P-b i C P)$

$\mathrm{F}_{2}$ Blue $(B i C P)$ Silver-fawn $(b i C P)$

3

DIFFERENT KINDS OF ALBINOS

Any one of the color types mentioned, if lacking in the factor $C$, will be an albino, though carrying the other factors for color. For example, there may be a Black-albino (BICP), a Blue-albino (BicP), a Chocolate-albino $(b I c P)$, or a Silver-fawn-albino (bic $P$ ).

That color factors are present in albinos may be shown by the following experiment. An albino had appeared in a Black stock and was crossed with a Silver-fawn, thus:

4. $P$ Silver-fawn $($ biCP $) \times$ Albino extracted from Black $(B I c P)$

$\mathrm{F}_{\mathrm{I}} \quad$ Ioo per cent Black (biCP-BIcP)

$\mathrm{F}_{2}\left\{\begin{array}{ccccc}\text { Black } & \text { Blue } & \text { Chocolate } & \text { Albino-Black } & \text { Silver-fawn } \\ (B I C P) & (B i C P) & (b I C P) & (B I c P) & (\text { biCP }) \\ 27 & 9 & 0 & 9 & 3 \\ \text { Albino-Blue } & \text { Albino-Chocolate } & \text { Albino-Silver-fawn } \\ (\text { BicP }) & (b I c P) & & (\text { bic } P) \\ 3 & 3 & \text { I }\end{array}\right.$


The ratios given are the theoretical ratios for al trihyloric Mendeiian experiment, and the actual results have closely approximated these. As a matter of fact, sixteen albinos appeared, and it is not possible, except by breeding, to tell one kind from another. Breeding each with, for example, Silver-fawn would readily reveal the differences; for the $F_{1}$ generation would all be of the color that is masked by the lack of $C$ in these albinos. In the language of Johanssen there is only one albino phenotype, but there are four albino genotypes. Similarly in experiments (I) and (4), which have just been described, the individuals are all Black (phenotypically identical), but that they are not genotypically alike is clearly shown by inbreeding them. In experiment ( $\mathrm{I}$ ) we get only individuals of the four color types, while in experiment (4) we get, in addition to the four color types, four albino types.

\section{FACTORIAL ANALYSIS OF COAT COLOR IN SWINE}

Some breeds of swine have a red coat color, as the Duroc Jerseys. Other breeds have a sandy yellowish color. Still others are white. There are other colors, but they may be ignored for present purposes. Wentworth has shown that there are two genotypicaily distinct, though phenotypically identical, sandy types, the factor analysis being as follows:

$$
\begin{aligned}
S S T T & =\text { red } \\
S S t t & =\text { sandy } \\
s s T T & =\text { sandy } \\
s s t & =\text { white }
\end{aligned}
$$

If this analysis be correct, when the two different sandy genotypes (SStt and ssTT) are interbred, the result would be as follows: All of the $F_{1}$ individuals would be red. These, when interbred, give the following $\mathrm{F}_{2}$ phenotypic ratio:

$$
\begin{aligned}
9 S T & =\text { red } \\
3 S t & =\text { sandy } \\
3 s T & =\text { sandy } \\
\text { I } s t & =\text { white }
\end{aligned}
$$

The phenotypic ratio is, therefore, 9 red to 6 sandy to I white, which is a rare modification of the $9: 3: 3:$ I dihybrid ratio. and is due to the fact that the phenotype, sandy, consists of two different genotypes in equal numbers. 
CO.AT COLORS IN GUINEA PIGS

In guinea pigs the wild type coloration is a kind of reddish-gray mixture called "agouti." There are also black coat colors and whites (albinos).

Agouti, when crossed with some types of white, gives all agouti in the $F_{1}$ generation, and 3 agouti to $I$ white in the $F_{2}$ generation. A black guinea pig crossed with agouti gives all agouti in the $\mathrm{F}_{1}$, and 3 agouti to $\mathrm{I}$ black in the $\mathrm{F}_{2}$ generation. Evidently both black and white are recessives to agouti; so agouti must be due to at least two dominant color factors, $A$ and $C$.

If we assume that $A$ is a dominant factor, whose recessive allelomorph, $a$, gives black color; and that $C$ is a dominant factor whose recessive allelomorph, $c$, gives white color, then we may put down the formulas for the genetic composition of the three coat colors as follows:

$$
\begin{aligned}
A A C C & =\text { agouti } \\
A A C C & =\text { albino (of one kind) } \\
a a C C & =\text { black }
\end{aligned}
$$

Then when black ( $a$ CCC) is crossed with white $\left(A \mathrm{ACc}\right.$ ), all of the $\mathrm{F}_{\mathrm{r}}$ generation would be agouti and the $\mathrm{F}_{2}$ ratio would be as follows:

$$
\begin{gathered}
9.4 C C=\text { agouti } \\
3.4 c c=\text { white } \\
3 a a C C=\text { black } \\
\text { I aacc }=\text { white }
\end{gathered}
$$

This would give a phenntypic ratio of 9 agouti to 3 blacks to 4 whites, another rather slight but unusual modification of the familiar $9: 3: 3: 1$ ratio, due to the fact that the phenotype "white" consists of two genotypes.

Characters that seemed quite simple at first have been found, by methods similar to those here presented, to be complex when subjected to analysis. Such apparently simple characters as human eye color and hair color, though never fully analyzed, would doubtless amply repay investigation. If we knew as much about these characters as we do about some animal characters, the testimony of a geneticist in a paternity case would be more valuable than it is at present. 


\section{CHAPTER XXI \\ REVIEW OF MENDELISMI}

At this point it seems well to pause and to take stock of what we have learned about heredity by following Mendel's lead. Let us first enumerate some of the rules or laws of heredity discovered by Mendel. These are commonly known as Mendel's law's.

Mendel's first law: the law of dominance.-When two parenttypes differing from each other with reference to a single unit character are crossed, the "hybrid-character resembles that of one of the parent forms so closely that the other either escapes observation completely or cannot be detected with certainty." The character that appears in the first-generation hybrids is called "dominant" and that which apparently becomes latent is called "recessive." The law of dominance has been shown to be far from universal in its application. In fact, complete dominance is relatively rare, and almost entire lack of dominance is not uncommon. Evidently, then, dominance is not an essential feature of Mendelian heredity.

Mendel's second law: the law of segregation, or purity of gametes. While the body cells and the germ cells of the $F_{\text {I }}$ parent, prior to the reduction divisions involved in gamete formation, contain the determiners (genes) of both alternative characters and are therefore hybrid in character, a segregation of the alternative genes (allelomorphs) takes place during maturation so that only one or the other gene comes to be present in any gamete. Thus gametes are pure for any gene. A gamete has one or the other of a pair of allelomorphs and is never hybrid with reference to any single character. This law is by far the most important of Mendel's discoveries. In fact, it might be called the discovery of Mendel, for it is almost unsurpassed among biological generalizations on account of its far-reaching applicability. The law has sometimes been called the law of the splitting of hybrids. Whether dominance is present or not, the law of segregation always holds. The second law, therefore, is much more important than the first.

Mendel's third law: the law of independent assortment of differ- 
ent allelomorphs.-To use Mendel's own expression, "the relation of cach pair of different characters in hybrid union is independent of the other differences in the two original parental stocks." This third law is only discoverable when we try to follow the assortment and recombination of at least two pairs of allelomorphs up to the second hybrid generation $\left(F_{2}\right)$. If each allelomorph be studied by itself, it will show nothing more than the facts indicated in the first two laws, but as soon as we try to follow the modes of inheritance of more than one character simultaneously, we find that we are merely dealing with the independent shuffling and assorting of two or more genes. The way in which we explain the third law is that all genes that exhibit independent assortment are located in different chromosomes. If two allelomorphs were in the same chromosome, it is obvious that their association with each other in heredity would be much closer than if they were in different chromosomes. Remember this when we come to consider a later proposition called linkage.

Mendel's fourth law: the law of recombination.-According to Mendel, this law means "that the constant characters which appear in the several varieties of a group of plants (or animals) may be obtained in all the associations which are possible according to the mathematical laws of combination." The genes carried by the chromosomes are shuftled about like a pack of cards and dealt out in all possible combinations according to the laws of chance. The result of this is that the particular deal, or "hand," that happened to be possessed by the parent is likely not to be repeated in any of the offspring if the number of differences involved is at all large. Of course, if there is only one point of difference between the two parents, the character of the parent will be repeated in one out of each four individuals of the $\mathrm{F}_{2}$ generation. If there are two pairs of allelomorphs concerned, there will be one in sixteen in the $F_{2}$ with the same combination as each original parent; if three pairs of allelomorphs, one in sixty-four; if four pairs, one in two hundred fifty-six; if ten or more pairs, one in hundreds of thousands or millions. Nearly all human beings differ from one another with regard to hundreds of allelomorphs. Is it not rernarkable, then, that there is as much resemblance between two brothers as there sometimes is? This condition will be better understood when we come to discuss the limitations of the law of independent assortment, which Mendel failed to discover, and which is explained by the law of linkage.

The concepts expressed in the above laws may be considered to have originated with Mendel. It must be remembered, however, that 
Mendel harl no knowterlge of chromosomes or of the chromosomal mechanism of maturation, which now seems to be the machine responsible for the regularities seen in the various Mendelian ratios and for segregation in general. It is remarkable, therefore, that Mendel foresaw a mechanism within the genetic apparatus of plants that coincides in principle with that sulsequently discovered. Among the great discoveries that have resulted from the use of Mendelian methods and procedures are the factor hypothesis, the chromosome theory of heredity and of sex determination, linkage and crossing-over, and the finer details of the heredity machine.

The presence and absence theory. - In its original form the presence and absence theory implied that some gene was present in the dominant individual that was absent in the recessive. It has been discovered, however, that this theory fails to hold, especiatly in cases of multiple allelomorphs, and probably does not holl at all. As an example of multiple allelomorphs, we may cite the various eye-color mutants of Drosophila (see page 294). A whole series of ere-color conditions ranging from red to white are alf known to be the result of mutational changes in the same gene, with red, the will type condition, being dominant over any of the mutant conditions. Now these various colors, such as vermilion, pink, salmon, cream, etc., are all recessive to red, but dominant over white. This shows that the gene for eye color is present in all these mitants but is merely modified in various ways or in varying degrees.

The presence and absence hypothesis, therefore, might then be stated as follows: There is some positive element present in the dominant gene that is absent in the recessive allelomorph, which prevents the recessive gene from expressing itself. In this form the theory is rather helpful and serves to rationalize the practice, now universal, of representing any dominant gene by a capital letter, such as $A$, and the recessive gene by the equivalent small letter, $a$.

The factor hypothesis. - Mendel believed that for each character there was a determiner; that each determiner produced a character unaided. According to the factor hypothesis, as we have seen, such simple characters as colors in plants and animals depend upon the interaction of several genes, which are called "factors" because they are not single causes but merely co-operative agents. It is now coming to be believed that each character of the organism is the product of the interacting of many, possilly all, of the genes in the organism, but that some of the genes affect a given character more than do others. 
It remains to be discovered to what extent each character is the result of the interaction of all the genes. When once we learn that a single character may depend upon the interaction of two or more independently inherited and segregating factors or genes, it becomes possible to understand all sorts of puzzling and apparently non-Mendelian ratios. The adoption of the factor hypothesis has justified itself over and over again, for it has been the instrument that has led to a really scientific genetics and has served to bring under one category all sorts of hereditary phenomena that had formerly been considered fundamentally different. Thus, there is now no further need for the three categories of heredity: alternative, blending, and particulate. All three are now seen to be phases of alternative, or Mendelian, heredity. Especially striking is the way in which the idea of multiple factors ("cumultative" or "duplicate factors" of some authors) has served to rationalize and to bring into line with other Mendelian phenomena the data about the inheritance of quantitative characters. Another service of the factor hypothesis comes out in connection with the discovery of lethal factors. There is a large number of genes or factors whose presence in the homozygous condition (i.e., when a given factor is present in both gametes that unite to form a zygote) leaves the individual derived from such a zygote lacking in something essential for life. All such individuals in any breeding experiment will fail to survive, and their absence will be noted when the ratios of the various combinations are worked out. The failure of a certain expected combination to appear in the $\mathrm{F}_{2}$ generation is attributed to the presence of a lethal factor in the stock. It can readily be proven that many of the surviving individuals possess the lethal factor in a heterozygous condition, having one dose of the normal allelomorph along with the lethal factor. These lethal factors can be identified and located as readily as characters that actually appear. The subsidiary hypothesis of lethal factors has had a far-reaching influence upon some of the most advanced phases of modern genetic practice. 


\section{CHAPTER XXII}

\section{SEX-LINKED HEREITT}

$\mathrm{U}_{\mathrm{p}}$ to this point we have been dealing with Mendelian experiments in which no more than one gene in any given chromosome was concerned. The various Menclelian ratios, including the modified ratios presented in connection with the factor hypothesis, depend upon each of the different allelomorphic factors involved being in a different pair of chromosomes. If two or more genes were in the same chromosome, one would not expect them to follow the laws of random assortment and random recombination. The study of sex-linked heredity opened the way to the discovery that particular genes are in particular chromosomes, that they tend to remain together in heredity, but that genes in homologous chromosomes are frequently exchanged in a mutual fashion. This discovery has led to a knowledge of linkage and crossing-over, and to the discovery of the detailed architecture of the germ plasm.

Nearly twenty years ago a peculiar kind of heredity, known as sexlinked heredity, was discorered and explained by Morgan. We had previously known of this kind of heredity in man, as in the case of color-blindness, free-bleeding, etc., but its mechanism was not even guessed at. It had long been known that color-blind individuals are almost invariably males, that such males marrying normal women never have any color-blind offspring, but that their daughters when mated with normal men have some color-blind sons, but never colorblind daughters. Thus color blindness shows a strong predilection for males, and is called a sex-linked character. Free bleeding, night blindness, and several other human characters are known to be inherited in the same fashion.

The mechanics of this form of heredity was worked out by Professor T. H. Morgan as the result of his work on the classic fruit fly Drosophile melunogaster. In this valuable little insect the eyes are typically bright red. In a stock of typical red-eyed tlies Morgan one day noted one white-eyed male. This had been born of typical redeyed ancestry, so the white-eye character in addition to being sexlinked was a mutant, appearing suddenly without any preliminary steps. To test the heritability of this new character, the white-eyed 
male was mated to a normal red-eyed female. The offspring of this mating were all recl-eyed in appearance (phenotypically), but the females were olsviously all genotypically hybrid red-and-white eyed, for when mated with normal red-eyed males half of their sons were white eyed and half red eyed, but all daughters were red eyed. Subsequent experiments showed that half of the daughters were pure red eyed and half hybrid red-and-white eyed. Now what sort of mechanism in the germ cells could account for this peculiar but very uniform type of hereditary behavior?

Professor Morgan explained the whole thing in a beautifully simple way by assuming that the gene of the sex-linked character was situated in the X-chromosome of the mutant male, for the male has but one X-chromosome along with a Y-chromosome (see Fig. 53). In the reduction division of the germ cells of this individual two kinds of male gametes (spermatozoa) are formed in equal numbers, one carrying the $\mathrm{X}$-chromosome with the white-eyred gene and the other the $\mathrm{Y}$-chromosomes. Now, whenever a female gamete (egg) of the normal red-eyed female used as a mate is fertilized by a sperm with the $\mathrm{X}$-chromosome, an XX individual or female will result, and all of these females will get the white-eye gene along with the X-chromosome from their white-eyed father. But whenever an egg is fertilized by a sperm with the $\mathrm{Y}$-chromosome, a male will be produced, and all of these will be red eyed because they get their X-chromosome from their mothers. Why are not these female offspring possessing the white-cye factor white eyed? Because they have also inherited an X-chromosome containing the red-eyed factor from their mothers, and red eye is dominant over white eye. These red-and-white-eyed hybrid daughters are now bred to normal red-eyed males, whose X-chromosome carries the redeye factor. The females will produce two kinds of gametes in equal numbers, one with the $\mathrm{X}$-chromosome carrying the red-eye gene, the other with the X-chromosome carrying the white-eye gene; while the male will produce two kinds of gametes, one with an X-chromosome carrying the red-eye gene and the other with only a $\mathrm{Y}$-chromosome. Each kind of male gamete will unite equally often with each kind of female gamete, and the result will be four kinds of zygotes in equal numbers: one in which two red-eyed X-chromosomes come together and produce a pure red-eyed female; one in which a red-eyed and a white-eyed $\mathrm{X}$-chromosome come together and produce a hybrid female; one in which a red-eyed $\mathrm{X}$-chromosome and a $\mathrm{Y}$-chromosome unite to produce a red-eyed male: and finally, one in which a white-eyed 
X-chromosome and a I-chromosone mite to produce a white-ered male. This is the detailed procedure followed by all sex-linked characters of this sort, and is shown diagrammatically in Figure 60.

We have seen that white eyes seem to be purely a male character, inasmuch as it does not seem to express itself in females even when present in the germ plasm. Why is this not just a secondary sexual character like the differences in size and shape of the body that characterize the two sexes? The answer to this query is that, if we perform the proper breeding experiment, it is possible to transfer the whiteye character to the female. For example, let us take one of the diaghters of a white-eyed male and mate her with a white-eyed male. The female is a hybrid carrying the white-eye gene in one of her X-chromosomes and the red-eye gene in the other X-chromosome. She will produce equal numbers of gametes with the two eye-color genes. The male will also have two kimls of ganetes, one with a whiteeve-bearing $\mathrm{X}$-chromosome and one with a Y-chromosone. Randont mairing of the types of gametes of the two parents will produce four classes of individuals in equal numbers: one female with a rutered $X$ and a white-eyed $X$ (phenotyically red-eyeri); one female with two white-cyed X-chromosomes, and therefore white-eyed; one nale with a red-yed $X$, and therefore red-eyed; and one male with a whiteeyed $\mathrm{X}$, and therefore white-eyed. It is clear, then, that the whiteeye character is not limited to one sex, but merely closely linker to the male sex under nomal breeding conditions. All sex-linked characters are recessive, for were they dominant they would express themselves somatically when either one dose or two doses of the gene are present. The reason why the character aprears nornaily in males only is that nales have only one X-chromosome, a situation which makes it possible for any recessive gene located in the $\mathrm{X}$-chromosome to express itself. The female, however, has always two X-chromosomes, and unless she inherits the recessive gene from both parents - a condition that would rarely occur in nature-she would always have the corresponding dominant character in one $\mathrm{x}$-chromosome to mask or offset the recessive character in the other r-chromosome. In man it is also the unfortunate male that falls heir to ail of the rather detrimental sex-linked characters, while the female, though inheriting the character more often than the male, practically never shows the efiects of it.

An interesting variant upon the usual type of sex-linked hrealing experiment is the so-called reciprocul cross, starting out with a white- 
eyed female, derived from such an experiment as that just described, and breeding her to a normal red-eyed male. The $F_{\mathrm{I}}$ hybrids will be white-eyed males and red-eyed females, the two eye colors simply changing sexes. This is explained by the fact that females always inherit an X-chromosome from both father and mother, while males always get their $\mathrm{X}$-chromosome from their mothers. We speak of this

Flies

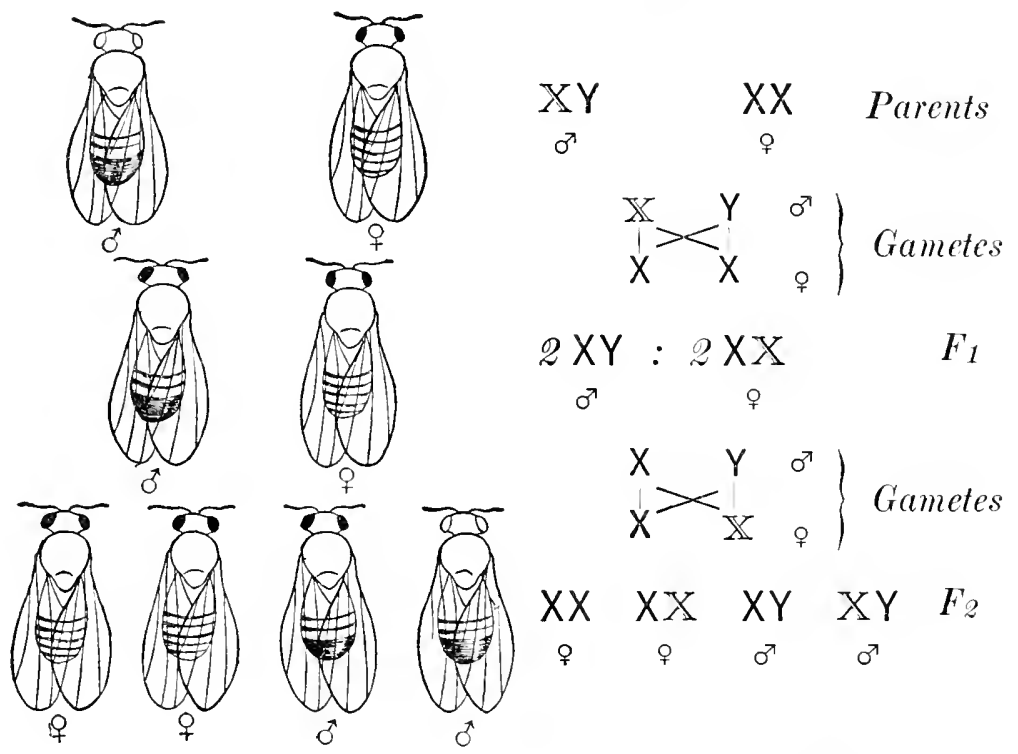

Chromosomes

$2 X Y: 2 X X$ $F_{1}$

FIG. 69.- Sex-linked inheritance of white and red eyes in Drosophila. Parents white-eyed male and red-eyed female; $F_{I}$, red-eyed males and females; $F_{2}$, redeyed females and equal numbers of red-eyed and white-eyed males. $\Lambda$ black $\mathbf{X}$ indicates an $\mathrm{X}$-chromosome bearing the gene for red eye, a white $\mathrm{X}$ bears white eye. $\mathbf{Y}$ is the $\mathbf{Y}$-chromosome. (From Conklin, after Morgan.)

phenomenon as crisscross inheritance. There are many evidences that, in general, daughters inherit more largely from fathers and sons from mothers, and it is probable that the mechanism of this condition is like that just described. But to continue the reciprocal-cross experiment to the $\vec{F}_{2}$ generation, let us breed together the males and females of $F_{1}$. The result will be red-eyed males and females in equal numbers (Fig. 70).

The type of sex linkage which we have just described for Dro- 
sophild and which also prevails in man has come to be called the Drosophilu type of sex-linkage. There is, however, quite a different type that is called the poultry type, which, while strikingly like the type already described, differs from it in one important respect.

The poultry type of sex linkage.-In the Drosophila type, the ienale is the homozygous sex (producing only one kind of gamete, each

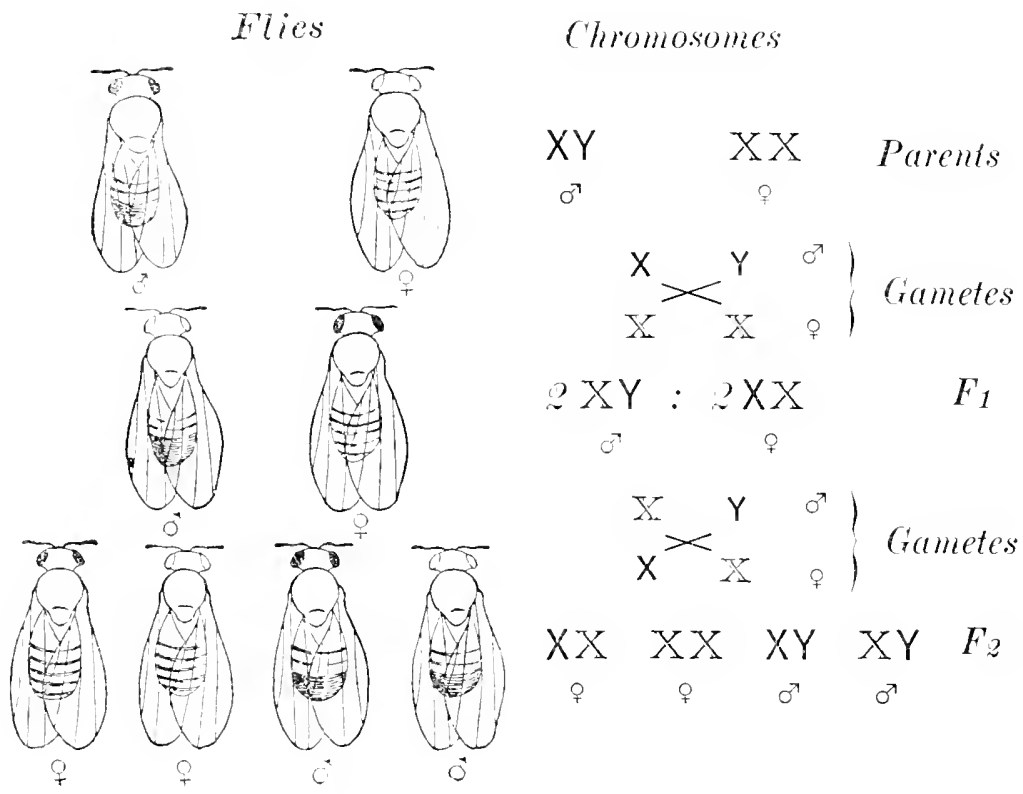

Fic. 7o.--Reciprocal cross to that shown in Figure 09. Parents, red-eyed male and white-eyed female; Fr, white-eyed males and red-eyed females ("crisscross inheritance"-Morgan); $F_{2}$ equal numbers of red-eyed and white-eyed individuals of both sexes. The distribution of the sex chromosomes is shown at the right, as in Figure og. (From Conklin, after Horgan.)

with an $\mathrm{X}$-chromosome), and the male is heterozygous (producing two kinds of gametes, one with an $\mathrm{X}$ - and one with a Y-chromosome). Now certainly in moths and butterflies, and probably in birds, the male is homozygous and the female heterozygous. It is the custom to lesignate the sex-chromosome condition as WW for the male and IVZ for the female, though why we should not use XX and XY it is difficult to say. With this reversal of sex-chromosome composition of the two sexes we might expect that sex-linked heredity woukl work out just 
the reverse of that described for Drosophila, so far as the sexes are concerned; and this, interestingly enough, is exactly what we get.

A typical instance of sex linkage of this sort is seen when a barred Plymouth Rock cock is mated with a Black Lanshan hen (Fig. 7I). All offspring, both males and females, of the $\mathrm{F}_{\mathrm{I}}$ generation are barred;

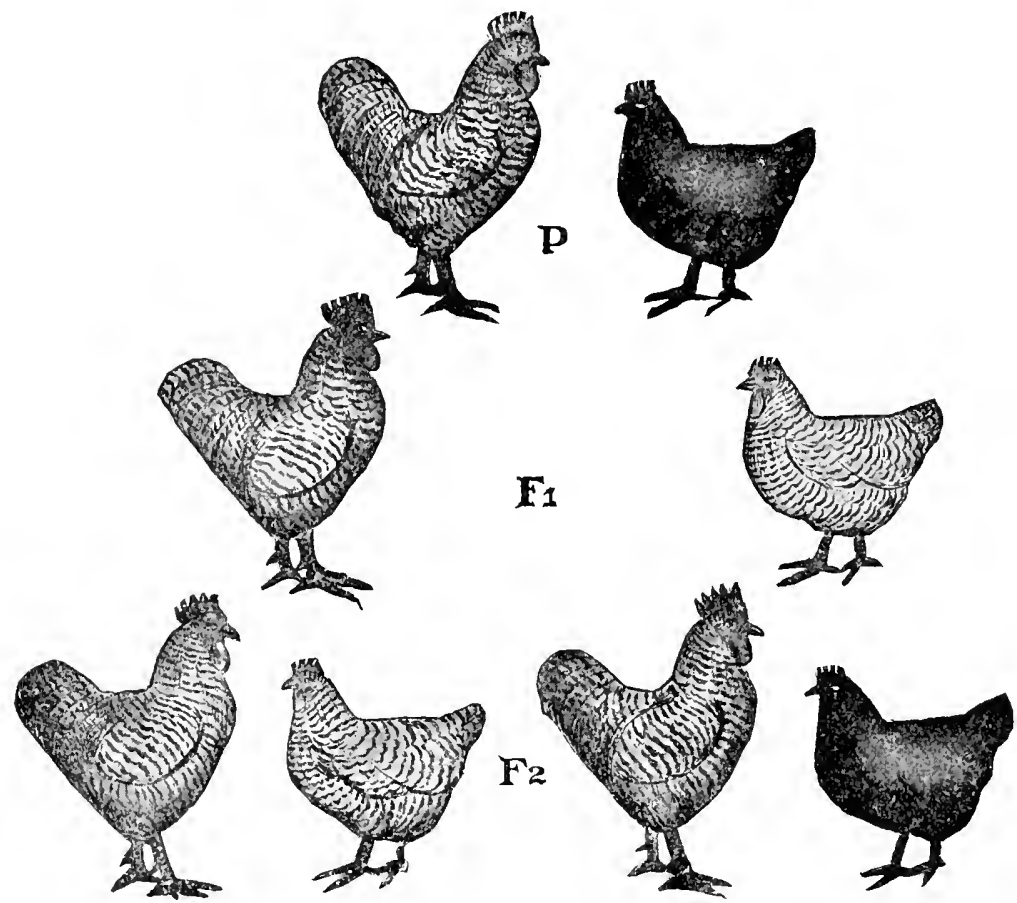

Fig. 7 I. - Sex-linked inheritance of barred and unbarred (black) plumage in poultry. $P$, parents, barred male, unbarred female; $F_{1}$, barred males and females; $\mathrm{F}_{2}$, males all barred, females in equal numbers barred and unbarred. (After $\operatorname{Morg} 2 n$.

but when the individuals of $F_{I}$ are interbred (or the $F_{I}$ males are bred with any barred females), all males are barred and half of the females are barred and half are black. Here we see that the recessive character, black, is linked with the female sex. If we cross a black female with an $\mathrm{F}_{\mathrm{r}}$ male we can get equal mumbers of barred and of black males and females. The reciprocal cross (Fig. 72) illustrates crisscross inheritance. Starting with a black male and a barred female, we get in $F_{I}$ barred males and black females. When the $F_{I}$ individuals are interbred we get half barred and half black males and females. 
While in the birds the chromosomal condition has never been completely worked out, on account of inherent technical difficulties likely to be overcome any day, the case of the currant moth, abraras, has been thoroughly analyzed. The sex linkage follows the poultry plan and the gametes of the male have been found to be all alike, while

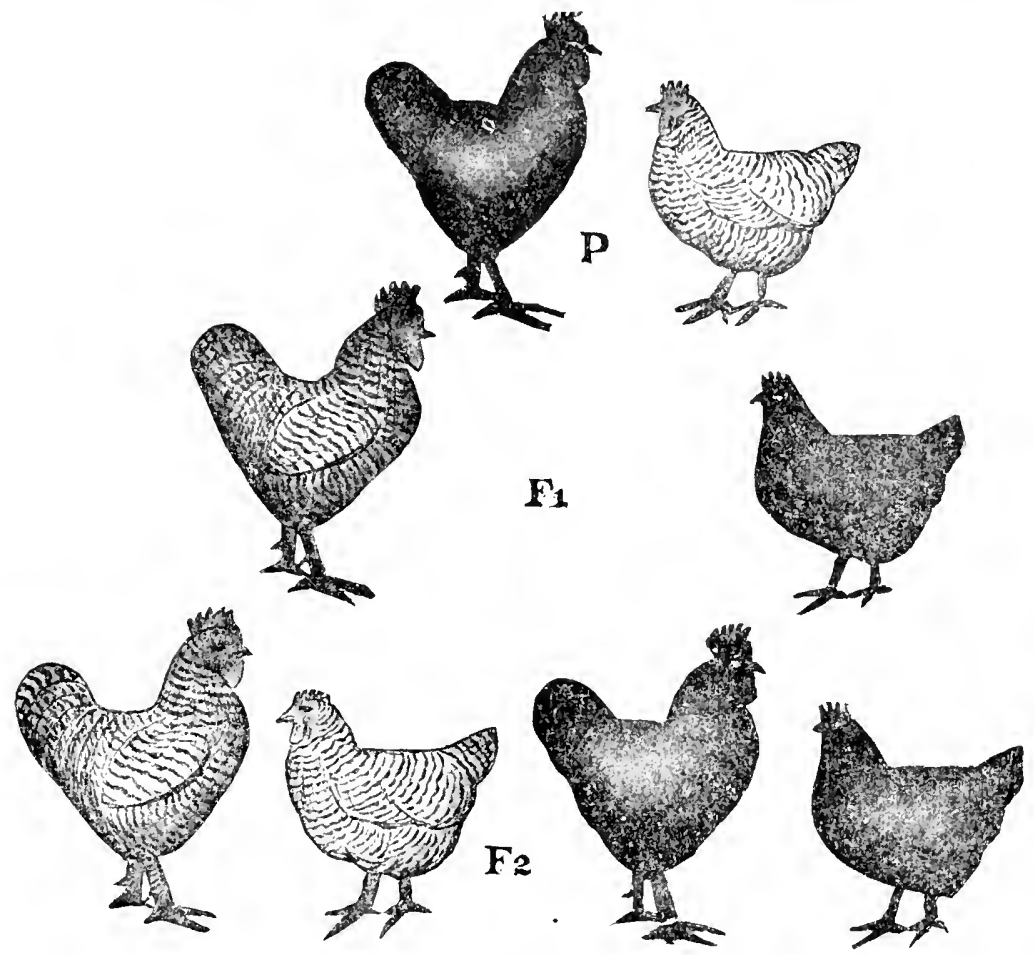

Fig. 72.- Reciprocal cross to that shown in Figure 7I. P, parents, unbarred male, barred female; $F_{1}$, barred males, unbarred females (crisscross inheritance); $\mathrm{F}_{2}$, barred and unbarred birds equally numerous in both sexes. (I rim Castle.)

those of the female are of two types, one containing an $\mathrm{X}$-chromosome (W-chromosome) and the other a Y-chromosome (Z-chromosome). The striking parallelism between the reversal in sex-linked herelity and in the visible reversal of chromosome composition in these two groups of animals (Drosophila and man, on the one hand, and the butterflies, moths, and birds, on the other) offers one of the most cogent proofs of the validity of the chromosome theory of heredity. which we have already come to rely upon and shall have further occasion to make use of later on. 
To bring the facts of sex-linked heredity sharply into focus by way of summary, let us quote from D. F. Jones a genetic formulation of the whole matter:

"Rules for sex-linked inheritance.-From this series of facts the following rules governing the transmission of sex-linked characters can be deduced.

"I. When the homozygous sex transmits the dominant factor, all of the offspring in the first generation exhibit the dominant character and the second generation is composed of three dominants to one recessive, the latter having the same sex as the recessive grandparent.

"2. When the homozyous sex transmits the recessic factor, both dominant and recessive characters are exhibited in the first generation, but exclusively upon the opposite sexes, and in the second generation both sexes show the sex-linked characters in equal numbers." 


\section{CHAPTER XXIII}

\section{LINKAGE, CROSSING-OVER, AND THE ARCHI- TECTURE OF THE GERII PLASM}

Owing to the fact that most of the important advances in our knowledge of the finer structure of the heredity machine have been made with the aid of the little fly Drosophila melanogaster, this chapter might be dedicated to the memory of this insect. "Although, like Cinderella, Drosophila comes from the humble environment of the garbage can," say's Walter, "yet this fly has easily outstripped all its sister competitors for genetical honors, until today it stands probably as the most famous experimental organism in the whole world."

But too much credit for the genetic revelations derived from a study of Drosophila must not be given to the fly, which of its own accord would never have told us anything. Though the name of Drosophila may now be famous all over the world, the one who made it famous is Professor T. H. Morgan, who in collaboration with an unusually able corps of assistants (especially Sturtevant, Brirlges, and Muller) has demonstrated to the scientific world the value of co-operation in research. The old adage that two minds are better than one has proven true in this long and arduous, and above all fruitful, investigation. The work done by "the fly squad," as it has been affectionately called by fellow-biologists, has resulted in an analysis of the heredity machine so detailed as to be almost unbelievable. It seems too good to be true, yet the keenest critics of the work have failed to find any real flaws in the intricate fabric of conceptions that has been woven. The whole story of this brilliant discovery, or series of discoveries, cannot be told in a way that would be intelligible to the layman or even to one with only a superficial knowledge of genetics. It requires long and arduous study to understand it all, and one of the reasons why the ideas have failed of general acceptance is that only relatively few biologists have been willing to devote to the study of the data the amount of time and labor necessary fully to understand them.

\section{LINKAGE}

In the last chapter a detailed account was given of the sex-linked inheritance of white eyes in Drosophila. This was the first of the sex- 
linked characters discovered in Drosophila, but by no means the last. Soon after the discovery of the white-eye mutant, there appeared in typical stock characterized by gray wing color a single male mutant distinguished by yellow wing color; and this character was found to be inherited exactly after the manner of white eyes. In other words, it is sex-linked, and therefore must have its gene in the $\mathrm{X}$-chromosome. As time went on, many new sex-linked characters appeared as mutants, always noted in males, and these characters had to do with all sorts of bodily characters. Several of these were new eye colors (vermilion, ruby, prune, garnet); others had to do with eye shape or eye texture (furrowed, bar eye, and small eye); others, with wing size and shape (broad wing, club wing, cut wing, vestigial wing); others, with bristles (scute, singed, forked); others, with body color (tan, sable); and some were lethal characters. Altogether, over sixty definite sex-linked mutant genes, with their allelomorphs, have been found to be sex-linked and therefore must have their loci in the $\mathrm{X}$-chromosome.

Now, during the twenty years of breeding millions and millions of drosophilas and examining them for signs of new hereditary characters, some hundreds of other mutations were noted and their modes of heredity studied. This latter great collection of mutant characters showed no sex linkage, so could not be assigned to the $\mathrm{X}$-chromosome. They must in all probability be located in the autosomes, as the rest of the chromosomes are called. But which of the remaining chromosomes carry the various non-sex-linked genes is not definitely known. An important fact, however, soon came to light, namely, that practically all of these non-sex-linked-genes fall naturally into two groups of nearly equal size. The basis for this distribution of genes into two groups is this: that some of the characters appear together more often than not, while other characters appear apart (i.e., in separate individuals) more often than together in the same individual. This process of classifying characters results in two large groups of characters of nearly equal size, each rather more numerous than the sex-linked group. The two large classes of genes that seem to hang together in heredity more often than they go apart have come to be assigned to chromosomes II and III (Fig. 53) respectively, and are known as the sccond and third linkage group. At present it is not possible to distinguish between Chromosome II and Chromosome III, for they are of the same size and shape; but the point is that there are only two other pairs of large chromosomes in Drosophila and only two large linkage groups besides the sex-linked group. What more natural, 
then, than to assign these two large linkage groups to the two large chromosomes that are present?

All went well with the linkage hypothesis for awhile, but before long one of the workers discovered a new character that was not at all linked with any of the three groups and therefore could not be assigned to any chromosome known at that time. This seemed at first like a staggering blow to the hypothesis then entertained, but it turned out to be one of the best demonstrations of its validity. A reexamination was made of the germ cells of Drosophila with the result that a pair of tiny chromosomes was found to be always present, which, because of their very small size, had been overlooked by the original students of this material. This tiny chromosome was called Chromosome IV, and the new mutant, bent wing, was assigned to it. Some time later another aberrant mutant, eyeless, was found that was closely linked with bent, and therefore assigned to Chromosome IV. So far, these are the only genes that have been located in the tiny chromosome. This may mean that there is not room for many genes in so small a body.

Now, if there is anything in the chromosome theory of heredity, and if the genes of individual differences have their seat in the chromosomes, all of the character differences in Drosophila melanogaster, no matter how many are found, must be in no more than four groups, for there are only four kinds of chromosomes in that species. For a while it was feared that some new character would appear that was not linked with any of the known linkage groups, for the discovery of such a character would strike a severe blow against the theory of linkage and against the chromosome theory in general. After the passage of several years, however, and the discovery of almost a hundred new mutants, not one has been found that does not show linkage with one of the four known groups. Just to the extent that the finding of a fifth group of characters would have weakened the chromosome theory, to that extent the failure to find any exceptions to the four linkage groups strengthens the theory.

The characters represented by genes in both second and third chromosomes have to do with all parts of the body, including eye color, eye shape, body color, wing size and shape, bristle characters, leg form, and lethal characters. It cannot then be said that any one chromosome carries genes characteristic of any one part of the body; instead, it seems that every chromosome carries genes that affect every part of the body or, in other words, the whole organism. 
Confirmatory evidence of the validity of the theory of linkage comes from the comparative study of other species of Drosophila, some of which have the same number of chromosomes as has D. melanogaster, others of which have a larger number. In one species that has four pairs of chromosomes, like the original species, only four linkage groups have been found, while in other species in which an extra pair of chromosomes has been found there is a fifth linkage group. Comparative studies upon the linkage groups and the kinds of genes in these linkage groups have revealed a striking parallelism between the different species and a beautiful conformity between the numbers of chromosomes and the number of linkage groups. Also it should be said that the relative numbers of genes discovered is in a rather definite proportion to the size of the chromosomes.

\section{CROSSING-OVER}

All of our studies of the mechanism of heredity up till now have led to the conclusion that chromosomes are very definite and individual structures that continue from generation to generation intact and are passed as wholes from parent to offspring. We have spoken of the process of pairing of homologous chromosomes in synapsis as though this pairing were no more intimate than a mere temporary embrace. We have spoken as if, during the reduction division to form gametes, the homologous chromosomes merely part company and proceed intact to opposite poles of the dividing cell and enter separate gametes unaffected by having associated in the embrace of synapsis. That this is far from true has been revealed by an exact numerical study of the varying degrees of linkage in the characters whose genes are supposed to be located in a single member of a given chromosome pair. On the basis that a chromosome is an inviolable body proceeding as a whole from generation to generation, we should, of course, expect any two characters that were once represented by genes in the same chromosome to stay together perfectly, i.e., always to appear together in the same individual. The fact that this result was not realized led to further advances in our understanding of the complex heredity machine. Let us see just how linkage works out with certain genes in the $\mathrm{X}$-chromosome. Remember that each of the characters was located in the X-chromosome because each one by itself followed the mode of heredity of a sex-linked character.

The mode of linkage of two sex-linked genes.-The wing color called "yellow" and the eye color called "white" have already been 
dealt with in the previous chapter, and were seen to be sex-linked. Now let us assume that by the proper breeding experiment we have a yellow-winged white-eved female (call her "yellow white" for short). Mate her with an ordinary normal male with gray wing and red eyes (call him "gray red"). All the daughters are gray red like the father (each having inherited an X-chromosome from lim), but the sons are yellow-white like the mother (having inherited her X-chromosome). The Y-chromosome does not affect the result at all. The daughters, in addition to receiving an $\mathrm{X}$-chromosome from the father, receive another X-chromosome from the mother; so they have two lifierent X-chromosomes. They are all phenotypically gray red because gray and red are dominant over yellow and white.

Now it is easy to test the composition of these hybrid females by breeding them with double-recessive (yellow white) males. The result is as follows: 49.5 per cent of offspring are yellow white, 49.5 per cent are gray red, 0.5 per cent are yellow red, and 0.5 per cent are gray white. Such a result as this could hardly be anticipated. If there were no linkare, but entirely independent assortment, as would be the case were the two pairs of genes in different chromosomes, we should expect the dihybrid ratio of nine gray reds, three gray whites, three yellow reds, and one yellow white. If, on the other hand, chromosomes retain their integrity when they separate after synapsis, we would expect $5^{\circ}$ per cent gray reds and 50 per cent yellow whites. Why do we find the anomalous ratios that we do? Obviously the chromosomes that pair in synapsis do not always part company without being affected by the chromosomal embrace, but instead they seem, at least occasionally, to undergo a mutual exchange of equivalent genes. Thus in one case in a hundred the gray and yellow wing allelomorphic genes are traded without also trading the red- and white-eye genes, and in exactly the same number of cases the red and white genes are traded between chromosomes without the yellow and gray being traded along with them. This mutual and perfectly equitable exchange of genes between homologous chromosomes is called crossing-over, and the percentage of crossing-over between any two allelomorphs is the same each time the same breeding experiment is repeated under the same conditions. In the case we have just described, the crossingover percentage is very small, only a per cent. Let us try another pair of sex-linked genes.

A female with white eyes and miniature wings is bred to a male with red eyes and long (or normal) wings. The miniature-wing gene 
has already been shown to be sex linked. The result in $F_{\mathbf{r}}$ is that all females are red long and all males are white miniature. Inbreed the individuals of $F_{1}$ and we get in $F_{2}: 33.5$ per cent white miniatures, 33.5 per cent red longs, 16.5 per cent white longs, and 16.5 per cent red miniatures. In other words, the crossing-over percentage is 33 . If the crossing-over percentage were to equal or exceed 50 per cent, it would mean that there is no linkage at all, for if the two allelomorphic genes were in different pairs of chromosomes we should have even chances of two independent characters coming together or staying apart. Thus we may say that in the first experiment the linkage (99 per cent) is very high and the crossover percentage is very low (I per cent), while in the second experiment the linkage is relatively weak ( 67 per cent, or only 77 per cent stronger than no linkage at all) and the crossover percentage is relatively high (33 per cent).

The mechanism of crossing-over.- "If it be admitted," say Morgan, Sturtevant, Muller, and Bridges, in their volume The Mechanism of Mendelian Heredity, "that Mendelian factors are carried by chromosomes it can not be denied that interchange between homologous chromosomes must occur, for sex-linked factors cross over from each other, and yet are known to be in the same pair of chromosomes, since they all follow the $\mathrm{X}$-chromosome in its distribution. The evidence allows no other interpretation. But why should crossing-over take place so rarely between certain factors and so often between others? We can make use here of certain information in regard to the chromosomes that gives a very simple answer to the question. In the early germ cells, before the maturation period begins, the chromosomes appear to be scattered in the nuclei, and the homologous chromosomes in many cases show no tendency to lie together, although in some animals, e.g., in many flies, the members of a pair are often found side by side. In this early period the germ cells divide as do other cells and thereby increase in numbers. But at the termination of this period, the homologous chromosomes unite in pairs. There has.been much controversy as to how this union takes place, but in some cases at least, the uniting chromosomes twist around each other as they come together. This is illustrated to the left in Figure 73. As a consequence, parts of one chromosome will come to lie now on one, now on the other side of the mate. If when the twisted chromosomes separate, the parts on the same side go to the same pole the end result will be that shown to the right of Figure 73. Each chromosome has interchanged a part with its mate. This process has been called crossing-over. It is, 
of course, also possible that the twisted chromosomes do not break and reunite where they cross, and if they do not, then when they begin to separate they simply pull apart irrespective of the side on which they lie. When this occurs each chromosome remains intact and no crossing-over takes place.

"The chance that such a process of crossing-over will occur between any two given points on the chromosome should obviously be greater the greater the distance between those points. If then the Mendelian factors lie along the chromosomes, the amount of crossing-over be-

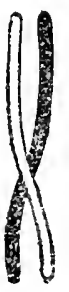

Á

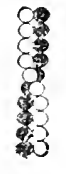

$B$

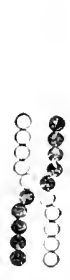

C

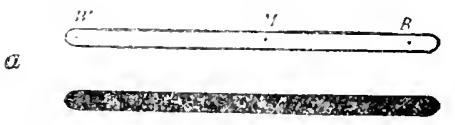

$b$

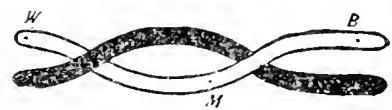

$c$

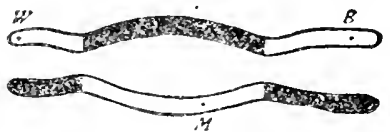

FIG. 73. - B and $C$ illustrate Niongan's idca of the linear arringement of the genes in the chromosomes. A and $D$ show hup the comprsitin of the chromosomes is supposed to change as the result of the crossurce. On the right, a frair of chromsomes, a, before; b, during; and $c$, after a double crosover. (1fter Morgtan.)

tween any two of them will depend upon their distance apart. Should two points lie near together a cross-over will only rarely occur between them; if they lie farther apart the chance of such a cross-over taking place at some point between them will be greater. From this point of view the percentage of crossing-over is an expression of the "distance' of the factors from each other."

\section{CHROMOSOME MAPS INDICATING THE ARRANGEMENT OF} ILENDELIAN FACTORS OR GENES IN THE CHROMOSOMES

By making use of the fertile idea explained in the last paragraph, that the percentage of crossing-over between any two factors indicates their relative distances apart, it was possible to map out the rela- 
tive positions of all known factors. The unit of distance on the map is that between two genes that have a crossover value of $\mathbf{I}$ per cent. Haldane has proposed the term morgan for this unit of map distance. These map units are only relative units, not absolute, as will be shown later. The validity of the crossing-over hypothesis and of the chromosome maps may be tested in an almost infinite number of ways. For example, let us take a simple case of the so-called threepoint method of locating a new factor. Suppose we have already determined the crossover percentage for two factors $A$ and $B$ to be 6 per cent. A new factor, $C$, appears which belongs to the same linkage group as $A$ and $B$, and we wish to locate it. First we work out its crossover percentage with $A$, and it turns out to be 4 per cent. We then can predict that the crossover percentage between $B$ and $C$ must be either $6+4$ (Io) or $6-4$ (2). If, on working out the percentage, it coincides with the theoretical prediction, the method of locating genes in the chromosome receives strong support. In practice, it may be said, the method works out perfectly for short sections of the map, but breaks down somewhat for long map distances, for the reasons indicated below.

Double crossing-over, an explanation of apparent discrepancies between map distances and crossover percentages.-This matter is best explained by the use of a concrete instance. Let us take three sex-linked genes, white, miniature, and bar. The crossover percentage observed between white and minature, as has already been shown, is 33 ; that between miniature and bar is 22 . The expected crossover percentage between white and bar is either $33+22$ (55) or 33-22 (I I); but the observed value is 44 per cent. The proposed explanation of this apparently serious discrepancy is given by the authors of the theory as follows:

"If we represent the percentages of crossing-over as relative distances along the chromosome the three points will lie as shown in Figure $73, a$. If crossing-over takes place between white and miniature and between miniature and bar, then it might be expected sometimes to take place in both regions at once, as shown in Figure $73, b$. The result here would be to produce two chromosomes like those shown in the lower figure (Fig. 73, c). The combinations of factors which these two chromosomes resulting from double crossing-over would contain, are white long bar and red miniature round. Since these two classes of gametes are actually produced, the results of the experiment fulfill the theoretical expectation. 
"There is a corollary of importance to this conclusion. When a cross is made that involves only white and bar, the double crossingover, that can be detected only when an intermediate point is followed, must still be supposed to take place. Whenever it does take place white bar flies and red round flies result. These will be added to the non-crossover classes since they have the same external characteristics. Consequently, the non-crossover classes will be increased and the crossover classes decreased. In fact, the sum of the two crossover percentages 33 and 22 (55) is much greater than the apparent amount (44) of crossing-over when only bar and white are involved. Here then we have an explanation of why long distances taken as a whole give too little crossing-over, as compared with the same distances taken section by section. The lowered percentage is an actual necessity owing to the occurrence of double crossing-over."

Interference.-One of the neatest confirmations of the crossover hypothesis is one that was first advanced by Muller. According to this idea, whenever double crossing-over occurs, two points of crossingover cannot be near together unless the chromosomes coil rather tightly about each other. Consequently, if crossing-over occurs at a given point there cannot be further crossing-over at the same time at nearby points. Now it has been actually demonstrated that this is true, for genes in the neighborhood of a crossed-over gene do not themselves cross-over with that gene in the degree expected on the luasis of the law of probability. This is supposed to be a sort of interference with free crossing-over. "It may be supposed," says Castle, "that chromosomes are somewhat like sticks of candy. Break one in two at one point and it is unlikely that a break will occur simultaneously within a short distance of the first break, the strain there being already relieved." The fact that what must be expected in this case is actually realized in every case goes far toward establishing the validity of the whole crossing-over hypothesis and the use of this hypothesis in showing the linear arrangement of the genes in the chromosomes.

In this chapter it is hardly feasible to present any further evidence in support of the claims of the Drosophila school of geneticists that they have actually discovered the inmost secrets about the finer details of the mechanism of Mendelian heredity. Suffice it to say that the evidence is voluminous and consistent. Not a single fact has come to light which is incompatible with the hypothesis, and new facts are continually coming to light that agree with the hypothesis and lend it 
further support. The opponents of the hypothesis are yearly becoming fewer and fewer, and the few remaining irreconcilables are having less and less to say. It should be said, then, in all fairness that the hypotheses discussed in this chapter have been most fruitful in leading to new discoveries, and in last analysis this is the only fair test of a hypothesis. If it is fruitful, it is good.

The crowning feat of the Drosophila workers is the making of the chromosome maps of the species studied. While it is impossible to obtain the latest version of the map, for the reason that new loci are continually being added, the accompanying map (Fig. 74) gives the locations of the genes that have been determined most carefully. It will be noted that not only have the genes in the X-chromosome been located, but also those in the other three chromosome pairs. A few additional situations that have arisen out of the studies involved in making the map will now be discussed, and then this somewhat difficult chapter will be brought to a close.

Muitiple alleiomorphs. - In a previous connection we have discussed the multiple-factor hypothesis as an explanation of quantitative heredity. Multiple factors are duplicate factors located in different chromosomes. Quite definitely in contrast with that situation is one in which different factors or different forms of the same factors occupy the same locus of the same chromosome. For example, red eye in Drosophila is a single factor. A change in the red-eye factor gives white eye; another change in red gives cherry; another gives eosin; and several other definite mutant colors resulting from changes in red have been observed. Now each of these changed color factors is an allelomorph of red and each is also an allelomorph of any of the others. By this we mean that, if a cross is made between individuals differing with respect to any two of these alternative colors of eye, one will be dominant over the other in the $\mathrm{F}_{\mathrm{I}}$ generation, and there will be three dominants to one recessive in the $F_{2}$ generation. One of the assumptions about allelomorphic genes is that they occupy equivalent locations in homologous chromosomes. This can be put to a crucial test. No more than two members of a set of multiple allelomorphs can be present in one individual because there are only two homologous chromosomes and hence only two equivalent gene loci. This proves to be true, for when red eye and white eye enter into a cross only these two eye colors come out of it; when cherry and white go in, only cherry and white come out; when red and cherry go in, only red and cherry come out. Several other authors have found interesting sets of multi- 


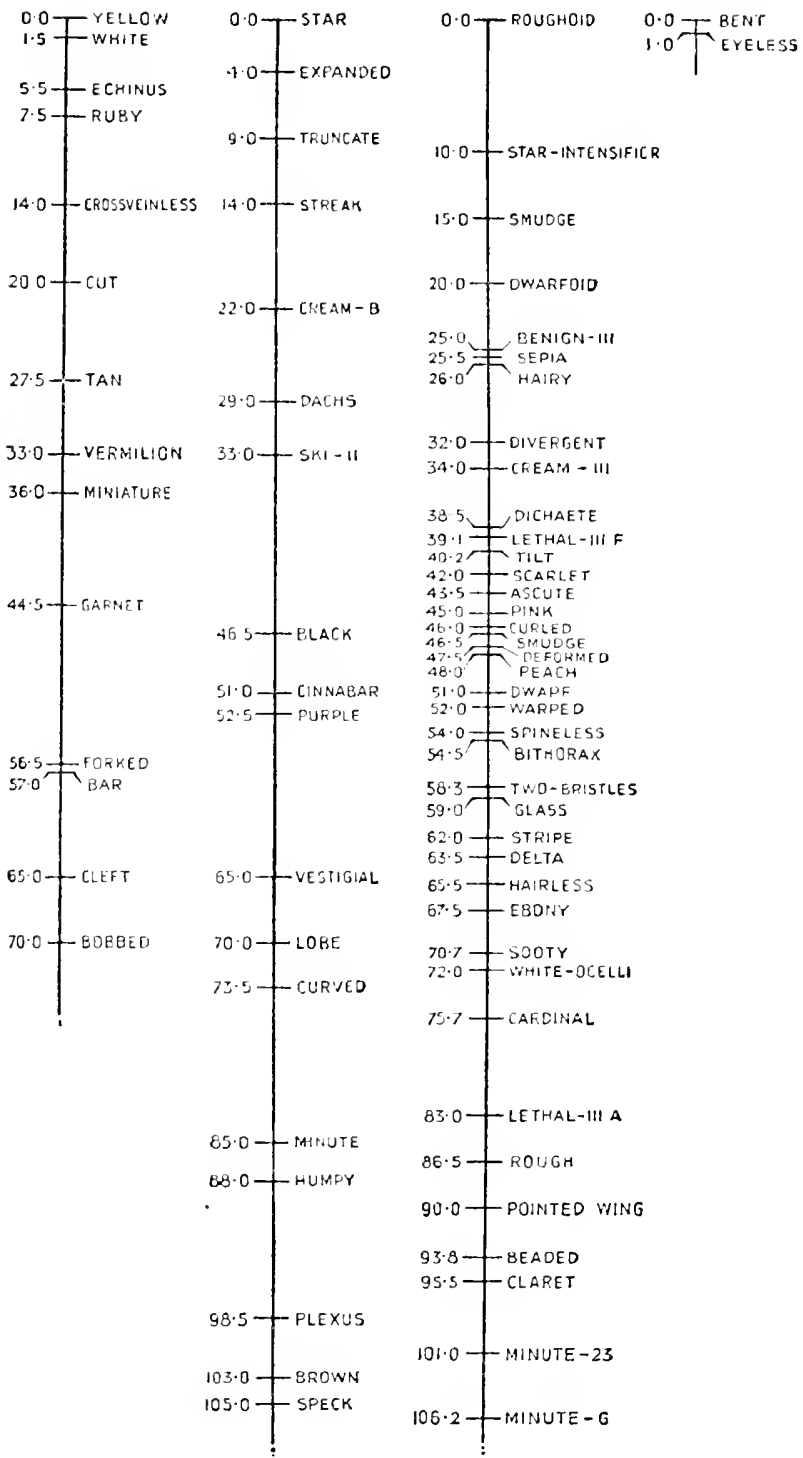

Fig. 74.-The chromosome map of Drosophila melanogaster. (After Morgan and Bridges.) 
ple allelomorphs in other animals. Nabours, for cxample, has described a very interesting series of the for the grasshopper, IIesperotettix; Sewall Wright has described a considerable number of such cases in guinea pigs; and Bellamy has worked out an explanation of a very intricate piece of hereditary behavior in fish hybrids that involves the use of the multiple-allelomorph scheme.

Lethal factors again. - A study of the chromosome map of Drosophila melanogaster will show that many of the located factors are lethal. This perhaps needs further explanation. Many of the factors that we have previously dealt with in this insect are more or less unimportant to the life of the animal. Such things as slight changes in eye color, body color, bristle arrangement, etc., are not very important, nor do they affect the viability of their possessors. Some factors, on the contrary, have been found to be so essential to the life of the individual that their absence causes death. The loss of or detrimental change in a vital character is known as a lethal factor. Of course all such factors are recessive; otherwise they never could be inherited. As it is, an individual may have a lethal factor in the heterozygous condition, balanced by the normal dominant character. When, however, two such heterozygous individuals breed together, one-fourth of their offspring, according to the simple Mendelian rule, will get the lethal factor from both parents. These homozygous recessive lethal zygotes cannot live; so the ratio that actually appears is one homozygous normal to two heterozygous individuals (phenotypically nor$\mathrm{mal}$ ), and that is all. One of the best-known cases of this kind of hereditary behavior occurs in mice. Yellow mice when mated together give one gray to two yellows. The production of grays from yellows shows that the yellows were heterozygous, or hybrid yellow and gray. It is noted that the litters of these mice average one-fourth smaller than other mice. What becomes of the lost one-fourth? An examination of the uteri of yellow mice reveals a number of dead embryos equal to the expected ratio of pure dominant yellows. These constitute the missing class and prove the presence in yellow mice of the recessive lethal factor associated with the yellow factor.

\section{LINKAGE IN OTHER ORGANISMS}

Lest the reader leave this chapter with the impression that linkage is a phenomenon confined to flies and mice, we shall close this chapter with the table on the next page taken from Castle, which shows how widespread is the occurrence of linkage and crossing-over in both the 
Cases of Linkage in Plants or in Animals Other Than Drosophila

\begin{tabular}{|c|c|c|c|c|c|}
\hline Species & 产 & Linked Characters & $\begin{array}{l}\text { Cross-over } \\
\text { Percentage }\end{array}$ & $\begin{array}{l}\text { Linkage } \\
\text { Strength }\end{array}$ & Authority \\
\hline Sweet pea & $\begin{array}{l}\mathrm{I} \\
\mathrm{I} \\
\mathrm{I} \\
2 \\
2 \\
2\end{array}$ & $\begin{array}{l}\text { Purple flowers, long pollen } \\
\text { Purple flowers, erect standard } \\
\text { Long pollen, erect standard } \\
\text { Dark axil, fertile anthers } \\
\text { Dark axil, normal (not cretin) } \\
\text { flower } \\
\text { Fertile anthers, normal (not } \\
\text { cretin) flowers }\end{array}$ & $\begin{array}{c}\text { I I Or I } 2 \\
0.78 \\
\text { I } 2.5 \\
6.2 \\
? \\
25.0\end{array}$ & $\left.\begin{array}{c}76-78 \\
98.4 \\
75 \\
87.6 \\
\cdots\end{array}\right\}$ & $\begin{array}{l}\text { Bateson } \\
\text { and } \\
\text { Punnett }\end{array}$ \\
\hline $\begin{array}{l}\text { Primula } \\
\text { sinensis }\end{array}$ & $\begin{array}{l}\mathrm{I} \\
\mathrm{I} \\
\mathrm{I} \\
\mathrm{I} \\
\mathrm{I}\end{array}$ & $\begin{array}{l}\text { Short style, magenta corolla } \\
\text { Short style, green stigma } \\
\text { Magenta corolla, green stigma } \\
\text { Tinged corolla, green stigma } \\
\text { Pale stem, green stigma }\end{array}$ & $\begin{array}{r}34.0 \\
40.6 \\
\text { II. } 6 \\
? \\
?\end{array}$ & $\left.\begin{array}{r}32 \\
18.8 \\
76.8 \\
\cdots \\
\cdots\end{array}\right\}$ & $\begin{array}{l}\text { Altenburg } \\
\text { Gregory }\end{array}$ \\
\hline Garden pea & $\begin{array}{l}\mathrm{I} \\
2\end{array}$ & $\begin{array}{l}\text { Round seeds, tendrils on } \\
\text { leaves } \\
\text { Late flowering, colored flow- } \\
\text { ers }\end{array}$ & $\begin{array}{r}\text { I. } 5 \\
\text { I } 2-16\end{array}$ & $\begin{array}{l}97 \\
68-76\end{array}$ & $\begin{array}{l}\text { Bateson and } \\
\text { Vilmorin } \\
\text { Hoshino }\end{array}$ \\
\hline$\overline{\text { Antirrhinum }}$ & I & $\begin{array}{l}\text { Red flower color, "pictur- } \\
\text { atum" pattern }\end{array}$ & 20.0 & 60 & Baur \\
\hline Maize & $\begin{array}{l}1 \\
2 \\
2 \\
2 \\
3\end{array}$ & $\begin{array}{l}\text { Waxy endosperm, Aleurone C } \\
\text { Aleurone R, Chlorophyl G } \\
\text { Aleurone R, Chlorophyl L } \\
\text { Chlorophyl G, Chlorophyl L } \\
\text { Starchy endosperm, tunicate } \\
\text { seed }\end{array}$ & $\begin{array}{r}26.7 \\
19.0 \\
0.0 \\
23.0 \\
8.3\end{array}$ & 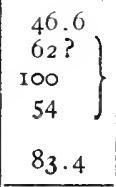 & $\begin{array}{l}\text { Breggar } \\
\text { Lindstrom } \\
\text { Jones }\end{array}$ \\
\hline Tomato & $\begin{array}{l}\mathrm{I} \\
\mathbf{2} \\
\end{array}$ & $\begin{array}{l}\text { Vine habit, fruit shape } \\
\text { Green foliage, 2-celled fruit }\end{array}$ & $\begin{array}{l}20.0 \\
0 ?\end{array}$ & $\left.\begin{array}{c}60 \\
100 ?\end{array}\right\}$ & Jones \\
\hline Beans & $\mathbf{I}$ & Seed pattern, vine habit & o? & I00? & Surface \\
\hline Silkworm & $\mathbf{I}$ & $\begin{array}{l}\text { Pattern } Q \text { of larva, yellow } \\
\text { silk }\end{array}$ & 26.1 & 47.8 & Tanaka \\
\hline A potettix & \begin{tabular}{l|}
$\mathrm{I}$ \\
$\mathrm{I}$ \\
$\mathrm{I}$ \\
$\mathrm{I}$ \\
$\mathrm{I}$ \\
$\mathrm{I}$ \\
$\mathrm{I}$ \\
$\mathrm{I}$ \\
\end{tabular} & $\begin{array}{l}\text { Patterns } G \text { and } M \\
\text { Patterns } M \text { and } K \\
\text { Patterns } K \text { and } Y \\
\text { Patterns } Y \text { and } R \\
\text { Patterns } Y \text { and } T \\
\text { Patterns } R \text { and } T \\
\text { Patterns } M \text { and } R \\
\text { Patterns } Y \text { and } Z\end{array}$ & 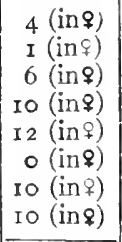 & $\begin{array}{r}92 \\
98 \\
88 \\
80 \\
76 \\
100 \\
80 \\
80\end{array}$ & Nabours \\
\hline Pigeon & I & Sex-linked factors I and $\mathrm{A}$ & 40 (in 5$)$ & 20 & $\begin{array}{l}\text { Cole and } \\
\text { Kelley }\end{array}$ \\
\hline Rat & $\begin{array}{l}\mathrm{I} \\
\mathrm{I} \\
\mathrm{I}\end{array}$ & $\begin{array}{l}\text { Albinism, red-eye } \\
\text { Albinism, pink-eye } \\
\text { Red-eye, pink-eye }\end{array}$ & \begin{tabular}{r|}
$1.0 ?$ \\
21.0 \\
18.3 \\
\end{tabular} & $\left.\begin{array}{c}95 ? \\
58 \\
03 \cdot 4\end{array}\right\}$ & $\begin{array}{l}\text { Castle and } \\
\text { Duinn }\end{array}$ \\
\hline Mouse & I & Albinism, pink-eye & $14 \cdot 3$ & 71.4 & $\begin{array}{l}\text { Castle and } \\
\text { Dunn }\end{array}$ \\
\hline
\end{tabular}


animal and the plant kingdom. In all probability it is a universal phenomenon, and if so, takes place in man. There are, in fact, strong indications in man that fair hair and blue eyes are linked, but they show also considerable crossing-over. Similarly, red hair and a certain type of disposition are popularly supposed to be linked, but crossing. over may be a saving grace in this as in other cases.

With this chapter we have arrived at the climax of discovery in the field of the mechanism of heredity. This is undoubtedly the most intricate consideration dealt with in this volume. In its very nature it is relatively difficult to understand. We have tried to explain everything in a decidedly circumstantial way, and it is hoped that some success in an endeavor to attain clearness has been attained. 


\section{CIIAPTER XXIV}

\section{CROSS-BREEDING AND INBREEDING}

Cross-breching is essentially the same as hybriclization, and we have alrearly studied various phases of hybridization in connection with Menclelian heredity. There are, however, certain other aspects of cross-breeding that have only a more or less remote connection with Mendelian analysis.

The rôle of hybridization in evolution. - "This," says R. R. Gates, "is a thorny subject, on which different investigators have taken quite different attitudes to the same facts. The extreme view that all flowering plants, or even all sexual organisms, are hybrids has been held. This has been accompanied in some cases (Lotsy) by the denial of any true germinal change, though why such labile substance as protoplasm should be incapable of undergoing a permanent or germinal change is difficult to understand. Jeffries and others appear to hold that polyploidy and other changes in which hybridization may be a factor, have nothing to do with evolution. A more reasonable view would appear to be that crossing has occurred in various groups from time to time, with more or less frequency and between sometimes more and sometimes less closely related forms. Crossing is therefore a condition under which much evolution has taken place. It by no means follows that crossing, any more than gravitation, is a vera causa, still less the ecra causa, of evolution, but it is a contributing condition. Polyploidy, frequently accompanied by hybrirlization, appears to be a common occurrence among flowering plants, but it would be futile to deny on this account that flowering plants have had an evolution; nor would it be safe to assume at present that the evolution of this group differs very essentially from that of any other."

The exact rôle of hybridization in the formation of new species is at present merely a matter for speculation, but that many new races have been the result of favorable combinations of the genetic factors of different strains can scarcely be doubted. In a sense, it may be said that hybrilization is the rule in all organisms that reproduce sexually, for no completely homozygous individuals exist in such groups, and therefore there will always be a certain amount of factor segregation in gamete formation and of recombination in the process of zygote formation. Also, it must be arlmitted that there are all grades of hetero- 
zygosity within a species and between one species and another. Moreover, sexual reproduction as an adaptation operates chiefly through bringing together a variety of combinations of characters possessed by strains genetically diverse; it is, in fact, a hybridizing mechanism. It seems probable therefore that hybridization as a factor in evolution operates up to the limit of the adaptive possibilities inherent in its mechanism. We may therefore conclude that hybridization is and has been an important evolutionary factor, though we have at present little information as to its precise mode of operation as an agent in species formation.

\section{SOME ANIMAL HYBRIDS}

Ons: of the arguments offered by the advocates of the theory that hybridization has played a prominent part in species-forming in nature is that man has carried on so much successful hybridization between different species of animals and plants and has produced many very useful hybrids, some of them better adapted than either of the parent types from which the hybrids were derived.

Especially interesting are animal hybrids produced by interbreeding distinct species of domestic and wild animals. Our brief account will be confined to horse, cattle, and fowl hybrids.

Horse hybrids. - These hybrids are all the product of crossing different species of the genus Equus. The commonest hybrid is that between the mare of the horse proper, Equus caballus, and the jack of the species E. hemionus. The result is the mule, a useful domestic animal combining some of the best features of the two species and superior to either in vigor, hardiness, capacity for work, and resistance to disease. The reciprocal cross, made by mating a jennet to a stallion, is called a "hinny," a sort of small mule. Neither mules nor hinnies are, as a rule, fertile, so they are not self-perpetuating. The rare reports of female mules giving birth to foals, when bred to jacks, are as yet not fully authenticated. There is some possibility that the particular females in question were either rather large jemnets, which of course would be fertile, or rather mulelike mares.

The sterility of mules has been shown by Wodsedalek to be due to differences in the numbers of chromosomes in the two species, the horse having in the female $\mathrm{I} 8$ autosomes and $2 \mathrm{X}$-chromosomes, the male $\mathrm{I} 8$ autosomes and one $\mathrm{X}$-chromosome; the ass having in the female 32 autosomes and $2 \mathrm{X}$-chromosomes, the male 32 autosomes and (according to Paynter) an $\mathrm{X}$ - and a $\mathrm{Y}$-chromosome. With this great discrepancy in chromosomes, it is hardly to be expected that meiosis could operate so as to give any sort of viable gametes or zygotes. 
A number of other Equus hybrids have been produced. The horse has been crossed with the now extinct quagga (E. quagga) and with several species of zebras. And the zebras have been crossed with asses. No particular use has been made of such hybrids.

Cattle hybrids. - There are many species of the genus Bos. The auroch is designated Bos tuturis primegenus. The now extinct wild ox of Europe, supposed to be the ancestor of European cattle, is called Bos taurus. The characteristic humped cattle of India is known as Bos indicus. The wild ox of Java is called Bibos sondaicus, and hence belongs to a different genus. The bison of Europe and the closely related American bison are called, respectively, Bison bonasus and Bison bison. There are three species of buffalos belonging to the genus Bubalus. Various hybrids, both interspecific and intergeneric, have been made by crossing these and other species of cattle-like animals. Hybridization of European and Brahman cattle, or zebus (Bos indicus), has been carried on very successiully in the southern states, especially in Texas and Louisiana. The hybrids are vigorous, and both sexes are fertile. The $F_{\mathbf{r}}$ hybrids are predominantly of the European breed, with only the suggestion of the zebu hump and much less of the hanging dewlap than in pure zebus. When the $\mathrm{F}_{\mathrm{I}}$ individuals are interbred, there is a great deal of variation among the $F_{2}$ offspring, of which no satisfactory analysis has yet been made. The chief advantage derived from introducing the zebu strain into American cattle is that zebus are immune to Texas fever, and hylbrids with as low as one-eighth zebu blood are also immune to this most serious of cattle diseases.

Bisons and European cattle have been successfully crossed, the cross usually made being between cattle cows and bison bulls. The cross is successful only in a small percentage of cases, and very frequently both dam and calf are lost. The sex ratio of these hybrids is very unequal, the ratio being at one time 33 females to 6 males. Usually the $F_{x}$ males are sterile, but the females are fertile and may be back-crossed to bison bulls or cattle bulls as desired, and there is no difficulty or danger of loss of life as in the $F_{I}$ cross. Animals that are the product of various grades of admixture of bison and cattle are called cattalos. It is expected that, by selection, a desirable hybrid type may be fixer, combining the best features of both genera.

Fowl hybrids. - The domestic fowl is commonly designated Gallus domesticus and is believed to have been derived from one or more of several wild species of the genus Gallus. Four wild species are recognized: G. gullus, the red jungle fowl of northern India, Malay states, 
and Sumatra; G. lafayctte, the Ceylon jungle fowl; G. sonnerate, the gray jungle fowl of southern India; and $G$. varius, the jungle fowl of Java. These birds are rather wild and do not hybridize well in captivity. Yet occasional uncontrolled hybrids have been produced which are of interest in throwing some light on the origin of the various domestic breeds. Darwin was of the opinion that all the domestic breeds have been derived from $G$. gallus, for sometimes in India cocks of $G$. gallus invade flocks of domestic fowls and mate with the hens, producing fully fertile offspring. The same has been claimed, since Darwin wrote, for the other species, and some authors are inclined to believe that domestic fowls of different breeds may have been derived from different wild species of Gallus. The evidence for the latter view, however, is less abundant than for Darwin's contention.

\section{SECONDARY EFFECTS OF CROSS-BREEDING AND INBREFDING}

A. CROSS-BREEDING

Hybrid vigor (heterosis). - It has long been known that the crossing of different races, varieties, or even species of animals or plants result in the production of first-generation hybrids characterized by a greater sturdiness, vitality, and size than either parent-species. This effect has received the name hybrid vigor or heterosis. A good example of this effect is the common mule, which is large and strong, thrives under adverse conditions, and is hardier than either parent. It has the disadvantage, or possibly advantage, of being sterile, a fact which makes it necessary to hybridize two species every time we want another mule.

Some of the manifestations of hybrid vigor as observed in various crosses are as follows:

a) Hastening of maturity.-This is particularly advantageous in plants reared in regions where the growing-period is short. Thus hybrid strains of cereals may be valuable because they can be harvested sooner than pure-bred strains. It is also true that hybrid plants, such for example as tomatoes, have a larger as well as an earlier yield.

b) Increased longevity. - Pearl has shown that hybrid strains of fruit flies have a longer average life-span than pure races. The same is true for a number of hybrid races of plants, as brought out by Gaertner.

c) Better viability. - The writer has shown that the hybrids produced by crossing the eggs of the fish Fundulus heteroclitus with the sperm of $F$. majalis were frequently more viable, faster growing, and more vigorous than the pure-bred young of either species; but the hvbrids from the reciprocal cross showed much-reduced viability. 
Similarly, he has shown that some of the hybrids produced by crossing the eggs of the sea-urchin Strongylocentrotus purpuratus with the sperm of S. franciscanus lived nearly twice as long under cultural conditions as did either pure breed, while the reciprocal cross showed very low viability.

d) Augmented facility of vegetative propagation.-Many hybrid plants are noted for their success in vegetative propagation. It is believed that plants such as strawberries, brambles, grasses, etc., that propagate so successfully by vegetative methods, are the products of hybridization. The vegetative method of reproduction not only maintains a fortunate combination of genetic characters that could hardly be repeated by gametic reproduction, but maintains their hybrid vigor as well.

These and perhaps some other effects, all of which are essentially beneficial, have been noted in both animals and plants. The following explanation of hybrid vigor has been given by D. F. Jones:

"Explanation of hybrid vigor.-From the illustrations given it is evident that there is a tendency for the features of both parents to be expressed in the offspring. This is the basis for an understanding of the vigor derived from crossing. There is a greater number of different hereditary factors in a hybrid individual than in either pure parent. Nearly all variations that are recessive are less favorable to the development of the organism than their dominant mates. . . . Since crossing brings out those qualities which help the individual in its growth and suppresses the abnormal and unfavorable characters, it is to be expected that hybrids will tend to be strong and vigorous. This will be true, however, only if each parent is able to supply the deficiency of the other, and if the forms crossed are not so diverse that their union is incompatible with normal growth. If the parents are themselves hybrids, further crossing may bring together no great number of dominant favorable growth factors but may even uncover recessive characters. Hence further crossing can not usually increase size and vigor, and in fact may even result in the appearance of weaknesses. This is clearly understandable from the operation of Mendel's principles of heredity."

The question now arises as to whether hybridization in general is advantageous or the reverse. Undoubtedly first-generation hybrids are generally an improvement upon either parent-race, especially if the parents belong to races not too distantly related. If we could stop hybridization after one generation, as Nature stops it in the case of the 
mule, nothing but good would apparently come out of it; but in man and among other animals and plants where mating is more or less indiscriminate, cross-breeding is sure to continue into the $F_{2}, F_{3}$, and subsequent generations, entailing the production of all sorts of unfortunate combinations and the outcropping of all sorts of unbalanced recessive weaknesses. In view of these considerations it is practically certain that hybridization, unless accompanied by rigid selection and the elimination from parentage of the less desirable combinations, is on the whole disadvantageous. In nature, natural selection serves to eliminate sooner or later the worst combinations resulting from continuous cross-breeding, but in man, little is done to prevent the worst racial admixtures from predominating, the result being that the populations of some parts of the New World are made up mainly of a rather homogeneous hybrid type possessing little more than the worst traits of the various races that have contributed to the melting-pot.

By way of a general summary let us quote the following paragraphs from D. F. Jones, ${ }^{\mathrm{I}}$ by whose book Crenetics in Plant and Animal Improvement this discussion has been largely suggested:

"Summary.-From the foregoing it will be realized that if any individual is deficient or handicapped in its hereditary make-up, there is a good chance that its needs will be supplied when it is crossed with other individuals, because all are not apt to be wanting in the same things. What one lacks is furnished by the other, and conversely, In other words, there is a pooling of hereditary resources, with the result that the combined effect is better than either could produce alone.

"It should now be clear that the beneficial effects of crossing follow from the workings of the laws of heredity and not from any mysterious stimulus from the act of crossing itself. If good qualities exist in the parents, but not in sufficient amount or not in their proper association, then there is a good opportunity for the offspring to bring together the favorable factors from both and surpass their parents in development. This is a temporary and transitory effect, however. The increased vigor is shown at its best only in the first generation following the cross, and is quickly lost in later generations unless it can be perpetuatel by some form of asexual reproduction."

\section{B. INBREEDING}

There is a widespread and deep-seated feeling among men that the mating of close relatives is unnatural and harmful. In most civilized countries there are laws both religious and civic forbidding the mar-

${ }^{\prime}$ Loc. cit. 
riage of close relatives. The aversion to the marriage of relatives has sometimes gone beyond the limits of genetic relationship and has invaded the realm of merely legal or conventional relationships, as in England, where it is, or at least once was, illegal to marry one's deceased wife's sister.

"Only exceptionally, as in the case of the royal families of Egypt and ancient Peru," says Castle, "has the marriage of brother and sister been sanctioned. The underlying reason in such cases was the belief that the family in question constituted a superior race whose members could find no fit mates outside their own number. There was probably no thought that inbreeding itself was beneficial but only the desire to conserve the superior excellence believed to reside in certain individuals. The same considerations probably have led to the occasional practice of inbreeding in animal husbandry, viz., the desire to conserve and perpetuate the superiority of particular individuals."

It appears that Robert Bakewell, a stock-breeder of the eighteenth century, was the first to show the value of close inbreeding in maintaining a uniform type of sheep and cattle. Bakewell adopted the plan of mating brother with sister or parent with offspring, much to the horror of his neighbors, who considered such a procedure immoral; but their scruples were soon broken down by the obvious improvements obtained and the greatly increased revenue that accrued. The practice of inbreeding has been a favorite one for a long time, and many fine breeds of standard character have been produced mainly in this way.

Opinions among breeders differ as to whether inbreeding if practiced expertly is injurious. Some believe that inbreeding itself involves no possible injury; others hold that it is always more or less harmful. In order to settle this question, geneticists have carried out extensive experiments under conditions of rigid control. Even these do not agree in their results. One group of workers (Crampe and Ritzema-Bos) found after extensive inbreeding of rats that there was a steady falling off in fertility and general health during the first six generations of inbreeding. The material used, however, was a mixed or hybrid stock to start with, a fact that makes a satisfactory conclusion difficult. Weismann inbred a race of white mice for twenty-nine generations. In the first ten generations the average number of young was 6.I; in the second ten generations it was 5.6; and in the last nine generations it was 4.2. Again, nothing was known about the genetic constitution of the original parents.

Recent experiments carried out by Dr. Helen Dean King at the 
Wistar Institute are entirely contrary to those of the workers just mentioned. This piece of work was carried out in a most precise manner, with large numbers of individuals. The original stock consisted of four rather undersized but otherwise normal albino Norway rats. Brothers and sisters were mated throughout the experiment. For six generations no selective mating was practiced, with the result that many of the defects previously noted were in evidence; but after the sixth generation some twenty females from about a thousand were selected for their superior qualities. From this stock the result of inbreeding for twenty-five generations was very good. Dr. King seems to have produced an essentially homozygous race of white rats that are superior in many ways to the race from which they have been derived. It seems probable that selection has rid the race of all or nearly all of the residual recessive characters, so that the present combination is highly normal and standard. Sewall Wright, under the auspices of the United States Department of Agriculture, has carried out a very extensive program of inbreeding with guinea pigs. His results are more in harmony with those of earlier workers than with those of Dr. King. In general, the result of brother- and sister-mating was a steady loss of vigor both bodily and reproductive. Both prenatal and postnatal mortality was increased. Some families, however, remained quite strong after long inbreeding; while other families declined so rapidly that it was impossible to perpetuate them after a few generations. Some strange combinations of traits appeared in different stocks. One stock was characterized by very low vitality, but remained normal in body size and in number of young produced. Another stock showed undiminished vitality but greatly lowered reproductivity and reduced size. The chief difference in method used in these two modern experiments seems to be that only the best were bred in Dr. King's experiments, while in Dr. Wright's experiments no such precautions were taken, probably because he preferred to approximate natural conditions.

A large amount of experimentation in inbreeding has been carried out with domestic animals and plants of all sorts, and the results have shown as much diversity as those already reported; consequently, opinions are still at variance as to the question whether inbreeding is injurious per se. D. F. Jones, who seems to have given this matter very careful consideration, takes the position that "the only injury that comes from inbreeding comes from the inheritance received." If the individuals inbred possess many undesirable recessive characters, nothing 
is surer than that inbreeding will bring these to the surface. Crossbreeding might succeed in masking such recessive characters, but they remain in the germ plasm, nevertheless. All inbreeding does is to reveal that which was masked behind dominant characters. Therefore it is not intreeding itself that is to blame, but a poor heredity. Inbreeding is a valuable instrument for detecting the unfavorable hereditary characters in a race and giving the breeder a chance to cull out the lefective factors from his stock.

Inbreeding should be followed by cross-breeding inbred stocks.Whatever loss of vigor or productiveness may be incidental to the inbreeding method of standardizing stock may be entirely done away with by suitalsle cross-breeding or outbreeding. No matter how good an inbred stock may be, great improvement can be brought about by introducing new blood even from an apparently very similar strain which is unrelated. It is well known that when two pure breeds are crossed there is an effect quite equivalent to that which we have called hybrid vigor. The animal-breeder commonly practices close inbreeding in building up families of superior excellence, which he maintains as pure-line stock, used for crossing with other stocks in order to produce exceptional $F_{1}$ offspring. Nan, of course, cannot practice this scheme in the present state of society, but it seems obvious that there lie in this method almost untold possibilities for racial improvement 


\section{CHAPTER XXV}

\section{CHANGE FACTORS. INTRODUCTION}

Change has already been contrasted with diversity by citing the analogy of the kaleidoscope (p. I87). Another analogy may help to emphasize this difference. If one were to shuffle and deal a very elaborate deck of cards, the hands dealt would show very great diversity, but there would be a certain statistical limitation to the number of possible combinations of cards. After a time the whole series of possible combinations would be dealt out and the series would go on repeating itself, and nothing new would appear so long as the cards remained unchanged. Add a new card or a new series of cards, or merely change some of the spots on a card, and at once the whole character of the combinations produced would be altered. Dealing an unchanged deck of cards is the sort of thing that the diversity mechanism (sex) does, but the mutation mechanism actually adds new cards or alters the spots. Changes in the germinal substances themselves are called mutations. Hence mutation is the change mechanism.

\section{CHANGING VIEIVS AS TO THE ORIGIN OF NEW HEREDITARY CHARACTERS}

Lamarck believed that all evolutionary change was initiated in the body (soma) directly or indirectly in response to environmental stimuli, causing increased or decreased functioning of parts. He had no theory as to how such changes could be inherited, but assumed that they were. This belief is embodied in his theory of the inheritance of acquired characters, known as the "Lamarckian theory."

Charles Darwin also believed that all variations that are frequent enough to serve as the raw material for selection originated in the soma in response to differences in the environment or indirectly, to changes in the amount of use to which a given part was put. To account for such changes being hereditary, he proposed a theory with which he was not very well satisfied, for he called it "the provisional theory of pangenesis." According to this view, each part of the organism is continually giving off into the blood stream minute particles, "pangenes," each of which is characteristic of the particular status of a part of the organism at the time when the pangene was given off. Thus a strengthened muscle or a more efficient eye, each resulting from in- 
creased functioning, would give off pangenes reflecting muscle or eye improvements. Similarly, a deteriorating organ or tissue or even a damaged or dieased part would produce pangenes reliecting their condition. Now these pangenes were believed to be collected in the gonads to form germ cells, a germ cell being a concentrated mass of all the kinds of pangenes of the organism. In this simple way somatic changes were believed to be inherited. But the clifficulty with this theory is that no such mechanism exists.

II cismann was the first biologist to depart from the idea that hereditary changes originate in the soma. He proposed the theory of the continuity and apartness of the germ plasm, and its corollary that all hereditary changes arise directly in the germ plasm. His picture of the method of germinal change is expressed in his theory of "germinal selection."

The essential feature of germinal selection, as the name implies, is a transfer of the struggle for existence to the germ cell. The germ cell is assumed to be a greatly reduced and simplified sample of the characters of the whole organism. Each independently variable part of the organism is supposed to be represented in the germ cell by a minute physiological unit, unique in composition and capable of reproducing the part in question in a new organism. These hereditary units are called "determinants." Thus there is a different kind of determinant for each muscle of the body, for each bone, or for each independently functioning blood vessel; but, since all red blood corpuscles are alike, there would be only one determinant for all of them. These determinants have to grow, and in cell division, to divide so as to furnish to daughter germ cells all of the necessary determinants for a whole individual. In their process of growth and multiplication, which goes on very rapidly at certain periods in the germ-cell cycle, these determinants are in competition among themselves for the available food supply. Some may be more favorably placed than others or may be more active chemically than others. There will thus arise a struggle within the germ for a chance to grow and reproduce their kind, which, for these determinants, might be as bitter as would be the struggle in nature among the whole organisms that are in conpetition for a place in the world. A determinant favored, perhaps accidentally or possibly because of inherent activity, by a good food supply would wax stronger and grow faster and would, logically, produce a larger and more effective part when that particular germ cell developed into an adult. Other germ cells that would be the offspring 
of this germ cell would continue the struggle among determinants, and it would be expected that the strong determinant would continue to gain further advantage until the structure it represents reached its maximum efficiency. Similarly, a determinant that was for some reason deprived of its fair share of nutriment at any time would be weakened and would produce in cell division weakened daughter determinants. These in turn, unless especially favored, would wage a losing fight and continue to grow smaller and weaker. Each individual that might develop from such germ cells would have the characters whose determinant had been wealiened in a reduced and progressively degenerating condition. Finally, certain determinants might starve entirely, and the part for which they stood would disappear entirely from the ontogeny of the individual arising from these germ cells.

In this way Weismann tried to explain the gradual dwindling and the final elimination of useless organs. So also he would explain definitely directed or orthogenetic variations, because germinal selection, once started in a given direction, continues automatically till the goal of adaptiveness is reached.

The most potent objections to the theory of germinal selection are as follows:

1. There should be, according to this theory, certain pronounced tendencies in variability in definite directions, whereas fluctuating variations nearly always distribute themselves evenly about the mean or mode, and the same specific mean or mode is stationary in successive generations.

2. The theory implies too rapid and too general modification of parts and therefore does not accord with the fact that species are decidedly constant, except for occasional mutations, over long periods of time. To meet this objection Weismann proposes a new selfcorrecting mechanism that checks too rapid a development of characters.

3. The over- or undernourishment of determinants might conceivably induce size changes in characters already present, but could hardly be responsible for the origin of qualitatively different characters.

4. Actual experiments in over- and underfeeding of animals have been carried on by certain experimenters in order to test out the theory of germinal selection. In the experiments of Kellogg, for example, involving feeding silkworm larvae only one-eighth of the norma! amount of food, the only result was that the mature individuals were 
dwarfed in size. The relative sizes of the parts were unaltered, showing that there had been no real struggle among the determinants; for, on the theory of germinal selection, only the stronger determinants would have survived and the weaker ones would have been starved out. Partial individuals, moreover, lacking certain organs and overdeveloped in others, would have been produced instead of individuals merely smaller in all parts.

These are the specific objections to the theory,but more important than all of these is the general objection that follows:

"Thus Weismann," says Morgan, "' "has piled up one hypothesis on another as though he could save the integrity of the theory of natural selection by adding new speculative matter to it. The most unfortunate feature is that the new speculation is skilfully removed from the field of verification, and invisible germs whose sole functions are those which Weismann's imagination bestows on them, are brought forward as though they could supply the deficiencies of Darwin's theory. This is, indeed, the old method of the philosophizers of nature. An imaginary system has been invented which attempts to explain all difficulties, and if it fails, then new inventions are to be thought of. Thus we see where the theory of selection of fluctuating germs has led one of the most widely known disciples of the Darwinian theory.

"The worst feature of the situation is not so much that Weismann has advanced new hypotheses unsupported by experimental evidence, but that the speculation is of such a kind that it is, from its very nature, unverifiable, and therefore useless. Weismann is mistaken when he assumes that many zoölogists object to his methods because they are largely speculative. The real reason is that the speculation is so of ten of a kind that cannot be tested by observation and experiment."

It seems almost impossible that the same Professor Morgan, who wrote the foregoing paragraphs in 1903 , should now be the leading exponent of a theory of the mechanics of hereditary transmission which depends upon hereditary units almost identical with Weismann's "determinants," for the "genes" or "factors" of Morgan are minute corporeal bodies in the germ cells which determine the characters of the adult individual.

The difference is, however, that the "genes" of Morgan are experimentally demonstrable and have behind them a vast amount of real evidence for their existence.

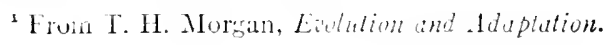




\section{MUTATIONS}

Mutations are, by definition, changes in the germinal substance. They may affect individual genes or whole bundles of genes (chromosomes). They may occur in the germ track or in the soma. If they occur in the soma, the resulting change is seen in a local patch of changed cells, the size of which depends on whether the mutation occurred early or late in ontogeny. Since body cells do not produce germ cells, somatic mutations are no more heritable than are functional changes in the soma. The only mutations of significance for evolution are those that occur in the germ track. The various kinds of germinal mutations will be discussed at some length in the following chapter. 


\section{CHAPTER XYVI}

\section{THE MUTATION THEORY}

It will be recalled that Darwin, although depending upon the ever-present fluctuating variations as the material for natural selection to work upon, recognized the occasional occurrence of "sports" or "saltatory variations." These, however, seemed to him to be so rare in nature as to offer no adequate basis for selection. During the latter part of the nineteenth century several investigators, feeling the inadequacy of fluctuating variations to produce qualitatively new characters, decided to make a more careful examination of animals and plants in nature in order to discover whether saltatory variations might not be of more frequent occurrence than Darwin had supposed.

In England William Bateson collected a large number of instances of a type of variation which he called discontinuous in contradistinction to the continuous type which we have been calling fluctuations. Such variations, instead of being in a closely graded series with the typical variations of a species, were frequently quite sharply different from the majority. Although no experiments were conducted in order to test the hereditability of these "discontinuous variations," it is probable that some of them were "mutations" in the sense of De Vries.

At about the same time Hugo De Vries in Holland, partially as the result of his rediscovery of Mendel's work and his confirmation of the latter's laws of heredity, became convinced that new species arise not by the accumulation, through natural selection, of minute fluctuating variations, but by the sudden appearance in one generation of fully formed new elementary species. He began a systematic research for species of plants in nature that were giving rise to new species. Many species were examined in their natural surroundings and were then brought into the experimental garden for more careful observation, but for a long time the search for a species throwing off new elementary species was unsuccessful. Finally, however, in a field near Hilversum, in the vicinity of Amsterdam, he found what seemed to him to be just the kind of plant he had been looking for in the cvening prinase (Ocnothera lamarckiana). 
"Lamarck's evening-primrose" (Fig. 75), says De Vries, "is a statcly plant, with a stout stem, attaining of ten a height of 1.6 meters and more. When not crowded the main stem is surrounded by a large

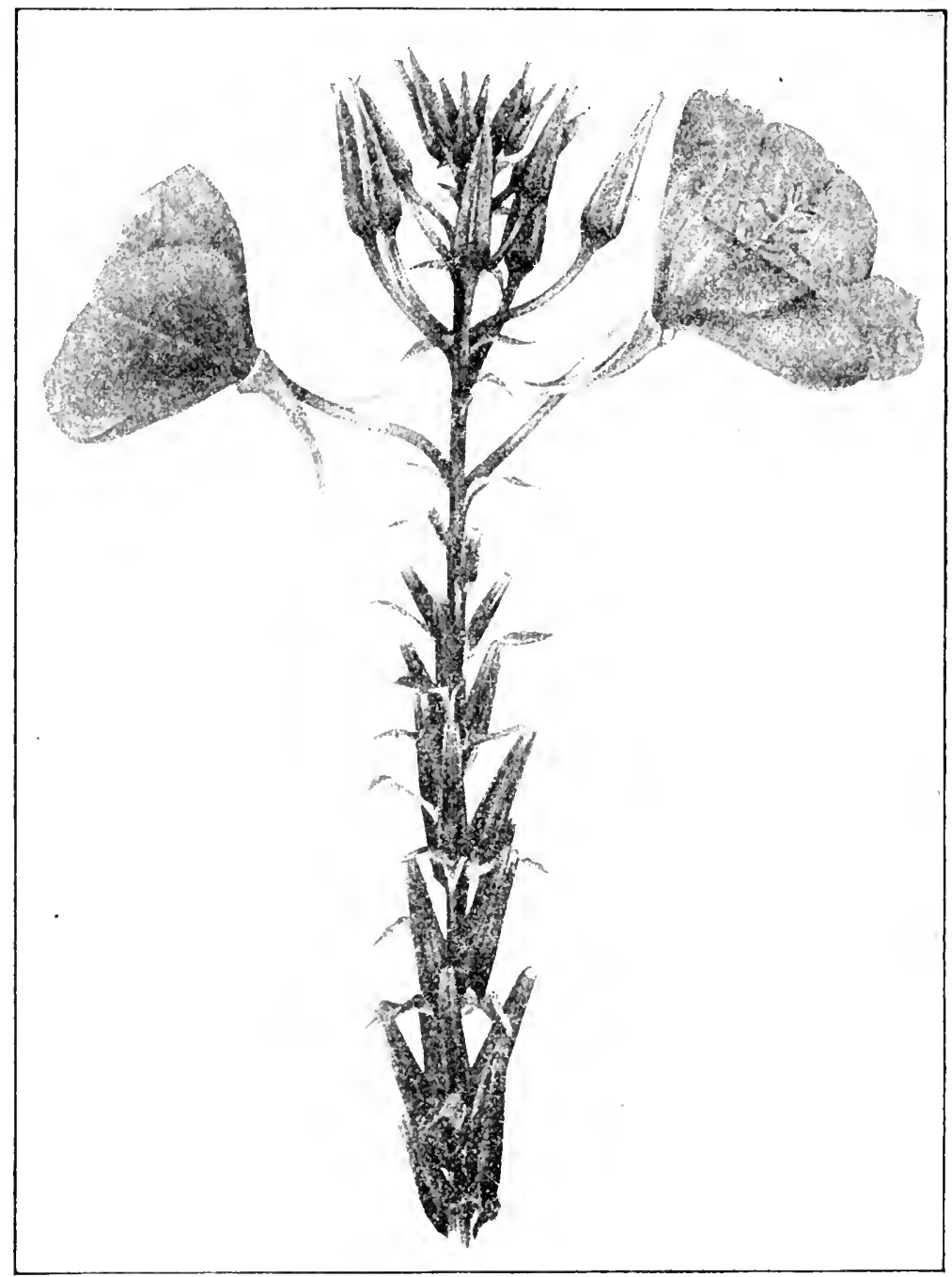

Fic. 75.-Ochothera lamurckima, the original type used by De Vries in his experiments. This is the stock from Ililversum, from which arose in successive generations a series of mutants. (From De Vries.) 
circle of smaller branches, growing upwards from its base so as to form a dense brush. . . . . The flowers are large and bright yellow attracting immediate attention even from a distance. They open toward evening, as the name indicates, and are pollinated by bumble-bees and moths."

On account of the classic character of De Vries's mutants of Oenothera lamarckiana we shall follow his own detailed description of the more significant of these.

\section{NEW SPECIES (MUTANTS) OF OENOTHERA ${ }^{\text {Y }}$}

HUGO DE VRIES

This striking species (Oenothera lamarckiana) was found in a locality near Hilversum, in the vicinity of Amsterdam, where it grew in some thousands of individuals. Ordinarily biennial, it produces rosettes in the first, and stems in the second year. Both the stems and the rosettes were at once seen to be highly variable, and soon distinct varieties could be distinguished among them.

The first discovery of this locality was made in I886. Afterwards I visited it many times, often weekly or even daily during the first few years, and always at least once a year up to the present time. This stately plant showed the long-sought peculiarity of producing a number of new species every year. Some of them were observed directly on the field, either as stems or as rosettes. The latter could be transplanted into my garden for further observation, and the stems yielded seeds to be sown under like control. Others were too weak to live a sufficiently long time in the field. They were discovered by sowing seed from indifferent plants of the wild locality in the garden. A third and last method of getting still more new species from the original strain was the repetition of the sowing process, by saving and sowing the seed which ripened on the introduced plants. These various methods have led to the discovery of over a dozen new types never previously observed or described.

Leaving the physiological side of the relations of these new forms for the next lecture, it would be profitable to give a short description of the several novelties. To this end they may be combined under five different heads, according to their systematic value. The first head includes those which are evidently to be considered as varieties.

- From H. De Vries, Species and Varielies (copyright 1904). Used by special permission of the publishers, The Open Court Publishing Company. 
in the narrower sense of the word, as previously given. The second and third heads indicate the real progressive elementary species, first those which are as strong as the parent-species, and secondly a group of weaker types, apparently not destined to be successful. Under the fourth head I shall include some inconstant forms, and under the last head those that are organically incomplete.

Of varieties with a negative attribute, or real retrograde varieties, $I$ have found three, all of them in a flowering condition in the field. I have given them the names of laevifolia, brevistylis and nannella.

The laevifolia, or smooth-leaved variety, was one of the very first deviating types found in the original field. This was in the summer of $r 887$, seventeen years ago. It formed a little group of plants growing at some distance from the main body, in the same ficld. I found some rosettes and some flowering stems and sowed some seed in the fall. The variety has been quite constant in the field, neither increasing in number of individual plants nor changing its place, though now closely surrounded by other lamarckianas. In my garden it has proved to be constant from seed, never reverting to the original lamarckiana, provided intercrossing was excluded.

It is chiefly distinguished from Lamarck's evening-primrose by its smooth leaves, as the name indicates. The leaves of the original form show numerous sinuosities in their blades, not at the edge, but anywhere between the veins. The blade shows numbers of convexities on either surface, the whole surface being undulated in this manner; it lacks also the brightness of the ordinary evening-primrose or Oenothera biennis.

These undulations are lacking or at least very rare on the leaves of the new laevifolia. Ordinarily they are wholly wanting, but at times single leaves with slight manifestations of this character may make their appearance. They warn us that the capacity for such sinuosities is not wholly lost, but only lies dormant in the new variety. It is reduced to a latent state, exactly as are the apparently lost characters of so many ordinary horticultural varieties.

Lacking the undulations, the laevifolia-leaves are smooth and bright. They are a little narrower and more slender than those of the lamarckiana. The convexities and concavities of leaves are a useful character in dry seasons, but during. wet summers, such as those of the last few years, they must be considered as very harmful, as they retain some of the water which falls on the plants, prolonging the action of the water on the leaves. This is considered by some writers 
to be of some utility after slight showers, but was observed to be a source of weakness during wet weather in my garden, preventing the leaves from drying. Whether the laevifolia would do better under such circumstances, I have, however, omitted to test.

The flowers of the laevifolia are also in a slight degree different from those of lamarckiana. The yellow color is paler and the petals are smoother. Later, in the fall, on the weaker side branches these differences increase. The laevifolia petals become smaller and are devoid of the emargination at the apex, becoming ovate instead of obcordate. This shape is often the most easily recognized and most striking mark of the variety. In respect to the reproductive organs, the fertility and abundance of good seed, the laevifolia is by no means inferior or superior to the original species.

$O$. brevistylis, or the short-styled evening-primrose, is the most curious of all my new forms. It has very short styles, which bring the stigmas only up to the throat of the calyx-tube, instead of upwards of the anthers. The stigmas themselves are of another shape, more flattened and not cylindrical. The pollen falls from the anthers abundantly on them, and germinates in the ordinary manner.

The ovary which in lamarckiana and in all other new forms is wholly underneath the calyx-tube, is here only partially so. This tube is inserted at some distances under its summit. The insertion divides the ovary into two parts: an upper and a lower one. The upper part is much reduced in breadth and somewhat attenuated, simulating a prolongation of the base of the style. The lower part is also reduced, but in another manner. At the time of flowering it is like the ovary of lamarckiana, neither smaller nor larger. But it is only reached by very few pollen-tubes, and is therefore always very incompletely fertilized. It does not fall off after the fading away of the flower, as unfertilized ovaries usually do; neither does it grow out, nor assume the upright position of normal capsules. It is checked in its development, and at the time of ripening it is nearly of the same $1 n^{-t h}$ as in the beginning. Many of them contain no good seeds at i.l; from others I have succeeded in saving only a hundred seeds from thousands of capsules.

These seeds, if purely pollinated, and with the exclusion of the visits of insects, reproduce the variety entirely and without any reversion to the lamarckiana type.

Correlated with the detailed structures is the form of the flowerbuds. They lack the high stigma placed above the anthers, which in 
the lamarckiana, by the vigorous growth of the style, extends the calyx and renders the flower-bud thinner and more slender. Those of the brevistylis are therefore broader and more swollen. It is quite easy to distinguish the individuals by this striking character alone, although it differs from the parent in other particulars.

The leaves of the $O$. brevistylis are more rounded at the tip, but the difference is only pronounced at times, slightly in the adult rosettes, but more clearly on the growing summits of the stems and branches. By this character the plants may be discerned among the others some weeks before the flowers begin to show themselves.

But the character by which the plants may be most easily recognized from a distance in the field is the failure of the fruits. They were found nearly every year in varying, but always small numbers.

Leaving the short-styled primrose, we come now to the last of our group of retrograde varieties. This is the O. nannella, or the dwarf, and is a most attractive little plant. It is very short of stature, reaching often a height of only $20-30 \mathrm{~cm}$., or less than one-fourth of that of the parent. It commences flowering at a height of ${ }^{\circ}-{ }^{1} 5 \mathrm{~cm}$., while the parent-form often measures nearly a meter at this stage of its development. Being so very dwarfed the large flowers are all the more striking. They are hardly inferior to those of the lamarckiana, and agree with them in structure. When they fade away the spike is rapidly lengthened, and often becomes much longer than the lower or vegetative part of the stem.

The dwarfs are one of the most common mutations in my garden, and were observed in the native locality and also grown from seeds saved there. Once produced they are absolutely constant. I have tried many thousands of seeds from various dwarf mutants, and never observed any trace of reversion to the lamarckiana type. I have also cultivated them in successive generations with the same result. In a former lecture we have seen that contrary to the general run of horticultural belief, varieties are as constant as the best species, if kept free from hybrid admixtures. This is a general rule, and the exceptions, or cases of atavism, are extremely rare. In this respect it is of great interest to observe that this constancy is not an acquired quality, but is to be considered as innate, because it is already fully developed at the very moment when the original mutation takes place.

From its first leaves to the rosette period, and through this to the lengthening of the stem, the dwarfs are easily distinguished from any other of their congeners. The most remarkable feature is the shape 


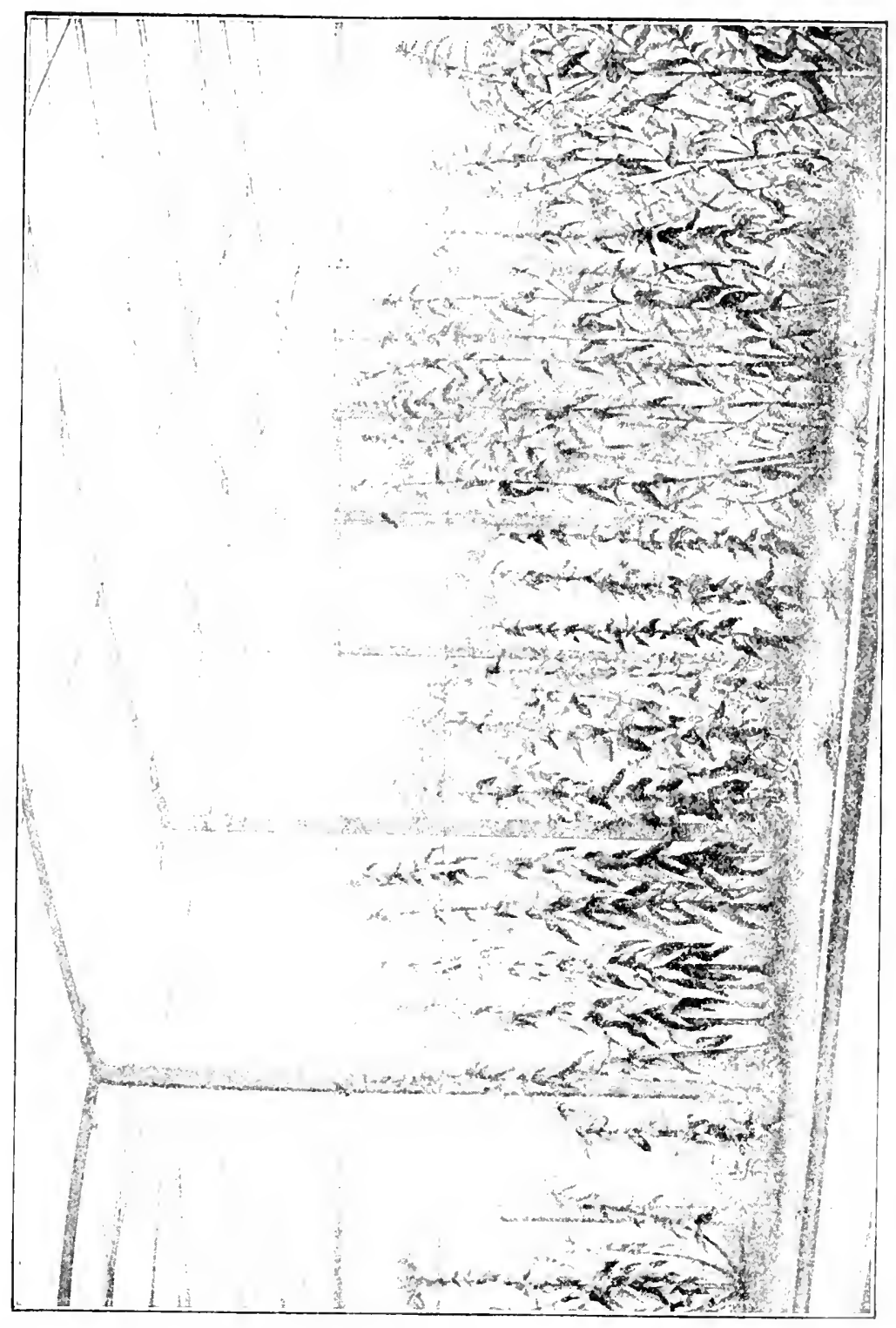


of the leaves. They are broader and shorter, and especially at the base they are broadened in such a way as to become apparently sessile. The stalk is very brittle, and any rough treatment may cause the leaves to break off. The young seediings are recognizable by the shape of the first two or three leaves, and when more of them are produced, the rosettes become dense and strikingly different from others. Later leaves are more nearly like the parent-type, but the petioles remain short. The bases of the blades are frequently almost cordate, the laminae themselves varying from oblong-ovate to ovate in outline.

The stems are often quite unbranched, or branched only at the base of the spike. Strong secondary stems are a striking attribute of the lamarckiana parent, but they are lacking, or almost so in the dwarfs. The stem is straight and short, and this, combined with the large crown of bright flowers, makes the dwarfs eminently suitable for bed or border plants. Unfortunately they are very sensitive, especially to wet weather.

Oenothera gigas and $O$. rubrinervis, or the giant, and the red-veined evening primroses, are the names given to two robust and stout species, which seem to be equal in vigor to the parent-plant, while diverging from it in striking characters. Both are true elementary species, differentiated from lamarckiana in nearly all their organs and qualities, but not showing any preponderating character of a retrograde nature. Their differences may be compared with those of the elementary species of other genera, as for instance, of Draba, or of violets, as will be seen by their description.

The giant evening-primrose, though not taller in stature than O. lamarckiana, deserves its name because it is so much stouter in all respects. The stems are robust, often with twice the diameter of lamarckiana throughout. The internodes are shorter, and the leaves more numerous, covering the stems with a denser foliage. This shortness of internodes extends itself to the spike, and for this reason the flowers and fruits grow closer together than on the parent-plant. Hence the crown of bright flowers, opening each evening, is more dense and more strikingly brilliant, so much the more so as the individual flowers are markedly larger than those of the parents. In connection with these characters, the flower-buds are seen to be much stouter than those of lamarckiana. The fruits attain only half the normal size, but are broader and contain fewer, but larger seeds. 
The rubrinervis is in many respects a counterpart to the gigas, but its stature is more slender. The spikes and flowers are those of the lamarckiana, but the bracts are narrower. Red veins and red streaks on the fruits afford a striking differentiating mark, though they are not absolutely lacking in the parent-species. A red hue may be seen on the calyx, and even the yellow color of the petals is somewhat deepened in the same way. Young plants are often marked by the pale red tinge of the mid-veins, but in adult rosettes, or from lack of sunshine, this hue is often very faint.

The leaves are narrow, and a curious feature of this species is the great brittleness of the leaves and stems, especially on annual individuals, for example, on those that make their stem and flowers in the first year. High turgidity and weak development of the mechanical and supporting tissues are the anatomical cause of this deficiency, the bast-fibres showing thinner walls than those of the parent-type under the microscope. Young stems of rubrinervis may be broken off by a sharp stroke, and show a smooth rupture across all the tissues, while those of lamarckiana are very tough and strong.

Both the giant and the red-veined species are easily recognized in the rosette-stage. The very young seedlings of the latter are not clearly differentiated from the lamarckiana, and of ten a dozen leaves are required before the difference may be seen. Under ordinary circumstances the young plants must reach an age of about two months before it is possible to discern their characters, or at least before these characters have become reliable enough to enable us to judge of each individual without doubt. But the divergencies rapidly become greater. The leaves of $O$. gigas are broader, of a deeper green, the blade more sharply set off against the stalk, the whole rosettes becoming stout and crowded with leaves. Those of $O$. rubrinervis on the contrary are thin, of a paler green and with a silvery white surface; the blades are elliptic, often being only $2 \mathrm{~cm}$. or less in width. They are acute at the apex and gradually narrowed into the petiole.

It is quite evident that such pale narrow leaves must produce smaller quantities of organic food than the darker green and broad organs of the gigas. Perhaps this fact is accouritable partly, at least, for the more robust growth of the giant in the second year. Perhaps also some relation exists between this difference in chemical activity and the tendency to become annual or biennial. The gigas, as a rule, produces far more, and the rubrinervis far less biennial plants, than the lamarckiana. Annual culture for the one is as unreliable as 
biennial culture for the other. Rubrinervis may be annual in apparently all specimens, in sunny seasons, which would allow a large part of the gigas to remain in the state of rosettes during the entire first summer. It would be very interesting to obtain a fuller insight into the relation of the length of life to other qualities, but as yet the facts can only be detailed as they stand.

Both of these stout species have been found quite constant from the very first moment of their appearance. I have cultivated them from seed in large numbers, and they have never reverted to the lamarckiana. From this they have inherited the mutability or the capacity of producing in their turn new mutants. But they. seem to have done so incompletely, changing in the direction of more absolute constancy. This was especially observed in the case of rubrinervis, which is not of such rare occurrence as $O$. gigas, and which it has been possible to study in large numbers of individuals. So for instance, "the red-veins" have never produced any dwarfs, notwithstanding they are produced very often by the parent-type. And in crossing experiments the red-veins gave proof of the absence of a mutative capacity for their production.

[Besides the mutants just described there occurred two weak forms that could survive only if reared under protection and would have failed to survive in nature. Here we have a place for the action of natural selection, but operating with mutations instead of with fluctuating variations. These two mutants are "the whitish and the oblong-leaved evening-primroses or the Oenothera albida and oblonga."

All of the mutants so far mentioned are constant forms that breed true to type. Certain other types were either incapable of being bred or else were decidedly inconstant. Oenothera lata had only pistillate flowers and therefore could not be fertilized by pollen of the same mutant. Oenothera scintillans and O. elliptica are fertile to their own pollen, but produce progeny only partly like the parent, the rest reverting to the original type, Oenothera lamarckiana.]

\section{SUMMARY OF DE VRIES'S MUTATION THEORY ${ }^{\mathrm{Y}}$ \\ THOMAS HUNT MORGAN}

We may now proceed to examine the evidence from which De Vries has been led to the general conclusions given in the preceding pages. De Vries found at Hilversum, near Amsterdam, a locality

'T. H. Morgan, Evolution and Adaptation (1903). Used by special permission of the publishers, The Macmillan Company. 
where a number of plants of the evening primrose, Oenother lamarckiana, grow in large numbers. This plant is an American form that has been imported into Europe. It often escapes from cultivation, as is the case at Hilversum, where for ten years it had been growing wild. Its rapid increase in numbers in the course of a few years may be one of the causes that has led to the appearance of a mutation period. The escaped plants showed fluctuating variations in nearly all of their organs. They also had produced a number of abnormal forms. Some of the plants came to maturity in one year, others in two, or in rare cases, in three, years.

A year after the first finding of these plants De Vries observed two well-characterized forms, which he at once recognized as new elementary species. One of these was $O$. brevistylis, which occurred only as female plants. The other new species was a smooth-leafed form with a more beautiful foliage than O. lamarckiana. This is O. laevifolia. It was found that both of these new forms bred true from selffertilized seeds. At first only a few specimens were found, each form in a particular part of the field, which looks as though each might have come from the seeds of a single plant.

These two new forms, as well as the common O. lamarckiana, were collected, and from these plants there have arisen the three groups of families of elementary species that De Vries has studied. In his garden other new forms also arose from those that had been brought under cultivation. The largest group and the most important one is that from the original O. lamarckiana form. The accompanying table shows the mutations that arose between I 887 and I 899 from these plants. The seeds were selected in each case from self-fertilized plants of the lamarckiana form, so that the new plants appearing in each horizontal line are the descendants in each generation of lamarckiana parents. It will be observed that the species, O. cblonga, appeared again and again in considerable numbers, and the same is true for several of the other forms also. Only the two species, O. gigas and $O$. scintillans, appeared very rarely (Fig. 77).

Thus De Vries harl, in his seven generations, about fifty thousand plants, and about eight hundred of these were mutations. When the flowers of the new forms were artificially fertilized with pollen from the flowers of the same plant, or of the same kind of plant, they gave rise to forms like themselves, thus showing that they are true elementary species. It is also a point of some interest to observe that all these forms differed from each other in a large number of particulars. 
Only one form, $O$. scinlillans, that appeared eight times, is not constant as are the other species. When self-fertilized its seeds produce always three other forms, O. scintillans, O. oblonga, and O. lamurckiana. It differs in this respect from all the other elementary species, which mutate not more than once in ten thousand individuals.

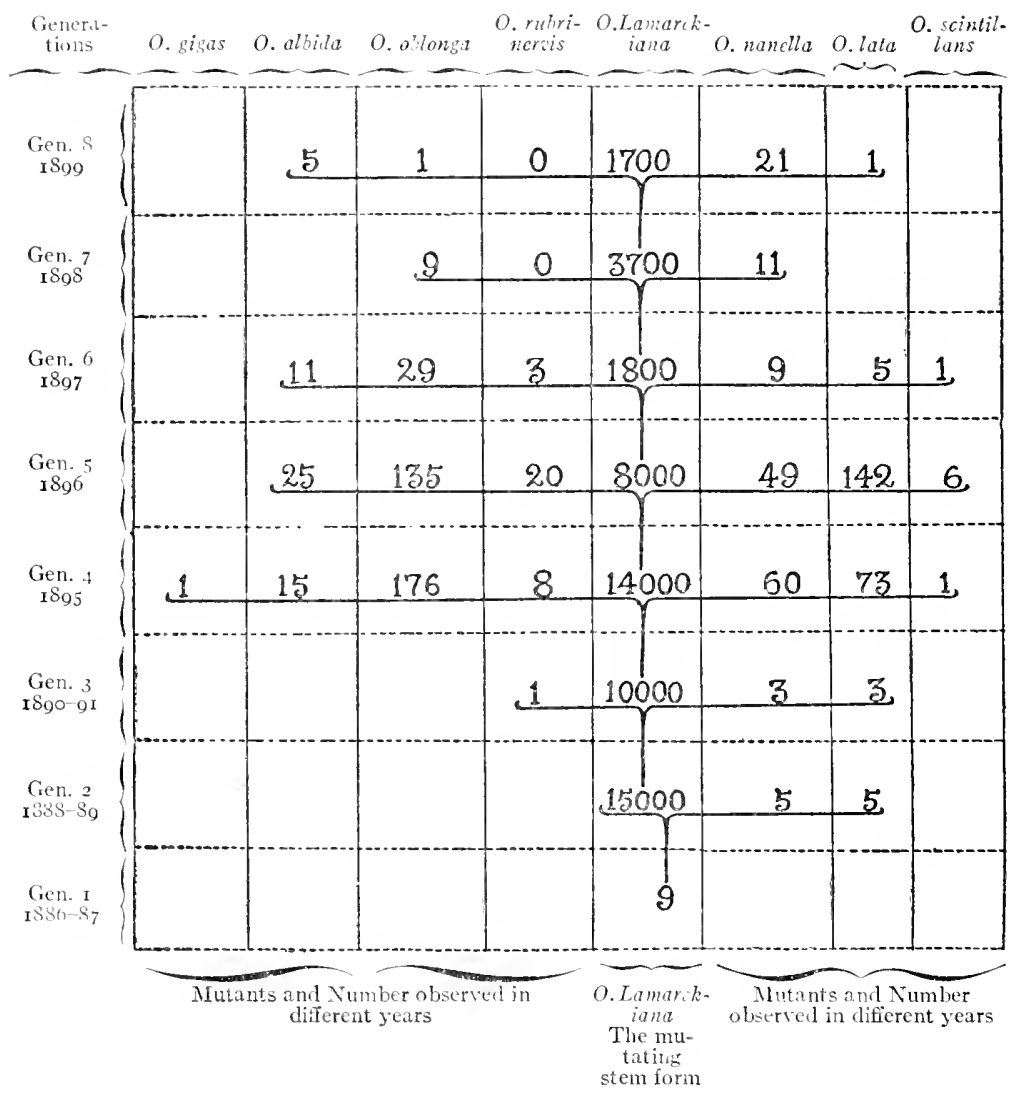

FIG. 77-Diagram showing in condensed form the genealogy of the Oenothera Lamarckian family and its various mutants during successive years. The numbers under each type represent the number of new types observed each year. (From Touer.)

From the seeds of one of the new forms, O. lacvifolia, collected in the field, plants were reared, some of which were O. lamarckiana and others O. lacvifolia. They were allowed to grow together, and their descendants gave rise to the same forms found in the lamarckiana 
family, described ahove, naniely, O. lata, elliftica, nannclla, rubri. nervis, and also two new species, O. spatulata and leptocarpa.

In the lata family, only female flowers are produced, and, therefore, in order to obtain seeds they were fertilized with pollen from other species. Here also appeared some of the new species already mentioned, namely, albida, nannella, lata, oblonga, rubrinervis, and also two new species, clliptica and suborata.

De Vries also watched the field from which the orisinal forms were obtained, and found there many of the new species that appeared under cultivation. These were found, however, only as weak young plants that rarely flowered. Five of the new forms were seen either in the Hilversum field, or else raised from seeds that had been collected there. These facts show that the new species are not due to cultivation, and that they arise year after year from the seeds of the parent form, O. lamarckiana.

Conclusions.-From the evidence given in the preceding pages it appears that the line between fluctuating variations and mutations may be sharply drawn. If we assume that mutations have furnished the material for the process of evolution, the whole problem appears in a different light from that in which it was placed by Darwin when he assumed that the fluctuating variations are the kind which give the material for evolution.

From the point of view of the mutation theory, species are no longer looked upon as having been slowly built up through the selection of individual variations, but the elementary species, at least, appear at a single advance, and fully formed. This need not necessarily mean that great changes have suddenly taken place, and in this respect the mutation theory is in accord with Darwin's view that extreme forms that rarely appear, "sports," have not furnished the material for the process of evolution.

As De Vries has pointed out, each mutation may be different from the parent form in only a slight degree for each point, although all the points may be different. The most unique feature of these mutations is the constancy with which the new form is inherited. It is this fact, not previously fully appreciated, that De Vries's work has brought prominently into the foreground. There is another point of great interest in this connection. Many of the groups that Darwin recognized as varieties correspond to the elementary species of De Vries. These varieties, Darwin thought, are the first stages in the formations of species, and, in fact, cannot be separated from species in most cases. The main difference between the selection theory and 
the mutation theory is that the one supposes these varieties to arise through selection of individual variations, the other supposes that they have arisen spontaneously and at once from the original form. The development of these varieties into new species is again supposed, on the Darwinian theory, to be the result of further selection, on the mutation theory, the result of the appearance of new mutations.

In consequence of this difference in the two theories, it will not be difficult to show that the mutation theory escapes some of the gravest difficulties that the Darwinian theory has encountered. Some of the advantages of the mutation theory may be briefly mentioned here.

r. Since the mutations appear fully formed from the beginning, there is no difficulty in accounting for the incipient stages in the development of an organ, and since the organ may persist, even when it has no value to the race, it may become further developed by later mutations and may come to have finally an important relation to the life of the individual.

2. The new mutations may appear in large numbers, and of the different kinds those will persist that can get a foothold. On account of the large number of times that the same mutations appear, the danger of becoming swamped through crossing with the original form will be lessened in proportion to the number of new individuals that arise.

3. If the time of reaching maturity in the new form is different from that in the parent forms, then the new species will be kept from crossing with the parent form, and since this new character will be present from the beginning, the new form will have much better chances of surviving than if a difference in time of reaching maturity had to be gradually acquired.

4. The new species that appear may be in some cases already adapted to live in a different environment from that occupied by the parent form; and if so, it will be isolated from the beginning, which will be an advantage in avoiding the bad effects of intercrossing.

5. It is well known that the differences between related species consist largely in differences of unimportant organs, and this is in harmony with the mutation theory, but one of the real difficulties of the selection theory.

6. Useless or even slightly injurious characters may appear as mutations, and if they do not seriously affect the perpetuation of the race, they may persist. 


\section{LATER INVESTIGATIONS OF MUTATIONS}

Since the publication of De Vries's classic investigations a large amount of attention has been paid both by botanists and by zoölogists to the subject of mutations. Some of the investigators, notably B. M. Davis, went far toward discrediting the whole of the exceptionally careful work of De Vries by claiming that Oenothera lamarckiana is of hybrid origin. It was pointed out that the form worked with is a domestic type escaped from cultivation and that there is nowhere in the known world any wild species comparable with it. It is supposerl to have been brought to Europe from America many years ago, but there is no such species in America today. Davis claims that he has succeeded in producing, by crossing two American wild species, a hybrid form distinctly resembling Oenothera lamarckiana, and that when inbred this hybrid produces offspring showing various combinations of the two parent-species that are not unlike some of the mutants observed by De Vries. Jeffreys has also pointed out that the pollen grains of Oenothera lamarckiana exhibit a high percentage of sterility, which he believes to be a stigma of hybridity. The general tenor of this type of destructive criticism is to invalidate the whole mutation theory as developed by De Vries and to reduce his mutants to the level of mere Mendelian recombinations of characters once introduced from two or more parental species.

The large amount of work on the cytology of Oenothera by Gates and others has, however, served to show that the mutants of De Vries are more than hybrid segregates. Moreover, the beautiful work of Blakeslee on the Jimson weed (Datura) and the work of many other botanists, whose findings are reported by Gates in a contribution quoted below, serve to indicate that the type of evolutionary behavior first observed in Oenothera is by no means exceptional, but is probably a common thing at least among plants and may be commoner than we at present know in animals. It may be said by way of anticipation of Gates' detailed account that nearly all of the mutations observed in various species of plants may be definitely correlated with observable changes in the chromosomes of the germ cells, involving changes in number or changes in arrangement of these nuclear elements.

While the botanists busied themselves with their type of mutations, the zoölogists, especially T. H. Morgan and his able collaborators, were making discoveries of equal moment in connection with their studies of the mechanism of Mendelian heredity in Drosophila. As has al- 
ready been shown in previous chapters, hundreds of new hereditary types arose, apparently spontaneously, in pure-pedigreed stock. Each new type is designated a mutant, and the cause of the changed hereditary condition is not a gross chromosomal change, but an invisible change at a definite point in a definite chromosome, whose cause is unknown but whose location can be exactly determined. Such mutations are known as gene mutations. Like the mutants of Oenothera, these Drosophila mutants do not differ from the parent species in just one or two characters, but in several or many characters. Usually some one or two characters in any given mutant are especially characteristic, and these serve to give a name to each mutant and make it easier to identify them. Both morphological and physiological characters are involved in these mutants, and every part of the body may be involved. Sometimes the change is so slight as to require an eye sensitized by much training to detect them. It may happen, for example, that two mutants of the eye are so much alike that the human eye is not sufficiently keen to tell them apart, but they may be distinguished by differences in their hereditary behavior. A large percentage of the mutants discovered in Drosophila are "lethals," which means that the change is decidedly for the worse, under the prevailing conditions of life, and that they render the individual unfit to live. Possibly under decidedly different conditions some of these lethal mutants might be better adapted than the normal individuals. A further discussion of the rôle of mutants in evolution will be given in a later connection.

The following two rather technical, but very interesting, discussions as to the nature, causes, and significance of mutations are from two men who are recognized as perhaps the leaders in the two branches of mutation study. R. R. Gates has done a large amount of important work especially upon the cytology of Oenothera, and H. J. Muller has done and is still doing much to enrich our understanding of the mutational phenomena exhibited by Drosophila. While these two workers do not agree as to the relative emphasis that should be placed upon the two types of mutation, it is obvious that both types are of very great importance in evolution.

THE NEO-MUTATIONIST POSITION

R. RUGGLES GATES

Since the original work of De Vries, the subject of mutation in Oenothera has advanced in many directions and the explanation of the phenomena has taken on various aspects. Mutation has become 
essentially a cell problem. Cytological investigations have shown that many of the mutations are concerned with new chromosome numbers, and the precise nature of the change which has led to the appearance of forms with a new number is known with more or less certainty in the various cases. The new number is in each case present throughout the plant and will be found whether the chromosomes be counted in growing petals, root tips or anthers. These discoveries led in 1915 to the conception that each mutation with its new external characters is the result of nuclear changes transmitted by mitosis to every cell of the plant during development. A fundamental advance in the analysiof mutations has thus been made.

Mutations can now be classified into two types. (I) Mutations which are inherited as Mendelian differences, and which may be looked upon provisionally as the result of a chemical change in one gene or locus of a chromosome. The great majority of the mutations in Drosophila are of this type. On the other hand, very few Mendelian mutations are known in Oenothera. The two best known are rubricalyx, which is a dominant in crosses, and brevistylis, which is inherited as a recessive. (2) Mutations resulting from a visible nuclear change involving a new number of chromosomes. Probably the majority of Oenothera mutations belong here. Similar mutations have been discovered in Lrosophila and also in Datura. Examination of the chromosome numiers in related species of wild and cultivated plants shows that such changes have been of relatively frequent occurrence in the evolution of many plant genera, but they appear to be less common in animals.

\section{CIROMOSOME MUTATIONS}

The mutations with new chromosome numbers, which are particularly characteristic of Oenothera, may be classified into three types:-(I) trisomic forms, i.e., mutations with one or sometimes two extra chromosomes $(2 n+\mathrm{I})$; (2) triploid forms $(3 n)$; and (3) tetraploid $(4 n)$ forms. Other forms with different numbers, as 20 or 30 , may be regarded as derivatives from these types.

Trisomic forms are known to arise through non-disjunction, or a reduction division in which both members of one pair of chromosome: enter the same daughter nucleus. The best known mutation of thikind is Oenothera lata with ${ }_{5}$ chromosomes (O. lamarckianu having I4). But a number of others are now known, including scintillans. albida, oblonga, subovata, and more recently cana, pallescens, laituca. and liquida. Several other derivatives of Oenothera lamarckiunt ar also from their behavior almost certainly trisomic. When pollinated 
from O. lamarckiana they give the two parental types of offspring having presumably $\mathrm{I}_{4}$ and $\mathrm{I}_{5}$ chromosomes. Since there are only seven pairs of chromosomes these trisomic types can not all be accounted for by duplication of a different chromosome in each case.

The genetic relationships between these trisomic mutants are also interesting and peculiar. Thus lata can give rise to scintillans in its offspring, and scintillans can similarly produce lata. Also lata (pollinated from lamarckiana) can give rise to several other trisomic mutations. Many of these relationships can be explained by the assumption of double non-disjunction, i.e., both members of one chromosome pair entering one germ cell while both members of another pair enter the opposite cell. It is highly probable that such cases occur. Thus germ cells would be produced with the chromosome content AACDEFG and BBCDEFG. It can be shown that by such a process one trisomic mutation could give rise to another in its offspring. It is very probable that lata is a primary trisomic mutation, e.g., $\frac{\mathrm{AABCDEFG}}{\mathrm{ABCDEFG}}$, i.e., with three A chromosomes, while some other trisomic $(2 n+\mathrm{I})$ mutations are probably secondary, e.g., $\frac{\mathrm{AABCDEFG}}{\mathrm{ACCDEFG}}$, i.e., with for example three $\mathrm{A}$ and three $\mathrm{C}$ chromosomes but only one $\mathrm{B}$ chromosome. All such irregular chromosome distributions are probably enabled to occur through a weakness in the attraction which normally leads to close pairing of homologous chromosomes during synapsis or on the heterotypic spindle. There is much evidence of variation in the strength of this attraction in Oenothera.

Cleland has recently found that the chromosomes in various Oenothera species retain their end-to-end connections even on the heterotypic spindle. He has also shown that in several species the arrangement of the chromosomes is more or less constant and characteristic during the stages immediately preceding the reduction division. Thus in $O$. franciscana four of the chromosomes form a ring while the other ten are arranged in five ring pairs which are at first linked to the circle of four in a definite way. In a form called $O$. franciscana sulphurea, which is derived from $O$. biennis $\times$ franciscana, I 2 chromosomes end-to-end form a circle and the other two form a pair which is at first linked round the larger chain of 12 , and this arrangement is said to be constant. Thus in the derived form a rearrangement of the chromosomes with relation to each other has taken place. Cleland finds similar fixed arrangements in other species. 
Thus in a race identified with $O$. muricata the ${ }_{14}$ chromosomes all form a single circle; in O. biennis they are usually in two interiooking circles, one with 6 and the other with 8 chromosomes; while in the mutarit oblonga with $1_{5}$ chromosomes the arrangement is more variable but frequently shows a ring of 5 single chromosomes with 5 pairs attached to it. In a trisomic mutant from $O$. rubricalys $\times$ hewettii a varying number of ring pairs was found by the writer. If the relative constancy of these arrangements is confirmed, it will show an essentially new type of integration in nuclear structure, that is, a fixed positional arrangement of the chromosomes in the nucleus with relation to one another. This will also confirm the hypothesis of the writer years ago, that the homologous maternal and paternal chromosomes in Oenothera are usually arranged alternately on the spireme thread before the reduction division. The fact that also, as olsserved by the writer in I90S, pairs of chromosomes are frequently detached from the rest of the spireme in certain forms at an early stage of diakinesis, would make it easier for double non-disjunction to occur on the heterotypic spindle in these forms. The further study of the clromosome arrangements in hybrids and mutants will throw more light on these rearrangements, and perhaps also on the nature of the forces which bring them about Such rearrangements without change of number, if they prove to be constant, are to be considered as mutations of another kind.

Whether non-disjunction has played a part in the appearance of species in nature with a different chromosome number is as yet uncertain. But there are certain genera, such as Carex, in which the haploid numbers usually increase by one from species to species. Heilborn suggests that this may have happened by non-disiuuction, as in Oenothera lata, followed by the division of the extra chromosome to form a pair.

Polyploidy.-An increase in the chromosome number by multiples of the haploid number (polyploidy) is a phenomenon of considerable phylogenetic significance in plants, although it appears to be relatively uncommon in animals. There has been a burst of new knowledge or: this subject in the last few years. Since the original mutant Oenothera gigas bas been shown to be tetraploid, and semigigas mutations triploid we have an experimental basis for the interpretation of ali such cases. It appears probable that the triploid condition in Oenothera arises through the union of two male nuclei with the egrog, as this condition has been actually observed in O. lamarckiana by Ishikawa, and in other plants as well. 
A difference of opinion has long existed as to whether $O$. gigas arose from the fusion of two diploid cells or from a suspended mitosis with division of the chromosomes in the fertilized egg. I am still inclined to adhere to the latter view as more probable, with perhaps a sudden lowering of temperature just after fertilization as the cause. Although it is a fact that diploid germ cells do sometimes occur, diploid pollen grains are not known to be viable in plants.

The frequency of polyploidy in flowering plants, and also in other groups of plants, is one of the surprises of recent years. Not only does the condition occur in such cultivated plants as pineapples, bananas; mulberries, wheat, oats, sugar-cane, dahlias, and tobacco, but also in such genera of wild plants as the roses, maples, chrysanthemums; Erigeron, Hieracium, Rumex, Rubus, Crataegus, Spiranthus, and a number of others. The multiplication of chromosome sets runs as high as $8 n$ in Rosa and in Acer, and even as high as ro $n$ in certain species of Rumex (8o chromosomes) and chrysanthemums (90 chromosomes). Such a widespread phenomenon must be of fundamental significance in the evolution of the genera in which it occurs. The higher degrees of polyploidy are probably often connected with hybridization, but there the higher chromosome numbers are usually accompanied by apogamous (asexual) reproduction, which renders constant even forms with an unbalanced chromosome number. This is true even of the triploid mulberries and Erigerons, etc. In every case of polyploidy the higher numbers have not arisen gradually by the addition of single chromosomes, but one or more complete sets have been added each time and the process is a mutation involving considerable discontinuity.

That still other kinds of chromosome change occur, is shown both from experimental work and by comparison of the chromosomes of related species. Thus transverse segmentation of all chromosomes has taken place in Primula kewensis, and end-to-end fusion of certain pairs has evidently occurred in some species of Drosophila. In the Japanese violets there is some indication that the small number of large chromosomes in certain species may have been derived by the fusion of smaller chromosomes found in other species. A process suggesting transverse fragmentation of certain pairs of long chromosomes appears to have occurred in various genera of Liliaceae. Further study will no doubt throw light on the nature of these processes. It appears already that the passage from one genus to another has not infrequently been marked by a visible change in the chromatin mor- 
phology of the nucleus. Such alterations in the conformation of the nuclear material are to be regarded as germinal changes, even though they are not accompanied by external changes in the organism.

\section{MUTATION}

\section{H. J. MULLER}

Beneath the imposing building called "Heredity" there has been a dingy basement called "Mutation." Lately the searchlight of genetic analysis has thrown a flood of illumination into many of the dark recesses there, revealing some of them as ordinary rooms in no wise different from those upstairs, that merely need to have their blinds flung back, while others are seen to be subterranean passageways of quite a different type. In other words, the term mutation originally included a number of distinct phenomena, which, from a genetic point of view, have nothing in common with one another. They were classed together merely because they all involved the sudden appearance of a new genetic type. Some have been found to be special cases of Mendelian recombination, some to be due to abnormalities in the distribution of entire chromosomes, and others to consist in changes in the individual genes or hereditary units. It seems incurnbent upon us, however, in the interests of scientific clarity, to agree to confine our use of the term mutation to one coherent class of events. The usage most serviceable for our modern purpose would be to limit the meaning of the term to the cases of the third type - that is, to real changes in the gene. This would also be most in conformity with the spirit of the original usage, for even in the earlier days, mutations were conceived of as fundamental changes in the hereditary constitution, and there were never intentionally included among them cases merely involving redistribution of hereditary units-when these cases were recognizable as such. In accordance with these considerations, our new definition would be: "mutation is alteration of the gene." And "alteration," as here used, is of course understood to mean a change of a transmissible, or at least of a propagable, sort.

In thus trimming down the scope of our category of mutation we do not deprive it of the material of most fundamental evolutionary significance. For all changes due to the redistribution of individual genes or of groups of genes, into new combinations, proportione, or quantities, are obviously made possible only by the prior changes thai

${ }^{x}$ Reprinted from Eugenics, Genetics and the Family, Vol. I (1923). Courtesy of the Williams and Wilkins Company. 
make these genes differ from each other in the first place. It should in addition be noted that changes due merely to differences in the gross proportions of entire groups of genes must be relatively incapable of that delicate adjustment which is required for evolutionary adaptation. And as to the question, frequently raised, whether all evolution is ultimately due to mutation, this is necessarily answered in the affirmative by our definitions of the gene and of mutation, which designate the gene as any unit of heredity, and mutation as any transmissible change occurring in the gene. The question of the basic mechanism of evolution thus becomes transferred to the problem of the character, frequency, and mode of occurrence of mutation, taken in this precise, yet comprehensive sense. And since eugenics is a special branch of evolutionary science it must be equally concerned with this problem.

In choosing the body of data wherewith to attack these questions of mutation, in their new form, it must unfortunately be recognized that the results with the evening primrose, Oenothera, although they for med the backbone of the earlier mutation theory, can no longer be regarded as having a direct bearing on the modern problem, since they cannot be shown to be due directly to changes in the genes. Certain of them, such as gigas, lata, scintillans, etc., have been proved by Geerts, Lutz, Gates, and others, to be due to abnormalities in the apportionment of the chromosomes. Very valuable information on the genetics of cases of this sort is now being obtained, especially in the work of Blakeslee, Belling, and Farnham on much clearer cases of similar character in the Jimson weed, and, finally, in the work of Bridges on the fruit fly Drosophila. Most of the other so-called mutations in the evening primrose appear to be due to the normal hereditary processes of segregation and crossing over, working on a genetic constitution of a special type. Evidence for this was obtained in my analysis of the analogous case existing in the fly Drosophila, as follows. It had previously been shown by de Vries, and further elaborated by Renner, that germ cells or individuals of Oenothera bearing certain genes always died, in such a way that all the surviving individuals were heterozygous (hybrid) in regard to these genes. I later showed, through work on Drosophila, that when such a condition (there called "balanced lethal factors") exists, the situation tends to become still further complicated through the presence of other heterozygous genes, which are linked to those which cause death. When one or a group of these non-lethal genes crosses over (separates) from the lethals, as they occasionally do, they may secome homozygous, producing a visible effect. Thus new types of individuals appear which may be ascribed to "mutation." whereas they 
are really due to crossing over. The work of Frost on stocks has shown that a precisely analogous situation exists in that form also, and G. $\mathrm{H}$. Shull is obtaining direct evidence for the same conclusion in the evening primrose itself. In any event, it must be granted that so long as this interpretation cannot be definitely refuted, these variations cannot be used as examples on which to base our theory of gene change. In place, then, of the elaborate system of conclusions which has derived its support chiefly from the results in the evening primrose, it will be necessary for our present theory of gene change to erect an independent structure, built upon an entirely new basis.

The data upon which the new theory must be built consist of two main sorts, which may be called direct and indirect. (I) In the cases giving the direct evidence, the occurrence of the gene change can be proved, and it is possible to exclude definitely all alternative explanations, such as contamination of the material, emergence of previously "latent" factors, non-disjunction, etc. So far, the only considerable body of such evidence is that gotten in the Drosophila work, where mutations have (in this sense) been actually observed in at least roo loci. Considered collectively, however, there exist in other orcanisms enough scattered data to afford ample corroborative evidence for the generality of occurrence of mutations like those observed in the Drosophila work. In addition several specially mutable genes have been found in a number of plants (as well as in Drosophila) that are giving highly valuable information along their particular lines. And a number of selection experiments that have been performed on non-segregating lines of various organisms have also given us direct evidence, if not of the frequency, then at least of the infrequency, of mutations. (2) As for the indirect data, these may be gotten by examination of Mendelian factor-differences of all kinds, on the assumption that they must have arisen through mutation. Although this assumption can be shown to be fully justified, these cases cannot provide information concerning the manner of origin of the mutants, nor can they furnish a reliable index of the frequency of mutations, since the mutant genes may have been subjected to an unknown amount of selective elimination or selective propagation before the observations were taken. As for the still more indirect data, derived from studies of phylogenetic series and comparisons between different species, genera, etc., these occasionally give suggestive results, but where crosses cannot be made or where the differences cannot be traced down to the individual genes, such facts can seldom lead to trustworthy genetic conclusions.

On these various data, duly weighted, we may found our new muta- 
tion theory. We know nothing, as yet, about the mechanism of mutation, or about the nature of the gene-aside from the fact that nearly all genes hitherto studied behave like material particles existing in the chromosomes. Nevertheless there is already evidence for a number of empirical principles regarding the changes of the genes, some of which may conveniently be listed here in the form of $\mathrm{r}_{4}$ statements. I shall have opportunity merely to present these principles, without attempting any adequate explanations of how they have been derived from the data.

r. The first and probably most important principle is that most genes-both mutant and "normal"-are exceedingly stable. Some idea of the degree of this stability may be obtained from some quantitative studies of mutation which Altenburg and I have made in the fruit fly Drosophila. It may be calculated from these experiments that a large proportion of the genes in Drosophila must have a stability which-at a minimum value-is comparable with that of radium atoms. Radium atoms, it may be recalled, have a so-called "mean life" of about two thousand years.

2. Certain genes are, however, vastly more mutable than others. For example, a gene causing variegation in corn, studied by Emerson, and another in the four-o'clock, studied by Maryatt, ordinarily have a mean life of only a few years; and that causing bar eye in Drosophila has a mean life of only about 65 years, as is shown by the resu'ts of Zeleny. (In expressing these results we are here using the physicists' index of stability, which seems most appropriate for the present purpose also.)

3. External agents do not ordinarily increase the mutability sufficiently (if at all) to cause an obvious "production" of mutation.

4. The changes are not exclusively of the character of losses; this is shown by the well established occurrence of reverse mutations, in bar-eyed and white-eyed Drosophila, in Blakeslee's dwarf Portulaca, Emerson's variegated corn, and probably in a number of other recorded instances. It is known that mutations having an effect similar to that of losses do occur, however, and they may be relatively frequent.

5. The change in a given gene is not in all cases in the same direction, and it does not even, in all cases, involve the same characters. The latter point is illustrated by a series of mutations which I am investigating in Drosophila, which all involve one gene, but which produce, as the case may be, either a shortened wing, an eruption on the thorax, a lethal effect, or any combination of these three. 
6. The direction of mutation in a given gene is, however, preferential, occurring oftener in some directions than in others. This is well illustrated in the studies on variegated corn and four-o'clocks, and on the bar eye and white eye and other series in Drosophila.

7. The mutability and preferential direction may themselves become changed through mutation, as illustrated by some of the same cases.

8. The mutations do not ordinarily occur in two or more different genes at once. In only two instances in Drosophila have mutations been found in two different, separated ${ }^{1}$ genes in the same line of cells of one individual. But a recurrent case, apparently of this kind, has recently been described in oats, by Nillson-Ehle.

9. Not only does the mutation usually involve but one kind of gene-it usually involves but one gene of that kind in the cell. That is, the allelomorphs mutate independently of one another, just as totally different genes do. There is evidence for this derived from corn, Portulaca, and Drosophila.

Io. Mutations are not limited in their time of occurrence to any particular period of the life history. This has been proved in the above mentioned studies on mutable plants, in Drosophila, and in other cases.

II. Genes normal to the species tend to have more dominance than the mutant genes arising from them. This is very markedly the case in Drosophila, where even the relatively few mutant genes that have been called dominant are very incompletely so, and might more justly be called recessive. In other organisms, the same condition of things is strongly suggested, although the direct data on occurrence of mutations is as yet too meagre to allow of certainty.

I2. Most mutations are deleterious in their effects. This applies not only to the organism as a whole but also to the development of any particular part: the delicate mechanisms for producing characters are more likely to be upset than strengthened, so that mutations should more often result in apparent losses or retrogressions than in "progressive" changes. This is both an a priori expectation and a phenomenon gencrally observed.

I3. Nutations with slight effects are probably more frequent than those with more marked effects. This must not be understood as referring to the different mutations of each given gene, but it applies in a comparison of the mutations occurring in different genes. Thus, there

"Contiguous genes may be affected in the rare cases known as "deficiencies," found by Bridges and Mohr. 
are more than a dozen mutations, in different loci, which reduce the size of the wing in Drosophila so slightly as to leave it more than half its original length, whereas only four reduce it to less than half-length. Mutant genes with effects so slight as to be visible only by the aid of specific co-genes seem to arise still more frequently. It is reasonable to conclude that the mutations with slighter effects would more of ten take part in evolution, because they should usually be less deleterious, and this conclusion is born out by observations on the multiplicity with which such factor-differences with relatively slight effects are found in species crosses.

14. The range of those mutations which are of appropriate magnitude to be visible is probably very small, in comparison with the entire "spectrum" of mutations, so that there are many more lethals than visible mutations, and probably more subliminal than visible.

The above empirical and semi-empirical principles must be regarded as a mere preliminary scaffolding, for the erection of a later, more substantial, theory of mutation. Time does not permit me here to discuss which directions of research, and what methods, seem the most promising for future results. Suffice it to say that it is especially important to obtain accurate data concerning the effect of various conditions upon the rate of mutation. This seems one of the logical routes by which to work towards the artificial production of mutation and consequent more perfect control of evolution. At the same time such results should also give a further insight into the structure of the gene. The way is now open, for the first time, to such studies on mutation rate, first through the finding, by Emerson, Baur, Maryatt, Zeleny, and Blakeslee, of a number of specially mutable factors in different organisms, and second, through certain special genetic methods which I have elaborated in Drosophila, for the detection of lethal and other mutations there.

It has now become recognized that advances in theoretical or "pure" science eventually carry in their train changes in practice of the most far reaching nature-changes which are usually far more radical than those caused by progress in the applied science directly concerned. It may therefore be asked at this point by eugenists: "Are there any applications of the knowledge which has already been gained about mutation in general, to eugenics and to the principles which should govern us in guiding human reproduction?" I think that one such application is already clearly indicated.

In order to understand the nature of this application it will be nec- 
essary first to consider the proposition-emphasized by East and Jones in their book, "Inbreeding and Cross-breeding" - that the only way for a genetically sound stock to be formed is by its going through a course of intreeding, with elimination, by natural or artificial selection, of the undesirable individuals that appear in the course of this inbreeding. The truth of this proposition depends upon the fact that many recessive genes of undesirable character are apt to exist in a population. Since the frequency with which these genes are able to produce their characteristic effects, i.e., to "come to light," depends on the closeness of the inbreeding, it is evident that inbreeding will be necessary in order to recognize the genes adequately, and hence to eliminate them.

Our present theory of mutation, however, carries us further than the proposition just considered. It shows that these undesirable genes have arisen by rnutation; in fact, as stated in point $\mathrm{I}_{2}$, the great majority of mutations are deleterious, probably even to the degree of being lethal, and it is also known, as noted in point $x$, that manyprobably the great majority-are recessive. In other words, our mutation theory shows that probably the majority of the mutations that are occurring are giving rise to genes of just the type specified in the above discussion. This immediately shows us that not only are inlreeding and selection desirable for raising the genetic level of a population, but they are absolutely necessary merely in order to maintain it at its present standard. For the same process of mutation which was responsible for the origination of these undesirable genes in the past must be producing them now, and will continue to produce them in the future. Therefore, without selection, or without the inreeding that makes effective selection possible, these lethals and other undesiralle genes will inevitably accumulate, until the germ plasm becomes so riddled through with defect that pure lines cannot be obtained, and progress through selection of desirable recessive traits can never more be effected, since each of them will have become tied up with a lethal. To avoid such a complete and permanent collapse of the evolutionary process, it is accordingly necessary for man or nature to resort to a periodically repeated, although not continuous, series of inbreedings and selections in the case of any biparental organism.

This conclusion is more than a mere speculation, or even a deduction from our principles. The reality of this process of mutational deterioration has been directly proved, in the case of Drosophila, through experiments that I have conducted on lines in which the 
processes that are essential for the effectiveness of inbreeding and selection were prevented: in these lines there was found an accumulation of lethal genes so rapid that it would have taken but a few decades to have brought about the presence of a lethal gene in practically every chromosome of every fly. Although the same general thesis undoubtedly applies also to mankind we do not yet know the speed of the process here. Its speed depends upon the actual frequency of mutations, which it will be very important-and extremely difficult-to determine in the case of mankind. Meanwhile, no matter what this rate may be, the process remains a real one, which must eventually be reckoned with, and either grappled in time, and conquered, or else yielded to.

I have dwelt at length upon this particular application to eugenics, of some of the mutation studies. I believe, however, that this is but one example of such applications, and that from an increasing knowledge of our theoretical science there will inevitably flow an increasingly adequate teclnique for coping with our refractory human material. Meanwhile, the crying need is for more of the theoretical knowledgeand for the support of pure science, in its investigation of the processes lying at the root of the germ plasm.

\section{THE CAUSES OF MUTATIONS}

In attempting to determine the causes of the appearance of new hercditary characters, we must first of all learn which of the categories of variation we are dealing with. If we find that a so-called mutant has a different number or arrangement of chromosomes, we may say that this change in the chromosomes is the cause of the somatic differences seen in the mutant, for it would be strange if a relatively large change in the hereditary material did not affect the somatic expression of specific characters. As has already been suggested by Gates, the cause of chromosomal aberrations may be environmental, as for example sudden lowering of temperature during critical periods of the germ-cell cycle. We have, however, no controlled experiments that prove this to be the case. Again, there is a tendency to account for non-disjunction and other types of chromosomal aberration through purely internal causes, such as weakness of attraction between homologous chromosomes resulting in a failure of synapsis. In general it may be said that, apart from being able to note a definite correlation between a changed somatic condition and a changed chromosomal 
condition, we do not know rery much about the causes of chromosomal mulations.

The causes of gene mutations in Drosophila have remained, until recently, a complete mystery. Muller had been able very slightig to increase the rate of mutation by raising the temperature of tly cultures, but he was not completely satistied with these results. In I026, however, he startled the scientitic world by the announcement that he had been able, by exposing atult animals to fairly heavy doses of X-rays, vastly to accelerate the rate of mutations. Where some gene mutation occurred under normal conditions in only about I in 300 ginetes, the $\mathrm{X}$-rays raised this ratio to $\mathrm{I}$ in 2 gametes, an increase of $\mathrm{s} 50$ per cent. All of the old familiar mutations that had leen occurring in untreated cultures were induced in much larger numbers by X-rays, but only a very few new mutations were produced. It seems that the $\mathrm{X}$ ray acts merely as a catalyst, hastening a process that would go on slowly without such an agent. Numerous experimenters have fol. lowed Muller's lead in the use of X-rays as an agent for accelerating the rate of mutations. Muller has proposed a general theory that the ordinary, so-called "spontaneous," mutation of genes may be due to the presence of minute amounts of radio-active substances accumulated in the tissues of plants and animals. This theory seems somewhat far-fetched at the present writing. We are still in almost complete ignorance as to the causes of gene mutations and probably shall continue to lse in innorance until we gain some more accurate information as to the ence thysical and chemical nature of genes and how they act in protucing character differences.

\section{MUTATION AND EVOLUTION}

\section{T. H. MORGAN}

What bearing has the appearance of these new types of Drosophila on the theory of evolution may be aslied. The objection has been raised in fact that in the breeding work with Drosophila we are dealing with artificial and unnatural conditions. It has been more than implied that the resuits oltained from the breeding pen, the seed pan, the flower pot and the milk bottle [used as breeding-container for Drosopinla) do not apply to exolution in the "open," nature "at large" or to "wild" types. To be consistent, this same objection should be extended to the use of the spectroscope in the study of the evolution

- From A Critique of the Theory of Esolution. Princeton University Press, 1916. 
of the stars, to the use of the test tube and the balance by the chemist. and of the galvanometer by the physicist. All these are unnatural instruments used to torture Nature's secrets from her. I venture to think that the real antithesis is not between unnatural and natural treatment of Nature, but rather between controlled or verifiable data on the one hand, and unrestrained generalization on the other.

If a systematist were asked whether these new races of Drosophiti are comparable to wild species, he would not hesitate for a moment. He would call them all one species. If he were asked why, he would say, I think, "These races differ only in one or two striking points, while in a hundred other respects they are identical even to the minutest details." He would add, that as large a group of wild llies would show on the whole the reverse relations, viz., they would differ in nearly every detail and be identical in only a few points. In all this I entirely agree with the systematist, for I do not think such a group of types differing by one character each, is comparable to most wild groups of species because the difference between wild species is due to a large number of such single differences. The characters that have been accumulated in wild species are of significance in the maintenance of the species, or at least we are led to infer that even though the visible character we attend to may not itself be important, one at least of the other effects of the factors that represent these characters is significant. It is, of course, hardly to be expected that any random change in as complex a mechanism as an insect would improve the mechanism, and as a matter of fact it is doubtful whether any of the mutant types so far discovered are better adapted to those conditions to which is fiy of this structure and habitat is already adjusted. But this is beside the mark, for modern genetics shows very positively that adaptive characters are inherited in exactly the same way as are those that are not adaptive; and I have already pointed out that we cannot study a single mutant factor without at the same time studying one of the factors responsible for normal characters, for the two together constitute the Mendelian pair.

And, finally, I want to urge upon your attention another question Evolution of wild species appears to have taken place by modifying and improving bit by bit the structures and habits that the animal or piant already pessessed. We have seen that there are thirty mutant factors at least that have an influence on eye color, and it is probable that the $\mathrm{e}$ are at least as many normal factors that are involved in the production of the red eye of the wild fly. 
Evolution from this point of view has consisted largely in introducing new factors that influence characters already present in the animal or plant.

Such a view gives us a somewhat different picture of the process of evolution from the old idea of a ferocious struggle between individuals of a species with the survival of the fittest and the annihilation of the less fit. Evolution assumes a more peaceful aspect. New and advantageous characters survive by incorporating themselves into the race, improving it and opening to it new opportunities. In other words, the emphasis may be placed less on the competition between the individuals of a species (because the destruction of the less fit does not in itself lead to anything that is new) than on the appearance of new characters and modifications of old characters that become incorporated in the species, for on those depend the evolution of the race. 


\section{CHAPTER XXVII}

\section{GUIDING FACTORS. INTRODUCTION}

Preliminary discussion.--All of the factors hitherto discussed appear to operate on a random basis, obedient to the laws of pure chance. Of themselves, then, they might be conceived of as producing a high degree of diversity and innumerable novelties, but that would be all. If there is something of orderliness, something of direction, something adliptive, something progressive, or even something purposive about erolution, there should be guiding factors responsible for each and all of them.

The extent to which guiding factors are a necessary part of the evolutionary mechanism depends upon the extent to which there actually exist in nature conditions that cannot be accounted for on a purely random basis. Guiding or directing factors imply goals, objectives, definite trends, improvements of one sort or another. What is there about nature that seems to require a guiding hand?

Adaptations.--One of the marvels of life is that the organism and the environment seem so well adapted to each other, that the particular organs of an individual seem so well designed to perform their many and varied functions, that the various species are so nicely adjusted to one another in any given natural community that each seems to be a strand in an intricate and delicately adjusted "web of life." One of the most important goals or objectives of evolution, then, must be adaptation. We are using these terms "goals" and "objectives" without implying any teleological considerations, though why there may not be purpose in nature I do not know. At least it is better for the scientist to shy away from any taint of teleology. So let us assume that adaptation is one of the main objectives of evolution, using the term "objective" only to imply that evolutionary processes somehow, by devious paths, seen to arrive at various degrees of fitness. The mechanism bringing about this fitness may be blind and may vision no goal, but it gets there just the same.

Since adaptation is so intimately associated with evolution-in fact, one of its principal attributes - it will be necessary to take a short excursion into natural history in order that we may come to realize at least some of the facts of adaptation that confront the evolutionist 
and that challenge explanation. The following chapter on "Adaptation in Nature" is frankly an interpolation, but an essential one, unless the sturent be already well informed in this field. Also the chapter on "The Web of Life" is necessary if we are to avoid thinking of species as isolated entities. The evolution of a species always takes place in a natural setting, part of which consists of the lifeless environment and part of which consists of its animal and plant neighbors.

Orthogenetic trends. - Various kinds of definitely directed evolutionary trends have been described. Sonetimes these trends concern themselves with such relatively trivial characters as the intricate markings on the shells of mollusks and brachiopods, sometimes they have to do with the horns of elks or of titanotheres, and sometimes they concern the toes and teeth of the horse family. One striking feature of these so-called "orthogenetic" series is that the trends have not always culminated in a condition of maximum efficiency, but have sometimes gone beyond this point and have become positively detrimental, in some cases even contributing to the extinction of the species possessing them. If there is some guiding factor other than natural selection that tends to push evolutionary changes forward in definite paths, such a force might be responsible for adaptive trends as well as the nonariaptive ones. In general, however, it may be said in advance of the more detailed discussion of this question in a later chapter, that most geneticists are either skeptical of the existence of any very definite orthogenesis, or else consider it explainable through natural selection.

Progressive evolution.-It is generally assumed that "evolution" and "progress" are synonymous terms. It is claimed that forms of life now living are on the whole "more advanced" than those that have lived in earlier times and that there has been a steady advance throughout the ages. But what do we mean by progress in evolution or by more or less advanced forms? Progress and advance imply both direction and a goal or goals. What are the goals toward which evolution is progressing?

Some claim that the final goal of life is perfect adaptation of all living things to the environment and to one another. But is there any evidence that life today is any better adlapted than was life in Cambrian times? Is there any ground for assuming that man is any better adapted to the environment than is the Amoeba? Man is adapted to a much more complex environment than is the Amocba, but is he any better adapted to the human environment than is Amoeba to the amoeban e.lvironment? I see no reason for assuming that there is any difference 
in the degree of perfection of adlaptation in these two widely different species, each highly successful in its own milieu and each cosmopolitan in distribution. In view of such consilerations as these, it is not easy to maintain that evolution is a process of becoming better and better adapted.

Specializalion.-Various other criteria of progress have been suggested. One of these is specialization. Are the most highly specialized organisms more advanced than the less specialized? Are the more specialized ones closer to the ultimate ideal goal of evolution than the more generalized? Now, many of the most intensely specialized types of organisms are the parasites that have, in many cases, undergone degeneration of sense organs, locomotor structures, and even digestive systems, but have developed specialized structures making it possible for them to live and thrive in some particular system of some species of host animal. Here is specialization carried to extremes, but is it progress? I believe it is, and for the following reasons:

A primary oljective of living organisms is that of exploiting to the fullest possible extent the energy resources of the world. Ultimate success will be attained only when no further energy resources remain to be exploited. Now the sources of energy are many and varied, and each different energy source requires a different type of energy-exploiting equipment. Progress in specialization would therefore involve the evolution of as many highly specialized types of organisms as there are highly specialized energy sources. Thus there is a very real value for life as a whole in the production of numerous highly specialized forms, even though some be, from the morphological viewpoint, degenerate and degraded parasites.

Another type of specialization that has had a long and steady progressive evolution is the specialization of parts of the sirgle organism for the performance of varied bodily functions. This type of specialization is commonly called "division of labor." In the course of animal evolution this specialization of parts begins at the lowest level in the Protozoa, where portions of the protoplasm are specialized to form organelles of various kinds, each kind performing its own special function. Among the lower Metazoa, such as Coelenterata and Platyhelminthes, we have a new level of organization, built up of aggregates of units, each equivalent, in a sènse, to a whole protozoan individual. In these multicellular individuals division of labor is accomplished by specializing the cell units for different functions, with a corresponding increase in general efficiency of the individual. 
Among segnental organisms we have another adrance in bortily specialization. Here chains of individuals, each, in a sense, morpholigically eciuivalent to a single individual of the flatworm type, becone welded tugether into more complex segmented organisms. With this new level of complexity of organization comes the ponsibility of specializing different segnents, ealch of them equivalent to a whole indivitual of the lower grade, for particular functions. Some perform chiefly nervous and sensory functions, others reproductive functions, and still others respiratory or digestive functions. Each segment in certain parts of the body becomes a specialist in some one function which it performs more efficiently when relieved of some of the other functions. Of course, specialization would be of no value unless integration and interdependence of part upon part kept pace with it. Hence, one of the results of the trends just described is the cluser integration of parts and the greater definiteness of individuality.

Even among segmental organisms, as for example the ants and lxes, division of labor takes place among segmental indiriduals, and a new and higher level of organization-social organization-emerges. Fere in these insect societies, indivituals are specialized in several ways: some becone functional males and females, others (immature females) becone specialized as workers or protective units known as "soldiers." Thus, a suciety is, in a sense, a fairly definitely integrated individual of a higher ievel, involving a high degree of interdepentence of the various kinds of specialists upon one another. The integrating factor seems to be assuciated with the family relationship of all members of a given colony. All members of a given coluny are offspring of the same mother and father. They are extremely clannish and resent vigurously any intrusion by outsiders.

It therefore appears that one of the principal progressive trends of erolution is one in which units of lower orders are aggregated into complex units of higher orders. Each aggregate is a new type of indivicual, with new properties not entirely the result of a summation of the proprties of the ingredient units. This idea has sometimes been spuken of as cmergent evolution, according to which, with each higher level of units, new properties of the whole emerge which are more than the sum of properties of the parts. This might atso be thought of as a lind of creation, for something new comes into being as though out of nothing.

While the foreguing discussion is, in a sense, a digression, it scems well to call atcention soncwhere in a book on evolution to these facts 
and theories. The facts are there for us to explain, and the theories are attracting so much attention at present that they should not be ignored.

Increase in size is one of the commonest trends of evolution; but is size increase progress? Many great groups of organisms have from age to age steadily increased in size of individuals. Many fossil pedigrees show clearly that size increase is one of the steadiest of progressive trends. But size, if carried to extremes, is disadvantageous; witness the complete extinction of the ancient dinosaurs and the rapidly progressing extinction of the whales and elephants today.

Increase in intelligence is claimed to be one of the signs of progress in evolution. In vertebrates, especially, there is a progressive series of forms showing greater and greater intelligence, ranging from fishes to man. Accompanying and underlying this increase in intelligence, there has gone on in vertebrates a steady increase in the size, specialization, and compactness of the brain and its associated sense organs. This steady trend is commonly spoken of by students of vertebrates as cephalization. Is the final goal of evolution then the production of more and more intelligent organisms? If that were true, why should so much evolution be going on that seems to be moving in the opposite direction, resulting in the decephalization of many seden'ary organisms and parasites?

You see it is difficult to discover any general or universal goal of evolution. We do not even agree as to the direction of evolution, so we cannot be sure what is progress and what is regress. Under these circumstances, it may seem, at first thought, rather futile to discuss guiding factors at all. Most of us, however, retain the firm conviction that evolutionary change has in it something of direction, something of fitness, and something of progress, though we may not always be able to demonstrate direction or fitness or progress in particular cases.

Evolutionists, however, have always assumed that evolution is progressive, that adaptation is a reality, and that there have been definite evolutionary trends. Believing in these phenomena, they have tried to explain them. The two classic attempts to explain progressive evolution are Darwin's theory of natural selection and Lamarch's theory of the inheritance of acquired characters. These theories are to be critically discussed in chapters $x x x$ and xxxi respectively. 


\section{CHAPTER XXTIII}

\section{ADAPTATION IN NATURE}

\section{THE NATURE OF ADAPTATIONS}

"The adaptation of every species of animal an! plant to its environment," says Jordan and Kellogr," "is a matter of everyday ohservation. So perfect is this adaptation in its details that its main facts tend to escape our notice. The animal is fitted to the air it breathes, the water it drinks, the food it finds, the climate it endures, the region which it inhabits. All its organs are fitted to its functions: all its functions to its environment. Organs and functions are alike spoken of in a half-figurative way as concessions to environment. And all structures and powers are in this sense concessions, in another sense, adaptations. As the loar is fitted to the pan, or the river to its bed, so is each species fitted to its surroundings. If it were not so fitted, it would not live. But such fitness on the vital side leaves large room for variety in characters not essential to the life of the animal."

The authors quoted above appreciate what is perhaps the most significant fact about adaptations: that the adaptations are to a large extent molded by the environment and therefore fit the environment. So long as the environment remains uniform, a given species will remain unchanged, except for minor fluctuations and occasional mutations; but if the enrironment changes, sometimes even sightly, the development of the individual responds in such a way as to give a radically different end product. So we may conclude that a large part of the fitness of the organism to the environment is due to the fact that the development of each inclivilual is molled by the environment so as to fit it. Thus some at least of the apperrat mystery of adaptations is dispelled.

When we think of the fitness of the organism to the environment we take an entirely one-sided view of the matter, for if the organism its the environment, no less certainly must the enviroument fit the rganism. This idea of the "fitness of the environment" has been

\footnotetext{
' From D. S. Jordan and V. L. Kellogg, Evolution and I nimut Life.
} 
arimirably discussed by Professor Lawrence J. IIenderson in a stimu lating volume. ${ }^{1}$

Henderson points out that the environ'nent, no less than organ. isms, has har an evolution. The particular environmental comples as it exists today is absolutely unique. There is hardly an element $\sigma$ the effective environment that coull be changed without causing th extinction of life or at least a transformation of it so profound that it might not be lifr at all as we know life. Water, for example, has a dozen unique properties that condition life. Carbon dioxile could not be replaced by any other substance. The properties of the ocean are so beautifully arljuster to life that we marvel at the exactness of its fitness. Finally, the chemical properties of carbon, hydrogen, and oxygen, the most abundant elements, are equally unique and unreplaceable. In brief, given the environment as it is, life could not be other than it is. The evolution of the environment and the evolution of organisms have gone hand in hand, or perhaps we might better say hand in glove, for this better expresses the idea of mutual fitness.

Within the realm of the general environment as conceived by Henderson there are almost innumerable special environments due to particular combinations of the various environmental units. Within the aquatic environment, for example, there are variations sucb a: differences in salinity, varying from extreme saltiness to almost total lack of salt; there are inshore conditions and open-sea conditions; there are surface conditions and those at relatively great depths; and there are great differences due to temperature. Similarly on land, there are surface conditions, subterranean conditions, arctic, tropical conditions, caves, deserts, forests, plains, mountains, and many others. No two areas on land are precisely similar in all respects. All of thimakes for a corresponding multiplicity of animal and plant forms. In the case of plants the action of the environment is remarkably direct; for the plant cannot get away from a fixed environment. If the environment undergoes material change, the plant's only response is a structural one. For example, if plants that are accustomed to a relatively humid climate are grown in the desert they develop numerous xerophytic adaptations such as small leaves with greatly diminished transpiration surface, a thick epidermis, hairs, or spines, small stature, deep-root system, and other similar protections against the inimical desert conditions. Similarly, plants accustomed to grow in relatively.

s. J. Henderson, The Fitness of the Environment, I9r3. 
dry soil, if grown in soil that is covered over with water, will produce aquatic leaves and roots and undergo appropriate changes in epidermis and loss of supporting tissues, for plants that are buoyed up by water need little support.

Animals, on the other hand, are for the most part not so intimately related to a local environment as are plants. They are characteristically mobile creatures with varying capacities for wandering about and selecting the habitat that best suits them.

"By virtue of being unlike or possessing different properties," says Shelford, " the various animal species require different conditions for the best adjustment of their internal processes. For example, the carp lives in shallow and muddy ponds and rivers, while the brook trout lives only in clear swift streams. These two organisms are able to move about and find places to which they are suited. The differences between them are clearly indicated by the differences in the habitats which they prefer.

"By observation and by experimentation it has been shown that animals select their habitats. By this we do not mean that the animal reasons, but that selection results from regulating behavior. The animal usually tries a number of situations as the result of random movements, and stays in the set of conditions in which its physiological processes are least interfered with. This process is called selection by trial and error. If animals are placed in situations where a number of conditions are equally available, they will almost always be found living in or staying most of the time in one of the places. The only reason to be assigned for this unequal or local distribution of the animals is that they are not in physiological equilibrium in all the places. However, some animals move about so much that it is with some difficulty that we determine what their true habitats are."

This idea of habitat preference and habitat selection is extremely important for a correct understanding of adaptation, or the fitness of organisms to environments. Much of the observed fitness may be due to the fact that an organism has chosen out of a wide range of environments the one that best suits it. We cannot in such a case say that the environment has had a direct influence in shaping the organism any more than we could say that, when a man tries on various shoes and finds a pair to fit, he has been responsible for the fitness of the shoes.

Many special adaptations may be explained through habitat choice. Thus animals such as the duckbill platypus, the lung-fishes,

'V. E. Shelford, Animil Communities in Temperate America (Igr3). 
and others whose teeth are replaced by bony or chitinous plates that are used for crushing the hard shells of molluscs and crustaceans, may not confidently be said to have developed these crushing appliances and to have abandoned the use of teeth in adaptation to a habit of feeding upon hard-shelled prey; but rather it seems more likely that the loss of teeth and the development of crushers occurred through a degenerative process incident to racial senescence and that the possession of the crushing equipment enabled them to avail themselves of a new type of food, formerly unavailable to them.

The organic environment.-In his admirable chapter entitled "The Web of Life," which we shall quote entire, Professor Thomson has given us a vivid picture of vast systems of interdependencies that exist throughout the organic world. No species, no creature, lives to itself alone; it is intimately tied up with a host of other creatures with interwoven destinies. Thus one species of animal is adapted to live upon certain plants or other animals, which in turn may be dependent upon still other animals or plants. The elimination of one species may cause the elimination or the radical change of a dependent species. We cannot afford ever to forget this great truth of the oneness of nature. It is the keynote of life and of evolution.

Adaptation due partly to functional activity.-It is a commonplace which needs no special demonstration to say that organs improve through use and deteriorate through disuse. Many organs, then, which in the adult condition appear to us to be so admirably adapted to perform certain duties, must be thought of as having been gradually molded by functioning during the entire period of individual development. If the motor nerve running to a limb bud of a growing embryo be severed at an early stage and no secondary nerve connection be established, the limb will continue to grow up to a certain point, but, in its paralyzed condition, will be incapable of exercising its functions and will cease to develop. A certain amount of development will therefore be seen to be independent of functioning, but full development of functional efficiency is obtained only through functioning.

"The relation between structure and function in an organism," says Professor Child, " "is similar in character to the relation between the river as an energetic process and its banks and channel. From the moment that the river began to produce structural configurations in its environment, the products of its activity accumulated in certain

C. M. Child, "Regulatory Processes in Organisms," Jour. Morpls., Vol. XXII (I9Ir). 
places and modified its flow. . . . . It moulds its hanks and bottom forming here a bar, there an island, here a bay, there a point of hard, but still howing on, though its course, its speed, its depth, the character of the substances which its carries in suspension or in solution, all are altered, built up by its own past activity." According to this view. structure is simply the resultant of the interaction of function and er vironment or of functional activity. Though perhaps a litile extres: for most of us, this view is, we believe, essentially correct. We ar. prone to overemphasize structure in our discussions of adaptation and evolution and to lay too little stress upon the enerry sile o development. Certainly no structure is ever formed without protoplasmic activity of a very definite sort, and in this sense adaptation. are to be thought of as the results of functioning. Why, then, do we claim to be astonished at the effective way in which certain organs accomplish their functions, when functioning has taught them their task ?

\section{TWO CATEGORIES OF ADAPTATIONS}

There are, according to E. G. Conklin, two categories of adapta. tions: $(a)$ racial or inherited adaptations, and $(b)$ individual, acquired, or contingent adaptations. All of the direct molding effects of environment or of developmental functioning, together with arlaptative relations resulting from habitat selection or from learning and experience, may well be classed as individual, acquired, or contingent adaptations. As such they do not offer any particular problem to the evolutionist, for they concern themselves with individuals, not with races. The adaptive condition is simply made over afresh in each generation, and the only thing that seems to extend beyond the immediate individual or generation is a general plasticity or responsiveness of the specific protoplasm which enables it to adjust itself to special life conditions. There is nothing mysterious or baflling about this situation, for it involves merely a repetition of certain appropriate responses by each individual. It is a problem of individual development, not of racial development or evolution.

Inherited Adaptations.-There is, however, a large category of adaptations which appear in the organism as though in anticipation of the rôle they are to play some time in the future and not in responce to any present need. In this category are the eyes, the lungs, the vocal organs, the taste buds, and many other organs of the human fetus. 
Thus, the eyes of the new-born infant are essentially finished mechanisms before they ever function as organs of vision. They cannot therefore have been molded for their visual function by functioning in a visual manner. Of course they must have been functioning in some way, as all living protoplasm must function, but they cannot have functioned in a way that would in itself account for the fact that the eye is a very intricate optic mechanism. Similarly, the human infant has good lungs and good vocal cords before it ever takes the first breath of air or gives the first cry. Such adaptive structures as these are said to be racial or inherited adaptations. Any theory of evolution worthy of the name must account for the origin and perpetuation of such inborn adaptations. It was partly to explain the origin and perfection of adaptations such as these that Lamarck proposed his theory of the inheritance of acquired characters and Charles Darwin devised his theory of natural selection. It is still unsettled as to which of these theories is the more adequate, but the consensus of expert opinion favors Darwin's explanation.

It would be impossible to give any comprehensive account of ani mal or of plant adaptations in the brief space of such a chapter as this. Let it suffice to classify adaptations and to describe a few representative adaptations, confining our attention to those which are obviously racial or inherited in character.

\section{ADAPTATIONS CLASSIFIED}

Adaptations are variously classified by different authors; and that of Jordan and Kellogg is as good as any: "( $a)$ food-securing; (b) selfdefense; $(c)$ defense of young; $(d)$ rivalry; $(e)$ adjustment to surroundinm.,"

Some very common adaptations may belong to several of these categories at once. Thus the sharp teeth and hooked claws of carnivorous mammals serve equally well for food-securing, for selfdefense, for defense of young, and for rivalry. Similarly, the horns of deer and other ungulates are equally adapted for self-defense. defense of young, and rivalry.

There can be no especial arlvantage, in this connection, in presenting a detailed review of adaptations of the sorts given in the foregoing classification; therefore we shall confine our efforts to a description of a few typical adaptations about which the greatest controversy has raged. 
The electric organ of the torpedo, a widely distributed elasmuranch fish, consists of a sort of honeycomb-like structure on each side if the head. This structure acts as a storage battery an'l is capable of storing up electricity of considerable voltage. The animel is capable of giving a very distinct shock to an attacker and can thus defend itself quite effectively. There is also an electric eel, native to the waters of Paraguay and Brazil, that is able to give severe shocks to bathers or to horses driven through the streams. A type of catfish native to the river Nile has a similar electric equipment. In all of these cases the storage battery is made up of modified voluntary muscles and is of consirerable size.

The mamrnary glands of mammals are skin glands usually with well-defined ducts leading to the surface and teminating in teats. These glands are quite voluminous and serve adinirably the purpose of feeding new-born young until the latter are able to use the more varied food normal to the adult. In the lowest mammals, the monotremes or egg-laying mammals, these glands are relatively pourly developer and diffuse; also they are known to be developed through a regional specialization of sweat glands. In the true mammals or Eutheria the glands are modified sebaceous or oil glands and may be seen to develop from the same embryonic rudiments as the latter.

The marsupial pouch of the kangaroo and its allies is a pocketlike fold of the integument, folded forward or backward over the region of the abdomen in which are located the mammary glands. This pouch is used as a shelter for the tiny immature larval foetuses Iartmann has recently described a very striking piece of behavior in connection with the birth of roung onossums. The young are born in an exceedingly inmature state and looking like tiny pink grubs. They crawl uniler their own power, by means of a swimming-like motion, through the hairs of the mother's abdomen, till they reach the pouch. This they enter unaided and each tiny larva inds for itself a slender tubular teat, which it swallows and holds in place by a specially adapted hold-fast mouth. The young remains attacher fixedly to this teat for some weeks, feeding almost constanlly on milk. After a long interval the teat is released, the mouth metamorphoses into the adult form and the young feeds only at intervals, as do the young of other mammals. This complex of adaptive structures and instincts is among the most remarkable in the annals of biology. 
The fetal membranes of higher mammals constitute one of the most cficient adaptive complexes known. Surrounding the embryo is a thuil-filled sack (amnion) which furnishes an aquatic environment for the suft and delicate body, preventing harmful contacts and allowing ample free space for expansion. The placenta is a co-operative structure, developed out of both fetal and maternal materials, that furnishes an excullent medium for nutritive and other metabolic exchanges between mother and fetus. Although there is no direct vascular connection between them, the mother gives of her nutritive materials to the fetus and takes up from the fetus and eliminates its wastes. As an adaptation for carrying out an intricate set of physiological exchanges between two otherwise entirely separate individuals the placenta is unexcelled.

Nest-making instincts in birds represent, on the behavior side, adaptations of extraordinary perfection. Some nests are built with the greatest care and precision, others represent a relatively crude and slovenly performance. Some nests are made of twigrs, fibres, and mud, others of mud alone, still others are hollowed out in clay or sand banks, and some are made in holes in the ground. In any case, the type of nest is highly specific and due to a hereditary instinct; for birds receive no instruction in nest-making.

Before bringing to a close this brief list of particularly noteworthy adaptations let us recall to mind the series of special adaptations listed as examples of the laws of adaptation, such as aquatic, arboreal, cursorial, flying, burrowing, ant-eating, and, especially, adaptations of deep-sea animals.

\section{PARASITISM AND DEGENERATION}

A vast number of animals and plants have given up the active search for foor and have taken up the relatively easy habits of parasitism. In adaptation to this life certain structures have developed and many of the characters found in independent, free-roving creatures have disappeared or become reduced to mere vestiges. Thus the more completely dependent or parasitic an animal becomes, the more completely does it lose its organs of locomotion and its sense organs such as eyes, auditory organs, tentacles, etc. Some animals are free-living when young or in the larval condition and only settle down to a parasitic life when near the end of the life-cycle; other animals are parasitic only when young or larval and become independent in the adult condition; still others are parasitic throughout the entire life-cycle and pass from host to host without any interval of independent life. Some of these complete parasites pass one phase of the life-cycle on one species of host and the remainder on another 
species of host. Thus the liver fluke in the adult condition lives in the gall bladder of the sheep, while the early larvae live within the body. cavities of a species of land snail. The transfer from host to host in this case must be a procedure involving many chances of failure to a very few chances of success, and, in adaptation to these vicissitudes, the number of egrgs and larvae produced by a single adult individual runs up into the millions.

The classic case of extreme parasitic ciegeneration is that of Sacculina. The young larva of Sacculina is a typical entomostracan crustacean larva which swims about and leads a free life for a time, but soon attaches itself by means of its antennae to a hair pit of a crab, a small hole in the latter's armor. The internal tissues of the larva then undergo degenerative processes and are reduced to an almost fluid mass of embryonic cells, which flow through the hair pore of the crab, and into the latter's lymph spaces. The small mass of cells then rounds up and is carricl about with the circulation of the crab's blood until it comes to a favoralle place of lodgment, usually the wall of the intestine just back of the stomach. Here it flattens out and sends rootlike branches almost all over the crab's body, like a malignant tumor in its invasion of foreign tissues. The unbranched part of the parasite is little more than a sac of reproductive organs, and these produce eggs and sperms, which unite to produce larvae. By this time the host is killed and, with the decay of its body, the larvae escape into the sea water ready for a brief period of free life before attacking another host.

Almost every group of animals and most of the groups of plants have their parasitic representatives and every degree of parasitism and the accompanying degenerative changes are to be found. Of course, it is an open question whether parasitism causes degeneration or whether degenerating creatures take refuge in parasitism; but in either case the adaptive features of the situation are obvious.

Commensalism.-If parasitism be defined as an association between two organisms in which one (the parasite) lives at the expense of and to the detriment of the other (the host), commensalism may be defined as an association in which the two organisms exist in close association without any positive detriment to either. In some cases the claim is made that the association is mutually beneficial, but as a rule the reiation is relatively one-sided.

An interesting example of conmensalism is that of the sea cucumber and the little fish Fierusfer. This strange little animal inhatits 
the rectum of the sea cucumber and may be seen to lie with only its head out. From this shelter it darts forth to capture its prey; which done, it returns to its shelter. Curiously enough the vent of the little fish is situated just back of its mouth so that its wastes may be roided when in its usual position. There can be no adrantage to the sea cucumber in such an arrangement, though no particular harm is done. Another case of this sort is that of several species of Remora which attach themselves by a large diskoid adlaptation on top of the head to various fish such as sharks, barracudas, etc.

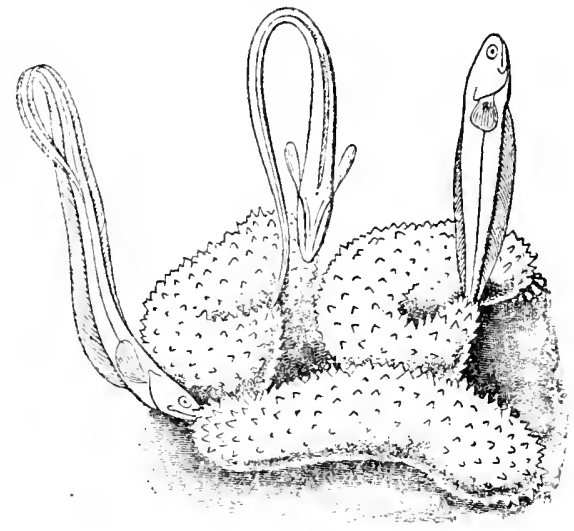

FIG. 78.-Ficrasfer acus, penetrating the anal openings of holothurians, $\tilde{z}$ natural size. (From Boulenger, after Emery.) The sucking disk is a modified dorsal fin. The remora merely gains free transportation to more favorable feeding-grounds. When the desired food is sighted the passenger leares its conveyance temporarily, but returns by a sudden swift dash and resumes its hold. The shark gets nothing except perhaps the sense of companionship, and is also undoubtedly somewhat hindered in its locomotion.

Some of the most remarkable cases of commensalism are found in connection with elaborate colonies of ants. In some cases two species of ants live together in the relationship of masters and slaves. The master species is unable to perform any of the ordinary duties of the colony, such as securing food, taking care of young, etc. In extreme cases the masters are only soldiers, specialized for fighting and marauding, and cannot even feed themselves unaided. The slave species would be able to carry on to some extent if not captured, but thrives exceptionally well under the protection of the soldier species. There are among ants many varieties of commensal relationship less extreme than this, but this will serve as a typical case.

Communal life.-Among the higher insects and higher vertebrates, especially among the ants and bees, we find a very elaborate social life. In ants, for example, the typical colony consists of a queen (the only fertile female in the colony), several males (mates of the queen), 
ordinary workers (sterile females of the first type), sol.1: r - sterile females of the second yee), and sometines officers (especially larere and powerful sterile females that seem to direct the line of march in legionary ants). All of these casts are produced from the ergs of on female and are the result of various special diets permited the larvat by the workers. Amonglees, similarly, there is one queen, a number of drones (males), and the sterile female workers, who perform the functions of nursing the larvae, cinaning up the hive, collecting pollen and nectar, and making honey and wax. Detailet accounts of the lives of bees have been given by various authors, notably by Maeterinck in his Life of the Bce.

\section{ADAPTATIONS OF DELP-SEA ANIMALS AND OF \\ CAVE ANILALS}

One of the weirdest environments the world affords is the bottom of the sea at great depths. There it is dark and cold and almost devoid of oxygen, while the pressure is almost unbelievably high. Iet in these vast and forbiclding alysses there lwell in apparent comfort representatives of most of the animal phyla. Fishes of many sorts, crabs, mollusks, worms, and many other forms thrive and multiply in this seemingly cheerless environment. We do not at all unlerstand the nature of the arlaptive mechanism that enables these animals to withstand with their frail bodies the steel-crushing pressures that prevail at all such lepths. We do know, however, how some of the deficiencies of the environment are made crood by these denizens of the deep. Thus many abysmal forms produce their own light by means of phosphorescent organs placed at aclvantageous points of their bodies. Not only tishes of the depths, but some mollusks possess forms of artificial lighting equipment. One species of cephalopod (related to the octopus) is descrihed by Wiesmann as bordered with twenty large phosphorescent lanterns that present the aspect of a display of variegated gems, colored ultramarine, ruby red, sky blue, and silvery white.

Equally highly adapied to life in a world of clarkness, the monotony of which is broken only by the occasional spots of light emanating from the various living lanterns just referred to, are the strange eyes of some of the abysmal fishes. Sometimes these eyes are enormously: large, and thus adapted to bring to the perception of the animal the weak light of the depths, or again they may be modified still further in a strikingly peculiar manner, each being drawn out into a cylinder and projecting from the side of the head like a telescope. Such eyes are in fact not telescopes, though they are called "telescope eyes," but are merely adaptations for concentrating the lights of low intensity 
and making the environment visible. Could man view the sea bottom through some of these instruments, he would doubtless add something very novel and weird to his scenic repertoire.

Other creatures of the darkness live strange lives in caves, such as the Nammoth Cave of Kentucky. Most cave dwellers are blind or nearly so, and usually have a pale and ghostlike appearance because of their lack of pigment. All grades of defective eyes are found, ranging from those that are merely somewhat smaller than normal to those that remain deeply imbedded in the head in a relatively undifferentiated state. It goes without saying that such animals are better adapted to life in caves than they would be outside. One pressing problem of biology is: How did the cave animals become blind? Did they wander into the caves as normal animals and become blind because their eyes were disused, or did they become blind outside through no fault of their own, as the result of a mutation, and by chance find safety in an underground stream or a cave? The first explanation is Lamarckian, the second Darwinian.

\section{COLOR AND PATTERN IN ANIMALS}

"The phenomena of color in both animals and plants," says Netcalf, " are among the most remarkable and interesting in the whole realm of nature. It is not so much the way in which the color is produced, whether by pigments or by refraction, that interests us in this connection, as it is the uses to which colors are put. Let us first refer to the colors of animals.

"According to the uses to which colors in animals are put, we may classify them, for purposes of description, as follows:

"Indinerent coloration, not useful, so far as we car judge;

Colors of direct physiological value;

Protective coloration and resemblances;

Aggressive coloration and resemblances;

Alluring coloration and resemblances;

Warning coloration;

Immunity coloration;

Minetic coloration and resemblances;

A. Protective

B. Aggressive

Signals and recognition marks;

Confusing coloration;

Sexual coloration."

'M. M. Metcalf, Organic Evolution (rgrr). 
Much has been written about these various categories of animai coloration nearly all of which assumes some special adaptive value for each type of color or pattern.

The above classification is typical of the older views as to animal coloration in that it recognizes no colors as merely incidental byproducts of metabolism, but assumes that all colors are valuable as adaptations. Lodern critics are inclined to consider that at least many colors are to be explained as the result of the fact that certain chemical materials are formed in the elaboration of tissues and in the physiological processes that must go on in these tissues, which, because of their light-absorptive properties, appear to our eyes as colored. The color may chance to enhance the protective resemblance of the animal or it may make it more conspicuous than it should be; in either case it may have an incidental value. But colors may come and colors may go irrespective of adaptive value, for many colors are so placed in the organism that they can never be visible; and color is only in the seeing. While we have no intention of denying the adaptive value of animal colors, it seems wise to get away from the extreme anthropomorphic interpretation of these colors, for some of the categories of coloration listed in the previous paragraph are largely, if not wholly, anthropomorphic. It has been the habit of students of coloration to assume that insects, birds, lizards, and other animals see colors and patterns as man sees them, that what is attractive to man must also be attractive to the lower animals, that what is confusing to man would also be confusing to a lizard or an owl. Experiments with lizards, which are supposed to be chief among the factors giving adaptive significance to insect coloration, have shown that the lizard apparently takes no notice of colors, at least when they are at rest, but will jump at any moving object of about the right size.

Modern students are inclined to think that many of the minor categories of animal coloration listed above are, at best, of very questionable significance and that practically all categories simmer down to one: obiliterative coloration or camouflage.

"All naturalists," says G. H. Thayer, "perceive the wonderful perfection of the twig mimicry by an inchworm, or of bark by a moth, or of a dead leaf by the Kallima butterlly. It is now apparent that almost equally marvelous concealment-devices, in one shape or another, are general throughout the animal kingdom; the most gor geuts

'G. H. Thayer, Concealing Coloration in the Animal Kingdom. The Macmillan Company, igi 8. 
costumes being, in their own way, climaxes of obliterative coloration scarcely surpassed even by moths or by inchworms.

"This discovery that patterns and utmost contrasts of color (not to speak of appendages) on animals make wholly for their 'obliteration,' is a fatal blow to the various theories that these patterns exist mainly as nuptial dress, warning colors, mimicry devices (i.e., mimicry of one species by another), etc., since these are all attempts to explain an entirely false conception that such patterns make their wearers conspicuous. So immeasurably great, in the case of most animals, must be the value of inconspicuousness, that such devices as achieve this to the utmost imaginable degree, upon almost every living creature, demand no further reason for being (although doubtless serving countless minor purposes). . . . . Apparently, not one 'mimicry' mark, nor one 'warning color' or 'banner mark' nor one of Gadow's light-andshadow-begotten marks, nor any 'sexually selected' color, exists anywhere in the world where there is not every reason to believe it is the very best conceivable device for the concealment of its wearer, either throughout the main part of this wearer's life, or under certain peculiarly important circumstances. .... . The so-called 'nuptial' costumes of animals are demonstrably an increase of such potency of ohliterative coloration as belongs to all gorgeously varied costumes, and this at the very period when concealment is most needed."

Thayer believes "that the colors, patterns, and appendages of animals are the most perfect imaginable effacers under the very circumstances wherein such effacement would most serve the wearer." Nany animals, when observed in a museum show case or in a menagerie, appear to us to be most conspicuous, but the elements that lend conspicuousness in the artificial environment may be the very ones that tend to efface the wearer when in his native haunts. The most brilliant birds, such as mandarin ducks, birds of paradise, flamingoes, peacocks, parrots, etc., are shown to be almost invisible in their natural surroundings.

The schemes for producing obliterative protection are much the same as those made use of during the recent war. The simplest scheme of all is that of having the same color and pattern as the background. Thus many green insects, amphibia, reptiles, birds, and a few mammals that live in trees, smaller plants, or grass, are colored green. Many desert animals are sand colored. Many marine animals living near the surface are transparent or nearly so. Another scheme is known as counter-shading, according to which most animals with little variety 
of color are concealed by having the upper surfaces dark, the lower surfaces light, and a blending of one into the other on the sides. Nearly all birds of the open, such as sea birds and soaring birds, use this method of concealment. The same is true for fishes that live near the surface, and for many mammals that are likely to be seen against a sky line. Actual demonstrations have shown that this method of concealment is highly efiective, no matter from what point of view the animal may be seen. A third scheme is one that was used most effectively during the war in concealing battleships, heavy artillery, and other large objects, namely, destroying the continuity of outline by usingr large, irregular patches of contrasting or light and dark colors. In this way a broken, irregular patchwork of color takes the place of a coherent, regular contour. It is probably in this way that many of the most brilliant coral-reef fishes attain concealment. Instead of the fish as a whole being the center of vision, the bright patches stand out against the dark, and these fail to give any picture likely to be interpreted as a fish either by enemies or by prey. Professor Reighard interpreted the brilliant patterns of reef fishes as examples of "immunity coloration," the idea being that these fishes were so safe from attack and so little in need of concealment from prey that they simply went the limit in color display, unchecked by natural selection. Longley has recently shown that the patterns and colors of such fishes are in reality obliterative, and if this be true, there is no need of introducing the idea of "immunity coloration."

In view of the above considerations, it now seems likely that essentially all types of animal coloration that have any adaptive value at all -and by no means all have any demonstrable adaptive significancemay be classed under the general head of concealing coloration; and if this be so, it reatly simplifies the problem of the evolutionist. Much of the controversy as to the efficacy of natural selection has been waged about some of the questionable categories of animal coloration, such as " $"$ arning coloration," "mimicry," "confusing coloration," "sexual coloration." If all of these turn out to be merely phases of concealment coloration, their origin could be explained as readily as that of any other adaptive character of deinite selective value.

The Case of Kallima.- With this general introduction to the subject of animal coloration, it does not seem necessary to list examples of ail the categories of color mentioned. Let us close the discussion with what appears to be the classic instance in biological literature of perfect pronctive resemblance: that of the "dead-leaf butterfly," Kallima (Fis. 79). 
"Its wing," says Herlert, "when upturned, represent on their underside a perfect copy of a leaf with a midrib and a regular succession of sille rinings. Differently colored spots on the wing imitate patches of decay and mildew, while the prolonged tail of the hindwing, which touches the stem in the sitting posture of the butterfly,

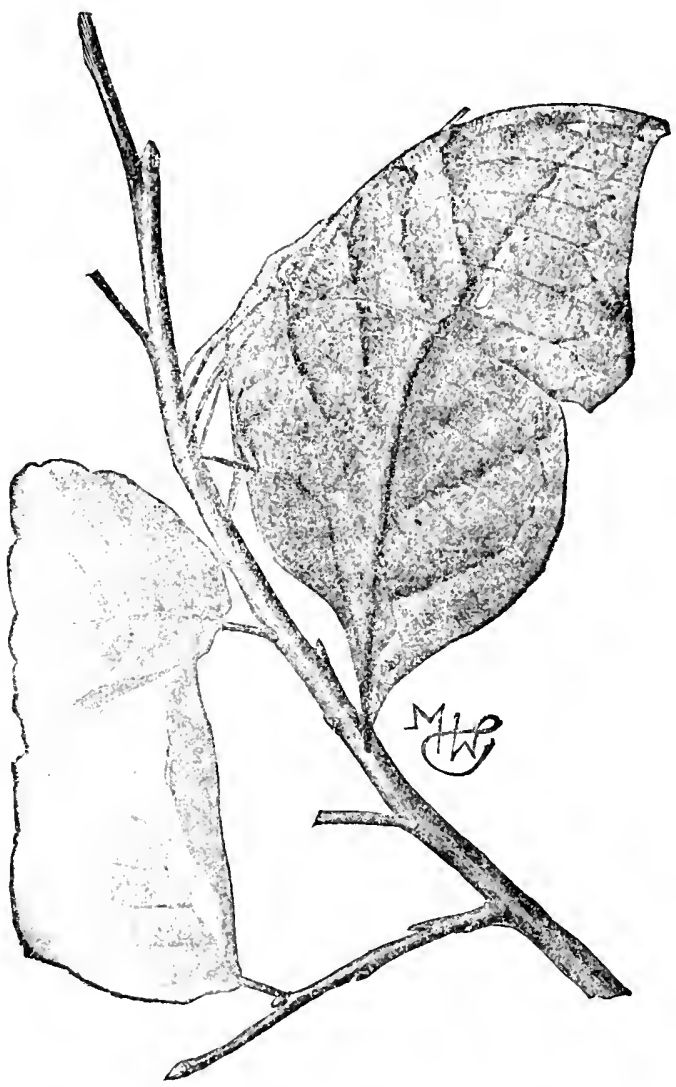

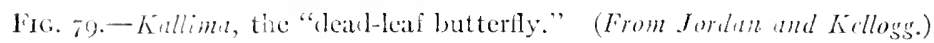

makes it appear as though the leaf was directly growing out of the stem." It is only when at rest upon the stem of a tree that the resemblance to a leai would lie effective, for it is only the under surfaces of the wings that are protectively colored. The upper surfaces of the wings are brightly colored and would supposedly be quite conspicuous when the insect is in flight. "These insects," salys Metcalf, "are very" noticeal te when in tight, lut when they light and close the wings, their 
sudden disappearance is most startling and confusing, greatly increasing the difficulty of observing their resting-place." According to this idea of "confusing coloration," a butterfly is supposed to mystify or confuse its enemies by first attracting their attention and then sucklenly becoming invisible. One is reminded of the prestidigitator of his favorite remark: "Now you see it and now you don't." But why. attract attention in the first place, when continued inconspicuousness would be much less risky? The best answer to this question is to use Thayer's interpretation, namely, that what looks like a conspicuous coloration when observed in the stationary insect held against an alien background is probably almost invisible when the animal is movinur its wings and flying through the air in the bright sunlight.

The case of Kallima is probably more or less typical of the somewhat uncritical tendency on the part of naturalists to invent adaptive explanations for every striking color or pattern seen among animals. Let us examine the situation a little further. Much has been said about the minute details of resemblance to a dead and decaying leaf on the part of this butterfly, yet, if its habits are at all like those of other members of its order, it is hardly likely that its most active period would coincide with that in which the leaves of trees would be decayed and mildewed or even brown. Butterflies are active when flowers, whose nectar forms their chief food, are numerous, and are usually in their pupa cases when the leaves have died on the trees. It has also been stated by critical observers that Kallimas do not frequently light on trees whose leaves are very similar in shape to the folded wings of a butterfly. Furthermore, there are many kinds of butterflies that are more or less like leaves; in fact, it would be difficult for a butterfly not to look somewhat like a leaf, since the wings are shaped like leaves. Again, many species of butterflies have the swallowtails on the lower wings without in other ways much resembling a leaf; others have spots that might be interpreted as resembling decay and mildew without in other ways being more than in general leaflike; and there are many other species that show all degrees of leaf resemblance, some very imperfect and others almost as perfect as that of Kallima, yet they all seem to be essentially successful in the life-struggle in spite of their less perfect protective resemblance.

Alleged cases of mimicry have failed also to meet critical examination. When a poisonous butterfly is mimicked by an edible species several conditions must be met in order that the deception be effective. The model and the mimic must both occupy the same range, 
have the same period of activity and the same general habits. The model must be much more numerous than the mimic. Unfortunately for the proponents of mimicry, it has sometimes been found that several of these requirements are lacking. Attempts to explain away the discrepancies have been far from satisfactory.

All these considerations should make us cautious about reading into the colors and patterns of animals too many adaptive details. It is more than likely that the majority, if not all, of these apparently marvelously exact instances of imitative resemblance would turn out, when critically examined, to be no more nor less adaptive in special ways than is Kallima and the mimics.

One lesson that the naturalist may well learn from the present discussion is this: There is enough in the way of adaptations for the evolutionist to explain without burdening him with hypothetical or interpretative adaptations. First find and prove your adaptation; then try to explain it. Don't explain it first and then find out iater that it was not so much of an adaptation after all.

\section{OSBORN'S LAWS OF ADAPTATION}

Adaptations have been variously classified by different writers. Perhaps the most significant classification is that of Osborn, which is based on their supposed evolutionary origin. According to this writer and others, there are two categories of adaptations to environmental conditions: the first has to do with the tendency of unrelated species to assume similar structures under similar environmental conditions; the second has to do with the tendency of related species to assume different adaptive structures under different environmental conditions. In both categories the environment appears to be the determining factor.

(I) A good example of the first category, which illustrates what Osborn calls "the law of convergence or parallelism of form," is seen in the tendency of many aquatic types of vertebrates to assume the fishlike form. As is well shown in Fig. 80, the shark (a fish), the ichthyosaur (an extinct aquatic reptile), and the porpoise (a marine mammal), all possess the same fusiform body best adapted for speed under water, the same types of locomotor structures, consisting of the great propeller fin (caudal fin) and the steering and balancing fins, the dorsal fins and paired fins. Apart from these superficial adaptations for swift locomotion in the water, the three types are profoundly different. The shark breathes with gills, the reptile and mammal with lungs, the fish and reptile are cold-blooded, the 

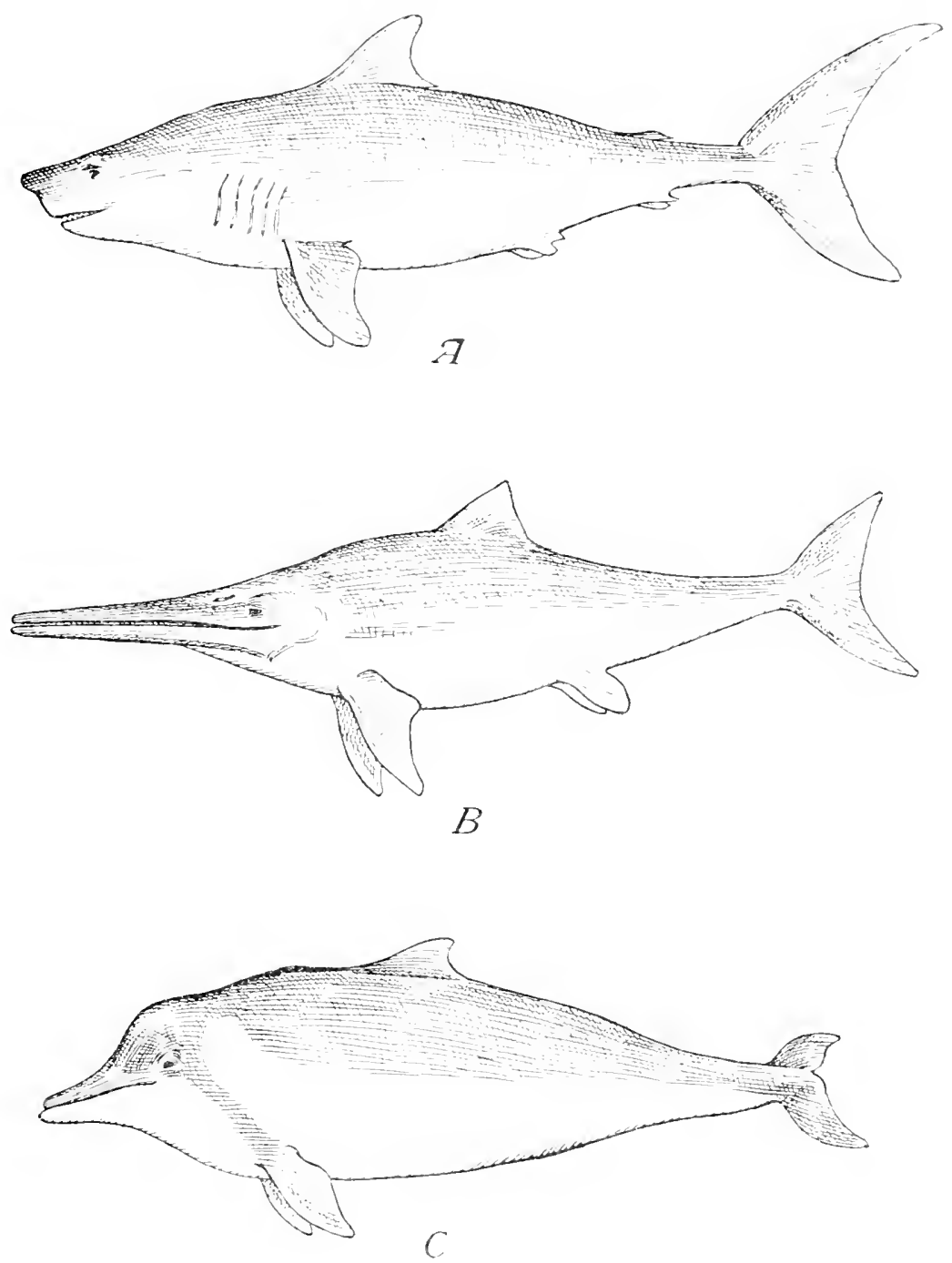

Fir. So.- Three aquativ tyes of rertebrate, to illustrate comergent adaptation of three wholly unrelated forms of marine life. All three shot the fusifurm body, median and paired lins, though the sketetal structures are rarlicilly different. A, shark (Pises); $R$, ichthyosur (Reptilit); C, porpoise (Mammalia). (From Vewman, after Osbom. 
mammal warm-blooded. The internal anatomy of the three differs fundamentally in every detail.

$A$ list of other types of convergence will more adequately illustrate the law.

Flying and parachuting animals occur among nearly all vertebrate and some invertebrate classes. Planes of some sort are found for supporting the body in the air. The plane is made in various ways in different groups, but functions much the same in all of them.

Rinning animals of various classes have long legs, and a tendency to stand on the toes. There is also in several unrelated groups the tendency to reduce the number of toes, the culmination of which is seen in the one-toed horses.

Climbing animals are all provided with clinging appendages of some sort, including such structures as hooked claws, prehensile fingers or tail, suction pads on the feet, and other similar adaptations.

Burrowing animals have, as a rule, extra-heavy shoulder girdle and strong fore limus with heavy gouging claws. Many of them also are blind or nearly so, as befits life in dark underground passages.

Desert-dwelling animals as a rule are provided with heavy scales, spines, or armor, to prevent excessive loss of moisture and as a protection against spiny plants. They also usually have burrowing habits enabling them to escape the extremes of heat and cold.

Cave animals are usually blind or nearly so and are relatively pale in color, sometimes without any pigmentation.

Deep-sea animals of many sorts have phosphorescent organs by means of which they either attract their prey or find their way about the dark sea floor. Some of these organs, called "lanterns," can be used as searchlights. The eyes of deep-sea fish are either enormously large or are "telescope eyes," adapted for sensing light of low intensities.

Ant-eating animals, belonging to several distinct groups, are heavily armored against the attacks of ants, have strong claws for digging up ant galleries, have long snouts or beaks with a long sticky tongue for capturing ants, and an arrangement of the glot tis to prevent ants from crawling into the lungs.

2. There are almost innumerable examples of the law of divergence of form, which is called also the law of adaptive radiation. Almost every successful class or order of vertebrate animals, for example, has members that have adjusted themselves to all of the main modes of living. Thus among lizards, for example, there are primitive 
running forms that prefer the surface life and swift motion; suhterranean burrowing types that sometimes are limbless like snakes, and are blind; many arboreal or climbing types; a few volant or flying types; a few ant-eating types; and several more or less completely aquatic types. Each of these types has the customary adaptations for its own mode of life.

We see, then, that whether divergent structures are molded into a semblance of similarity to fit a definite environment, or whether similar structures are modified in diverse ways to fit various divergent environments, the adaptation is related very definitely to the environment and to the functional life of the organism. No wonder, then, that so many biologists consider that the environment has been a molding force in the evolution of adaptations.

General considerations.-Adaptations are characteristic of $a^{\text {! }}$ living organisms and must be accounted for by any evolutionary theory that is to be acceptable. Any theory that claims to account for new species but does not account for adaptations is at best only a partial explanation. All of the phenomena which have been briefly mentioned in this chapter, together with the more intricate phases of general adaptiveness involved in the idea of "the web of life," are part of the background of Darwinism and were in the mind of Darwin when he thought out the great generalization called "natural selection." The "web of life" idea has been admirably presented by Professor Thomson, Scotland's most skilful and prolific biological writer. The present writer feels that no student of evolution should miss the opportunity of getting into the spirit of Darwinism with this distinguisher? author, and to make this desideratum easily attainable, the chapter is quoted unchanged as part of the general text and immediately follows this discussion. 


\section{CHAPTER XXIX}

\section{THE WEB OF LIFE'}

J. ARTHUR THOMSON

Naturalists, in the true sense, who study the life of living creatures in nature, have always been distinguished by a keen perception of the interrelations of things. Whether we take Gilbert White as representing the old school, or W. H. Hudson as representing the new, we get from their observations the same impression of nature as a vibrating system, most surely and subtly interconnected. But it seems just to say that no naturalist, before or since, has come near Darwin in his realisation of the web of life, in his clear vision and picture of the vast system of linkages that penetrates throughout the animated world.

Correlation of organisms as well as correlation of organs.-In thinking of a living body we are accustomed to the idea of the correlation of organs. It is of the very nature of an organism that there should be mutual dependence among its parts. The organs are all partners in the business of life, and if one member changes others also are affected. This is especially true of certain organs that have developed and evolved together, and are knit by close physiological bonds. We know in health how nerve and muscle, brain, and sense organs, heart and lungs, are closely bound together in the bundle of life. We know in disease that a change in one organ often affects another, and the fact remains though the nexus is sometimes mysterious. The state of our liver may give colour to our whole intellectual firmament, and a slight ocular derangement may warp a wise man's philosophy. The far-reaching importance of a little organ like the thyroid gland heside the larynx is well known; our intellectual as well as our bodily health depends on its soundness. Now, just as there is a correlation of organs within the body, so there is a correlation of organisms in that system of things which we call Nature. In both cases we are here using the word "correlation" in its deeper sense-

"From J. A. Thomson, Darwinism ant. Human Lifo (copyright ıooo). Useu by special permission of the publishers, Henry Holt \& Company. 
that the various parts are more than mutually dependent, that they are in some measure co-orlinated, making larger systems workable.

What the inctaphor of "the web of life" suggests.- We may use the metaphor "web of life" in two ways. On the one hand, Nature ias a woven pattern which science sceks to read, each science following the threads of a particular colour. There is a warp and woof in this web, which to the zoölogist usually appear as "hunger" and "love." There is a changing pattern in the web, becoming more complex as the tres pass; and this is evolution. But the essential idea of a web is that of interlinking and ramifying. We can never tell where a thread will ead to. If one be pulled out, many are loosened. This is true of Nature through and through.

The phrase "web of life" suggests another picture-the web of a spider-often an intricate system, with part delicately bound to part so that the whole system is made one. "The quivering fly entangled in a corner betrays itself throughout the web; often it is felt rather than seen by the lurking spinner. So in the substantial fabric of the world part is bound to part. In wind and weather, or in the business of our life, we are daily made aware of results whose first conditions are very remote; and chains of influence, not difficult to demonstrate, link man to beast, and flower to insect. The more we know of our surroundings the more we realise that nature is a vast system of linkages, that isolation is impossible."

Dependence of living creatures on their surroundings. - We do not know what life in principle is, but we may describe living as action and reaction between organisms and their environment. This is the fundamental relation-the dependence of living creatures on appropriate surroundings, and the primary illustrations of linkages must be found here. The living creatures are real, just in the same sense as the surroundings are real; but it is plain that we cannot abstract the living creatures from their surroundings. When we try to do this they dieeven in our thought of them, and our biology is only necrology. Huxley compared a living creature to a whirlpool in a river; it is always changing, yet always apparently the same; matter and energy stream in and stream out; the whirlpool has an individuality and a certain unity, yet it is wholly dependent upon the surrounding currents. One may push the whirlpool metaphor too far, so as to give a false simplicity to the facts, for when vital whirlnools began to be there also emerged what cannot be discerned in crystal or dewdrop--the will to live, a capacity of persistent experience, and the power of giving rise to 
other lives. To ignore this is to attempt a falsely simple natural history. But what Huxley's metaphor of the whirlpool does vividly express is the dependence of living creatures on their surroundings. We cannot understand either the whirlpool or the trout apart from the stream.

When we think out this fundamental dependence upon surroundings, we see, for instance, that all our supplies of energy, all our powers of every kind-with our own hands, or by the use of animals, or by means of machinery-are traceable to the sun. Or again, it is easy to show that our society depends fundamentally not on gold, but on iron. We depend for food on plants and animals, and through these animals on plants ultimately; the plants feed upon air, water, and salts, which, with the aid of the energy of the sunlight, they build up in to complex organic compounds; they cannot do this unless the sun shines through a screen of green pigment called chlorophyll; there cannot be chlorophyll without iron; therefore our whole social framework is founded on iron.

Nutritive chains.-Plants feed on their inanimate environment in a direct way that is impossible to animals, so we pass insensibly from dependence on surroundings to those mutritive chains which bind living creatures together in long series often quaintly suggestive of "The House That Jack Built" and similar old rhymes. We have ceased to wonder at the circulation of the blood in our body; have we begun to wonder enough at the ceaseless circulation of matter in the

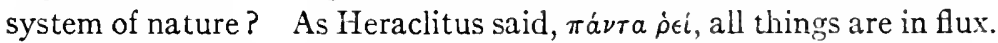
"The rain falls; the springs are fed; the streams are filled and flow to the sea; the mist rises from the deep and the clouds are formed, which break again on the mountain-side. The plant captures air, water, and salts, and, with the sun's aid, builds them up by vital alchemy into the bread of life, incorporating this in to itself. The animal eats the plant and a new incarnation begins. All flesh is grass. The animal becomes part of another animal, and the reincarnation continues." The silver cord of the bundle of life is loosed, and earth returns to earth. The microbes of decay break down the dead, and there is a return to air and water and salts. We may be sure that nothing real is ever lost; we are sure that all things flow. Penelope-like, Nature is continually unravelling her web and making a fresh start.

Nexus between mud and clear thinking.- - To keep a famous inland fish-pond from giving out, some boxes of mud and manure were placed at the sides. Bacteria-the minions of all putrefaction- 
worked in the mud and manure, making food for minute Infusorians which multiply so rapilly that there may be a million from one in a week's time. A cataract of Infusorians overflowed from box to pond, and the water-fleas and other small fry gathered at the foot of the fall and multijlied exceedingly. Thus the fishes were fed, and, as fishflesh is said to be good for the brain, we can trace a nexus from mud to clear thinking. What was in the mud became part of the Infusorian, which became part of the Crustacean, which became part of the fish, which became part of the man. And it is thus that the world goes round.

Correlation between catches of mackerel and amount of spring sunlight.-A curious and most interesting correlation has been discovered by Dr. E. J. Allen between catches of mackerel and the amount of sunlight. The more sunshine in May, the more mackerel at Billingsgate. How does this work out? Mr. G. E. Bullen shows that "for the years $1903-1907$ there appears to be a correlation between the number of mackerel taken during May, and the amount of Copepod plankton, upon which the mackerel feed, taken in the neighborhood of the fishing grounds during the same month." Mr. W. J. Dalin shows that the food of Copepods consists largely of the vegetable organisms of the plankton, such as diatoms, and of Infusoria-like organisms called Peridinidae. But the production of this microscopic plankton, the "stock" of the "seasoup," depends partly on the composition of the sea-water, partly on the temperature, and partly on the amount of light available. There seems to be no correlation between the surface temperature and the abundance of mackerel, but Dr. Allen has shown a correspondence between sunshine and the catches. Thus we see that, if all flesh is grass, then in the same sense all fish is diatom.

Nutritive chains in the deep sea.- If we pass from the sunlit open sea to the floor of the deep sea-that strange, dark, cold, silent, plantless world -we find carnivorus animal preying upon carnivorous arimal through long series-fish feeds on fish, fish on Crustacean, Crustacean on worm, worm on still smaller fry, and all ultimately depend on the bisal food-suply--the ceaseless shower of moribund atomies sinking from the suriace waters nany miles, it may be, overheaci, like the snowfakes on a quiet winter day.

Donendence of one organism on another for the continuance of the species.-I'assing from "nutritive chains," we may select a few illuatrations of the froentmin of one creature upon another for the 
continuance of its kind. The crowning instances are to be found in interrelations between plants and animals which secure cross-fertilisation and the distribution of seeds. To both of these Darwin devoted much attention, and they were always favourite subjects with him.

Everyone knows that flowering plants and flower-visiting insects have grown up throughout long ages together, in alternate infuence and mutual perfecting. They are now fitted to one another as han 1 to glove. The insects visit the flowe's for food; in so doing they carry the fertilising golden dust from blossom to blossom, so that the possible seeds become real seeds.

In 1793 a Berlin naturalist, Christian Konrad Sprengel, like Darwin in his perception of the web of life, published a pioneer book entitled The Secret of Nature Discovered in the Structure and Fertilization of Flowers, in which he showed that most flowers have nectar which insects enjoy; that by the insects' visits pollination is secured; that there is no detail of the flower without its meaningthe colour is a flag to attract the insect's eye, conspicuous spots are honey-guides to the explorers, there are arrangements for keeping the pollen dry and for dusting it on the insects, and so on. If Sprengel had only discovered the utility of the cross-fertilisation, which Darwin proved experimentally, his work could hardly have been overlooked for nearly seventy years. In I84 I it came into Darwin's hands, and impressed him as being "full of truth," although "with some little nonsense." In Darwin's work Sprengel had his long-delayed reward.

Darwin's instance of the connection between cats and clover.One of Darwin's instances of the web of life-given in connection with the pollination of flowers-has become familiar all over the worlu. It should never become trite to us and it should never be regarded as more than a particularly clear illustration of a general fact. "Plants and animals, remote in the scale of nature, are bound together $b y$ a web of complex relations. . . . I I have found, from experiments, that humble-bees are almost indispensable to the fertilisation of the heart'sease (Viola tricolor), for other bees do not visit this flower. I have also found that the visits of bees are necessary for the fertilisation of some kinds of clover-thus, roo heads of red clover (Trifolium prutense. produced 27,000 seeds, but the same number of protected heacls pro duced not a single seed. Humble-bees alone visit red clover, as o: het bees cannot reach the nectar. . . . . Hence we may infer as highy probable that, if the whole genus of humble-bees became extinct of very rare in England, the heart's-ease and red clover would become 
very rare, or wholly disappear." WVe know that the red clover imported to New Zealand did not bear fertile seeds until humble-bees were also imported. "The number of humble-bees in any district depends in a great measure on the number of field-mice, which destroy their combs and nests; and Colonel Newman, who has long attended to the habits of humble-bees, believes that more than two-thirds of them are thus destroyed all over England." Now the number of mice is largely dependent, as everyone knows, on the number of cats; and Colonel Newman says: "Near villages and small towns I have found the nests of humble-bees more numerous than elsewhere, which I attribute to the number of cats that destroy the mice." Thus we may say, with Darwin, that next year's crop of purple clover is influenced by the number of humble-bees in the district, which varies with the number of field-mice; that is to say, with the abundance of cats!

Scattering of seeds. - It is a fascinating chapter of natural history which tells us how cross-pollination is effected-here by a bee and there by a butterfly, occasionally by a long-billed humming-bird beautifully poised before the flower with almost invisibly rapid vibrations of its wings, and occasionally by a slowly moving snail of epicure appetite. But not less important is the part played by animals in the scattering of seeds, and here again Darwin gives us the classic case of fourscore seeds germinating out of a ball of mud from a bird's foot. From one instance you may learn all, and see that much of Darwin's work has been an eloquent commentary on that memorable saying about the sparrow that falls to the ground. Such a simple event literally sends a throb through surrounding nature; we can follow its effects a few steps, just as we follow for a few yards the ripples made when we throw a stone into a still lake; in either case can we doubt that the spreading influences are real, though they pass beyond our ken?

Interrelations between fresh-water mussels and fishes.-As a striking illustration of the inter-linking of different forms of life, we may take the case of the fresh-water mussels and their larvae. The fertilised eggs develop in the outer gill-plate of the mother-mussel, and minute bivalve larvae, called Glochidia, are formed. The mussel keeps these within the cradle until a frcsh-water fish-such as the minnowcomes into the vicinity, and then she sets them free. In a way that we do not understand, the simple constitution of the larvae is tuned to respond to the presence of minnows and the like, and with snapping valves they manage to fix themselves to their host. After a short 
period of temporary parasitism, at the end of which there is a metamorphosis, they drop off from the fish into the mud, often far from their birth-place. This is curious enough, but the idea of linkages becomes incandescent in the mind when we note that, just as the freshwater mussel has young temporarily parasitic on fishes, so a freshwater fish, the bitterling (Rhodeus amarus), has its young temporarily parasitic in the gills of the mussel.

Life-histories of parasites. - When we pass to parasites in a stricter sense we find the most extraordinary interconnections, the most widely separated animals of ten sharing a parasite between them. Liver-rot, which has repeatedly killed a million sheep in a year in Britain alone, is due to a parasite which passes from sheep to water, from water to water-snail, from water-snail to grass, from grass to sheep. The tapeworm of the cat has its bladder-worm stage in the mouse, the sturdie-worm of the sheep's brain has its tape-worm stage in the dog, and similar relations hold for hundreds of species. The troublesome threadworm of human blood (Filaria sanguinis hominis) is transferred from man to man by the mosquito, and the guinea-worm which was probably the fiery serpent that vexed the Israelites in the desert, which passes into man in drinking-water, spends its youth in a minute water-flea, called by the giant's name of Cyclops. The importance of tse-tse flies in transmitting the minute animals which cause sleeping-sickness and allied diseases is known to all. We have spoken of the connection between cats and clover, and there is a not less striking connection between cats and plague. For it seems to have been shown in India that the more cats the fewer rats, and the fewer rats the fewer rat-fleas, which are the agents in passing the plaguegerms to man.

Far-reaching influence of certain animals; earthworms.-We realise the idea of the web of life in another way when we consider the far-reaching influence of particular kinds of activity, the best instance being the work of earthworms. In 1777 Gilbert White got at the very root of the matter. "The most insignificant insects and reptiles are of much more consequence and have more influence in the economy of nature than the incurious are aware of. . . . . Earthworms, though in appearance a small and despicable link in the chain of nature, yet, if lost, would make a lamentable chasm. . . . . Worms seem to be the great promoters of vegetation, which would proceed but lamely without them, by boring, perforating, and loosening the soil, and rendering it pervious to rains and the fibres of plants; by drawing straws and 
stalks of leaves and twigs into it; and, most of all, by throwing up such infinite numbers of lumps of earth called worm-casts, which, being their excrement, is a fine manure for grain and grass. Worms probably provicle new soil for hills and slopes where the rain washes the earth away; and they affect slopes probably to avoid being flooded. .... The earth without worms would soon become cold, hardbound, and void of fermentation, and consequently sterile. . . . These hints we think proper to throw out, in order to set the inquisitive and discerning at work. A good monograph of worms would afford much entertainment and information at the same time, and would open a large and new field in natural history."

The monograph that Gilbert White wished for in 1777 was published by Darwin in ISSr, the year before he died--" the completion," he said, "of a short paper read before the Geological Society more than forty years ago." With his characteristic thoroughness and patience he worked out the part that earthworms have played in the history of the earth, and proved that they deserve to be called the most useful animals. By their burrowing they loosen the earth, making way for the plant rootlets and the raindrops; by bruising the soil in their gizzards, they reduce the particles to more useful, powdery form; by burying the surface with castings brought up from beneath, they have been for untold ages ploughers before the plough, and by burying leaves they have made a great part of the vegetable mould over the whole earth. In illustration of the last point, we may notice that we recently found thirteen midribs of the leaves of the rowan, or mountain ash, radiating round one hole like the spokes of a wheel; the withering leaflets had been carried down, and two were sticking up at the mouth of the burrow; that meant 9 r leaflets to one hole. Darwin showed that there often are 50,000 (and there may be 500,000) earthworms in an acre; that they often pass ten tons of soil per acre per annum through their bodies; and that they often cover the surface at the rate of three inches in fifteen years. Though our British worms only pass out about $20 \mathrm{oz}$. of earth in a year, the weights thrown up in a year on two separate square yards which Darwin watched were respectively $6.75 \mathrm{lb}$. and $8.387 \mathrm{lb}$, which correspond to $14 \frac{1}{2}$ and 18 tons per acre per annum.

We follow the work furiher and it becomes evident that the constant exposure of the soil bacteria on the surface is bound to be important, on the one hand, in allowing them to be scattered by wint and rain, on the other in exposing them to the beneficent action of the 
sunlight - which is the most universal, effective, and economical of all germicides.

In Yorubaland, on the West Coast of Africa, Mr. Alvan Millson calculated that about 62,233 tons of subsoil are brought every year to the surface of each square mile, and that every particle of earth, to the depth of two feet, is brought to the surface once in twenty-seven years. It need hardly be added that the district is fertile and healthy.

Earthworms play their part in the disintegration of rocks, letting the solvent humus-acids of the soil down to the buried surface. Their castings on the hill-slopes are carried down by wind and rain and go to swell the alluvium of the distant valleys or the wasted treasures of the sea. The well-known parallel ledges along the slopes of grass-clad hills are partly due to earthworm castings caught on sheep-tracks, and thus we begin to connect the earthworms not only with our wheatsupply but with our scenery. Well may we say, with Darwin: "It may be doubted whether there are many other animals which have played so important a part in the history of the world as have these lowly organised creatures." Those who wish to understand Darwinism should always begin with Darwin's last book-The Formation of Vegetable Mould through the Action of Worms (I88I). It illustrates the web of life, the idea of which is essential to an understanding of the struggle for existence and natural selection. But it also illustrates what Darwin had learned from Lyell-that great results may be brought about by accumulation of infinitesimal items. As Professor A. Milnes Marshall said: "The lesson to be derived from Darwin's life and work cannot be better expressed than as the cumulative importance of intinitly litlle things."

Termites, or white ants.-Henry Drummond, in his Tropical Africa, tried to make out a case for the agricultural importance of termites, or white ants. It is well known that these old-fashioned insects have a pruning action in the forest, destroying dead wood with great rapidity. Houses and furniture, fences and boxes, as well as forest-trees, fall under their jaws. In some places, "if a man lay down to sleep with a wooden leg, it would be a heap of sawdust in the morning." But what of the ternites' agricultural importance? The point is that they keep the soil circulating by constructing earthen tunnels up the sides of trees and posts and by making huge obelisk-like ant-hills, or termitaries. "The ear th-tubes crumble to dust, which is scattered by the wind; the rains lash the forests and soils with fury, and wash off the loosened grains to swell the alluvium of a distant 
vailey." It must be noted, however, that Drummond did not prove his case with sufficicint precision, and there is, as Escherich points out in his beautiful study of termites, this cilficulty, that, while the castings of earthworms are soft and loose, the earth-tubes and constructions of termites are stony.

Escherich does, however, admit that the termites have some agricultural importance, and he points out that there are other services to be put to the credit side of their account. They prune off wood that has begun to go; they destroy rotting things, including the bodies of small animals; they malie for cleanliness and health. In some low-lying tracts, as Silvestri has shown, there are dry stretches, "termite islands," which have been gradually built up from the broken-down remains of termitaries. Nor should it be forgotten that the white ants are often used as food. On the other hand. Escherich does not hesitate to rank them as among the great hindrances to the spread of civilisation. They insidiously derour everything wooden, from the telegraph-post to the wooden butt of the gun hanginis against the wall, from books in the library to corks in the cellar. There does not seem suficiently precise information in regard to the living plants that they attacis, and no safe general statement can be made except that their appetite is large and catholic.

With a centre in earthworms, what a variety of interests must be included within the radius of their life and work!-centipedes, birds, moles, seedlings, man. The same is true of termites, and two further iilustrations may be given. Observers have reported about thirty different species of termites with the habit of feeding on fungi grown within the termitary on specially constructed mazy beds. The habit is interesting in many ways; for instance, because the fungi afford a supply of nitrogenous material which is scarce in the ordinary diet of wood, and also because a similar habit occurs in the quite unrelated true ants. Finally, the web is illustrated by the numerous boarders, mostly beetles, that are found in the termitaries-not hostile intruders or parasites, but guests which are fed and cared for apparently for the sake of a palatable exudation with a pleasant, narcotising effect on the termites. With a centre in termites, what a variety of interests must we not include within the radius of their life and work! - fungi and trees, beetles and birds, lizards and anteaters, and man more than any.

The hand of lise upon the earth. - The hand of life has been working upon the earth for untold ages. Take plants, for instance. The seaweeds lessen the force of the waves, the lichens eat into the 
rocks, the mosses form huge sponges on the moors which keep the streams flowing in days of drought. Many little plants are forever smoothing away the wrinkles on the earth's - their mother's-face, and they adorn her with jewels. Others that have formed coal have enriched her with ages of entrapped sunlight. The grass-which began to appear in Tertiary ages-protects the earth like a garment; the forests affect rainfall and temper climate, besides sheltering multitudes of living things, to many of whom every blow of the axe is a deathknell. No plant, from bacterium to oak-tree, lives or dies to itself, or is without its influence upon the earth. So among animals there are destructive borers and burrowers and conservative agents, such as the coral-polyps and the chalk-forming Foraminifera.

Practical importance of a realisation of the web of life.-What has Darwinism to do with human life? The answer at this stage in our inquiry is clear: we must respect the web of life if we wish to master Nature. She must be humoured, not bullied. Emerson included in his vision of a perfected earth the absence of spiders, but the absence of spiders-which snare so many injurious insects-would mean the absence of much else, man probably included. In a northern county in Scotland the proprietors were justly annoyed at the injuries inflicted on young trees by squirrels, and they formed a squirrel club, setting a price on the beautiful rodent's head. Perhaps a wiser course would have been to begin by inquiring what disturbance of the balance of nature had allowed the squirrels to multiply so disastrously. But, after a period of squirrel-slaughter and some jubilation thereat, a cloud began to rise in the sky. The wood-pigeons were multiplying worse than ever, and the farmers, at least, said with no uncertain voice that they preferred the squirrels. An imperfect recognition of the web of life had left out of account the notable fact that squirrels destroy large numbers of young wood-pigeons.

One of the hopeful symptoms of the last few years is the reawakening of an interest in woods and forests. Everyone knows how terribly these have been wasted, and how the disastrous results have affected rainfall and irrigation, climate and crops, and even the character of the people. Here what was once a pleasant stream is now like a gravelly road, and there the fertile plains are flooded; here the wind is sweeping away the soil, and there both beauty and health have departed. The birds which the woods once sheltered are driven elsewhere, and the insect-pests are rife among the crops. For "the cheapest and most effective insecticides are birds." 
The recognition of consequences-often far-reaching-grows with us as we work with the idea of the web of life, as we see in proper perspective the criminality of those who are ruthless. President Roosevelt has declared his abomination of "the land-skinner" - "the individual whose idea of developing the country is to cut every stick of timber off it, and then leave a barren desert for the home-maker who comes in after him. That man is a curse, and not a blessing to the country. The prop of the country must be the man who intends so to run his business that it will be profitable to his children after him." Every right-thinking man, and especially those who have grasped the idea of the web of life, will say with Roosevelt, "I am against the landskinner every time."

It may be said that man must exterminate a good deal if he is to go on peaceably with his business, and it will be admitted that there has never been a strong enthusiasm, humanitarian or otherwise, against the elinination of rattlesnakes, and such like. The naturalist's answer is that every crusade should be carefully considered on its own merits, and that every careless and hasty destruction of life is to be condemned. Even in regard to snakes killing may be carried too far. Some creatures are, as it were, on the fringes of the web, while others occupy a position where many threads meet. It is scientifically and aesthetically deplorable that birds like the great auk and mammals like the quagga should have been extermınated, but it is practically much more deplorable that we have lost so many hawks and weasels and other members of that pertinacious army whose guerilla warfare keeps hundreds of more humdrum creatures up to the scratch, and kecps "vermin" from becoming a plague. Moreover, it is extremely difficult to tell what may be the consequences of cxterminating any creature-remote as it may seem from the beaten track of human affairs. One of the obvious lessons of Darwinism is that we should be slow to call any change unimportant. Everything counts, or may count. A so-called unimportant animal is destroyed and no immeliate ill effects are seen. But who can tell?

Very pertinent, for instance, is the question: What about the parasites that used to complete their life-history in romantic routine in this extinguished animal? Have we extinguished the parasite also ? Or is it waiting, with a whip of scorpions, to chastise mankind for their ignorance of Darwinism?

The practical inportance of recognising the web of life has been proved by the heavy penalties which man has often had to pay for 
disturbing the balance of nature, careless of results and ruthless of beauty, for not admitting that if we would master Nature we must first understand her. How much has Australia had to pay for the introduction of rabbits in $\mathbf{1 8 6 0}$, or America for sparrows? Sometimes the introduction has been unconscious, and man has only to blame himself for letting the intruder take hold, as in the case of the Phylloxera in France, or of the Colorado Beetle in Ireland. "Ignorance of nature," Mr. A. H. S. Lucas says, "is costly. By disturbing the balance of nature, man has introduced foes into his own household." Speaking of Australia, he says: "How much is needed for the eradication of Bathurst Burr, Prickly Pear, Water-hyacinth, Bramble and Sweetbriar, Codlin Moth, Waxy Scale, Pear Slug, and Red Spider. owing to carelessness or lack of knowledge in early days?"

An obvious moral is that we should be careful in our introductions of new organisms-man included-into new surroundings. The primary consequences may be predictable, but the secondary and the tertiary consequences-who is sufficient for these things? We have records of the unconscious introduction of rats into Jamaica, where they became a pest. To destroy them mongooses were imported, and the rats were soon checked. But the mongooses, having finished the rats, began to eat up the poultry and young birds of various kinds. As this went on the injurious insects and ticks, that the birds used to eat, began to gain the ascendant. A recent report-which requires confirmation-says that the increase of ticks is making life a burden to the mongooses. Thus a balance will be again arrived at. There is no doubt of that, but how much is often unnecessarily lost by the way! 


\section{CHAPTER XXX \\ NATURAL SELECTION}

In the Appendix will be found a chapter of excerpts irom Larwin's Origin of Species. In this chapter he offers four objections to his theory and attempts to answer them. These four objections are not by any means all that Darwin foresaw, for he presented in another chapter a discussion of "Miscellaneous Objections to the Theory of Natural Selection." Before entering upon a general cricicism of Darwinism, it would be advantageous to have before us a brief and pointed summary of Darwin's theory-natural selection--now known technically as "Darwinism." The writer knows of no better short statement of the true content of Darwinism than the following sunmary by Professor Vernon L. Kellogg.

\section{SUMAIARY OF DARWIN'S NATLR.IL-SELECTION THEORY'}

"Darwinism may be defined as a certain rational, causo-mechanical (hence, non-teleofogic) explanation of the origin of new species. The Darwinian explanation rests on certain observed facts, and certain inductions from these facts. The observed facts are: (I) the increase by multiplication in geometrical ratio of the individuals in every species, whatever the kind of reproduction which may be peculiar to each species, whether this be simple division, sporulation, budding, parthenogenesis, conjugation and subsequent division, or amphimixis (sexual reproriuction); (2) the always apparent slight (to greater) variation in form and function existing among all individuals even though of the same generation or brood; and (3) the transmission, with these inevitahle slight variations, by the parent to its uffspring of a form and physiology essentially like the parental. The inferred (also party observed) facts are: (I) a lack of room and food for all these new individuals produced by geometrical multiplication and conscquently a competition (active or passive) a mong those individuals having any cologic relations to one another, as, for example, among

I From V. L. Kelluge, Darinism To-Diy (copyright 1907). Used by permission of the publishers, Henry Inolt \& Company. 
those occupying the same locality, or needing the same food, or needing each other as food; (2) the probable success in this competition of those individuals whose slight differences (variations) are of such a nature as to give them an advantage over their confrères, which results in saving their life, at least until they have produced offspring; and (3) the fact that these "saved" individuals will, by virtue of the already referred to action of heredity, hand down to the offspring their advantageous condition of structure and physiology (at least, as the "mode" or most abundantly represented condition, among the offspring).

"The competition among individuals and kinds (species) of organisms may fairly be called a struggle. This is obvious when it is active, as in actual personal battling for a piece of food or in attempts to capture prey or to escape capture, and less obvious when it is passive, as in the endurance of stress of weather, hunger, thirst, and untoward conditions of any kind. The struggle is, or may be, for each individual threefold in nature: (I) an active struggie or competition with other individuals of its own kind for space in the habitat, sufficient share of the food, and opportunity to produce offspring in the way peculiar and common to its species; (2) an active or passive struggle or competition with the individuals of other species, which may need the same space and food as itself, or may need it or its eggs or young for food; and (3) an active (or more usually passive) struggle with the physicochemical external conditions of the world it lives in, as varying temperature and humidity, storms and floods, and natural catastrophes of all sorts. For any individual or group of individuals any of these forms of struggle may be temporarily ameliorated, as is (I) the intra-specific struggle among the thousands of honey-bee individuals living together altruistically, in one hive, or (2) the inter-specific struggle, when two species live together symbiotically as the hermit crab Eupagurus and the sea-anemone Podocoryne, or (3) the struggle against untoward natural conditions as in special times or places of highly favourable climate, etc. Or for any individual or group of individuals all forms of the struggle may be coincidently active and severe. The resultant of these existing conditions is, according to Darwin and his followers, an inevitable natural selection of individuals and of species. Thousands must die where one or ten may live to maturity (i.e., to the time of producing young). Which ten of the thousand shall live depends on the slight but sufficient advantage possessed by ten individuals in the complex struggle for 
existence due to the fortuitous possession of fortunate congenital differences (variations). The nine hundred and ninety with unfortunate congenital variations are extinguished in the struggle and with them the opportunity for the perpetuation (by transmission to the offspring) of their particular variations. There are thus leit ten to reproduce their advantageous variations. The offspring of the ten of course will vary in their turn, but will vary around the new and already proved advantageous parental condition: among the thousand, say, offspring of the original saved ten the same limitations of space and food will again work to the killing off before maturity of nine hundred and ninety, leaving the ten best equipped to reproduce. This repeated and intensive selection leads to a slow but steady and certain modification through the sucressive generations of the form and functions of the species; a modification always toward adaptation, toward fitness, toward a moulding of the body and its behaviour to safe conformity with external conditions. The exquisite adaptation of the parts and functions of the animal and plant as we see it every day to our infinite admiration and wonder has all come to exist through the purely mechanical, inevitable weeding out and selecting by Nature (by the environmental determining of what may and what may not live) through uncounted generations in unreckonable time. This is Darwin's causo-mechanical theory to explain the transformation of species and the infinite variety of adaptive modification. A rigorous automatic Natural Selection is the essential idea in Darwinism, at least in Darwinism as it is held by the present-day followers of Darwin."

\section{OBJECTIONS TO SELECTION}

r. Darwin in a letter to his friend Hooker (January II, I844) expresses his contempt of Lamarck's ideas in the following words: "Heaven defend me from Lamarck's nonsense of a 'tendency to progression,' 'adaptations from the slow willing of animals,' etc. . . . . Lamarck's work appeared to me to be extremely poor; I got not a fact or idea from it."

In spite of these views Darwin's Origin of Species is interlarded with Lamarckian explanations. Whenever the author feels the shortcomings of the selection factor he lapses into an explanation involving the idea that the effects of use and disuse of organs are inherited. Followers of Darwin, especially Weismann, felt this to be the chief defect in the fabric of Darwinism and bent their efforts chiefly toward purging Darwinism of all taint of Lamarckism. 
2. Darwin insisted upon the idea that minute fluctuating variations, which we now know are to a large extent non-heritable, were the principal, if not the sole, materials for natural selection to work upon. He knew of a considerable number of "sports" or "saltatory variations" (now called mutations), but considered these too infrequent to furnish the necessary basis for selection. We now know that mutations may be as snall as fluctuating variations or as large as "sports" and that they are of much more frequent occurrence than Darwin supposed.

3. Darwin considered all variations as heritable. He did not distinguish between somatic variations and germinal variations. In fact, as we learn from a study of his pangenesis theory, he considered all variations as in the first instance somatic, and subsequently transferred by means of gemmules to the germ cells. Every somatic variation, whether induced by use, disuse, in response to environmental stimulus, or through mere spontaneous variability, was supposed to be able to give off gemmules into the blood stream that would carry to the germ cells the physical basis of the varying character. The pangenesis mechanism is now known to have no basis in fact.

4. The natural-selection theory is based upon a mistaken conception of the methods of artificial selection. Darwin believed, without having any proof for this belief, that the way in which domestic varieties had been so profoundly modified at the hands of man was by the conscious or unconscious selection of slight fluctuating variations in favorable or desired directions, and that this resulted in the cumulative improvement or enhancement of the desired characters over a long series of generations. Darwin supposes that the radically changed conditions of domestication hasten and stimulate variability, thus offering a better opportunity for selection. Transferring this idea to nature, he thinks that changed natural conditions stimulate variability, just as does domestication, and that this is seized upon by natural selection to make for adaptation to the new environment and the resultant origin of new species.

Our modern experimental studies have shown that somatic modifications due to environmental changes are not hereditary, and that all of the recent domestic varieties whose origin has been observed have been the result of suddenly appearing germinal variations or mutations, that arrive fully formed and cannot be improved by selection, except that they usually need to be selected out or isolated in 
orrler to prevent swamping out through intercrossing with the parent-type.

5. Objection has frequently been made to Darwin's irlea of the purely fortuitous or chance character of variations. According to this view variations occur in all structures and in all directions at haphazard, so that there would be the widest possible opportunity for a given adaptive variation to occur just when the circumstances would demand. It now appears that variations do not occur in all directions in random fashion, but that they tend to follow certain definite paths of change; in other words, variations are, to a considerable extent at least, orthogenetic. If variations really tend to follow certain definite lines, owing to purely internal causes, natural selection would be unnecessary, at least until orthogenesis went too far for the good of the species, or far enough to be of real importance in the struggle for existence.

6. The difficulty of explaining how natural selection could make use of the initial stages of adaptive structures is obvious. It is inconceivable that the first, almost imperceptible variation in a favorable direction could be of selective value, so as to effect the survival of the individual or the relative number of its offspring. What would be the advantage of the first few hairs of a mammal or the first steps toward feathers in a bird when these creatures were beginning to diverge from their reptilian ancestors? This objection is, of course. based on the fluctuating-variation idea. If the mutation idea were substituted, the dificulty would, to a great extent, clear up; for a mutation might be of sufficient importance in one generation to have selective value from the very first.

7. Natural selection is said to be incapable of explaining the origin of coadaptive and highly complex adaptations whose effectiveness depends upon the perfection of their adjustments to one another. For example, we may refer to some of the perfected adaptations described in chapter xiv. In the case of the electric organs of certain fish, the Darwinian assumption would be that the first step in the direction of an electric organ would be a very small one, and that it was built up little by little by means of natural selection. But, say the critics, the electric organ would be of no value until it became powerful enough to impart an effective shock to the intruder, and this woul. not be possible if the character began in a small way. The whole phenomenon of protective resemblance is open to the same type of criticism. As a specific example of this we may cite the case of the dried-leaf 
butterfly, Kallima, previously described (pp. 226-228). In its present condition this animal has a strikingly detailed resemblance to a dried leaf, which is therefore doubtless of some value. But of what value would be the first tiny change in the direction of resemblance? Until its resemhance became close enough actually to deceive the enemies of but terflies, the critics claim, there would be no chance for selection to act.

8 . It is frequently objected that a vast number of characters of organs are useless or non-adaptive and, as such, could not have arisen through the instrumentality of natural selection. If these useless characters, which are sometimes quite large and prominent, are independent of natural selection, why do we need natural selection to explain adaptive characters? It is also claimed that a vast number of specific peculiarities are useless and therefore could not have helpec in the differentiation of species. It should be said in defense that Darwin realized this difficulty quite as clearly as do his critics and was greatly puzzled by it. His idea of correlated variability, however, helps to answer it, for it may well be that many of these apparently useless characters are correlated, or linked in inheritance, with characters of supreme selective value such as general hardiness or great fecundity. Darwin also points out that we are not in a position at present to pronounce judgment on the value of many structures or functions that have been adjudged non-adaptive.

9. Certain characters in organisms, past and present, have been interpreted as overspecializations, organs that have evolved beyond the range of usefulness or that are more elaborate than is demanded for survival under the conditions of life. The case of the extinct Irish elk is often cited as an examplc of overspecialization. This group of animals went to extremes in the development of size and elaboration of horns far beyond the range of usefulness, so that it is said to have brought about the extinction of the race. Natural selection, which is supposed to have brought the horns up to the point of adaptive perfection, should have kept them within the bounds of usefulness.

Again, the cnormously overgrown and overspecialized dinosaurs of long ago are thought of as having followed their lines of evolution iar beyond the point of greatest effectiveness and adaptability.

I0. The rudimentation of structures, which is such a common phenomenon in nature, is said to meet with no adequate explanation on a selection basis. The case of the whale's vestigial hind limbs is a case in point. Darwin's explanation would be that under aquatic conditions the first whale ancestors would be handicapped by hind 
legs and that any decrease in their size, which would be enhanced by disuse, woukl be of advantage. This might seem reasonable during the main period of limb reduction, but, after the limb is reluced to a subcutaneous rudiment, there could be little advantage in carrying the rudimentation still farther. Some whales have the hind limbs much more profoundly reduced than others, although they are all thoroughly out of the way and involve no hindrance in swimming. Any number of similar cases of the same kind might be cited. Darwin had no explanation to offer except a resort to Lamarckism; but Heismann, the ablest neo-Darwinian, offered the theory of panmixia to cover this objection, a theory which is mentioned in chapter $\mathrm{i}$ and will be discussed later.

II. It is objected that, unless favorable variations occur in a large number of individuals at the same time, the character would be swamped out by intercrossing with individuals not possessing the favorable variation. 'The probability that such a swamping-out would occur was shown mathematically by various critics. By way of answer to this objection there arose a number of "isolation theories," according to which favorably varying individuals would be protected from back-crossing with the non-varying individuals. We might also point out that the Mendelian laws of dominance and segregation would serve to prevent loss of any new favorable character.

I 2. It is objected that natural selection might explain the "survival, but not the arrival, of the fittest." But Darwin met this perfectly when he said: "Some have even imagined that natural selection induces variability, whereas it implies only the preservation of such variations as arise and are beneficial to the being under its conditions of life."

13. Criticism has been directed against natural selection because of the fact that some of the supporters of Darwinism, notably Weismann, have made the claim that natural selection is the sole cause of evolution. This idea of the Allmacht or all-sufficiency of natural selection was not Darwin's, as is clear from the following statement: "I am convinced that natural selection has been the most important, but not the exclusive means of modification."

14. It is objected that many, if not most, of the fluctuating variations with which Darwinism deals are purely quantitative or plusand-minus variations; whereas the differences between species are qualitative. 'This is a serious objection and difficult to meet, yet a fair defense has been formulated by leading neo-Larwinians. 
15. There is a growing skepticism on the part of biologists as to the extreme fierceness of the struggle for existence and of the consequent rigor of selection. It may be answered that no very obvious fierceness is implied in the theory. So long as overproduction and a shortage of space and food exists the struggle for existence is inevitable.

16. Special objections are offered to the subsidiary theory of sexual selection. It is said that the type of sexual selection involving active rivalry and battling for mates needs no special theory, inasmuch as this is a mere phase of the struggle for the maintenance of the full life, including the chance to leave offspring. It is against the other side of sexual selection, which involves passivity on the part of the male and active choice on the part of the female of the more beautiful or otherwise attractive male, that objection is raised. It is claimed that such choice implies too high aesthetic powers in animals of relatively poor vision and mentality. Experiments have been performed with moths, in which the male and female coloration is strikingly different, in order to determine whether females actually do exercise any choice of mates that is based on considerations of appearance. The result proved conclusively that color patterns have no value in mating, but that the female is passive and mates with the first male to present himself, while the male finds the female through his exquisitely effective sense of smell.

We know now, however, that secondary sexual characters are intimately bound up in a physiological way with the functioning of the sex glands and are therefore doubtless to be interpreted as mere non-adaptive correlative variations or else as examples of obliterative coloration.

\section{DEFEXSE OF SELECTION}

In presenting these sixteen objections, we have in most cases indicated the lines upon which the objections have been met, if they have been met. Not all of these objections are considered serious at the present time, for some are based upon lack of a full knowledge of what Darwin actually wrote; others are largely academic in character and fail to stand up under actual test; still others have been more or less adequately met by subsidiary or supporting theories which have been advanced by various neo-Darwinians.

Most of the special objections raised in this chapter have received the attention of various able Darwinians, and the student of evolution, would doubtless be interested in the expert and fair-minded defense 
of Darwinism at the hands of Professor V. L. Kellogr as it appears in his book Darwinism To-l)ay.

A much briefer and consilcrably more general defense is that of J. L. Tayler, which is as follows.

GENERAL DEFHASE OF SILECTION

J. I. T.ISI.1.K

To realise how far the theory of selection is capable of explaining the facts of ormanic evolution, it is necessary to bear in mind the postulates in which the theory is founded.

I. It is obvious that natural selection can only act by preserving or eliminating the complete organism. Selection must therefore be organismal. This Larwin and other selectionists have clearly recognised.

2. As the whole orcanism must survive, if the favourable variation or variations are to he preserved, it follows that certain minor unfavourable variations may also be preserved if they happen to exist in an individual which survives on account of its major favourable variations. And since no individual is completely adapted to its environment, it follows that there must be always a variable amount of residual unfavourable variability in every organism.

3. This residual unfavourable variability may be of considerable utility under changed conditions.

4. Complementary specialisation of parts, as Spencer has shown, is favourable to successful competition, and as it is the whole organism that is selected or eliminated, it follows that any weakness of one specialised part, since it would disturb the balance of all, would be detrimental. The more complex the or sanism, the more specialised the structures, the more dependent one part will be on the others for its existence, hence a complementary specialising tendency will be favoured by selection, and therefore all struggles of one part of an organism with another will be reduced to a minimum.

It is clear that there must be some underlying criterion which determines whether any given organism shall be selected or not, and that criterion must be the net result of its adaptalility to its environment. One organism may conceivably survive, $l y$ its possession of a large number of small favourable variations, while another ma! survive in virtue of a single valuable one, but in each case it would be

"From J. L. Tayler, "The Scope of Natural Selection," A ataral Science, I Roy. 
the whole value of that organism which determined its survival. This fact is continually disregarded by opponents of the neo-Darwinian position, yet this selection of the organism as a whole is the fundamental postulate from which the theory of selection starts. Thus it is not uncommom to read criticisms bearing on the early development of some organ, in which the inadequacy of selection is supposed to be proved by the writer demonstrating, or believing he has demonstrated, the fact that the particular variation in question must have been too small to be by itself of selection value. In many cases the particular variation would, no doubt, if taken alone be, as the objector asserts, too unimportant to be selected, but as it is the whole organism that is selected, it is not logical to make an artificial separation and study the development of one organ or structure irrespective of the other organs with which it is in nature associated. Every organ in its evolution must be considered in relation to the whole of the particular organism in which that particular stage of development of that organ is found.

Starting, therefore, with this fact that the net value of adaptability of the whole organism to its environment must be the basis which determines selection or elimination, it will follow that certain lines of development will result from the application of this criterion. In a series of organisms placed under new conditions, elimination will proceed along lines essential to bring about a proper adjustment to the new conditions. If the offspring of these adjusted organisms merely repeated in their generation the characters of the exterminated as well as of the surviving organisms, that temporary adjustment would be permanent as long as the conditions were unchanged. But since the offspring are produced only by the surviving organisms, selection is continually raised to higher and higher planes of adaptation, and, therefore, as long as conditions remain constant, the tendency of selection must be, as Darwin clearly saw, cumulative. $\mathrm{He}$ did not, however, apparently see that from this cumulative tendency definite variability must arise out of indefinite.

Selection in direct relation to climatic conditions is, therefore, of very minor importance, while selection among the members of a species and all forms of inter-organismal selection is of infinitely more importance, since it is this interaction, produced by the offspring in different degrees inheriting the advantages of both parents (both of whom have survived on account of certain advantages), that leads to the cumulative development and never-ending struggle for survivai. 
Darwin came very near to this conception of definite variability when he pointed out that "if a country were changing, the altered conditions would tend to cause variation, not but what I believe most beings vary at all times enough for selection to act on." Extermination would expose the remainder to the "mutual action of a different set of inhabitants, which I believe to be more important to the life of each being than mere climate," and as "the same spot will support more life if occupied by very diverse forms," it is evident that selection will favour very great diversity of structure.

Bearing in mind this cumulative action of selection it will follow that under constant or relatively constant conditions the struggle for successful living will become more and more selective in character, even if the actual number of inhabitants remain more or less the same as when the struggle first commenced. The selection of variations will thus tend to pass through certain more or less ill-defined, but nevertheless, real stages. In proportion as the struggle becomes intense, either from the number or from the increasing adaptability of the organisms, or both, certain major essential adaptations, which were necessary for the climatic and other more or less comparatively simple conditions, will be supplemented by minor auxiliary variations which in the earlier stages would not have appeared. And still later, as more and more rigorous conditions of life were imposed, the advantage would tend to rest with those organisms which possessed highly co-ordinated adaptations, since this would entail more rapid responsiveness to environment.

As evolution advances from the unspecialised to the specialised, and higher and higher forms of life come into being, with increasing complexity and specialisation of parts entailing an increasingly delicate adiusiment of those parts to each other's needs, the relation of each part to the whole organism becomes of more and more importance, and it follows that selection must become more and more generalised in its action. No single variation could be of service to any of the higher forms of life unless it was in more or less complete harmony with the whole tendency of the individual. The adjustment of parts and their mutual interdependence make it essential for adaptation that the relation of parts be preserved; consequently, correlated minute favourable variations will tend to be more and more selected as evolution passes from the unspecialised to the specialised forms of life. This response of the whole organism should be still more delicate in those forms of life that are continually subjecting themselves to 
changed conditions; hence this delicacy of adjustment is far more necessary in the higher forms of animal life than in more stationary plant organisms, and in the developing nervous systems of animals we have just the central adjusting system that is required for these conditions. With evolution of type there will thus be an increasingly definite tendency given to organic, especially the animal, forms of life, if the acting principle of evolution has been selectional. Selection is, therefore, able to account for the steadily progressive tendency of life as a whole without calling to its aid any unknown and doubtful perfecting principle.

To summarise: Natural selection, acting on the whole organism, tends to produce more and more definite tendencies in all surviving forms of life, which tendencies are progressive and continuous in character. Variable conditions, by partially altering the line of selection, induce a temporary indefiniteness. And lastly, the process of selection being itself able to be the indirect, though not the direct, cause of those favourable variations, which it subsequently selects from, is able to dispense with any subsidiary factors, provided it has a certain number of elementary properties of life which afford sufficient material to work with.

EXPERIMENTAL SUPPORT OF THE EFFECTIVENESS

OF NATURAL SELECTION

Weldon's experiments with the shore-crabs of Plymouth Sound.These experiments seem to show that under changed environmental conditions natural selection acts upon minute fluctuating variations of linear or quantitative type so as to produce an alteration in the species; exactly as Darwinism would hold. A large breakwater was so placed near the mouth of Plymouth Sound that the rate of flow of the river water was greatly slowed down in certain regions. This allowed an increased settling of the fine china-clay sediment that is carried by the river, and the changed condition caused the death of numerous crabs of the species Carcinus maenas. The question arose as to whether the survivors and those that had perished showed any consistent differences on the basis of which selection could be operating. Careful measurements of hundreds of individuals showed that the mean breadth of frontum is slightly less in the survivors than in the perished. Measurements were repeated in two subsequent years and it was found that there was a progressive narrowing of the frontum. As an experimental check upon these conclusions Weldon 
placed a number of crabs in a large aquarium, in which china-clay was kept partly in suspension, and found that about half of them died. Again the survivors were compared statistically with the perished and the same relation was found to hold: that the survivors had a mean frontal breadth distinctly narrower than that of the perished. Weldon concludes that his experiments "have demonstrated two facts about these crabs; the first that their mean frontal breadth is diminishing year by year at a measurable rate, which is more rapid in males than in females; the second is that this diminution in frontal breadth sccurs in the presence of a material, namely, fine mud, which is increasing in amount, and which can be shown experimentally to destroy broad-fronted crabs at a greater rate than crabs with narrower frontal margins .... and I see no escape from the conclusion that we have here a case of Natural Selection acting with great rapidity, because of the rapidity with which the conditions of life are changing."

Cesnola's experiments with Mantis.-To test the selective value of color markings Cesnola fixed specimens of the brown and green Mantis religiosa on plants, some of which were against harmonious, others against disharmonious backgrounds. The result was that most of those which were inconspicuous because of a harmonious background escaped, while most of the others were eaten up by birds.

Poulton's and Sanders' experiments with butterfy pupae.-Numerous pupae of various colors were placed under conditions favoring protective coloration and others under opposite conditions. The conclusion was that protective coloration is a real survival factor, and one that operates so as to give the protectively colored individual a decided advantage in the struggle for existence.

Davenport's experiments with chickens.-A number of chickens, some black, some white, and some barred or checkered in color, were allowed to wander free in the fields. Hawks killed most of the whites and many of the blacks, but spared, to a large extent, the less conspicuous checkered and barred types which are harder to detect against a mixed background.

All of these experiments merely tend to show that discriminate survival actually occurs, but only the experiment of Weldon has a bearing on the possibility that mere quantitative changes of small dimensions might under certain conditions be of selective value. We badly need more experimental evidence of this sort and until this is forthcoming we shall have to admit that there is very littie 
experimental evidence in favor of the type of natural selection that Darwin stood for.

\section{THE PRESENT STATL'S OF NATURAL SELECTION}

It has come to be rather generally believed that the natural selection that Darwin himself believed in stands almosi unscathed as one very important causal factor. In fact it is the only explanation ever offered for adaptation that even approaches adequacy. As an explanation of the origin of new types or new species it falls far short of adequacy, and I think Darwin evidently realized this, although he was unfortunate enough to entitle his book Origin of Species. As an explanation of the origin and perfection of adaptation natural selection has only one rival, the far less satisfactory Lamarckian theory of the inheritance of acquired characters. There is a strong tendency among geneticists to conclude that the modern germ-plasm hypothesis, with the aid of mutations and the mechanism of Mendelian inheritance, furnishes all the necessary explanation of the causes of evolution. There is, however, marked dissent to this extreme position. In his critique of De Vries's rather extreme position that the mutation theory needs no aid from natural selection, Weismann shows in most able fashion the inadequacy of mutations to account for adaptation, and, in contrast, how well natural selection accounts for them.

In a very recent paper Professor C. C. Nutting attempts to show that natural selection is still an important factor in evolution and quite in harmony with both the mutation theory and Mendelism. We perhaps can close the present chapter no more fittingly than by quoting Professor Nutting's paper.

\section{THE RELATION OF MENDELISM AND THE MUTATION THEORY TO NATURAL SELECTION ${ }^{1}$}

\section{C. NUTTING}

Two marked tendencies are evident in the history of any important theory after its publication.

First. The followers of the discoverer carry the theory too far and attempt too universal an application. This is manifestly true of Wallace and Weismann who out-Darwined Darwin in their claims for natural selection: of the followers of Mendel, such as Morgan and

- From an address given before the Genetics branch of the American Assucrition for the Advancement of Science, December, rozo; Sciense N.S., Vol. LIII. 
Pearl; and of many mutationists who make much greater claims for that theory than does De Vries himself.

Second. Each generation of biologists is so occupied with its own work and contemporary theories that it makes no real effort to understand preceding theories.

This second tendency seems to me most marked in the attitude of present workers along genetic lines towards natural selection. They reveal an apparent lack of understanding of what Darwin really meant and of what he clairned; and when criticising that theory they are often engaged in the classic, but unprofitable, exercise of "fighting windmills."

In view of these facts I hope you will pardon me if I present in as few words as possible just what I believe to be the main factors which Darwin presented as resulting, in their actions and reactions, in natural selection. These factors are three in number:

First. Heredity, by which the progeny tend to resemble their parents more than they do other individuals of the same species.

Second. Individual variation, by which the progeny tend to depart from the parental type and sometimes from the specific type.

Third. Geometrical ratio of increase, by which each species tends to produce more individuals than can survive.

Each of these factors is practically axiomatic, so little is it open to argument.

No one doubts the fact of heredity, whether pangenesis, Weismannism or Nendelism be the correct expression of the mechanism involved. These do not affect the fact of heredity nor invalidate it as a factor in natural selection.

No one doubts the fact of variation; whether it is the "individual variation" of Darwin, the "fluctuating variety" or the "mutation" of De Vries. All that is necessary for Darwin's purpose is that there be heritable variations. That there are such things all parties agree and it matters little what you call them. They are adequate to act as a factor in the Darwinian scheme.

No one doubts the fact of geometrical ratio of increase. It is a proposition easily capable of mathematical demonstration, and that is sufficient for Darwin's purpose.

These three factors, then, are not debatable as facts, whatever their mechanism or causes.

A moment's reflection will show that geometrical ratio of increase is a quantitative factor, giving an abundance of individuals from 
which to select; that individual variation is a qualitative factor, giving the differences which make a selection possible; and that heredity is a conservative factor, holding fast those characters which better fit the organism to its environment.

Now it seems to me that there is no possible outcome of the necessary action and interaction of these three factors that would not be a selection of some sort. Darwin thought it comparable in a large way to the selection by which the stock-breeder improves his herd, and therefore called it "natural selection," carefully guarding the phrase from misinterpretation from the teleological angle as well as from a too close parallelism between artificial and natural selection. And I believe no one has suggested a more acceptable term for the process of selection resulting from the interplay of natural laws.

Three outstanding theories have been advanced since the publication of the Origin, each involving an advance in our knowledge of the mechanism of heredity on the one hand and the origin of variations on the other.

Weismann's theory of the continuity and stability of the germ plasm was of immense importance in its discussion of the mechanism of heredity, and his amphimixis gave a plausible explanation of the origin of variations. His results were almost universally regarded as confirming and greatly extending the scope of natural selection.

Mendel's theory regarding the purity of the gametes, their segregation in the sex cells, and the whole complex Mendelian mechanism so admirably described by Morgan; all of these, fascinating and important as they are, deal with the mechanism rather than the fact of heredity. In my opinion their acceptance or rejection does not affect the status of natural selection as a theory of organic evolution.

But it is the theory of mutation that has furnished most of the ammunition for the opponents of natural selection; and this in spite of the fact that De Vries, the originator of the mutation theory, expresses himself with great clarity as follows:

"My work claims to be in full accord with the principles laid down by Darwin and to give a thorough and sharp analysis to some of the ideas of variability, inheritance, selection, and mutation which were necessarily vague in his time."

In I904, when these words were published, there did seem to be a sharp distinction between the ideas of Darwin and those of De Vries. The former believed that natural selection acted upon many small variations and accumulated them until the differences were sufficient 
to constitute new species; while De Vries claimed that new species were formed by the sudden appearance by mutations of forms specifically distinct from the parents. That mutants were new species!

It seems evident that Darwin did not regard "saltatory evolution" as the common method, while De V'ries did.

Darwin believed that individual, usually small, variations furnished the material on which selection acts; while De Vries thought that mutants, usually large variations, furnished the material. Both, however, believed thoroughly that natural selection was a vera causa of evolution.

But things have changed greatly since i904. The work of Morgan, Castle, Jennings and a host of others has shown that many mutations are so small, from a phenotypic standpoint, that they are quantitatively no greater than the individual variations of Darwin; and that they are heritable in the Mendelian way.

Castle produced a perfectly graded series of hooded rats which exhibits almost ideally the steps by which a new form might be oroduced by natural selection. He says:

"If artificial selection can, in the brief span of a man's lifetime, mould a character steadily in a particular direction, why may not natural selection in unlimited time also cause progressive evolution in directions useful to the organism?"

Jennings says:

"Sufficiently thorough study shows that minute heritable variations-so minute as to represent practically continuous gradationsoccur in many organisms: some reproducing from a single parent, others by biparental reproduction. . . . . It is not established that heritable changes must be sudden large steps; while these may occur, minute heritable changes are more frequent. Evolution according to the typical Darwinian scheme, through the occurrence of many small variations and their guidance by natural selection, is perfectly consistent with what experimental and paleontological studies show us; to me it appears more consistent with the data thin does any other theory."

Many believers in mutation have been needlessly befuddled by the diverse meanings of "variations" as used by Liarwin and De Vries. Darwin included in his "individual variations" both the "fluctuating varieties" and the "mutations" of De Vries. Phenotypically they cannot even now be distinguished. De Vries nimself candidly admits that this was Darwin's attitude, thus proving himself 
more clear-sighted than many of his followers. All that Darwin needed for his purpose was proof of variations that are heritahle, and these are found in mutations, be they large or small.

Just as Mendelism has to do with the mechanism and not the fact of heredity, so the mutation theory deals with the nature and not the fact of variations. Neither, in my opinion, has any implication that is antagonistic to the theory of natural selection.

The statement has been made that natural selection "originates nothing" because it does not explain the origin of variations. I must confess scant patience with this point of view. As well say that the sculptor does not make the statue because he does not manufacture the marble or his chisel; or that the worker in mosaic originates nothing because he does not make the bits of stone which he assembles in his design!

The material corresponding to the bits of stone in the mosaic is furnished by hererlity and variation, and its quantity by geometrical ratio of increase. Natural selection acts in selecting and putting together this material in the formation of new species. Thus, in a true sense, it seems evident that something new has appearedsomething that is, but was not.

Another favorite figure, introduced I believe by De Vries, is "Natural selection acts only as a sieve" determining which forms shall be retained and which shall be discarded. This also seems to me to fall short of a complete statement of the truth. If the material subjected to the sifting process be regarded as changing with each generation by the addition of variations, or mutations if you prefer, some of which are favorable to a nicer adjustment of the species to its environment, the figure would be more nearly correct. To make it complete, however, the mesh of the sieve must change from generation to generation so that a quantitative variation which would be preserved in one generation would be discarded in a later one. But in this case natural selection would do more than a sieve could do. It woulc combine a number of favorable variations in the production of something new, a new species!

In conclusion it seems to me that we are justified in maintaining that Mendelism and the mutation theory, while forming the basis of the most brilliant and important advances in biological knowledge of the last half-century, have neither weakened nor supplanted the Darwinian conception of the "Origin of species by means of Natural Selection." 


\section{CHAPTER XXXI}

\section{ARE ACQUIRED CHARACTERS (MODIFICATIONS) HEREIITARY?}

Ixtroductory Note.-In a previous chapter (chap. xvi), under the headin"Heredity in Pure Lines," it was pointed out that germinal variations are hered. itary, and somatic variations (molifications) are not hereditary. That germinal variations are hereditary and may be produced in a number of different ways wat also made clear in the discussion of mutations. but the statement that somatic modifications are never in the least hereditary is equivalent to a total denial of the doctrine of the "inheritance of acquired characters," the so-called Lamarckian theory, which was brietly presented in chapter ii.

This is not a closed question and the final answer has been given neither in the negative nor in the affirmative. The problem is of utmost import for evolutionists and for all who are interested in race improvement. So important is it to view this question fairly that we shall quote extensively from several of the leading students of the problem.

\section{MISUNDERSTANDINGS AS TO THE QUESTION AT ISSUE}

\section{J. ARTIIUR THOMSON}

The precise question is this: Can a structural change in the body induced by some change in use or disuse, or by a change in surrounding influence, affect the germ-cells in such a specific or representative way that the offspring will throush its inheritance exhibit, even in a slight degree, the modification which the parent acquired?

Before we pass to cliscuss the evidence pro and con it will be useful to notice some frequently recurring misunderstandings, the persistence of which would make further argument futile.

Misunderstanding I.- - How can there be progressive evolution if acquired characters are not transmitted?-Those who have not thought clearly on the subject often shake their heads sagely and remark that they "do not see how evolution could have been possible at all unless what is acquired by one generation is handed on to the next." To this we have simply to answer (I) that our first business is to find out the facts of the case, careless whether it makes our interpretation of the history of life more or less difficult, and (2) that in the supply of germinal variations, whose transmissibility is unquestioned, there is ample raw material for evolution. We know a little about the abundant

' From J. A. Thomson, Heredity (copyright 1907). Used by special permission of the publisher, John Murray, London. 
crop of variations at present supplied; there is no reason to believe that it was less abundant in the past.

Misunderstanding II.-Interpretations are not facts.-There are many adaptive characters in plants and animals which may be superficially interpreted as due to the direct result of use and disuse or of environmental influence. The Lamarckians have so interpreted them, and the Lamarckian way of looking at adantations has become habitual to many uncritical minds. They see on modern flowers the footprints of insects which have visited them for untold ages; they* speak of the dwindling of the whale's hind-limbs through disuse, of the hardening of the ancestral horses' hoofs as they left the marshes and ran on harder ground; they picture the giraffe by persistent effort lengthening out its neck a few millimetres every century, as the acacia raised its leaves higher and higher off the ground; and they say that animate nature is so full of evidences of the inheritance of acquired characters that no further argument is needed.

But all this is a begging of the question. It is easy to find structural features which may be interpreted as entailed acquired characters, if acquired characters can be entailed. Obviously, however, we must deal with what we can prove to be modifications, or with what we can plausibly regard as modifications because we find their analogues in actual process of being effected to-day.

It is easy to say that the blackness of the negro's skin was produced by the tropical sun, and that it is now part of his natural inheritance. It is easy to say this, but absolutely futile. Let us first catch our modifications.

The Golden Rod (Solidago virgaurea) growing on the Alps is precocious in its flowering when compared with representatives of the same species growing in the lowlands. Hoffmann found that Alpine forms transplanted to Giessen remained precocious, therefore the acquired precocity had become heritable. But there is no evidence that the precocity was acquired; it may have been the outcome of the selection of germinal variations.

The African Wart-hog (Phacochoerus) has the peculiar habit of kneeling down on its fore-limbs as it routs with its huge tusks in the ground and pushes itself forward with its hind-limbs. It has strong horny callosities protecting the surfaces on which it kneels, and these are seen even in the embryos. This seems to some naturalists to be a satisfactory proof of the inheritance of an acquired character. It is to others simply an instance of an adaptive peculiarity of germinal origin wrought out by natural selection. 
Misunderstanding III.--Begging the question by starting with what is not procel to be a modification.-There is no relevancy in citing cases where an abnormal bodily peculiarity re-appears generation after generation, unless it be shown that the peculiarity is a modification, and not an inborn variation w'hose transmissibility is admitted by all. Short-sightedness may recur in a family-series generation after generation, but there is no evidence to prove that the original short-sightedness was a modification. In all probability, shortsightedness is in its origin a germinal variation, like so many other bodily idiosyncrasies.

In regard to some diseases, such as rheumatism, it is often said dogmatically by those who know little about the matter that the original affection in the ancestor was brought about by some definite external influence - such as a cold drive or a damp bed; but it seems practically certain that in all such cases we have to do with an inborn predisposition, to the expression of which the cold drive or the damp bed were merely the liberating stimulus, comparable to the pulling of the trigger in a loaded gun. The liberating stimulus is, of course, of great importance, both in the case of the gun's discharge and the organism s discase, but it only goes a little way towards a satisfactory interpretation in either case. Not that we can explain the origin of rheumatism or shortsightedness or any such thing-there is no explanation in calling them germinal variations that cropped up; but we are almost certain that they never are modifications or acquired characters.

Herbert Spencer twits those who are scentical as to the transmission of acquired modifications with assigning the most flimsy reasons for rejecting a conclusion they are averse to; but when Spencer cites the prevalence of short-sightedness among the "notoriously" studious "Germans, the inheritance of a musical talent, and the inheritance of a liability to consumption, as evidence of the inheritance of modifications, we are reminded of the pot calling the kettle black.

Over and over again in the prolific literature of this discussion the syllogism is advanced, either in resar! to sout or something analogous-

Gout is a modification of the boly, an acquired character;

Gout is transmissible;

Modifications are sometimes transmissible.

It may be formally a good argument, but there is every reason to deny the major premise. There is no proof that the gouty habit had an exogenous origin-that it was, to begin with, for instance, the direct result of high living: though it is generally admitted that 
excesses in eating or drinking may give a stimulus to its expression. "The conclusion that I have arrived at," says Prof. D. J. Hamilton, "is that the gouty habit of body has arisen as a variation, and as such is hereditarily transmissible, and that excess of diet and alcohol merely renders the habit of body apparent." It may also be pointed out that gout and rheumatism and the like are rather processes of metabolism than structural modifications, though the latter may ensue.

After pointing out the irrelevancy of citing cases of the hereditary recurrence of polydactylism, haemophilia, colour-Jjlindness in man, or the absence of horns in cattle or of tails in cats, as instances of the transmission of acquired characters, Prof. Ernst Ziegler says: "Only that can be regarded as 'acquired' which is produced in the course of the individual life, during and after the period of development, exclusively under the influence of external conditions; the term is in no wise applicable to peculiarities which, as one says, arise of themselves from a predisposition already present in the germ."

Misunderstanding IV.-Mistaking the reappearance of a modification for transmission of a modifuation.-It is of little service to cite cases where a particular modification reappears generation after generation unless it be shown that the change recurs as part of the inheritance, and not simply because the external conditions which evoked it in the first generation still persisted to evoke it in those that followed. Reappearance is not synonymous with inheritance.

Misunderstanding V.-Mistaking re-infection for transmission.A particular form of the fourth misunderstanding has to do with facts so special that it may be conveniently treated of separately. It has to do with microbic diseases. It is admitted that a parent infected with tuberclc-bacillus or with the microbe of syphilis may have offspring also infected. But such cases are irrelevant in the discussion. Infection, whether before or after birth, has nothing to do with inheritance. As Dr. Ogilvie says, "Wherever the transmission of infectious disease from parent to offspring has been adduced to support the doctrine of the inheritance of acquired characters, it has been done in utter misconception of its meaning and scope."

Medical men have sometimes condescended to make a subtle distinction between "hereditary" and "congenital" syphilis-the latter manifested at birth, the former some time afterwards! It seems strange that they have failed to recognise that there is no reason to use the word "hereditary" at all in this connection. What occurs is an infertion, and it is theoretically inmaterial at what stage the infection occurs. A microbe cannot he part of an inheritance. 
Misunderstanding VI.-Transmission in unicellulars is not to the point.-It is not to the point to cite cases where unicellular organisms, such as bacteria or monads, have been profoundly and heritably modified by artificial culture, so that, for instance, the descendants of a virulent microbe have been made to lose their evil potency. It is irrelevant because in regard to unicellular organisms we cannot draw the distinction between body and germinal matter, apart from which the concept of modifications is of no value. In artificial culture the whole character of the unicellular organism-its particular metaholism - is altered; it multiplies by dividing into two or more parts, which natirally retain the altered constitution. But this is worlds away from the supposed case of an alteration in the structure of the little toe so affecting the germ-cells that the offspring inherit a corresponding deformation.

Professor L. Errera (I899) reported an experiment with a simple but multicellular mould (Aspergillus niger), which adapted itself to a medium more concentrated than the normal. The second greneration of the mould was more adapted than the first, and the adaptation to the concentrated medium was not wholly lost after rearing in the normal medium again. This looks like evidence of the inheritance of the acquired adaptive quality which was brought about as a direct modification. But the case does not really help us, since the distinction between soma and germ-plasm is not more than incipient in the mould in question. And even if the distinction were more marked, it would only show that the germ-plasm is capable of being affected along with the body, by a deeply saturating influence, which nobody has ever denied.

Misunderstanding VII.-Changes in the germ-cells along with changes in the body are not relevant.-Another misunderstanding is due to a failure to appreciate the distinction between a change of the reproductive cells along with the body, and a change in the reproductive cells conditioned by and representative of a particular change in bodily structure. The supporters of the hypothesis that modifications may be transmitted point to the tragic cases where some poisoning of the parent's system, by alcohol, opium, or some toxin, is followed by some deterioration in the offspring. There is no doubt as to the fact; the question is as to the correct interpretation.

I. In some cases it may be that the whole system of the parent is poisoned-reproductive cells as well as body; the effect may be as direct on the germ-cells as on the nerve-cells. These, therefore, are not cases on which to test the transmissitility of an acquired character-i.e.. 
of a particular somatic modification. If a local poisoning had a structural effect on some particular organ, and if that structural effect was reproduced in any degree in the offspring, the case would be relevant; but when the whole organism is soaked in a poison the case is irrelevant. If it could be said that the sunshine, which brings about sun-burning in the skin, soaks through the organism even to its reproductive cells and specifically affects them, in a manner analogous to the saturating poison, we should have a physiological basis for expecting the inheritance of sun-burning. But we cannot make this assumption. We have no warrant for believing that the modification of a part re-echoes in a definite specific way through the organism until even the penetralia of the germ-cells reverberate.

2. A parent organism is poisoned, and there are structural results of that poisoning. The offspring are born poisoned, and show similar structural peculiarities. This may be due to the fact that the germcells were poisoned along with the parental body; but it may also be due, in the case of a mother, to a poisoning of the embryo before birth, in a manner comparable to a pre-natal infection.

3. In some cases-e.g., of alcoholism in successive generationsthere may be poisoning of the germ-cells along with the body, there may be poisoning of the embryo before birth, and of the infant after; but it may also be that what is really inherited is a specific degeneracy of nature, an innate deficiency of control, perhaps, which led the parent to alcoholism, and which may find the same or some other expression in the child.

Cases are known in which the children of a dipsomaniac father and a quite normal mother have exhibited a tendency to alcoholism, insanity, and the like. In this case the possibility of poisoning the unborn child is eliminated, but there remain three possibilities of interpretation-that there was specific poisoning of the paternal germcells; that what was inherited was the constitutional weakness which expressed itself as alcoholism in the father; and that there were detrimental influences in the early nutrition, environment, education"nurture," in short-of the offspring.

But while we have admitted a good deal, we have not admitted the transmissibility of a particular structural modification brought about in the parental body as a result of the toxin.

Misunderstanding VIII.-Failure to distinguish between the possible inheritance of a particular modification and the possible inheritance of indirect results of that modification, or of changes correlated with 
it.--At first sight this seems hair-splitting, but it is a crucial point. Through his vigorous exercise the blacksmith develops a muscular arm worthy of admiration; the shoemaker acquires skeletal and muscular peculiarities less admirable. There are many permanent and profound modifications associated with particular occupations. Are we to believe, it is asked, that the occupation of the parents has no influence on the offspring? Are we to believe, it is asked, that the children of soldier, sailor, tinker, tailor, are in no way affected by the Darental functions?

It would be interesting to have precise data in regard to this, but it is generally admitted that when parents have healthful occupations their offspring are likely to be more vigorous. The matter is complicated by the difficulty of estimating how much is due to good nurture before and after birth. It is not unlikely, too, that some profound parental modifications may influence the general constitution, may' even affect the germ-cells, and may thus have results in the offspring. But unless the offspring show peculiarities in the same direction as the uriginal modifications, we have no data bearing precisely on the question at issue.

A belief in the inheritance of modifications was perhaps expressed in the old proverb, "The fathers have eaten sour grapes, and the children's teeth are set on edge" - a proverb which Ezekiel with such solemnity said was not any more to be ased in Israel. Now if "setting on edge" was a structural modification, and if the children's teeth were "set on edge" as their fathers' had been before them, there would be a presumption in favour of the transmission of this acquired character, though it would be still necessary to inquire carefully whether the children had not been in the vineyard too. But if, as Romanes said, the children were born with wry necks, we should have to deal with the inheritance of an indirect result of the parent's vagaries of appetite, and not with any direct representation in inheritance of the particular modification produced in the paternal dentition.

Misunderstanding IX.- Appealing to data from not more than two generations.- - It has often been pointed out that animals transported to a new country or environment may exhibit some modification apparentiy the result of the novel influence, and that their offspring in the same environment may exhibit the same modification in a greater degree. Thus sheep may show a change in the character and length of their fleece, and their progeny may show the same change more markedly. 
But it is perfectly clear that if the evidence does not go beyond this, nothing is proved that affects the cuestion at issue. It was to be expected that the offspring should show the modification in a more marked degree than their parents did, since the offspring were subjected to the modifying influences from birth, whereas their parents were influenced on!y from the date of their importation.

What would be welcome is evidence that the third generation is more markedly modified than the second; then there would be data worth considering. Only then would it be necessary to consider Weismann's somewhat subtle discussion as to the influence of climate.

THE INIIERITANCE OR NON-INHERITANCE OF ACQUIRED CHARACTERS EDWIN GRANT CONKLIN

Few questions in biology have been discussed so fully and so fruitlessly as this. It is a problem of the greatest interest not only to students of biology but also to sociologists, educators and philanthropists and yet it is still to a certain extent an unsolved problem.

Opinions of Lamarck and Darwin.-It is well known that Lamarck taught that characters due to desire or need, use or disuse, and to changed environment or conditions of life were inherited and thus brought about progressive evolution. Long ago desire or need was repudiated as a factor of evolution. Lowell satirized it in his Biglow Papers in these words:

"Some filosifers think that a fakkilty's granted The minnit it's felt to be thoroughly wanted.

That the fears of a monkey whose holt chanced to fail Drawed the vertibry out to a prehensile tail."

I)arwin wrote to Hooker, "Heaven forfend me from Lamarck's nonsense of adaptation from the slow willing of animals"; but although he repudiated this feature of Lamarckism he held that characters due to use or disuse and to changed conditions of life might be inherited and he proposed his hypothesis of pangenesis in order to explain the process of the transmission of such characters to the germ cells.

Weismann's theories.-Weismann introduced a new era in biology by denying the inheritance of all kinds of acquired characters, and by challenging the world to produce evidence that would stand a

'From E. G. Conklin, Ileredity and Environment (copyright I9ig). Used by special nermission of the publishers, The Princeton University Press. 
rigorous analysis. But Weismann's greatest service lay in his constructive theories rather than in destructive criticism; he forever disposed of theories of pangenesis and the like by showing that the germ cells are not built up by contributions from the body and that characters are not transmitted from generation to generation; but on the other hand that there is transmitted a germ plasm which is relatively independent of the body and which is relatively very stable in organization. This epoch-making theory of Weismann's has naturally undergone some changes, as the result of new discoveries. It is no longer believed that the germ plasm is really independent of the body, nor that it is absolutely stable, as Weismann at one time held. There is no doubt that the germ cells and the germ plasm are physiologically related to other cells and to other plasms, and similarly there is no doubt that the germ plasm although very stable can and does change its constitution under some rare conditions. But in the main the germ plasm theory is accepted by the great majority of biologists to-day, and recent work in genetics and cytology has brought many confirmations of this theory.

Distinctions between hereditary and acquired characters.-As long as it was believed that the developed characters of an organism could be transmitted as such to its descendants it was customary to speak of developed characters as hereditary or acquired and to talk of the inheritance or non-inheritance of acquired characters. This distinction is not a logical one for all developed characters are invariably the result of the responses of the germinal organization to environmental stimuli; and of course no developed character can be purely hereditary or purely environmental. But when a given character arises in many individuals of the same genotype under different environmental conditions it is probable that heredity, which is the constant factor in this case, is also the determining factor for that character. On the other hand if a character develops in response to peculiar stimuli and does not appear in other individuals of the same genotype in which such stimuli are lacking it is said to be an environmental or acquired character. In fine, inherited characters are those whose distinctive or differential causes are in the germ cells, while acquired characters are those whose differential causes are environmental.

Statement of problem.-Briefly stated the question of the inheritance of acquired characters is this: Can the differential cause of a character be shifted from the environment to the germ plasm? Can 
peculiarities of the environment which influence the development of somatic characters so affect the germ cells that they will produce these somatic characters in the absence of the peculiar environment? Can the characteristics of a developed organism enter into its germ cells and be born again in the next generation? Considering the fact that germ cells are cells and contain no adult characteristics, it seems very improbable that any peculiarity of environment whether of nutrition, use, disuse or injury, which brings about certain peculiarities of developed characters in the adult, could so change the structure of the germ cells as to cause them to produce this same character in subsequent generations in the absence of its extrinsic cause. How, for example, could defective nutrition, which leads to the production of rickets, affect the germ cells, which contain no bones, so as to produce rickets in subsequent generations, although well nourished? Or how can over-exertion, leading to hypertrophy of the heart, so affect the germ cells that they, in turn, would produce hypertrophied hearts in the absence of over-exertion, seeing that germ cells have no hearts? Or how could the loss or injury of eyes or teeth or legs lead to the absence or weakened development of these organs in future generations, seeing that inheritance must be through germ cells which possess none of these structures?

Lack of evidence for inheritance of acquired characters.-But, apart from these general objections to the doctrine of the inheritance of acquired characters, there are many special difficulties. There is no conclusive and satisfactory evidence in favor of such inheritance. Almost all the evidence adduced serves to show only that characters are acquired, not that they are inherited.

It is a matter of common observation that mutilations are not inherited; wooden legs do not run in families, although wooden heads do. The evidence for the inheritance of peculiarities due to use or disuse is wholly inconclusive; for example, did the giraffe get his long neck because he browsed on trees, or does he browse on trees because he has by inheritance a long neck? Did attempts to fly lead to the development of wings in birds, or do birds fly because heredity has given them wings? Did life in caves make cave animals blind, or did blind animals resort to caves because the struggle for existence there was less severe for them? The evidence is in favor of the second of each of these alternatives rather than of the first.

There still remains the question of the inheritance of certain characters due to environment, though here also the most clear-cut 
evidence is against this proposition. That unusual conditions of food, temperature, moisture, etc., may affect the germ cel's so as to produce general and indefinite variations in offspring is proballe, but this is a very different thing from the inheritance of acquired characters. The germ celli being a part of the parental organism may be modified by such changes in the environment as affect the body as a whole, they may be well nourished or starved, they may be modified by changed conditions of gravity, salinity, pressure, temperature, etc., and these modifications of the germ cells probably lead to certain general modifications of the adult, which may be larger or smaller, stronger or weaker, according as the germ is well or poorly nourished, but it is incredible that the environment which produces rickets, or hypertrophied heart, or loss of sight in one generation should modify the germ cells in such a peculiar and deinite way that they should give rise in the next senuration to these particular peculiarities, in the absence of the extrinsic cause which first produced them. The inheritance of acquired characters is incredible, because the egg is a cell and not an adult organism; and in this case there is no suficient evidence that the thing whi h is incredible really does happen.

No iniverited influence of stuck on graft. - If specific changes of environment produced specific changes in heredity we should expect to fird that where different plants or animals are grafted together each would modity more or less the hereditary constitution of the uther. But this does not occur. Everylody knows that when a branch of a particular kind of fruit tree is grafted upon a tree of a different variety the quality of the fruit borne by that branch is not altered by its close union with the new stock. The same is true of all forms of aninal grafts. Harrison cut in two young tadpoles of two species of fros, Rana sylvatica and Rana palustris, and splliced the anterior hall of one to the posterior half of the other. These frogs and their tadpoles differ in color as well as in other respects, $R$. sylodica leing more deep'y pigmented thail $R$. palustris. In the grafted tadpoles each half preserved its own peculiarities even up to the adult condition.

A stiil more striking case of the persistence of heredity in spite 0 : environmental changes is found in experiments in which the ovaries are removed from one variety of animal and trarisplanted to anothes viriety. Guthrie made such transplantation in line case of fowls and conchided that there was some influence of the foster mother upon the tramsplanted ovary, but bavenport, who repeated his experiments, was unable to confirm his results. Finally Castle and Phillips furnished 
the most conclusive demonstration that the hereditary characteristics of the transplanted ova are in no wise changed by the foster mother. 'They removed the ovary from a pure black guinea-pig and put it in the place of the ovary of a pure white animal. After recovering from the operation this white female with the "black" ovary was bred to a pure white male. Three litters of offspring from these parents were all pure black. Although both parents were pure white all the offspring of the $F_{I}$ generation were black because they came from "black" eggs and black is dominant over white. The fact that these "black" eggs developed in the body of a white female did not in the least change their hereditary constitution.

Dominants and recessives remain pure.-A still more intimate union takes place when the dominant and recessive characters come together in any zygote. These characters, or rather the factors which determine them, may be intimately associated in organism throughout an entire generation and yet we may get a clean separation of these characters in the next generation; in many cases neither the dominant nor the recessive character has been at all modified by its most intimate association with the other.

Climatic effects not inherited.-A striking instance of the purely temporary effect of the environment and of the long persistence of hereditary constitution amidst new environmental conditions, which have greatly changed the appearance of the developed organisms, is found in the case of alpine plants. Nägeli says that such plants, which have preserved the characters of high mountain plants since the ice age, lose these characters perfectly during their first summer in the lowlands.

Summary.-If acquired characters were really inherited we should expect to find many positive evidences of this instead of a few sporadic and doubtful cases. In particular why do we not find in plant or animal grafting that the influence of the stock changes the hereditary potencies of the graft? Why do we not find that transplanted ovaries show the influence of the foster mother as Guthrie supposed-a thing which has been disproved by Castle? Why do dominant and recessive characters remain pure, even after their intimate union in a hybrid, so that pure dominants and pure recessives may be obtained in subsequent generations from this mixture? Why does every child have to learn anew what his parents learned so laboriously before him? Even the strongest defenders of the inheritance of acquired characters are constrained to admit that it occurs only sporadically and exceptionaltv 
Neo-Lamarckism.-Many modifications of the Lamarckian hypothesis of the inheritance of acquired characters have been proposed in recent years. Foremost among those are the "mneme" theory of Semon and the "centro-epigenesis" theory of Kignano. To semon as to many other biologists the apparent resemblance between memory and heredity has seemed significant, and this furnishes the basis of his theory. Semon holds that every condition of life, every functional activity of an organism leaves a permanent record of itself in what he calls an "engramme." If these conditions or activities are long continued their engrammes are heaped up and affect heredity. semon does not ask if "acquired characters" are inherited, but rather "Are the hereditary potencies of the germ cells altered by stimuli acting on the parental body?" This is a very different thing from the inheritance of a particular acquired character, and there is some evidence that such stimuli may in rare instances produce changes in the hereditary constitution of the germ plasm though these evidences are by no means conclusive.

Temporary effects of environment; "induction."-On the other hand certain changes may be produced in germ cells or embryos which last for only a generation or two and then disappear. It is well known that plants grown in poor soil are smaller and produce smaller seeds than those grown in good soil, and De Vries, Bauer and Harris find that such seeds produce smaller plants having smaller seeds than do seed of normal size. This is an after effect of poor nutrition which changes the amount of food material in the seeds and through this the size of the plant which develops from the seed, but it does not change the hereditary constitution. Woltereck found that in Daphmia there is an after effect of cold lasting for one or two generations, and this he calls "induction," when the effect lasts for one generation, or "preinluction" when it lasts for two or three generations. Whitney found that rotifers poisoned with alcohol were weaker in resistance to copper salts and were less fertile than others, and when brought back to normal conditions the first generation was weak but the second was normal. On the other hand Stockard finds that the injurious effects of alcohol on guinea pigs persist through two or more generations. In man alcohol may have an "induction" effect on offspring, but fortunately it does not seem to alter hereditary constitution. Probably of a similar character are Sumner's results; he found that mice raised in the cold have shorter tails than those raised in higher temperatures arid this modified character appears in the next generation. If this is an after effect or "induction" it should dismpear in the following generations. 
Kammerer found that salamanders with black and yellow syots when reared on yellow soil gradually lose their black color, becoming more yellow, and their young continue to grow more yellow until finally almost all black may disappear. The offspring of such salamanders are said to be more yellow than normal; but this work has been called in question and needs confirmation. Even if confirmed the result may be an after effect or "induction" which would soon disappear under usual conditions, and there is no evidence that it is really inherited.

Such cases are not instances of true inheritance; they do not signify a change in the hereditary constitution but an influence on the germ cells of a nutritive or chemical sort comparable with what takes place when fat stains are fed to animais; the eggs of such animals are stained, and the young which develop from such eggs are also stained, though the germinal constitution remains unchanged. The very fact that the changed condition is reversible and that it disappears within a short time is evidence that it is not really inherited.

In conclusion: (I) Developed characters, whether "acquired" or not, are never transmitted by heredity, and the hereditary constitution of the germ is not changed by changes in such characters. (2) Possibly environmental stimuli acting upon germ cells at an early stage in their development may rarely cause changes in hereditary constitution, but changes produced in somatic cells do not cause corresponding changes in the hereditary constitution of the germ cells. (3) Germ cells like somatic cells may undergo modifications which are not hereditary; if starved they may produce stunted individuals and this effect may last for two or three generations; they may be stained with fat stains and the generation to which they give rise be similarly stained; they may be poisoned with alcohol or modified by temperature and such infuence be carried over to the next generation without becoming herelitary. All such cases are known as "induction" and many instances of the supposed inheritance of acquired characters come under this category. (4) Environment may profoundly modify individual development but it does not generaily modify heredity.

\section{THE OTHER SIDE OF THE QUESTION}

It will have been noted that the chief objection to the idea of the possibility of acquired characters being inherited comes to us as a heritage of the rather extreme Weismannian concept of the "germ 
plasm." According to this view as brought out in another place (p. 20I), there is an unbroken continuitv from generation to generation of the germ plasm. Germ cells are thought of as remaining entirely undifferentiated for any somatic function and as therefore capable of starting at the beginning to develop a new individual. The germ cell is supposed to be "set apart at an early period in a given individual; it takes no part in the formation of the individual's body, but remains a slumbering mass of potentialities which must bide its time to awaken into expression in a subsequent generation."

Physiologists object to this idea that the germ cells are so distinctly different from body cells and that they are so insulated, as it were, from the soma as to be immune to any changes that may affec. the latter. Two kinds of data are offered in opposition to this con cept. A few observers, notably Professor C. M. Child, have described cases in which somatic cells, that already had become differentiated as primitive muscle cells, lost their differentiation and returned to a germinal condition. If this kind of thing were general, and it is probably not, germ cells might conceivably be prorluced from functioning soma cells and might therefore furnish a mechanism for the transmission of the effects of use and disuse. It should be emphasized, however, that, among animals at least, there is extremely little evidence in support of the idea that differentiated body cells give rise to germ cells.

Among plants, however, a different situation prevails. In the Begonia, for example, any part of a plant if cut off is capable of producing a whole new plant. Even a purely vegetative organ like a leaf, if cut off and partially buried in soil, will bud off a new plant which will produce flowers with perfectly typical germ cells. We have to admit, in this case, either that leaf tissues contain undifferentiated germ cells or that somatic tissues give rise to germ cells. The first alternative is in harmony with the germ-plasm hypothesis, the second is the preferred view of the opponents of this hypothesis.

Among animals, as for example annelid worms, it is quite conmmon to find the germ cells aggregated in a few segments of the body. If a part of the body in which there are no recognizable germ cells be cut off, it will, under proper conclitions, regenerate the lost parts and become a complete worm with functional germ cells. The same alternative explanations that were offered for the Begonia case apply equally well here. Numerous other cases of the same sort are well known to all zor̈logists. To the advocate of the "germ-plasm" theory 
they offer no difficulties because he can always fall back upon the statement that, among the lower forms at least, there is reserve germ plasm equilly distributed over the whole body ready to differentiate into detinite germ cells when needed. This type of appeal is abhorrent to the physiologist, and with some justification, for it really begs the question by assuming that any cell that is capable of forming germ cells belongs to the more or less sacred lineage of germ plasm.

If we confine the application of the germ-plasm idea to the higher animals, such as vertebrates and insects, we would obviate these chief objections, and the present writer would take the view that it is only among the upper ranges of highly specialized animals that the continuity of the germ-plasm concept holds solidly.

Another chief objection to the germ-plasm concept has to do with the supposed insulation or apartness of the term plasm. Physiologists have found that there is an extremely intimate correlation in function between practically all parts of a living organism. Many of the structures, such as the rudimentary pituitary body, the thyroids, the adrenal body, and various other bodies whose function was long unknown, have now been shown to exercise a profound effect on the development of the whole body. Since practically all tissues are known to affect at least some other tissues, is it likely, the physiologist asks, that none of the other tissues affect the germinal tissues? The organism is to be viewed, it is said, not as a collection of independently functioning parts, but as a single coherent unit. On this view no tissue can be thought of as beyond the influence of organic changes.

The classic argument of the Weismannians was that we can conceive of no mechanism by means of which somatic changes can be carried back into the germ cells, and therefore there is no such mechanism. Now the fallacy of this argument is obvious; even if we could conceive of no suitable mechanism for this purpose, this does not preclude the existence of such a mechanism. Moreover, according to Professor Guyer, just such a mechanism actually exists, as will be brought out in the follorving quotation from one of his recent publications.

\section{A POSSIBLE MIECHANISM FOR TIE TRANSMISSION OP ACQUIRED CHARACIERS ${ }^{1}$}

\section{MICHAEL F. GUYER}

Some selectionists glibly assert that new characters arise as the result of spontaneous changes in the germ. What is meant by this?

"From M. F. Guyer, "Immune Sera and Certain Biological Problems." American Naturalist, Vol. LV ( 102 r) 
Just what is a spontaneous change? No one has ever succeeded in telling us. And we may suspect, though perhaps it is heresy to do so, that it is a well-sounding phrase that is the equivalent of the three words, "I don't know." Unwilling to admit of the modifying influence of external agencies on the germ, such theorists resort to the fiction of a spontaneous change. Coleridge somewhere has said, "What's gray with age becomes religion." We have toyed so long with this idea of germinal continuity and the invulnerability of the germ, that it has become for some of us wellnigh sacrosanct. Living matter is living matter wherever it may be found, but when it hoppens to be in the germ-cells, verily, "this corruptible has put on incorruption and this mortal immortality"!

Now, no one to-day, qualified by his knowledge of embryology and genetics to the right of an opinion, would, I think, deny that the new organism is in the main the expression of what was in the germline, rather than of what it got directly from the body of its parents, but does this fact necessarily carry with it the implication that the germ is insusceptible to modification from without? Is not the serum of organisms with blood or lymph an excellent medium through which external influences may operate upon it? Is it not more reasonable to postulate the origination of germinal changes through some such mechanism as this than to attribute it to nysterious "spontaneous changes"?

With such thoughts in mind $I$ and my research associate, Dr. E. A. Smith, set about making various tests. Without attempting to tell you of our as yet unsuccessful attempts to secure cytolysins which will operate in the developmental stages of such periodically renewed structures as feathers, or to weary you with the history of our various other failures-of which there are an abundance-I wish to speak briefly about certain antenatal effects we secured in rabbits by neans of fowl-serum sensitized against rabbit crystalline lens, and of the fact that such induced defects may bccome heritable.

The crystalline lens of the rabtit was selected as antigen, and fowls as the source of the antibodies. The lenses of newly killed rabbits were pulped thoroughly in a mortar and diluted with normal saline solution. About four cubic centimeters of this emulsion was then injected intraperitoneally or intravenously into each of several fowls. Four or five weekly treatments with such lens-emulsions were given. Then a week or ten days after the last injection the blood-serum of one or more of the fowls was used for injection into pregnant rabbits. The rabbits had been so bred as to have the young advanced to about 
the tenth day of pregnancy, since from the tenth to the thirteenth day seems to be a particularly important period in the development of the lens. It is then growing rapidly and becomes surrounded by a rich vascular network that later disappears. From four to seven cubic centimeters of the sensitized fowl-serum were injected intravenously nto the pregnant rabbits at intervals of two or three days for from ten days to two weeks. Several rabbits died from the treatment and many young were killed in utero. Of sixty-one surviving young from mothers thus treated, four had one or both eyes conspicuously defective and five others had eyes which were clearly abnormal. It is possible that still others were more or less affected, since we judged only by obvious, visible effects. We found later in some of the descendants of these individuals that rabbits which passed for normal during their earlier months subsequently manifcsted traces of defects in their lenses or in other parts of the eye.

The commonest abnormality seen in both the original subjects and in their descendants was partial or complete opacity of the lens, usually accompanied by reduction in size. Other defects were cleft iris, persistent hyaloid artery, bluish or silvery color instead of the characteristic red of the albino eye, microphthalmia and even almost complete disappearance of the eyeball. Taking into account the method of embryological development, however-the relation of lens, optic cup, and choroid fissure - the defects are probably all attributable to the early injury of the lens. In some cases, both among originals and descendants, an eye microphthalmic at birth may undergo further degeneration such as collapse of the ball and what appears to be a resorption as if some solvent were operating upon it. The eyes of the mothers apparently remained unaffected. This is probably due to the fact that the lens tissue of the adult rabbit is largely avascular and therefore did not come into contact with the injected antibodies.

That the changes in the eyes of the fetuses resulted from the action of lens antibodies is indicated by the fact that in not one of the fortyeight controls obtained from mothers which had been treated with unsensitized fowl-serum or with fowl-serum sensitized to rabbit tissue other than lens, was there evidence of eye-defects, and I may add, that among the hundred or more young obtained later from mothers which were being experimented upon with various types of sera or protein extracts, for other purposes, not a single case of eye-defect has appeared. 
As already stated, once the anomaly is secured it may be transmitted to subsequent generations through breeding. So far we have succeeded in passing it to the eigh th generation without any other than the oririnal treatment. The imperfection, indeed, tends to become worse in succeeding generations and also to occur in a proportionately greater number of young. Though not analyzed completely as to its exact mode of inheritance, it has in general, the characteristics of a Mendelian recessive. Like such anomalies as brachydactyly or polydactyly in man, the transmission is not infrequently of an irregular, unilateral type, sometimes only the right, at others only the left eye showing the defect. In the later generations, probably in some measure as the result of selective breeding, there is an increasing number of young which have both eyes affected.

To determine whether the reappearance of the defect was due merely to the passing on of antibodies or kindred substances from the blood stream of the mother, or to true inheritance, we mated defectiveeyed males to normal females from strains of rabbits unrelated to our defective-eyed stock. The first generations produced in this way were invariably normal-eyed, but when females of this generation were mated to defective-eved males again, we secured defective-eyed young after the manner of an extracted Mendelian recessive. It is ofvious that in such cases the abnormality could only have been conveyed through the germ-cells of the male, and that it is, therefore, an example of true inheritance. Subsequent matings have shown that these young transmit the eye-anomalies as effectively as do individuals of the original lines. A new strain of defective-eyed young, established about the time our original paper went to press, is also flourishing and, as regards transmission of the defect, seems to differ in $\mathrm{n}$ o way from the earlier stock.

But now, let us inquire as to where all this leads. Without entering into a discussion of just what, serologically, is taking place in the body or in the germ of fetuses borne by the lens-treated mothers, the point I wish to emphasize is that a certain specific effect has been produced; and, what is of greater moment, once the condition is established it may be not merely transmitted, but inherited. Whether the lens of the uterine young is first changed and then in turn induces a change in the lens-producing antecedents in the germ-cells of these young, or whether the specific antibody simultaneously affects the eyes and the germ-cells of the young is not clear. In any event it is evident that there is some constitutional identity hetween the 
substance of the mature organ in question and the material antecedents of such an organ as it exists in the germ.

Biologically considered, the most significant fact is that specific antibodies can induce specific modifications in the germ-cell. Whether these antibodies are transmitted from the mother's blood or engendered in that of the young would seem to be of secondary importance. It stancls to reason that antibodies originated in an animal's own blood will modify germinal factors if corresponding antibodies introduced from without can accomplish this.

The whole question as to how important such a fact may be in contributing to an understanding of the causes of the geminal changes in organisms in general, which lead to variation and evolution, hinges on the question of whether changes in an animal's tissue will induce the formation of antibodies or kindred active substances in its own body. We have been steadily accumulating evidence that such reactions do occur.

In our own laboratory, for example, after many attempts we have succeeded in securing a defective-eyed young rabbit from a mother of normal stock by injecting her repeatedly with pulped rabbit lens before and during pregnancy. Since the young rabbit in question has both eyes badly affected there can be no question that a rabit can build antibodies against rabbit-tissue which are as effective as those engendered in a foreign species such as the fowl. We have likewise found it relatively casy to secure spermatoxins by directly injecting rabbits, both male and female, with rabbit spermatosoa. Moreover, a given male will develop antibodies against his own srermatozoa if he is injecter intravenously with the latter.

Vie are also securing evidence that seroloric reactions induced in the fetus through operations on the mother are not mere passive transmissions, but may become actively participated in by the tissues of the letus. For example, female rabbits sensilized with typhoid vaccine followed by living typhoid germs may transmit to their young and even to their grand descendants the ability to agrolutinate typhoid hacilli in serum dituter from 60 to 60 times. From the standpoint of heredity we have no reason so far for maintaining that this is anything but placental transmission, though we are going to practice immumization gentration after greneration for a number of generations w detemine if a truly hereditary immunity will be established. However, facis have come to light which show that there is more concerned in the oferalion than a mere transfer of antibodies from mother to 
fetus. For instance, the blood of young shortly after birth may show a higher titer than that of the mother. Arain, after two or three months of development the young of certain of the sensitized mothers have shown a rather sudden rise in titer, much above that of the mothers. In such cases it would seem that some mechanism in the young rablit itself is constructing antibodies which supplement those passively derived from the mother. Possibly in the process of development some organ important in such reactions just came into functioning. If this is true further experiments may throw some light on the perplexing question of the source or sources of the antibodies in an animal. After a few weels, in such cases, the titer drops back again. In still another set of experiments we found that young from a sensitized mother, when nursed by a normal untreated mother, retained a fairly high titer for several months and even showed the rise of titer mentioned. On the other hand, young of an untreated mother when nursed by a sensitized mother acquired a fairly high titer from the milk of the foster mother but lost it rapidly after weaning time. Thus there are evidently constitutional factors operative in the young which have acquired their immunity through the placenta which are absent in the young whose antibodies were conveyed through food.

That clianges in the blood serum may be caused by changed conditions in the tissues is further attested by many facts. For example, in pregnancy, the newly forming placenta may set free cells or cellproducts which, sometimes at least, cause changes in the blood-serum of the mother, though the exact nature of these changes is in dispute. Romer, using the complement-tiration technique, found that the serum of adult human beings may possess antibodies for their own lens proteins. Bradley and Sansum, employing anaphylactic reactions, found that guinea-pigs injected with guinea-pig tissue-proteins (liver, heart, muscle, testicle, kidney) develop immunity reactions. Again during the late war, the type of toxic action to which anaphylactic shock conforms was found to exist after extensive injury of the soft tissues. It resulted apparently from the absorption of poisonous substances of tissue origin into the circulation. In fact, various cells and tissues when injured liberate such poisons, and even blood in clotting is known to acquire a transient toxicity of this type.

With facts such as these before us, is it not a rational hypothesis to assume that changes in various parts of a body may on occasion influence the representatives of such parts in the germ-cells borne by that bodv? This appears all the more probable when we recall the 
facts learned from a study of precipitins and of anaphylaxis that each species of animal has a thread of fundamental similarity underlying the proteins of all its tissues. There is no reason to suppose that germinal tissue forms an exception. The further fact that homologous tissues, though existing in different species of animals, possess similar chemical characteristics, shows that to get an effect there need not be absolute chemical identity between the substance of such a tissue as the lens and the germinal constituents of which it is the expression. And if this is true for lens, why not for other tissues?

The blood-serum of any organism with blood thus affords a means of conveying the effects of changes in a parental organ to the germcell which contains the antecedent of such an organ. As long as there is little change in the somatic element its germinal correlative would presumably remain constant, but any alternations of the soma which give rise to the formation of anti-bodies or other active agents, particularly if long continued, might induce changes in the germ. Such a hypothesis would seem to be plausible at least in accounting for degenerative changes such as the deterioration of eyes in such forms as the mole, or in fact, in the formation of vestigial organs in general.

On the other hand, there is no reason to infer that changes induced in the blood-serum may not also be instrumental in leading to progressive as well as regressive evolution. If we may have germinally destructive constituents engendered in the blood there is no valid reason for supposing that we may not also have constructive ones. When we learn more about what initiates and promotes growth in a part through exercise, or what causes hypertrophy of an organ, we may likewise find how corresponding germinal antecedents of that part may be enhanced. Until such time we shall probably remain in the dark regarding the mechanism of progressive germinal changes. As already indicated, in the hormones and chalones we have a wonderful series of secretions normally circulating in the blood and maintaining general physiological equilibrium. That reciprocal stimulations of various organs occur by this means is a well-established fact. Hypertrophy or atrophy of an endocrine gland may produce pronounced effects in the furthermost reaches of the body. Again we may inquire, is it reasonable to suppose that the germinal tissues will be inviolate to all this ebb and flow of chemical influence? Should we not expect specific reactions or selections here no less surely than in other tissues? Destruction of the pars buccalis of the hypophysis in the frog-tadpole will cause profound alteration in other endocrine organs such as the 
adrenals and thyroids, will retard the growth rate, render the entire organism albinous, and produce in the individual pigment cells a condition of sustained contraction. Shall we conclude that such a farreachin $r$ influence as this, particularly in a developing organism, will pass the germ-cells by unscathed?

Similarly, growth in man is known to be controlled by a pituitary secretion that is carried by the blood to the various organs. The normal development of secondary sexual characters is determined by products from the testes or ovaries, and the activities of the generative organs themselves are intimately associated with the functioning of the adrenal and other glands. The periods of ovulation are inhibited by secretions from the corpus luteum; lactation is incited by products of the corpus luteum, the involuting uterus and the placenta; the carbohydrate metabolism in the liver and even in the most distant muscles is profoundly influenced by substances formed in the pancreas; the pancreas, liver, and intestinal glands are set to secreting through the stimulus of a product formed in the duodenal and jejunal mucosae. And still others of such remarkable interrelations can be cited.

Truly one may pronounce that social complex of reciprocating individuals termed cells which make up an organism, "members one of another." And with ail of these co-operative activities of the various parts of the body it is inconceivable to me, at least, that the germ-cells, bathed in the same fluid, nourished with the same food, stand wholly apart.

May we not surmise then that as regards inheritance and evolution, Lamarck was not wholly in error when he stressed the importance of use and disuse of a part, or of modifications due to environmental change, in altering the course of the hereditary stream, particularly if we conceive of these influences as being prolonged, possibly over many generations? Have we not in the serological mechanism of the body of animals an adequate means for the incitement of the germinal changes which underly certain aspects of evolution?

\section{RECENT EXPERIMENTS BELIEVED TO FAVOR THE LAMARCKIAN THEORY}

Guyer and Smith, in continuation of their earlier program, reporı that they have induced hereditary changes in the eyes of fetuses by a much simpler method than that described above. By simply destroy- 
ing the lens of the living female rabbit by "needling" in situ, anti-lens serum has been produced in the blood of these animals. This material was as effective in preventing the development of lenses in some of the fetuses of these mothers as was the material produced by more elaborate scrological methods. Also the effects seem to be inherited in the same way as in the former experiments. It should be noted that Guyer is very cautious in his statements and makes no claim that his work demonstrates the inheritance of acquired characters. He realizes that the same specific material that is supposed to inhibit the development of eye structures in the young fetus might readily at the same time exert a specific influence upon the genes or factors for eye structures in the primordial germ cells that live contemporaneously with the somatic structures. Thus two generations might be affected simultaneously - a case of parallel induction.

Every important experiment in science becomes the target of attack, and the experiments of Guyer and Smith are no exception. Bagg and Hanson and Little have performed some very interesting experiments on the effects of radium emanations and of $\mathrm{X}$-rays on mammalian germ cells, and Stockard has used alcohol in the same way. All of these workers show that eye defects, especially lens defects, are found most commonly, occurring sometimes in the entire absence of other observable defects. It would seem, then, that eye defects are far from being specific, and they may not be specific in the experiments of Guyer and Smith. There is no question but that the eye is the most susceptible part of the organism and that eye defects can be induced in vertebrates by almost any kind of inhibiting agent. It was only when Guyer used the lens material, however, that he got lens defects; for when he used sera developed from other tissues no effect upon the lens was noted. But no effect upon any other tissue was noted, seeming to show that no effective antigens of any sort were formed. It is impossible at the present writing to predict what will be the final bearing of Guyer's and Smith's very significant experiments upon the problem of the inheritance of acquired characters.

Griffith and Detlefson have recently reported some experiments upon mice that at first seemed almost crucial for our problem. Rats were reared for several months in cages placed upon rotating tables. They became adapted to the rotating condition to such an extent that when the rotation was stopped they seemed upset, showing signs of nystagmus (dizziness) and other symptoms of a changed physiological condition. Some of the young born outside the cages showed irregulari- 
ties in their gait and other signs of nystagmus. Moreover, the young of parents rotated of the keft showed different effects from these of parents rotated to the right. The condition is said to have been inherited for several generations. Inelefson, however, noted that the whirled rats and their offojomg showed frequent pathologrical sequetale, such as discharges from the cars, and is now inclined to wonder "whether Griftith has not morely presented us with numerous specimens of some vertelnal disease." The implication is that the disease once starter! might be massed on to future generations by infection. It

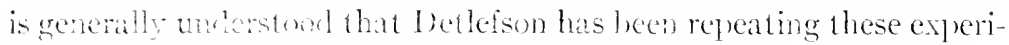
ments upon the Wistar Institute standard white rats, and that his results are so far negative.

And thus stands the problem torlay. It is no more settled than it was fifty years ago, but most of us are growing to be at little pessimistic about the whole matter. 


\section{CHAPTER XXXII}

\section{OTHER POSSIBLE GUIDING FACTORS}

Orthogenesis.-Geneticists as a rule feel that natural selection is the only guiding factor needed to account for the ar'aptive features of erolution. They are inclined to be skeptical about the definiteness of the pathways of change that have been so strongly emphasized by palaeontologists and others. T. H. Morgan at one time expressed the view that most of the beautifully precise orthogenetic pedigrees, such as that of the horse family for example, might be made up by selecting only those fossil forms that fitted well into the progressive series and ignoring those that did not fit so well. He showed that one could make out a very pretty phylogeny of the spear heads displayed in museums, in which each type leads to another type and all are capable of arrangement into a few "orthogenetic" series. Since such a series is merely an artificial arrangement without phylogenetic significance, the same might also to some extent be true for the orthogenetic series of the palaeontologist. Some geneticists are inclined to think that the erolution of the horse family, for example, had been much less definitely directed than it is commonly supposed to be. In each period there existed numerous less progressive types and many aberrant species, as well as those that seem to follow the more direct lines leading to the modem horses. In other words, much of the definiteness of direction is the result of focusing attention upon a few of the types that make a good series and ignoring the ones that are not in line. This criticism is pussibly too iconoclastic. There surely is in the horse pedigree some cefiniteness of trend amidst a flux of indefiniteness. Hence the problem of explaining this residual definiteness still remains.

In recent years one of the staunch supporters of the reality of orthogenesis has been $H . F$. Osborn. His most striking material, perhaps, consists of the fossil pedigrees of the Titunotheres, a group of extinct ungulates somewhat resembling the modern rhinocerus. They appeared relatively early in the evolution of mammals, and attained giant proportions, great abundance, and wide distribution before becoming extinct at the close of the Oligocene period. Though the titanotheres started as small creatures about the size of terricrs, they reached almost the dimensions of elephants near the close of their career. One of 
their outstanding peculiarities consists of a unique type of horn on the tip of the nose, a horn branching at the base and diverging laterally into two llat prongs. Osborn distinguishes at least four divergent lines of evolution among these mammals. Line I retained the front teeth (incisors) and remained heavy bodied. Line II lost the incisors and became longer limbed, lighter bodied, speedier, and went in for grazing. In neither of these lines did the horns grow very large. Line III, the first of the large-hornerl lines, lost the incisors and remained relatively smail boriied. Line $\mathrm{IV}$, to which the giant Brontothcrinm belongs, retained the incisors, grew extremely bulky, and went in for slow, leisurely browsing.

In all these four lines that are known to have separated early and to have remained genetically independent throughout their careers, the evolution of the horns has run parallel courses. All four lines started hornless, each dereloped homs independently, and the steps in horn evolution ran the same course in all the four lines, going somewhat farther in the larger types than in the smaller. In the last surviving representatives of all four lines the horns had reached the same characteristic form, being attached to the same bones of the shull and having a shape quite unlike that known for any other group of mammals.

The inferences that have been drawn from this situation are as follows: The original ancestral titanotheres must have had something in the germ plasm that was predestined to vary along certain definite lines and to produce certain definite structures, in spite of any differences in environment or haljits of the different lines of descendants. The horns were compelled to appear at a certain stage in the evolution of each of the four lines, though they may have had little or no adaptive value. Osborn has no very satisfactory theory as to the mechanism involved in this renarkable orthogenesis, but Julian Huxley has offered a purely physiological explanation of horn evolution in titanotheres, an explanation that may apply equally well to many other cases. He has discovererl that in horned animals in general, the larger the individual is, the larger are the horns in proportion to the body size. Yow, as is true of most phylogenetic series, there was a steady increase in size in all four lines of titanotheres. Thus the earliest titanotheres were too small to have horns at all, the first horned types were of moderate size, the most claborately horned types were the giant endroducts of each of the four lines, and especially was this the case for he great Brontotherizm. 
If, then, as scems to be the case, horn evolution is merely a secondary and purcly incidental consequence of increase in size, we may well ask why increase in size goes on so steadily. Is this not an orthogenetic process itsclf? But increase in size may be guided by natural selection without the aid of other factors, for increase in size confers a personal advantage upon the individual, though it may in the end be damaging to the race. Thus, a larger bull in a herd will be stronger and win more mates, thus tending to pass on the genes for larger size to descendants.

Darwin would have called the case of horns in titanotheres an example of "correlated variation" and would have said that here we have an instance of some adaptive characteristic such as body size carrying along with it a variable character that may have little or no adaptive value. Thus this classic case of orthogenesis would be explained satisfactorily as the result of correlated variation and natural selection without dragging in any inner guiding principle.

In view of these and many other facts, it seems advisable, for the present at least, to say nothing further about orthogenesis. No very good case of orthogenesis has been presented that cannot be explained as well by natural selection as in any other way that has been suggested. So little do geneticists as a group think of orthogenesis as a possible guiding factor in evolution that most textbooks of genetics do not mention the word even in the index. Orthogenesis is at present a concept that belongs rather to the philosophy of evolution than to the science of genetics.

Vitalistic theorics.-All theories of evolution based on known mechanisms are considered as mechanistic and belong in the realm of science, but there are some theories known as "vitalistic" that belong more to the realm of philusophy than to that of science. Several of these theories deal with some kind of immaterial force or forces that are believed to guide the course of evolution. Bergson's élan vilal, or vital urge, is one of these immaterial forces. This force is belicved to be practically symonymous with life itself. It is that property of life that gives to it a drive forward, a tendency to grow, multiply, and adapt itself. In a sense, it is a sort of inarticulate purpose residing in the living substance itself. This protoplasmic purpose continually expresses itself in adaptive development and arlaptive behavior. It realizes itself most completely as mind, purpose, and reason in higher organisms; but its essence is present in even the lowest organisms and in the youngest stages of the inclividual. It guides the course of in- 
dividual development, each step of which seems to be in preparation for the next, as though taken in anticipation of it.

The reater may well revolt against the introduction of speculations of this sort into a treatment of the mechanism of erolution; lut if such a concept as fin rital does nothing more than to serve as a commast with the more tangible and verifable mechanisms of evolution we have previously dealt with, it will have justified the space given 10 it. 


\section{CHAPTER XXXIII}

\section{DIVIDING FACTORS. ISOLATION}

Introductory.-As has so often been pointed out, one of the most conspicuous features of animal and plant life is their subdivision into a multiplicity of taxonomic divisions, such as phyla, classes, orders, families, genera, species, and varieties. In any one particular environment one finds large numbers of representatives of numerous groups, a fact that seems to imply that the environment alone is an insufficient cause of multiplicity of forms, for if it were, a single environment should produce only one type, and the same environment should always produce the same type. Also, it is very frequently true that differences distinguishing two allied species are not obviously adapted to the differences in the environment, but are rather trivial characters such as color markings, proportions of parts, etc. Hence we cannot explain the multiplicity of types on purely environmental grounds.

Our studies of geographic distribution as evidences of evolution have emphasized the fact that mere geographic isolation, apart from climatic differences involved, are invariably accompanied by various degrees of divergence between the isolated members of the same group, the divergence sometimes being so great as to constitute family distinctions, more frequently generic, and very commonly specific or varietal. The degree of divergence parallels closely the degree of completeness of isolation and the extent of time during which isolation has been operative.

Opinions among authorities differ as to whether mutations and selection alone are sufficient to account for the multiplicity of forms and their distribution in space. Some of the more extreme neoDarwinians, on the one hand, are inclined to believe that natural selection is sufficient unto itself to explain all of the observed facts. Extreme advocates of the isolation theory, on the other hand, look upon isolation as an absolutely essential mechanism for species formation nearly as important as natural selection itself. The writer believes that isolation is an absolutely essential part of any complete explanation of evolution, but that it is a subsidiary factor often working in such intimate relation with natural selection and Mendelian heredity as to be almost inseparable from them. 
"Isolation" used in the broadest sense.-The term "isolation" is a somewhat unfortunate one to use for the type of factor we are here dealing with. It implies physical separation in the geographical sense, whereas there are very many types of isolation not at all based upon spatial separation. In the broadest sense, any factor may be said to play an isolating rôle if it interferes with free interbreeding among all the members of a species. Completely free interbreeding within the entire range of a species would result sooner or later in an equal distribution among the individuals of the species of all viable hereditary changes. Unless something were to interfere with free interbreeding within the species, it would remain indefinitely one evolving unit and would not sublivide.

But there are a great many ways in which free interbreeding may be interfered with. Among the most important isolating agents are the following: (a) geographic isolation, involving the setting-up of geographic barriers between subdivisions of the species; (b) sheer distance apart of extreme sections of a species covering a large territory, not involving any other isolation agencies; $(c)$ climatic differences within the range of the species; $(d)$ physical differences in the environment, such as differences in water, soil, sunlight, elevation of land, etc.; (e) biotic differences in the environment, involving the presence of various other animals and plants within the range of the species in question; $(f)$ reproductive differences among individuals, due to genetic changes, that alter the developmental rhythm or the copulatory apparatus, bringing about assortative mating; and $(g)$ psychic differences, that result in what is known as clannishness among human beings, according to which changed forms tend to mate with their own kind more readily than with others.

All these, and doubtless other agencies, promote isolation of small or large groups within the species and tend to split the species up into a number of more or less separately breeding groups.

Isolation and inbreeding. - One of the inevitable consequences of the isolation of a relatively small group from the main body of the species is inbreeding, more or less close. In extreme cases of geographic isolation a new race may be derived from one pair of individuals. The offspring of such a pair, if they breed at all, must breed together, and for successive generations there will be much close inbreeding. Geneticists have demonstrated that continuous inbreeding results in a decrease of heterozygous and an increase in homozygous individuals. Now, even if no new mutations occurred nor any selection of types due 
to changed environmental requirements took place, such an isolaterl group would alrearly have a good start toward becoming a separate race or species because of the effects of inbreeding.

Isolation and selection.-Divergence may also be promoted by selection. When an isolated group of a species finds itself in a different environment from that of the parent stock, selection may tend to preserve individuals with either the dominant or the recessive of any unit character or any combination of these that may happen to be more arlvantageous than others under the changed conditions of life. In this way some genes may be entirely eliminated from a stock, thus increasing the genetic differences between the parent species and their isolated derivatives. If, for example, a small section of a species were to become isolated in a region where the available food was quite different from that in the main range of the species, some of the individuals, because of favorable combinations of unit characters, might immediately find themselves better equipped to cope with the new food conditions than others. Those adapted to the new food conditions would live and breed together and would tend to become homozygous for the various characters that favored their survival under the new conditions.

\section{TIIE VARIOUS CATEGORIES OF ISOLATION}

a) Geographic isolation.--Taxonomists who have studied and plotted the distribution of species of animals and plants are most familiar with the effects of geographic isolation. They consider that one of the most certain facts of nature is that isolation is always accompanied by marked differences between the isolated branches of a species. The late Darid Starr Jordan, ${ }^{\mathrm{I}}$ a leading student of geographic isolation in America, rliscusses the subject in a very illuminating fashion:

"It is now nearly forty years since Moritz Wagner (IS6S) first marle it clear that geographic isolation (rïumlicke Sonderung) was a factor or condition in the formation of every species, race, or tribe of animal or plant we know on the face of the earth. This conclusion is accepterl as almost self-evident by every competent student of species or of the geographical distribution of species. But to those who approach the subject of evolution from some other side the principles set forth by Wagner seem less clear. They have never been confuted, scarcely ever attacked, so far as the present writer remem-

rScience, N.S., Vol. XXII (1905) 
bers, but in the literature of evolution of the present lay they hat been almost universally ignored. Nowarlays much of our discusion turns on the question of whether or not minute favorable varations would enable their possessors lit tle by lit le to gain on the parent stock so that a new race would be established side by sile with the okl, or on whether a wide fluctuation or mutation would give rise to a new species which would hold its own in competition with the parent. In theory. either of these conditions might exist. In fact, both of them are virtually unknown. In mature a closcly related distinct species is not often quite side by side with the old. It is simply next to it, geographically or geologically speaking, and the degree of distinction almost always bears a relation to the importance or the permanence of the barrier separating the supposed new stock from the parent stock.

"A flood of light may be thrown on the theoretical problem of the origin of species by the study of the probable, actual origin of species with which we are familiar or of which the actual history or the actual ramifications may in some degree be traced.

"In regions broken by few barriers, migration and interl)reeding being allowed, we find widely distributed species, homogeneous in their character, the members showing individual fluctuation and climatic effects, but remaining uniform in most regards, all representatives slowly changing together in the process of adaptation by natural selection. In regions broken by barriers which isolate groups of individuals we find a great number of related species, though in most cases the same region contains a smaller number of genera or families. In other words, the new species will be formed conditioned on isolation, though these same barriers may shut out altugether forms of life which would invade the open district.

"Given any species in any region, the nearest related species is not likely to be found in the same region nor in a remote region, but in a neighboring district separated from the first by a larrier of some sort.

"Doubtless wide fluctuations or mutations in every species are more common than we suppose. With free access to the mass of the species, these are lost through interbreeding. Isolate them as in a garden or an enclosure or on an island, and these may be contimued and intensified to form new species or races. Any horticulturist will illustrate this.

"In all these and in similar cases we may conficiently affirm: The adaptive characters a species may present are due to natural selection 
or are developed in connection with the demands of competition. The characters, non-adaptive, which chiefly distinguish species do not result from natural selection, but from some form of geographical isolation and the segregation of individuals resulting from it."

J. T. Gulick, another exponent of the efficacy of geographic isolation in species-forming, has offered in evidence of his views facts about the distribution of Hawaiian land snails. In the island of Oahu, for example, the volcanic ridges have been eroded out into a series of isolated valleys in the bottoms of which grows abundant vegetation, while on the highlands there is little but barren rock. The climatic conditions of all the numerous valleys are the same, but, remarkably enough, each variety of snail is confined not only to one island, but to a definite valley on an island. The degree of difference, moreover, between varieties is in proportion to the distance that separates them. Gulick claimed that he was able to estimate the degree of divergence between the snails of any two valleys by measuring the number of miles that lay between them. Gulick's findings have been extensively corroborated by recent explorations on the snails of other oceanic islands by Crampton.

An interesting type of isolation that hardly can be termed geographic, yet is essentially equivalent to the latter in its effects, is found in connection with the extensive group of lice (Mallophaga) that live their whole lives buried among the feathers of birds or the hair of mammals. These animals cannot fly and are quite effectively isolated for life upon a particular bird. They do, however, during the intimate period of nesting, pass from parent to offspring, so that they may be said to be isolated upon definite genetic lines. In the case, especially, of birds like the eagle, a bird of long life and monogamous habits, the parasite becomes as isolated as might be a race on a small island. The result is that sometimes the lice of a single bird and its offspring are of quite a distinct variety, which has become fixed by inbreeding until a high degree of uniformity has been attained. Such an isolated variety may be almost as distinct as a true species. Obviously in this case, as in others, isolation must have had a real effect upon speciesforming quite apart from natural selection, except in so far as the unfit variants have not survived.

Populations of "lakes and ponds-Just as islands of land in seas of water serve to isolate terrestrial forms, so islands of water in seas of land, if we may be pardoned the expression, just as effectively isolate aquatic organisms. Thus, isolated ponds and lakes commonly harbor 
species of fishes and other aquatic types different from those found anywhere else in the world. As a young naturalist, I became interested in the fauna of Lake Maxinkuckee in Indiana, a spring-fed lake that is practically cut off from communication with other bodlies of water. While I was there, Evermann and Clark were making a very exhaustive biological survey of this lake and discovered a surprising number of species peculiar to this one body of water. Hundreds of similar situations doubtless exist all over the world.

Populations of mountuins.-Certain types of plants characteristic of high mountains are commonly isolated from others of their kind by valleys and by discontinuities in mountain chains. Patches of lowland thus isolate patches of mountains; and the result is, as one might expect, that each isolated high mountain chain has its own local races or sub-species of plants.

b) Isolation due to sheer distance apart.---If a species ranges all over a wide extent of territory which is unbroken by barriers, there may be isolation because of the great distances between extreme outlying sections of the range. Students of the evolution of great groups of mammals, for example, consider that very large continental bodies must have been the main theaters of evolution, because smaller land bodies would not permit of diversification of types through isolation. Thus the body of land known as "Holarctica," embodying Northern Asia, Northern Europe, and Northern America, is believed to have been the principal theater of mammalian evolution. In this great area there was plenty of room for groups to become spatially isolated even without positive barriers, and in this area it is believed that all the original divergences occurred that gave origin to the princple subdivisions of mammals. Migration along many southern routes has subsequently more completely isolated and fixed the various mammalian faunas of Southern Asia, Australasia, Africa, and South America.

The original divergences resulting from mere spatial isolation would be the result of the inability of the most widely separated sections of a species to interbreed. If they failed to interbreed, mutations occurring in one section would remain in that section and those occurring in another section would likewise remain in that section. Thus two independent evolutions would go on and local races or varieties would result that in time would become separate species, especially if they subsequently migrated along different paths to different isolated regions. 
A good example of geographic races or sub-specics arising in an extensive area unbroken by effective barriers is seen in the case of the wrens of South America. Wrens are found practically all over that continent; but those in one region differ from those in others in color patterns, size, proportions, and habits. In the absence of barriers all these local races grade into each other. In certain regions, however, that happen to be more than usually isolated, as when a high mountain range intervenes, transitional forms are missing. The point is, however, that whether barriers are present or not, sheer distance apart tends to produce local races.

c) Climatic isolation.--There often occur distinct and more or less abrupt climatic differences within the range of a species which may act as barriers to migration or involve different arlaptive changes on the part of individuals living under these different climatic conditions. Thus, without the presence of any geographic barricrs, a species may split up into a northern and a southern race or sub-species that are genetically distinct, neither thriving in the territory occupied by the other. Similarly, in the oceans there exist rather abrupt differences in temperatures that act as effective barriers. The waters north and south of Cape Cod, for example, have almost entirely different faunas. The reason for this is that the shore-line north of Cape Cod is made cold by the Labrador Current and that south of the Cape is more influenced by the warm Gulf Stream. Species north of the Cape and south of the Cape are almost as distinct as if they belonged to different oceans.

d) Biotic isolation. - The territory occupied by any species of animal or plant is always occupied by many other species. Some of these associated species may occupy one part, some another part, of the range of the species in question. Now each species affects all the other species with which it is spatially associated; each species is a part of the biotic environment of all the others. If, then, the biotic environment varies within the range of the species, the pressure of selection will vary also, certain characters or combinations of characters being more favorable for one biotic environment than another. This being the case, groups in different biotic environments will tend to be isolated from one another and will diverge in both adaptive and non-adaptive directions.

e) Reproductive isolation.--The simplest type of reproductive isolation is one that involves changes due to mutations in the copulatory organs. In some insects, for example, the copulatory organs are con- 
structed on the lock-and-key principle, only a certain pattern of key fitting a certain pattern of lock. Any change in the pattern of these organs prevents the members of the changed type from breeding with the unchanged individuals and forces them to breet only with those that have changed in appropriate fashion. Fortunately, when a change occurs, it usually afiects buth sexes in such a manner that males and females of the changed tỵe can mate. No actual observations of new races arising in this way have been olserved, but there are numerous cases of closely allied species that are intersterile because of slight aiferences in the pattern of their copulatory organs.

One of the most effective moans of bringing about reproductive isolation is a change in the developmental rhythm of a section of a species. If, for example, some plants of a species flower earlier or later in the season than others, they are able to interbreed only with those having the same developmental rate. If such a difference in developmental rate be crenetic, a real isolation of these different races will be effected and further divergence will follow. A similar situation also occurs among animals. The genus ( icada, commonly called "locusts," has probably split up into numerous specics as the result of genetic molifications in the lengths of their life-cycles. Whereas there are only slight morphological differences among the species of Cicala, there are pronounced clifferences in the lengths of the larval periods. In the "seventeen-year locusts," for example, the larval life underground is over sixteen years. As a result of this, only once in seventeen years do the adult broods appear above ground. They must, therefore, mate only with members of their own brood in the same teritory. Similarly, there are fouteen-year, eleven-year, nine-year, and serenvear species, etc., each of which is reproductively isolated in any. territory from all others, for rarely do two species reach maturity in any region during the same season. Even in one species scattered over a wide expanse of territory, different broods appear one or two seasons apart, and this tends to isulate sections of the present species from one another and will doubtless produce further splitting-up of species as time goes on. 1) oubtes many other situations similar to these, but less extreme, exist anong boll animals and plants. That changes in derelopmental rate do exist within a species and have a genetic batsis, is attested by the fact that many early and late fruiting varieties of lomestic plants have lecen isolated, some of which are more suitable for a long sombern growing season and others for the relatively short northens 
f) Psychic isolation.-A synonym for psychic isolation is "clannishness." Even among lower animals there appears to be a welldefined tendency for like to mate with like. "Assortative mating" is another term commonly used to denote this tendency. In man conventional mating is highly assortative. Sporadic sex unions between members of radically different races not uncommonly occur, but formal marriages are rare between members of distinct races. This tends to preserve a residue of racial separateness that would long ago have disappeared except for clannishness.

Examples of this sort of thing in the animal world are not far to seek. Becbe cites the interesting case of two color phases of gannets occupying an old volcanic crater together, but keeping absolutely separate in their breeding activities. The main gannet population consisted of white birds; but out toward the center of the crater there was a small, compact, and unmixed clump of sooty birds, which could doubtless have readily interbred with whites, but never did so, preferring their own kind.

It was Darwin, I believe, who described the case of droves of wild horses of the Caucasus region that were all of one color in a drove. One drove would be all bays; another all blacks; another all chestnuts. Apparently these droves consisted of closely related individuals that preferred to mate only with their own kind. Long-continued reproductive isolation of this sort might readily bring about the origin of separate races, and in time separate species.

Most of the types of isolation briefly discussed above are somewhat nypothetical in that they are derived from observations of nature "after the event," as it were. Very little real cxperimental work has been done in this field except in connection with inbreeding and selection. In animal and plant breeding, man merely isolates a pair of inclividuals, usually beginning with a brother and sister, and begins an inbred line, selecting usually the most promising individuals for further inbreeding. In this way excellent homozygous strains are produced that have peculiar characteristics of their own unlike those of any other strain. Hence, artificial inbreeding and selection is a kind of reproductive isolation having the same effects as has extreme isolation in nature. There can be no dould, then, that the various types of isolation have the effects attributed to them, namely, these of splitting up species and of preserving incipient races from being swamped out by back-crossing with the parent stock 
PART IV

EUGENICS 


\section{CHAPTER XXYIV \\ INTROIUCTLON TO ELGENICS}

Definitions of eugenics.--"Eugenics" is a term coined by Sir Francis Galton in 1833 , and was defined by him as the "study of agencies under social control that may improve or impair the racial qualities of future generations, either physically or mentally." Nore specifically, eugenics is that science which deals with human variation and heredity and attempts to improve the human stock by selective breeding according to the known laws of genetics. In still different words, eugenics may be defined as the application of genetics to man with the hope that man might control his own evolution and save himself from racial degeneration.

Eugenists feel that many of the ills of the world might be cured by an application of eugenic measures. "We must endeavor," says a presildent of the American Eugenic Society, "to show that elgenics supplies the most effective and permanent solution to the problems that have been so ineffectively dealt with hitherto by physicians, public health officials, social workers, clergymen and reformers-the problems of combating disease, disability, deiectiveness, degeneracy, delinquency, vice and crime."

This rather sanguine statement is echoed in somewhat different words ly lennings: "The troubles of the world, and the remedy of these trouliles lie fundamentally in the diverse hereditary constitutions of human beings. Some men are strong, healthy, wise, virtuous. Others are weak, foolish, diseased, immoral, criminal; and it is these that cause the troubles of the world. Laws, customs, education, material surroundings, are the creations of men and reflect their fundamental nature. To attempt to correct these things is merely to treat superficial symptoms. To go to the root of the troubles a better breed of men must be produced; one that shall not contain the inferior types. When a better breed has taken over the business of the world, laws, customs, education, material conditions will take care of themselves. Geod men, wise men, will make a good worle."

In a somewhat roundalout way we have thus defined eugenics by stating the views of some of the leading advocates of engenics. 
The scope of eugenics.-The range of subjects usually considered within the realm of interest of students of eugenics may well be stated by quoting from the prospectus published in connection with the Second International Congress of Eugenics that met in New York in September, r921. The Congress met in four sections each of which devoted itself to one of the major fields of eugenics. The four sections are described as follows:

"I. In the first section of the Congress will be presented, on the one hand, the results of research in the domain of pure genetics in animals and plants and, on the other, studies of human heredity. The application to man of the laws of heredity and the physiology of reproduction as worked out on some of the lower animals will also be presented.

"II. The second section will consicler factors which influence the human family, and their control; the relation of fecundity of different strains and families and the question of social and legal control of such fecundity; also the differential mortality of the eugenically superior and inferior stocks and the influence upon such mortality of special factors, such as war and epidemic and endemic diseases. First in importance among the agencies for the improvement of the race is the marriage relation, with its antecedent mate selection. Such selection should be influenced by natural sentiment and by a knowledge of the significant family traits of the proposed consorts and of the method of inheritance of these traits. In this connection will be brought forward facts of improved and of unimproved families and of the persistence, generation after generation, of the best as well as the worst characteristics.

"III. The third section will concern itself with the topic of htmman racial differences, with the sharp distinction between racial characteristics and the unnatural associations often created by political and national boundaries. In this connection will be considered the facts of the migrations of races, the influence of racial characteristics on human history, the teachings of the past with bearings on the policies of the future. Certain prejudices directed toward existing races will be removed when allowance is made for the influence of their social and educational environment, and their fundamentally sound and strong racial characteristics are brought to light. On the other hand, limits to development of certain races and the inalterability through education and environment of the fundamental characteristics of certain stocks will be considered. Finally the advantages and disadvantages 
of the mingling of races, of unions which have proved to be fateful to sociat progress, should be discussed. In this section will be presented the results of researches upon racial mixtures in relation to human history. Also the topics of racial differences in disease and psychology. will be taken up. The history of race migrations and their influence on the fate of nations, especially modern immigration should be set forth.

"IV. The fourth section will discuss eugenics in relation to the state, to society and to education. It will include studies on certain practical applications of eugenic research and on the value of such findings to morals, to education, to history, and to the various social problems and movements of the day. In this section will be considered the benting of genetical discoveries upon the question of human differences arid lipon the desirability of adjusting the educational program to such differences. Here will be considered the importance of family history studies for the better understanding and treatment of various tyges of hospital cases and those requiring custodial care. The bearings of genetics on sociology, econonies and the fate of nations may be considered in this section."

This outline of the program of the Lugenics Congress shows clearly. that eugenics is a broadly conceived subject. It is not merely a branch of genetics, but has intimate relations with sociology, economics, legal science, political science, the scientific study of crime and delinguency, medical science, and education.

The aims and ideals of eugenics. - The hopes and ideais of eugenists are well expresse! in the closing paragraph of the address of the president of the last International Congress of Eugenics, Major Leonarl Darwin, an illustrious grandson of Charles Darwin:

"Eugenics aims at increasing the rate of multiplication of stocks above the average in heritable qualities, and at decreasing that rate in the case of stocks below that average. But if the bamer under which we are to fight should only have inscribed on it some such an arid definition of policy as this. our defat would be certain. We must prove that we are monder the guilinnce of a noble ideal. We of this generation are responsible for the production of the next generation and, therefore, of all mankind in the future; and all in whom thi: sense of racial responsilility acts ats a deep-seated sentiment, greatly. affecting their action and their policy, are in truth guided by the eitgenic ideal. The belief that man has been slowly dicreloped from some apc-like prugenitor came tumard the cluse of the last century to be near- 
ly universally held by thoughtful persons; this belief gave rise to a new hope that this upward march of mankind might be continued in the future; and out of this new hope sprang the eugenic ideal. This growing understanding of the past history of the world has led us to see that, if we are to imitate Nature in her methods, we must be content to advance by a long succession of small steps; just as rain falling in drops on the earth has slowly carved out mighty valleys in the hardest rocks. Without constructing wild Utopias, we must be content if some little racial progress can be ensured as each generation succeeds another; for to work in this spirit is to work in harmony with the knowledge which gave birth to the eugenic ideal. Progress on eugenic lines will make mankind continually nobler, happier, and healthier; whilst those who imagine that our sole aim is to make man a stronger animal or a better beast of burden are utterly ignorant of the meaning of the eugenic ideal. But science, whilst giving us good grounds for hope, also issues a grave warning concerning the danger of national deterioration resulting from the unchecked multiplication of inferior types. In the past many nations of the first rank, when apparently advancing without check on the path of prosperity, have begun to decay from unseen causes, and have in time so fallen from their high estate as to cease to count as factors making for progress. A determination that such a downfall shall not be the fate of his nation is a sentiment felt by every man who is animated by the eugenic ideal, an irleal to be followed like a flag in battle without thought of personal gain."

Methods of research in eugenics.-The programs of research in the ficld of eugenics, as broadly stated in the four paragraphs outlining the four sections of the Congress, cover so many interests and impinge upon so many fields of research that have little, if any, bearing on the subject matter of the present course, that we shall limit our discussion of methods to those applicable to the study of human heredity. The chief methods of discovering the facts about human heredity are as follows:

a) The pedistee method.-According to this method, a study is made of the history of human matings, including all generations simultaneously living and the recortis of those recently deceased. The method of the experimental breeder cannot be used, but each fertile human mating is lookerl upon as an experiment in genetics, the results of which we may record and from which we may draw conclusions. 
b) The stutistical method.- A great deal can be learned about the herdity of fluctuating and graduated differences, such as those of height, weight, longevity, etc., by determining the degree of correlattion that exists letween a lurge group of parents and a large group of offspring. Galton and his successor, Karl Pearson, are the chief exponents of this method.

c) The twin method.-This method is quite distinct from either of those just listerl, though it may tse statistical methods. Many facts may be detemined, by the use of one-erg (monozyotic) and two-egg (dizygotic) twins, about what is inherited in man and what characters are commonly modified by the environment.

A separate chapter will he reverted to a discussion of ach of thesc methods and the contributions to our knowlerle of human heredity that have acerued from their use. 


\section{CHAPTER XXXV}

\section{HUMAN HEREDITY AS REVEALED BY PEDIGREES}

Weaknesses of the pedigree method.-The older type of pedigree study involved the collecting of perligrees made out by persons untrained in genetics and dealing with individuals in their own family connections. Questionnaires were sent out to large numbers of individuals asking them to give data as to characteristics of their ancestors and other relatives. Much of the material thus collected depended upon the vague memories of individuals about the characteristics of long-clead ancestors or of relatives in collateral lines. The low degree of reliability of such data makes conclusions therefrom almost useless. Considerably more reliable data were obtained by field workers who actually observed individuals belonging to four, in extreme cases five, generations, all living simultaneously. The reliability of such data depends upon the training and scientific aptitude of the field worker. Fortunately, there has developed in recent years a new profession, that of eugenic field worker, and there are not a few very capable persons belonging to this profession. Another weakness of the pedigree method is that it affords no check on the actual parentage of offspring. The mother is usually not in doubt, but there is often some question as to the actual father. This is principally true in connection with the study of pedigrees of feeble-minded and delinquent stocks and of primitive peoples with moral codes somewhat less rigid than our own. In other words, the genetic data acquired by this method are not scientifically controlled. Still another weakness of this method is that it is not always possible to distinguish between conditions that are hereditary and those due to disease or poor environment. In spite of these weakinesses, the pedigree method has brought to light a great deal of valuable information about human heredity. So long as one retains a properly critical attitude toward data and conclusions, no harm and much good may accrue from a reveiw of the principal results of this method of research.

Two postulates underlying the study of the heredity of human traits may be set down as follows: (I) When characters are inherited according to the laws of Mendel, that is, when one of a pair of characters is dominant, or partly so, and the other recessive, and they segre- 
gate in Mendelian ratios in subsequent generations, such character differences are determined by genes. (2) Allelomorphic differences have arisen through the process of gene mutation, a process so well established for lower organisms. These postulates are justified, for it is hardly likely that so universal a method of heredity as the Mendelian method operates for the rest of the organic world and not for man. Also, the method of gene mutation is the only method by means of which allelomorphic differences are yet known to arise, and it is hardly likely that man is an exception to the rule.

The rate of mutation for man has been worked out for various races of mankind. The number is almost the same in the various races. For every I I 5 normal genes in the Russian race there are about 5 more mutant genes than in the Negro race. "If 6,000 generations," says Danforth, "represents anywhere nearly the time since these two groups, along with others, diverged from a common ancestor, these additional mutant genes must have been acquired in this length of time. ... . These figures indicate that in the course of 6,000 generations at least 5 in every i 5 gene lines which have persisted underwent mutation in this one direction. Since there is no evidence of selection, this may be presumed to be the rate of mutation in this particular germplasm, from which it follows that there has been, on the average, one mutation in every generation for each $\mathrm{I}_{3} 8,000$ genes. If, as some might be inclined to think, the two germplasms have passed through more than 6,000 generations since they separated, the rate of mutation has been less than this."

Thus we see that mutations, though infrequent, continue to appear at a slow and steady rate. Like the mutations in Drosophila and those of other animals studied, the majority of mutations in man are poor, many are indifferent, and very few are good. It has evidently taken a long time for man to acquire the better hereditary traits he now possesses. In the past, natural selection has tended to eliminate most of the undesirable mutants, especially the dominant ones; but under civilized conditions mankind has done much to nullify the good work of natural selection by doing everything in his power to preserve the poorer mutants and help them to multiply.

\section{SOME HEREDITARY TRAITS IN MAN}

Studies of nearly 200 human traits have been made. In the majority of cases they can be classified as dominants, ordinary recessives, and sex-linked recessives. The latter are the easiest to detect, for 
they follow the familiar mode of heredity described for sex-linked characters in Drosophila. Dominants may fairly readily be distinguished by the fact that at least one of the parents, one grandparent, one great-grandparent, etc., exhibit the character; a dominant character appears in every generation. Ordinary autosomic, or non-sexlinked, recessives are characterized by the irregularity of their incidence in pedigrees. They may skip one or several generations and only appear at all when the same recessive gene is present in the germplasm of two mating individuals, in which case it will appear in the following ratios according to the genetic make-up of the parents: (a) If both are heterozygous, three out of four offspring will show the dominant and one the recessive character; $(b)$ if one is a heterozygote and one a recessive, the offspring will be half heterozygous dominants and half recessives. Thus we see that recessive characters may be hidden for a long time awaiting a favorable mating to give them expression.

Most of the best pedigrees of human characters deal with relatively rare and atypical or abnormal characters; in fact, most of them deal with what we ordinarily call freaks or pathological conditions. The reason for this is that rare and unusual conditions are much more easily detected and recognized. Ordinary, common differences are hard to detect and hard to distinguish, and therefore difficult to follow in pedigrees.

It is not our intention in this chapter to attempt an exhaustive treatment of the facts of heredity ascertained by the pedigree method. We shall merely list some of the commonest cases of hereditary characters and give a few pedigrees illustrating them.

The following is a list of human unit characters classed as dominants, ordinary recessives, and sex-linked recessives:

Skin and II air:

A. DOMINANT CHARACTERS

Dark skin

Tylosis and ichthyosi . .

Epidermolysis...............

Brown or black hair...........

Red hair.

Beaded hair.
Dominant over blond or albino (probably due to two or more pairs of genes)

Dominant over uniformly colored

Thickened or scaly skin

Excessive blisters of skin

Dominant over red and flaxen (probably due to more than one gene)

Dominant over flaxen

Single hairs are not uniform in diameter 
White forelerk............... White pateh of hair in front

Hypotrycheif............. hairheseness asseciated with lack of tecth

Pattern bihines ........... I'artly sex-limited Eyes:

Front of iris pirnented egeliak, browm, hazel, etc.) . . . . . D. binint over lack of pirment in iront of iris (blue eyes)

Ieveritary cataract. () macity of lens

Nishthlindiness, when not sex-linked............ Inability to see in dim lisht

I)isplaced lens.............. Caukine defective vision

Girucoma.............. Swelling of coball due to internal presisure

Cololoma............... (gen suture of the iris

Pigmentarydegerationuf retina Cousinglinhness Skelotin aid Hestes:

lirachyda tyly............

Polydactyly.

Dicits lackine one joint

Symblacty

Extra dicits

Symphalan $\because \ldots \ldots \ldots \ldots \ldots \ldots$

Split hani?

Funed or webled dirits

Lobster tliw ....................

ruserl joints of digits, stifi fingers

Palm cleft to the wrist

Erustoses..................

Jiritle bones

No diwits but thumb,

Nimormal outgrowthe of long bones

Absence of palmaris $\mathrm{n}$ his muscie läk of a certain muscle in palm of bones very fracile hind

Muscular atrophy.......... Partially dominant Pinly Buil:

Achondroplat:

1) warfs with thort, stout limbs, normal londy and lieal

Short stature...... ..... Partly dominant oser tallness

Obesity not hite to eslinelular defects............. l'artially dominant

Serouts Sutem and Kidmer:

Huntington's clorea ......... A type of st. Vitus' dance

bialdetes insipidus . . . . . . . Parially dominant

Diabetes me!litus. .......... Partid!ly dominant

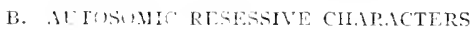

Alhinism............. Lack in pigment in skin and hair-

Atedersis............ True dwarts, bendy small with parts in normal prop ortions

Cretinism

Dwarfism due to hereditary thyroid deficiency 


\begin{tabular}{|c|c|}
\hline Alkaptonuria. & Urine dark after oxidation \\
\hline Otoschlerosis & Thickening of ear-drum \\
\hline Left-handedness. & Probably recessive \\
\hline Tendency to twinning. . . . . . . . & Probibly recessive \\
\hline Susceptibility to tuberculosis..... & Probably recessive \\
\hline Thomsen's diseilse . . . . . . . . . & Lack of muscular tone \\
\hline Menier's disease . . . . . . . . . . . & 1)izziness and roaring in ears \\
\hline 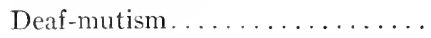 & Congenital deafness \\
\hline Friederick's disease..... & $\begin{array}{l}\text { Degeneration of the upper part of } \\
\text { the spinal cord }\end{array}$ \\
\hline Multiple sclijerosis... & $\begin{array}{l}\text { Diffuse degreneration of nervous } \\
\text { tissue }\end{array}$ \\
\hline Chorea & Ordinary St. Vitus' dance \\
\hline Hereditary feeble-mindedness..... & Probably recessive \\
\hline Hereditary epilepsy . . . . . . . . . & Probably recessive \\
\hline Manic depressive insinity . . . . . . & Probably recessive \\
\hline Dementia praecox........... & Probably recessive \\
\hline
\end{tabular}

\section{Charicters DUE TO CUMUlative FACTORS}

It is suspected that a good many of the characters listed as incompletely dominant may be due to cumulative factors producing the condition usually called "blending hereditary." Those that almost certainly belong to this category are: stature, body weight (except certain types of obesity), skin color, shape of head, and proportions of features.

\section{SEX-LINKED RECESSIVES}

Color-blindness

Night-blindness.

Gower's disease

Neuritis optical
Lack of discrimination between red and green

One form of this defect, which involves inability to see in dim light

Free bleeding

Muscular atrophy

Progressive atrophy of the optic nerve

Some pedigrees of dominant characters. - Perhaps the best example of a dominant trait that has been thoroughly worked out is brachydactyly, a type of hand in which one joint is lacking in each digit. In the normal hand the thumb has one less joint than the fingers. Hence in a brachydactylous person all the fingers are thumbs and the thumb is a subthumb. Such a type of hand is broad, thick, and clumsy. It is not at all a well-adapted character, but it is not so bad but that it can survive. Drinkwater has studied a number of brachydactylous pedigrees one of which is shown in Figure $8 r$. Males in this chart are shown by $\sigma^{\prime}$ and females by $q$, solid circles indicate affected 
and open circles unafecterl individuals. Notice that the character appears in at least one parent in each generation, which is characteris-

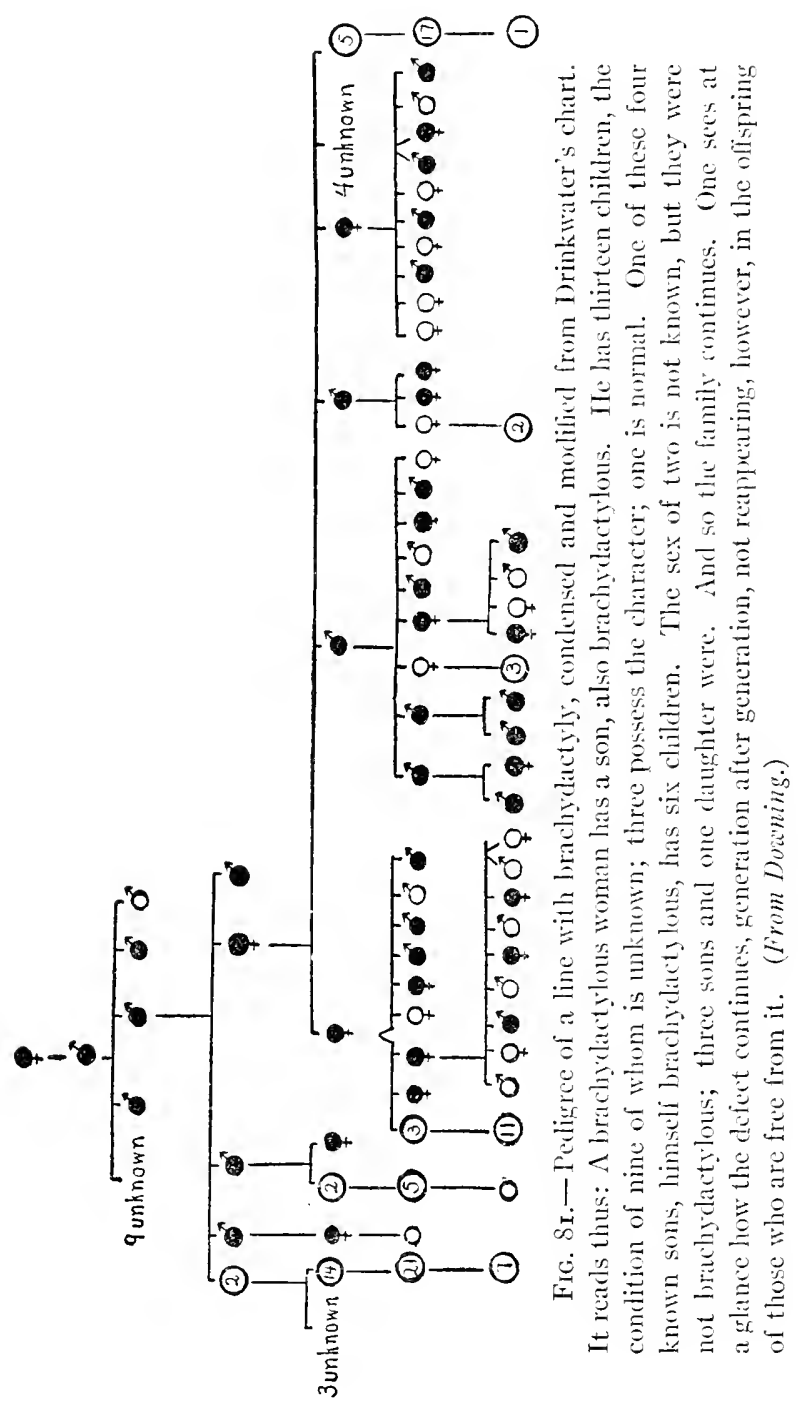

tic of the morle of inheritance of dominant characters. Also the number of individuals affected is about what one would expect in the case of a dominant character. 
The question arises with reference to this, as well as to many other, dominant characters as to why, being dominant, the character does not become more prevalent rather than remaining relatively rare. The answer that seems most probable is that the brachydactylous hand is very poorly adapted to human uses and those individuals possessing it are seriously handicapped. Hence there may be marriage selection against it. If it were more adrantageous than the normal, doubtless the incirlence of the character would increase and it might in time become the typical condition for the species. The same explanation would apply equally well to all other cases of dominant abnorma!

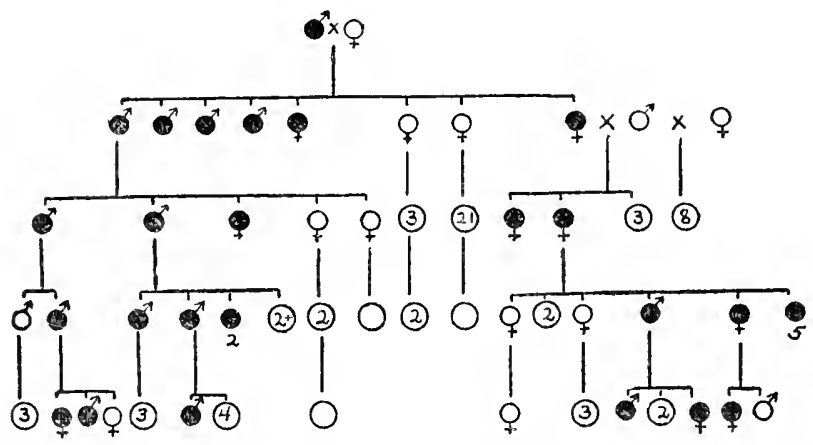

FIG. S2.- Inheritance of one form of cataract. Modified from Nettleship's chart. The diagram reads thus: A man with cataract married a normal woman; of their cight children six were affected with the disease. One of these married an unaffected man; three of the children of this union were normal, sex unrecorded, two defective. This same man married a second wife who was normal; their eight children were all unaffected. So continue reading through five generations. (From Downing.)

Menclelian traits. It might also be asked why all the offspring of a dominant parent do not show the character. The reason should be obvious, namely, that most individuals are heterozygous for the character. A heterozygote mating with a recessive is expected to produce one-half heterozygotes and one-half recessives, which is about what the accompanying peligree shows.

Another case of a dominant character, not so definitely analyzed as the last, is a type of hereditary caturact (Fig. 82). This condition is due to an opaque region in the lens of the eye, which, when well arlvanced, may cause blindness. "In the particular form of the disease here considered," says Downing, "it does not develop until middle life. 
Clarence Locil in a study of hereditary blindness tabulated the results of 304 fanilies in which such blindness occurs. There were 1,0 , 2 chitdren, of whom 58 per cent were aflicterl, which is about the perentage expected when hy brid defectives mate with normal individuals and the liefect is a deminent character."

A typical pedigree of a recessive character. - 1 good example of the mode of inheritance of an uncommon raesive character is shown i. Figure $8_{3}$, the pedigree of a family line showing outcropping of ulbinism, lack of pigment in hair, skin, and eyes. It is noteworthy that the appearance of the charater is relatively are, only in out of I 58 individuals in the perligree being altimos or partial allinos; that alibino offspring are produced by two phenotypically normal (pigmented) parents; and that in generation VII, where several of the children are albinos, the two parents are descended from common ancestors a few generations back, and are mokulstedly both heterozygous. In this pecligree there are no cases of the mating of two abines. If such matings had recurred, the expectation, of course, would be that all offspring woull be allinos. Since we shall have to present further examples of peligres of recessive characters in connection with the account of the heredity of mental characters, we need give no further eximples here.

It is also umecesary to repeat in this place the description of such sex-linked human characters as color-blindness, haemophilia, etc. The accompanying chart (Fig. $8_{4}$ ), which represents an investigation of a Texas family comection made by the writer in 19ro, is typical for sex-linked characters. The existence of sex-linked herdity in man goes far to support the contention of eugenists that heredity in man follows the same rules as have been found to hold for the lower animals.

As an example of human characters probably determined by cumulutive fuctors, we may cite the case of skin color. Whole races of man are dark-skimned, others light-skinned. Some idea as to the mode of heredity of skin color is obtained by studies of crosses between negro and white individuals. "In a cross between a negro and a white person," says Castle, "children are proluced that are of an intermediaite, but frequently varialle skin color, and are known as mulattoes. Mulat tues mating inter se produce an $F_{2}$ generation of high!y variable sin-color but rarely pure white. Davengert has concluked that two imlepentent Nentelian fitctors affecting skin-color are involved. This explanation would leat us to expect one in sixteen of the $F_{2}$ malathe offspring to have skin as white as an European, even thuugh his negru 


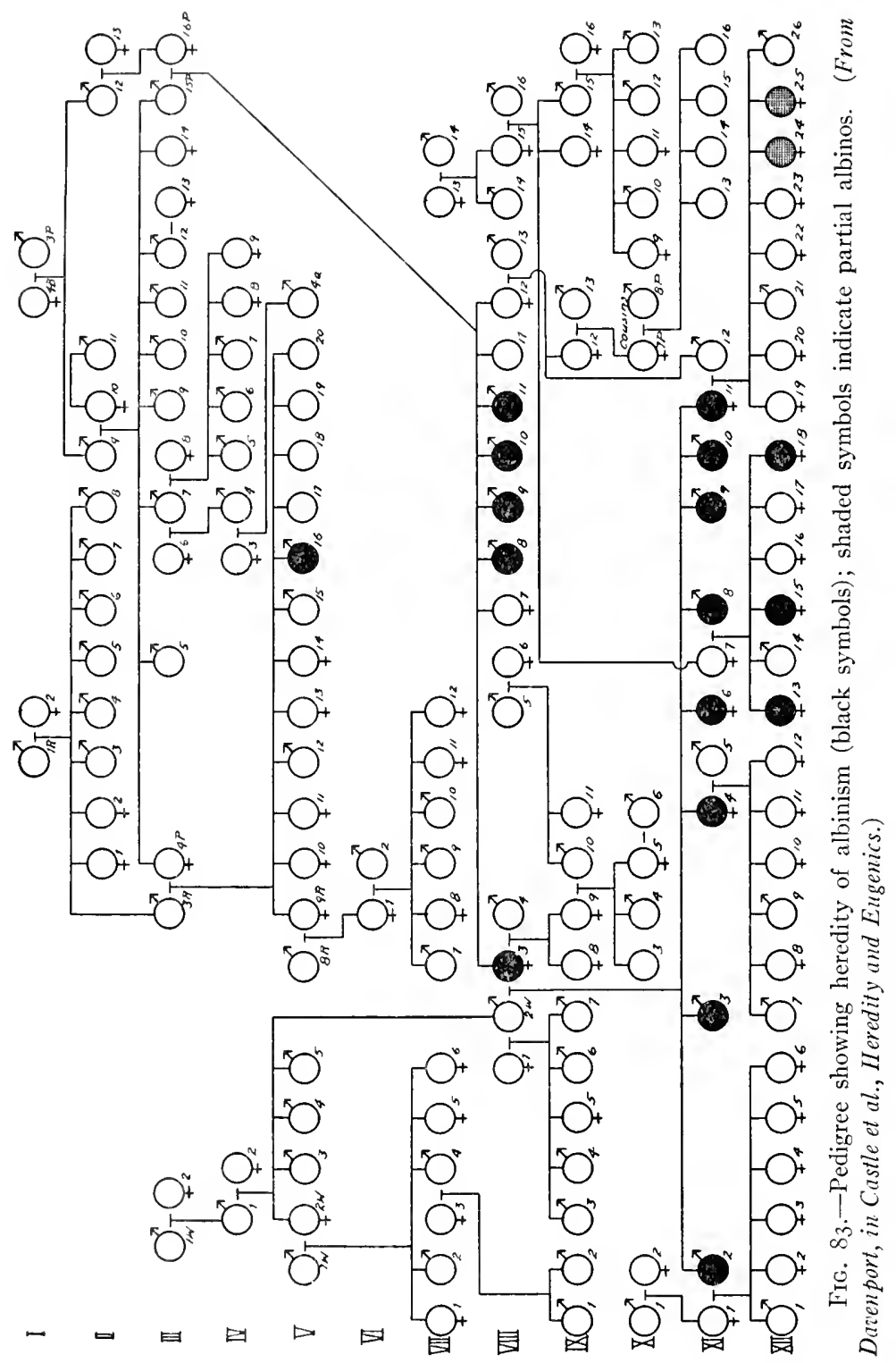




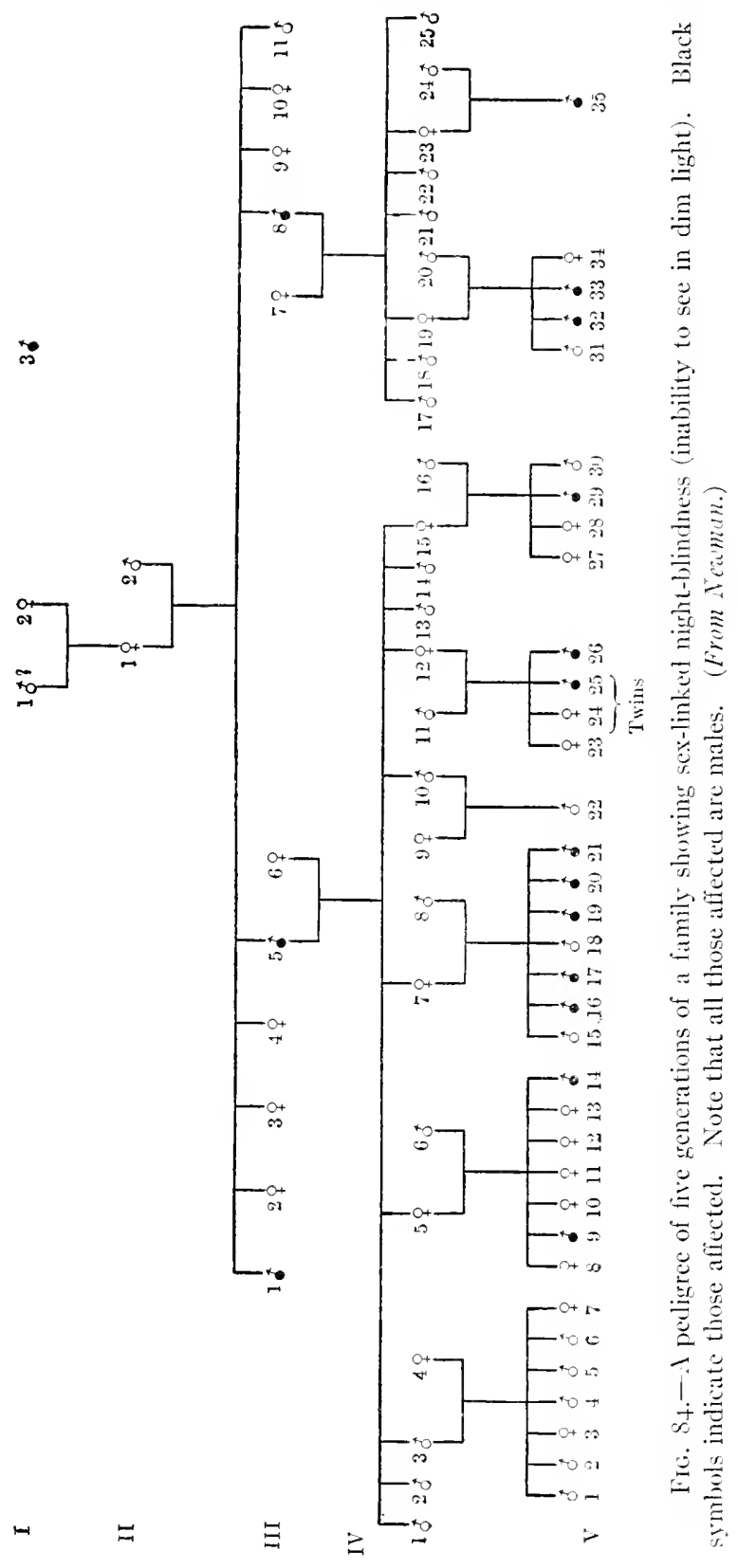


ancestry might show in other characteristics, such as curly hair, broad iose, thick lips, ete. It is difficult to get any wholly satisfactory evilence either for or against this explanation. That published by Davenport can scarcely be considered conclusive, for the data studied are derived from a population in which illegitimacy, by Davenport's own statement, is as high as 72 per cent. On the whole, it seems prolyable that segregation of skin pigmentation in mulattoes is cither incomplete or rarely complete, because multiple or modifying factors are involved."

Having given examples of perligrees of physical characters exhibiting all of the principal modes of Mendelian heredity, let us now pass to a consideration of the facts al out the heredity of mental traits in man as revealed by pedigree studies.

\section{IHEREDITY OF MENTAL TRAITS IN MAN}

The studies of the heredity of mental traits in man consist principally of those of exceptional genius and of definite mental defects and abmormalities. Very little effort has been expended upon the heredity of normal average intelligence, such as the great majority of us possess.

Long ago, in 1869 , Sir Francis Galton published a fascinating book on The Ilerdity of Gonins, in which he presented a large number of pedigrees of families showing definite and special types of genius, such as musical genius, genius for astronomy and mathematics, genius for science, etc. Among those described in some detail are the Bach family of great musicians in Germany, the Herschell family of great astronomers in England; and he might have added his own pedigree composed of the interrelated families of Darwins, Galtons, and Wedgewoods, the present generation of which consists of many outstanding and influential persons (Fig. 85). No family today shows more plainly than this one what can be done in the way of racial improvement through a certain amount of concentration of good germ plasm by judicious inbreeding (cousin marriages), when the inbreeling stocks are strong and sound. Charles Darwin, the most eminent member of this family conncetion was the son of an eminent physician, a member of the Royal Society. One of Darwin's grandlathers was the wellknown Erasmus 1)arwin, referred to in the II istory of Evolution (chap). ii). The other grandfather was Josiah Wedgewood, F.R.S., founder of the Wedgewood potteries. Chitrles Darwin married his own cousin, Emma Wedgewood. Four of Darwin's sons are eminent members of 


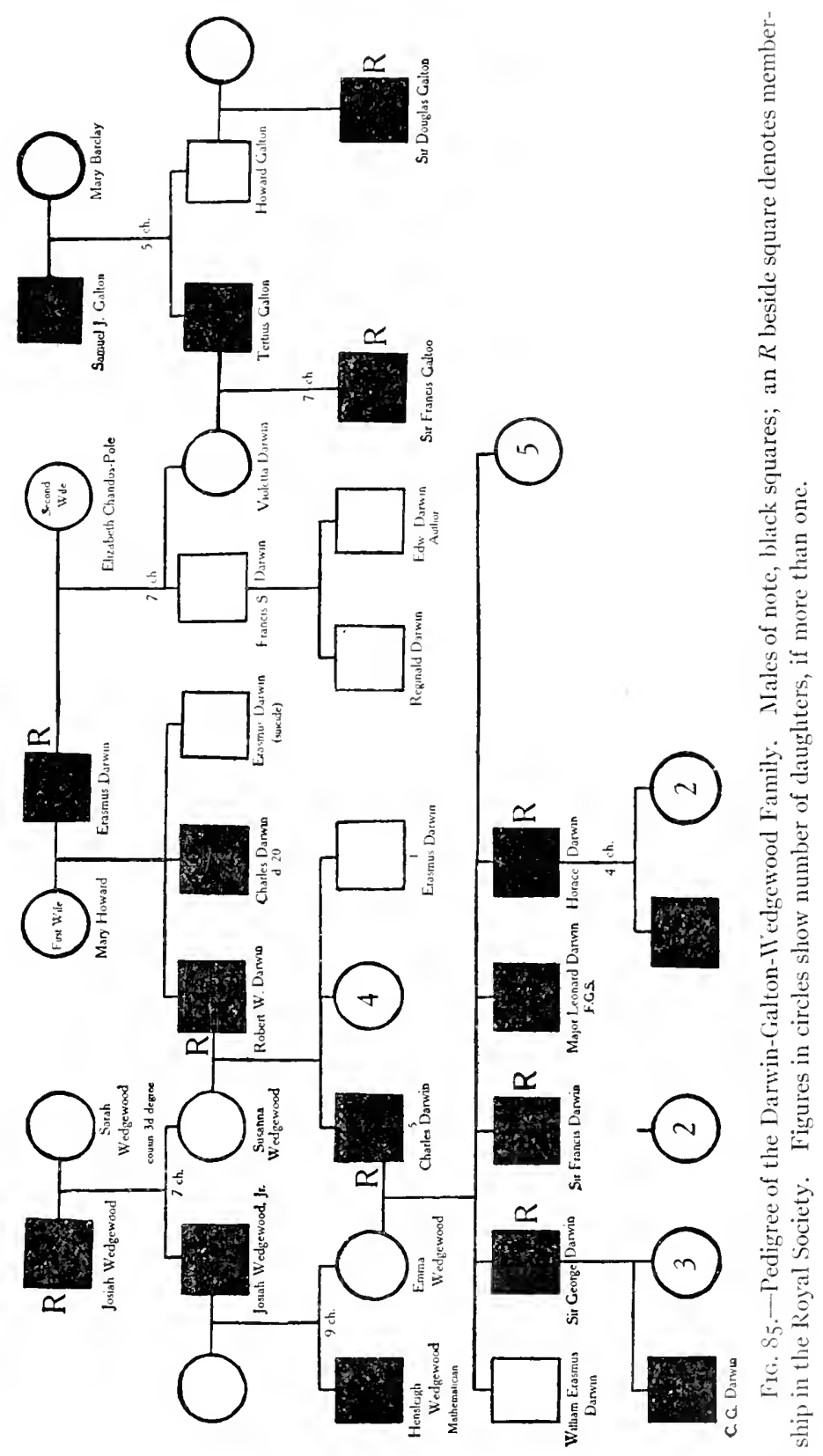


the Royal Society, one of them being Major Leonard Darwin, president of the Second International Congress of Eugenics, from whose speech we quoted a paragraph in the previous chapter. Darwin's aunt married into the famous Galton family and her son was the late Sir Francis Galton, the originator of the term "eugenics," whose work we have just referred to. This is perhaps the greatest eugenic family' on record.

The Bach family of musicians is another outstanding example of the heredity of genius. The best-known member of the family is the famous Johann Sebastian Bach. In six generations of Bachs there were 47 musicians of note, 29 of whom ranked high in musical circles. Johann Sebastian Bach was married twice and both times to a relative bearing the name of Bach. His father married an aunt. There was a great deal of rather close intermarriage in the family, which seems to have helped to concentrate and preserve the high qualities of the stock.

Most of the work done on the heredity of mental traits has been expended on the study of defective and abnormal heredity, including feeble-mindedness and the various so-called "insanities."

The heredity of Feeble-mindedness.-Feeble-mindedness, as defined by Goddard, is "a state of mental defect existing from birth or from an early age, and due to incomplete or abnormal development, in consequence of which the person affected is incapable of performing his duties as a member of society in the position of life to which he is born." This is not a very exact definition, for, according to the statement, a normal individual born into a community of geniuses might be classed as feeble-minded. More specific are the following definitions of various types of mental defectives. An idiot is one who, when adult, has no greater capacity to learn than a child of two years or less. An imbecile is one who rates mentally between two and seven years. A moron is one who rates mentally from seven to twelve years. Usually the so-called "feeble-minded" individual is either an imbecile or a moron, and much more often the latter than the former. Obviously, then, there are many kinds and degrees of feeble-mindedness, and it will often be dificult to draw the line between the high-grade moron types and the lower levels of normal individuals. "This classification," says East, "is arbitrary, but it serves a useful purpose when dealing with feeble-mindedness as a social problem. Medically and genetically it means nothing - at present." If this is true, and we believe it at least largely so, attempts to deal with feeble-mindedness as a simple Mendelian recessive are likely to be only partially successful. 
We must, therefore, take all genetic studies of feeble-mindedness with a grain of salt.

II. II. Goddard, probably the most distinguished of the sturlents of feeble-mindedness, has studied many pedigrees and compriled statistics concerning 300 of the best of these. Of the cases of feeble-mindedness diagnosed as such by him, I64 ( $5+$ per cent) are considered unquestionably hereditary, if $(23$ per cent) probably heretitary, and the rest probably non-hereditary. Goddard seems to be convinceri that feeblemindedness is due to a single recessive gene. He cites 42 cases in which heterozygous, phenotypically normal, mothers (NF), when mated with feeble-minded fathers (FF) producerl is feeble-minded and 73 normal offspring out of a total of 144 . This is almost too close an approximation to the expected Mendelian ratio of $\mathrm{I}$ to $\mathrm{I}$. From 26 matings of apparently heterozygous fathers and mothers (presumably $\mathrm{NF}$ ) there were produced 122 known children, $S_{3}$ of whom were normal and 39 feeble-minded, suggesting the exprected Mendelian ratio of 3 to $\mathrm{x}$. Of 476 children of parents both of whom were feeble-minded (FF), only 6 were nomal in intelligence, and thes are suspected of being illegitimate. In Figures 86 and 87 are presented two typical pedigrees of feeble-minded families studied by Goddard. The first of these pedigrees (Fig. So) shows the rlire effects resulting from the interbreeding of feeble-minded parents. The children are all feelle-minded cxcept the considerable number that died in infancy, presumally because of neglect and ignorance of the parents. The second perligree (Fig. S7) $^{2}$ illustrates what approximates a controlled scientific experiment, for one woman was married twice, once to a normal man and once to a feelle-minded man, and had several children by each. All of the offspring from the normal father are normal (but evidently heterozygotes), while all those of the feeble-minded father were feeble-minded and otherwise abnormal.

It is interesting to note that a very large proportion of juvenile criminals and prostitutes, when given the Binet test, rank as feebleminded. Tests of juvenile criminals in various states show the following facts: In New Jersey 46 per cent of juvenile criminals are feebleminded; in Ohio, 7o per cent; in Virginia, 79 per cent; and in Illinois, 89 per cent. It would seem to be a conservative estimate that fully half of juvenile criminals are feeble-ininderl.

It has also been shown that the great majority of prostitutes and girls who have been placed in reformatories for sex-delinquency are feeble-minded. Tests of large numbers of girls in an sllinois reforma- 
tory show that 97 per cent are feeble-minded. In Massachusetts a prominent commission reports that of 300 immoral women under detention in that state $57 \mathrm{per}$ cent were feeble-minded, while the rest rated from nine to twelve years in mental age. On the basis of data

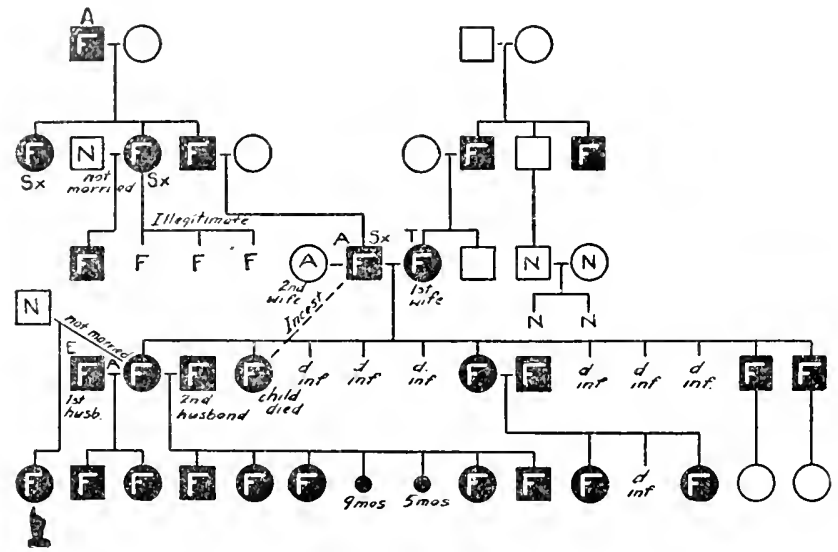

Fig. 86.--Pedigree of a family with a high proportion of feeble-mincled persons $(F)$, Squares, males; circles, females; $d$. inf., died in infancy. (From Daven port, after Goddard.)

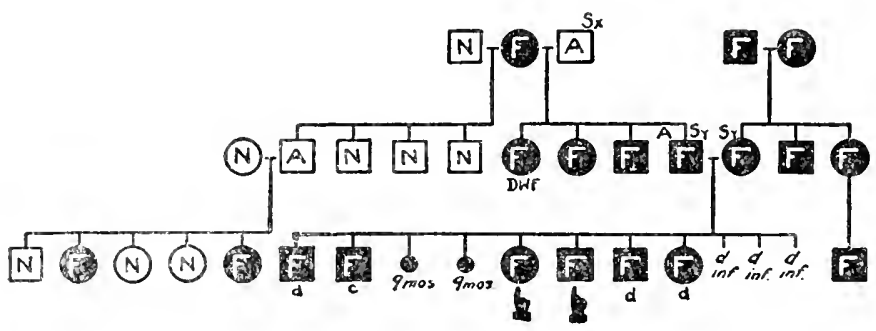

Fic. 87 .- Pedigree of a family in which the feeble-minded grandmother married twice; by a normal husband she had normal children; but by an alcoholic, sex-offending $(S x)$, doubiless fecble-minded husband she had only feeble-minded children. (From Duzenport, after Goddard.)

such as these, Goddard and others maintain that there is a very intimate relation between crime, vice, and feeble-mindedness. Wipe out the feeble-mindedness, say they, and you wipe out most of the vice and crime.

Feeble-mindedness has come to be the most pressing of all eugenic problems-one that should at once be recognized and solved if possible. 
Statistics seem to indicate that this defect is on the increase; certainly it is far too common to be ignored. Records show r 78,000 mental clefectives in Great Britain and Ireland in I02r, and these include only the very positive cases. It has been estimated by one expert that in the United States one person in every $29+$ is feeble-minded; by another expert, one in every 138 . In Indiana it is claimed that over 2 per cent of the population of ten unselected counties are mental defectives. If the incidence is the same in the whole state, there are 56,000 defectives in Indiana alone, and Inthana is in no way exceptional. Calculations indicate that in the United States as a whole there are not less than half a million feeble-minder individuals, and several times that many individuals phenotypically nomal but carrying the gene or genes for feelłte-mindedness. I large proportion of these indivituats are charges of the rarious states and cost the public many millions of dollars annually without contributing anything of value to the community.

Insanity and heredity.-.. I great deal of careful work has becn done on the heretity of insanity. For example, Datid IIcron in Scotland has studier 33 I family histories exhibiting insanily. There are sereral distinct and different conditions included under the blanket ferm "insanity." It is olswinus that they could not all be determined by the same gene or genes. Ileron's data on insanity are summed up in the following talle:

IIERONS DITA ON THE HEREITTY

OF INS.TITY

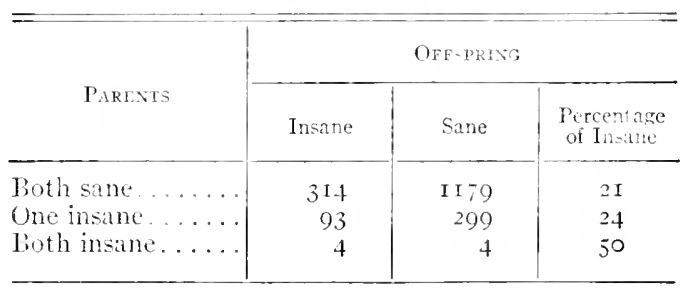

These figures are not at all readily fitted into any simple Mendelian ratio. Douldless the rarious insanities are not due to single Mendelian units, but are complex cases. That they are to some extent and in some manner herditary, seems beyond question.

Rosumell and Orr, two prominent American psychiatrists, seem somewhat more simguine about fitting the insanities into the Mendelian system. Their data are given here in tabular form: 
ROSANOFF AND ORR (DATA ON INHERITANCE OF INSANITY)

( $\mathrm{N}=$ Normal; $\mathrm{I}=$ Insane)

\begin{tabular}{|c|c|c|c|c|}
\hline \multirow[b]{2}{*}{ Parents } & \multirow[b]{2}{*}{ MITINGS } & \multicolumn{3}{|c|}{ Childpen } \\
\hline & & Neuropathic & Normal & $\begin{array}{l}\text { Mendelian } \\
\text { Expectancy }\end{array}$ \\
\hline 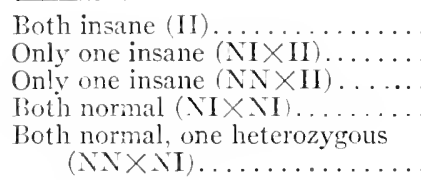 & $\begin{array}{l}\mathbf{Y}_{7} \\
9.3 \\
\mathbf{I} 7 \\
62\end{array}$ & $\begin{array}{r}54 \\
190 \\
\ldots \ldots \\
107\end{array}$ & $\begin{array}{r}10^{*} \\
239 \\
45 \\
215 \\
77\end{array}$ & $\begin{array}{l}\text { All insane } \\
\mathrm{I}: \mathrm{I} \\
\text { All insane } \\
\mathrm{I}: 3 \\
\text { All sane }\end{array}$ \\
\hline
\end{tabular}

* Eight have not passed the age of incidence.

These data might readily be taken to prove that insanity is a simple Mendelian recessive, but a scrutiny of the methods of collecting data make geneticists somewhat skeptical. "The data," says Castle, "have the scientific value of gossip, consisting of answers made by "informants' to leading questions designed to bring out any weakness in the pedigree. Like inquiries made concerning any individual in the community would show him an unmistakable victim of insanity..... Three-fourths of their persons insane for pedigree purposes would be classed as fully normal, if they occurred in families free from insane patients. Such classification has little scientific value." This statement may be severe, but it seems justified by the fact that persons who are described as "a crank"; "easily excited, nervous temperament"; "very nervous"; "erratic, excitable"; "nervous, little things bothered her, worried a great deal"; are classed as insane. Doubtless many of us who think we are normal might be classed in some of these categories by our acquaintances.

As yet it would be quite unsafe to classify any of the insanities as simple Mendelian unit characters. The subject is a very complex and difficult one, and genetic results will continue to be unsatisfactory until the psychiatrists are able more accurately to diagnose and classify the "insanities."

Pedigrees of royal families. - Members of royal families have been used as data for the study of human heredity. Records of these individuals and their traits are preserved in the archives and should furnish good material for genetic study. The well-known writer Frederick Adams Woods has made an exhaustive study of the pedigrees of European royal families and has published the results of these studies. 
It happens that rather complete data about the members of royal families are to he foum in hiographical dictionaries. From these sources it is usually possible to form a fairly accurate estimate of the capacities of these persons. In adlition the portraits of most members of royal families are preserved in art galleries. The following summary of F. . Woods' findings is quoted from Proiessor E. R. Downing:

"Early modern European history centers about the doings of a few great men and women. Peter the Great of Russia, Ferdinand and Isabella and Charles $V$ of Spain, Frederick the Great of Prussia, Gustavus Acolphus and Charles XII of Swerlen, are among the most brilliant of these potent individuals that shaperl the destinies of Europe during this period. It is interesting to note how their characters are determined (and through them national destinies are apparently decided in no small me:sure) by the hereditary concentration of ability due to lucky roval matings, and how their genius is dissipated by unwise matings.

"Peter the Great of Russia came as a brilliant type from a good stock, though with a very evirent taint of epilepsy and feeblemindedness. He hims lf was an epileptic. His father, grandfather. and great-grandfather had been men of large ability. They had married peasant girls, as was the custom of the czars. Peter's own brothers and sisters were in no way remarkable. His half-sister Sophia was a woman of marked ability, although two of her brothers were imbeciles. one also an epileptic. As will be seen from the perligree, the epilepsy, imbecility, and mediocrity appear in both Peter's children and grandchildren, as well as in those of his imbecile half-brother, Iran. It is interesting to note from the pedigree that the feeble-mindedness and epilepsy seem to cling to the males quite persistently. The females of the family are much more apt to be brilliant and virtuous. Peter the Great's own son Alexis was a poor dissolute specimen, and although he married Charlotte, the angelic daughter of a great line, the house of Brunswick, the son of this mating was Peter II, of unstable mind, while the daughter Natalia was as sweet as she was energetic.

"Isaluelia and Ferdinand were both descendants from lines of very great individuals, although in each case there is insanity in the family. Isabella herself comes from an insane mother and an imbecile father, but her grandparents and great-grandparents were well-balanced and able. The data for the charts of these royal families were taken largely from F. A. Woorls's Mcnklal and Woral Heredity in Royally, supplemented with information from other sources. He grarles the 


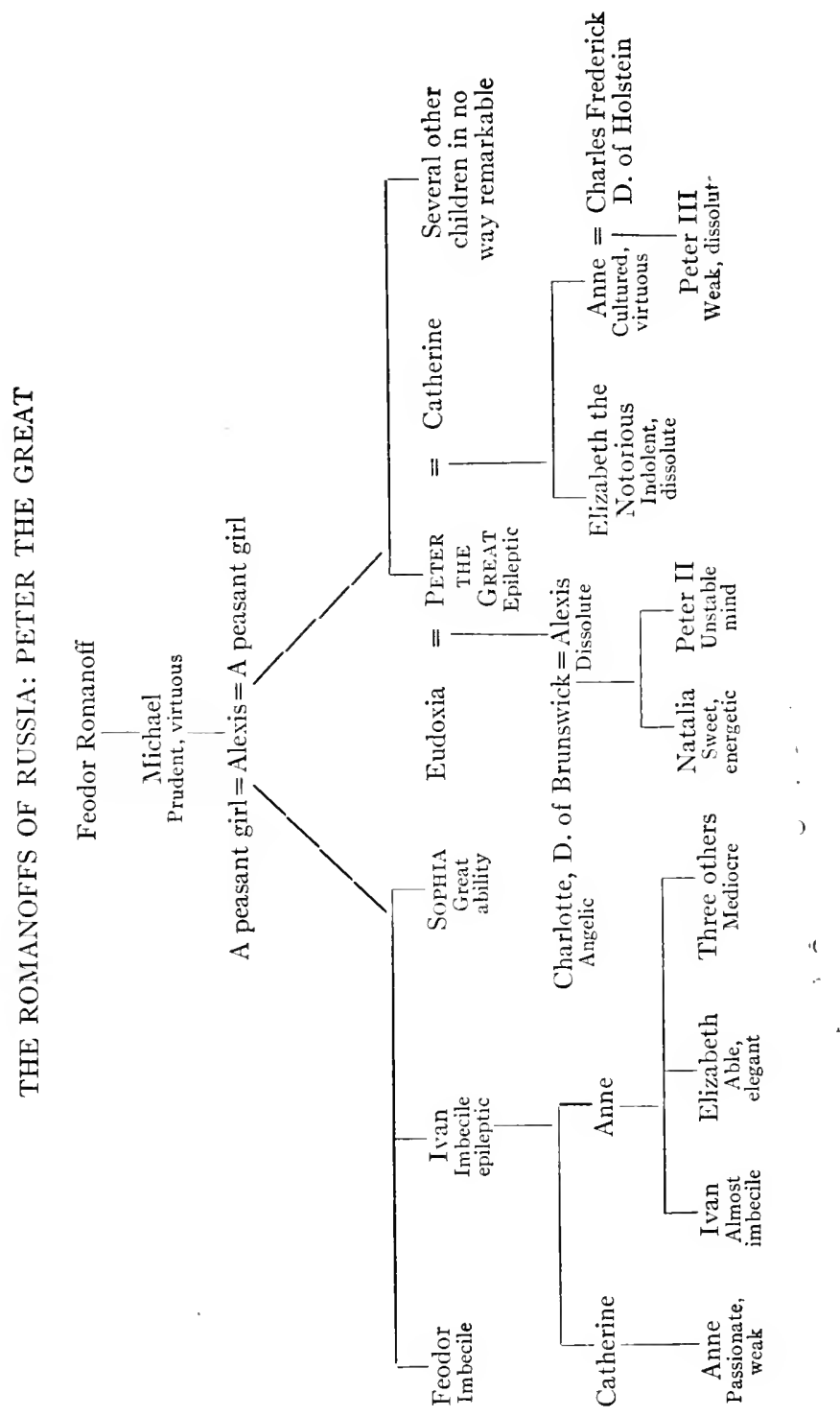




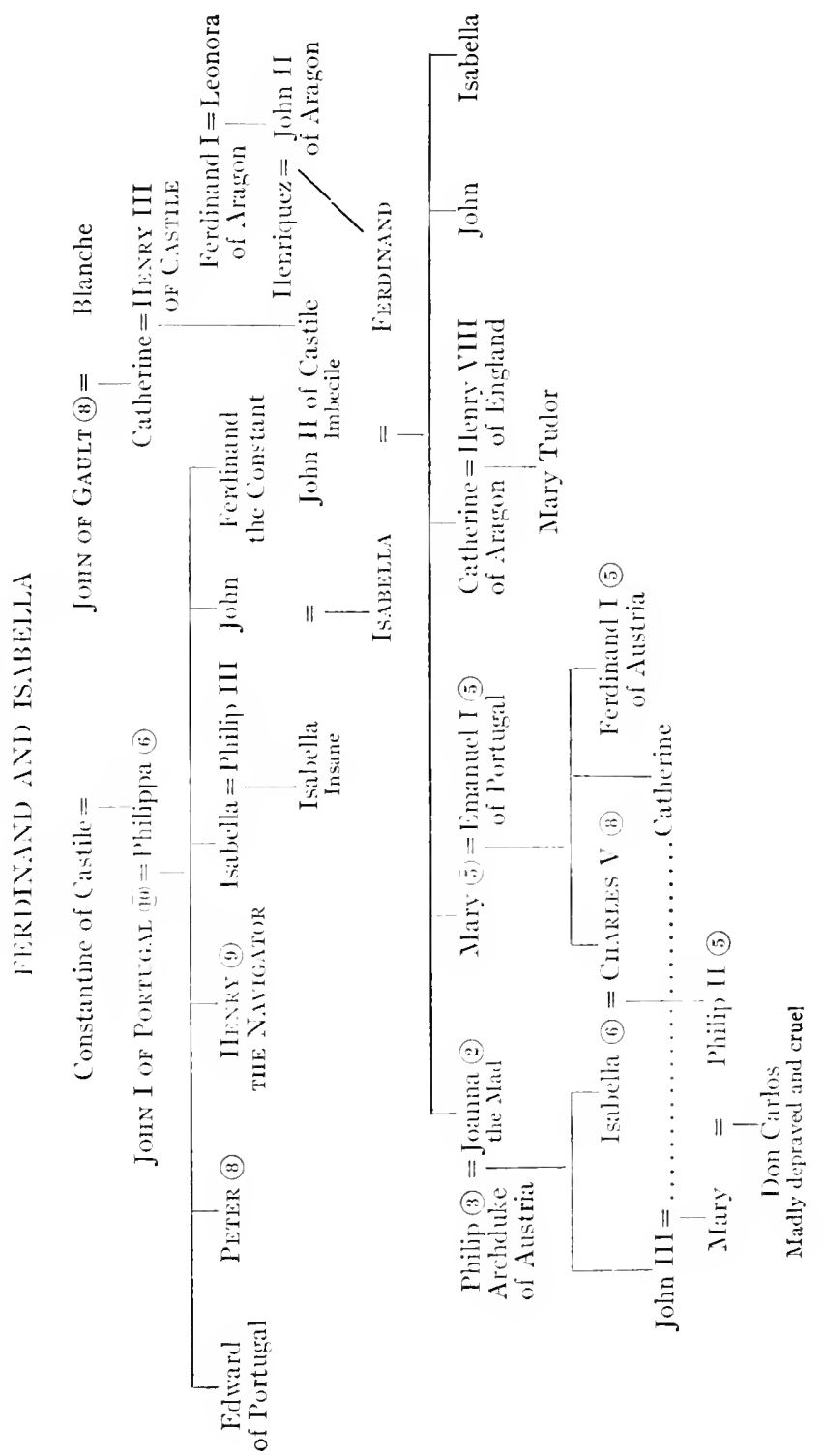


individuals on a scale of ro. Ten represents very high ability, as determined by the comparative amount of space and laudation given to the individual in such standard works as Lippincott's Biographical Dictionary. Five out of eight of Isabella's great-grandparents rank very high. John the Great of Portugal, twice her great-grandfather, has a grade of io. John of Gault, twice her great-grandfather, has a grade of 8, as does also John of Castile, while Henry III of Castile, one of her grandparents, is designated the model king. Ferdinand I of Aragon, the grandfather of Ferdinand, is a brother of this same Henry III of Castile, and is also an exceedingly able king. Of the children of Ferdinand and Isabella, most were mediocre or distinctly inferior. Joanna was insane. In the next generation, however, appears Charles V, whose reign marked the acme of Spain's greatness, partially due to his own ability, partially due to the momentum of those movements that were instituted by his illustrious grandparents. Charles V married his own cousin, as did also John III. Children of these two matings married, and Don Carlos, child of this latter marriage, was madly depraved and cruel.

"When insanity and brilliancy are found in the ancestry it seems merely a matter of chance as to whether the determiners for greatness will be thrown together in the union of sperm and egg or those for insanity. We can predict with some certainty, that, in a large number of offspring, ability will reappear and insanity will reappear, but just what individual each will strike it is impossible to prophesy without knowing much more definitely the nature of the germ plasm involved. One may say that the convergence of a number of lines of descent from great ancestors toward one individual makes it probable that he will be exceptionally ahle.

"This is nowhere hetter illustrated than in the family tree of Frederick the Great of the Prussian house of Hohenzollern, as will be seen from the chart on page 467 . Of his great-grandparents, three scale ro, one 9 , one 8 , two 7 , and one 6 . Not one is below mediocrity, and the majority are of very high grade. Of his fourteen ancestors back three generations, only one is distinctly inferior. Of his brothers and sisters, four are distinctly great, three mediocre, and one inferior.

"It is interesting to trace the effect of the mating of such splendid stock with another brilliant line, that of the Swedish royal house. Gustavus I, or Gustavus Vasa, is another instance of the brilliant mutant, with some taint of neurosis. He married a gentle and tactful princess; their son Charles IX was a very able man, although of their 


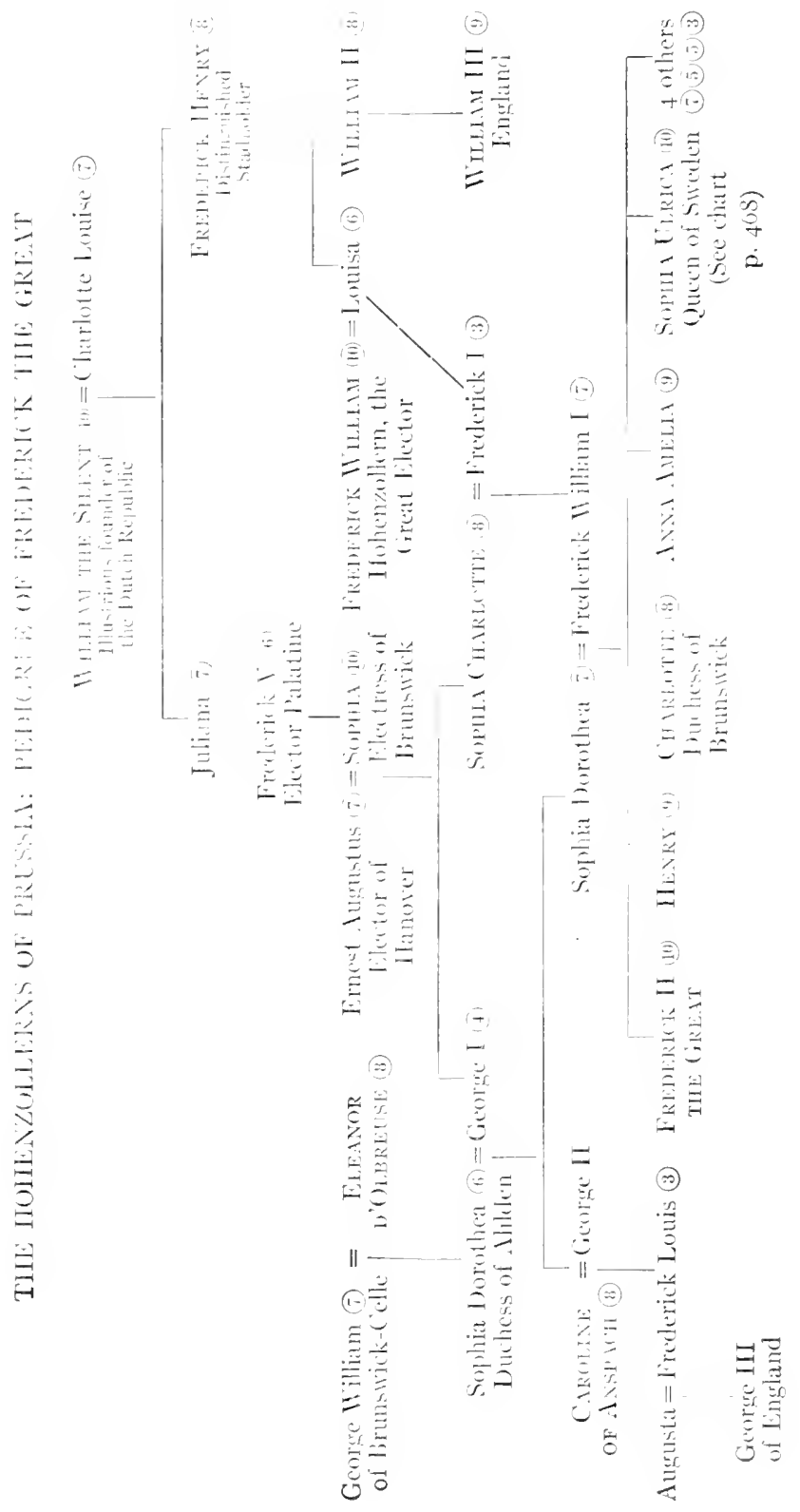




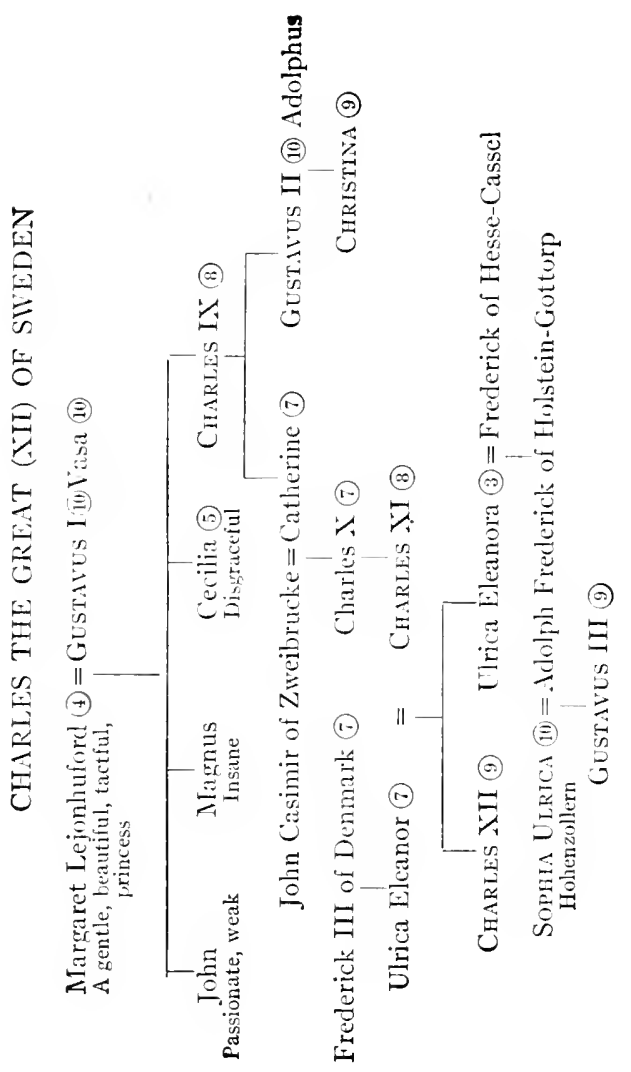


three other children one was insane and two weak. The chiluren of Charles LX were hoth remarkably able. The daughter Catherine becomes the mother of a later succession of kings. Her son Charles $\mathrm{X}$ and his son Charles XI were rather mediocre; but Charles XI, with this fine stock behind him, married Ulrica Eleanor (7), granddaughter of Christian IV of Denmark, the most brilliant of all Danish sovereigns, and Charles XII, their son, is pronounced by Voltaire the most remarkable man who ever existed. Charles XiI had no children: the succession passed to his sister's son, Adolph Frederick of HolsteinGottorp, who married Louisa Ulrica, sister of Frederick the Great of Prussia. The result of this union of two great lines of hereditary ability was Gustavus III, a fit successor of Gustavus Vasa, Gustarus Adolphus, and Charles XII; he was 'a prodigy of talents,' statesman, poit, dramatist." 


\section{CHAPTER XXXVI}

\section{THE STATISTICAL STUDY OF HEREDITY IN MIAN}

Introduction. - A good example of this method is afforded by Popenoe and Johnson's studies of the heredity of longevity (chap. xxxix). Other examples are found in Heron's and in Orr and Rosenoff's studies of the heredity of insanity presented in the last chapter. The proof of a given character being hereditary is believed to be attained when it is shown that affected parents have a significantly larger proportion of affected offspring than have non-affected parents.

The statement that twinning is hereditary is based on the fact that twins are far more common in certain strains than in the general population. A twin birth occurs in about $\mathrm{I}$ out of every 88 confinements. C. H. Danforth found that in the case of 50 newhorn twins there were I 7 I single brothers and sisters and Io pairs of twin brothers and sisters, a ratio of about I to $\mathrm{I} 8$, as compared with that in the general population, I to 88 . Moreover, with respect to the mothers of these twins, their brothers and sisters numbered $3 \mathrm{r} 8$ singles to ro pairs of twins, a ratio of $\mathrm{I}$ to 32 . With respect to the fathers of these twins, there were $2 \mathrm{I} 9$ brothers and sisters born singly and 8 pairs of twin brothers and sisters, a ratio of $\mathrm{I}$ to 37 . A number of similar studies give comparable results, showing that twinning has a hereditary basis, but indicating nothing as to the exact mode of heredity.

The strength of heredity between different groups of relatives has been determined for a large number of human characters by determining the coefficient of correlation (see chap. xiii) existing between selected groups. Complete correlation is represented by the unit, I. If correlation is $\mathrm{I}$, heredity is perfect, and various grades of imperfect heredity are represented by decimals, such as $0.9,0.6,0.25$, etc. It has been shown that for most characters the correlation of offspring to fathers is about 0.4 , the same to mothers. The correlation between sibs (brothers and sisters) is about 0.5 , that between cousins about 0.25 , that between one-egg (identical) twins $0.9+$. These indices of correlation run strictly parallel with degrees of closeness of genetic relationship. 


\section{GALTON'S STATISTICAL STUDIES OF IHEREDITY IN MIX}

Galton was the first to make extensive use of the statistical nethori of studying the degree of heredity existing between parents and offspring and between sibs.

His hirst investigation concerned itself with the heredity of stature, a highty rariable character in man. He tried to find just how nearly parents and offspring are correlated as to adult stature. Certain difficulties were met at the vutset. First, there is a pronounced sexual dimorphism in stature, males bejng comsiderably taller on the arerage than females. To get ricl of this dificulty, he first letermined that males are, on the average, about I inch to the fout taller than fomales, and then transmuted all female statures into equivalent male statures by adling an inch to the fout to the stature of each female. Second, there are atways two parents and they mat be of very different statures, even after the mother's stature is transmuter into the male equivalent. To overeme this dificulty, he averaged the statures of each pair of parents and callex it the mir-parent stature. The statures of the mil-parents were grouped into nine classes, ranging from 64 to 73 inches, each class having a range of an inch. Thus one class consisted of those millparents falling between 72 and 73 inches, the next class from $i_{1}$ to 72 inches and so on down to the shortest class, from 64 to 65 iriches. The following schematic diagram (Fig. SS) shows the extent to which offspring inherit stature differences from the parents. If heredity were perfect, parent and offspring statures would coincide on the diagonal line, but they do not coincide. Arerage parents have nearly average wifsping, but very tall and very short parents have offspring deciledly less tall or less short, respectively, than their parents. In the chart the arrow-heads indicate the points where the average statues of offspring of each of the mid-parent classes fall. Note that mid-parents which average a little over 64 inches have offspring areraging about $65 \frac{1}{2}$ inches, and that mid-parents which have an average stature of $7 \mathrm{I}_{2}^{1}$ inches have offspring averaging 70 inches. It is clear that, on the average, the more exceptional the midlarents are, the more the offspring regress toward the mean stature of the group, or tomard mediucrity. This is true of all but the extreme tall group, where there is only a half inch of regression in the offspring. The reason for this is probalily associated with the fact that very tall persons are homozgous (double recessives), shortness of stature being incompletely dominant orer tallness.

Galton calculated that, with regard to stature, the offspring of 
exceptional parents tend to be, on the average, one-third less exceptional than the parents. This he called the Law of Filial Regression.

Similar results were obtained with several other types of human differences that were capable of being graded quantitatively and arranged in classes. Thus when eye-colors were graded on the basis

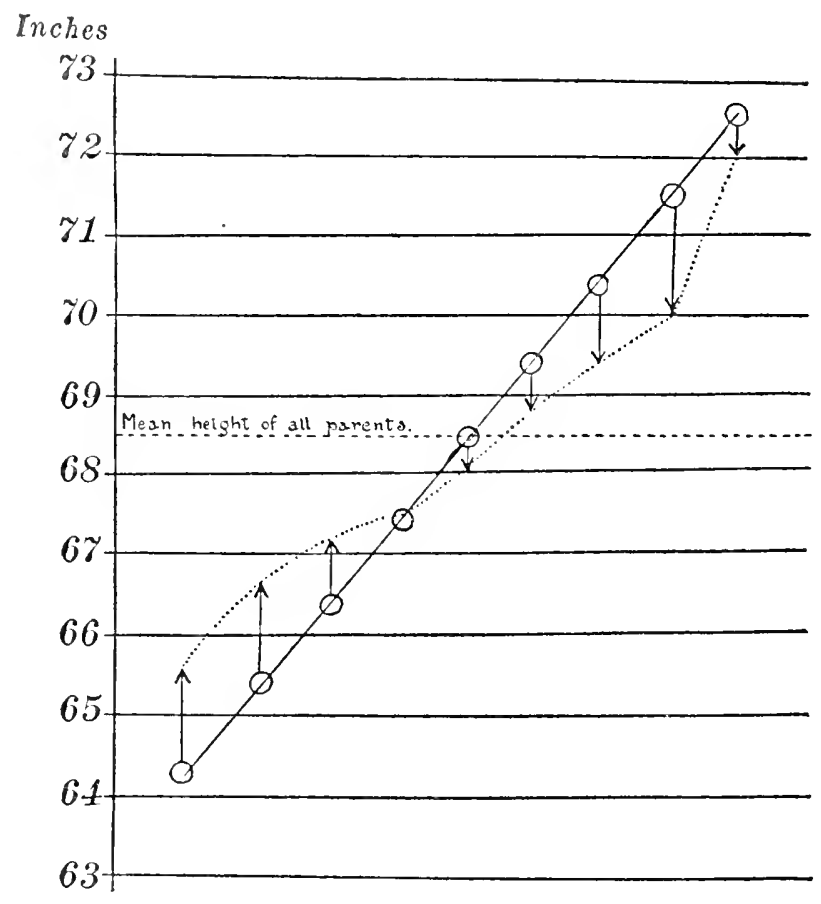

IIG. S8. - Diagram to illustrate Galton's "Law of Filial Recrression" as shown in the stature of parents and children. The mean height of all parents is shown by the dotted line between 68 and 69 inches. The circles through which the diagonal line runs represent the heights of graded groups of parents, and the arrowheads indicate the average heights of their children. The offspring of undersized parents are taller and of oversized parents are shorter than their respective parents. (From Conklin, after Italter.)

of the amount of pigment in the iris and arranged in nine or ten classes, it was found that there was practically the same amount of filial regression as there was in the case of stature. This was true for all except the pure blue-eyed parents, with no pigment in the front of the iris, where no regression in the offspring was noted. Blue-eyed individuals, are, of course, homozygous, if they are really blue-eyed in the genetic sense. 
The same law was shown to hold also for mental characters, or grades of mental ability. "The more bountifully" a parent is gifterl hy nature," says Galton, "the more rare will be his gool fortune if he begets a son as richly endlowed as himself." Galton considered that any law that applied to such diverse characters as stature, eye-color, and mental ability must be a universal law of heredity.

The problem then arose as to the reason why heredity between parents and offspring is so imperfect. Let us remember that Galton did all his work long before the rediscovery of Mendel's pulbications. Had he known about Mendel's laws, about the difference between

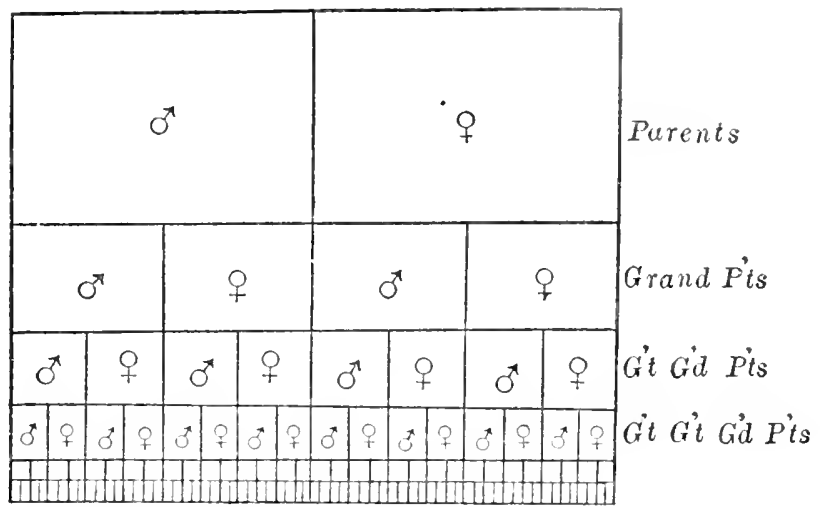

Fis, ro.-- Hiagram to illustrate Galton's "Law of Incestral shates in Inheritance." The whole heritage is represented by the entire rectan le; that derived from each progenitor by the smaller squares; the number of the linter doubles in each ascending generation while its area is halved. (From (onklin, afler Thomsen.)

phenotypic and genotypic conditions, and that recessive characters concealed for some generations crop out when two recessive genes meet, he would have understood at once why offspring are not always as exceptional as parents. Without any of this background, Gaiton had to solve the problem of imperfect heredity in his own way.

He arrived at a conclusion not unlike that of Weismann, that in heritance dues not come from the bodies of parents but from a racial "stirp," which is about the same as Weismann's "germ plasm." The reason assigned for filial regression was that offspring do not get all their hereditary characters from their immediate parents, but some of it comes from the four grandparents, some from the eight great-grandparents, and some from more remote ancestors. Just how much each of the different grades of ancestors contribute to the total heritage of 
an individual was worked out by statistical methods, and the result was Galton's Law of Ancestral Shares in Inheritance (Fig. 89).

According to this law, the two parents contribute between them on the average about one-half of each inherited character, each parent contributing a quarter of the whole. The four grandparents combined contribute one-half of the remainder, or one-fourth of the whole, each of them one-sixteenth. The eight great-grandparents contribute half of the remaining one-quarter, or one-eighth of the whole, each contributing one-sixty-fourth. The remaining ancestors contribute the remaining eighth. The total heritage would be $I$. This is an infinite mathematical series whose principal property is that each term is equal to the sum of all those which follow: thus, $\frac{1}{2}=\frac{1}{4}+\frac{1}{8}+\frac{1}{16}+\frac{1}{3}+\frac{1}{64}$, etc. No account is taken of the prepotencies of particular ancestorsand there is no question that such prepotencies exist-but all individual peculiarities are averaged up. The results are mass results, inapplicable to any particular individual or pedigree.

The exact shares of various grades of ancestors, as stated by Galton, have been questioned by Pearson, who, after careful study, has revised Galton's figures to read: parents $\frac{1}{2}$, grandparents $\frac{1}{3}$, greatgrandparents $\stackrel{2}{y}$, etc.

Criticism of Galton's work.-The scheme used by Galton assumes that the number of ancestors is far greater than is actually the case. "Theoretically," says Conklin, "the number of ancestors doubles with each ascending generation; there are two parents, four grandparents, cight great grandparents, etc. If this continued to be true indefinitely the number of ancestors in any ascending generation would be $(2)^{n}$, in which $n$ represents the number of generations. There have been 57 generations since the beginning of the Christian Era; and if this rule held true indefinitely, each of us would have had since the time of the birth of Christ a number of ancestors represented by (2)57, or about I 20 quadrillions - a number far greater than the entire human population of the globe since that time. As a matter of fact, owing to intermarriage of cousins of various degrees, the actual number of ancestors is much smaller than the theoretical number. For example, Plate says that the late emperor of Germany had only I62 ancestors in the tenth ascending generation, instead of $5^{\text {I2 }}$, the theoretical number.

"Davenport concludes that no people of English descent are more distantly related than 3 oth cousins, while most people are much more closely related than that. If we allow three generations to the century, and calculate that the degree of cousinship is determined by the num- 
ber of generations less two, since first cousins appear only in the thirel generation, the first being that of the parents and the second that of the sons and daughters, we find that zoth cousins at the present time would have had a common ancestor about one thousand years ago or approxinately at the time of William the Concpueror. As a matter of fact, most persons of the same race are much more closely related than this, and certainly we need not go back to Adam or even Shem, Ham, or Japheth, to find our common ancestor."

Galton's data in the light of genetics.- The two main laws of Galton seem to us, in the light of our present knowlerlge of genetics, to be peculiarly barren. The laws are true enough, but throw little or no light upon the mechanism of heredity. They and the laws of Mendel are not contrarlictory; in fact, each type of laws could be transmuterl into terms of the other. The main clifferences between Galton's and Mendel's laws of heredity are (a) that Galton's laws do not distinguish between genotypic and phenotypic difierences; $(b)$ character differences are often not capable of being arranged in graded series at al! but are qualitatively different and without intergrades, thus being unsuitalle for statistical study; (c) the statistical method often luses sight of the exceptional cases, which are usually the most interesting and instructive.

On the whole, it may be said that Galton's work is now considered as chiefly of historical value. It served a useful purpose mainly in that it definitely called attention to the fact of heredity in man, a fact that was at the time hardly recognized in political, educational, and sociological circles. 


\section{CHAPTER XXXVII}

\section{TWINS AND HEREDITY}

\section{THE BIOLOGY OF TWINS}

Twins have always been a source of interest and amusement to other people. There is something inherently comic in the existence of two individuals so similar that their identities are likely to be confused. Stories and plays have been written, the chief plot of which involves the mistaken identity of two brothers, two sisters, or a brother and sister. Quite recently I came to know an attractive lady who told me an interesting story of her girlhood-a story from real life that bears out those of drama and fiction. This young woman had a sister so much like herself that her best friends could not tell them apart. It so happened that a young man became attracted to one of the twins and called practically every night to pay his court. This assiduous wooing soon became burdensome, and, to relieve herself, the young lady had her twin sister substitute for her on some of the evenings. In the course of time the young man approached a proposal of marriage, but unfortunately selected an evening for popping the question when the substitute twin was on duty. He told her that, though some claimed to see no difference between her and her sister, he himself thought there was a great difference and all in her favor. He said he could not see why other people thought them so much alike. The substitute was forced to confess the deception; but in spite of this, the young man insisted that she was the one he wanted, and suspected her of merely testing his fidelity. In the resultant confusion the young man made such an ass of himself that neither twin had any further use for him.

This is, however, not to be a romance about twins, but a serious discussion about the scientific value of twins; so let us get on with it.

Various kinds of twins.- Several different kinds of human twins are recognized, among which the most significant are identical (duplicate) twins, "Siamese twins," and fraternal twins. Duplicate twins are, as the name implies, extremely similar in their personal characteristics (Fig. 9I). They are always of the same sex in a pair, have the same or very similar temperaments, dispositions, and mental capacities. They are believed to be derived from the division of a single zygote. There is no such reality in nature as that useful and romantic 
type of twin in which brother and sister are so much alike that one may take the place of the other. Such twins are purely literary significance and justified only for dramatic and fictional purposes.

Siamese twins are of the same origin as duplicate twins. They are the product of the division of a single individual into two, but in their case the division has been incomplete. Sometimes they are double in the head region and single back of that; sometimes they are double in the fower trunk region and single anterior to that; and

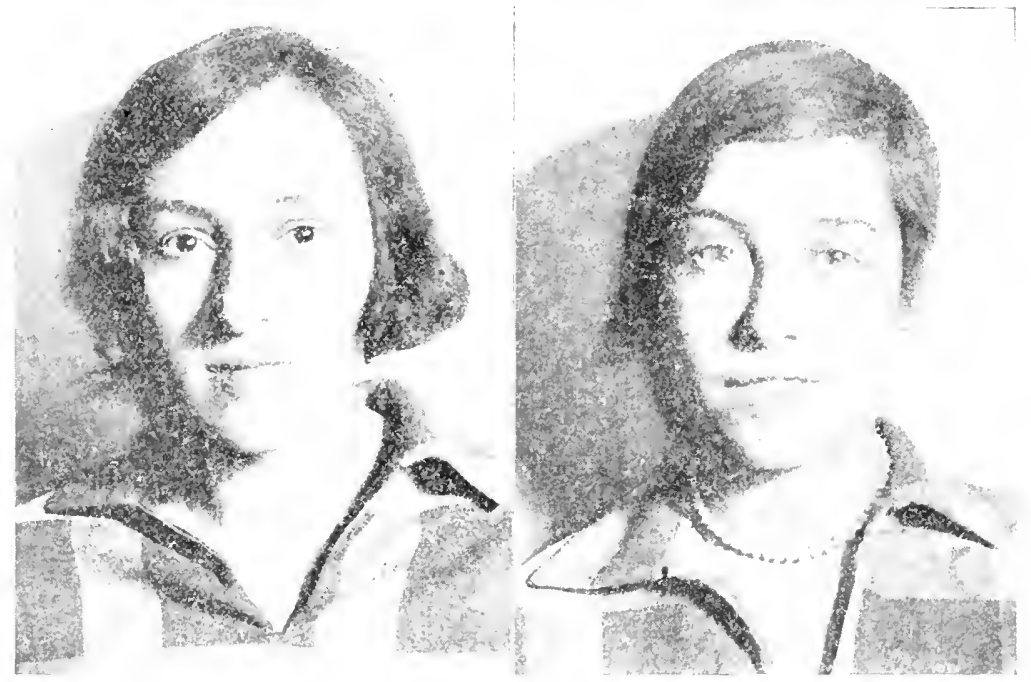

FIG. 90.- I pair of typical fraternal twins, showing differences in eye color, features, body build, etc.

sometimes they are double in the hearl and leg regions and united only in a small area at the hips or sides. Cases of Siamese twins that survive are exceedingly rare, the number recorded being so small that they could be counted on one's fingers. Yet it has been my privilege to have examined within recent years two of these cases.

Fraternal twins are quite different in origin. They arise from the simultaneous fertilization of two eggs and, except that they develop together in the same uterus, they have no closer kinship than ordinary brothers and sisters. They may be of the same sex or of opposite sexes in just the same way that families of two children may be both boys, both girls, or a boy and a girl. Fraternal twins are therefore, 
only about as similar as ordinary brothers or sisters. A typical pair of fraternal twins is shown in Figure go.

The origin of identical twins. - While there is no doubt in the minds of biologists that human identical twins are derived from the division of a single egg or embryo, it has never been possible to demonstrate this directly. Early stages in the development even of ordinary single human embryos are exceedingly rare, and there are no specimens

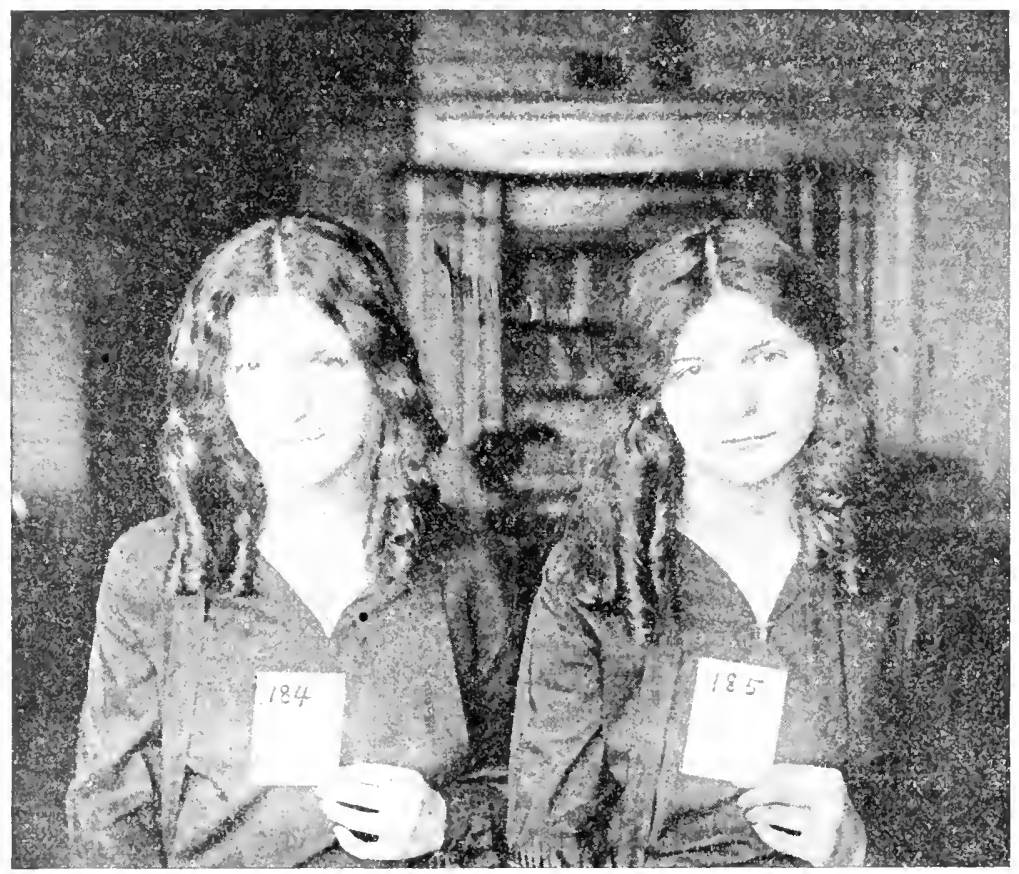

Fig. 9I.-A pair of typical identical twins, showing no genetic differences.

known that are young enough to show the beginnings of normal twinning. Hence our belief that identical twins come from a single egg is based on a mass of indirect, but none the less conclusive, evidence.

In the first place, it so happens that the entire developmental history has been worked out for another mammal, the nine-banded armadillo, an animal which bears one-egg identical quadruplets at nearly every birth (see Fig. 52). The peculiarities of both egg and uterus are very similar to those of man. The known steps of embryology of the two species accord so closely that it is believed that the 
process of twinning in man must be essentially the same as in the armadillo. Now, in the armadillo, every step in the double twinning process has been observed, and we have some rather well-supported theories as to why the egg divides into four individuals instead of dereloping into but one. There is in the armadillo a well-defined hitch in the process of the attachment of the young embryo to the membranes of the uterus. For a month or more after the embryo descends the egg tube into the uterus it lies free in the uterine cavity, whereas it should normally have attached itself immediately to the maternal tissues so as to receive food and oxyen from the maternal blood. During this period the young embryo is completely stopped down and is unable to develop at all. Its vitality becomes so lowered that, when finally the meehanism of attachment does right itself and the embryo is afforded the chance to feed and respire, the fires of life have furned so tow that the embryo camnot maintain its unity, but starts to develop first at two regions and then at four. These four growing points develop into the four separate embryos.

That a lowering of the rate of vital activity during early development is able to induce twinning has been demonstrated experimentally in several species of animals, notably certain fishes and echinoderms. Apparently some embryos cannot maintain their singleness under conditions that lower vitality. On this account right-and left-hand sides cease to co-operate to form a single individual, and each half grows independently into a whole embryo. In armadillo quadruplets. some hundreds of which have been examined, there are frequent cases of mirror-imaging, that is, peculiarities found in the right sile of one twin occur on the left side of the other. Again, it has been found that armadillo quadruplets are about 90 per cent identical, on the average, and are always all of the same sex in a litter.

Applying these known facts to the case of human twins, we find the following correspondences. Identical twins in man average about 90 per cent identical; they are always of the same sex in a pair; they show frequent instances of mirror-imaging. Thus, in about one-third of the cases one twin is right-handed, the other left-handed; also in about one-third of the cases the whirl of hair at the crown is clockwise in one twin, counter-clockwise in the other. Minor peculiarities of features-skin, teeth, finger prints, and palm patterns-are commonly: on opposite sides of the two individuals. In arlition to these evidences for the one-egg origin of human identical twins, it should be said that many prenatal human twins have been observed by obste- 
tricians and these show peculiarities in embryonic membranes similar to those of armadillo quadruplets. Thus it will be seen that the human twinning situation rests largely on the armadillo quadruplet situation.

As to the causes of human one-egg twinning, we have no positive knowledge. It seems probable, however, that the cause is somewhat similar to that described for the armadillo. Some early hitch in the normal correlation of embryonic and maternal physiological relations, involving a delay in placentation, is believed to be responsible for twinning in man. Technical studies of tubal pregnancies strongly support this view; but lack of space forbids the introduction of this testimony.

In concluding the discussion of the causes of human twins, it must be admitted that as yet we do not know enough to enable us to control or to permit the production of twins. So we can give no practical advice to those who desire to have twins or to avoid them.

\section{TIIE TIIN IIETHOD OF STUDYING HEREDITY IN MAN}

In recent years there has grown up a new method of studying heredity in man by making use of twins, and especially of identical twins. A number of European workers, notably Siemens and von Verscheur, have written extensively on this method and have contributed many new facts about the heredity of pathological conditions and normal peculiarities in man.

The validity of the method rests on the ability of experienced students of twins to diagnose twins accurately as to whether they are identical (monozygotic) or fraternal (dizygotic). Both Siemens and von Verscheur are confident of their ability to do this, and I fully agree with them, having had no real difficulties in making this diagnosis in considerably more than a hundred cases.

Assuming that the two types of twins can be accurately separated by experts, how can twins be used in determining what characters are hereditary? The working hypothesis is that those characters that are the same in all cases of identical twins, but are usually different in fraternal twins, are hereditary; and that those characters that are different in identical twins, or that occur in one such twin and not in the other, are non-hereditary. Now there is one weakness of this hypothesis, namely, that some undoubtedly hereditary characters actually do express themselves differently in the two individuals of a monozygotic pair. This is not surprising, for often in a single individual a hereditary character may express itself on one side of the body 
and not on the other, or else it may express itself much more extensively on one side than on the other. For example, there are certain finger-print and patm-print patterns that may occur on the right hand of an individual and not on the leit, or may lo present in one form on one hand and in another form on the other hand. Now, if inlentical twins are derived from the separated right and leit hatves of an embryo that typically woukl produce a single individual. such twins may be expected to be only as similar as are the tro sietes of a single individual. In view of this circumstance, we would be inclined to modify the working hyothesis of siemens to the extent wif sing that characters which are always the same in both individuals of a pair of identical twins are undouldedly hereditary, but that the failure of certain characters to be the same in both members of a pair does mot prove that such characters are non-herelitary. 'That this print is well taken is demonstrated by a study of armadillo equadruphets, which are unquestionably monogygotic. In these animals it frequently hafpens that a well-defined peculiarity, such as a local doubling of a band in the armor of the back, a rare anomaly known to be inheriterl from the mother, does not appear in all four offoring from a single zyote. One of the four may have it on the right sile, another on the leit sikte. a third on both siles, and a fourth may fiil to show any sirn of it. Yet it would be fonlish to claim that, because the character filited to appear in one out of the four quadruplets, such a character is monhercuitary.

Using the working hypothesis. however, in its original form, Siemens has been able to show that a large number of path logical conclitions are hereditary. He has specialized on lirthmarks (naevi) and has shown that various types of naevi comatantly appear in both twins, if they appear at all. He has shown that even moles and freckles are hereditary.

Bomnevie, Wilder, and I, working independently, have shown that various peculiarities of finger prints and palm patterns are herelitary. This has been done by the method of determining the cuthicients of correlation between right and leit sides of the same indivilual. Comparisons of the extent of correlation in irlentical twins is male with those in fraternal twins, silss, ank unrelated persons. For exanule. I have studied statistically the numbers of ridges in the fingtr pattems of fifty pairs of inlentical and of fifty pairs of fratemat twins. and the coefincients of correlation ohtained are as follows: 


\section{COEFFICIENTS OF CORRELATION BETWEEN TOTAL RIDGE COUNTS OF FIVE FINGERS OF EACH HAND}
Correlation between right and left hands of same individual...................... $r=0.93 \pm 0.01$
Correlation between right plus left hands of identical twins........................ $r=0.95 \pm 0.01$
Correlation between right plus left hands of fraternal twins............................. $r=0.46 \pm 0.08$
Correlation between right plus left hands of 30 pairs of brothers and sisters (Bonnevie) ........... $\quad r=0.59 \pm 0.08$
Correlation between right plus left hands of 30 un- related individuals (Bonnevie) ............ $r=0.27 \pm 0.12$

It will be seen that identical twins are even more alike in total ridge counts of finger patterns than are the two sides of the bodies of single individuals. This is in itself strong proof of the hereditary character of finger patterns. Fraternal twins are no more alike (in this series not as much alike) as are ordinary sibs. The extremely close resemblance between identical twins should be contrasted with the very low correlation in unrelated individuals. The slight positive correlation in unrelated inciividuals may be taken as a residuum of racial hererlity.

In contrast with finger patterns, which everyone knows are fixed at birth and do not change throughout life - a fact that makes them valuable as an aid in personal identification - let us examine the degree of correlation in mental qualities as exhibited by groups of varying grades of relationship. Taking the Intelligence Quotient (I.Q.) as a measure of mental capacity, the following table was worked out by Kohn, a capable German student of twins:

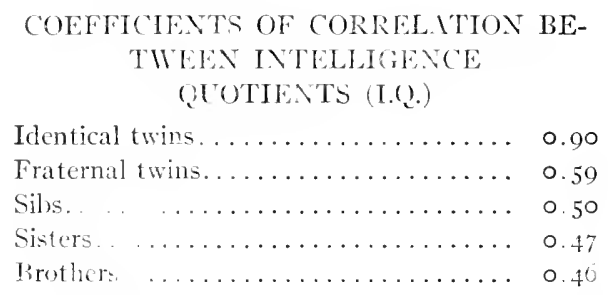

It is highly significant that mental differences show substantially the same grades of correlation as do the finger patterns, which are generally admitted to be purely hereditary. Various other authors, including our own local investigators, have found essentially the same 
situation. Moreover, we have found that, in identical twins, the more alike they are physically, the more alike they are mentally. These studies tend to show one thing most clearly, that there is no distinction as to heredity between physical and mental characters.

A great many reports have come in from clinics all orer the work conceming cases of identical twins in which both show rare and peculiar phrsicat anomalies. Only a few examples can be given out of a large number that lie before me:

Bruce and Daugherty report seven cases of identical twins both aflicted with the same form of diabetes mellitus. Kelly Hale reports a pair of twins both afflicted with congenital diskcation of the hips, one with left hip dislocated and right eve crossed, the other with right hip dislocated and left eye crossed. This is a case of pronouned mirror-imaging and shows an unusual association of characters. Meierowski reports a striking case of inentical twins, woth with uni lateral strabismus, one with right eye badly crossed and the other with leit eye shightly less crossed. Croon reports a case of a pair of irientical twins who began menstruation on the same day, were normat unt thirty, then suffered aike from menstrual diffenties. Buth har menopause at fify and three years later both leveloped the same type of carcinoma of the uterus. Ton Verscheur reports a striking case af inguinal hemia (rupture) in a pair of cherly twin men, in wheh the rupture appears on the right sicle of one and the left side of the other. Goldstein and Gchenck report an unusual case of dwarfism in twins. The smaller of the twins was smaller in all organs on one half of the body, a case of hemihypertionhy. Ahfeld reports seven cases of twins in which similar bodily malformations were present in both members of a pair. D'Outrepont reports a case of twins of which both had spina bifida and both had six fingers or six toes on each limb. Lehmann reports cases of twins both afflicted with cerebral hernias and hypospadias. Davis reports six cases of hare hip and cleft palate present in both members of the twin pairs. Parker reports two cases of twins both of whom dereloped dementia praecox, at nearly the same age. Brarley reports several cases of twins both afficted with similar forms of manic depressive psychoses. Gesell reports whing wo both showed extrioldinary precosity, who sat up at six months, walked and talked at eleven months, leamed French at three years, and were in the seventh grate at the age of nine.

No one has ever taken the troulle to get together all the thata reported by observers of twins. If we hat all this information together 
in available form, it would doubtless constitute a most valuable contribution to the sturly of human heredity. The twin method is a new one and not yet so well established as the others, but it is growing in favor every year.

\section{CRIME AND DESTINY}

One of the most remarkable uses of the twin method in the study of heredity has to do with the problem of the heredity of criminal tendencies. Professor Johannes Lange, of Munich, has recently reported the results of many years of work on the criminal records of twins one or both of whom had been in Bavarian prisons or reformatories. This work was a part of the program of research of the Bavarian Institute for Criminal Biology, and is held in high esteem by leaders in the field. Lange's book entitled Crime and Destiny reports in some detail the criminal records of thirteen pairs of identical twins and seventeen pairs of fraternal twins, one or both menbers of a pair being in every case a confirmed and inveterate criminal. But what absut the other twin in the two groups? The answer to this question is astonishing. Of the thirteen pairs of identical twins, there were ten cases in which the other twin of the pair was also an equally confirmed criminal. Not merely this, but the twin criminals of each pair exhilited the same types of criminality: both were swindlers, both thieves, both sex-offenders, both drunken ne'er-do-wells, etc., though in no case were the two members of a pair associated in their crimes. Of the three pairs of identical twins in which only one was a criminal, there were two cases in which one member of the pair had suffered a serious head injury at birth or in infancy, which might well have been responsible for his criminal tendencies, while in the remaining case one twin suffered severely from a goiter which might have profoundly affected his conduct. From Lange's description of the last case, however, it seems highly probable to me that this case is incorrectly diagnosed as identical, but Lange leans over backward in his attempt to weight the evidence against the conclusion that criminal tendencies are hereditary.

In contrast with this impressive study of identical twins, is that of the seventeen cases of fraternal twins, of which there were only two cases in which both members of a pair were criminal, and these exhibited relatively mild forms of criminality, such as might not have appeared at all in a more favorable environment.

In one of the cases of identical twins, both of whom were criminal, one twin, after a long criminal record, married a good woman of strong 


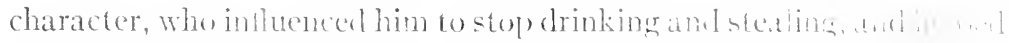
him to become a farly uselul member of socioty. This cas $\{(-1, \ldots$ w show that there is an environmental element in crime; fut the paint of the whole study is that there are certain heretitaly types of mind that yeld more readily than others to the ordinary social comblitions that learl to crime. In this sense, and in this sense only, may it the said that criminality is hereditary.

\section{TWIS AND THE RELATIT POTHNCY OF IHEREDTY AXD ENITHOAEXT}

Trou sets of factors are involverl in the derehopent ol an individ-

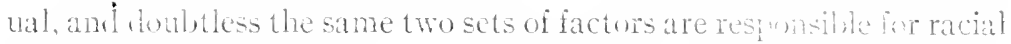
development, or evolution. One catterery of factors is intrinsic and

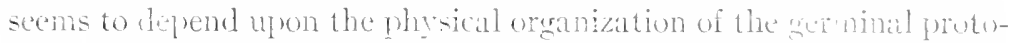
plasm or upon the medanisms that are insolved in cell multiplication and lifferentiation: all such factors are here incluber winter the turn "heredity" The other categury of faters is extriscic and sems to involve both enviromment and training: these factors are usubly incluled together under the term "enviromment." The controversy as to the relitive importance of these two setsol factors is so okt as to be time-homoret. In the case of man entecialiy, the question as to what characters are due to nature and what to nurture has long leen an ative issue.

Before the rise and growth of demoraley the opinion was rery commonly held that man was born noble or base, with hich qualities or low, according as hecame from goul or bat stoti. The rariouswell-defined strata of society were believed to have a basis in bloul. Bhe bloud was the criterion of nubility or of high character. Whth the rise of democracy, however, the view has come to prevail that "all men are created equal" and that inequalities arise mly as the result of inequitable distribution of envirommental and entuctional adrantages. This has been unill rectuty the prevaiing opinion in educational, sociological, and political circlis. This riew, ignoring hereditary difierences and ureremphasizing oi the potency of enviromment, has calised the pentivim to swing to the olposite extreme.

The present century has seen such a suprising atrance in our knowledge of the laws and the mechaniem of herelity lhat it is no wonder that biokerists have come to feel that heredity is far and andy the chief factor in human derelopment and that ensirunnent and training are only minor modifying factors. 
In one sense, the controversy about the relative importance of heredity and environment is rather silly and futile, for both heredity and environment are absolutely essential for development to take place at all. The real controversy hinges on this question: With respect to any given character, do the actually existing differences in heredity have agreater or a less effect in determining the differences found in the adult than do the actually existing differences in the environment?

Now some characters, such as eye-color, hair-color, shape and arrangement of teeth, finger and palm patterns, features, body build, and a long list of others, are evidently not much altered by existing differences in the environment and may therefore be called purely hereditary - and by this we do not mean that the environment has nothing to do with their determination. Other characters, such as body weight, muscular development, skills of various kinds, extent of tanning of the skin, certain types of eye defects, effects due to the ravages of disease, and many others, seem to be very largely influenced by existing differences in the environment, and may be called environmental. Large numbers of characters fall in between these extremes, characters that are surely predetermined, within linits, by heredity but are also much modified by actually existing differences in the environment. Among the most significant types of human difference that are both hereditary and environmental, in the sense just discussed, are differences in mental capacity (as determined by intelligence tests) and differences in temperamental and emotional make-up (as determined by psychological tests).

Identical twins have furnished some highly significant data on this point. As a preliminary step it was necessary to determine the average differences in mental capacity and in temperament for fifty pairs of identical twins reared together and for the same number of same-sexed fraternal twins reared together. Since the heredity was the same and also the environment essentially the same for iclentical twins reared together, the observed differences must be due largely to the workings of the asymmetry mechanism, the same mechanism that makes the two halves of a single individual different. In order to test the effect of differences in environment, therefore, we must compare the differences found in identical twins reared together with those of identical twins reared apart. In both those reared together and those reared apart the asymmetry mechanism works in the same way; therefore, greater differences in separated twins than in those reared together may fairly be attributed to differences in environment. 
Now scientists cammot cold-bloodeclly seprate irlentical fwins in infancy and rear the two under radically different enviroments, but fortunately this very thing has sometimes been come fer them without their knowledge. When by a stroke of good fortune we are alsle to locate such cases, we have before us a scientibe experiment completed and only needing to be studied. During the last few vears we have completed the study of five such cases. A lirict arcuant of these five cases, (one studied by Muller and hve by Newman) may interest the reatler:

Muller studied a pair of twin sisters, left orphans and separated at two weeks. They diel not meet mat they were cighteen vears ohl. They lived under somewhat similar social conditions, in northwestern mining and ranch country, but there were marked difierences in their educational and social experiences. Physically, although entirely separated from infancy to adulthool, they were as identical as are identical twins reared logether. Their heights, weights, features, teeth and finger nails, eye-color, hair-colur, glore size, bloos grotip, etc. were indistinguishably similar. In addition, both were left-ianded, both had the same peculiar prominences on the ankles, and loth had at droop of the mouth on the left side. Both had had two or three attacks of tuberculosis almost simultaneously. Intelligence tests showed them to be both very bright, and their scores were as similar as those commonly made by the same individual taking the tests twice over. In the temperament and emotimal tests, on the other hand, they showed a very wide divergence, as great or greater than those between two indiviluals taken at random. In this case the environmental differences hul leit the physical and intellectual characters ummorlined, but had produced a proiound effect un the emotional nature of the trins.

Newman's first case consisted of a pair of twin sisters separated at eighteen months. One was taken to Ontario, and the other remained in London, Enghnd, where they we bom. After seventeen years of complete separation, the English twin joined ber sister in Canada, where they now live in a pleasunt medium-sized wmen. Their environments were very different during the perioul of separation, as different as one is erer likely to find in cases of separated identical twins. One was reared in a congested district of London and passer the trying period of the war there; the other lived under good circumstances in at suburban town in Ontario, and did not feel the pressure of war conditions. Their educational careers were cqual in amount and kind. 
Tests showed, however, that they were very different in mental capacity, the Canadian twin being decidedly the brighter of the two. The difference was three times as great as the average difference of fifty pairs of identical twins reared together, and even somewhat greater than the average differences of fifty pairs of fraternal twins reared together. Physically, the Canadian twin was much superior, weighing IO2 pounds, as compared with 92 for the English twin, a great difference for such small persons. They were strikingly similar in height, build, features, hair and eye-color, and finger and palm patterns. Also, they showed great sinilarity in their will-temperament qualities and in emotional reactions. Thus the differences in environment had caused marked divergence in the physical condition of the body and in mental capacity, but lad left the emotional nature unmodificd. In every respect this case is the direct opposite of Muller's case.

Newman's second case consisted of two twin sisters, whe never heard of each other until they were about twenty-one years of age, but came together through the lucky accident of an acquaintance of one accosting the other by mistake. They were separated at eighteen months, adopted by two different families, reared in much the same stratum of society, but one had only grade-school education, while the other went through secondary and normal schools and taught grade school. These twins were physically almost complete duplicates when examined, as similar as the most similar identical twins reared together. The mental tests showed that the more highly educated twin ranks far above her less educated sister, the difference being more than three times as great as the average difference of fifty pairs of irlentical twins reared together and even greater than the average difference of fifty pairs of fraternal twins reared together. In contrast with this stands the fact that in all tests of emotional traits and of temperament, the twins give the impression of being remarkably and unusually similar. To summarize, these twins show a profound effect upon mental capacity due to vastly different educational careers, but physically and temperamentally they are nearly identical.

Newman's third case consists of two young men, one of whom lived in fairly large cities and the other in small country towns and villages. They had been separated at two months and had never met until they were about twenty-two years old, when one discovered that he had a twin brother while looking over some old papers. By a little detective work he located him. Their educational experiences were 
nearly the same, the city twin having perhaps slightly better training. When examined, they were very similar in all genetic characters, but the city boy was in much better physical condition, weighing over to pounds more than his brother, though they were both small persons. In mental capacity the city boy was, on the basis of most of the tests given, definitely superior, though they were nearly equal on the Stanford-Binet test. In will-temperament and emotional tests they were very far apart, as far apart as were Muller's twins in this respect. In summary, this pair shows marked differences physically, mentally, and temperamentally, but more pronounced differences in temperament than in either of the others.

Newman's fourth case concerns itself with a pair of young women, now twenty-nine years of age, separated at five months, and reared in different families in the same part of Ohio. One was reared entirely on a farm, while the other lived mostly an indoor life in a town. The town girl had grade-school and high-school education, the farm girl only country grade-school training. They were almost identical physically until about twelve years ago, but now the farm girl is in far better physical condition, weighing i 3 pounds as compared with i Io pounds for the town girl, and being very much stronger and more vigorous. The town girl had a mental rating much higher than her sister, the difference being over three times as great as the average difference of fifty pairs of identical twins reared together and considerably greater than the average differences of fifty pairs of fratemal twins reared together. In will-temperament and emotional reactions they are extremely different, as far apart as were Muller's twins or Newman's third case. In summary, these twins were about equally different in physical, mental, and temperamental characteristics.

A fifth case is being studied just as this revised edition goes to press. It concerns itself with a pair of twin women, now thirty-eight years old, separated at three months. 'They did not know of each other's existence till they were sixteen years old. A preliminary study of the data shows rather close similarity mentally and temperatmentally, but a great difference in physical condition.

It is still too early to attempt to draw general conclusions on the basis of these six cases, but some facts confront us that cannot be dodged. Perhaps the most disconcerting fact revealed by the data is that fraternal twins reared together are on the average somewhat more similar in mental rating, as judged by intelligence tests, than are identival twins reared a part. This seems to mean that when heredity is different 
and the environment the same, twins tend to become more similar than when the environment is different and the heredity is the same. Extreme environmentalists may see in this situation evidence that environmental differences are more powerful in determining mental capacity than are hereditary differences. I do not believe that this is true, and for several reasons. In the first place, if environment were more powerful than heredity, identical twins reared together should not be twice as similar as fraternal twins reared together; yet this is the case. In the second place, all the tests used to determine mental ability, except possibly the International test, measure largely the effects of training. This tends to mask or cover up hereditary resemblances and differences, increasing the difference in cases where educational experiences are widely divergent and decreasing the differences (in fraternal twins reared together) where educational experiences are alike. Thus the tests used tend to exaggerate the potency of environmental differences and to minimize the potency of hereditary differences.

In spite of these weaknesses in method, however, the data at least warrant the conclusion that both hereditary differences and environmental differences play important rôles in determining mental characteristics. In so far as a person's mental status is measurable in terms of ability to perform well or poorly on intelligence tests, it seems fair to conclude from our data that differences in heredity and differences in environment are about equally responsible for the mental status of an individual. On the other hand, since a large part of what is measured by intelligence tests is merely achievement and not real mental capacity, some will say we are not really measuring mental status at all. There is doubtless some justification in this criticism of intelligence tests, yet I cannot help but believe that one's individual mind, his mental rating, is at any time the product of his hereditary make-up and his training. If this be true, it is only fair to rate him according to this product.

In spite of all this apparent evidence that hereditary differences and environmental differences are of about equal potency in determining mental status, I have a deep-seated conviction, which I am unable completely to justify at this time, that differences in heredity are considerably more influential, perhaps twice as influential, in determining one's mental status, as are differences in environment. 


\title{
CHAPTER XXXVH
}

\section{DOES HEREDITY OR ENVIRONMENT MAKE MEN?!}

\author{
ALBERT EDWARD WIGGAM
}

All men are born unequal. When the Declaration of Independence made its pronunciamento, it was merely to serve notice upon King George that the American colonists were equal in their sociai, political and human rights to the citizens of England. It was not meant as a scientific formula from some laboratory of psychology which had tested several thousand human beings and found them all exactly equal. In all the common rights of man, the right to life, liberty and the pursuit of happiness, the world now concedes that one man is as good as another.

But, when we study not men's rights, but men's natures and capacities, nothing is more obvious than that all men are unequal; they are born unequal; they will always be unequal; nature intended them to be unequal; and no system of government, social control, or education has yet been devised or ever will be devised, that will make them equal. Indeed, the astonishing and delightful discovery of modern psychology and biology is that the more you educate men the more unequal you make them. The more you equalize opportunity, the more you unequalize men. The more nearly you treat men alike, the more unlike they become. It was Henry van Dyhe, I think, who said that there is one thing in which all men are exactly alike, and that is that they are all different. And the more you educate and develop these differences, the more they grow into larger differences.

As a matter of fact, that is what educarion and good environment are for, to draw out and develop each man's individual and particular capacities and powers. The old Romans invented the word "education"-edwo-a leading out of what was in a man, and not a pouring in of some magic fire from Heaven to melt and mold his soul into a likeness to other men. You can teach three boys the same knowledse of history. You can inform them of exactly the same facts of the past. But I do not believe any school-teacher in the world would maintain that he had filled them with the same spirit and viewpoint. One boy

' Reprinted from The Fruil of the Family Tree. Copyright I924 by the BobbsMerrill Company. 
will be inspired by these facts to write historical novels and dramas; another will find them helpful in shaping economic and social legislation; while the third may remain almost wholly unaffected and devote his life to keeping a country grocery or to inventing a new method of making soap. They all had the same facts, the same teacher, the same school-room. But they all reacted differently, each according to his own ability and temperament-that is, his inborn make-up.

So an unalterable fact of human nature is that men are different. The whole question at issue in this world-old heredity-environment debate is, what causes these differences?

All modern biology and psychology support the view that heredity plays a great part, and probably a preponderant part, in shaping a man's actions and reactions, his goings and comings, his health and happiness in this world. We found in the chapters on twins and on the royal families that this is true. But it may be of interest to present here some of the main arguments on both sides of this question, with these scientific discoveries as their background.

It is commonly said that it is impossible to separate heredity from environment. This is probably true when we consider merely one individual. I doubt if we shall ever be able to determine whether a particular act by a particular individual, say whether he takes a drink of alcohol on some particular occasion or whether he commits a crime, is due to his heredity or to his environment. The causes are so hopelessly intertwined that no one so far as I am aware has presented the slightest hope of measuring the relative influence of the two forces within the individual. As I have already pointed out in a foot-note to a previous chapter, the Behaviorists--a school of psychologists founded by Doctor John B. Watson-assert (at least some of the leading exponents of this school assert) that "ninety per cent. of a man's behavior is due to his environment."

This may be entirely true, but so far it seems to me it has not been removed from the realm of assertion into the realm of exact measurement. No one doubts that a man's early education is of great influence in determining his character and behavior in later life, but exactly how great-whether ninety per cent. or twenty per cent.-has not as yet so far as I am aware been measured. And I do not believe we can speak of percentages until we have measurements. Environment is important in determining behavior, but precisely how important I doubt very much if we have any means at present for determining, when it comes to one individual, whether we consider one particular act or the 
sum total of his character. Indeed, it seems to me it would he prefty difficult to determine what one hundred per cent. of a man's charicter really is, and when we har measured either ten per cent. or ninety per cent. of its total.

I am inclined to believe from what Thorndike and his students, especially Doctor Paul F. Voelker, have proved as to the enormous influence of moral education and as to how much more we can influence the moral character than we can develop the purely intellectual traits, that by proper education and environment we could prevent nearly. all individuals from committing actual crimes. Crime is not itself inherited, lecause crime is a particular act by a particular individual. And whether he commits that act, no doubt depends very greatly upon previous education, habits, the particular stimulus before him and all the forces of his environment. For all we know a man may commit a particular crime or take a particular drink entirely from environment. And it may be that he can be prevented from these particular acts entirely by enviromment. We know that moral ideas tend to diffuse themselves very widely over the mental life-or as the psychologists say, there is a very large "transfer of learning" from one set of brain centers to others. No doubt moral ideals set up wider transfers of learning and thus influence larger areas of behavior than the cultivation of particular mental abilities or aptitudes. For this reason teaching a boy trustworthiness, as Voelker has proved, influences his conduct far more widely than teaching him algebra improves his proficiency even in algebra. All of this is granted.

What we know of heredity, therefore, should not in the least discourage us (indeed, when deeply considered it ought to encourage us) from throwing every possible good influence about our youth. The very stability of society depends on our doing this. But when it comes to the question as to which one of two individuals is the more likely to commit crime at some time in his life or to take to excessive drink, we are in reality dealing with a different set of scientific problems. And when we come to the question as to which family is likely to have more members who, in any one age of the world, will be unable to adjust themselves to sound social behavior or who will easily be filled with aspirations for building a worthy character and maintaining the social and political order, we are in a field where we can measure the factors involved by fairly exact methods, and predict results with considerable conficlence.

Doctor Charles F. Goring, of the Galton Eugenics Lahoratory of 
London, has shown in the most exact and elaborate study ever made of the influence of heredity upon the criminal tendencies of men-or what more technically is called the "etiology of crime"-that heredity is by all means the more important factor in the problem. Some families easily react, naturally, to high social ideals, and some lack the foresight and the power to develop that true synthetic wisdom of life which we call in a general way self-control. Education and environment will alter the weight and influence of these factors within each individual, but I am not aware of sufficient evidence to prove that they will much alter the central tendencies either of such individuals or of such families.

Perhaps Woods's illustration will illuminate this problem. As he pointed out in 1912 at the First Eugenics Congress in London (the first time, I think, this distinction had been made), it is only when we come to measure the differences between one or two groups of individuals, that we can really separate heredity from environment. When we consider, as Woods suggests, what causes a white man to be white or a negro to be black, or one person to have brown eyes and one blue, it is evident that these characteristics are the resultant of all the combined forces of heredity and environment. We can not, therefore, by any means now known, separate the two sets of forces within any one individual. But that the differences in pigmentation between the white and black races are almost wholly due to the differences in their germ plasm, no one can very well doubt. True, a tropical sun will develop all the skin pigment a white man has the power to produce, and rearing a negro in a northern climate will reduce his pigmentation; but when placed in the same climate their differences are almost wholly due to heredity.

Therefore we can not consider the heredity-environment problem with much assurance of success, either in method or logic, unless we consider it as the problem of the differences among men. And since, as Thorndike pointed out long ago in his Educational Psychology, the prizes of life, whether of health or wealth or social position, are nearly all relative matters, the result is that heredity is the most important factor in determining who shall secure these prizes and who shall not. If the ideal of human health were an individual who could barely hobble about, then to attain this minimum of energy would be our highest ambition. The healthiest man would be one who was almost helpless. Health would still be, as it is now, a relative matter. Just so wealth and influence are relative matters. Among our ancestors a 
man with a few shells or arrow heads was rich. The fact, as Thorndike suggrests, that Crocsus and Rockefeller were the two richest men in the world is due almost wholly to their superior natural powers over those of other men to acquire wealth. But the fact that Croesus accumulated only a few thousands, or at most a few millions, while Rockefeller has accumulated perhaps a billion, is almost wholly a matter of the differences in environment between the ancient and modern world.

The differences among men, therefore, as I trust we have shown throughout this book, are almost entirely due to their differences in natural powers and aptitudes. But none of this remotely discourages us from stimulating and educating those powers and aptitudes, nor should it discourage the individual from developing his own inner natural capacities and tendencies to the utmost. To do this is the only way to attain his prize in life. And whether he starts with one talent, two, five or a hundred, makes very little real difference. We all regret that we do not have greater natures than we have. I should really like to be such a man in intellect as was Plato or Pericles. I should like especially to have the musical appreciation of Fritz Kreisler and the power to play the piano like Josef Hofmann. But as William James pointed out, we can not be everything. And to want to be everything is as foolish and as much a waste of good energy as it is for a dog to bay at the moon. If we had everything we would probably lose that inmense incentive of ambition and rivalry which, just because men are different, probably leads them to make nearly all the practical achievements and moral conquests of life.

In his wonderful little book, Talks to Teachers and Students, James relates a story that goes to the heart of the problem. He says that one day he had an old carpenter making some repairs on his house at Cambridge. They were talking about the differences among men-why it is that some men begin at the bottom of the ladder and climb up, while others start at the top and slide down. Incidentally I remember that Josh Billings said, when a man starts down-hill in this world, it seems that all creation is greased for the occasion. However, the old carpenter finally made a remark which James states was one of the most profound observations upon human life he had ever heard or read in all the philosophies of men. "There is very little difference," said the carpenter, "between one man and another; but, what little there is, is very important."

Have we not here the crux of the whole matter? I suppose, if, 
when a baby, Abraham Lincoln had been placed by the side of all the other babies in the world of that time, the best baby-show judges on earth could have found very little difference between him and the thousands of others. And I am sure that if all the germ-cells from which these babies were born had been weighed and measured and analyzed and peered at through microscopes by all the biologists on earth, they could not have told which one would produce Abraham Lincoln. Yet existing somewhere, somehow, within this tiny microscopic cell, which had been handed down to his parents and which represented his combined ancestry, were mighty and resplendent forces which ordained in advance that the child born from it would be one of the greatest human beings in all the tide of time.

But it will be said that the Civil War "gave Lincoln his opportunity." Certainly it gave him this particular opportunity. No man could ask for a greater chance to serve mankind and enter among the human immortals. But the same opportunity existed for the four or five million other men who were born and grew up about the same time. The Civil War discovered Lincoln, but Lincoln also discovered the Civil War. Even the men in his Cabinet who had the stimulus of his overwhelming personality did not become Lincolns. Millions of men since then have taken him as their example and striven to be like him.

Of course we are all better because of the example of Lincoln. That is the value of a rich environment full of high ideals. I am a better man and so are you because this great soul lived and blessed the world. And I do not doubt that Lincoln himself was stimulated by his studies in the firelight of the lives of the men of the great generations gone. I do not doubt he tried to emulate them. Just in pro. portion to his own greatness does a man try to be like other great men. He does not try to copy them, he tries to expand his own powers in the light of their radiant examples. And I have noticed that the greater men are in real character, the more they have blessed the world with beauty, and truth and happiness, men such as Lincoln and Washington, and Foch and William the Silent, and Gustavus Adolphus, and Faraday and Huxley and Darwin and Pasteur and William James, the more nearly do they approach in their lives and personal characters to the Supreme Teacher - that other Carpenter who two thousand years ago also uttered some sayings that have changed the whole course of human history. Huxley, a thoroughgoing agnostic in philosophy, was almost fierce in his admiration of the character of Tesus. 
As Professor Thorndike has pointed out, when it comes to the absolute achievements of men, the outward performance to which they can attain, environment is well-nigh all powerful. But when it comes to determining which indivicluals in that civilization will profit the most by it and contribute the most richly to its expansion and continuance, the all-important thing is each inclividual's heredity. A man gives to his environment and receives from it just in proportion to the richness of his own nature. Was any great environment ever built by a race of fools? No. Was any truly small and mean environment ever built by a race teeming with genius? No. Where there is no vision, no genius, the people perish.

As another example, I walked down the street a while ago upon a pavement which took all the combined physics, chemistry, social, political and economic organization of a great industrial age to construct. I had nothing to do with it. It was a part of my environment. But I was able to walk faster and reach my journey's end earlier-that is, make a greater absolute achievement-because of it. By my side walked a laboring man with a basket of groceries for his family. Now, it may be that this man has a son in college who will some day write a much better book on heredity and eugenics than this one. But it certainly would surprise me to find that all the students in colleges and all writers of books were laboring men's sons, and all the sons of the abler and more successful classes should to-morrow be handling the picks and shovels of our civilization.

The whole point of this is that the things which men can do depend upon the tools that are at hand in the forms of environment, machinery, social organization, ideals and systems of education-in short, what we call the social heritage. But the relative performances of one man as compared with another, that is, what each man does with these tools - this social heritage, depends almost entirely upon his individual, inborn heritage. Consequently, it is the duty of all men to improve the general social heritage because this furnishes multiplied opportunities for each man to develop and express his personal heritage.

Let us see if, in a rough way, we can not measure this. The other day I motored through the western part of the state of New York, where I had learned the lives and histories of the farmers in considerable detail. I was being driven by a man who knew them all intimately. We passed a farm which a few years ago had been one of the model farms of western New York. At the death of the owner, whom 
we shall call John Crosby, its broad acres were divided into three equal shares for his sons. Within three years the appearance of two of the farms had changed. The fences were run down, the stock was run down, the buildings were run down, while the weeds and underbrush had run up. But on the third farm, which fell to the youngest son, the conditions were better than when the father died. This son, Joseph, was rapidly acquiring the lands of his two brothers, William and Alexander. The parts which he acquired promptly became models of successful tillage. I have no doubt that, as the neighbors prophesied, within a short time William and Alexander will be working as hired laborers for Joseph.

Now here is a clear case where the environment remained unchanged, while the heredity did change and had a chance to reveal its overwhelming power. All the stimulus was there for each one of the sons. But only one reacted to it. Any biologist would say in the light of his own studies, that Joseph was the only son who inherited his father's vigor and decision of character. However they came by it, no one could talk with the three brothers without discerning that they were radically different men.

But let us drive on and see a like phenomenon on another farm. We passed down the road and stopped in front of a large, handsome frame house. Two different men had been on this farm within the last twenty years and "couldn't make it pay." It had grown up in thickets and underbrush, the buildings had become dilapidated, the fruit trees were wind broken and worm eaten, until finally a poor immigrant named Conrad from Switzerland had bought it for a song. Within ten years he had developed it into one of the finest dairy farms in the region. And when I looked at his five-thousand-dollar Holstein bull and his prize cows giving from ten to fifteen thousand pounds of milk a year, I thought on the one hand of what glorious achievements American environment permits men to make, and on the other of what a small percentage of the millions of job-hunting immigrants America has admitted in the past forty years could do as well as Conrad. Had we had the wit to select and admit only the Conrads and the Joseph Crosbys, what a glorious future for our country! What wonderful cows, what splendid hogs, what brilliant poets, painters, inventors, politicians and statesmen would fill this country for all the generations to come!

It always straightens out this whole tangle of heredity and environment for me to think of two boys I knew in a western state-let us 
call them George and James. There was no great outward difference in them as boys. Their parents tried their utmost to treat them exactly alike, hut the more they treated them alike, the more amazingly unlike they grew. When their mother sent them on an errand James would always loiter and show up an hour late, while George was on time. George was always devising new ways of doing the farm work, while James was content to get by in any old way or not get by at all.

When they went to school the teacher saw no great difference between them, but soon discovered that while James was two years older, still, George could do his class work better and within a year was one grade ahead of his brother. In spite of expending very little effort on George and every possible effort on James, it was impossible to make them progress alike. Of course two or three hundred years ago James and perhaps George also, might have been mere ignorant louts about the village. Quite possibly both might have been bandits and criminals according to the ideas of crime in that day. But if so, George would have been the leader and James the follower. Consequently the absolute mental and moral achievements of both were enormously increased by the wonderful modern environment. But their achievements and character remained relatively the same.

However, the community saw no outstanding differences between these two boys. They were both good, well-behaved lads. But let us look thirty years later. George was in the United States Senate, one of the great orators, one of the great political and economic thinkers of our time, one of the keenest and most graceful writers of the day and, had he not made a political blunder, would probably have been president of the United States; while James was keeping a fourthclass pie counter in western Illinois.

Now this world is made up of Jameses and Georges. And in the careers of these men and these families, the Crosbys, and the Conrads, the Jameses and Georges, are exhibited in simple relief the vast forces that make and unmake empires, that create and separate social classes, that evolve great cultures and intellectual disciplines and overthrow them-in short, the forces that make our lives, and make history and civilization what they are. I might add that George married into one of the great families of the world and his two children show promise of helping to glorify the age. James married a woman of his own type and his two children show every promise of continuing in pie-counter channels. Now it is necessary to have pie counters as well as Senates. And I have little doubt that James blames his situation on his environ- 
ment or upon "bad luck," or complains that "things went against him." We all blame our misfortunes upon something or somebody else and lay our successes to ourselves.

The inspiring thing about all this to me is that it gives us such an exalting view of life. It proves, not that we are slaves, but that we are masters of our environment. Look back at your own schoolboy or schoolgirl friends. Have they not all carved out their own fortunes, in the main? Have they not all developed about as you would expect from your own intimate knowledge of their natures, their heredity? The point is, have they not selected, chosen and built their own environments? There are seeming exceptions; but is not this the general rule? It would fill me with despair if I thought that enviroment was the main shaping influence of my life. It has some influence on my character, and immense influence on my outward career; but if it had the overwhelming power that many people ascribe to it, the power to change my fundamental character then I should not have the slightest idea what sort of man I would be twenty years from now. I have not the slightest fear of the future because I know that my environment, and above all my own inner character are mainly in my own hands. I might be thrown to-morrow among criminals. I have not the slightest doubt that if I were I would begin at once to try to reform them, probably without great results. But if I am the mere victim of my environment, I have precisely the same mathematical chance as any criminal has, of committing murder and being hanged within the year.

Do you suppose that your grandchildren are going to be the victims of their environment as far as their inner characters and mental capacities are concerned? Wars may disrupt the nation. Civilization may go to pieces. But if you marry the right mate and endow your children with your own royal nature and your marked abilities, you may be sure they will rise amid its ashes and build a great and heroic life.

I have no doubt that there were great men among the cave men. But they lived a poor and mean life. In a poor environment men must live a poor life, as we look at it, although men always find excitement, interest and adventure under any set of circumstances. We see that in the case of our Puritan forefathers. Compared to the great buildings, laboratories and libraries of Yale, Harvard or Columbia, their little log academy looks poor indeed. Yet I doubt seriously if the men within this little structure lived a life of less mental excitement or of less true inner glory. 
As Karl Pearson has said, "It is man who makes his own environment, and not environment that makes the man." Now while, in the main, this is true, it is not altogether true. The choice of a man's profession is often seemingly a matter of mere accident. I chanced to read a sentence in a book thirty years ago that seems to me was the cause of my devoting my life to the study of heredity. But it was not this sentence nor any sentence that determined whether I should be a success or a failure at the undertaking. Nor was it this sentence nor any sentence that caused me from boyhood to have an overpowering ambition to be a professional scholar of some sort. My parents left me a heredity, an inner urge, to do the best I could in the study of science and in lecturing and writing for my fellow-men. I could not stop this inner urge any more than I could stop Niagara with a pitchfork.

Of course people always say, "But don't you think you can take children from the slums and do wonders for them?" Most assuredly. You can do a great deal for them. But you can, as has been shown by experience, take the same number of children from good homes, which have been built by the good heredity of their parents, and do vastly greater wonders for thern with the same money, effort and time. Many chikdren from the slums rise by their own heredity and become ornaments to our civilization. This proves that you can put good heredity into bad environment and not wreck the heredity. The trouble is that many people assume that all the children in the slums are bad. You will find many in the slums that are good and many on the avenue that are bad. But you will find a vastly higher percentage of poorly endowed, mentally, morally and physically-that is to say, the poor heredity -in the slums than on the avenue. Slums are the product of many injustices in our socia! and industrial organizations; but if we have slums, it is those with poor heredity who, in the main, fall into them.

To test this, go if you will, into some small town in a rich farming region. It would surely seem that there opportunity is wide open to all; every tub stands on its own hottom; there is almost no actual want. I was in one town in Jowa where they took up a collection fo: the poor. But the preacher told me he did not know what to do with the money, as they had no poor. I wen' into many homes in that 'own and found some with lace curtains at the front windows and Victrolit in the "settin'-room," and yet their houses were truly the dirtiest, most ill-smelling places I have ever seen. I have scarcely seen such utter 
cess-pool dirt in the lowest sections of New York. The "settin'room" was properly named, for they seemed to do nothing but just "set."

Now honestly, my uplifting environmental friend, what can you do for such people? They had plenty of money and ample opportunity. They went to picture shows, and their children attended, or rather were forced to attend, school. "The old man" got three to ten dollars a day. The farmers about the town were crying for tenants, and willing, practically, to set a man and his family up in business if they would only properly till the land. But their poverty was pure biological poverty, inborn, ineradicable. Their real poverty was poor heredity. And do you suppose that if those people drifted into the larger cities they would build residences on the avenue, or would they simply fall naturally into the slums? Many a strong man goes into the slums, under the wicked crush of modern industrialism. But such stock does not long remain there. Many of the children or the grandchildren fight their way out. The vast slums of the world are in the main inhabited by breeds that have been there for centuries. Sydney, Australia, has probably the largest slums relative to its size of any city in Anglo-Saxon countries. The belief of Doctor Charles B. Davenport, who investigated it, is that this is largely due to the fact that Sydney was originally settled chiefly by criminals and lower stocks deported from England one hundred and fifty years ago. Anyone who will read the account of the character of these shipments of slums stocks which England sent for many years to Sydney in ship loads, as given in the Encyclopedia Britannica, will, I think, be impressed with the high probability of the truth of Doctor Davenport's conclusion.

We have seen then that heredity is the preponderant factor in the relative character of men, and almost the whole factor in mental capacity; and that our success as compared with that of our fellows is largely a matter of our natural endowments. But the real lessons that emerge for us all are, first, that you "can't make a silk purse out of a sow's ear": and second, that human success and human happiness are largely relative things. "We are not trying to get ahead in this world," as Professor Thorndike says, "but to get ahead of somebody." To be the most beautiful girl in the county is beauty enough. The most beautiful girl in Podunk feels no envy of Agnes Soret, long the reigning beauty of France. I suppose President Wilson and Theodore Roosevelt were eager to get ahead of each other. But you and I never gave a thought about getting ahead of either one of them. The third 
conclusion is that environment does not much change the relative situations and achievements and characters of men. But a rich environment gives all men the chance for greater achievements and a wider life. If Roosevelt had been born in Africa he would not have been the Roosevelt he was. But even in Africa he would have been the "Iuanna Tumbo"- the big hunter as the natives called him, the mighty man with the big stick with the power to move things and men. And he would have had a "perfectly corking time."

You should remember always that by the herectitarian view you are not mastered by fate, but you are the masters of fate. You make your environment to a far greater extent than it makes you. Life is self-expression, self-realization. Every one should study his heredity, and the lives of his immediate ancestors. He should choose his vocation with a view of aroiding their failures and imitating their successes. If they drank to excess, it should be a special warning. If they har particular talents, these should be emulated. You probaljly have some or all of them. Let your natural, inborn light shine, to be seen of all men. You are always going to live with yourself. Then make yourself a good person to live with. You probably have a great deal of good heredity going to waste. Explore yourself and find out. You can not express anybody else's heredity. Tou must express your own. For there is no antagonism between heredity and environment. Heredity has furnished you with untold powers and no one ever develops all of them as much as he could and ought. It is your duty to use those powers in building an environment amid which and with which both you and your descendants may make the noblest possible practical achievements.

It seems to me that this view of life, far from being fatalistic, as the extreme environmental view surely is, is filled with the most inspiring optimism. A boy may never hear the chance sermon, or read the inspiring book which our environmental friends often point out as heing the "cause" of his fine career in life. If such things are the "causes" of the success or failure of men, then we are mere pawns upon the chess-board of environment, mere marionettes upon the stage whose wires are pulled by this mysterious and awful hand of doom. In a bad environment a boy would be bound to turn out to be had, and in. a good environment he would be bound to turn out to be good. Whatever the optimism or pessimism of such a view may be, we see simply that this is not true. Good boys constantly come up out of bad environment, and boys turn out badly amid the best environment that human wisdom can devise. 
But the thing to reflect upon is that every child who is not positively idiotic has within him those glorious powers by which he can seek out the inspiring man who will preach to him the inspiring sermon; he has the power to seek out the good book and read it; he has the power to choose his companions, his teachers, the way he spends his time and money, and in the long run build his own surroundings.

Obviously, however, even here environment plays a very strong hand; for the more choices that are opened before a child, the more it is encouraged to make this choice instead of that, the more surely will it be enabled in the end to form those right habits of choosing the good instead of the bad, and also have those right objects and courses before it to choose which lead to self-mastery and success. And self-mastery is merely success in the utilization of one's heredity. For success itself by and by becomes a habit, ingrained in the very motor patterns of the nerve system itself. Every child should be guarded against, and should guard itself against the habit of failure. As James says, you may forget the fine resolution you made and failed to carry out, but the nerve cells do not forget. Down in the very depths of our bodily organization, each tiny nerve cell is registering every act and thought, and laying it up in store for some future occasion, either for or against you. "Make your nervous system," he says, "your ally instead of your enemy." This contains almost the whole basis of moral education. And one should always remember with old Spinoza, the German philosopher, that "if you can keep from doing a thing because it is bad, you can keep from doing the same thing because something else is good." This is the whole difference between living the positive and the negative life. One can not build a successful and liappy life unless he has filled his mind and tuned his nerves to be up and alive with the things he must do, instead of always holding them back with the checks, inhibitions and prohibitions of the things he must not do. The theological hell which is pictured for lost souls in the future, says James, can be no worse than the hell which many of us build for ourselves in this world by continually fashioning our nervous systems-our wills-in the wrong way. And, granted that there is in us a power of choosing at all, granted that thinking has any purpose in it, then the opportunity to build daily more stately mansions for our souls in this world at least, is every moming opened anew to us all.

Thus, notwithstanding our belief, and I think our demonstration, that a man's inborn nature is the chief cause of his being different from other men, the cause of his making different choices, building a different "personality picture" of himself and his life, from the personality 
picture of other men, our enthusiasm for environment continues as rreat as ever. The poorest soil will increase its yield somewhat if iertilized; lout the same stimulus given to rich soil will increase its yield manyfold. The one-talent man will improve a great deal by education; but the five-talent man will improve enormously. This -hould be the chiefest source of comfort to the environmentalist himself-that the better the heredity upon which he expends his efforts the richer will be his rewards. It takes all the skill of teachers trained in the best pedagogy in the world to teach some children to read and write, while other children practically teach themselves. By doubling our educational efiorts we would likely quadruple men's achievements, their generosity, integrity, courage, determination, and thus quadruple what Woodrow Wilson called "the world's fitness for affairs"; but if we could double men's hereditary powers, their inborn virtue and excellence, the range and delicacy of their imaginations; the sweetness and charm of their personalities, and the exaltation of their natural desires, the humanism that would result-and what is civilization for except for a larger and finer humanism-would be beyond our power to foresee. And this difference between the two alternatives that are always before mankind - the alternative of building either a better heredity or devoting all their efforts to building a better environment-is not a fanciful difierence; for we see always before us that some men have many times-Galton thought thirty times-as great natural endowments as have others. Some men have in some directions a thousand or a million times greater powers than have other men.

The millennium, therefore, will be hastened by better education; lut it will be vastly more accelerated by better men. And after all, is not this the final answer to the whole tangle of heredity and environment? Better social machinery will make better men and better men witl enormously enhance the efficiency of the social machinery. Our enthusiasm for environment will increase as we see more clearly through the improved education the modern world has given us how a well-born race would use education for still more exalted ends.

Instead, therefore, of being antagonistic, heredity and environment are reciprocal agencies, both placed at last by science within the grasp of man, by which he can lift his species out of the bloody sea of natural selection and fare happily forward to richer and more fruitful goals. The Garden of Eden is not in the past, it is in the future. And the trees of knowledge grow along the whole highway that leads io it. It is an arduous highway; but its hardships need not be those, 
as in the past, of the red tooth and claw of nature, but the striving passions of men to realize in richer cultures higher values for which to live.

A rightly directed environment, not by brute death-selection but by the happier method of birth-selection, will improve man's heredity and in turn this better heredity will enrich the social heritage. To instil the "will to believe" in a humanity naturally better than ours is as necessary an aim for education as to instil merely, as education does now, the will to believe in better conditions amid which humanity shall live. Education will be doubly effective when it learns this great lesson.

The ancient Greeks pictured ambition as a beautiful goddess rolling golden apples down the pathway of pursuing youth. Like these fleeting prizes the Eden of eugenics can never be attained. But science and progress has at least stamped the picture of that Eden upon the imagination of mankind: the Eden of a perfect humanity dwelling in an environment of paradise. And, while it is unattainable it is not a mirage. It is merely the great dream of human destiny and possibility which men began to dream back in that mysterious time when they started their organic journey from the jungle to their present high estate. Only science and progress have drawn it for us in clearer outlines, drawn it nearer, and made it the conscious goal of the world's desire. And while it can not be attained any more than Heaven can be here on earth attained, yet the passion for it, the going toward it, the belief in it, the training and education of men for it, constitute that "new religion" of a better humanity which Galton said would "sweep the world." The goddess of humanity's ambitions can never be captured nor embraced; but as Thackeray said of the woman that a man loves, on that last noble page of Henry Esmond, "To think of her is to praise God."

Nore.-The reader must understand that what is handed from one generation to the next is merely these little packets or genes in the germ-cell and not the completed character such as tallness or black color. Neither the tall character nor black color nor any other feature will develop unless proper environment is supplied, and if there should be a radical change in the environment it might be some other color than black would develop. If either the hereditary material in the germ-cell is changed ever so slightly or the environment changed some other character develops than the one which we commonly speak of as "inherited." The reader must not gain the idea that these determiners will develop into some certain characteristics irrespective of the environment. Professor Herbert S. Jennings, of The Johns Hopkins University, has brilliantly and profoundly argued this whole 
matter in an article in The Scientific Monthly for September, 1924, entitled Heredity and Enironment. As Professor Jennings puts it: "Clearly it is not necessary to have a characteristic merely because one inherits it. Or more properly, characteristics are not inherited at all; what one inherits is certain material that under certain conditions will produce a particular characteristic; if those conditions are not supplied, some other characteristic is produced."

In this sense a man's knowledge of Latin grammar is just as much an inherited character' as is his bald head. Both developed because certain packets of chemicals called factors were in the germ-cell from which he was born, and these factors under the conditions that he met in life developed into these characteristics. Had he met different conditions he would have developed other characteristics in their stead. It is not true that a man is predetermined in or by the gerna-cell and that a foreordained man with foreordained characteristics is going to grow up willynilly. Ilowever, because of merely practical difficullies we can not very radically alter men by education and environment, partly because we do not as yet have the proper technical means and partly because the environment is fairly uniform for all human beings during the first nine months of their lives and they come into the world as quite far advanced organisms. But in frogs and fruit flies and other animals where the egg itself and the early embryo can be radically interiered with, changes can easily be produced which make the adult animal strikingly different irom what it would have been in the usually expected environment. We predict a certain kind of man by studying his ancestry merely because we expect for him d certain type of general environment not profoundly different from that of his ancestors. It is the expected environment which leads us to count pretty strongly on heredity and not that the heredity in the germ package predetermines all he shall be. F. A. Woods pointed this out nearly fifteen years ago. Of course there are limits to the alterations possible by environment, but they are far from being reached as yet with human beings. None of this alters the fact that very moderate environmental measures, such as education and moral suasion, expended on rich hereditary material yield far greater results than when expended on poor material. Other measures might produce as marked results with poor material, but in society as a practical matter there is neither the time nor money as yet to try to make imbeciles into geniuses when by proper marriages they can be produced free of charge. The differences among men are, I think, larcely due to differences in the original hereditary packets in the germ-cells because so much of the environment of men is common io them all. I can not reproduce all of Professor Jennings' fine presentation and can only urge the thoughtful to study it with care as the most penetrating discussion of the heredity-environment problem that has been made from the stand. point of a geneticist and embryologist. 


\section{CHAPTER XXXIX EUGENICS AND EUTHENICS}

PAUl popenoe AND ROSWELl H. JOHNSON

Emphasis has been given, in several of the foregoing chapters, to the desirability of inheriting a good constitution and a high degree of vigor and disease-resistance. It has been asserted that no measures of hygiene and sanitation can take the place of such inheritance. It is now desirable to ascertain the limits within which good inheritance is effective, and this may be conveniently done by a study of the lives of a group of people who inherited exceptionally strong physical constitutions.

The people referred to are taken from a collection of histories of long life made by the Genealogical Record Office of Washington. One hundred individuals were picked out at random, each of whom had died at the age of ninety or more, and with the record of each individual were placed those of all his brothers and sisters. Any family was rejected in which there was a record of wholly accidental death (e.g., families of which a member had been lilled in the Civil IVar). The roo families, or more correctly fraternities or sibships, were classified by the number of children per fraternity, as follows:

\begin{tabular}{ccc}
$\begin{array}{c}\text { Number } \\
\text { of } \\
\text { Fraternities }\end{array}$ & $\begin{array}{c}\text { Number of } \\
\text { Children per } \\
\text { Fraternity }\end{array}$ & $\begin{array}{c}\text { Total Number } \\
\text { of Children } \\
\text { in Group }\end{array}$ \\
I & $\mathbf{2}$ & $\mathbf{2}$ \\
II & 3 & 33 \\
8 & 4 & 32 \\
I7 & 5 & 85 \\
I3 & 6 & 78 \\
I4 & 7 & 98 \\
9 & 8 & 72 \\
II & 9 & 99 \\
I0 & I0 & 100 \\
3 & I I & 33 \\
2 & I 2 & 24 \\
I & I3 & 13 \\
\hline I00 & & 150
\end{tabular}

- From P. Popenue and K. II. Jolinson, Applied Eugenics (copyright igr8; Used by special permission of the pullishers, The Macmillan Company. 
The average at death of these 669 persons was 64.7 years. The child mortality (first 4 years of life) was 7.5 per cent of the total mortality, 69 families showing no deaths of that kind. The group is as a whole, therefore, long-lived.

The problem was to measure the resemblance between brothers and sisters in respect of longevity - to find whether knowledge of the age at which one died would justify a prediction as to the age at death of the others-or technically, it was to measure the fraternal correlation of longevity. A zero coefficient here would show that there is no association; that from the age at which one dies, nothing whatever can be predicted as to the age at which the others will die. Since it is known that heredity is a large factor in longevity, such a finding would mean that all deaths were due to some accident which made the inheritance of no account.

In an ordinary population it has been found that the age at death of brothers and sisters furnishes a coefficient of correlation of the order of .3, which shows that heredity does determine the age at which one shall die to considerable extent, but not absolutely. ${ }^{\mathrm{I}}$

The index of correlation ${ }^{2}$ between the lengths of life within the fraternity in these roo selected families, furnished a coefficient of $-.0163 \pm .0672$, practically zero. In other words, if the age is known at which a member of one of these families died, whether it be one month or roo years, nothing whatever can be predicted about the age at which his brothers and sisters died.

- Mary Beeton, and Karl Pearson, Biometrika, I, p. 6o. The actual correlation varies with the age and sex: the following are the results:

COLLATERAL INHERITANCE

Elder adult brother and younger arlult hrother.... . $2290 \neq .0194$

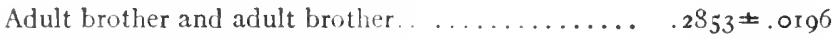

Minor brother and minor brother............. . ro26 \pm .0294

Adult brother and minor brother ........... .0262 t. 0246

Elder adult sister and younger arlult sister......... . $346_{4} \pm .0183$

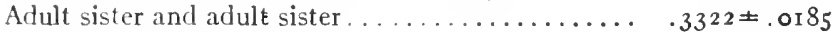

Minor sister and minor sister............... I748 \pm .0307

Adult sister and minor sister................ .0260 $029 \mathrm{I}$

Adult brother and adult sister..............2319 $\$ .0145$

Minor brother and minor sister............. . I $435 \pm .025$ I

Adult brother and minor sister ............... $0062 \pm .0349$

Arult sister and minor brother............ $0274^{ \pm} .0238$

"The method used is the ingenious one devised by J. Arthur Harris (Biomitrika, IX, P. 40I). The probable error is based on $n=100$. 
Remembering that longevity is in general inherited, and that it is found in the families of all the people of this study (since one in each fraternity lived to be 90 or over) how is one to interpret this zero coefficient? Evidently it means that although these people had inherited a high degree of longevity, their deaths were brought about by causes which prevented the heredity from getting full expression. As far as hereditary potentialities are concerned, it can be said that all their deaths were due to accident, using that word in a broad sense to include all non-selective deaths by disease. If they had all been able to get the full benefit of their heredity, it would appear that each of these persons might have lived to 90 or more, as did the one in each family who was recorded by the Genealogical Record Office. Genetically, these other deaths may be spoken of as premature.

In an ordinary population, the age of death is determined to the extent of probably 50 per cent by heredity. In this selected longlived population, heredity appears not to be responsible in any measurable degree whatsoever for the differences in age at death.

The result may be expressed in another, and perhaps more striking, way. Of the 669 individuals studied, a hundred-namely, one child in each family-lived beyond 90 ; and there were a few others who did. But some $55^{\circ}$ of the group, though they had inherited the potentiality of reaching the average age of 90 , actually died somewhere around 60 ; they failed by at least one-third to live up to the promise of their inheritance. If we were to generalize from this single case, we would have to say that five-sixths of the population does not make the most of its physical inheritance.

This is certainly a fact that discourages fatalistic optimism. The man who tells himself that, because of his magnificent inherited constitution, he can safely take any risk, is pretty sure to take too many risks and meet with a non-selective-i.e., genetically, a premature-death, when he might in the nature of things have lived almost a generation longer.

It should be remarked that most of the members of this group seem to have lived in a hard environment. They appear to belong predominantly to the lower strata of society; many of them are immigrants and only a very few of them, to judge by a cursory inspection of the records, possessed more than moderate means. This necessitated a frugal and industrious life which in many ways was favorable to longevity but which may often have led to overexposure, overwork, lack of proper medical treatment, or other causes of a non-selective 
death. We would not push the conclusion too far, but we can not doubt that this investigation shows the folly of ignoring the environment-shows that the best inherited constitution must have a fair chance. And what has here been found for a physical character, would prolably hold good in even greater degree for a mental character. All that man inherits is the capacity to develop along a certain line under the influence of proper stimuli, food and exercise. The object of eugenics is to see that the inherent capacity is there. Given that, the educational system is next needed to furnish the stimuli. The consistent eugenist is therefore an ardent euthenist. He not only works for a better human stock but, because he does not want to see his efforts wasted, he always works to provide the best possible environment for this better stock.

In so far, then, as euthenics is actually providing man with more favorable surroundings-not with ostensibly more favorable surroundings which, in reality, are unfavorable - there can be no antagonism between it and eugenics. Eugenics is, in fact, a prerequisite of euthenics, for it is only the capable and altruistic man who can contribute to social progress; and such a man can only be produced through eugenics.

Eugenic fatalism, a blind faith in the omnipotence of heredity regardless of the surroundings in which it is placed, has been shown by the study of long-lived families to be unjustified. It was found that even those who inherited exceptional longevity usually did not live as long as their inheritance gave them the right to expect. If they had had more euthenics, they should have lived longer.

But this illustration certainly gives no ground for a belief that euthenics is sufficient to prolong one's life beyond the inherited limit. A study of these long-lived families from another point of view will reveal that heredity is the primary factor and that good environment, euthenics, is the secondary one.

For this purpose we augment the roo families of the preceding section by the addition of 240 more families like them, and we examine each family history to find how many of the children died before completing the fourth year of life. The data are summarized in the table on page. 5 I.

The addition of the new families (which were not subjected to any different selection than the first roo) has brought down the child mortality rate. For the first 100, it was found to be 7.5 per cent. If in the ahove table the number of child deaths, $\mathbf{1} \mathbf{9}$, be divided by the 
total number of children represented, 2,259, the child mortality rate for this population is found to be 5.27 per cent or 53 per 1,000 .

The smallness of this figure may le seen by comparison with the statistics of the registration area, U.S. Census of 1880 , when the child mortality (o-4 years) was 400 per thousand, as calculated by Alexander Graham Bell. A mortality of 53 for the first four years of life is smaller than any district known in the United States, even to-day, can show for the first year of life alone. If any city could bring the deaths of babies during their first twelve months down to 53 per $\mathrm{r}, 000$, it would think it had achieved the impossible; but here is a population

\section{CHILD MORTALITY IN FAMILIES OF LONG-LIVED STOCK, GENEALOGICAL RECORD OFFICE DATA}

$\begin{array}{cccc}\begin{array}{c}\text { Size } \\ \text { of } \\ \text { Family } \\ \text { I child }\end{array} & \begin{array}{c}\text { Number of } \\ \text { Families } \\ \text { Investigated }\end{array} & \begin{array}{c}\text { Number of Families } \\ \text { Showing Deaths } \\ \text { under Five Years }\end{array} & \begin{array}{c}\text { Total Number } \\ \text { of } \\ \text { Deaths }\end{array} \\ \text { 2 children } & 6 & 0 & 0 \\ 3 & 6 & \circ & 0 \\ 4 & 38 & 4 & 5 \\ 5 & 40 & 6 & 7 \\ 6 & 38 & 4 & 4 \\ 7 & 44 & 12 & 13 \\ 8 & 34 & 8 & 11 \\ 9 & 46 & 13 & 18 \\ \text { 10 } & 31 & 14 & 20 \\ \text { II } & 27 & 14 & 14 \\ \text { I2 } & 13 & 6 & 9 \\ \text { I3 } & 13 & 9 & 16 \\ \text { I4 } & 1 & 0 & 0 \\ \text { I7 } & 2 & 0 & 0 \\ & \text { I } & 1 & 2 \\ & 340 & 91 & -119\end{array}$

in which 53 per 1,000 covers the deaths, not only of the fatal first I 2 months, but of the following three years in addition.

Now this population with an unprecedentedly low rate of child mortality is not one which had had the benefit of any Baby Saving Campaign, nor even the knowledge of modern science. Its mothers were mostly poor, many of them ignorant; they lived frequently under conditions of hardship; they were peasants and pioneers. Their babies grew up without doctors, without pasteurized milk, without ice, without many sanitary precautions, usually on rough food. But they had one advantage which no amount of applied science can give after birth-namely, good heredity. They had inherited exceptionally good constitutions. 
It is not by accident that inherited longerity in a family is asure i. ated with low mortality of its children. The connection between the two facts was first dicovered by Mary Beeton and Karl Pearson in their pioner work on the inheritance of duration of life. They found that high infant mortality was assuciated with early death of parents, while the offspring of long-lived parents showed few deaths in childhood. The correlation of the two facts was quite regular, as will be evident from a glance at the following tables prepared by A. Ploetz:

LENGTH OF LIFE OF MOTHERS ANI CHILD MORTALITY OF THEIR DAUGHTERS (ENGLISH QUAKER FAMILIES, DATA OF BEETON AND PEARSON, ARRANGEI BY PLOETZ)

\begin{tabular}{|c|c|c|c|c|c|c|}
\hline & \multicolumn{5}{|c|}{ Year of Life in Wigich Mothers i)ied } & \multirow{2}{*}{$\begin{array}{l}\text { AT } \\
\text { ALL } \\
\text { AGES }\end{array}$} \\
\hline & to $3^{8}$ & $39^{-5}-53$ & $54-68$ & $60-3_{3}$ & $8.4 \mathrm{up}$ & \\
\hline $\begin{array}{l}\text { Number of daughters............ } \\
\text { Number of them who died in first five }\end{array}$ & 234 & 304 & 395 & 666 & 247 & 1,846 \\
\hline years $\ldots \ldots \ldots \ldots \ldots \ldots \ldots$ & I 22 & $1 I_{4}$ & I I 8 & I3I & 26 & $5^{\text {II }}$ \\
\hline Per cent of daughters who died... & 52.1 & $37 \cdot 5$ & $29 \cdot 9$ & I 0.7 & 10.5 & $27 \cdot 7$ \\
\hline
\end{tabular}

LENGTH OF LIFE OF FATHERS AND CHILD MORTALITY OF THEIR DAUGHTERS

\begin{tabular}{|c|c|c|c|c|c|c|}
\hline & \multicolumn{5}{|c|}{ Year or Life in Weich Fathers Died } & \multirow{2}{*}{$\begin{array}{c}\text { AT } \\
\text { ALE }\end{array}$} \\
\hline & to 38 & $39-53$ & $54^{-68}$ & $69-83$ & 84 up & \\
\hline $\begin{array}{l}\text { Number of daughters............. } \\
\text { Number of them who died in first five }\end{array}$ & 105 & 284 & $53_{5}$ & 797 & 236 & 2,009 \\
\hline $\begin{array}{l}\text { years . . . . . . . . . . } \\
\quad \text { Per cent of daughters who died... }\end{array}$ & $\begin{array}{r}51 \\
+3.6\end{array}$ & $\begin{array}{r}98 \\
34.5\end{array}$ & $\begin{array}{r}156 \\
20.7\end{array}$ & $\begin{array}{r}177 \\
22.2\end{array}$ & $\begin{array}{r}40 \\
17.0\end{array}$ & $\begin{array}{r}522 \\
26.0\end{array}$ \\
\hline
\end{tabular}

To save space, we do not show the relation between parent and son; it is similar to that of parent and daughter which is shown in the preceding tables. In making comparison with the 340 families from the Genealogical Record Office, above studied, it must be noted that Dr. Ploetz's tables include one year longer in the period of child mortality, heing computed for the first five years of life instead of the first four. His percentages would therefore lie somewhat lower if computed on the basis used in the American work.

These various data demonstrate the existence of a considerable correlation between short life (brachybioty', Karl I'earson calls it) in parent and short life in offspring. Not only is the tendency to live long inherited, but the tendency not to live long is likewise inherited. 
But perhaps the reader may think they show nothing of the sort. He may fancy that the early death of a parent left the child without sufficient care, and that neglect, poverty, or some other factor of euthenics brought about the child's death. Perhaps it lacked a mother's loving attention, or perhaps the father's death removed the wage-earner of the family and the child thenceforth lacked the necessities of life.

Dr. Ploetz has pointed out that this objection is not valid, because the influence of the parent's death is seen to hold good even to the point where the child was too old to require any assistance. If the facts applied only to cases of early death, the supposed objection might be weighty, but the correlation exists from one end of the agescale to the other. It is not credible that a child is going to be deprived of any necessary maternal care when its mother dies at the age of 69 ; the child herself was probably married long before the death of the mother. Nor is it credible that the death of the father takes bread from the child's mouth, leaving it to starve to death in the absence of a pension for widowed mothers, if the father died at 83 , when the "child" herself was getting to be an old woman. The early death of a parent may occasionally bring about the child's death for a reason wholly unconnected with heredity, but the facts just pointed out show that such cases are exceptional. The steady association of the child deathrate and parent death-rate at all ages demonstrates that heredity is a common cause.

But the reader may suspect another fallacy. The cause of this association is really environmental, he may think, and the same poverty or squalor which causes the child to die early may cause the parent to die early. They may both be of healthy, long-lived stock, but forced to live in a pestiferous slum which cuts both of them off prematurely and thereby creates a spurious correlation in the statistics.

We can dispose of this objection most effectively by bringing in new evidence. It will probably be admitted that in the royal families of Europe, the environment is as good as knowledge and wealth can make it. No child dies for lack of plenty of food and the best medical care, even if his father or mother died young. And the members of this caste are not exposed to any such unsanitary conditions, or such economic pressure as could possibly cause both parent and child to die prematurely. If the association between longevity of parent and child mortality holds for the royal families of Europe and their princely 
relatives, it can hardly be regarded as anything but the effect of heredity - of the inheritance of a certain type of constitution.

Dr. Ploetz studied the deaths of 3,2 10 children in European royalty, from this viewpoint. The following table shows the relation between father and child:

LENGTH OF LIFE OF FATHERS AND CHILD MORTALITY OF THEIR CHILDREN IN ROYAL AND PRINCELY

FAMILIES (PLOETZ DATA)

\begin{tabular}{|c|c|c|c|c|c|c|c|c|c|}
\hline & \multicolumn{8}{|c|}{ YeAR OF LIFE IN Which FatBERS Died } & \multirow{2}{*}{$\begin{array}{c}A \Gamma \\
A \in E\end{array}$} \\
\hline & $16-25$ & $26-35$ & $36-45$ & $45-55$ & $56-65$ & $66-75$ & $76-85$ & 86 un & \\
\hline Number of children............. & 23 & 90 & 367 & 545 & 725 & $9 s_{3}$ & 444 & 33 & 3210 \\
\hline Number who died in first five years. & I 2 & 29 & II 5 & $17 I$ & 200 & 254 & 105 & I & $88 ;$ \\
\hline Per cent who died.......... & 52.2 & 32.2 & $3 \mathbf{I} \cdot 3$ & $3 I .4$ & 27.6 & 25.8 & 23.6 & 3.0 & 27.6 \\
\hline
\end{tabular}

Allowing for the smallness of some of the groups, it is evident that the amount of correlation is about the same here as among the English Quakers of the Beeton-Pearson investigation, whose mortality was shown in the two preceding tables. In the healthiest group from the royal families-the cases in which the father lived to old age-the amount of child mortality is about the same as that of the Hyde family in America, which Alexander Graham Bell has studied-namely, somewhere around $25^{\circ}$ per 1,000 . One may infer that the royal families are rather below par in soundness of constitution.

All these studies agree perfectly in showing that the amount of child mortality is determined primarily by the physical constitution of the parents, as measured by their longevity. In the light of these facts, the nature of the extraordinarily low child mortality shown in the 340 families from the Genealogical Record Office, with which we began the study of this point, can hardly be misunderstood. These families have the best inherited constitution possible and the other studies cited would make us certain of finding a low child mortality among them, even if we had not directly investigated the facts.

If the interpretation which we have given is correct, the conclusion is inevitable that child mortality is primarily a problem of eurenics, and that all other factors are secondary. There is found to the no warrant for the statement so often repeated in one form or another, that "the fundamental cause of the excessive rate of infant mortalit" in industrial communities is poverty, inadequate incomes, and low standards of living." Royalty and its princely relatives are not 
characterized by a low standard of living, and yet the child mortality among them is very high-somewhere around 400 per 1,000 in cases where a parent died young. If poverty is responsible in the one case, it must be in the other-which is absurd. Or else the logical alssurdity is involved of inventing one cause to explain an effect today and a wholly different cause to explain the same effect tomorrow. This is unjustifial,le in any case, and it is particularly so when the single cause that explains both cases is so evident. If weak heredity causes high mortality in the royal families, why, similarly, cannot weak heredity cause high infant mortality in the industrial communities? We believe it does account for much of it, and that the inadequate income and low standard of living are largely the consequence of inferior heredity, mental as well as physical. The parents in the Genealogical Record Office files had, many of them, inadequate incomes and low standards of living under frontier conditions, but their children grew up while those of the royal families were dying in spite of every attention that wealth could command and science could furnish.

If the infant mortality problem is to be solved on the basis of knowledge and reason, it must be recognized that sanitation and hygiene cannot take the place of eugenics any more than eugenics can dispense with sanitation and hygiene. It must be recognized that the death-rate in childhood is largely selected, and that the most effective way to cut it down is to endow the children with better constitutions. This cannot be done solely by any euthenic campaign; it cannot be done by swatting the fly, abolishing the mid-wife, sterilizing the milk, nor by any of the other panaceas sometimes proposed.

But, it may be objected, this discussion ignores the actual facts. Statistics show that infant mortality campairns hive consistently produced reductions in the death-rate. The figures for New York, which could he matched in dozens of other cities, show that the number of dcaths per r.000 births, in the first year of life, has steadily declined since a determined campaign to "Save the Babies" was started:
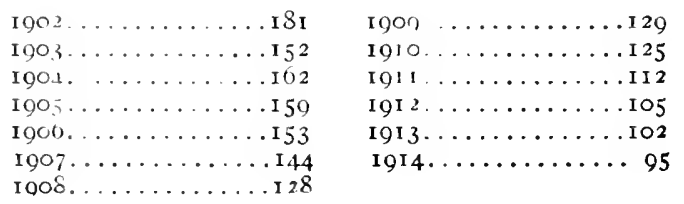
To one who cannot see beyond the immediate conseciutences (n) in action, such firgures as the ahove indeed give quite a different idein of the effects of an infant mortality campaign, than that which we have just tried to create. And it is a great misfortune that euthenics so often fails to look beyond the immediate effect, fails to see what may happen next year, or Io years from now, or in the next generation.

We admit that it is possible to keep a lot of children alive who would otherwise have died in the first few months of life. It is being done, as the New York figures, and pages of others that could be cited, prove. The ultimate result is twofold:

I. Some of those who are doomed by heredity to a selective death, but are liept alive through the first year, die in the second or third or fourth year. They must die sooner or later; they have not inherited sufficient resistance to survive more than a limited time. If they are by a great effort carried through the first year, it is only to die in the next. This is a statement which we have nowhere olserved in the propaganda of the infant mortality movement; and it is perhaps a disconcerting one. It can only be proved by refined statistical methods, but several independent determinations by the English biometricians leave no doubt as to the fact. This work of Karl Pearson, E. C. Snow, and Ethel M. Elderton, was cited in our chapter on natural selection; the reader will recall how they showed that nature is weeding out the weaklings, and in proportion to the stringency with which she weeds them out at the start, there are fewer weaklings left to die in succeeding years.

To put the facts in the form of a truism, part of the chiklren born in any district in a given year are doomed by heredity to an early death: and if they die in one year they will not le alive to die in the succeeding year, and vice rersa. Of course there are in addition infant deaths which are not selective and which if prevented would leave the infant with as good chance as any to live.

In the light of these researches, we are forced to conclude that haby-saving campaigns accomplish less than is thought; that the supposed gain is to some extent temporary and illusory.

2. There is still another consequence. If the gain is lyy great exertions. made more than temporary; if the baly who would otherwise have died in the first months is hrought to adult life and reproduction, it means in many cases the dissemination of another strain of wcak heretity, which natural selection would have cut off ruthlesisty 
in the interests of race betterment. In so far, then, as the infant mortality movement is not futile it is, from a strict biological viewpoint, often detrimental to the future of the race.

Do we then discourage all attempts to save the babies? Do we leave them all to natural selection? Do we adopt the "better dead" gospel?

Unqualifiedly, no! The sacrifice of the finer human feelings, which would accompany any such course, would be a greater loss to the race than is the eugenic loss from the perpetuation of weak strains of heredity. 'The abolition of altruistic and humanitarian sentiment for the purpose of race betterment would ultimately defeat its own end by making race betterment impossible.

But race betterment will also be impossible unless a clear distinction is made between measures that really mean race betterment of a fundamental and permanent nature, and measures which do not.

We have chosen the Infant Mortality Movement for analysis in this chapter because it is an excellent example of the kind of social betterment which is taken for granted, by most of its proponents, to be a fundamental piece of race betterment; but which, as a fact, often means race impairment. No matter how abundant and urgent are the reasons for continuing to reduce infant inortality wherever possible, it is dangerous to close the eyes to the fact that the gain from it is of a kind that must be paid for in other ways; that to carry on the movenuent without adding eugenics to it will be a short-sighted policy, which increases the present happiness of the world at the cost of diminishing the happiness of posterity through the perpetuation of inferior strains.

While some euthenic measures are eugenically evils, even if necessary ones, it must not be inferred that all euthenic measures are dysgenic. Many of them, such as the economic and social changes we have suggested in earlier chapters, are an important part of eugenics. Every euthenic measure should be scrutinized from the evolutionary standpoint; if it is eugenic as well as euthenic, it should be wholeheartedly favored; if it is dysgenic but euthenic it should be condemned or adopted, according to whether or not the gain in all ways from its operation will exceed the damage.

In general, euthenics, when not accompanied by some form of selection (i.e., eugenics) ultimately defeats its own end. If it is accompanied by rational selection, it can usually be indorsed. Eugenics, 
on the other hand, is likewise inadequate unless accompanied by constant improvement in the surroundings; and its advocates must demand euthenics as an accompaniment of selection, in order that the opportunity for getting a fair selection may be as free as possible. If the euthenist likewise takes pains not to ignore the existence of the racial factor, then the two schools are standing on the same ground, and it is merely a matter of taste or opportunity, whether one emphasizes one side or the other. Each of the two factions, sometimes thought to be opposing, will be seen to be getting the same end result, namely, human progress.

Not only are the two schools working for the same end, but each must depend in still another way upon the other, in order to make headway. The eugrenist cannot see his measures put into effect except through changes in law and custom-i.e., euthenic changes. He must and does appeal to euthenics to secure action. The social reformer, on the other hand, cannot see any improvements made in civilization except through the discoveries and inventions of some citizens who are inherently superior in ability. He in turn must depend on eugenics for every advance that is made.

It may make the situation clearer to state it in the customary terms of biological philosophy. Selection does not necessarily result in progressive evolution. It merely brings about the adaptation of a species or a group to a given environment. The tapeworm is the stock example. In human evolution, the nature of this environment will determine whether adaptation to it means progress or retrogression, whether it leaves a race happier and more productive, or the reverse. All racial progress, or eugenics, therefore, depends on the creation of a good environment, and the fitting of the race to that environment. Every improvement in the environment should bring about a corresponding biological adaptation. The two factors in evolution must go side by side, if the race is to progress in what the human mind considers the direction of advancement. In this sense, euthenics and eugenics luear the same relation to human progress as a man's two legs do to his locomotion.

Social workers in purely euthenic fields have frequently failed to remember this progress of adaptation, in their efforts to change the environment. Eugenists, in centering their attention on adaptation, have sometimes paid too little attention to the kind of environment to which the race was being adapted. The present book holds that the 
second factor is just as important as the first, for racial progress; that one legr is just as important as the other, to a pedestrian. Its only conllict with euthenics appertains to such euthenic measures as impair the adaptalility of the race to the better environment they are trying to malie.

Some supposedly euthenic measures opposed by eugenics are not truly euthenic, as for instance the limitation of a superior family in order that all may get a college education. For these spurious euthenic measures, something truly euthenic should be substituted.

Measures which show a real conflict may be typified by the infant mortality movement.' There can be no doubt but that sanitation and hygiene, prenatal care and intelligent treatment of mothers and babies, are truly euthenic and desirable. At the same time, as has been shown, these euthenic measures result in the survival of inferior children, who directly or through their posterity will be a drag on the race. Euthenic measures of this type should be accompanied by counterbalancing measures of a more eugenic character.

Barring these two types, euthenics forms a necessary concomitant of the eugenic program; and, as we have tried to emphasize, eugenics is likewise necessary to the complete success of every euthenic program. How foolish, then, is antagonism between the two forces! Both are working toward the same end of human betterment, and neither can succeed without the other. When either attempts to eliminate the other from its work, it ceases to advance toward its goal. In which camp one works is largely a matter of taste. If on a road there is a gradient to be leveled, it will be brought down most quickly by two parties of workmen, one cutting away at the top, and the other filling in the bottom. For the two parties to indulge in mutual scorn and recrimination would be no more absurd than for eugenics and euthenics to be put in opposition to each other. The only reason they have been in opposition is because some of the workers did not clearly understand the nature of their work. With the dissemination of a knowledge of biology, this ground of antagonism will disappear. 


\section{CHAPTER XL \\ HUMAN CONSERVATION}

HERBERT E. WALTER

\section{HOW MANKIND MAY BE IMIPROVED}

There are two fundamental ways to bring about human betterment, namely, by improving the individual and by improving the race. The first method consists in making the best of whatever heritage has been received by placing the individual in the most favorable environment and developing his capacities to the utmost through education. The second method consists in seeking a better heritage with which to begin the life of the individual. The first method is immediate and urgent for the present generation. The second method is concerned with ideals for the future, and consequently does not usually present so strong an appeal to the individual.

The first is the method of euthenics, or the science of learning to live well. The second is eugerics, which Gatton defines as "the science of being well born."

These two aspects of human betterment, however, are inseparable. Any hereditary characteristic must be regarded, not as an independent entity, but as a reaction between the germplasm and its entirnment. The biologist who disregards the fields of educitional endeavor and environmental influence, is equally at fault with the sociologist who fails sufficiently to realize the fundamental importance of the germplasm.

Without euthenic opportunity the best of heritages would never fully come to its own. Without the eugenic foundation the best opportunity fails of accomplishment. The euthenic point of view, however, must not distract the attention now, for the present chapter is particularly concerned with the program of eugenics.

\section{HORE FACTS NEEDED}

Since the point of attack in human heredity must be largely statistical, it is of the first importance to collect more facts. Our actual knowledge is confused with a mass of tradition and opinion,

${ }^{I}$ From II. E. Walter, Gentics (coprright 1913). Used by special permission of the publishers, The Macmillan Company. 
much of which rests upon questionable foundations. The great present need is to learn more facts; to sift the truth from error in what is already known; and to reduce all these data to workable scientific form. Much progress is being made in this direction, owing to the impetus given by the revival of Mendel's illuminating work, but as yet the science of eugenics is in its infancy.

The most systematic and effective attempt in this country to collect reliable data concerning heredity in man has been initiated by the Eugenics Section of the American Breeders' Association under the secretaryship of Dr. C. B. Davenport. In Igro the Eugenics Record Office, with a staff of expert field and office workers and an adequate equipment of fire-proof vaults, etc., for the preservation of records, was opened at Cold Spring Harbor, Long Island, New York, with Mr. H. H. Laughlin as superintendent. "The main work of this office is investigation into the laws of inheritance of traits in human beings and their application to eugenics. It proffers its services free of charge to persons seeking advice as to the consequences of proposed marriage matings. In a word, it is devoted to the advancement of the science and practice of eugenics." The publication of results from the Eugenics Record Office has already been begun.

The Volta Bureau, founded about twenty-five years ago in Washington by Dr. Alexander Graham Bell, is collecting data with reference to deafness and has now systematically arranged particulars concerning the history of over 20,000 individuals. In England, also, the Galton Laboratory for Eugenics, founded in 1905 , is systematically collecting facts about human pedigrees and publishing the results in a compendious "Treasury of Human Inheritance."

Besides these special bureaus of investigation, innumerable facts about the inheritance of particular traits are being incidentally brought together and made available in various institutions and asylums throughout the world which are immediately concerned with the care of defectives of different types. It is in connection with such institutions for defectives that much of the most successful "field work" of the Eugenics Section of the American Breeders' Association is being accomplished in the United States.

\section{FURTHER APPLICATION OF WHAT WE KNOW NECESSARY}

Human performance always lags behind human knowledge. Many persons who are fully aware of the right procedure do not put their knowledge into practice. It follows, therefore, that any pro- 
gram of eugenics which does not grip the imagination of the common people in such a way as to become an effective part of their very lives is bound to remain largely an academic affair for utopians to quarrel and theorize over.

It is not enough to collect facts and work out an analysis and interpretation of them, for, important as this preliminary step is, it must be followed by a convincing campaign of education.

The lives of the unborn do not force themselves upon the average man or woman with the same insistency as the lives already begun. In the milst of the overwhelming demands of the present, the appeal of posterity for better blood is vague and remote. If every individual regarded the germplasm he carries as a sacred trust, then it would be the part of an awakened eugenic conscience to restrain that germplasm when it is known to be defective or, when it is not defective, to hand it on to posterity with at least as much foresight as is exercised in breeding domestic animals and cultivated plants.

The eugenic conscience is in need of development, and it is only when this becomes thoroughly aroused in the rank and file of society as well as among the leaders, that a permanent and increasing betterment of mankind can be expected.

\section{THE RESTRICTION OF UNDESIRABLE GERMPLASM}

A negative way to bring about better blood in the world is to follow the clarion call of Davenport, and "dry up the streams that feed the torrent of defective and degenerate protoplasm." This may be partially accomplished, at least in America, by employing the following agencies: control of imnigration; more discriminating marriage laws; a quickened eugenic sentiment; sexual segregation of defectives; and finally, drastic measures of asexualization or sterilization when necessary.

\section{a) CONTROL OF IMMIGRATION}

The enforcement of immigration laws tends to debar from the United States not only many undesirable individuals, but also incidentally to keep out much potentially lsad germplasm that, if admitted. might play havoc with future generations.

For example, during the year of 1908,65 idiots, I 2 I feeble-minded, I84 insane, 3,741 paupers, 2,900 individuals having contagious diseases, 53 tuberculous individuals, ${ }_{3} 6$ criminals, and 124 prostitutes were caught in the sieve at Ellis Island alone and turned back from this country by the immigration officials. These 7,000 and more 
individuals probably were the bearers of very little germplasm that we are nationally not better of without.

Eugenically, the weak point in the present application of immigration laws is that criteria for exclusion are phenotypic in nature rather than genotypic, and consequently much bad germplasm comes through our gates hidden from the view of inspectors because the bearers are heterozygous, wearing a cloak of desirability over undesirable traits.

It is not enough to lift the eyelid of a prospective parent of American citizens to discover whether he has some kind of an eye-disease or to count the contents of his purse to see if he can pay his own way. The official ought to know if eye-disease runs in the immigrant's family and whether he comes from a race of people which, through chronic shiftlessness or lack of initiative, have always carried light purses.

In selecting horses for a stock-farm an expert horseman might rely to a considerable extent upon his judgment of horseflesh based upon inspection alone, but the wise breeder does more than take the chances of an ordinary horse trader. He wants to be assured of the pelligree of his prospective stock. It is to be hoped that the time will come when we, as a nation, will rise above the hazardous methods of the horse trader in selecting from the foreign applicants who knock at our portals, and that we will exercise a more fundamental discrimination than such a haphazard method affords, by demanding a knowledge of the germplasm of these candidates for citizenship, as displayed in their pedigrees.

This may possibly be accomplished by having trained inspectors located abroad in the communities from which our immigrants come, whose duty it shall be to look up the ancestry of prospective applicants and to stamp desirable ones with approval. The national expense of such a progran of genealogical inspection would be far less than the maintenance of introduced defectives, in fact it would greatly decrease the number of defectives in the country. At the present time this country is spending over one hundred million dollars a year on defectives alone, and each year sees this amount increased.

The United States Department of Agriculture already has field agents scouring every land for desirable animals and plants to introduce into this country, as well as stringent laws to prevent the importation of dangerous weeds, parasites, and organisms of various kinds. Is the inspection and supervision of human blood less important? 


\section{b) MORE DISCRIMINATING MARRIAGE LAWS}

Every people, including even the more primitive races, make customs or laws that tend to regulate marriage. Of these, the laws which relate to the eugenic aspect of marriage are the only ones that concem us in this connection. "Marriage," says Davenport. "can be looked at from many points of view. In novels as the climax of human courtship; in law largely as two lines of property descent; in society, as fixing a certain status; but in eugenics, which considers its biological aspect, marriage is an experiment in breeding."

Certain of the United States have laws forldilding the marriage of epileptics, the insane, hahitual drunkards, paupers, idiots, feebleminded, and those afllicted with venereal diseases. It would be well if such laws were not only more uniform and wirlespread, hut also more rigidly enforced.

It is quite true that marriage laws in themselves do not necessarily control buman reproduction, for illegitimacy is a factor that must alwiys te reckoned with; nevertheless such laws do have an important influence in regulating marriage and consequent reproduction.

Yarriare laws may, however, sometimes bring about a deploraile result eurenically, as in the case of forced marriage of sexual offenters in order to legalize the offense and "save the woman's honor." To compel, under the guise of legality, two defective streams of armplasm to combine repeatedly and thereby result in defective offspring just lecause the unfortunate event happened once illegitimately, is fundmentally a mistalie. Darwin says: "Except in the case of man himself hardly any oue is so ignorant as to allow his worst an:mals to breed."

\section{c) AN EDUCATEd SENTIMENT}

A far more effective means of restricting bad germplasm than placing elaborate marriage laws upon our statute-books is to educate public sentiment and to foster a popular eugenic conscience, in the absence of which the safeguards of the law must forever be largely without avail.

Such a sentiment already generally exists to a large extent with respect to incest, and the marriage of persons as noticeably defective as idiots or those afficted with insanity, and also in America with respect to miscerrenation, but a cautious and intelligent examination of the more obscure defective traits, exhibited in the somatoplasms of the various members of families in question, is larrely an ideal of the 
future. Under existing conditions non-eugenic considerations such as wealth, social position, etc., often enter into the preliminary negotiations of a marriage alliance, but an equally unromantic caution with reference to the physical, moral, and mental characters that make up the biological heritage of contracting parties is less usual.

The scientific attitude is not necessarily opposed to the romantic way of looking at things. Science is simple "organized common sense," and romance, that dispenses with this balance-wheel, although it may be entertaining and always exciting at first, is sure to be disappointing in the end. Marriages may be "made in heaven," but, as a matter of fact, children are born and have to be brought up on earth. It follows without saying that it will be much easier to stamp out bad germplasm when an educated sentiment becomes common among all people everywhere.

\section{d) SEGREGATION OF DEFECTIVES}

Persons with hereditary defects, such as epileptics, idiots, and certain criminals, who become wards of the state, should be segregated so that their germplasm may not escape to furnish additional burdens to society. "We have become so used to crime, disease and degeneracy that we take them for necessary evils. That they were in the world's ignorance, is granted. That they must remain so, is denied" (Davenport).

"The great horde of defectives once in the world have the right to live and enjoy as best they may whatever freedom is compatible with the lives and freedom of other members of society," says Kellicott, but society had a right to protect itself against repetitions of hereditary blunders.

There is one grave danger connected with the administration of our humane and commendable philanthropies toward the unfortunate, for it frequently happens that defectives are kept in institutions until they are sexually mature or are partly self-supporting, when they are liberated only to add to the burden of society by reproducing their like.

Furthermore, if defectives of the same sort are collected together in the same institutions, unless sexual segregation is strictly maintained, they may by the very circumstance of proximity tend to reproduce their kind just as defectives in any isolated community tend to multiply.

David Starr Jordan cites the interesting case of cretinism which occurs in the valley of Aosta in northern Italy, to prove the wisdom 
of the sexual segregation of defectives. Cretinism is an hereditary defect connected with an abnormal development of the thyroid gland which results in a peculiar form of idiocy usually associated with goitre.

"In the city of Aosta the goitrous crelin has been for centuries an object of charity. The idiot has received generous support, while the poor farmer or laborer with brains and no goitre has had the severest of struggles. In the competition of life a premium has thus been placed on imbecility and disease. The cretin has mated with cretin, the goitre with goitre, and charity and religion have presided over the union. The result is that idiocy is multiplied and intensified. The cretin of Aosta has been developed as a new species of man. In fair weather the roads about the city are lined with these awful paupershuman beings with less intelligence than a goose, with less decency than the pig."

Whymper, writing in I $\$ 80$, further observes: "It is strange that self-interest does not lead the natives of Aosta to place their cretins under such restrictions as would prevent their illicit intercourse; and it is still more surprising to find the Catholic Church actually legalizing their marriage. There is something horribly grotesque in the idea of solemnizing the union of a brace of idiots, and, since it is well known that the disease is hereditary and develops in successive generations the fact that such marriages are sanctioned is scandalous and infamous."

Since 1890 the cretins have been sexually segregated, and in 1910 Jordan reported that they were nearly all gone.

\section{e) DRASTIC MEASURES}

A fifth method of restricting undesirable germplasm in the case of confirmed criminals, idiots, imbeciles, and rapists may be mentioned, namely, the extreme treatment of either asexualization or vasectomy. The latter is a minor operation confined to the male which occupies only a few moments and requires at most only the application of a local anaesthetic, such as cocaine. There are no disturbing or even inconvenient after effects from this operation. It consists in removing a small section of each sperm duct, and is entirely effectual in preventing subsequent parenthood.

In the female the corresponding operation, which consists in removing a portion of each Fallopian tube, is much more severe, but not impracticable or dangerous.

Eight states already have sterilization laws providing for certain cases and "could such a law be enforced in the whole United States, 
less than four generations would eliminate nine tenths of the crime, insanity and sickness of the present generation in our land. Asylums, prisons and hospitals would decrease, and the problems of the unemployed, the indigent old and the hopelessly degenerate would cease to trouble civilization."

\section{THE CONSERVATION OF DESIRABLE GERMPLASM}

Not only negatively by the restriction of undesirable germplasm, but also positively by the conservation of desirable germplasm, may the eugenic ideal be approached.

It is possible that if some of the philanthropic endeavor now directed toward alleviating the condition of the unfit should be directed to enlarging the opportunity of the fit, greater good would result in the end. In breeding animals and plants the most notable advances have been made by isolating and developing the best, rather than by attempting to raise the standard of mediocrity through the elimination of the worst.

One leader is worth a score of followers in any community, and the science of genetics surely gives to educators the hint that it is wiser to cultivate the exceptional pupil who is often left to take care of himself than to expend all the energies of the instructor in forcing the indifferent or ordinary one up to a passing standard. The campaign for human betterment in the long run must do more than avoid mistakes. It must become aggressive and take advantage of those human mutations or combinations of traits which appear in the exceptionally endowed.

There are various ways in which this improvement of society may be brought about.

\section{a) BY SUBSIDIZING THE FIT}

The following unconfirmed newspaper clipping illustrates the point of what is meant by subsidizing the fit so far as certain physical characteristics are concerned. "Berlin, Dec. II, I9I I. The Emperor is reported to be interested in a plan proposed by Professor Otto Hauser for the propagation of a fixed German type of humanitya type which will be as fixed as the Jewish in its characteristics, if the suggestions of the professor can ever be carried out. The fixed type is to be produced as follows:-Only 'typical' couples are to be allowed to mate. The man is to be not more than thirty years old, the woman not over twenty-eight, and each have a perfect health certificate. The man should be at least five feet seven inches tall; the woman not under 
five feet six inches. Neither the man nor the woman should have dark hair. Its tint may range from blonde to auburn. The eyes of the pair should he pure blue without any tint of hrown. The crmplexion should be fair to ruddy without any suggestion of heaviness or 'beefiness.' 'The nose ought to be strong and narrow, the chin square and powerful, and the skull well developed at the back. The man and the woman must be of German descent and must bear a German name and speak the language of Germany. 'These 'mated couples' are to get a wedding gift of $\$ 125$ and an additional grant for each child born. The couples may settle in the United States if they prefer." This reported attempt to estallish a Prussian type of "Hauser lilondes" at least points the way to one sort of a positive eugenic method that might possibly be employed with respect to certain physical characteristics.

It should be remembered, however, that the eugenic ideal is not by any means confined to physical traits alone.

b) BX ENLARGING INDIVTDUAL OPPORTUNITY

Much good human germplasm goes to waste inrough ineffectiveness on account of unfavorable environment or lack of a suitable opportunity to develop.

Every agency which contributes loward increasing the opportunity of the individual to attain to a better development of his latent possibilities is in harmony with a thoroughly positive eugenic practice. Thus better schools, better homes, better living conditions, in short, all euthenic endeavor, directly serves the eugenic ideal by making the best out of whatever germinal equipment is present in man.

\section{c) BX PREvesting GerMinal WASTE}

Much good protoplasm fails to find expression in the form of of:spring because one or the other of possible parents is cut off either ly preventable death or by social hindrances. To avoid such calamities is a part of the positive program of eugenics.

I. Prevenlable death.-War, from the eugenic point of view, is the height of folly, since presumably the brave and the physically fit march away to fight, while in general the unqualified stay at home to reprodice the next generation. When a soldier dies on the lattlefield or in the hospital, it is not alone a brave man who is cut off, but it is the termination of a probably desirable strain of germplasm. The Thirty Years' Nar in Germany cost 6,000,000 lives, while Napoleon in his campaigns drained the best blood of France. 
David Starr Jordan has presented the matter very clearly. He points out that the "man with a hoe" among the European peasantry is not the result of centuries of oppression, as he has been pictured, but rather the dull progeny resulting from generations of the unfit who were left behind when the fit went off to war never to return.

Benjamin Franklin, with characteristic wisdom, sums up the situation in the following epigram: "Wars are not paid for in war time; the bill comes later."

2. Social hindrances. - There are many conditions of modern society which act non-eugenically.

For instance, the increasing demands of professional life prolong the period necessary for preparation, which, with the "cost of high living," tends toward late marriage. In this way much of the best germplasm is very often withheld from circulation until it is too late to be effective in providing for the succeeding generation.

Certain occupations such as school-teaching and nursing by women are filled by the best blood obtainable, yet this blood is denied a direct part in molding posterity, since marriage is either forbidden or regarded as a serious handicap in such lines of work. Advertisements concerning "unincumbered help" and "childless apartments" tell their own deplorable tale.

One of the darkest features of the dark ages from a eugenic standpoint was the enforced celibacy of the priesthood, since this resulted, as a rule, in withdrawing into monasteries and numneries much of the best blood of the times, and this uneugenic custom still obtains in many quarters today.

\section{WHO SHALL SIT IN JUDGMENT?}

In the practical application of a program of eugenics there are many difficulties, for who is qualified to sit in judgment and separate the fit from the unfit?

There are certain strongly marked characteristics in mankind which are plainly good or bad, but the principle of the independence of unit characters demonstrates that no person is wholly good or wholly bad. Shall we then throw away the whole bundle of sticks because it contains a few poor or crooked ones?

The list of weakling babies, for instance, who were apparently physically unfit and hardly worth raising upon first judgment, but who afterwards became powerful factors in the world's progress, is a notable one and includes the names of Calvin, Newton, Heine, Voltaire, Herbert Spencer, and Robert Louis Stevenson. 
Or, take another example. Elizabeth Tuttle, the grandmother of Jonathan Edwards whose remarkalule progeny was referred to in a preceding chapter, is described as a "woman of great beauty, of tall and commanding appearance, striking carriage, of strong will, extreme intellectual vigor and mental grasp akin to rapacity," but with an extraudinary deficioncy in moral sense. She was divorced from her husband "on the ground of adultery and other immoralities. . . . . The evil trait was in the blood, for one of her sisters murdered her own son and a brother murdered his own sister." That Jonathan Edwards owed his remarkable qualities largely to his grandmother rather than to his grandfather is shown by the fact that Richard Edwards, the grandfather, married again after his divorce and had five sons and one daughter, but none of their numerous progeny "rose above mediocrity, and their descendants gained no abiding reputation." As shown by subsequent events, it would have been a great eugenic mistake to have deprived the world of Elizabeth Tuttle's germplasm, although it would have been easy to find judges to condemn her.

Dr. C. V. Chapin recently said with reference to the eugenic recrulation of marriage by physician's certificate: "The causes of heredity are many and very conflicting. The subject is a difficult one, and I for one would hesitate to say, in a great many cases where I have a pretty good knowledge of the family, where marriage would, or would not, be desirable."

Desirability and undesirability must always be regarded as relative terms more or less indefinable. In attempting to define them, it makes a great difference whether the interested party holds to a puritan or a cavalier standard. To show how far human judgment may err as well as how radically human opinion changes, there were in England, as recently as I8I9, 233 crimes punishable by death according to law.

One needs only to recall the days of the Spanish Inquisition or of the Salem witchcraft persecution to realize what fearful blunders human judgment is capable of, but it is unlikely that the world will ever see another great religious inquisition, or that in applying to man the newly found laws of heredity there will ever be undertaken an equally deplorable eugenic inquisition.

It is quite apparent, finally, that although great caution and broadness of vision must be exercised in bringing about the fulfilment of the highest eugenic ideals, nevertheless in this direction lies the future path of human achievement. 


\section{CHAPTER XLI \\ THE PROMISE OF RACE CULTURE}

CALEB WTLLIAMS SALEEBY

The best is yet to $\mathrm{de}$.

In its form of what we have called negative eugenics, the practice of our principle would assuredly reduce to an incalculable extent the amount of human defect, mental and physical, which each generation now exhibits. This alone, as has been said, would he far more than sufficient to justify us. A world without hereditary disease of mind and body would alone warrant the hint of Ruskin that posterity may some day look back upon us with "incredulous disdain." Yet, assuming that this could be accomplished, as it will be accomplished, what more is to be hoped for? Must race-culture cease merely when it has raised the average of the community by reducing to a minimum the proportion of those who are thus grossly defective in mind or body? Such lisease apart, are we to be content, must we be content, with the present level of mediocrity in respect of intelligence and temper and moral sentiment? Can we anticipate a London in which the present ratio of musical comedy to great opera will be reversed, in which the works of Mr. George Meredith will sell in hundreds of thousands, whilst some of our popular novelists will have to find other means of earning a living? Can we make for a critical democracy which no political party can fool, and which will choose its best to govern it? Yet more, can we undertake, now or hereafter, to provide every generation with its own Shakespeare and Beethoven and Tintoretto and Newton? What, in a word, is the promise of positive eurenics? It is to this aspect of the question that Mr. Galton has mainly directed himself. Indeed he was led to formulate the principles and ideals of the new science by his sturly of hereditary genius some four decintes ing. Let us nuw attempt to answer some of these questions.

The production of genius.-And first as to the production of genius. It is this, perhaps, that has licen the main butt of the jesters who pass for philosophers with some of us today. It may be said

I From C. W. Saleeby, Parenthood and Race Culure (copyright I9og). Used by special permission of the publishers, Moffat, Yard, and Company. 
at once that neither Mr. Galton nor any other responsible person has ever asserted that we can produce genius at will. The difficulties in the way of such a project-at present-are almost innumerable. One or two may le cited.

In the first place, there is the cardinal-but by no means universal-dificulty that the genius is too conmonly so occupied with the development and expansion of his own individuality that he has little time or energy for the purposes of the race. This, of course, is an example of Spencer's great generalization as to the antagonism or inverse atio between individuation and genesis.

Again, there is the generalization of heredity formulated by Mr. Galton, and named by him the law of regression twats mediocrity. It asserts that the children of those who are above or lelow the mean of a race, tend to return towards that mean. The children of the born criminal will be probably somewhat less criminal in tendency than he, though more criminal than the average citizen. The children of the man of genius, if he has any, will prolably be nearer medicrity than he, though on the average possessing greater talent than the average citizen. It is thus not in the nature of sheer genius to reproduce on its own level. It is only the critics who are totally ignorant of the elementary facts of heredity that attribute to the eugenist an expectation of which no one knows the absurdity so well as he does.

On the other hand, it is impossible to question that the hereditary transmission of genius or great talent does occur. One may cite at random such cases as that of the Bach family, Thomas and Natthew Arnold, Janes and John Stuart Mill; and the reader who is inclined to believe that there is no law or likelihood in this matter, must certainly make himself acquainted with Mr. Galton's Hereditary Genius, and with such a paper as that which he printed in Sociological Papers, 1904, furnishing an "index to achievenents of near linsfoll: of some of the Fellows of the Royal Society." There is, of course, the obvious fallacy involved in the possibility that not lieredity but enviromment was really responsible for many of these cases. It must have been a great thing to have such a father as James Mill. But it would be equally idle to imagine that the evidence can be dismissed with this criticism. A Matthew Arnold, a John Stuart Xill, could not be manufactured out of any chance material by an ideal education continued for a thousand years.

The transmission of genius.-One single instance of the transmission of genius or great talent in a family may be cited. We shall 
take the family which produced Charles Darwin, the discoverer of the fundamental principle of eugenics, and his first cousin, Francis Galton. Darwin's grandfather was Erasmus Darwin, physician, poet and philosopher, and independent expounder of the doctrine of organic evolution. Darwin's father was a distinguished physician, described by his son as "the wisest man I ever knew." Darwin's maternal grandfather was Josiah Wedgwood, the famous founder of the pottery works. Amongst his first cousins is Mr. Francis Galton. He has five living sons, each a man of great distinction, including Mr. Francis Darwin and Sir George Darwin, both of them original thinkers, honored by the presidency of the British Association. No one will put such a case as this down to pure chance or to the influence of environment alone. This is evidently, like many others, a greatly distinguished stock. The worth of such families to a nation is wholly beyond any one's powers of estimation. What if Erasmus Darwin had never married!

No student of human heredity can doubt that, however limited our immediate hopes, facts such as those alluded to furnish promise of great things for the future. But let us turn now from genius to what we usually call talent.

The production of talent.- There can be no question that amongst the promises of race-culture is the possibility of breeding such things as talent and the mental energy upon which talent so largely depends. In the Inquiries into Human Faculty, Mr. Galton shows the remarkable extent to which energy or the capacity for labor underlies intellectual achievement. He says, of energy:

"It is consistent with all the robust virtues, and makes a large practice of them possible. It is the measure of fullness of life; the more energy the more abundance of it; no energy at all is death; idiots are feeble and listless. In the enquiries I made on the antecedents of men of science no points came out more strongly than that the leaders of scientific thought were generally gifted with remarkable energy, and that they had inherited the gift of it from their parents and grandparents. . . . . It maybe objected that if the race were too healthy and energetic there would be insufficient call for the exercise of the pitying and self-denying virtues, and the character of men would grow harder in consequence. But it does not seem reasonable to preserve sickly breeds for the sole purpose of tending them, as the breed of foxes is preserved solely for sport and its attendant advantages. There is little fear that misery will ever cease from the land, or that the 
compassionate will fail to find objects for their compassion; but at present the supply vastly exceeds the demand; the land is over-stocked and over-burdened with the listless and the incapable. In any scheme of eugenics, energy is the most important quality to favor; it is, as we have seen, the basis of living action, and it is eminently transmissible by descent."

Need it be pointed out that any political system which ceases to favor or actively disfarors energy, making it as profitable to be lazy as to be active, is antieugenic, and must inevitably lead to disaster ? That, however, by the way. Our present point is that eugenics can reasona!ly promise, when its principles are recognized, to multiply the human and diminish the vegetable type in the community. In so doing, it will greatly further the production of talent, and therefore of that traditional or acquired progress which men of talent and genius create. Such a result will also further, though indirectly, the production of genius itself. For, as Mr. Galton points out, "men of an order of ability which is now very rare, would become more frequent, because the level out of which they rose would itself have risen."

This is by no means the only fashion in which an effective and practicable race-culture would serve genius, and I shall not be blamed for considering this matter further by any reader who realizes, however faintly, what the man of genius is worth to the world. If it were shown possible to establish such social conditions that genius could never flower in them, we should realize that their establishment would mean the putting of an end to progress and the blasting of all the highest hopes of the highest of all ages.

The immediate need of this age, as of all ages, is perhaps not so much the birth of babies capable of developing into men and women of genius, as the full exploitation of the possililities of genius with which, as I fancy, every generation on the average is about as well endowed as any other. There is, of course, the popular doctrine that there are no mute inglorious Miltons, that "genius will out," and that therefore if it does not appear, it is not there to appear. In expressing the compelling power of genius in many cases this doctrine is not without truth. Yet history abounds in instances where genius has been destroyed by environment-and we can only guess how many more instances there are of which history has no record. To take the single case of musical genius, it is a lamentable thought that there may be those now living whose natural endowments, in a farorable environment, would have enabled them to write symphonies fit to place 
beside Beethoven's, but whom some environmental factors--conventional, economic, educational, or what not-have silenced; or worse, have persuaded to write such sterile nullities as need not here be instanced. There is surely no waste in all this wasteful world so lamentable as this waste of genius.

If, then, anyone could devise for us a means by which the genius, potentially existing at any time, were realized, he would have performed in effect a service equivalent to that of which eugenics repudiates the present possibility - the actual creation of genius. But if we consider what the conditions are which cause the waste of genius, we realize at once that they mainly inhere in the level of the human environment of the priceless potentiality in question. As we noted elsewhere, in an agre like that of Pericles genius springs up on all hands. It is encouraged and welcomed because the average level of the human environment in which it finds itself is so high. But if eugenics can raise the average level of intelligence, in so doing not merely does it render nore likely, as Mr. Galton points out, the production of men of the highest ability, but it provides those conditions in which men of genius, now swamped, can swim. We could not undertake to produce a Shakespeare, but we might reasonably hope to produce a generation which would not destroy its Shakespeares. And even if men of genius still found it necessary, as men of genius have found it necessary, to "play to the gallery," they would play, as Mr. Galton says of the demagogue in a eugenic age, "to a more sensible gallery than at present."

D)arwin somewhere points out that it is not the scientific, but the unscientific man who denies future possibilities. Thus though an arlvocate of eugenics may be applauded for his judgment if he declares that the creation of genius will forever be impossible, yet I should not care to assert that the ultimate limitations of eugenics can thus be lefined. We have yet to hear the last of Mendelism.

Eugenics and unemployment.--Let us look now at another aspect of the promise of race-culture. When the time comes that quality rather than quantity is the ideal of those who concern themselves with the population question, it is quite evident that not a few of the social prollems which we now find utterly insoluble will disappear. In this brief outline, we can only allude to one or two points. Take, for instance, the question of unemployment. We know that some by no means small proportion of the unemployed were really destined to be unemployalle from the first, as for instance by reason of hereditary 
disease. It were letter for them and for us that they had never been horn. Many more of the unemployed have heen made unemployalte by the influence of over-crowling, to which they were subjected in their years of development. Is there, can there be, any real and permanent remedy for overcrowding, but the erection of parenthood into an act of personal and provident responsibility?

Eugenics and woman.-Take, again, the woman question. No one will deny that in many of its gravest forms, especially in its economic form, and the question of the employment of women, wisely or horribly, this depends (to a degree which few, 1 think, realize) upon the fact that there are now (I909), for instance, I, 300,000 women in excess in this country. Is it then proposed, the reader will say, by meaus of race-culture to exteminate the superfluous woman? Indeed, no. But is the reader aware that Nature is not responsible for the existence of the superiluous woman? There are more boys than girls born in the ratio of alout IO3 or 104 to 100 ; and Nature means them all to live, boys and girls alike. If they did so live, we should have merely the problen of the superfuous man, which would not be an economic problem at all. But we destroy hosts of all the children that are born, and since male organisms are in general less resistant than female organisms, we destroy a disproportionate number of boys, so that the natural balance of the sexes is inverted. Unlike ancient societies we largely practice male infanticide. Can the reader believe that there is any permanent and final means of arresting this wastage of childlife, with its singulir and lar-reaching consequences, other than the elevation of parenthoud, wholly apart from the question of the selection of parents? We shall not succeed in keeping all the children alive (with a trivial number of exceptions), therehy abolishing the superfluous woman by keeping alive the boy who should have grown up to be her partner, until we greatly reduce the birth-rate; as it must and will be reduced when the ideal of race-culture is realized, and no child comes into the world that is not already loved and desired in anticipation.

Eugenics and cruelty to children.--This ideal, also, offers us in its realization the only complete remedy for the present ghastly cruelty under which so many children suffer even in Great Eritain, even in the twentieth century. Is the reader aware that the National Society for the Prevention of Cruelty to Children inquired into the ill-treatment or cruel neglect of I 5,000 children in the year beginning April Ist, rgo6? It has been reasonably and carefully estimated that "over 
half a million children are involved in the total of the wastage of childlife and the torture and neglect of child-life in a single year." Surely Mr. G. R. Sims, to whom I would offer a hearty tribute for his recent services to childhood, is justified in saying, "Against the guilt of race suicide our men of science are everywhere preaching their sermons to-day. It is against the guilt of race murder that the cry of the children should ring through the land." As regards race suicide and the men of science, I am not so sure as to the assertion. But the truth of the second sentence quoted is as indisputable as it is horrible.

Now no legislation conceivable will wholly cure this evil nor avert its consequences. At bottom it depends upon human nature, and you can cure it only by curing the defect of human nature. This, in general, is of course beyond the immediate powers of man, but evidently we should gain the same end if only we could confine the advent of children to those parents who desired them - that is to say, those in whom human nature displayed the first, if not indeed almost the only, requisite for the happiness of childhood. To this most beneficent and wholly moral end we shall come, notwithstanding the blind and pitiable guidance of most of our accredited moral teachers today. By no other means than the realization of the ideal defined, that every new baby shall be loved and desired in anticipation-an ideal which is perfectly practicable--can the black stain of child murder and child torture and child neglect be removed from our civilization.

Ruskin and race-culture.-The name of Ruskin, perhaps, would not occur to the reader as likely to afford support to the fair hopes of the eugenist. Consider then, these words from Time and Tide:

"You leave your marriages to be settled by supply and demand, instead of wholesome law. And thus, among your youths and maidens, the improvident, incontinent, selfish, and foolish ones marry, whether you will or not; and beget families of children necessarily inheritors in a great degree of these parental dispositions; and for whom, supposing they had the best dispositions in the world, you have thus provided, by way of educators, the foolishest fathers and mothers you could find; (the only rational sentence in their letters, usually, is the invariable one, in which they declare themselves 'incapable of providing for their children's education'). On the other hand, whosoever is wise, patient, unselfish, and pure among your youth, you keep maid or bachelor; wasting their best days of natural life in painful sacrifice, forbidding them their best help and best reward, and carefully excluding their prudence and tenderness from any offices of 
parental duty. Is not this a beatific and beautifully sagacious system for a Celestial Empire, such as that of these British Isles?"

Apart from the point as to wholesome law rather than the education of opinion as the eugenic means, the foregoing passage must win the assent and respect of every eugenist. It indicates the promise of race-culture as it appeared to John Ruskin. The passage has been quoted in full, not for the benefit of the ordinary thoughtful reader but for that of the professional literary man who, in this remarkable age, so far as I can judge, reads nothing but what he writes, and thus qualifies himself for dismissing Spencer or Darwin or Galton by any casual phrase.

Race-culture and human variety.-Now let us turn to another question. Let it be asserted most emphatically that, if there is anything in the world which eugenics or race-culture does not promise or desire, it is the production of a uniform type of man. This delusion, for which there has never been any warrant at all, possesses many of the critics of eugenics, and they have made pretty play with it, just as they do with their other delusions. Let us note one or two facts which bear upon this most undesirable ideal.

In the first place, it is unattainable because of the existence of what we call variation. No apparatus conceivable would suffice to zliminate from every generation those who varied from the accepted type.

In the second place, this uniformity is supremely undesirable from the purely evolutionary point of view, because its attainment would mean the arrest of all progress. All organic evolution, as we know, depends upon the struggle between creatures possessing various variations and the consequent selection of those variations which constitute their possessors best adapted or fitted to the particular environment. If there is no variation there can be no evolution. To aim at the suppression of variation, therefore, on supposed eugenic grounds (which would be involved in aiming at any uniform type of mankind) would be to aim at destroying the necessary condition of all racial progress. The mere fact that all the critics of race-culture attribute to evolutionists, of all people, the desire to suppress variation, is a pathognomonic symptom of their critical quality.

And, of course, quite independently of the evolutionary function of variation-though this is cardinal and must never be forgotten by the politician of any school, since what we call individuality is variation on the human plane - the value of variation in ordinarv life is wholly 
incalculable. It is not merely that, as Mr. Galton says, "There are a vast number of conflicting ideals, of alternative characters, of incompatible civilizations; but they are wanted to give fullness and interest to life. Society would be very dull if every man resembled the highly estimable Marcus Aurelius or Adam Bede." The question is not merely as to the interest of life. Much more important is the fact that it takes all sorts to make a world. What is the development of society but the result of the psychological division of labor in the social organism? And how could such division of labor be carried out if we had not various types of laborers? What would be the good of science if there were no poetry or music to live for? How would poetry and music help us if we had not men of science to protect our shores from plague? Obviously the existence of men of most various types is a necessity for any highly organized society. Even if eugenics were capable - as it is not-of producing a complete and balanced type, fit up to a point to turn out a satisfactory poem, a satisfactory symphony or a satisfactory sofa, the utmost could not be expected of such a man in any of these directions. In a word, as long as their activities are not antisocial, men cannot be of too various types. We require mystic and mathematician, poet and pathologist. Only, we want good specimens of each. "The aim of eugenics," says Mr. Galton, "is to represent each class or sect by its best specimens; that done, to leave them to work out their common civilization in their own way. . . . Special aptitudes would be assessed highly by those who possessed them, as the artistic faculties by artists, fearlessness of inquiry and veracity by scientists, religious absorption by mystics, and so on. There would be self-sacrificers, self-tormentors, and other exceptional idealists." But at least it is better to have good rather than bad specimens of any kind, whatever that kind may be. Mr. Galton thinks that all except cranks would agree as to including health, energy, ability, manliness, and courteous disposition amongst qualities uniformly desirable-alike in poet and pathologist. We should desire also uniformity as to the absence of the antisocial proclivities of the born criminal. So much uniformity being granted, let us have with it the utmost conceivable variety-more, indeed, than most of us can conceive.

This point, of course, is cardinal from the point of view of practice. No progress could be made with eugenics, it would be impossible even to form a Eugenics Education Society, if each of us were to regard the particular type he belongs to as the ideal, and were to seek merely 
to obtain the best specimens of that type. The doctrine that it takes all sorts to make a world - a doctrine very hard for youth to learn, yet unconsciously learnt by all who are capable of learning at all-must be regarded as cardinal truth for the cugenist. All he asks for, all he is wise in seeking, is good specimens rather than bad. Poets certainly but not poetasters; jesters certainly, but not clever fools.

Time and its treasure.-Taking the modern estimates of the physicists, we are assured that the total period of past human existence is very brief compared with what may reasonably be predicterl. Granted, then, practically unlimited time, what inherent limits are there to the upward development of man as a moral and intellectual Jeing? Shall we answer this question by a study of the nature of matter? Plainly not. Shall we answer it by a study of the nature of mind? Surely not, for the study of the mind cannot inform us as to what mind might be. One source of guidance alone we have, and this is the amazing contrast which exists hetween the mind of man at its highest, and mind in its humblest animal forms; or shall we say even between the highest and lowest manifestations of mind within the human species? The measureless height of the ascent thus indicated offers us no warrant for the conclusion that, as we stand on the heights of our life, our "climpse of a height that is higher" is only a hallucination. On the contrary.

There is no warrant whaterer for supposing that the forces which have brought us thus far are yet exhausted; they have their origin in the inexhaustible. Who, gazing on the earth of a hundred million years ago, could have predicted life-could have recognized, in the forces then at work and the matter in which they were displayed, the promise and potency of all terrestrial life? Who, contemplating life at a much later stage, even later mammalian, coukl have seen in the simian the prophecy of man? Who, examining the earliest nervous ganglia, could have foreseen the hmman cerebrum? The fact that we can imagine nothing higher than ourselves, that we make even our gods in our own image, offers no warrant for supposing that nothing higher will ever be. What ape could have predicted man, what reptile the bird, what amoel a the bee? "There are many events in the womb of time which will be delivered" and the fairest of her sons and daughters are yet to be.

But even grant, for the sake of the argument, that the intelligence of a Newton, the musical faculty of a Bach, the moral nature of any gond mother anywhere, represent the utmost limits of which the 
evolution of the psychical is capable. There is every reason to deny this, but let us for the moment assume it true. There still remains the thought of Wordsworth, "What one is, why may not millions be?"-a thought to which Spencer has also given utterance. What is shown possible for human nature here and there, he says, is conceivable for human nature at large. It is possible for a human being, whilst still remaining human, to be a Shakespeare or a St. Francis; these things are thus demonstrably within the possibilities of human nature. It is therefore at the least conceivable that, in the course of almost infinite time (even assuming, say, that intelligence must ever be limited, as even Newton's intelligence was limited)-some such capacities as his may be common property amongst men of the scientific type; and so with other types. We may answer Wordsworth that there is no bar thrown by Nature in the way of such a hope.

What is possible.-This of course is speculation and of no immediate value. I would merely remind the reader that the doctrine of optimism, as regards the future of mankind, which the principles of race-culture assume and which they desire to justify, was definitely shared by the great pioneers to whom we owe our understanding of those principles. Notwithstanding grave nervous disorder, such as makes pessimists of most men, both Darwin and Spencer were compelled by their study of Nature to this rational optimism as regards man's future. The doctrine of organic evolution, and of the age-long ascent of man through the selection of the fittest (who have, on the whole, been the best) for parenthood, is one not of despair but of hope. Exactly half a century ago it struck horror into the minds of our predecessors. Man, then, is only an erected ape, they thoughtas if any historical doctrine, however true, could shorten the dizzy distance to which man has climbed since he was simian; and man being an ape, they thought his high dreams palpably vain. But the measure of the accomplished hints at the measure of the possible, and the value of the historical facts lies not in themselves, all facts as such being as dead as are the individual atoms of the living body, but in the principles which grow out of them. It is of no importance as such that man has simian ancestors; it is of immeasurable importance that he should learn by what processes he has become human, and by what, indeed, they became simian - which would have been a proud adjective for its own day. The principles of organic progress matter for us because they are the principles of race-culture, the only sure means of human progress. Our looking backwards does not turn us 
into pillars of salt, but traches us that the hest is yet to be, and how alone it is to be attained.

Elsewhere the optimistic argment of Wordsworth is quoted. Here also John Ruskin:

"There is as yet no ascertained limit to the nobleness of person and mind which the human creature may attain, by persevering observance of the laws of God respecting its birth and training."

And Herbert Spencer:

"What now characterizes the exceptionally high may be expected eventually to characterize all. For that which the lest human nature is capable of, is within the reach of human nature at large."

And Francis Galton:

"There is nothing either in the history of domestic animals or in that of evolution to make us cloul,t that a race of sane men may be formed, who shall be as much superior, mentally and morally, to the modern European, as the modern European is to the lowest of the Negro races.

"It is earnestly to be hoped that inquiries will be increasingly" directed into historical facts, with the view of estimating the possible effects of reasonalle political action in the future, in gradually raising the present miserably low standard of the human race to one in which the Etopias in the dreamland of philanthropists may hecome practical possifilities."

Conclusion - eugenics and religion.--In an early chapter it wan attempted to show that eugenics is not merely moral, but is of the very heart of morality. We saw that it involves taking no life, that rather it desires to make philanthrophy more philanthropic, that, at any rate so far as this eugenist is concemed, it recognizes and bows to the supreme law of love; and claims to serve that law, and the ideal of social morality, which is the making of human worth. Eugenics may or may not lue practicalle, it may or may not be based upon natural truth, lout it is assuredly moral; though I, for one, would proclaim eternal war between this real morality and the damnahle shan, which approves the unlridled transmission of the most hideous cliseases, rotting loody and soul, in the interests of good.

Ancl if religion, whatever its origin and the more questionable chapters in its past, be now "morality touched with emotion," I claim that eugenics is religions, is and will ever be a relicion. Elsewhere I have attempted to show that religion has survived and will survive hecause of its survival-value-its services to the life of the 
societies wherein it flourishes. The religion of the future, it was sought to argue, will be that which "best serves Nature's unswerving desire-fullness of life." The Founcler of the Christian religion sair]. "I am come that ye might have life, and that ye might have it more aloundantly." It is higher and more abundant life that is the eugenic ideal. Progress I define as the emergence and increasing dominance of mind. Of progress, thus conceived, man is the highest fruit hitherto. He is also its appointed agent and eugenics is his instrument.

To this end he must use all the powers which have blossomed in him from the dust. He must claim Art: and indeed in Wagner's great music-drama, at the moment when the prophetic Briinnhilde tells Sieglinde who has just lost her mate that she, the expectant mother, may look for the resurrection of the dead and the life of the world to come in the child Siegfried; and when the heroic theme is pronouneed for the first time and followed by that which signifies redemption by love; then, I think, the eugenist may thrill not merely to the music, nor the humanity of the story, but to the spiritual and scientifie truth which it symbolizes.

If the struggle towards individual perfection be religious, so, assuredly, is the struggle, less egoistic indeed, towards racial perfection. If the historic meaning and purport of religion are as $I$ conceive them, and if its future evolution may thence be inferred, there ean be no doubt in the prophecy that in ages to come those high aspirations and spiritual visions which astronomy has dishoused from amongst the stars, and which, at their best, were ever selfish, will find a place on this liuman earth of ours. If we have transferred our hopes from heaven to earth and from ourselves to our children, they are not less religious. And they that shall be of us shall build up the old waste places; for we shall raise up the foundations of many generations.

"We feel the high tradition of the world And leave our spirits on our children's breasts." 
PART Y

ACCESGORT REIIING 
. 


\title{
CIIAP'TER XLII
}

\section{THE RELATION OF EVOLUTION TO MATERIALISM ${ }^{1}$}

\author{
JOSEPH LE CONTE
}

It is seen in the sketch given in the previous chapter that, after every strugg!e between theology and science, there has been a readjustment of some beliefs, a giving up of some notions which really had nothing to do with religion in a proper sense, but which had become so associated with religious belief as to be confounded with the lattera giving up of some line of defense which ought never to have been held because not within the rightful domain of theology at all. Until the present the whole difficulty has been the result of misconception, and Christianity has emerged from every struggle only strengthened and purified, by casting off an obstructing shell which hindered its growth. But the present struggle seems to many an entirely different and far more serious matter. To many it seems no longer a struggle of theology, but of essential religion itself-a deadly life-and-death struggle between religion and materialism. To many, both skeptics and Christians, evolution seems to be synonymous with blank materialism, and therefore cuts up by the roots every form of religion by denying the existence of God and the fact of immortality. That the enemies of religion, if there be any such, should assume and insist on this identity, and thus carry over the whole accumulated evidence of evolution as a demonstration of materialism, although wholly unwarranted, is not so surprising; but what shall we say of the incredible folly of her friends in admitting the same identity!

A little reflection will explain this. There can be no doubt that there is at present a strong and to many an overwhelming tenclency toward materialism. The amazing achievements of modern science; the absorption of intellectual energy in the investigation of external nature and the laws of matter have created a current in that direction so strong that of those who feel its influence-of those who do not stay at home, shut up in their creeds, but walk abroad in the light of modern thought-it sweeps away and bears on its bosom ail

${ }^{2}$ From J. Le Conte, Evolution (copyright I883). Used by special permission of the publishers, D. Appleton \& Company. 
but the strongest and most reflective minds. Materialism has thus become a fashion of thought; and, like all fashions, must be guarded against. This tendency has been created and is now guided by science. Just at this time it is strongest in the department of biology. and especially is evolution its stronghold. This theory is supposed by many to be simply demonstrative of materialism. Once it was the theory of gravitation which seemed denonstrative of materialism. The sustentation of the universe by law seemed to imply that Nature operates itself and needs no God. That time is passed. Now it is evolution and creation by law. This will also pass. The theory seems to many the most materialistic of all scientific doctrines only because it is the last which is claimed by materialism, and the absurdity of the claim is not yet made clear to many.

The truth is, there is no such necessary connection between evolution and materialism as is imagined by some. There is no difference in this respect between evolution and any other law of Nature. In evolution, it is true, the last barrier is broken down, and the whole domain of Nature is now subject to law; but it is only the last; the march of science has been in the same direction all the time. In a word, evolution is not only not identical with materialism, but, to the deep thinker, it has not added a feather's weight to its probability or reasonableness. Evolution is one thing and materialism quite another. The one is an established law of Nature, the other an unwarranted and hasty inference from that law. Let no one imagine, as he is conducted by the matcrialistic scientist in the paths of evolution from the inorganic to the organic, from the organic to the animate, from the animate to the rational and moral, until he lands, as it seems to him, logically and inevitably, in universal materialism-let no such one imagine that he has walked all the way in the domain of science. He has stepped across the boundary into the domain of philosophy. But, on account of the strong tendency to materialism and the skilful guidance of his leaders, there seems to be no such boundary; he does not distinguish between the inductions of science and the inferences of a shallow philosophy; the whole is accredited to science, and the final conclusion seems to carry with it all the certainty which belongs to scientific results. The fact that these materialistic conclusions are reached by some of the foremost scientists of the present day adds nothing to their probability. In a question of science, viz., the law of evolution, their authority is deservedly high, but in a question of philosophy, viz., 
materialism, it is far otherwise. If the pure scientists smile when theological philosophers, unacquainted with the methods of science. undertake to dogmatize on the subject of evolution, they must pardon the philosophers if they also snile when the pure scientists imagine that they can at once solve questions in philosophy which have agitated the human mind from the earliest times. I am anxius to show the absurdity of this materialistic conclusion, but I shall try to do so, not by any labored argument, but by a few simple illustrations.

I. It is curious to observe how, when the question is concerning a work of Nature, we no sooner find out how a thing is made than we inmediately exclaim: "It is not made at all, it became so of itself!" So long as we knew not how worlds were made, we of course concluded they must have been created, but so soon as science showed how it was probably done, immediately we say we were mistakenthey were not made at all. So also, as long as we could not imagine how new organic forms originated, we were willing to believe they were created, but, so soon as we find that they originated by evolution, many at once say: "We were mistaken; no creator is necessary at al!." Is this so when the question is concerning a work of man? Yes, of one kind-viz., the work of the magician. Here, indeed, we believe in him, and are delighted with his work, until we know how it is done, and then all our faith and wonder cease. But in any honest work it is not so; but on the contrary, when we understand how it is done, stupid wonder is changed into intellectual delight. Does it not seem, then, that to most people God is a mere wonder-worker, a chief magician? But the mission of science is to show us how things are done. Is it any wonder, then, that to such persons science is constantly destroying their superstitious illusions? But if God is an honest worker, according to reason-i.e., according to law-ought not science rather to change gaping wonder into intelligent delight, superstition into rational worship?

2. Again, it is curious to o.serve how an old truth, if it come only in a nere form, often strikes us as something unheard of, and even as paradoxical and almost impossible. A little over thirty years ago a little philosophical toy, the gyroscope, was introduced and became very common. At first sight, it seems to violate all mechanical laws and set al naught the law of gravitation itself. A heary brass wheel, four to five inches in diameter, at the end of a horizontal axle, six or eight inches long, is set rotating rapidly, and then the free end of the 
axis is supported by a string or otherwise. The wheel remains suspended in the air while slowly gyrating. What mysterious force sustains the wheel when its only point of support is at the end of the axle, six or eight inches away? Scientific and popular literature were flooded with explanations of this seeming paradox. And yet it was nothing new. The boy's top, that spins and leans and will not fall, although solicited by gravity, so long as it spins, which we have seen all our lives without special wonder, is precisely the same thing.

Now, evolution is no new thing, but an old familiar truth; but, coming now in a new and questionable shape, lo, how it startles us out of our propriety! Origin of forms by evolution is going on everywhere about us, both in the inorganic and the organic world. In its more familiar forms, it had never occurred to most of us that it was a scientific refutation of the existence of God, that it was a demonstration of materialism. But now it is pushed one step farther in the direction it has always been going - it is made to include also the origin of species-only a little change in its form, and lo, how we start! To the deep thinker, now and always, there is and has been the alternative-materialism or theism. God operates Nature or Nature operates itself; but evolution puts no new phase on this old question. For example, the origin of the individual by evolution. Everybody knows that every one of us individually became what we now are by a slow process of evolution from a microscopic spherule of protoplasm, and yet this did not interfere with the idea of God as our individual maker. Why, then, should the discovery that the species (or first individuals of each kind) originated by evolution destroy our belief in God as the creator of species?

3. It is curious and very interesting to observe the manner in which vexed questions are always finally settled, if settled at all. All vexed questions-i.e., questions which have taxed the powers of the greatest minds age after age-are such only because there is a real truth on both sides. Pure, unmixed error does not live to plague us long. Error, when it continues to live, does so by virtue of a germ of truth contained. Great questions, therefore, continue to be argued pro and con from age to age, because each side is in a sense-i.e., from its own point of view-true, but wrong in excluding the other point of view; and a true solution, a true rational philosophy, will always be found in a view which combines and reconciles the two partial, mutually excluding views, showing in what they are true and in what they are false-explaining their differences by transcending 
them. This is so universal and far-reaching a principle that I am sure I will be pardoned for illustrating it in the homeliest and tritest fashion. I will do so by means of the shield with the diverse sides, giving the story and construing it, however, in my own way. There is, apparently, no limit to the amount of rich marrow of truth that may be extracted from these dry bones of popular proverbs and fables by patient turning and gnawing.

We all remember, then, the famous dispute concerning the shield, with its sides of different colors, which we shall here call white and black. We all remember how, after vain attempts to discover the truth by dispute, it was agreed to try the scientific method of investigation. We all remember the surprising result. Both parties to the dispute were right and both were wrong. Each was right from his point of view, but wrong in excluding the other point of view. Each was right in what he asserted, and each wrong in what he denied. And the complete truth was the combination of the partial truths and the elimination of the partial errors. But we must not make the mistake of supposing that truth consists in compromise. There is an old adage that truth lies in the middle between antagonistic extremes. But it seems to us that this is the place of safety, not of truth. This is the favorite adage, therefore, of the timid man, the time-server, the fence-man, not the truth-seeker. Suppose there had been on the occasion mentioned above one of these fence-philosophers. He would have said: "These disputants are equally intelligent and equally valiant. One side says the shield is white, the other that it is black; now truth lies in the middle; therefore, I conclude the shield is gray or neutral tint, or a sort of pepper-and-salt." Do we not see that he is the only man who has no truth in him? No; truth is no heterogeneous mixture of opposite extremes, but a stereoscopic combination of two surface views into one solid reality.

Now, the same is true of all vexed questions, and I have given this trite fable again only to apply it to the case in hand.

There are three possible views concerning the origin of organic forms whether individual or specific. Two of these are opposite and mutually excluding; the third combining and reconciling. For example, take the individual. There are three theories concerning the origin of the individual. The first is that of the pious child who thinks that he was made very much as he himself makes his dirt-pies; the second is that of the street-gamin, or of Topsy, who says: "I was not made at all, I grower"; the third is that of most intelligent 
Christians-i.e., that we were made by a process of evolution. Observe that this latter comlines and reconciles the other two, and is thus the more rational and philosophical. Now, there are also three exactly corresponding theories concerning the origin of species. The first is that of many pious persons and many intelligent clergymen, who say that species were made at once by the Divine hand without natural process. The second is that of the materialists, who say that species were not made at all, they were derived, "they growed." The third is that of the theistic evolutionists, who think that they were created by a process of evolution-who believe that making is not inconsistent with growing. The one asserts the divine agency, but denies natural process; the second asserts the natural process, but denies divine agency; the third asserts divine agency by natural process. Of the first two, observe, both are right and hoth wrong; each view is right in what it asserts, and wrong in what it denies-each is right from its own point of view, but wrong in excluding the other point of view. The third is the only true rational solution, for it includes, combines, and reconciles the other two; showing wherein each is right and wherein wrong. It is the combination of the two partial truths, and the elimination of the partial errors. But let us not fail to do perfect justice. The first two views of origin, whether of the individual or of the species, are indeed both partly wrong as well as partly right; but the view of the pious child and of the Christian contains by far the more essential truth. Of the two sides of the shield, theirs is at least the whiter and more beautiful.

But, alas! the great bar to a speedy settlement of this question and the adoption of a rational philosop.hy is not in the head, but in the heart-is not in the reason, but in pride of opinion, self-conceit, dogmatism. The rarest of all gifts is a truly tolerant, rational spirit. In all our gettings let us strive to get this, for $i t$ alone is true wisdom. But we must not imagine that all the dogmatism is on one side, and that the theological. Niany seem to think that theology has a"pre. emptive right" to dogmatism. If so, then modern materialistic scienco has "jumped the claim." Dogmalism has its roots deep-bedded in the human heart. It showed itself first in the domain of theology, because there was the seat of power. In modern times it has gone over to the side of science, because here now is the place of power and fashion. There are two dogmatisms, both cqually opposed to the true rational spirit, viz., the old theological and the new scientific. The old clings fondly to old things, only because they are old; the new grasps eagerly 
after new things, only because they are new. True wisdom and true philosophy, on the contrary, tries ali things both old and new, and holds fast only to that which is good and true. The new dogmatism taunts the old for credulity and superstition; the old reproaches the new for levity and skepticism. But true wisdom perceives that they are both equally credulous and equally skeptical. The old is credulous of old ideas and skeptical of new; the new is skeptical of old ideas and credulous of new. Both deserve the unsparing rebuke of all rightminded men. The appropriate rebuke for the old dogmatism has been already put in the mouth of Job in the form of a bitter sneer: "No doubt ye are the people, and wisdom shall die with you." The appropriate rebuke for the new dogmatism, though not put into the mouth of any ancient prophet, ought to be uttered-I will undertake to utter it here. I would say to these modern materialists, "No doubt ye are the men, and wisdom and true philosophy were born with you."

Let it be observed that we are not here touching the general question of the personal agency of God in operating Nature. This we shall take up hereafter. All that we wish to insist on now is that the process and the law of evolution does not differ in its relation to materialism from all other processes and laws of Nature. If the sustentation of the universe by the law of gravitation does not disturb our belief in God as the sustainer of the universe, there is no reason why the origin of the universe by the law of evolution should disturb our faith in God as the creator of the universe. If the law of gravitation be regarded as the Divine mode of sustentation, there is no reason why we should not regard the law of evolution as the Divine process of creation. It is evident that if evolution be materialism, then is gravitation also materialism; then is every law of Nature and all science materialism. If there be any difference at all, it consists only in this: that, as already said, here is the last line of defense of the supporters of supernaturalism in the realm of Nature. But being the last line of defensethe last ditch-it is evident that a yielding here implies not a mere shifting of line, but a change of base; not a readjustment of details only, but a reconstruction of Christion theology. This, I believe, is indeed necessary. There can be little doubt in the mind of the thoughtful observer that we are even now on the eve of the greatest change in traditional views that has taken place since the birth of Christianity. But let no one be greatly disturbed thereby. For then, so now, change comes not to destroy but to fulfil all our dearest 
hopes and aspirations; as then, so now, the germ of living truth has, in the course of ages, become so encrusted with meaningless traditions which stifle its growth that it is necessary to break the shell to set it free; as then, so now, it has become necessary to purge religious belief of dross in the form of trivialities and superstitions. This has ever been and ever will be the function of science. The essentials of religious faith it does not, it cannot, touch, but it purifies and ennobles our conceptions of Deity, and thus elevates the whole plane of religious thought. 


\section{CHIPTER XLIII \\ THE STATISTICAL STUUY OF VARIATION \\ STITISTICAL METHODS}

The pioneer workers in the application of statistical methods to biological study were Sir Francis Galton and his leading disciple, Karl Pearson. The use to which Galton and Pearson put their statistical methods appears later in this chapter. For present purposes we may limit our study of biometry to that part of it which has to do with variation. We have already discussed fluctuating variations, the small plus and minus differences that exist between the different members of the same species or variety. This was the type of variation that Darwin considered the main raw material of evolution. Examples of fluctuating variations are not far to seek. Pearson cites as an illustration of fluctuating variation the number of veins in two sets of beech leaves, each set from a different tree:

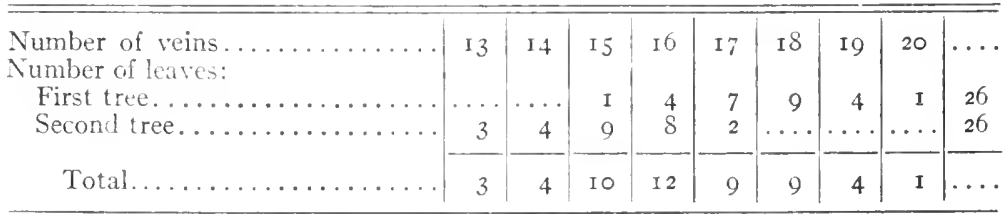

It will be noted that though there were r6-veined leaves on both trees, as well as I5-and I7-veined, the general distribution is quite different in the two trees. In the first tree the most frequently occur. ring type is the $\mathrm{I} S$-reined leaf, and the other types may be said to fluctuate about this (the "mode"). In the second tree the mode is the I5-reined type and the other types fluctuate about it. It will be seen also at a glance that the types that differ most from the mode are the least frequent and that those nearest the mode are the most frequent.

Some years ago the writer had occasion to study the heredity of scale numbers in the banded region of the nine-banded armadillo. As a preliminary to this sturly it was necessary to know the degree and 
extent of variability present in the species. Consequently 508 individuals were taken at random and their scale or scute number counted. It was found that the total number of scutes in the nine bands ranged from 5 I 7 to 625 and that the commonest number was about 557 . In order to get a definite idea of the distribution of the different types,

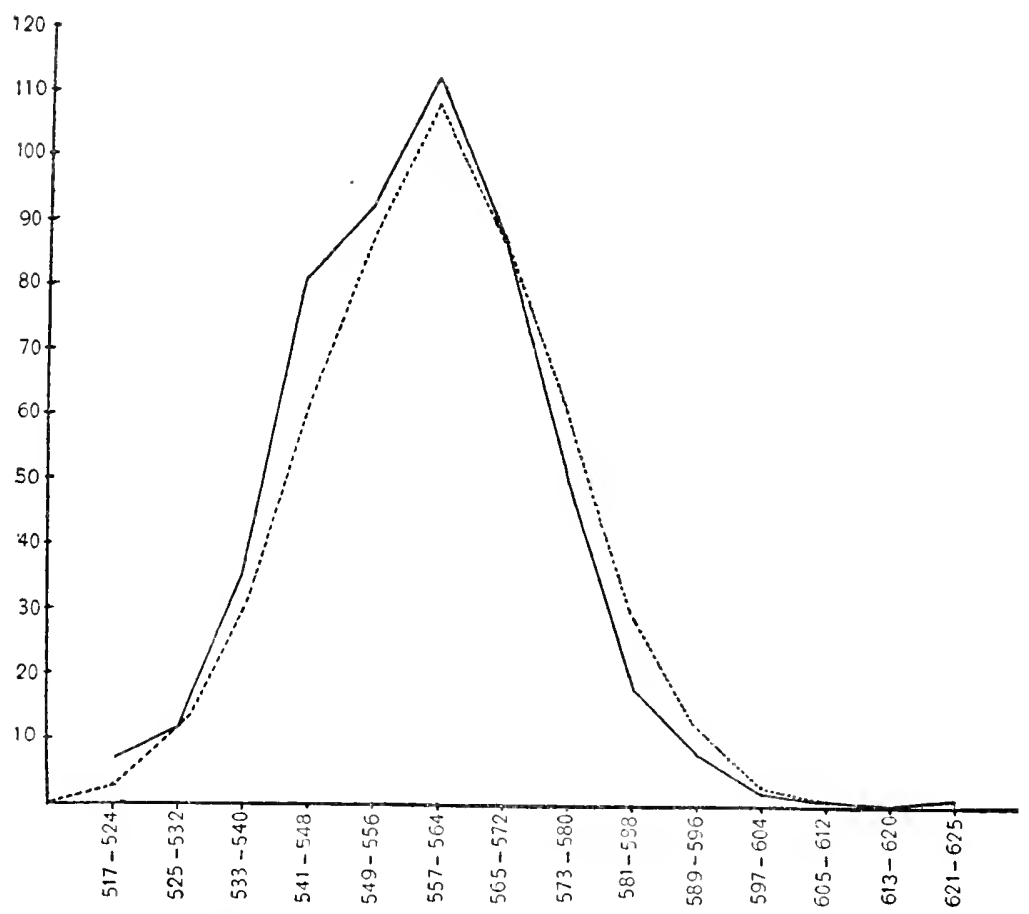

FiG. 92.-Polygon of variation for the total number of scutes in the nine bands of the armadillo (Dusypus now minctus), as determined by the seriation of 5o8 individuals. Class range $=8$ scutes. The solid line represents the observational, and the broken line the theentical, normal curve. The abscissae refer to the number of scutes, and the ordinates to the number of individuals. (From Nciman.)

they were arranged in a variation polygon as shown in Figure 92. On the abscissa are arranged groups including individuals between 517 and 524 scutes inclusive, those between 525 and 532 , those between 533 and 540 , on up to a group of those from 621 to 625 . All of these except the last included a small class with a range of 8 scutes. This arranging in classes was essential, for without it there would have been 
113 classes and a very irregular and meaningless distribution. On the ordinate we find by tens the numbers of individuals in each class. It will be noted that the solid line is one connecling the points of intersection between the class of scute numbers and the number of individuals in these classes. The dotted line represents an ideal fluctuating variation curve, which is practically a mathematical curve of chance. The closeness of fit between the actual and the theoretical curve is very good. The mode is the class including individuals with a scute count of $557^{-64}$, and there is a fairly even balance of individuals in the plus and the minus directions. It seems fairly evident from examination of the curve that the individuals with $61_{3} 3$ scutes and over are beyond the limits of the theoretical distribution. A further study of these exceptional individuals shows that they are mutations, in which a splitting up of single scutes into paired and twinned scutes has taken place to such an extent as greatly to increase the total number of scutes.

From the data used in constructing this variation polygon several significant constants may be obtained. The "arithmetical mean" (average number of scutes in the entire 508 individuals) is 558.2 . The "median" or halfway point between the extremes is $55^{8}$. The "mode" or most frequently occurring single type is 557 (the theoretical value being 557.6).

If we wished to compare a large group of parents with a large group of offspring, or if it were necessary to compare the armadilios of Texas with those of Mexico or Brazil, we could compare them as to mean, median, and mode, and also as to the shape of the polygon of variation. This would give us a very good idea as to whether or not the old species present in these three regions is tending to evolve in different directions under different conditions of life.

Instead of having to depend on the visual comparison between the variation polygon of two or more different populations, we can reduce the facts about the distribution of the different types about the mean or mode to a simple arithmetical constant, called the "standard deviation," which is usually given the symbol $\sigma$. This constant is computed as follows:

$$
\sigma=\sqrt{\frac{2\left(x^{2} \cdot f\right)}{n}}
$$

In this formula $x$ represents the leviation of each class from the arithmetical mean; $f$, the number of individuals in each separate class: 2 , the sum of all the classes, and $n$, the total number of individuais 
By the use of this formula we have calculated the standard deviation $(\sigma)$ of the individuals represented in Figure 92 to be $14.89 \pm$ 0.31 scutes. This means that the average deviation from the mean is about $r_{4} .89$ scutes.

The $\pm 0.3 \mathrm{I}$ scutes is called the "probable error" and means that the figure $\mathrm{I}_{4} .89$ is inaccurate to the extent of being $0.3 \mathrm{I}$ scutes too high or too low. The probable error is an essential feature of such computations, as, without it, we would not be able to rely on the significance of small differences. Suppose, for example, we should find that the armadillos of Brazil had a standard deviation of $15.43 \pm 0.44$ scutes, we might conclude that the variability of the Brazilian individuals was 0.54 scutes greater than that of the Texas individuals. In view of the fact, however, that the probable error in one case is $\pm 0.3 \mathrm{I}$ scutes and in the other \pm 0.44 scutes we would have to conclude that there was no significant difference. In actual practice it has been decided that unless the actual difference between two constants is about 4.6 times as great as the probable error, the difference is not significant.

The method of determining the probable error of any calculated constant is difficult to understand, but easy to put into practice. For example, the formula for calculating the probable error of the standard deviation is as follows:

$$
E \sigma=\frac{ \pm 0.6745 \sigma}{\sqrt{2 n}}
$$

where $E$ is the probable error, and $n$ the number of individuals. It will be seen that the probability of error diminishes steadily with the increase in number of individuals studied. With very large numbers the error due to what is known as "random sampling" practically disappears.

\section{BIMODAL AND MULTIMODAL CURVES}

If we confine our biometrical studies to homogeneous populations, we get only fairly simple monomodal curves that resemble the normal curve of variation, which is a curve of chance; but when we study ordinary wild populations, we frequently find that we are dealing with a complex of several races, each of which has its own mode and standard deviation. Batteson has given us a classic example of this type of phenomenon. In studying the length of pirchers in the common earwig (Forficulata auricularia), he found that he got a two-humped or bimodal curve as shown in Iigure 93. It then became evident that there were two distinct varieties as figured above. Such studies have frequently revealed the heterogeneity of supposedly homogeneous 
populations. Opinion differs as to the significance of these finclings. The more optimistic erolutionists look upon such instances as that of Batteson's e etrwigs as visual demonstrations of a species actually splitting up into two or more species. It seems quite likely that one of these types is a succesiful mutant type that has not fully segregated itself as a true species from the parent-type. Another view of the significance of bimodal curves is that the condlition results from hybridization and that the bimodality is the result of the segregation of dominant and recessive types.
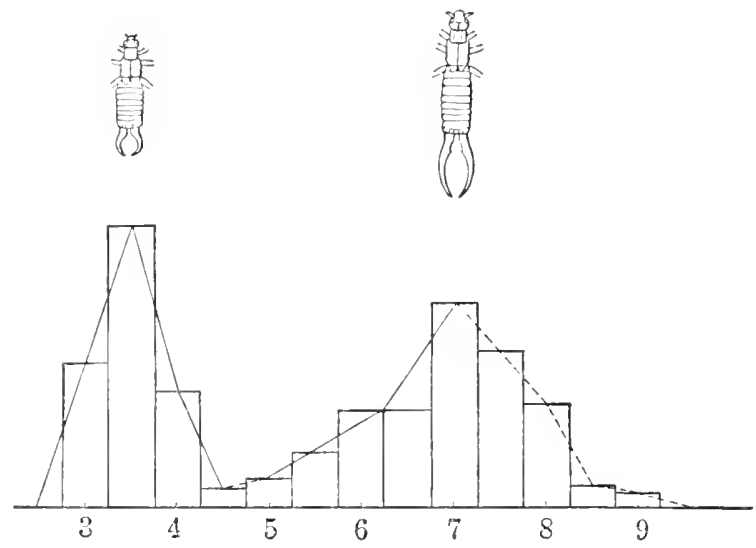

Fis. 93.-Dimodal polygon plotted from data on the earwis. Nean types (C. indicated above corresponding modes. Numbers below the base line indicate length of pincers in millimeters. (From Bateson and Johansen.)

THE COEFFICILNT OF CORRLLATION

Only one more biometrical constant need be mentioned here: the "coefficient of correlation." It is often necessary to discover the exact relation that exists between two sets of variables in order to discoser whether they are totally indepentent or partially correlated with each other. For example, we have found that there is a close corrclation between stature and head length in man, also between color of hair and color of eyes; but it is very important to be able to reduce the degree of correlation to a simple arithmetical constant. This is called the "coefficient of correlation" (commonly expressed as $r y$, where $x$ is one variable and $y$ the other). The formula for computing $r_{x y}$ is as follows:

$$
r_{x y}=\left(\begin{array}{c}
\Sigma\left(d_{x} d_{y}\right) \\
n
\end{array}\right)\left(\frac{\mathrm{I}}{\sigma_{x} \sigma_{y}}\right),
$$


where $d$ represents the actual deviation and $\Sigma$ the sum, $n$ the number of individuals; $\sigma$ the standard deviation.

"Correlation tables" show graphically whether or not there is correlation. If, as in Figure 94, we want to find out what is the relationship between total yield of oats and number of culms to the plant, we may make a table with subject classes arranged perpendicularly, and the relative classes, horizontally. If the individuals tend to group themselves about a diagonal ranging from upper left- to lower righthand corners, the amount of correlation is quite marked. Complete correlation would be represented by a single line of points along this diagonal. No correlation would be shown by random distribution

\begin{tabular}{|c|c|c|c|c|c|c|c|}
\hline & 2 & 3 & 4 & 5 & 6 & 7 & \\
\hline $0-1$ & 3 & & & & & & 3 \\
\hline $1-2$ & $2 s$ & 19 & 3 & & & & 50 \\
\hline $2-3$ & 18 & 66 & 20 & 1 & & 1 & 106 \\
\hline $3-4$ & 1 & 42 & 58 & 7 & 1 & & 109 \\
\hline $4-5$ & & 7 & 59 & 11 & 3 & & 80 \\
\hline $5-6$ & & & 26 & 14 & 2 & & 42 \\
\hline $6-7$ & & & & 4 & 3 & & 7 \\
\hline $7-8$ & & & 1 & 1 & & & 2 \\
\hline $8-9$ & & & & & 1 & & 1 \\
\hline & 50 & 134 & 167 & 38 & 10 & 1 & 400 \\
\hline
\end{tabular}

FIG. 94.-Correlation table of 400 plants of Sixty-Day oats. Total yield of plant in grams, subject. Number of culms per plant, relative. 1910. Coefficient of correlation $=0.7$ I2 \pm 0.017 . (From Love and Lcighty, I9I.)

over the whole rectangle. Inverse correlation would tend to give a grouping about a diagonal ranging from the upper right- to lower left-hand corners.

In the particular correlation table used for illustration, the coefficient of correlation $\left(r_{x y}\right)$ turns out to be 0.7 I $2 \pm 0.017$. Since complete correlation would be $\mathrm{I}$, the degree of positive correlation is very high, as we might expect. The correlation table was used quite effectively by Galton, as we have already shown in chapter xxxvi. 


\section{CHAPTER XLIV}

\section{THE PHYSICAL BASIS OF MENDELISM ${ }^{z}$}

ERNEST B. BABCOCK AND ROY E. CLAUSEN

Recent investigations in heredity have focused attention upon the chromosome mechanism as the physical basis for the segregation and recombination of the units of Mendelian inheritance. The importance of cytological phenomena to students of genetics is admirably summed up by $\mathrm{E}$. $\mathrm{B}$. Wilson in the brief statement that "heredity is a consequence of the genetic continuity of cells by division, and the germ cells form the vehicle of transmission from one generation to another." It is appropriate, therefore, to introduce the subject of Mendelism with a formal and brief treatment of the chromosome mechanism and its mode of operation, on the one hand, in the building up of the body from the single cell with which the individual begins its existence, and, on the other hand, in the production of germ cells when the individual reaches the reproductive period of its life cycle. It is the purpose of this chapter merely to deal with the fundamental facts of cytology which are necessary to an understanding of the connection between cell behavior and Mendelian phenomena. Details unessential to such an understanding, however well established cytologically, will not be dealt with in this treatment to the end that the cardinal points may be presented as simply and as clearly as possible.

The chromosomes. - With few exceptions the number of chromosomes in the cells of any individual is constant and characteristic of the species to which the individual belongs. Thus it is characteristic of Drosophila ampelophila that the cells contain eight chromosomes. In maize the cells contain twenty chromosomes, in wheat sixteen, and in man forty-eight, and so on through the entire plant and animal kingdoms.

Not only is the number of chromosomes in a particular species constant, but the chromosomes themselves possess a definite individuality. Man and tobacco have cells with the same number of chromosomes. It is needless to point out that these chromosomes,

IFrom E. B. Babcock and R. E. Clausen, Genetics in Reiation to Agriculture (copyright 1918). Used by special permission of the publishers, The McGrawHill Book Company. 
however, are qualitatively very different. Similarly within the species the chromosomes are not all alike; on the contrary, especially in certain forms, they exhibit very marked differences in size and shape. This is peculiarly well illustrated in Drosophila as shown in Fig. 95. Here it is possible to recognize in the female two large pairs of curved chromosomes very similar in size and shape. There is also a very small pair of chromosomes, and finally there is a pair of straight ones about two-thirds as long as the large curved chromosomes. In the male the same relations hold except that instead of the pair of straight chromosomes there is a pair consisting of one straight and one somewhat larger hooked chromosome. The significance of this difference in chromosome content in the sexes will be pointed out in a consideration
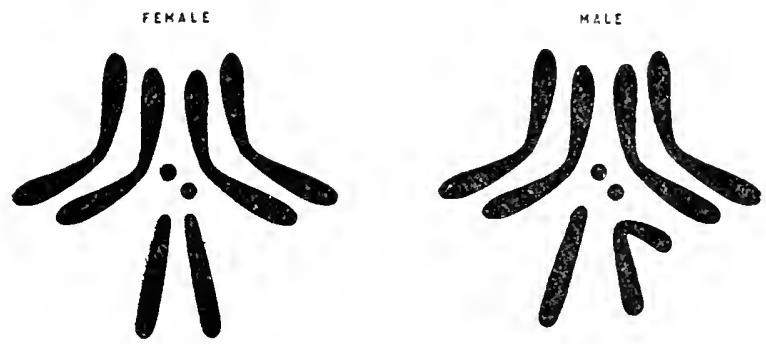

FIG. 95--Diagram showing the characteristic pairing, size relations, and shapes of the chromosomes of Drosophila melanogister. In the male an $X$ and a $Y$ chromosome correspond to the $X$ pair of the female. On the basis of $X$ roo the length of each long autosome i 59, of each small autosome i2, and of $V^{\prime}$ i I 2, of the long arm of $Y 7 \mathrm{I}$, and of the short arm of $Y_{4}+\mathrm{I}$. (From Babcock and Clausen, after Bridges.)

of the inheritance of sex. The pair of straight chromosomes we call the sex or $\mathrm{X}$-chromosomes, the unequal mate of the $\mathrm{X}$-chromosome in the male of this species is called the $\mathrm{Y}$-chromosome. The other chromosomes are called autosomes when it is desired to distinguish them as a class from the sex chromosomes. Drosophila is not unique in possessing chromosomes of such characteristic shapes and sizes; but more and more as cytology advances it is becoming possible to distinguish chromosomes, and to recognize them at every cell division.

Moreover, the characteristic paired relations which exist among the chromosomes of Drosophila are of general signiifance. When mature germ cells are formed in an individual, reduction divisions occur by means of which the chromosome number is reduced in the germ cells to one-half that characteristic of the body cells. Thus the 
germ cells of Drosophila contain four chromosomes as the result of it reduction which takes place in such a manner that each germ cell cint. tains one member of each pair of chromosomes. As a consequenc: the germ cell of Drosophila contains two large curverl autosomes, representing the two pairs of these chromosomes, one small autosome, and one $\mathbf{X}$ - or one $\mathrm{Y}$-chromosome. The same thing is true for other species of plants and animals-in the reduction divisions the chromosomes are distributed in such a manner that each germ cell receives one member of each pair of chromosomes. It follows from this that in general a definite number of pairs of chronosomes is characteristic of the body cells of individuals of a given species, and, taking the chromosomes by pairs, one member of each pair is cierived irom one parent and the other from the other parent.

From the standpoint of interpretation the chromosomes are aggregates of chromatin material which in itself is definitely and highly organized. Our conceptions of this feature of cell organization are based on appearances of the cytological preparations from certain of the more favorable plants and animals and further interpreted by investigations on heredity. Accordingly the entire chromatin content of the nucleus is regarded as made up of a definite number of individual chromatin elements called chromomeres. The number of chromomeres in a cell of any species must run into the thousands. A certain definite group of these elements make up each chromosome, and at every cell division this chromosome is reformed from the same group of chromomeres, but the chromosome is definitely organized with respect to the position or locus occupied by each chromomere. At certain stages in the history of chromosomes, they are simply lines of chromomeres, very much like single strings of beads with each bead corresponding to a chromomere. Now it appears probable that all the chromomeres in a chromosome are different, as though our string of beads had no duplicates throughout its length. Moreover, each chromomere has a definite place or locus in the particular chromosome in which it belongs and it is always found at that particular locus. The chromomeres of this discussion are identified with the factors of Mendelian heredity, and how closely this concertion of the nature of chromatin and its complex organization corresponds to the modern view of Mendelian phenomena will be pointed out as each new phase of Mendelism is taken up.

Somatic cell division.-The phenomena of cell division (called mitosis) are represented in outline in Fig. 96 , for a species having four 
chromosomes in its body cell. Bearing in mind the description which has just been given of the organization of the chromatin material we may follow the steps involved in mitosis as they are outlined in this figure. In the "resting" cell at $A$ the chromatin is scattered throughout the nucleus in clumps or knots loosely strung together to form an irregular network. As the cell prepares for division the chromatin elements appear in more definite form until at $B$ the chromomeres have
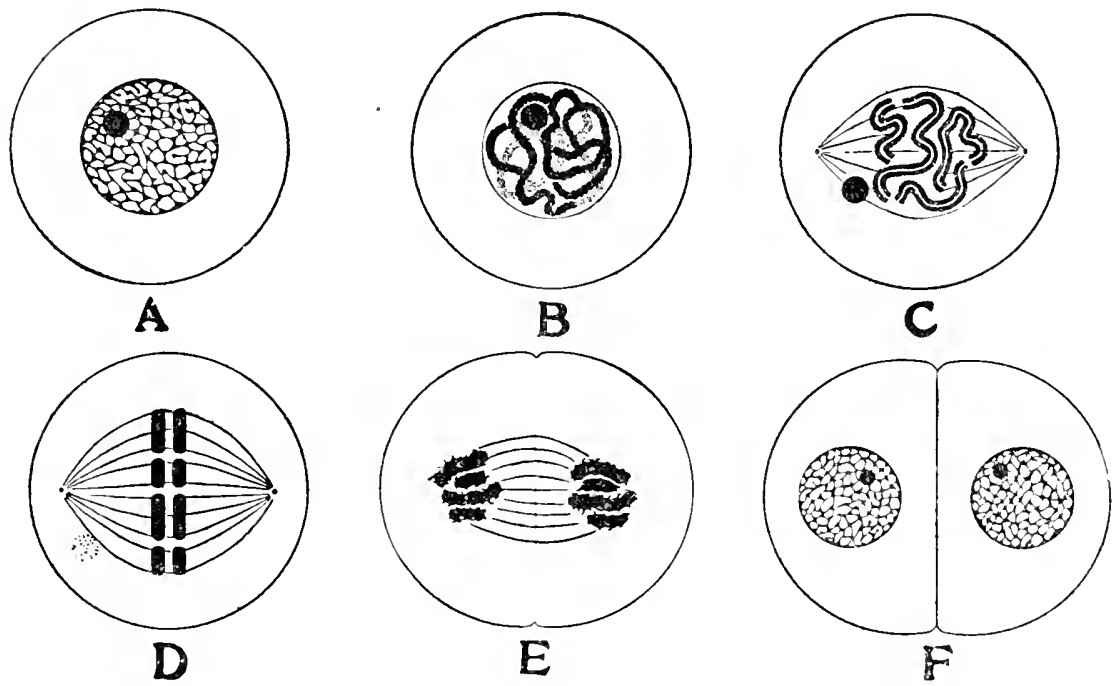

FIG. 96.-Diagram of mitosis in a species having four chromosomes in its cells. $A$, the "resting" cell; $B$, formation of the spireme thread; $C$, longitudinal division of the spireme thread and transverse segmentation into four chromosomes; $D$, separation of the daughter chromosomes formed by longitudinal splitting of spireme thread; $E$, beginnings of nuclear reconstruction and division of the cell body; $F$, cell division complete and daughter nuclei in the "resting" stage. (From Babcock and Clauscn.)

arranged themselves in a single row in a long continuous spiremethread. This spireme-thread may be considered to be made up of the four chromosomes united end to end with the chromomeres arranged in a linear series. As mitosis progresses to the next stage represented at $C$, each chromomere of the spireme-thread divides into two, so that a double spireme-thread results from the longitudinal splitting of the original thread. Both parts of the thread are quantitatively and qualitatively equal, for, by the splitting of all the chromomeres both of the 
threads come to possess all of the individual elements of the original spireme threar. Following the splitting of the chromomeres and the formation of a double spireme, the spireme-thread contracts and segments transversely forming four louble chromosomes, the number characteristic of the cells of this individual. This is the stage shown at $C$ where also is shown the origin of the spindle, a part of the mechanism in mitosis. The chromosomes now still further contract until they assume their characteristic shapes and sizes. They next appear in an equatorial position on the spindle as shown at $D$, where the two pairs of double chromosomes, one larger and one smaller, are diagrammed and the nucleolus, the large black body of the previous steps, is shown cast out and degenerating. The daughter chromosomes of each pair now separate from each other until at $E$ they have moved nearly to the opposite poles of the spindles and are beginning to fray out and seemingly to lose their identity. At this stage actual division of the cell body has begun. Finally at $F$, the chromosomes have completely lost all appearance of their identity, the chromatin material is distributed thruout the nucleus as in the original cell shown at $A$, and the nucleolus has been reformed in each nucleus. Division of the cell-body has resulted in two daughter cells, each of which, so far as chromomeres are concerned, contains exactly the same chromatin elements as the original cell.

There are many variations in this process particularly in the order of occurrence of the steps, but these variations in nowise modify the essential fact of mitosis which is that the chromatin material of the cell is converted into a thread which splits thruout its entire length into two halves so that the daughter nuclei receive exactly equivalent portions of chromatin material. This precise division of the chromatin is brought about by a division of each chromomere so that not only do the daughter nuclei receive equivalent portions of chromatin but these portions are also equivalent qualitatively to the entire chromatin content of the mother cell. By this method then each of the cells of the body finally comes to possess not only the whole number of chromosomes contributed by the two parents, but also the entire set of chromatin elements which it received from them. The extreme care with which the cell mechanism partitions the chromatin material in each successive cell division is in itself eloquent testimony of the fundamental importance of this material.

The production of germ cells. - In the production of germ cells a different set of phenomena occur which result in a reduction of this 
number of chromosomes to one-half that characteristic of the somatic cells. Preceding the actual reduction division the chromatin passes through a complex series of steps which may be included under the term synapsis. (This term is sometimes applied in a specific sense to the pairing of homologous chromosomes and sometimes to the contraction of the chromatin threads in the conjugation stage.) The essential steps in the prereduction process are shown in outline in Fig. 97. At 1 is diagrammed a "resting" nucleus at the completion of
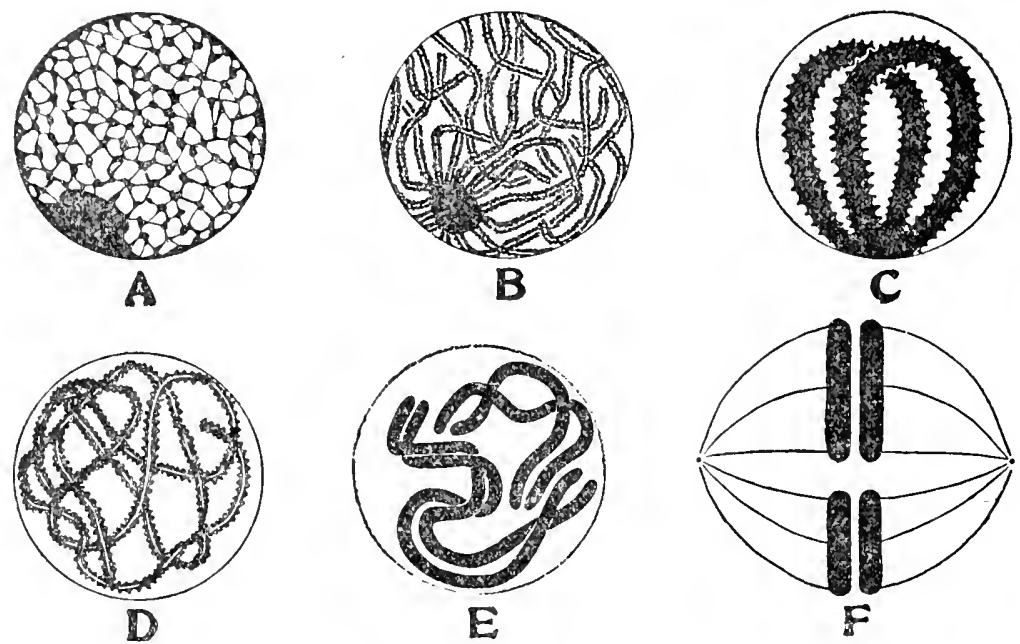

Fig. 07.-The reduction division as represented for a species whose diploid number is four. 1 , "resting" nucleus of a primary germ cell; $B$, formation of paired threads of chromomeres; $C$, conjugation of homologous chromosomes (synapsis); $D$, loosening of the synaptic knots; $E$, condensation of the chromosomes and disappearance of the nuclear membrane; $F$, homologous chromosomes about to pass to opposite poles, thus giving each secondary germ cell a member of each pair and one-half the somatic number. (From Babcock and Clauscn.)

the multiplication divisions in the germ plasm. As a result of the exact type of mitosis which has been outlined above it contains the full number of chromosomes characteristic of the species. The chromatin of the nucleus next becomes organized into threads of chromomeres which pair as shown at $B$. In this diagram the paired threads are taken to represent homologous chromosomes, and the opposite chromomeres of the two chromosomes. The pairer threads contract and 
fuse along their entire length giving the figure diagrammerl at $C$ in which the two loops represent two pairs of homologras chromnsomes in the conjugation stage, the essential step in synapsis. Following this stage the two contracted loops of chromatin split lengthwise and unravel in somewhat the manner shown in $D$. These filaments contract again forming the intertwined pairs of chromosomes shown at $E$, and the nuclear membrane thereupon begins io disappear. Further contraction and the formation of a spindle results in the reduction figure at $F$, the significant feature of which is the fact that each of the daughter nuclei resulting from this division receives only two chromosomes instead of the four which the original cell at $A$ contained. Since the original cell contained one pair of larger and one pair of smaller chromosomes, the daughter cells which are formed each receive one larger and one smaller chromosome.

Cytological investigation is not yet in agreement as to the interpretation of synapsis especially as to the manner in which the phenomena therein concerned are connected with preceding mitotic divisions. Considering certain cytological investigations and the results of research in heredity together, it appears that the threads which pair in stage $B$ renresent pairs of chromosomes with homologous chromomeres occupying corresponding positions along their entire length. Likewise the contraction stage at $C$ is taken to represent a conjugation of the members of pairs of chromosomes which later again separate. Other cytological evidence indicates that in some forms the conjugation of pairs of homologous chromosomes is brought about in another way. However, the essential fact is the same in cither case. In the reduction figure the nembers of each pair of chromosomes are dis tributed to the opposite poles of the spindle so that the daughter nuclei received only one member of each pair.

The significance of synapsis lies in the conjugation of homologous chromosomes. In the mitoses which have preceded this particular division, the chromosomes wcre each time conceived to be reformed from the identical group of chromomeres which they contained originally. In symasis, however, as shown at $E$ there is a certain amount of intertwining of the pairel threads and in the unraveling of the chronosomes after the contraction stage there is likewise a twisting of the filaments about each other. The indications are, therefore. that in symapsis there is a possibility of interchanes of chromatin material between the members of a pair of homologous rtiromosonies. In all cases, however, in order to uphold our conception of the definite 
organization of the chromosomes with respect to the chromomeres which they contain, this interchange of material must involve exactly equivalent portions of the two chromosomes. The chromosomes of

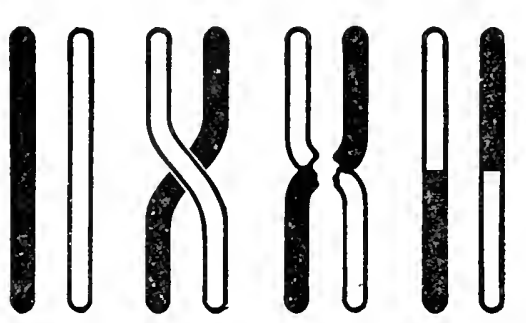

FIG. 98.-Diagram of chromatin interchange between homologous members of a pair of chromosomes. (From Babcock and Clausen, after Huller.) the reduction division shown at F may not, therefore, be identical with the four originally present in $A$, but may represent various combinations of portions of both members of a particular pair of chromosomes. The results of such interchange between members of homologous pairs of chromosomes is shown in Fig. 98 . At the left is shown a pair of chromosomes, one in outline, the other in full black. In the middle the steps in chromatin interchange are diagrammed and finally at the right this interchange results in a pair of chromosomes each of which is made up of parts of both members of the original pair of chromosomes. Various combinations may result depending on the points at which interchange takes place, but in every case the exchange involves corresponding portions of the two chromosomes.

Independent distribution of chromosomes.-In Fig. 99 are illustrated diagrammatically the chromosomes of Drosophila, with particular reference to their size and form relations and to their characteristic pairing in the cell. One member of each of these pairs of chromosomes was contributed by the female parent and one member by the male parent. In the reduction divisions these chromosomes are separated so that each germ cell contains one member of each pair of chromosomes. The simplest condition which could obtain is that of independent distribution in each pair of chromosomes such that the particular member of one pair which went to a given pole of the reduction spindle would have no influence on the distribution of the members of any other pair. Such independent distribution of chromosomes appears to be actually the type followed in reduction. As a consequence the germ cells conta in various combinations of chromosomes with respect to their original parental derivation. In Fig. 99 the types of combinations of maternal and paternal chromosomes and their mode of derivation in Drosophila are shown diagrammatically. Two germ cells, one from the female with the chromosones in outline, 
and the other from the mate with the chromosomes in full black, unite to form the fenale zrgote shown in the midtle of the figure. The combinations of matemal and patemal chromosomes which result in the production of germ cells in such an individual are shown diagram-
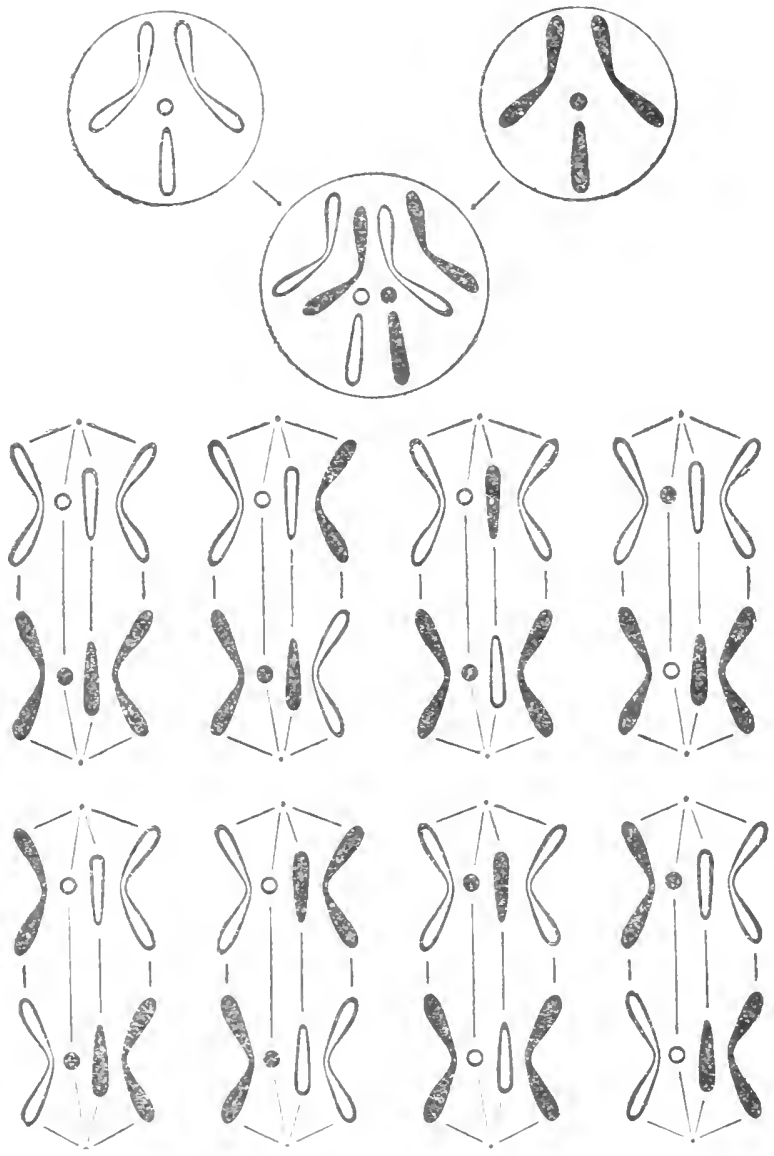

FIG. 99-Diarram showing ansequences of independent sexrewation of

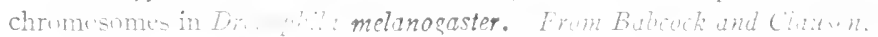

matically in the fower portion of the figure. There are eisht different ways in which the chronusumes nay be grouped in the retuction figures and on the busis of chance any one of these types is as likely to occur as any other. As a result there are sixteen pusithe combinations of chromosomes in the germ cells with respect to the original 
derivation of the chromosomes, whether from the female or from the male parent. This of course represents only the total number of possible combinations of entire chromosomes. By exchange of chromatin material between homologous chromosomes resulting in the formation of combination-chromosomes the number of actual combinations is greatly increased.

The number of chromosome combinations resulting from independent distribution is that number possible when each pair of chromosomes is consillered separately, and every combination has an equal chance of occurrence. With a form having but two pairs of chromosomes there would be only four possible combinations, three pairs would give eight, four pairs sixteen, and in general the number of possible combinations is given by the expression $2^{n}$ in which $n$ is the number of pairs of chromosomes in the individual in question. In tobacen which has 24 pairs of chromosomes the number of possible combinations in the germ cells reaches the enormous total of $16,777,-$ 216. This means that in the formation of zygotes in a self-fertilized tobacco plant the actual parental combinations, i.e., combinations identical with those of the germ cells which united to form the individual in question, occur only twice in over sixteen million times, and this proportion is still further lessened when the interchange of chromatin material between homologous chromosomes is taken into account. The condition of independent distribution although simple in itself results in a rapid increase in complexity with the increase in the number of pairs of chromosomes involved.

Chromosomes and sex in Drosophila.-The relation between inheritance and the chromosome mechanism is perhaps most simply displayed in the inheritance of sex in those animal forms in which the sexes occur in approximately equal proportions. Thus in Drosophila as indicated in Fig. 100 there are three pairs of autosomes which are alike in both the male and the female. The remaining pair of chromosomes, however, differ, for the female possesses two $\mathrm{X}$-chromosomes whereas in the male a single $\mathrm{X}$-chromosome is paired with a $\mathrm{Y}$-chromosome and these differences are characteristic of all normal males and females of this species. The bearing of these differences on the inheritance of sex is shown diagrammatically in Fig. 100. Beginning with the parents, the diploid number is shown in the circles representing the female and the male.

In the female the three pairs of autosomes are outlined and the $X$-chromosomes only are drawn in black to indicate that they are the ones primatrily concerned in the determination of sex. Similarly in 
the male the theer mairs of autosomes which are exictly like those in the femate are oudinet. but the X-chromome and the H-chromosome are drawn in black. The reflaction division in the ferale results in a
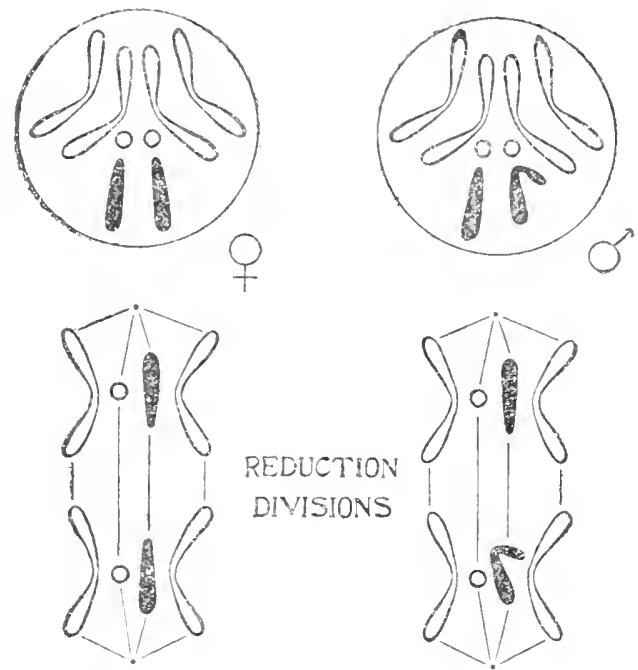

REDUCTION
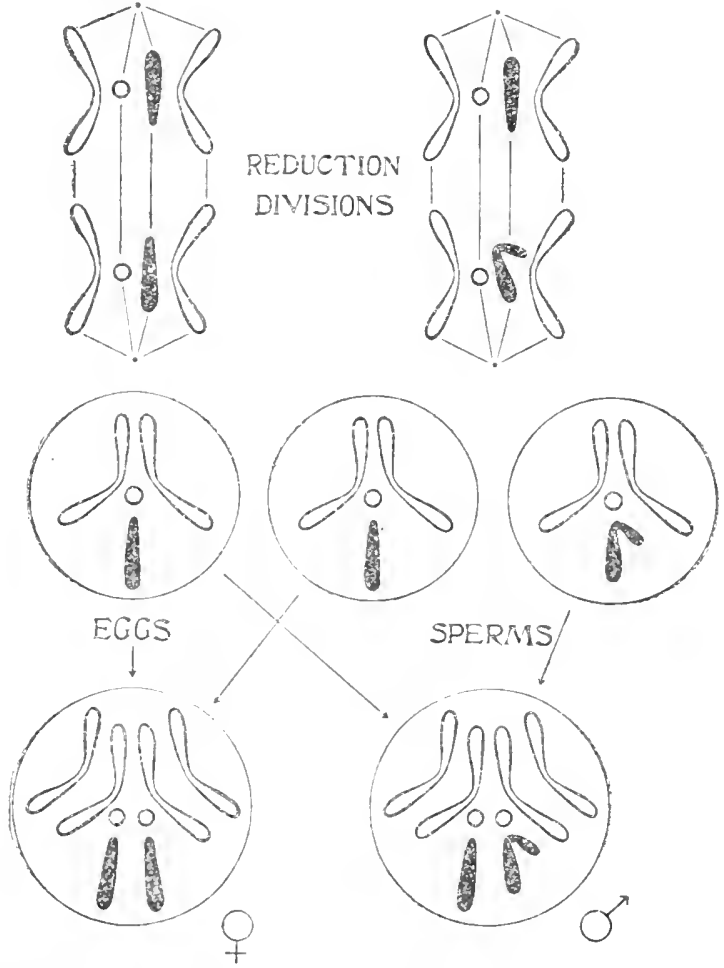

SPERMS/

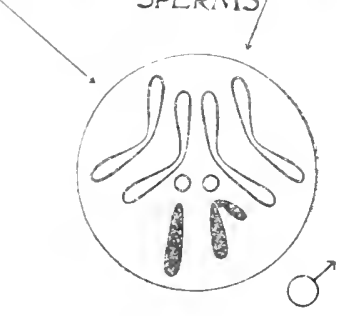

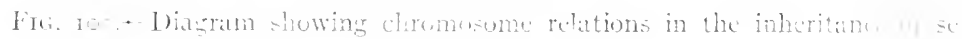

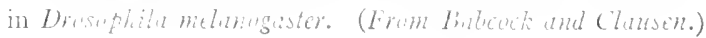

separation of the member of each par of chromosomes, so that ered !

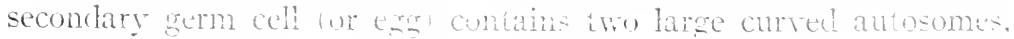

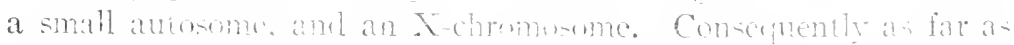

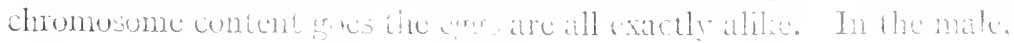


however, the separation of the members of the chromosome pairs results in sperms half of which contain an X-chromosome and half a $\mathrm{Y}$-chromosome in addition to the three autosomes. The reduction division in the male insures an equality in numbers for the two kinds of sperm cells and the chances that either kind of sperm will fertilize an egg-cell are equal. By this arrangement the numerical equality of the sexes is maintained. When, later, the egg cells of the female are fertilized by the sperm cells of the male, as shown in the lower portion of the figure, half of them being fertilized by sperm cells which contain an X-chromosome will give females, and half uniting with sperm cells which contain $Y$-chromosomes will produce males. The inheritance of sex in Drosophila provides a beautiful illustration of the parallel behavior of the chromosome mechanism and a somatic difference, in this case, sex.

To recapitulate, the essential phenomena of cell behavior which furnish the mechanism for the distribution of hereditary factors are these:

r. Every species is characterized by a refinitely organized group of chromosomes. The chromosomes occur in pairs, in each of which one member is derived from each parent. In ordinary somatic mitosis the distribution of chromatin is such that each daughter cell receives a full complement of chromosomes which are equivalent qualitatively to those of the mother cell.

2. In germ cell formation the homologous chromosomes conjugate during synapsis, then separate, and pass into a division figure in which entire homologous chromosomes are opposed to each other. The resulting reduction division gives daughter cells with half the number of chromosomes characteristic of the species, the half number being made up of one member of each pair of chromosomes. During synapsis there is an opportunity for the members of a pair of chromosomes to exchange chromatin material. When such interchange takes place equivalent portions of chromosomes both qualitatively and quantitatively are involved. In the reduction division segregation within one pair of chromosomes is entirely independent of that of any other pair so that the combinations of parental chromosomes in the germ cells represent all those to be expected on the basis of chance distribution.

The student should constantly endeavor to harmonize this conception of the distributing mechanism of the chromatin material with the Mendelian interpretations of hereditary phemomena which will be presented in what follows, to the end that he may obtain a clear and definite idea of the interrelations between the known facts of heredity and cell behavior. 


\title{
CHAPTER XLV
}

\section{NATURAL SELECTION}

\author{
CHARLES DARWIN
}

INTRODUCTORY NOTE.-This entire chapter is made up of carefully chosen oassages from Darwin's Origin of Species. So much has falsely been called "Darwinism" that it is well for the reader to have a statement of Darwin's views in his own words. Every student of evolution should read the whole of the Origin of Species. It is all so good that one finds it difficult to leave out any thing. 'The following excerpts will, we believe, give the gist of natural selection.

We present first certain of the ideas that underlie or are postulates of the theory; then the theory itself is presented; the theory of sexual selection interpolated; and then follow examples of the way in which adaptations are accounted for by natural selection. Darwin's own statement of the most serious difficulties and objections to the theory, and his answers to these, bring this chapter to a close.

\section{FOUNDATION STONES OF NATURAL SELECTION}

DARWIN'S OWN ESTIMATE AS TO THE RÓLE OF NATURAL SELECTION IN EVOLUTION

No one ought to feel surprised at much remaining as yet unexplained in regard to the origin of species and varieties, if he make due allowance for our profound ignorance in regard to the mutual relations of the many beings which live around us. Who can explain why one species ranges widely and is very numerous, and why another allied species has a narrow range and is rare? Yet these relations are of the highest importance, for they determine the present welfare and, as I welieve, the future success and modification of every inhabitant of this world. Still less do we know of the mutual relations of the innumerabie inhabitants of the world during the many past geological epochs in its history. Although much remains obscure, and will long remain obscure, I can entertain no doubt, after the most deliberate study and dispassionate judgment of which I am capable, that the view which most naturalists until recently entertained, and which I formerly entertained-namely, that each species has been independently created-is erroneous. I am fully convinced that species are not immutable; but that those belonging to what are called the same genera are lineal descendants of some other and generally extinct species, in the same manner as the acknowledged varieties of any one species are the descendants of that species. Furthermore, I am convinced that Natural Selection has been the most important, but not the exclusive, means of modification. 


\section{EFFECTS OF HABIT AND OF THE USE OR DISUSE OF PARTS; CORRELATED VARIATION; INHERITANCE}

Changed habits produce an inherited effect, as in the period of the flowering of plants when transported from one climate to another. With animals the increased use or disuse of parts has had a more marked influence; thus I find in the domestic duck that the bones of the wing weigh less and the bones of the leg more, in proportion to the whole skeleton, than do the same bones in the wild-duck; and this change may be safely attributed to the domestic duck flying much less, and walking more, than its wild parents. The great and inherited development of the udders in cows and goats in countries where they are habitually milked, in comparison with these organs in other countries, is probably another instance of the effects of use. Not one of our domestic animals can be named which has not in some country drooping ears; and the view, which has been suggested that the drooping is due to disuse of the muscles of the ear, from the animals being seldom much alarmed, seems probable.

Many laws regulate variation, some few of which can be dimly seen, and will hereafter be briefly discussed. I will here only allude to what may be called correlated variation. Important changes in the embryo or larva will probably entail changes in the mature animal. In monstrosities, the correlations between quite distinct parts are very curious; and many instances are given in Isidore Geoffroy St. Hilaire's great work on this subject. Breeders believe that long limbs are almost always accompanied by an elongated head. Some instances of correlation are quite whimsical: thus cats which are entirely white and have blue eyes are generally deaf; but it has been lately stated by Mr. Tait that this is confined to the males. Color and constitutional peculiarities go together, of which many remarkable cases could be given amongst animals and plants. From facts collected by Heusinger, it appears that white sheep and pigs are injured by certain plants, whilst dark-colored individuals escape: Professor Wyman has recently communicated to me a good illustration of this fact; on asking some farmers in Virginia how it was that all their pigs were black, they informed him that the pigs ate the paint-root (Lachnanthes), which colored their bones pink, and which caused the hoofs of all but the black varieties to drop off; and one of the "crackers" (i.e., Virginia squatters) added, "we select the black members of a litter for raising, as they alone have a good chance of living." Hairless dogs have imperfect teeth; long-haired and coarse-haired animals are apt io 
hilve, as is asserted, long or many horns; pigeons with feathered feet have skin between their outer toes; pigeons with short beaks have small feet, and those with long beaks large feet. Hence if man goes on selecting, and thus augmenting, any peculiarity, he will almost certainly modify unintentionally other parts of the structure, owing to the mysterious laws of correlation.

DARIIN'S IDEA OP THE CAUSES RESPONSIBLE FOR THE ORIGIN OF DOMESTIC RACES

To sum up on the origin of our domestic races of animals and plants. Changed conditions of life are of the highest importance in causing variability, both by acting directly on the organization, and indirectly by affecting the reproductive system. It is not probable that variability is an inherent and necessary contingent, under all circumstances. The greater or less force of inheritance and reversion determine whether variations shall endure. Variabilityis governed by many unknown laws, of which correlated growth is probably the most important. Something, but how much we do not know, may be attributed to the definite action of the conditions of life. Some, perhaps a great, effect may be attributed to the increased use or disuse of parts. The final result is thus rendered infinitely complex. In some cases the intercrossing of aboriginally distinct species appears to have played an important part in the origin of our breeds. When several breeds have once been formed in any country, their occasional intercrossing, with the aid of selection, has, no doubt, largely aided in the formation of new sub-breeds; but the importance of crossing has been much exaggerated, both in regard to animals and to those plants which are propagated by seed. With plants which are temporarily propagated by cuttings, buds, etc., the importance of crossing is immense; for the cultivator may here disregard the extreme variability both of hybrids and of mongrels, and the sterility of hybrids; but plants not propagated by seed are of little importance to us, for their endurance is only temporary. Over all these causes of Change, the accumulative action of Selection, whether applied methodically and quickly, or unconsciously and slowly but more efficiently, seems to have been the predominant Power.

DARWIN'S IDEA OP THE ORIGIN OP VARIETIES, SPECIES, AND GENERA IN NATURE

Finally, varieties cannot be distinguished from species-except, first, by the discovery of intermediate linking forms; and, secondly, by a certain indefinite amount of difference between them; for two 
forms, if differing very little, are generally ranked as varietien, notwithstanding that they cannot be closely connected; but the amount of difference considered necessary to give to any two forms the rank of species cannot be defined. In genera having more than the average number of species in any country, the species of these genera have more than the average number of varieties. In large genera the species are apt to be closely, but unequally, allied together, forming little clusters round other species. Species very closely allied to other species apparently have restricted ranges. In all these respects the species of large genera present a strong analogy with varieties. And we can clearly understand these analogies, if species once existed as varieties, and thus originated; whereas, these analogies are utterly inexplicable if species are independent creations.

We have, also, seen that it is the most flourishing or dominant species of the larger genera within each class which on an average yield the greatest number of varieties; and varieties, as we shall hereafter see, tend to become converted into new and distinct species. Thus the larger genera tend to become larger; and throughout nature the forms of life which are now dominant tend to become still more dominant by leaving many modified and dominant descendants. But by steps hereafter to be explained, the larger genera also tend to break up into smaller genera. And thus, the forms of life throughout the universe become divided into groups subordinate to groups.

\section{THE TERM "STRUGgLE FOR EXISTENCE" USED IN A LARGE SENSE}

I should premise that I use this term in a large and metaphorical sense including dependence of one being on another, and including (which is more important) not only the life of the individual, but success in leaving progeny. Two canine animals, in a time of dearth, may be truly said to struggle with each other which shall get food and live. But a plant on the edge of a desert is said to struggle for life against the drought, though more properly it should be said to be dependent on the moisture. A plant which annually produces a thousand seeds, of which only one of an average comes to maturity, may be more truly said to struggle with the plants of the same and other kinds which already clothe the ground. The mistletoe is dependent on the apple and a few other trees, but can only in a far-fetched sense be said to struggle with these trees, for, if too many of these parasites grow on the same tree, it languishes and dies. But several seedling mistletoes, growing close together on the same branch, 
may more traly be said to struggle with each other. As the mistletoe is disseminated by birds, its existence depends on them; and it may metaphorically be said to struggle with other fruit. bearing plants, in tempting the birds to devour and thus disseminate its seeds. In these several senses, which pass into each other, I use for convenience' sake the general term of Struggle for Existence.

GEOMETRICAL RATIO OF INCREASE

A struggle for existence inevitably follows from the high rate at which all organic beings tend to increase. Every being, which during its natural lifetime produces several eggs or seeds, must sufier destruction during some period of its life, and during some season or occasional year, otherwise, on the principle of geometrical increase, its numbers would quickly become so inordinately great that no country could support the product. Hence, as more individuals are produced than can possibly survive, there must in every case be a strugrle for existence, either one individual with another of the same species, or with the individuals of distinct species, or with the physical conditions of life. It is the doctrine of Malthus applied with manifold force to the whole animal and vegetable kingdoms; for in this case there can be no artificial increase of food, and no prudential restraint from marriage. Although some species may be now increasing, more or less rapidly, in numbers, all cannot do so, for the world would not hold them.

NATURAL SELECTION; OR THE SURVIVAL OF THE FITTEST

How will the struggle for existence, briefly discussed in the last chapter, act in regard to variation? Can the principle of selection, which we have seen is so potent in the hands of man, apply under nature? I think we shall see that it can act most efficiently. Let the endless number of slight variations and individual differences occurring in our domestic productions, and, in a lesser degree, in those under nature, be borne in mind; as well as the strength of the hereditary tendency. Under domestication, it may be truly said that the whole organization becomes in some degree plastic. But the variability, which we almost universally meet with in our domestic productions, is not directly produced, as Hooker and Asa Gray have well remarked, by man; he can neither originate varieties, nor prevent their occurrence; he can only preserve and accumulate such as do occur. Unintentionally he exposes organic beings to new and changing conditions 
of life, and variability ensues; but similar changes of conditions might and do occur under nature. Let it also be borne in mind how infinitely complex and close-fitting are the mutual relations of all organic beings to each other and to their physical conditions of life; and consequently what infinitely varied diversities of structure might be of use to each being under changing conditions of life. Can it, then, be thought improbable, seeing that variations useful to man have undoubtedly occurred, that other variations useful in some way to each being in the great and complex battle of life, should occur in the course of many successive generations? If such do occur, can we doubt (remembering. that many more individuals are born than can possibly survive) that individuals having any advantage, however slight, over others, would have the best chance of surviving and of procreating their kind? On the other hand, we may feel sure that any variation in the least degree injurious would be rigidly destroyed. This preservation of favorable individual differences and variations, and the destruction of those which are injurious, I have called Natural Selection, or the Survival of the Fittest. Variations neither useful nor injurious would not be affected by natural selection, and would be left either a fluctuating element, as perhaps we see in certain polymorphic species, or would ultimately become fixed, owing to the nature of the organism and the nature of the conditions.

Several writers have misapprehended or objected to the term Natural Selection. Some have even imagined that natural selection induces variability, whereas it implies only the preservation of such variations as arise and are beneficial to the being under its conditions of life. No one objects to agriculturists speaking of the potent effects of man's selection; and in this case the individual differences given by nature, which man for some object selects, must of necessity first occur. Others have objected that the term selection implies conscious choice in the animals which become modified; and it has even been urged that, as plants have no volition, natural selection is not applicable to them! In the literal sense of the word, no doubt, natural selection is a false term; but who ever objected to chemists speaking of the elective affinities of the various elements?-and yet an acid cannot strictly be said to elect the base with which it in preference combines. It has been said that I speak of natural selection as an active power or Deity; but who objects to an author speaking of the attraction of gravity as ruling the movements of the planets? Everyone knows what is meant and is implied by such metaphorical expres- 
sions; and they are almost necessary for brevity. So again it is diticult to ayois personifying the word Nature; but I mean by Nature only the ageregate action and product of many natural laws, and $b y$ laws the sequence of events as ascertainerl by us. With a little familiarity such superficial oljections will be forgotten.

We shall best understand the probable course of natural selection by taking the case of a country undergoing some shight physical change, for instance, of climate. The proportional numbers of its inhabitants will almost immediately undergo a change, and some species will probably become extinct. We may conclude, from what we have seen of the intimate and complex manner in which the inhabitants of each country are bound together, that any change in the numerical proportions of the inhabitants, independently of the change of climate itself, would seriously affect the others. If the country were open on its borders, new forms would certainly immirrate, and this would likewise seriously disturb the relations of some of the former inhabitants. Let it be remembered how powerful the influence of a single introduced tree or mammal has been shown to be. But in the case of an island, or of a country partly surrounded by barriers, into which new and better adapted forms could not ireely enter, we should then have places in the economy of nature which would assuredly be better filled up, if some of the original inhabitants were in some manner modified; for, had the area been open to immigration, these same places would have been seized on by intruders. In such cases, slight modifications, which in any way favored the individuals of any species by better adapting them to their altered conditions, would tend to be preserved; and natural selection would have free scope for the work of improvement.

We have good reason to believe, as shown in the frrst chapter, that changes in the conditions of life give a tendency to increased varialility and in the foregoing cases the conditions have changed, and this would manifestly be favorable to natural selection, by afforling a better chance of the occurrence of profitable variations. Unless such occur, natural selection can do nothing. Under the term of "variations," it must never be forgotten that mere individual differences are inclurled. Is man can produce a great result with his domestic animals and plants by adding up in any given direction individual differences, so could natural selection, but far more easily from having incomparahly longer time for action. Nor do I believe that any great physical change, as of climate, or any unusual degree of isolation to check immigration, 
is necessary in order that new and unoccupied places should be left, for natural selection to fill up by improving some of the varying inhabitants. For as all the inhabitants of each country are struggling together with nicely balanced forces, extremely slight modifications in the structure or habits of one species would often give it an advantage over others; and still further modifications of the same kind would often still further increase the advantage, as long as the species continued under the same conditions of life and profited by similar means of subsistence and defense. No country can be named in which all the native inhabitants are now so perfectly adapted to each other and to the physical conditions under which they live, that none of them could be still better adapted or improved; for in all countries, the natives have been so far conquered by naturalized productions, that they have allowed some foreigners to take firm possession of the land. And as foreigners have thus in every country beaten some of the natives, we may safely conclude that the natives might have been modified with advantage, so as to have better resisted the intruders.

As man can produce, and certainly has produced, a great result by his methodical and unconscious means of selection, what may not natural selection effect? Man can act only on external and visible characters: Nature, if I may be allowed to personify the natural preservation or survival of the fittest, cares nothing for appearances, except in so far as they are useful to any being. She can act on every internal organ, on every shade of constitutional difference, on the whole machinery of life. Man selects only for his own good: Nature only for that of the being which she tends. Every selected character is fully exercised by her, as is implied by the fact of their selection. Man keeps the natives of many climates in the same country; he seldom exercises each selected character in some peculiar and fitting manner; he feeds a long- and a short-beaked pigeon on the same food; he does not exercise a long-backed or long-legged quadruped in any peculiar manner; he exposes sheep with long and short wool to the same climate. He does not allow the most vigorous males to struggle for the females. He does not rigidly destroy all inferior animals, but protects during each varying season, as far as lies in his power, all his productions. He often begins his selection by some half-monstrous form; or at least by some modification prominent enough to catch the eye or to be plainly useful to him. Under nature, the slightest differences of structure or constitution may well turn the nicely balanced scale in the struggle for life, and so be preserved. How fleeting are the 
wishes and effcrts of man! how short his time! and consequintly how poor will be his results, compared with those accumulated by Nature during whole geological periods! Can we wonder, then, that Nature's productions should be far "truer" in character than man's productions: that they should be infinitely better adapted to the most complex conditions of life, and should plainly bear the stamp of far higher workmanship?

It may metaphorically be said that natural selection is daily and hourly scrutinizing, throughout the world, the slightest variations; rejecting those that are bad, preserving and adding up all that are good; silently and insensibly working whenever and wherever opportunity offers, at the improvement of each organic being in relation to its organic and inorganic conditions of life. We see nothing of these slow changes in progress, until the hand of time has marked the lapse of ages, and then so imperfect is our view into long-past geological ages, that we see only that the forms of life are now different from what they formerly were.

In order that any great amount of modification should be effected in a species, a variety when once formed must again, perhaps after a long interval of time, vary or present individual differences of the same favorable nature as before; and these must be again preserved, and so onwards step by step. Seeing that individual differences of the same kind perpetually recur, this can hardly be considered as an unwarrantable assumption. But whether it is true, we can judge only by seeing how far the hypothesis accords with and explains the general phenomena of nature. On the other hand, the ordinary belief that the amount of possible variation is a strictly limited quantity is likewise a simple assumption.

Although natural selection can act only through and for the good of each being, yet characters and structures, which we are apt to consider as of very trifling importance, may thus be acted on. When we see leaf-eating insects green, and bark-feeders mottled-gray; the alpine ptarmigan white in winter, the red-grouse the color of heather, we must believe that these tints are of service to these birds and insects in preserving them from danger. Grouse, if not destroyed at some period of their lives, would increase in countless numbers; they are known to suffer largely from birds of prey; and hawks are guided by eyesight to their prey-so much so, that on parts of the Continent persons are warned not to keep white pigeons, as being the most liable to destruction. Hence natural selection might be effective in giving 
the proper color to each kind of grouse, and in keeping that color, when once acquired, true and constant. Nor ought we to think that the occasional destruction of an animal of any particular color would produce little effect: we should remember how essential it is in a flock of white sheep to destroy a lamb with the faintest trace of black. We have seen how the color of the hogs, which feed on the "paint-root" in Virginia, determines whether they shall live or die. In plants, the down on the fruit and the color of the flesh are considered by botanists as characters of the most trifling importance: yet we hear from an excellent horticulturist, Downing, that in the United States smoothskinned fruits suffer far more from a beetle, a Curculio, than those with down; that purple plums suffer far more from a certain disease than yellow plums; whereas another disease attacks yellow-fleshed peaches far more than those with other colored flesh. If, with all the aids of art, these slight differences make a great difference in cultivating the several varicties, assuredly, in a state of nature, where the trees would have to struggle with other trees and with a host of enemies, such differences would effectually settle which variety, whether a smooth or downy, a yellow- or purple-fleshed fruit, should succeed.

In looking at many small points of difference between species, which, as far as our ignorance permits us to judge, seem quite unimportant, we must not forget that climate, food, etc., have no doubt produced some direct effect. It is also necessary to bear in mind that, owing to the law of correlation, when one part varies, and the variations are accumulated through natural selection, other modifications, often of the most unexpected nature, will ensue.

As we see that those variations which, under domestication, appear at any particular period of life, tend to reappear in the offspring at the same period; for instance, in the shape, size, and flavor of the seeds of the many varieties of our culinary and agricultural plants; in the caterpillar and cocoon stages of the varieties of the silk-worm; in the eggs of poultry, and in the color of the down of their chickens; in the horns of our sheep and cattle when nearly adult; so in a state of nature natural selection will be enal,led to act on and modify organic beings at any age, by the accumulation of variations profitable at that age, and by their inheritance at a corresponding age. If it profit a plant to have its seeds more and more widely disseminated by the wind, I can see no greater difficulty in this being effected through natural selection, than in the cotton-planter increasing and improving by selection the down in the pods on his cotton-trees. Natural 
selection. may modify and adapt the larva of an insect to a score of contingencies, wholly different from those which concern the mature insect; and these modifications may affect, through correlation, the structure of the adult. So, conversely, modifications in the adult may affect the structure of the larva; liut in all cases natural selection will ensure that they shall not be injurious: for if they were so, the species would become extinct.

Natural selection will morlify the structure of the young in relation to the parent. and of the parent in relation to the young. In social animals it will adlapt the structure of each individual for the benefit of the whole community, if the community profits by the selected change. What natural selection cannot do, is to modify the structure of one species, without giving it any advantage, for the good of another species; and though statements to this effect may be found in works of natural history, I cannot find one case which will bear investigation. A structure used only once in an animal's life, if of high importance to it, might be modified to any extent hy natural selection; for instance the great jaws possessed by certain insects, used exclusively for opening the cocoon-or the hard tip to the beak of unhatched birds, used for hreaking the egg. It has been asserted, that of the best shortheaked tumbler-pigeons a greater number perish in the egg than are athle to get out of it; so that fanciers assist in the act of hatching. Now if nature had to make the beak of a full-grown pigeon very short for the bird's own advantage, the process of modification would be very slow, and there would be simultaneously the most rigorous selection of all the young birds within the egg, which had the most powerful and hardest beaks, for all with weak beaks would inevitably perish; or, more delicate and more easily broken shalls might be selected, the thickness of the shell being known to vary like every other structure.

It may be well here to remark that with all beings there must l, much fortuitous destruction, which can have little or no influence on the course of natural selection. For instance a vast number of esiss or seeds are annually devoured, and these could te molified through natural selection only if they varied in some manner which protected them from their enemies. Yet many of these exors or seeds would perhaps, if not destroyed, have yielded individuals better ulay,ted to their conditions of life than any of those which happened to survive. So agrain a vast number of mature animals and plants, whether or not they be the best adapted to their conditions, must be annually 
destroyed by accidental causes, which would not be in the least degree mitigated by certain changes of structure or constitution which would in other ways be beneficial to the species. But let the destruction of the adults be ever so heavy, if the number which can exist in any district be not wholly kept down by such causes, or again let the destruction of eggs or seeds be so great that only a hundredth or a thousandth part are developed, yet of those which do survive, the best adapted individuals, supposing that there is any variability in a favorable direction, will tend to propagate their kind in larger numbers than the less well adapted. If the numbers be wholly kept down by the causes just indicated, as will often have been the case, natural selection will be powerless in certain beneficial directions; but this is no valid objection to its efficiency at other times and in other ways; for we are far from having any reason to suppose that many species ever undergo modification and improvement at the same time in the same area.

\section{SEXUAL SELECTION}

Inasmuch as peculiarities often appear under domestication in one sex and become hereditarily attached to that sex, so no doubt it will be under nature. Thus it is rendered possible for the two sexes to be modified through natural selection in relation to different habits of life, as is sometimes the case; or for one sex to be modified in relation to the other sex, as commonly nccurs. This leads me to say a few words on what I have called Sexual Selection. This form of selection depends, not on a struggle for existence in relation to other organic beings or to external conditions, but on a struggle between the individuals of one sex, generally the males, for the possession of the other sex. The result is not death to the unsuccessful competitor, but few or no offspring. Sexual selection is, therefore, less rigorous than nutural selection. Generally, the most vigorous males, those which are best fitted for their places in nature, will leave most progeny. But in many cases, victory depends not so much on general vigor, as on having special weapons, confined to the male sex. A hornless stag or spurless cock would have a poor chance of leaving numerous offspring. Sexual selection, by always allowing the victor to breed, might surely give indomitable courage, length to the spur, and strength to the wing to strike in the spurred leg, in nearly the same manner as does the hrutal cock-fighter by the careful selection of his best cocks. I Tow low in the scale of nature the law of battle descends, I know not; male alligators have been described as fighting, bellowing, and whirl- 
ing around, like Indians in a war-dance, for the possession of the females; male salmons have been observed fighting all day long; male stag-beetles sometimes bear wounds from the huge mandihles of other males; the males of certain hymenopterous insects have been frequently seen by that inimitable observer M. Fabre, fighting for a particular female who sits by, an apparently unconcerned beholder of the struggle, and then retires with the conqueror. The war is, perhaps, severest between the males of polygamous animals, and these seem oftenest provided with special weapons. The males of carnivorous animals are already well armed; though to them and to others, special means of defense may be given through means of sexual selection, as the mane of the lion, and the hooked jaw to the male salmon; for the shield may be as important for victory as the sword or spear.

Amongst birds, the contest is often of a more peaceful character. All those who have attended to the subject believe that there is the severest rivalry between the males of many species to attract, by singing, the females. The rock-thrush of Guiana, birds of paradise, and some others, congregate; and successive males display with the most elaborate care, and show off in the best manner, their gorgeous plumage; they likewise perform strange antics before the females, which, standing by as spectators, at last choose the most attractive partner. Those who have closely attended to birds in confinement well know that they often take individual preferences and dislikes: thus Sir R. Heron has described how a pied peacock was eminently attractive to all his hen birds. I cannot here enter on the necessary details; but if man can in a short time give beauty and an elegant carriage to his bantams, according to his standard of beauty, I can see no good reason to doubt that female birds, by selecting, during thousands of generations, the most melodious or beautiful males, according to their standard of beauty, might produce a marked effect. Some well-known laws, with respect to the plumage of male and female birds, in comparison with the plumage of the young, can partly be explained through the action of sexual selection on variations occurring at different ages, and transmitted to the males alone or to both sexes at corresponding ages; but I have not space here to enter on this subject.

Thus it is, as I believe, that when the males and females of any animal have the same general habits of life, but differ in structure, color, or ornament, such differences have been mainly caused by sexual 
selection: that is, by individual males having had, in successive generations, some slight advantage over other males, in their weapons, means of defence, or charms, which they have transmitted to their male offspring alone. Yet, I would not wish to attribute all sexual differences to this agency: for we see in our domestic animals peculiarities arising and becoming attached to the male sex, which apparently have not been augmented through selection by man. The tuft of hair on the breast of the wild turkey-cock cannot be of any use, and it is doubtful whether it can be ornamental in the eyes of the female bird; indeed, had the tuft appeared under domestication, it would have been called a monstrosity.

\section{ILLOSTRATIONS OF THE ACTION OF NATURAL SELECTION, OR THE SURVIVAL OF THE FITTEST}

In order to make it clear how, as I believe, natural selection acts, I must beg permission to give one or two imaginary illustrations. Let us take the case of a wolf, which preys on various animals, securing some by craft, some by strength, and some by fleetness; and let us suppose that the fleetest prey, a deer for instance, had from any change in the country increased in numbers, or that other prey had decreased in numbers, during that season of the year when the wolf was hardest pressed for food. Under such circumstances the swiftest and slimmest wolves would have the best chance of surviving and so be preserved or selected, provided always that they retained strength to master their prey at this or some other period of the year, when they were compelled to prey on other animals. I can see no more reason to doubt that this would be the result, than that man should be able to improve the fleetness of his greyhounds by careful and methodical selection, or by that kind of unconscious selection which follows from each man trying to keep the best dogs without any thought of modifying the breed. I may add, that, according to Mr. Pierce, there are two varieties of the wolf inhabiting the Catskill Mountains, in the United States, one with a light greyhound-like form, which pursues deer, and the other more bulky, with shorter legs, which more frequently attacks the shepherd's flocks.

It should be observed that, in the above illustration, I speak of the slimmest individual wolves, and not of any single strongly marked variation having been preserved. In former editions of this work I sometimes spoke as if this latter alternative had frequently occurred. I saw the great importance of individual differences, and this led me fully to discuss the results of unconscious selection by man, which 
depends on the preservation of all the more or less valuable individuals, and on the destruction of the worst. I saw, also, that the preservation in a state of nature of any occasional deviation of structure, such as a monstrosity, would be a rare event; and that, if at first preserved, it would generally be lost by subsequent intercrossing with ordinary individuals. Nevertheless, until reading an able and valuable article in the North British Review (I867), I did not appreciate how rarely single variations, whether slight or strongly marked, could be perpetuated. The author takes the case of a pair of animals, producing during their lifetime two hundred offspring, of which, from various causes of destruction, only two on an average survive to pro-create their kind. This is rather an extreme estimate for most of the higher animals, but by no means so for many of the lower organisms. He then shows that if a single individual were born, which varied in some manner, giving it twice as good a chance of life as that of the other individuals, yet the chances would be strongly against its survival. Supposing it to survive and to breed, and that half its young inherited the favorable variation; still, as the Reviewer goes on to show, the young would have only a slightly better chance of surviving and breeding; and this chance would go on decreasing in the succeeding generations. The justice of these remarks cannot, I think, be disputed. If, for instance, a bird of some kind could procure its food more easily by having its beak curved, and if one were born with its beak strongly curved, and which consequently flourished, nevertheless there would be a very poor chance of this one individual perpetuating its kind to the exclusion of the common form; but there can hardly be a doubt, judging by what we see taking place under domestication, that this result would follow from the preservation during many generations of a large number of individuals with more or less strongly curved beaks, and from the destruction of a still larger number with the straightest beaks.

\section{SCMMARY OF CHAPTER ON NATURAL SELECTION}

If under changing conditions of life organic beings present individual differences in almost every part of their structure, and this cannot be disputed; if there be, owing to their geometrical rate of increase, a severe struggle for life at some age, season, or year, and this certainly cannot be disputed; then, considering the infinite complexity of the relations of all organic beings to each other and to their conditions of life, causing an infinite diversity in structure, constitution, and habits, to be advantageous to them, it would be a most 
extraordinary fact if no variations had ever occurred useful to each being's own welfare, in the same manner as so many variations have occurred useful to man. But if variations useful to any organic being ever do occur, assuredly individuals thus characterized will have the best chance of being preserved in the struggle for life; and from the strong principle of inheritance, these will tend to produce offspring similarly characterized. This principle of preservation, or the survival of the fittest, I have called Natural Selection. It leads to the improvement of each creature in relation to its organic and inorganic conditions of life; and consequently, in most cases, to what must be regarded as an advance in organization. Nevertheless, low and simple forms will long endure if well fitted for their simple conditions of life.

Natural selection, on the principle of qualities being inherited at corresponding ages, can modify the egg, seed, or young, as easily as the adult. Amongst many animals, sexual selection will have given its aid to ordinary selection, by assuring to the most vigorous and best adapted males the greatest number of offspring. Sexual selection will also give characters useful to the males alone, in their struggles or rivalry with other males; and these characters will be transmitted to one sex or to both sexes, according to the form of inheritance which prevails.

Whether natural selection has really thus acted in adapting the various forms of life to their several conditions and stations, must be judged by the general tenor and balance of evidence given in the following chapters. But we have already seen how it entails extinction; and how largely extinction has acted in the world's history, geology plainly declares. Natural selection, also, leads to divergence of character; for the more organic beings diverge in structure, habits, and constitution, by so much the more can a large number be supported on the area, of which we see proof by looking to the inhabitants of any small spot, and to the productions naturalized in foreignlands. Therefore, during the modification of the descendants of any one species, and during the incessant struggle of all species to increase in number, the more diversified the descendants become, the better will be their chance of success in the battle for life. Thus the small differences distinguishing varieties of the same species, steadily tend to increase, till they equal the greater differences between species of the same genus, or even of distinct genera.

We have seen that it is the common, the widely-diffused and widely ranging species, belonging to the larger genera within each 
class, which vary most; and these tend to transmit to their modified oflespring that superiority which now makes them dominant in their own countries. Natural selection, as has just been remarked, leads to divergence of character and to much extinction of the less improved and intermediate forms of life. On these principles, the nature of the affinities, and the generally well-defined distinctions between the innumerable organic heings in each class throughout the world, may be explained. It is a truly wonderful fact-the wonder of which we are apt to overlook from familiarity---that all animals and all plants throughout all time and space should be related to each other in groups subordinate to groups, in the manner which we everywhere behold-namely, varieties of the same species most closely related, species of the same genus less closely and unequally related, forming sections and sub-genera, species of distinct genera much less closely related, and genera related in difierent degrees, forming sub-families, families, orders, sub-classes and classes. The several subordinate đroups in any class cannot be ranked in a single file, but seem clustered round points, and these round other points, and so on in almost endless cycles. If species had been independently created, no explanation would have been possible of this kind of classification; but it is explained through inheritance and the complex action of natural selection, entailing extinction and divergence of character, as we have seen illustrated in the diagram.

The affinities of all the beings of the same class have sometimes been represented by a great tree. I believe this simile largely spealss the truth. The green and budding twigs may represent existing species; and those produced during former years may represent the long succession of extinct species. At each period of growth all the growing $\uparrow$ wigs have tried to branch out on all sides, and to over top and kill the surrounding twigs and brancliss, in the same manner as species and groups of species have at all times overmastered other species in the great battle for life. The limbs dividud into great tranches, and these into lesser and lesser branches, were themselves once, when the tree was young, budlling twigs; and this connection of the former and present buds by ramifying branches may well represent the classification of all extinct and living species in groups subordinate to groups. Of the many twigs which flourished when the tree was a mere bush, only two or three, now grown into great branches, yet survive and bear the other branches; so with the species which lived during long-past scole i al perivals, very lew have ledt living and modified descendants. 
From the first growth of the tree, many a limb and branch has decayed and dropped off; and these fallen branches of various sizes may represent those whole orders, families, and genera which have now no living representatives, and which are known to us only in a fossil state. As we here and there see a thin straggling branch springing from a fork low down in a tree, and which by some chance has been favored and is still alive on its summit, so we occasionally see an animal like the Ornithorliynchus or Lepidosiren, which in some small degree connects by its affinities two large branches of life, and which has apparently been saved from fatal competition by having inhabited a protected station. As buds give rise by growth to fresh buds, and these, if vigorous, branch out and overtop on all sides many a feebler branch, so by generation I believe it has been with the great Tree of Life, which fills with its dead and broken branches the crust of the earth, and covers the surface with its ever-branching and beautiful ramifications.

\section{DIFFICULTIES AND OBJECTIONS TO NATURAL SELECTION AS SEEN BY DARIIN}

Long before the reader has arrived at this part of my work, a crowd of difficulties will have occurred to him. Some of them are so serious that to this day I can hardly reflect on them without being in some degree staggered; but, to the best of my judgment, the greater number are only apparent, and those that are real are not, I think, fatal to the theory.

These difficulties and objections may be classed under the following heads: First, why, if species have descended from other species by fine gradations, do we not everywhere see inuumerable, transitional forms? Why is not all nature in confusion, instead of the species being, as we see them, well defined?

Secondly, is it possible that an animal having, for instance, the structure and habits of a bat, could have been formed by the modification of some other animal with widely different habits and structure? Can we believe that natural selection could produce, on the one hand, an organ of trilling importance, such as the tail of a giraffe, which serves as a fly-llapier, and, on the other hand, an organ so wonderful as the eye?

Thirdly, can instincts be acquired and modified through natural selection? What shall we say to the instinct which leads the bee to make cells, and which has practically anticipated the discoveries of profound mathematicians? 
Fourthly, how can we account for species, when crossed, being sterile and producing sterile offspring, whereas, when varieties are crossed, their fertility is unimpaired?

\section{ANSWER TO THE FIRST DIFFICULTY}

On the Absence or Rarity of Transitional Varieties.-As natural selection acts solely by the preservation of profitable modifications, each new form will tend in a fully stocked country to take the place of, and finally to exterminate, its own less improved parent-form and other less-favored forms with which it comes into competition. This extinction and natural selection go hard in hand. Hence, if we lock at each species as descended from some unknown form, both the parent and all the transitional varieties will generally have been exterminated by the very process of the formation and perfection of the new form.

But, as by this theory innumerable transitional forms must have existed, why do we not find them embedded in countless num' ers in the crust of the earth? It will be more convenient to discuss this question in the chapter on the Imperfection of the Geolorical Record; and I will here only state that I believe the answer mainly lies in the record being incomparably less perfect than is gencrally supposed. The crust of the earth is a vast museum; but the natural collections have been imperfectly made, and only at long intervals of time.

\section{ANSWER TO THE SEROND DHEICULTY: ORGANS OF EXTREME PERFELTION AND COMPLICATION}

To suppose that the eye with all its inimitable contrivances for adjusting the focus to different distances, for adnitting different amounts of licht, and for the correction of spherical and chromatic aberration, could have been formed by natural selection, seems, I freely confess, absurd in the highest degree. When it was first sald that the sun stood still and the world turned round, the common sense of mankind declared the doctrine false; but the old saying of $V o x$ populi, vox Dei, as every philosopher knows, cannot be trusted in science. Reason telis me, that if numerous gradations from a simple and imperfect eye to one complex and perfect can be shown to exist, each grade heing useful to its possessor, as is certainly the case; if further, the eye varies and the variations be inherited, as is likewise certainly the case; and if such variations should be useful to any animal under chanering conditions of life, then the dithculty of helieving 
that a perfect and complex eye could be formed by natural selection, though insuperable by our imagination, should not be considered as subversive of the theory. How a nerve comes to be sensitive to light, hardly concerns us more than how life itself originated; but I may remark that, as some of the lowest organisms, in which nerves cannot be detected, are capahle of perceiving light, it does not seem impossible that certain sensitive elements in their sarcole should become aggregated and developed into nerves, endowed with this special sensibility.

In searching for the gradations through which an organ in any species has been perfected, we ought to look exclusively to its lineal progenitors; but this is scarcely ever possible, and ware forced to look to other species and genera of the same group, that is to the collateral descendants from the same parent-form, in order to see what gradations are possible, and for the chance of some gradations having been transmitted in an unaltered or little altered condition. But the state of the same organ in distinct classes may incidentally throw light on the steps by which it has been perfected.

The simplest organ which can be called an eye consists of an optic nerve, surrounded by pigment-cells and covered by translucent skin, but without any lens or other refractive body We may, however, according to M. Jourdain, descent even a step lower and find aggregates, of pigment-cells, apparently serving as organs of vision, without any nerves, and resting merely on sarcodic tissue. Eyes of the above simple nature are not capable of distinct vision, and serve only to distinguish light from darkness. In certain star-fishes, small depressions in the layer of pisisment which surrounds the nerve are filled, as described ly the author just quoted, with transparent gelatinous matter, projecting with a convex surface, like the cornea in the higher animals. He suggests that this serves not to form an image, but only to concentrate the luminous rays and render their perception more easy. In this concentration of the rays we gain the first and by far the most important step towards the formation of a true, picture-forming eye: for we have only to place the naked extremity of the optic nerve, which in some of the lower animals lies deeply buried in the body, and in some near the surface, at the right distance from the concentrating apoaratus, and an inage will be formed on it.

In the great class of the Articulata, we may start from an optic nerve simply coated with pigment, the latter sometimes forming a sort 
of pupil, but destitute of a lens or other optical contrivance. With insects it is now known that the numerous facets on the cornea of their great compound eyes form true lenses, and that the cones include curiously modified nervous filaments. But these organs in the Articulata are so much diversified that Müller formerly made three main classes with seven subdivisions, besides a fourth main class of aggregated simple eyes.

When we reflect on these facts, here given much too briefly, with respect to the wide, diversified, and graduated range of structure in the eyes of the lower animals; and when we bear in mind how small the number of all living forms rnust be in comparison with those which have become extinct, the dificulty ceases to be very great in believing that natural selection may have converted the simple apparatus of an optic nerve, coated with pigment and invested by transparent membrane, into an optical instrument as perfect as is possessed by any member of the Articulate Class.

He who will go thus far, ought not to hesitate to go one step further, if he finds on finishing this volume that large bodies of facts, otherwise inexplicable, can be explained by the theory of modification through natural selection; he ought to admit that a structure even as perfect as an eagle's eye might thus be formed, although in this case he does not know the transitional states. It has been objected that in order to modify the eye and still preserve it as a perfect instrument, many changes would have to be effected simultaneously, which, it is assumed, could not be done through natural selection; but as I have attempted to show in my work on the variation of domestic animals, it is not necessary to suppose that the modifications were all simultaneous, if they were extremely slight and gradual. Different kinds of modification would, also, serve for the same general purpose: as Mr. Wallace has remarked, "if a lens has too short or too long a focus, it may be amended either by an alteration of curvature, or an alteration of density; if the curvature be irregular, and the rays do not converge to a point, then any increased regularity of curvature will be an improvement. So the contraction of the iris and the muscular movements of the eye are neither of them essential to vision, but only improvements which might have been added and perfected at any stage of the construction of the instrument." Within the highest division of the animal kingdon, namely, the Vertebrata, we can start from an eye so simple, that it consists, as in the lancelet, of a little 
sack of transparent skin, furnished with a nerve and lined with pigment, but destitute of any other apparatus. In fishes and reptiles, as Owen has remarked, "the range of gradations of dioptric structures is very great." It is a significant fact that even in man, according to the high authority of Virchow, the beautiful crystalline lens is formed in the embryo by an accumulation of epidermic cells, lying in a sacklike fold of the skin; and the vitreous body is formed from embryonic sub-cutaneous tissue. To arrive, however, at a just conclusion regarding the formation of the eye, with all its marvellous yet not absolutely perfect characters, it is indispensable that the reason should conquer the imagination; but I have felt the dificulty far too keenly to be surprised at others hesitating to extend the principle of natural selection to so startling a length.

It is scarcely possible to avoid comparing the eye with a telescope. We know that this instrument has been perfected by the longcontinued efforts of the highest human intellects; and we naturally infer that the eye has been formed by a somewhat analogous process. But may not this inference be presumptuous? Have we any right to assume that the Creator works by intellectual powers like those of man? If we must compare the eye to an optical instrument, we ought in imagination to take a thick layer of transparent tissue, with spaces filled with fluid, and with a nerve sensitive to light beneath, and then suppose every part of this layer to be continually changing slowly in density, so as to separate into layers of different densities and thicknesses, placed at different distances from each other, and with the surfaces of each layer slowly changing in form. Further we must suppose that there is a power, represented by natural selection or the survival of the fittest, always intently watching each slight alteration in the transparent layers; and carefully preserving each which, under varied circumstances, in any way or in any degree, tends to produce a distincter image. We must suppose each new state of the instrument to be multiplied by the million; each to be preserved until a better one is produced, and then the old ones to be all destroyed. In living bodies, variation will cause the slight alterations, generation will multiply them almost infinitely, and natural selection will pick out with unerring skill each improvement. Let this process go on for millions of years; and during each year on millions of individuals of many kinds; and may we not believe that a living optical instrument might thus be formed as superior to one of glass, as the works of the Creator are to those of man? 
DARWTN'S SUMMARY OF HIS ANSWER TO THE THIRD DIFEICULTY, THAT OF ACCOUNTINI; FOR THE ACQUISITION AND MODIFICATION OF INSTINCTS THROUGH NATURAL SELECTION

I have endeavored in this chapter briefy to show that the mental qualities of our domestic animals vary, and that the variations are inherited. Still more briefly I have attempted to show that instincts vary slightly in a state of nature. No one will dispute that instinct: are of the highest importance to each animal. Therefore there is no real difficulty, under changing conditions of life, in natural selection accumulating to any extent slight modifications of instinct which are in any xay useful. In many cases habit or use and disuse have prol,ably come into play. I do not pretend that the facts given in this chapter strengthen in any great degree my theory; but none of the cases of difficulty, to the best of my judgment, annihilate it. On the other hand, the fact that instincts are not always absolutely perfect and are liable to mistakes: that no instinct can be shown to have been produced for the good of other animals, though animals take adrantage of the instincts of others; that the canon in natural history, of "Natura non facit saltum," is applica?le to instincts as well as to corporeal structure, and is plainly explicable on the foregoing views, but is otherwise inexplicable, all tend to corroborate the theory of natural selection.

This theory is also strengthened by some few other facts in regard to instincts; as by that common case of closely allied, but distinct, species, when inhabiting distant parts of the world and living under considerably different conditions of life, yet often retaining nearly the same instincts. For instance, we can understand, on the principle of inheritance, how it is that the thrush of tropical South America lines its nest with mud, in the same peculiar manner as does our British thrush; how it is that the Hornbills of Africa and India have the same extraordinary instinct of plastering up and imprisoning the females in a hole in a tree, with only a small hole left in the plaster through which the males feed them and their young when hatched; how it is that the male wrens (Troglodytes) of North America buijd "cocknests," to roost in, like the males of our Kitty-wrens, a habit wholly unlike that of any other known bird. Finally, it may not be a logical deduction, but to my imagination it is far more satisfactory to look at such instincts as the young cuckoo ejecting its foster-brothers, ants making slaves, the larvae of ichneumonidae feeding within the live bodies of caterpillars, not as specially endowed or created 
instincts, but as small consequences of one general law leading to the advancement of all organic beings, namely, multiply, vary, let the strongest live and the weakest die.

DARWIN'S SUMMARY OF HIS ANSWER TO THE DIFFICULTY AS TO THE INABILITY OF NATURAL SELECTION TO ACCOUNT FOR THE F.ACT THAT SPECIES WHEN CROSSED ARE STERILE OR PRODUCE STERILE OFFSPRING, WHEREAS WHEN VAßIETIES ARE CROSSED THEIR FERTILITY IS UNIMP.AIRED

First crosses between forms, sufficiently distinct to be ranked as species, and their hybrids, are very generally, but not universally sterile. The sterility is of all degrees, and is often so slight that the most careful experimentalists have arrived at diametrically opposite conclusions in ranking forms by this test. The sterility is innately variable in individuals of the same species, and is eminently susceptible to the action of favorable and unfavorable conditions. The degree of sterility does not strictly follow systematic afinity, but is governed by several curious and complex laws. It is generally different, and sometimes widely different in reciprocal crosses between the same two species. It is not always equal in degree in a first cross and in the hybrids produced from this cross.

In the same manner as in grafting trees, the capacity in one species or variety to take on another, is incidental on differences, generally of an unknown nature, in their vegetative systems, so in crossing, the greater or less facility of one species to unite with another is incidental on unknown differences in their reproductive systens. There is no more reason to think that species have been specially endowed with various degrees of sterility to prevent their crossing and blending in nature, than to think that trees have been specially endowed with various and somewliat analogous degrees of difficulty in being grafted logether in order to prevent their inarching in our forests.

The sterility of first crosses and of their hybrid progeny has not Deen acquired through natural selection. In the case of first crosses it seems to depend on several circumstances; in some instances in chief part on the early death of the embryo. In the case of hybrids, it apparently depends on their whole organization having been disturbed by being compounded from two distinct forms; the sterility being closely allied to that which so frequently affects pure species, when exposed to new and unnatural conditions of life. He who will explain these latter cases will he able to explain the sterility of hybrids. This view is strongly supported by a parallelism of another kind: namely, that firstly, slight changes in the conditions of life add to the 
vigur and fertility of all organic beings; and secondly, that the crossing of forms, which have been exposed to slightly different comelition? of life or which have varied, favors the size, vigor, and fertility of their offspring. The facts given on the sterility of the illegitimate unions of dimorphic and trimorphic plants and of their illegitimate progeng, perhaps render it probable that some unknown bond in all cases connects the desree of fertility of first unions with that of their offsprins. The consideration of these facts on dimorphism. as well as of the results of reciprocal crosses, clearly leads to the conclusion that the primary cause of the sterility of crossed species is confined to differences in their sexual elements. But why, in the case of distinct species, the sexual elements should so generally have become more or less modified, leading to their mutual infertility, we do not know; but it seems to stand in some close relation to species having been exposed for long periods of time to nearly uniform conditions of life.

It is not surprising that the diffculty in crossing any two species, and the sterility of their hybrid offspring, shouid in most cases corre$\because$ ond, even if due to distinct causes: for both depend on the amount of difference between the species which are crossed. For is it sirprising that the facility of effecting a first cross, and the fertility of the hybrids thus produced, and the capacity of being grafted togetherthough this latter capacity evidently depends on widely different circumstances-should all run, to a certain extent, parallel with the systematic affinity of the forms subjected to experiment; for systematic affinity includes resemblances of all kinds.

First crosses between forms known to be varieties, or sufficiently alike to be considered as varieties, and their monerel offspring, are very generally, but not, as is so often stated, invaris ly fertile. Nor is this almost universal and perfect fertility surprising, when it is remembered how liable we are to argue in a circle with respect to varieties in a state of nature: and when we remember that the greater number of varieties have been produced under lomestication by the selection of mere external differences, and that they have not heen long exposed to uniform conditions of life. It should also be especially kept in mind that lons-continued domestication tends to elimimate sterility, and is therefore little likely to induce this same quality. Independently of the question of fertiity, in all other respects thare is the closest general resemblance between hybrids and morels, in their variability, in their power of absorbing each other ly reseated crosses, and in their inheritance of characters from both paront-forms. 
Finally, then, although we are as ignorant of the precise cause of the sterility of first crosses and of hybrids as we are why animals and plants removed from their natural conditions become sterile, yet the facts given in this chapter do not seem to me opposed to the belief that species aboriginally existed as varieties. 


\section{BIBLIOGRAPHY}

Babcock, Ervest Brown, and Clatsex, Roy Elwond. Genetics in Relation to 1 gricalture. McGraw-Hill Book Co., Iols.

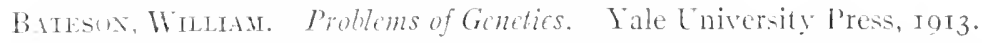

Batr, E.; Fischer, E.; Lexz, F. IImman Heredity. Macmillan Co., I93I.

Castle, Wildan E. Gontics and Eugchics. IHarvard University Press, 3 d ed. I024.

Chid, Charles Mhricr. "Regulatory Processes in Organisms." Jour. Morph.. XXII (IOII).

Coxkix, Edwix Graxt. IIerdity and Environment. Princeton University Press. $31 \mathrm{led}$. Inzo.

Coulter, Juhxi M., and Curlter, Merle C. Plant Genetics. University of C'hicago l'ress, rous.

(ramptos, Hexrl EDward. The Dotrine of Eiolution. Columbia University I'ress. IoI

IARMIX, Cifartes. The Origin of Speries. D. Appleton \& Co., with additions from the sixth and last edition, IS93.

JARWIX, Fraxcis. Lifo and Letters of Charles Damoin. John Murray, Lonton, ISSS.

DeBeEr. (r. R. Embrylogy and Eiolution. Oxford University Press, I9zo.

DExDr, AkThtr. Oullines of Eiolutionary Biology. D. Appleton \& Co., I 916.

De Vries, Hugo. Species and Tarietics. Open Court Publishing Co., 1004 .

Downig, Eldot Rowlaxd. The Third and Fourth Generation. University of Chicago T'ress, IoIs.

Enmer, Tufudure. On Orthegenesis. Open Court Publishing Co., rSoS.

Eugenics, cincties and the Irmity. (Papers of the Second International Confress of Eugenics.) Williams \& Wilkins Co., I923.

Gadow, HAxs. The It unlerings of lnimals. Cambridge University Press, IOI.3.

Guyer, Michael F. Being W'cll-Bom. Bobbs-Merrill Co., r9i8.

-. "Immune Sera and Certain Biological Problems." Amer. Natur., L.T (

Hexdersox, Lawrexce J. The Fitness of the Ensironment. Macmillan CO., IOI3.

Herrert, S. The First Principles of Eiolution. Adam and Charles Black, London, IQ13.

Jexpmas, H. S. The Biological Basis of IIman Nature. W. W. Norton \& Co., I930. 
Jones, Donald F. Genetics in Plant and Animal Improvement. John Wiley \& Sons, I925.

Jordan, David Starr, and Kellogg, Vernon L. Eiolution and Animal Life. D. Appleton \& Co., igos.

Judd, JoIn W. The Coming of Evolution. Cambridge University Press, IOI I.

Kellogg, Vernon L. Darwinism To-Day. Ilenry Holt \& Co., I907.

Le Conte, Joseph. Evolution. D. Appleton \& Co., 2 d ed., i 897.

Lindsey, A. W. The Problems of Evolution. Macmillan Co., I93I.

Locy, Willian A. The Main Currents of Zoölogy. Henry Holt \& Co., IOIS.

Lull, Richard Swann. Organic Eiolution. Macmillan Co., r9i 7 .

Mason F. (ED.). Creation by Evolution. Macmillan Co., I920.

McFarland, Joseph. Biology, General and Medical. W. I3. Saunders Co., 3d ed., i 9 i 8 .

Metcalf, Maynard M. An Outline of the Theory of Organic Evolution. Macmillan Co., igir.

Morgan, Thomas IT. Erolution and Adaptation. Macmillan Co., I903.

- A Critique of the Theory of Evolution. Princeton University Press, I9I6.

- The Theory of the Gone. Yale University Press, I026.

Morgan, Sturtevant, Muller, and Bridges. The Mechanism of Mendelian Heredity. Henry Holt \& Co., I9I5.

Newalan, Horatio H. "The Limits of Hereditary Control in Armadillo Quadruplets: A Study of Blastogenic Variation." Jour. Morph., XXII (I9II).

- The Biology of Twins. University of Chicago Press, I9I5.

- Vertcbrate Zoölogy. Macmillan Co., iozo.

- "Twins and the Relative Potency of Heredity and Environment in Development." Publications of the American Sociological Society, I 922 .

- The Physiology of Twinning. University of Chicago Press, I923.

- The Gist of Evolution. Macmillan Co., го26.

- and Otmers. The Nature of the World and of Mann. University of Chicago Press, I927.

Nuttall, G. H. F. Blood Immunity and Blood Relationship. Cambridge University Press, I904.

Nutisng, C. C. "The Relation of Mendelism and the Mutation to Theory Natural Selection." Science, N.S., LIII (Feb. II, I02I).

Osborn, Henry Fairfield. From the Greels to Durin. Macmillan Co., IgOS.

- The Origin and Evolution of Life. Charles Scribner's Sons, I9I S.

Plate, Ludwig. Über die Bedeutung des Durwin'schen Selectionsprincips und Probleme der Artbildung. Engelmann, Leipzig, 2d ed., I903. 


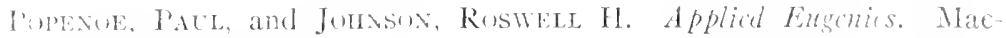
millan Co., 10IS.

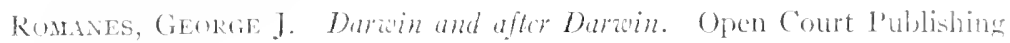
Co., $1 \mathrm{SO2}$.

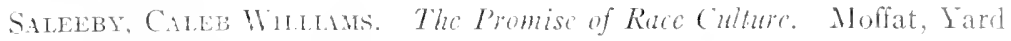
\& Co., roou.

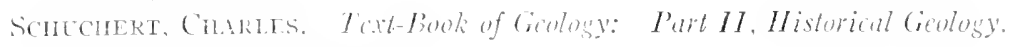
John Wiley \& Sum sor 5 .

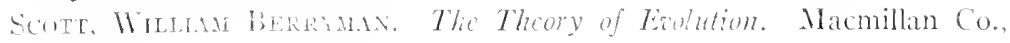
I()II.

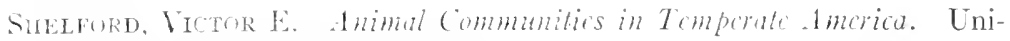
versity of ('licato P'ress, to13.

Sinul, A. Fravidin. Primiples of Animal Biology. Mcciraw-Hill Book Co., rozo.

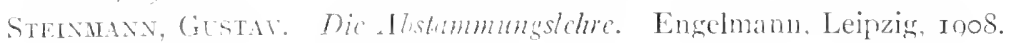
Taveer, J. 1. "The sonpe of Natural Selection." Natmal Science, Vol. XY., ISOB.

TuAger, CiEkitd II. Comcoling Colontion in the Animal Kingtom. Macmillan Co., Ius

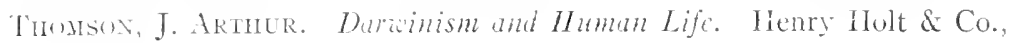
1000 .

Nonedity. John Nurray, London, I907.

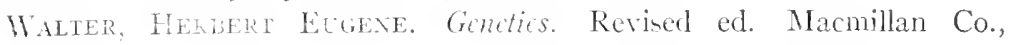
I922.

Melis, IJ. G.; Hexter, J. S.; and Wells, G. P. The Science of Life. Doubletay. Doran \& co., rost.

Wintan. Cintefficis. "The I'roblem of the Origin of Species." Pro-

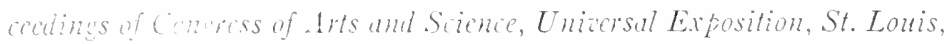
I 006 .

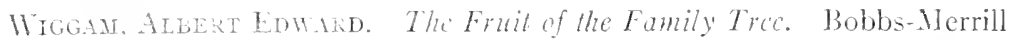
Co., 1924 .

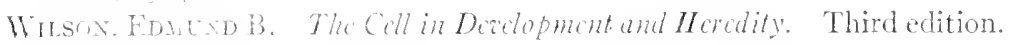
Nacmitian $(0 .$, I 025.

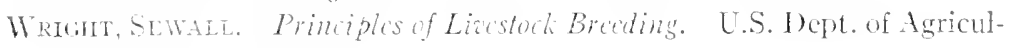
ture, Bull. 005 , I920. 


\section{GLOSSARY}

Acquired character.-Any change in the body (soma) of an individua due to change of function or change of environment. Same as Modification.

Adaptation.- Any character, structural or functional, in an organism that helps to enhance the fitness of that organism.

Agamic reproduction.-See Asexual reproduction.

Allelomorph. - One of a pair of contrasted characters; one of a pair of genes (factors) determining the development of such characters, and believed to occupy equivalent loci in homologous chromosomes; a Mendelian pair.

Analogous structures.-Any two or more structures that subserve the same function in the different kinds of animals or plants, but which arise from different embryonic rudiments and have fundamentally different structural constitutions. Contrast with Homologous structures.

Anthropoid.--Literally, manlike; refers especially to the manlike apes.

Apogamy.-A term used by botanists, synonymous with Parthenogenesis.

Asexual reproduction.-Any method of reproduction that does not involve the union of gametes. (Some authorities consider parthenogenesis as a phase of asexual reproduction.)

Atavism. - The cropping out of ancestral characters in an individual

Atrophy. - The dwindling away of a structure in an individual or in a race.

Autosome.-Any chromosome other than those that are recognized as especially involved in the heredity of sex. See Sex chromosome.

Biometry. - That branch of biology that investigates organic differences by statistical methods.

Blastula.-An early embryonic stage consisting typically of a hollow ball of cells.

Castration.-The removal from an organism of the gonads (testes or ovaries).

Catastrophism.--The idea, held by Cuvier and others, that the geologic strata were sharply marked off from one another because great catastrophies had brought each era to an end, and that all life was destroyed in each catastrophe. Contrast with Uniformitarianism.

Cell.-The smallest unit of living substance that can exist in a free state; the unit out of which tissues are composed.

Centrosome.-An organ of a cell which seems to be a center of forces that express themselves in mitotic cell division.

Character.-One of many structural or functional details that characterize an individual or a race. 
Chromatin.--The substance of which chromosomes are largely composed, the chemical composition of which is not exactly known; supposed to be the hereditary substance; so called because it stains readily with certain dyes and can be easily seen under the microscope.

Chromosomes. - The definite masses of chromatin that have a characteristic number, size, and shape in any given species.

Combinations.-New organic conditions due to a new assortment of vid factors already present in the germ plasm of parents.

Commensalism.-The habitual living together of two or more different species of animals or plants, involving more or less interdependence.

Crossing-over.--Exchange of genes (factors) between homologous chromosomes, believed to occur during synapsis.

Cytology.--The detailed microscopic study of the structure of cells especially of germ cells.

Cytoplasm.-All of the living material of the cell outside of the nucleus

Determiner.-See Gene or Factor.

Dihybrid cross.--A crossing of two parents differing from each other in only two pairs of allelomorphs.

Diploid.--The maximum or full (duplex) number of chromosomes, found in body cells and in the unmaturated germ cells; twice the gametic or haploid number.

Dominant.-A term applied to that member of an allelomorphic pair of characters that has the capacity of manifesting an effect wholly or partly to the exclusion of the effect of the other member (the recessive).

Duplicate factors (genes).---Two or more factors located in different chromosomes, either of which produces the same result.

Egg.-The female germ cell; more precisely, the female gamete.

Environment.-The sum of all influences upon the organism that have their origin outside of the body.

Epigenesis.-The doctrine that the germ cell is absolutely or relatively structureless and that differentiation arises de noro through the interaction of the protoplasm and the environment. Contrast with Preformation.

$F_{1}$ generation. - The first hybrid generation of a hybrid cross; exhibits only the dominant characters of the two parents.

$\mathrm{F}_{2}$ generation.-The offspring resulting from the interbreeding of individuals of the $F_{1}$ generation.

$\mathrm{F}_{3}$ generation.- The offspring resulting from the interbreeding of individuals of the $\mathrm{F}_{2}$ generation.

Factor.-A unit of inlleritance situated at some particular locus of d particular chromosome and transmitted according to the laws of Mendel, a determiner, or gene.

Faunas.-Groups of animals inhabiting a given geographic region uf geologic period. 
Fertilization.-The union of male and female gametes and the consequent initiation of development of a new individual.

Floras.-Groups of plants inhabiting a given geographic region or geologic period.

Gamete.-A mature male or female reproductive cell, containing the haploid number of chromosomes; an egg or a spermatozoön.

Gametic Reproduction.-See Sexual reproduction.

Gastrula.-A stage in the development of metazoan animals in which the embryo consists of two germ layers, ectoderm and endoderm.

Gemmules.-Hypothetical inheritance units involved in Darwin's provisional theory of pangenesis.

Gene.-See Factor.

Genetics.-The science which seeks to explain the resemblances and differences in organism related by descent; the modern analytic and experimental study of variation, heredity, and sex.

Genotype.-A group of individuals all of which are alike in their genes or factors. Contrast with Phenotype.

Genotypic.-Pertaining to the germinal or hereditary constitution of an organism. Contrast with Phenotypic.

Genus.-An arbitrary group in the systematic classification of animals or plants, ranking above the species and containing one or more species possessing structural characters differing from those of other genera.

Germ cell.-A cell specialized for sexual reproduction. Matured germ cells are known as gametes.

Germ plasm. - That part of the cell protoplasm which is believed to be the material basis of heredity and is transferred from one generation to the next. Contrast with Somotoplasm or Soma.

Germinal continuity.-The concept of an unbroken stream of germ plasm from generation to generation back to the beginning of life.

Gonads. - The organs (ovaries or testes) that contain the reproductive cells or germ cells, and sometimes also contain glandular tissue that functions in the differentiation of secondary sexual characters.

Gynandromorph.-An animal in which one part exhibits male characters and another part female characters.

Habitat.- The complex of environmental factors making up the surroundings of any species or race.

Haploid.- The reduced (one-half) number of chromosomes present only in gametes. Sce Liploid.

Hermaphrodite.-An individual organism possessing both ovaries and testes.

Heterogenesis.-See Mutation.

Heterozygote.-An individual or a zygote resulting from the union of unlike gametes. 
Heterozygous.-Having the allelonorphic pairs composed of dissimilar elements, resulting in the production of more than one kind of gametes.

Heterozygous sex.--The sex in which the members of the chromosome pair that determines sex are mlike.

Homologous structures.--Any two structures either in the same or in different individuals or species that arise from equivalent embryonic rudiments and have the sime structural relations to other parts, irrespective of the function sulpserved. Contrast with Analogous structures.

Homozygote.-An individual or a zygote resulting from the union of like gametes.

Homozygous.- Having the allelomorphic pairs composed of similar elements, resulting in the production of only one kind of gamete.

Homozygous sex.-The sex in which the members of the chromosome pair that determines sex are alike.

Hormone.-A substance, secreted by one of the endocrine glands, that affects the development of or the functioning of some other part or parts of the body.

Indigenous.-Living naturally in any country or climate. Contrast with Introduced.

Induction.-Any clange in a germ cell or an embryo that persists for only a few generations and then disappears. Contrast with Mutation.

Introduced.- Brought in from another country and living more or less successfully under forein conditions. Contrast with Indigenous.

Isolation.-The process of separating one section or strain of a species from another section or from the main body of the species; believed to facilitate the establishment of new species.

Lamarckian.--Pertaining to Lamarck's doctrine of the inheritance of acquired characters.

Lamarckism. - The theory of the inheritance of acquired characters.

Larva.-A self-supporting embryo; a developmental stage of an animal in which various adaptive structures for self-support appear that may or may not be significant for the development of adult structures.

Lethal.-Producing death; destructive of life.

Linin.-An achromatic or non-chromatin substance that forms a network of threads in the nucleus.

Linkage.-'The type of inheritance in which genes (factors) tend to remain together in transmission from generation to generation, owing to their location in the same chromosome.

Locus ( $p l$ loci).-A definite point or region in a given chromosone at which is located a genetic factor or gene.

Maturated germ cell.--See Gamete.

Naturation. - The process through which germ cells pass in preparation for fertilization, usually resulting in the formation of ganetes.

Mitosis.--The normal process of cell division, involving the formatiou 
of spindle, chromosomes, etc., and resulting in longitudinal splitting of each chromosome.

Modification.-A change in the body or soma of an individual due to functioning or to use and disuse; same as Acquired character.

Monohybrid cross.-A cross between two individuals differing in only one pair of allelomorphs.

Morphological.-Structural; opposed to physiological.

Multiple allelomorphs.-Different factors or genes occupying the same locus of homologous chromosomes; the character conditioned by such factors.

Multiple factors. - Two or more factors, usually alike in character, which unite in various numbers to produce different quantitative expressions of one character. Same as Duplicate factors.

Mutant.-An individual having a different genotypic constitution from its parents, as the result of a change in the germ plasm, and not as the result of segregation or crossing-over. Some authorities include the type of changes due to chromosomal aberrations under the head of mutants, while others limit mutants to those resulting from factor changes.

Mutation.-The germinal change resulting in the production of a mutant. The definition of mutation differs according to differences of opinion as to what should be included under the definition of a mutant. Contrast with Induction.

Neo-Darwinian.-A descriptive term applied to theories based on Darwin's theory of natural selection.

Neo-Lamarckian. - A descriptive term applied to theories based on Lamarck's theory of the inheritance of acquired characters.

Neo-mutationist.-A modern adherent of the mutation theory; especially one who is interested chiefly in tracing the origin of germinal changes that are responsible for the appearance of mutants.

Non-disjunction. - The failure of the two members of a pair of homologous chromosomes to separate in cell division, with the result that they both pass into one daughter-cell, making one too many chromosomes in one gamete and one too few in the other.

Nucleus.-The body within a cell that contains the chromatin.

Ontogenetic.-Pertaining to the life history of the individual. Contrast with Phylogenetic.

Ontogeny.-The developmental history of the individual; same as development or somatogenesis. Contrast with Phylogeny.

Orthogenesis.-The apparent fact that races or groups of animals or plants vary progressively along definite lines, each variation forming the threshold of departure fur the next and the whole series forming a definite sequence; definitely directed evolution.

Ovule.- The body that contains the egg of flowering plants and becomes the seed after fertilization and maturation.

Ovum ( $p l$. ova).-The egg; the type of gamete produced by a female.

Pangenesis.-A provisional theory as to the mechanism of hereditary 
transmission devised by Charles Darwin. It implies the idea that the germ cells are made up through the process of collecting from the blood stream "gemmules" or representatives of all parts of the body. In this way each structure of the adult parent would be present in the germ cell and would be transmitted to the offspring.

Panmixia. - An early theory of Weismanu designed to account for the rudimentation of structures; almost equiralent to cessation of natural selection.

Parthenogenesis.-The derelopment of an egg without fertilization. A process in animals equivalent to Apogamy in plants.

Peculiar.-A term used technically to describe a species or higher group of organisms occurring in one region and nowhere else.

Pedigree.-An ancestral history; a genealogical tree.

Phenotype.-A group of individuals which are alike somatically and look alike, but which may differ germinally; the sum of the visible features of an individual or a race. Contrast with Genotype.

Phenotypic.-Pertaining to the somatic appearance of the individual or group of individuals. Contrast with Genotypic.

Phylogenetic.-Pertaining to the ancestral history of a group. Contrast with Ontogenetic.

Phylogeny.-The history of the evolution of a species or a group. as distinguished from Ontogeny.

Preformation. - A theory that the individual is preformed in the egg and needs only to grow or to unfold in order to reach its definitive state. Contrast with Epigenesis.

Protoplasm.-The living substance of cells.

Pure line.-The descendants of a single individual that have not undergone any germinal change.

Quadrumana.-An old name for apes and monkeys implying that their hands and feet are both grasping appendages like hands.

Recessive.-The opposite of dominant.

Reduction division.--That division in germ cells when the chromosome number is reduced from the diploid to the haploid condition; usually one of the two maturation divisions of a germ cell.

Segregation.--The separation into separate gametes of the two members of a pair of allelomorphs, resulting in gametes pure for one or the other of a pair of allelomorphic genes.

Serology.-That branch of experimental biology or medicine that deals with the reactions of the blood to foreign materials and the production of antibodies; the science of serums.

Sex chromosome.-The particular chromusome (the X-chromusome, for example) that seems to carry the factors for sex and through which sex is inherited.

Sex linked.-A term applied to characters located in the sex chromosomes.

Sex ratio.-The relative proportion of the two sexes in a population. 
Sexual reproduction.-That mode of reproduction that involves the union of gametes to form a zygote. Same as Gametic reproduction.

Simian.--Pertaining to apes.

Soma.-The body of an organism as contrasted with the germ cells.

Somatic.-Pertaining to the body. Contrast with Germinal.

Somatoplasm. - Same as Soma. Contrast with Germ plasm.

Special creation.-A popular doctrine holding that all species existing today were created by divine fiat within a few days and that they have not materially changed.

Species. - A group of varieties or a single variety which, in botanical or zoölogical characters and genetic relationship, can be differentiated from all other groups or varieties.

Sperm.-A short term for the male gamete.

Spermatozoön.-The longer technical term for the functional male gamete.

Sporadic.-Occurring singly, scatteringly, or apart from others of the same kind.

Symbiosis.-See Commensalism.

Systematist.-A taxonomist or specialist in the science of classification.

Synapsis.-The pairing off and lying together of homologous chromosomes, prior to the maturation division.

Taxonomy.-The science of classification.

Teleology.-The doctrine that the processes of nature were originally purposed or planned; the doctrine of design.

Tetraploidy.-That chromosomal condition where the germ cells in some way acquire four times the haploid number of chromosomes; thus some socalled plant mutants are tetraploid.

Trihybrid cross.-A hybridization experiment in which the parents differ with regard to three pairs of allelomorphs.

Triploidy. - That chromosomal condition where the germ cells in some way acquire three times the haploid number of chromosomes; some so-called plant mutants are triploid.

Uniformitarianism.- The theory that the changes of the past may be interpreted in terms of the changes of the present, and that most changes are of a slow, gradual kind. Contrast with Catastrophism.

Variety. - A group of individuals within a species which resemble one inother but differ in some respects from other members of the species.

$\mathrm{X}$-chromosome.-The so-called sex-chromosome.

Y-chromosome.- The chromosome that usually pairs off with the $\mathrm{X}$ chromosome in synapsis. It does not seem to carry any genetic factors except possibly that of fertility.

Zygote.-A combination germ cell formed by the fusion of two gametes; the individual, with the diploid number of chromosomes, that result from the development of a fertilized egg.

Zygotically.--Pertaining to the zygote or fertilized egg. 
INDEX 


\section{INDEX}

\section{Abiogenesis, I 2}

Acquired characters: inheritance of, io20, fOr-25: discussion by E. C. Conklin, tos- i f; lack of evidence for, tioII; misumerstandings concorning. 40I-8: other side of the question, 4I-10; recent experiments apparently fatrorine, $+2,3-25$; statement of the prolkm, for, $409^{-} \mathrm{I} 2$

Adaptation, I I, 30, 314-4.7, 340-60; classification of arlaptations, $354-56)$; Osborn's laws of, joo-for

Adaptive radiation, law of, $73-7+, 270$ TI

Agouti, 272

Albinism. hererlity of, +54

Mllen, E. J., 3.3

Altenburs, 200,336

Amplioxus, in

Amphisbatenilae, 05

Analogous, versus homologous structures, $5^{6}, 57$

Analogy, principle of, 56-57; versus homolingy, 5t-5i

Anaphase of mitosis, 195

Anaxargoras, 12

Anaximander, I I

Anaximencs, I I-I 2

Ancestral inheritance, Galton's litw of, $+73$

Angistomum nispochusum, 225

Inti-lens scrum, Guvers experiments with, $4[1-23$

dpartness of the atrm plasm, $3 \mathrm{r}, 201$, 4If-I 0

Aphids, $22+$

Appendix vermiformis, in man and apes. 8384

Ipotettix, 201

Apleryx mustis, $75-72$

Iquinas, Thumas, 8 , I5

Iristotle, $\mathrm{I}_{3} \mathrm{I}+4$, is

Arithmetical meatn, $55^{\text {S }}$

Armadillo quadruplets: and classification, ys go: and the furrlumental assumption about erolution, 54-55; bearing of, on origin of human identical tivins, $47^{5}$ so; and sex-determination, 220-2I

Armarlillss, $5+-55,160,220-21,478-80$

Artificial propugation, ros

Artificial sulection, 25-20

Ascaris, germ tratct in, $20 \mathrm{r}-2$

Aserual reproduction, $107-09$

-1spertilus kir 105

Asortment, independent, 223, 273-74

Atarism, Ij

Itropa, $2+.5$

dugustine, $8, \mathrm{I}_{5}$

Autosemes, 223, 2211 22, 296

Azores, faunat of, Irt

Babeock, E. T:, 222, 373-04, 56 $\mathrm{I}-72$

Bager, H. T., 370, 424

Bakewell, K., 305

Balanoglessus, i i $8-$ I 9

Pusconion antinny, 93

liat, wing of, 13

Batesm. II, ㄱ. 2I, 4.3-46, 232, 248, $25.3,31.3,+119$

Bathminn. 3.5

Eamer, L.e, $3399+13$

"liearle," I aruin's voyge on the, 23 , $25-20$

Ireate, $11 ., 438$

Iiecronia, 45

licllinis. 2.3.3. 3.34

Bembirlitim, i 72

Fergsom. II, if, $2 S 7,+28$

Bermulis, fizunat of, $100-67$

Pibliograing, 100 to 2

Bimextal and multimedal cumes, $554^{-5} 5$

Biometry: discussion of $5.5-50$ : rise and vosue of, 3 ir-39; shert lessun in, 2IO-II

Birds: rudimentary tecth of, I22; wins of 63

Birgus lutro, 67-08, 70

Bisun antiques, 14 s

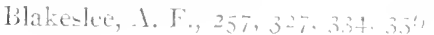




\section{Blastoderm, I I 7}

\section{Blastula, I I 7}

Blends, in heredity, 255-57

Blood-precipitation tests, evidences from, 52, 100-104

Bonnet, R., I6

Bonnevie, K., $48 \mathbf{I}$

Bos taurus, $30 \mathrm{I}$

Boveri, T., 201, 203

Boyd-Dawkins, 90

Brachydactylism, inheritance of, $25 \mathrm{I}-$ $52,+50^{-} 5^{2}$

Breeding, experimental, I84

Bridges, C. B., 226, 253, 285, 290, 295, 327,334

Brontotherium, $427^{-28}$

Brünn, 40, 4I

Buffon, G. L. L., 7, I5-I 7

Bullen, G. E., 373

Cameline: forefoot, I 38 ; skull, evolution of, 137

Camels, fossil pedigree of, $13^{6-} 3^{8}$

Cape de Verde Islands, fauna of, I 69

Carex, $33 \mathbf{I}$

Carsinas maenas, 394-95

Castle, IV. E., 39, 40, 4I, 43, 25I, 270, $305,308-9,399,4 \mathrm{II}-\mathrm{I} 2$

Cataract, inheritance of, $45^{2-53}$

Catastrophism, 22-23

Cattle hybrids, 3 or

Cave animals, eyes of, 73-74

Cebilate, 102

Cell: diagram of typical, I92; division, indirect or mitotic, $194-96$

Cenogenetic, II5

Central body, 193

Centrosome, I93

Cephalization, 348

Cesnola, 395

Cetacea, I 20,

Chamberlin, T. C., 49

Chambers, R., 23, 26

Change factors in evolution, $187,308-12$

Child, C. M., 352, 4I 5

Child mortality in long-lived families, 585 fi.

Chimpanzee, I5 I

Ihromatin, I9I, I93; interchange between homologous chromosomes, 283,568
Chromosomal aberrations, I 87

Chromosomes, I9I-03; conjugation of pairs of, 204; in heredity, 207-8; independent distribution of, 568-69; maps to show loci of crenes, $291-95$; number and appearance, I93; reduction of, $204-5,567,572$; and sex in Drosophilit, 22 I ff.

Clark, J. M., I 47

Classification: basis of, 03-94; evidences from, 52, 93-95; international code of, 93

Clausen, R. E., 96-97, 222, 56I-72

Cleavage of egir, I 15

Cocoa-nut crab, $67-68,70$

Coeficient of correlation, 559-60

Color blindness, heredity of, 277

Color in animals, 300-66

Coluber anthonyi, 93

Coluliridae, 93

Colubrinae, 93

Commensalism, as adaptation, $357^{-58}$

Communal life, as adaptation, 358-59

Comparative anatomy, evidences from, $52,5^{S-92}$

Conklin, E. G., 280-8I, to8-It $47 \mathrm{I}$, $472,473-74$

Conjugation, of homologrous chromosomes, $5^{67}$

Convergence, Osborn's law of, 366-69

Cope, E. D., 39

Correlation: coefficient of, 559-60; tables, $56 \mathrm{I}$

Correns, C., 40, 43, 232, 245-47, 255-56, 264

Cossonidae, 17 I

Coulter, J. MI., $23^{8-44,} 253^{-68}$

Coulter, M. C., 238-4.4, 253-68

Crampe, II., 205

Crampton, II. E., 5, 32, 434

Crataegus, 4, 332

Crime, and destiny, $48+\frac{1}{-9} 5$

Crisscross inheritance, $2 S_{2}$

Cross-breeding, 299-304

Crossing-over, in Mendelian heredity, 288-90

Cuénot, L., 250

Cumulative filctors, $26.4 \mathrm{fi} ., 276$

Cuvier, G., 10, 2I-22

Cytogenic reprodurtion, $198-200$ 
Cytology, is 4

('ytoplasm, sen

l)akin, II, I., 373

I)anforth, $+1+7$

Thaphia. +r, 3

Marbishire, 1. 1), 245,250

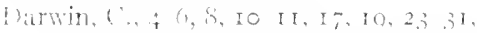

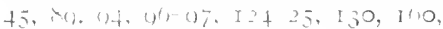
$305,37+77+25 .+4$

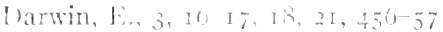

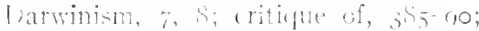
defenee of, reneral, 300 94; oljectic $n \leq\left\{1, s^{2} ;\right.$

Dosypus num inulus, 54-55, os 90, $220-21$

Tratura, 2,32, 32\%

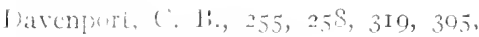
$430-3$ !

J)avis, H, ML, 327

the Cantulle, 1., 2, , 0.5

Jefectiver, sureation of, 5 xi- 27

1)emocritus. I 2

inendy, 1., 134,136

l)escartes, R, is

Jeterminunta I Cismann's', 30-32, 310

leternination of sex, 219-27

1)etlefirn, 1. $\therefore, 42+25$

levelofoun nt: focts of, ro5-6, outline

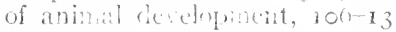

Iie Vries, 11. 7,36 31) $+3,232,245$, $260,2 \div 2,313-3 I, 30 \%$ of

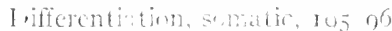

lifficultice and whictiones to natural

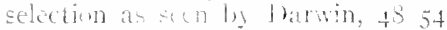

bigamety, formetco, 22324

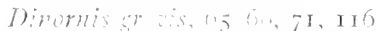

J)iploirl (handusone numb.r. 205

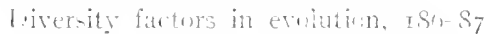

bowling factore in owolution, 1 se $+30-$ 3,8

J rominame, Mentel's law wi, to 42, $2.3324,2,4,293$

bominant charaters in man. $448-40$

1)omm, I. I., 220,30

loncastir, L., 251

jowning. I. IR, + +1,3-60

1)riesch, it, 3t, Ist

brinkwater, II, 252,450

Drusophil a meluneguter, chromosomes of, 562 ; sex-linlied heredity in, $277^{-}$
8I; mutations in, 200; linkage ansl crosingerser in, $285 \mathrm{ff}$.

Drummond, 11,378 i9

]) uplicate facturs, 256

I) Whtam, l: .H., 260-7I

Fars of min and apes, $8_{4}-86$

farthoums and regetalle mold, 376泬

Inst, I. YI, 4.3, 250, 339

Eat, Rer. A. k, 72

Litublast, 107

Elentates, dietribution of, $\mathbf{x} 6 \mathbf{x}$

Iincer, T. it s

Elan rita? +2र 20

liketrie wrang of hines, 355

Elephants, evolution of, $I, 30-+3$

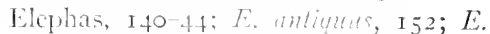

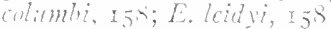

Finhlirylury, esidences from, $105^{-16}$

Emerson, R. 1., 338

limpetoucles, $12-13$

Endoblast, is 7

Ensrammes of Rignane, 43

linteleche, 3+, Ifit

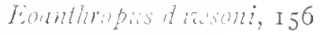

Ejricurus, $\mathrm{J}_{4}$

Tpigenesis, I3

Jilleps, inleritance of, 450

Equiritie. I3.3,30

Equus, $134^{-3} 3^{\prime \prime}, 1+9,300-301$

Litigent 332

Jischerich, sio

Eugenics: Achnitions of, ftr: scope of,

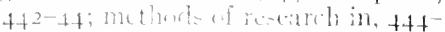

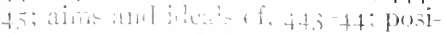
tive, sor retritise, $52.3-28$; and unenipdgyment, 5.36 37; and woman, 537

Tupromerte, 385

luthenter on 20

lirhition, orwanic: causal factors of,

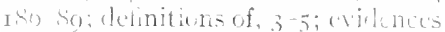
of, 5I-52; experimentid, 52; inetitnism of 1 shs so: nature ef forat of

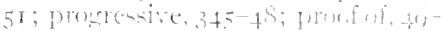

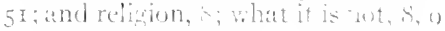

Factor hypothesis, $293-72.25570$

Fictorial an?lytion of ofo in mie, $260-$ 7 ; in swine, $27 \mathrm{r} ; 2$; in muinea pigs, 272 
Factors, in Neo-Mendelian heredity: complementary, 257-6r; cumulative, 263 ; inhilitory, $26 \mathrm{I}-62$; lethal, 276 ; in quantitative inlseritance, $263^{-68}$; of evolution, I $86-89$

Feeble-mindedness, inheritance of, $45^{8-}$ 60

Fertilization, I86, 199, 207-8

Fetal membranes, as adaptations, $35^{6}$

Fierasfer acus, $357^{-} 5^{8}$

Filaria sanguinis hominis, 376

Filial regression, Galton's law of, $47 \mathrm{I}^{-}-73$

Flower, Professor, $9 \mathbf{I}$

Forficulata auricularia, 558-59

Fraternal twins, 477

Freemartin, 530-3I

Fossils: actual remains, r27; Cambrian, I25; casts and impressions, I2S; classification of, 125 ; conditions necessary for, I 28-30; Darwin's opinion as to the adequacy of the record of the, I 24-26; definition of (by T. H. Huxley), I27; ïrst recognized, I 2 ; general facts revealed by, $132-34$; pedigrees of well-known vertebrates, 133-43; petrifications, 127

Fowl hybrids, 3or-2

Fundamental assumption underlying evidences of evolution, $53-57$

Fundulus, 302

Gadow, H., I $77^{-7} \mathrm{~S}$

Gallus domesticus, $30 \mathrm{rff}$.

Galapagos Islands, fauna of, I68-70

Galton, Sir F., 38-39, 44I, 4.45, 456-57, $471-75$

Gametes, I98, I99

Gametic reproduction, $198-99$

Gastrula, 107

Gates, R. R., 299, 327, 328-33, 340

Gazelle-camels, I39

Geerts, $33+$

Gegenbaur, i 6

Gemmules, 28, 30

Gene mutations, 187

Genes, I 86, I93

Genetics: biological background of, I go-208; defimitions of, $\mathrm{I}_{3}$; evidences from, $2 S$; methods of study of, 183 ; methods of, 184 ; nature and scope of, $\mathrm{I}_{3}-84$; prerequisites for the study of, $184-85$
Genius: hereditary, $456 \mathrm{ff}$.; production of, $53^{2-33}$; transmission of, $533^{-3.4}$

Genotype, $215,271,272$

Genotypic, 21 5, 27I, 272

Geograplic distribution, evidences from, 52, I $60-79$

Geologic time: lapse of, $130-31$; scale in millions of years, I3 I

Germ-cells: early setting apart of, $201-$ 3 ; maturing of, 203-7

Germinal continuity, 31, 200-202

Germinal selection, 30-3I

Germ-plasm theory, 3I-32, 200-202

Germ track, 200-202

Giekie, Sir A., 132

Gill arches in vertebrates, II 7-I8

Giraffe-camels, I 39

Glochidia, 375

Goddard, H. II., ${ }_{45}{ }^{8-60}$

Goethe, J. IV., 2 I

Goldschmidt, R., 227

Gonads, 20 I

Gorilla, 78

Goss, J., 40

Graham-Smith, G. L., IoI

Greek evolutionists, I I-I 4

Gregory of Nyssa, 14

Gregory, II. K., I 45

Griffith, C. R., 42t-25

Guacanos, 136

Guiding factors in evolution, $r \delta 7-88$, $3+4^{-48}$

Gulick, J. T., 32, +34

Guthrie, C. C., fII

Guyer, M. F., 204, 205, 206, 207, 208, $4 \mathrm{I}^{6-23},+23^{-24}$

Gynandromorplis, sex-chromosomes in, $225^{-26}$

Mabitat: preference, $35 \mathrm{I}$; selection, $35 \mathrm{I}$

Haeckel, E., I9, 30, II $3^{-1} 4$

Hair of man and apes, $85-89$

Hamilton, I). J., tot

Hanson, $\mathrm{F}$. B., 424

Hapalidae, ro2

Haploid chromosome number, 205

Harris, J. A., 413

Harrison, R. G., 4 I I

Harte, Bret, $I_{4} 8$

Harvey, W., I3 
Jlegner; R. II., 204

IIelix hortensis, 24 ; II. Wmomblis, 248

Ienderson, I. J., 350

1 leraclitus, I2, 219

Iterbert, s., $3^{\circ}+$

Iferedity: environment and training, 485-60; cialton's lawe of, tir-75; in

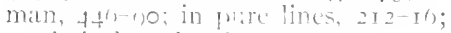
statistical sturly of $4: 0-5$

IIermaphrodites, 200; stx-chromosomes in, $225-20$,

Hermit cralss, $11-00$

Iferon, I bavil, tox

Herschel, : ir $\mathbf{j} . .3$

Heteromesis theory, 36

IIcterosis, 302-5

Heterozygote, 242

II ieracimm, 3.32

Ilippocrates, 210

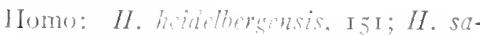
picns, I5I, I53, I55-5); ll. nethderthalensis, I $22-50 ; 11$. priningenius, 152

Iomologies: cridences from, 52 ; validit $y^{+}$of the principle of, $55^{-5}$; versus analogy, $50-57$

Ilomozygote, $2+2$

INooker, sir J., 385, to

Hormone theory of sex diferentiation, $22 S-3 \pm$

Hormones, 229-3I

Horse: ancestry of. s; fowt and teeth in fossil pedigree of, i.3.; inswil perligree

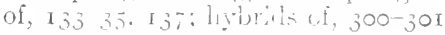

Iorseshoe-cral, II 3

Hirdlicka, 1., I.to

Human antiquity, widenes of, 156-57

IIuman concervation. 5;o so

llumanity, future of, $15 \mathrm{~s} 50$

Humerus, perforations of, in suartumanil, gI

IIurst, C. C.., 43, 24.5, 24., $25 \mathrm{I}-52$

IJutton, J., 22, 57

Huxley, T. II., 24 20, I25 20, 154, 37 I

Iyatt, . 1., 35

IIylurid vimor, 302-3

Itybrillation: and the oritrin of species, 43 ; rible of, in exolution, 2 of 1 .

Iymenopterit, parthenogenesis in, 225 i] yracotherium, I3t
Identical twina, writin of, 47,5 , reated apart, tiy yo

Immigration and cugenics, 523-24

Inbrecding, 304-7

Induction: a temporary chanese in wremcells, 4I $3^{-I}+$; of horeditary ariations, 45

Infant mortality movement, $5 \mathrm{R}$, ff.

Inheritance: of acraired characters fsee Acquired characters); of brachydactylism, $4.50-52$; of catarue,$+52-53$; of feethe-minrleriness, tze tir wi human chanacters, $44^{5}, 50$; if insinity, $\left.t^{t} I-t\right)$; in royalty; $f^{\prime \prime 2}(x)$; sexlinked, $277^{-8}+$

Insinity, inleritance of, $46 \mathrm{I}_{-1}-\mathrm{t}_{2}$

Interference, in cm-sing-over, 20.3

Interseses: in biris. $221-3 \mathrm{I}$; in cattle, $23 \mathrm{I}-32$; in Diwsolnth, 220 27; in gypsy moth, 227

Isclation: 430-34; and selection, tis-

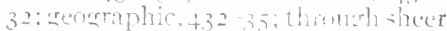

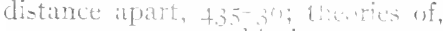
$20,32-33,+30-34$; bintic, $+37,+32$ reproductive, $430-37$; p-yhic, 439 ; types of, iss

Jeffries, E. C., 327

Jennings, H. S., 217, 300, 4+1, 506-7

Johannsen, II, 212-Ij

Johnsim, R. II, 50 - -20

Jones, D. F., I 26, I 24, 254, 303, 304, 306

Jordan, D. S., 4. $323+07,106-13,186$, 349,43234

Judl, J. II., 10, 2324

Kullima, 34iz is

hammerer, I', +14

Sant, E., I, - 16

Kelluter, $: .4 .,+32-3+.97,106-13$, I $21-30,340,3.54,31,3-85,391$

Kelvin, Lort, I 30-3 I

Kinetorenesis, 35

King, ('., I 30

King, lielen 1)., 305-6

Knight, T., to

hohlruter, J. G., 40-71

Korchinsky, H., $3^{0}$

Lamarck, J. P., 7, ro II, IS-2I, 94, $30 \%, 385$

Lamarckism, 7, 21, $30 \mathrm{~S}$ 
Lang, A., 248

Lange, J., 484-85

Laplace, P. S., 49

Laplacian hypothesis, I 30

Le Conte, J., 3, 547-55

Leibnitz, I5

Leighty, C. E., 559

Lemuroidea, IO2

Lepas, metamorphosis of, I I 2

Leptinotarsa decemliniata, 215-16

Liliaceae, 332

Lethal faciors, 276,296

Lillic, F. R., $23^{-} 3^{I}$

Lincoln, A., 24

Linkage: in Mendelian heredity, 285 ff.; chromosome thenry of, $285-88$; in many species, 296-97

Limmaeus, I 6, 43, 93

Little, C. C., 424

Locy, W. A., 41-43

Loeb, C., 453

Loess Man, i +4

Lotsy, J. P., 43, 299

Love, H. H., $56 \mathrm{I}$

Lucas, A. H. S., 382

Lucretius, 14

Lull, R. S., 3, 5, 24, 25, I 37, I39, I42, I $44^{-}-59$

Lutz, $33+$

Lydekker, R., i i 9

Lyell, Sir C., 3, 8, 23, 26, 49-50, I30

Maas, O., I $2 \mathrm{I}$

McCracken, I., 248

McFarland, J., 28

McGregor, J. H., 153

Madagascar, fauna of, $173-74$

Nacterlinck, 359

Maize, linkage in, 297

Mallophaga, 26 $\mathbf{x - 6 2 , 4 3 4}$

Malthus, $17,23-24,26$

Mammalian dispersal, $177-78$

Manmary glands, as aclaptations, 355

Man: of Chappelle-aux-Saints, I54; Crô-Magnon Man, ${ }^{66-57}$; chronological table of fossil man, i 50; descent from trees, significance of, I4I ; evolution of, $144^{-59}$; evolutionary changes of 147 ; fossil man, 147-57; Heidelberg Man, 151-52, I54; im- pelling cause, of origin, I46; Neanderthal Man, 152-53; origin of, $145-$ 47; Piltdown Man, $155^{-5} 6$; stock of, I 45 ; time of origin, $146-47$

Mantis religios.1, 395

Marriage laws and eugenics, 525

Marsh, O. C., I35

Marshall, A. M., $37^{8}$

Marsupial pouch, as adaptation, 355 $5^{6}$

Naryatt, 338

Mastodon, I39-4.3, I48

Materialism, the relation of evolution to, $548-57$

Matthew, IV. T., I 44

Maturation: of egg-cell, 205-7; of sperm-cell, $203^{-5}$

Maupertuis, I 5

Median, in variation, 558

Megalons.x jeffersoni, 170

Meiosis, $186,204^{-7}$

Nendel, G., 40, 232-37; his conception of purity of gametes, $238-39$; his conception of unit characters, $23 s$; his experiments, $23 \mathrm{I}$; his explanations, $233-44$; his law of dominance, $233-35,238$; his law of segregation, $40-42,234-36$; his life and character, 232 ; his results, $233^{-34}$

Mendelian heredity, in cats, $25 \mathrm{I}$; in guinea-piss, 251 ; laws of, $273-76$; linkarge in, $285 \mathrm{ff}$; in maize, $240-47$; in man, 251-52, 448-50; in mice, $236-37,25 \circ$; in nettles, 247 ; in numerous species, $245^{-} 4^{6}$; in peas, $235^{-}$ 36 ; in pirreons, 24.4 ; in rabbits, 25 ; in silkworms, $2-17-48$

Mendelism: physical basis of, 56I-72; review of, $273-70$

Mesoluippus, I35

Metaphase of mitosis, 104-95

Metcalf, M. M., 6, 32, $3^{6 \mathrm{rO}}, 3^{6}+\mathrm{f}^{-65}$

Meyer, L., S4

Miastor americand, 201, 202, 20.4

Millson, $\Lambda ., 37 \mathrm{~S}$

Milton, J., I4

Mimicry, 135

Miolippus, I 35

Mirabilis julupa, 248, 255-56, 264-65; M. rosen, 246

Misconceptions about evolution, 8, 9

Mitotic cell division, I86, 194, 195, 56465 ; spindle, I 94 
Mivart, $64-6,5$

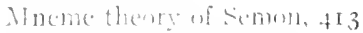

Molle, in ramiti n, 557

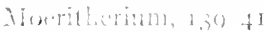

Monuctions, 200

Monomythil ratio, 24

liome, $\{$. R., 221$\}$

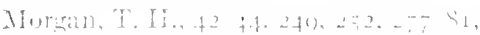
$242,243,2458-211,311 \quad 12,322$ $21+3+1+3$

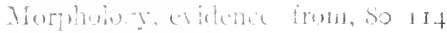

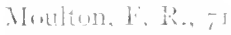

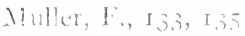

Muller, H. J., $45,200,200,324,3.35+40$, $3+1,+17$

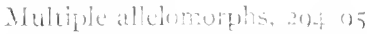

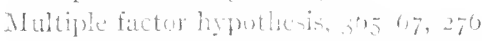

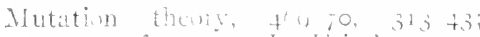
cantes of, $3 \div 0+1$; I e Yrits own atc-

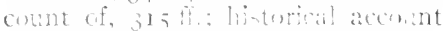

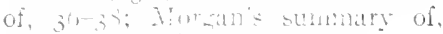
32224 ; rate of on inath, $4+4$

Mlutations, ats chenete facture, 312

Mysis larrat of t'eleus, I33

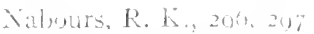

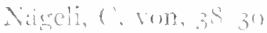

Natural edection, 4, $12,21-26,35,37$

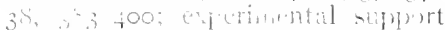

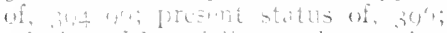

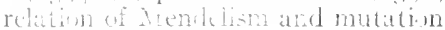
to 30 jor 100

Nauclin, ( . , i

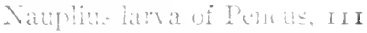

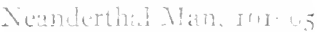

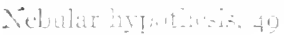

Neo-longerlism, 20, +13-1t

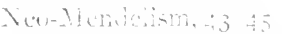

Nest-mating instibcts, as addaptations, $35^{\circ}$

Actilesiep, li., 252,452

Xewnstir, (c)lomet, 375

Newtun air ! $, 7,53$

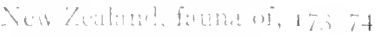

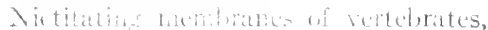

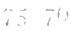

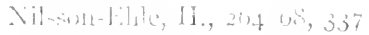

Vitste. lir. it

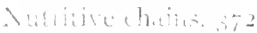

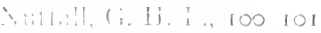

Whtine, C.C..., s's 100
Obliterative coloration, if i 2

Oeconic islands, fatura of , $14+73$

Cotopus, ere of, 04

Oenothera, $35,313-26$

()glivie, 1)r., tot

Oken, L., I2, I0

dricyte, 207

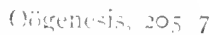

(ximeniusu. 20;

Gri-in of new hereditary characters, $30,4-11$

Orisin of she its, 1he, 4, 5, 7, 24, 27 , $12+25,1,30$

Orohipuse, 137 , 35

(orr, H. li. fin 62

Grthorenesis, 333 36, $157,345^{-47}+426-$ 25

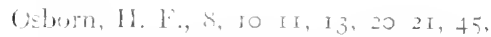
$150-51,153,153,51,300-00,+20-27$

Uverepecializationse, 3 I

(1) Win? 10.5

Owen, K., 59,97

Puginus bernh lidus, of

Paliteomastorton, I.39-4I

Paluentulory, withecofrom, 52; opinjons as to the aderavater of, $125^{-26}$; strenth and weatiness of I $_{2} 4^{-25}$

Ialingenetic, is 5

$P, n \in t / 1,5$, I $5 \mathrm{t}$

l'angenesid, 2s, 30, 305-9

Panmixia, is

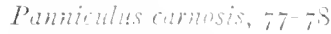

Parancium, 217

Parasitism, as arlaptation, 3515-57

Parthenomenesis: at more of reproduction, 200; lipiold, 22+-25; haskoid, 225:as a methoul oi arevait revelopmilt. Iofies determination in connection with, 22+25

Parlow, I. P., +24

Pearsm, K., t.3, 474

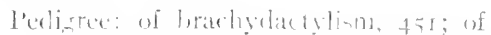

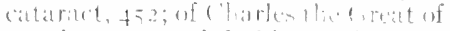

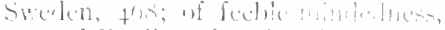

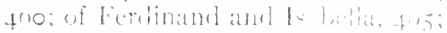

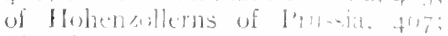
of night blindness, 450 th hemantols of linsial, tht

Pencuspotiminim, III-I

Persistence fartors in cowlontion a iso; introduction to thestidy of, 201 - I I 
Phenotype, 215, 242

Phenotypic, 215, 242

Phillips, J. C., 4I I-I 2

Phocochaerus, $402-3$

Phyloxerans, 224

Physiological units, 28

Pisum quadrutum, 233; P. saccharatum, ${ }_{233}$; P. sutioum, 245 ; P. tumbellatum, 233

Pithecunthropus erectus, I $49^{-5}$

Planetesimal hypothesis, 49

Pliny, 14

Pliohippus, I 35

Poëbrotherium, I $35^{-} 3^{6}$

Polar bodies, 206

Polyploidy, 299, 331-32

Popenoe, P., 508-20

Post-Aristotelians, I4

Poulton, E. B., 395

Poultry, sex-linked heredity in, $28_{2}-S_{3}$

Preformation doctrine, 117

Prenatal influences, I 3 - 4

Presence and absence hypothesis, 253$54,27.5$

Primates: geologic record of, 145 ; origin of, I $4+45$; place of origin, 144 ; stock of, 144 ; time of origin of, 144

Primuld kewensis, 332; P. sincnsis, 246, 297

Priority, law of, 93

Probable error, 559

Procamelus, $137-3 \mathrm{~S}$

Promise of race culture, $532 \mathrm{ff}$.

Protohippus, I 35

Prophases of mitosis, 194

Protylopus, $137^{-}-3 \mathrm{~S}$

Pterodactyl, wing of, $\sigma_{3}$

Punnett, R. C., 237, 247, 248

Pure lines, heredity in, 200, 2 10, 21 2-16

Purity of gametes, $235-39$

Python, hind limbs, of, 70-7I

Quadrumana, $77^{-79}$

Rabl, C., 107

Race culture and human variety, $539^{-} 4^{-}$

Races, and individuals, I90; as evolutionary units, 190

Rand syliatica, 41 ; R. pulustris, 411

Recapitulation, doctrine of, 60, I $12^{-1} 3$; critique of, $114-22$
Recessive characters in man, 449-50

Recombination, Mendel's law of, $274-75$

Reduction divisions in maturation, 204, 566-67

Reproduction, modes of, r $9^{6-98}$

Reproductive processes, 196-2os

Reversion, I3

Revival of science, the $15^{-16}$

Rhodeus amurus, $37^{\circ}$

Rignano, E., 4 '3

Robinson, L., $S_{I}$

Rodentia, loss of teeth in, $\mathrm{r} 2 \mathrm{I}$

Romanes, G. J., 35, 57, 58-92, I64-73

Roosevelt, T., $3 \mathrm{~S}_{\mathrm{I}}$

Rosi 33 I

Rosanoff, A. J., 46I-62

Rubus, 332

Rumcx, 332

Ruminants, collar-bone of, I 2 I

Ruskin, J., 544

Ruskin and race culture, 544

Sacculina, I 1 2, I 22, 357

Saleeby, C. II., $53^{2-45}$

Salatory, variations, $3^{8}, 3^{1} 3$

Sandwich Islands, fauna of, I $72-73$

Saunders, 395

Schoetensack, Dr., 152

Schuchert, C., 130-32

Scott, IV. B., 5, 6, 100-104, II 4-23, I25$26,136-37,145$

Sears, comparative anatomy of, $5^{8-59}$

Secondary sexual characters, 228

Segregation, Mendel's law of, 40-42, $23+37,273$

Semon, R., 4I 3

Serology, evidences from, 52

Sex determination, 219-27; chromosome mechanism of, in Drosophila, 221 fi.; in parthenogenetic species, $224-25$; nutrition theory of, 219 ; relation of, to genetics, 2 I 8 ; at time of fertilization, 219-20; various theories of, $219 \mathrm{fi}$.

Sex differentiation, $227-3 \mathrm{I}$

Sex, heredity and, 44

Sex-linked inheritance, $277-S_{4}$; rules for, 28.4 ; in man, $45^{\circ}$

Sexual selection, 26, $5^{\delta_{5}}$

Shelford, V. E., $35 \mathrm{I}$

Shull, A. F., $93^{-95}, 13^{6}, 139-43,163^{-64}$ 
Shull, G, I! : +3, 332, 335

siemens, R., q i I

Simmithopus pinensis, 559

Somith, E. 1., +17, +23-24

smith, (i., 227

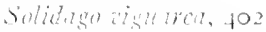

somatorenic reproduction, I47-08

species, delinitions of, $0 \%$ os

Spencer, 11, 4, 10, 2 24, 273, 403-4

Ppermatid, 20,5.207

Sipermatectet, 205. 207

spermaterenc-is, $20,3-5$

Spermatosuniming, 205.20\%

spermatozoin, 106, 205, 207

Spirmthus, 332

Spontancous bencrition, 12

sports, 35

Sprengel, C. K., 3it

standard deviation, $454^{-55}$

Staples-lirowir, K., zfo

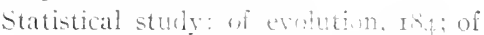
variation, 530 b 1 of hererlity, 47075

Stegrodon, 1 to 43

Steinacin, l:. 228

steinmann, $(:, 6$

Stcjiterel, 93

Sterilization laws, 529-29

stockard, C. R., +13

St. Helena, fatuna of, r $70-72$

St. Hilaire, I. (i., $2 \mathrm{I}-22$

Strangeways, T'. S. P', IOI

Strongylocentrotus, 303

Sturtevant, 1. 1. 1., 215, 200

Subsidizing the fit, 525-29

Swainson, 00

Synapisis, 204,560

Systema Vaturate of I.ninacus, 93

Tail, vestigial in man, 8182

Talent, the production wi, 53435

Casmanian malf, IO:

Payler, I. i., zor ws

Faxonomy, the methud of, 95 go

Feleolosy. I

Jelophase of mitosis, 195

ormites, 3,5

letrads, 204

Tetraplod mutations, 329
Thales, I I

Thayer, (s. II., 361-0 3

Theolusians, the carly (hristian, If, Is

Thompson, 1., 82

Thomson, J. 1., I60, 232-37, $245-52$, $370-82$

Tilial. Hattenines of, in man, 9r

Titanetheres, $+26-27$

Tomes, ('. S., no

liner, II. L., $-15-16,324$

Toyma. K., $2+5-47$

Irithidentions, rs

Trihylurid iatios, $2+3-44$

Tributhudon, I 31! $\$ 2$

Triplonel notatations, 329

Trisomic mulations, 329

Tschemak, $40,+3,2+5$

Tumur, sir 11,90

Twins: evirlences from, in support of clamification, ys and the fundament:al astumption of evolution, 54, 55; and the relative potency of heredity and emironment, $+5-00$; method of studying limman heredity, $455,480-$ (1)

Typlolopirlate 95

Inifumitarianism, 22-23

Lnit dharacters, Nendelian, 23S

(ritid Inderli, 247 t); U. pilulifera, $24 ;+11$

Lisileim, I2, I6

Viacutory, 528

lestizl structures, exidences from, 52 . (n) -92

Virthow, R., I, t

Thatiotic therries, $+2 \mathrm{~S}$

Von Serticeur, fio

Materes, $11,+32-33$

IIthott, ( 11 . I $2526,1,32$

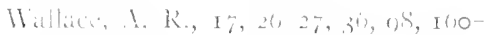
$(, 3,1 \%, ; j)$

Haller, il, L., 285, 452,521-31

Weismiti1, 1., 3, 7, 30 32, 202, 300 11, 315,4080

Weismanduism, 7, 202, 300 I I

Helem, II. F. K., 3n+ 35

Whake, comparative abutomy of, wo 62; entryoling of, 12021

White, (i., 370, $3,11,7$ 
Whitman, C. O., 35

Whitney, D. D., 4I3

IViggam, A. I., 49I-507

Viilberforce, Bishop, 28-29

Wilder, II. H., 48I

Williston, S. W., 35

Wilson, E. B., 6, 44, 146-48, 192, I94, 195, 196, 222, 223, 227

Wings, comparative anatomy of, 63

Wistar Institute, +25

Woltereck, R., 4I3

Woods, F. A., 462-63, 494

Woodard, I5 I, I 55

Woolner, $S_{4}$
Wright, Sewall, 105-6, 216, 306

Wyman, Professor, 79

$\mathrm{X}$-chromosome, $22 \mathrm{I}-27$; variations of, 223 ; linkage with autosone, 223

X-rays, $45,340^{-}+\mathrm{I}, 424$

Xenophanes, 12

Y-chromosome, 222-27

Yellow mice, lethal factors in, 296

Zea muys, 247

Zeleny, 338

Ziegler, E., tot

Zoëa larva of Peneus, I I I

Zygote, 106, 200-20I, 207-S 


\section{.}





$$
\text { , }
$$


